COMMERCIALIZATION DEVELOPMENT OF OXYGEN FIRED CFB FOR GREENHOUSE GAS CONTROL

VOLUME I

PILOT SCALE TESTING AND DESIGN STUDY OF AN EXISTING CFB RETROFIT TO OXYGEN FIRING AND $\mathrm{CO}_{2}$ CAPTURE

VOLUME II

DESIGN STUDY OF A CAPTURE READY CFB STEAM PLANT RETROFIT TO OXYGEN FIRING AND $\mathrm{CO}_{2}$ CAPTURE

FINAL REPORT

SUBMITTED BY

ALSTOM POWER INC. POWER PLANT LABORATORIES

2000 DAY HILL ROAD

WINDSOR, CT 06095

(860) 688-1911

Principal Authors:

Nsakala ya Nsakala

Gregory N. Liljedahl

David G. Turek

PREPARED FOR

NETL AAD DOCUMENT CONTROL BLDG. 921 US DEPARTMENT OF ENERGY NATIONAL ENERGY TECHNOLOGY LABORATORY P.O. BOX 10940

PITTSBURGH, PENNSYLVANIA 15236-0940

(COOPERATIVE AGREEMENT NO. DE-FC26-04NT42205)

FINAL REPORT SUBMITTAL DATE: AUGUST 24, 2007 PERFORMANCE PERIOD: OCTOBER 1, 2004 - JUNE 30, 2007

PPL REPORT NO. PPL-07-CT-20 


\title{
COMMERCIALIZATION DEVELOPMENT OF OXYGEN FIRED CFB FOR GREENHOUSE GAS CONTROL
}

\author{
VOLUME I
}

PILOT SCALE TESTING AND DESIGN STUDY OF AN EXISTING CFB RETROFIT TO OXYGEN FIRING AND $\mathrm{CO}_{2}$ CAPTURE

FINAL REPORT

SUBMITTED BY

ALSTOM POWER INC. POWER PLANT LABORATORIES

2000 DAY HILL ROAD WINDSOR, CT 06095

(860) 688-1911

Principal Authors:

Nsakala ya Nsakala

Gregory N. Liljedahl

David G. Turek

PREPARED FOR

NETL AAD DOCUMENT CONTROL BLDG. 921

US DEPARTMENT OF ENERGY

NATIONAL ENERGY TECHNOLOGY LABORATORY

P.O. BOX 10940

PITTSBURGH, PENNSYLVANIA 15236-0940

(COOPERATIVE AGREEMENT NO. DE-FC26-04NT42205)

FINAL REPORT SUBMITTAL DATE: AUGUST 24, 2007

PERFORMANCE PERIOD:

OCTOBER 1, 2004 - JUNE 30, 2007

PPL REPORT NO. PPL-07-CT-20 


\section{DISCLAIMER}

This report was prepared as an account of work sponsored by an agency of the United Sates Government. Neither the United States Government nor any agency thereof, nor any of their employees makes any warranty, express or implied, or assumes any legal liability or responsibility for the accuracy, completeness, or usefulness of any information, apparatus, product, or process disclosed, or represents that its use would not infringe privately owned rights. Reference herein to any specific commercial product, process, or service by trade name, trademark, manufacturer, or otherwise does not necessarily constitute or imply its endorsement, recommendation, or favoring by the United States Government or any agency thereof. The views and opinions of authors expressed herein do not necessarily state or reflect those of the United States Government or any agency thereof. 


\section{ACKNOWLEDGMENTS}

The authors gratefully acknowledge the following people for their contributions to the successful performance of the work presented herein:

Larry Cellilli, Ray Chamberland, Gene Dallaire, Bill Gurski, Kurt Johnson, Glen Jukkola, Armand Levasseur, Ray MacWhinnie, Dana Raymond, Paul Panos, and Peter Stromberg of ALSTOM Power Inc., and Pedro Jaldin, Dave Vogel, and Paul Milios of ABB Lummus Global Inc. for their contributions.

The financial support of this project by DOE National Energy Technology Laboratory (Contract No DE-FC26-04NT42205) and ALSTOM Power Inc. is also acknowledged. 


\section{PUBLIC ABSTRACT}

Given that fossil fuel fired power plants are among the largest and most concentrated producers of $\mathrm{CO}_{2}$ emissions, recovery and sequestration of $\mathrm{CO}_{2}$ from the flue gas of such plants has been identified as one of the primary means for reducing anthropogenic (i.e., man-made) $\mathrm{CO}_{2}$ emissions.

In 2001, ALSTOM Power Inc. (ALSTOM) began a two-phase program to investigate the feasibility of various carbon capture technologies. This program was sponsored under a Cooperative Agreement from the US Department of Energy's National Energy Technology Laboratory (DOE).

The first phase entailed a comprehensive study evaluating the technical feasibility and economics of alternate $\mathrm{CO}_{2}$ capture technologies applied to Greenfield US coal-fired electric generation power plants. Thirteen cases, representing various levels of technology development, were evaluated. Seven cases represented coal combustion in CFB type equipment. Four cases represented Integrated Gasification Combined Cycle (IGCC) systems. Two cases represented advanced Chemical Looping Combined Cycle systems. Marion, et al. reported the details of this work in 2003.

One of the thirteen cases studied utilized an oxygen-fired circulating fluidized bed (CFB) boiler. In this concept, the fuel is fired with a mixture of oxygen and recirculated flue gas (mainly $\mathrm{CO}_{2}$ ) - see schematic below. This combustion process yields a flue gas containing over 80 percent (by volume) $\mathrm{CO}_{2}$. This flue gas can be processed relatively easily to enrich the $\mathrm{CO}_{2}$ content to over 96 percent for use in enhanced oil or gas recovery (EOR or EGR) or simply dried for sequestration.

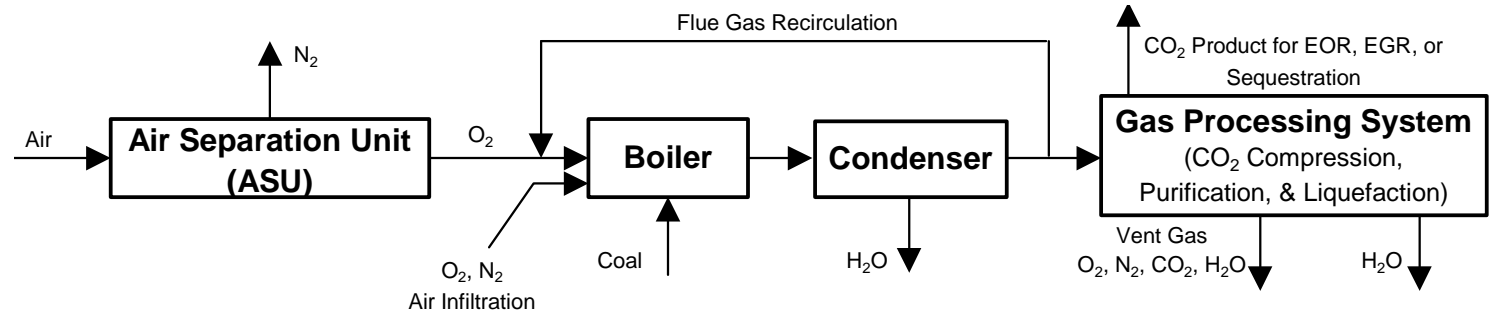

The Phase I study identified the $\mathrm{O}_{2}$-fired CFB as having a near term development potential, because it uses conventional commercial CFB technology and commercially available $\mathrm{CO}_{2}$ capture enabling technologies such as cryogenic air separation and simple rectification or distillation gas processing systems. In the long term, air separation technology advancements offer significant reductions in power requirements, which would improve plant efficiency and economics for the oxygen-fired technology.

The second phase consisted of pilot-scale testing followed by a refined performance and economic evaluation of the $\mathrm{O}_{2}$ fired CFB concept. As a part of this workscope, ALSTOM modified its $3 \mathrm{MW}_{\text {th }}(9.9 \mathrm{MMBtu} / \mathrm{hr}$ ) Multiuse Test Facility (MTF) pilot plant to operate with $\mathrm{O}_{2} / \mathrm{CO}_{2}$ mixtures of up to 70 percent $\mathrm{O}_{2}$ by volume. Tests were conducted with coal and petroleum coke. The test objectives were to determine the impacts of oxygen firing on heat transfer, bed dynamics, potential agglomeration, and gaseous and particulate emissions. The test data results were used to refine the design, performance, costs, and economic models developed in Phase-I for the $\mathrm{O}_{2}$-fired CFB with 
$\mathrm{CO}_{2}$ capture. Nsakala, Liljedahl, and Turek reported results from this study in 2004.

ALSTOM identified several items needing further investigation in preparation for large scale demonstration of the oxygen-fired CFB concept, namely:

- Operation and performance of the moving bed heat exchanger (MBHE) to avoid recarbonation and also for cost savings compared to the standard bubbling fluid bed heat exchanger (FBHE).

- Performance of the back-end flash dryer absorber (FDA) for sulfur capture under high $\mathrm{CO}_{2}$ / high moisture flue gas environment using calcined limestone in the fly ash and using fresh commercial lime directly in the FDA.

- Determination of the effect of recarbonation on fouling in the convective pass.

- Assessment of the impact of oxygen firing on the mercury, other trace elements, and volatile organic compound (VOC) emissions.

- Develop a proposal-level oxygen-fired retrofit design for a relatively small existing CFB steam power plant in preparation for a large-scale demonstration of the $\mathrm{O}_{2}$ fired CFB concept.

Hence, ALSTOM responded to a DOE Solicitation to address all these issues with further $\mathrm{O}_{2}$ fired MTF pilot testing and a subsequent retrofit design study of oxygen firing and $\mathrm{CO}_{2}$ capture on an existing air-fired CFB plant. ALSTOM received a contract award from the DOE to conduct a project entitled "Commercialization Development of Oxygen Fired CFB for Greenhouse Gas Control," under Cooperative Agreement DE-FC2604NT42205 that is the subject of this topical report.

Results from this study show the following:

Pilot Scale Testing Results:

The main results from the 2005 pilot scale testing are summarized here.

- There were no operational problems due to recarbonation or any other issues due to the oxygen firing over the range of CFB conditions tested.

- The sulfur capture with lime only to the back-end baghouse/FDA system was slightly lower with oxygen firing compared to air firing. The sulfur capture in the furnace with limestone addition was higher with oxygen firing than with air firing.

- The $\mathrm{N}_{2} \mathrm{O}$ and VOC emissions were low under all circumstances.

- The emissions of mercury, VOC, and other trace metals when oxy-firing were at least as low as with air firing.

- The MBHE performed as expected in terms of heat transfer. The performance did not deteriorate or change due to changes in firing conditions of the test campaign: load, fuel, limestone, or air vs. $\mathrm{O}_{2}$.

\section{Retrofit Study Results:}

The retrofit of an existing CFB boiler steam plant to oxygen firing and $\mathrm{CO}_{2}$ capture causes several significant impacts on the overall plant performance, $\mathrm{CO}_{2}$ emissions, and cost of electricity as compared to the air fired Base Case. The net plant output is reduced 
from 90 to $62 \mathrm{MWe}$, a 31 percent reduction. The plant thermal efficiency (HHV basis) is reduced by about 12.0 percentage points (from $36.6 \%$ to $24.6 \%$ ). Specific $\mathrm{CO}_{2}$ emissions are reduced more than 91 percent from 0.88 to $0.08 \mathrm{~kg} / \mathrm{kWh}(1.94$ to $0.17 \mathrm{lbm} / \mathrm{kWh})$.

Retrofitting the existing CFB boiler to oxygen firing capability is technically straightforward, with the CFB boiler requiring relatively minimal modifications. Boiler modifications include a new flue gas recirculation system, new oxygen supply piping, new $\mathrm{CO}_{2}$ product ductwork to the new gas processing system, the addition of a new $\mathrm{SO}_{2}$ removal system (Flash Dryer Absorber), and associated new controls and instrumentation for these systems. Pressure part changes to the existing boiler are not required.

The major new systems required for the boiler retrofit are a cryogenic air separation unit (ASU) and a gas processing system (GPS). The ASU and GPS have significant land area requirements for the location of new equipment. The new cryogenic air separation unit requires about $3,600 \mathrm{~m}^{2}(0.9$ acres $)$ and the new gas processing system requires about $6,500 \mathrm{~m}^{2}$ (1.6 acres). By comparison, the area required for the existing $90 \mathrm{MWe}$ Boiler Island (including the CFB boiler, fans and blowers, air and flue gas ductwork, fuel and limestone silos, and baghouse) is about $3,600 \mathrm{~m}^{2}$ ( 0.9 acres $)$. Location of this new equipment on the selected study unit site was not difficult but on some existing sites this can be complicated and may require long duct and piping runs between the new and existing equipment.

The plant retrofit is extimated to cost about $1,545 \$ / \mathrm{kW}$, based on the new power output $(1,060 \$ / \mathrm{kW}$ on the basis of original plant output). Modifications to the existing boiler cost $72 \$ / \mathrm{kW}\left(\right.$ new). The new Flash Dryer Absorber $\mathrm{SO}_{2}$ removal system costs 94 $\$ / \mathrm{kW}($ new). The remaining costs - nearly $90 \%$ of the total - are for the cryogenic air separation and gas processing systems. Though costly, these systems are commercially proven and technically straightforward.

Cost of electricity is calculated to increase by about 3.1 cents $/ \mathrm{kWh}$ as compared to the study unit before retrofit and the associated $\mathrm{CO}_{2}$ mitigation cost is projected to be about 39 \$/tonne (35 \$/ton) of $\mathrm{CO}_{2}$ avoided. These economic results used a credit value of 16.5 $\$ /$ tonne of $\mathrm{CO}_{2}(15.0$ \$/ton) for this assumed EOR application.

It should be emphasized that because of the small size of this unit (62 MWe after retrofit), some of the impacts listed above are strongly influenced by "economy of scale" effects. The retrofit costs required and the resulting economic impacts are significantly greater than would be expected with state of the art sized CFB- or PC-based power plants. Additionally, the relatively low steam conditions for this existing unit contribute to the large impact on efficiency and a smaller impact on the economics.

The technology development has proceeded to where it is now ready for large-scale demonstration. To prepare for demonstration of the $\mathrm{O}_{2}$ fired CFB concept, ALSTOM is now actively seeking partners for this important next step. Following a successful largescale demonstration of the technology, commercial offerings would be possible. Based on these results, it is recommended that this technology be demonstrated.

ALSTOM also identified a need to investigate the design of the $\mathrm{CO}_{2}$ capture ready oxygen-fired CFB power plant concept, which is the subject of Volume-II of this report. 


\section{TABLE OF CONTENTS}

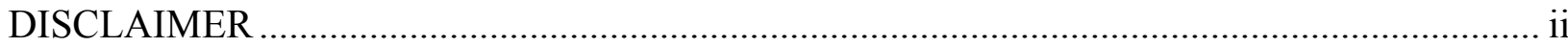

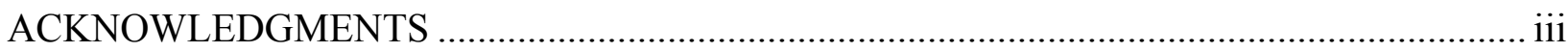

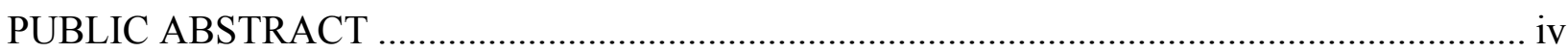

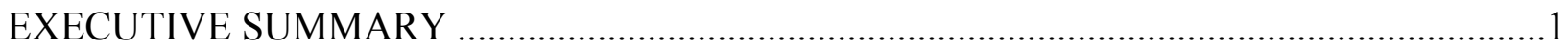

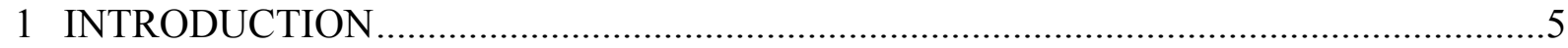

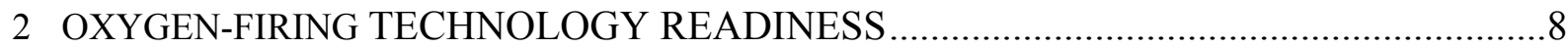

$2.1 \mathrm{O}_{2}$ Fired CFB Technology Development by ALSTOM ............................................

2.1.1 ALSTOM's Development Roadmap .................................................................. 8

2.1.2 Brief Project Descriptions ……………………............................................. 11

2.1.3 Summary of Results.................................................................................... 14

$2.2 \quad \mathrm{O}_{2}$ Fired Pulverized Fuel Technology Development..................................................21

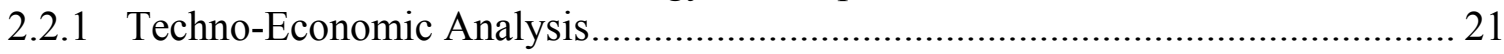

2.2.2 Combustion Testing in Pilot-Scale and Demonstration Plant ............................... 23

2.2.3 Vattenfall Demonstration Project ..................................................................... 27

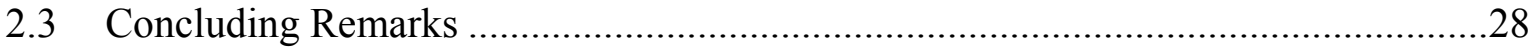

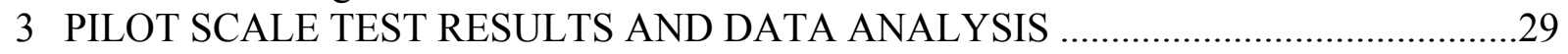

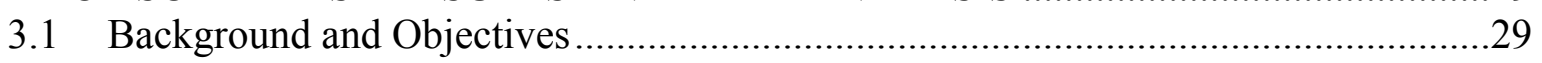

3.1.1 MTF Pilot Tests Conducted in Year 2004 .......................................................... 29

3.1.2 Objectives of the 2005 MTF Pilot Tests............................................................. 30

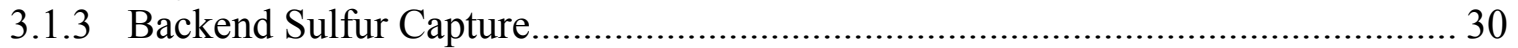

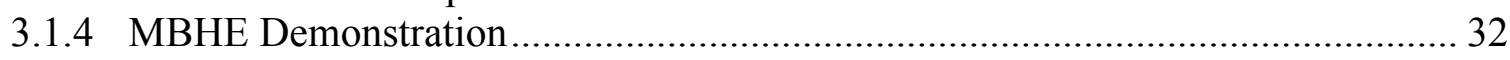

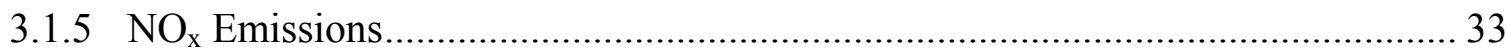

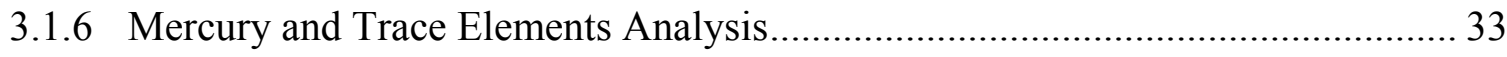

3.1.7 Convective Pass Fouling and Heat Transfer.......................................................... 33

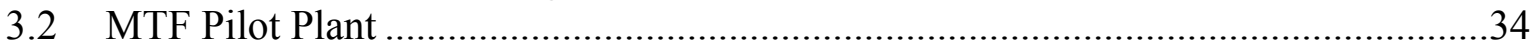

3.2.1 General Facility Description............................................................................ 34

3.2.2 Facility Modification for Oxygen Firing ………………………....................... 39

3.2.3 Differences Between 2004 and 2005 Pilot Plant Modifications............................ 42

3.2.4 Differences Between Pilot Plant and Commercial Unit .......................................... 43

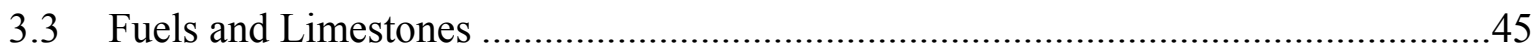

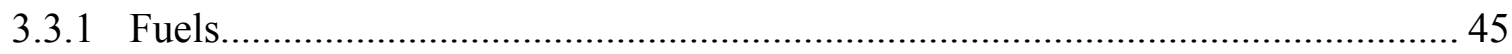

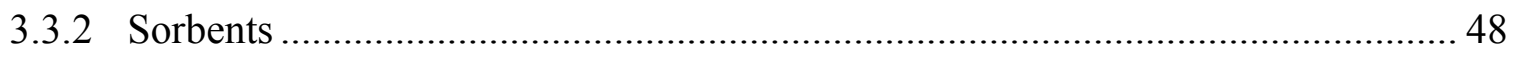

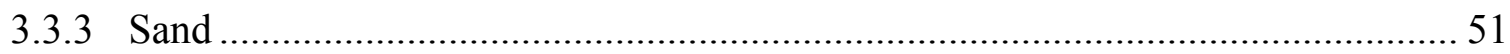

3.4 Test Description and Conditions ………………….........................................51

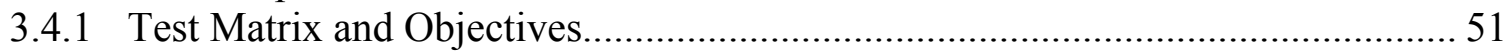

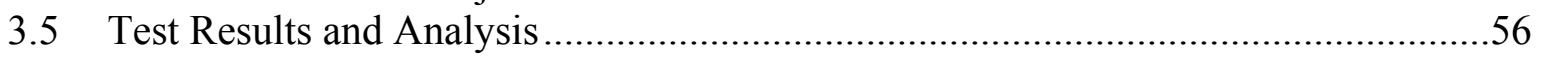

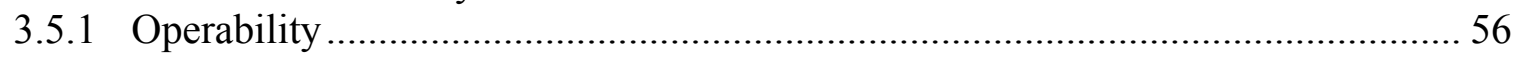

3.5.2 Approaches to Steady State ………………………………………………..... 56

3.5.3 Furnace Temperature and Pressure Profiles ....................................................... 57

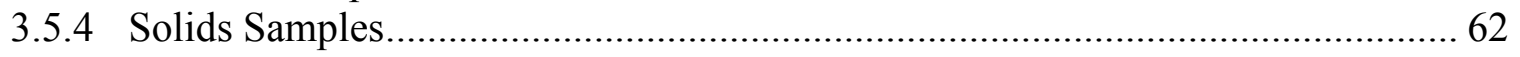

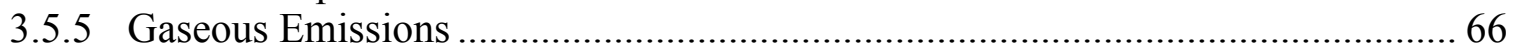

3.5.6 Sulfur Emissions and Backend Capture …………............................................ 70

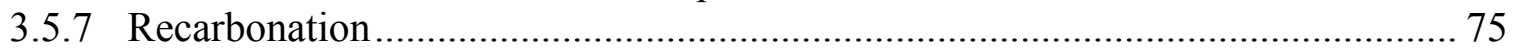

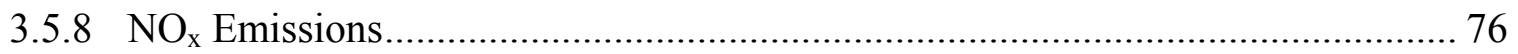




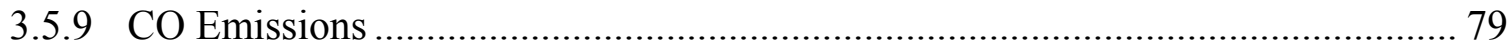

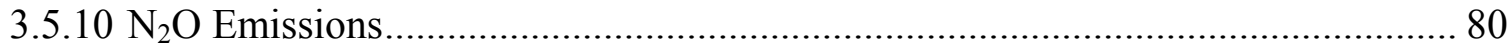

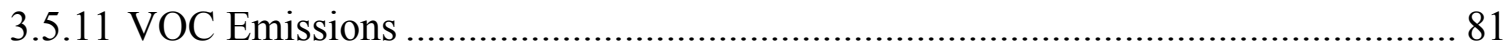

3.5.12 Combustion Efficiencies/Unburned Carbon (UBC) Emissions ........................... 82

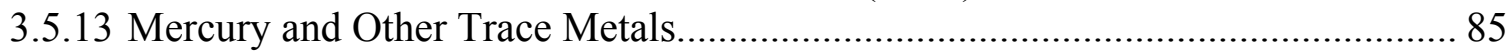

3.5.14 Convective Pass Heat Transfer and Fouling....................................................... 89

3.5.15 Moving Bed Heat Exchanger ……………........................................................ 90

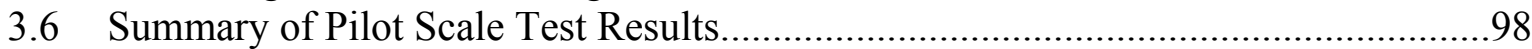

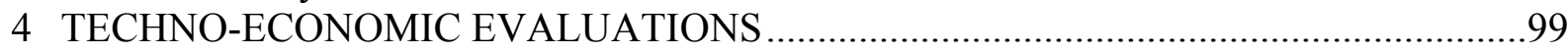

4.1 Study Unit Selection and Description..............................................................100

4.1.1 Study Unit Selection Criteria........................................................................ 100

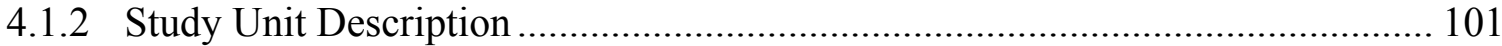

4.2 Plant Performance Basis, Equipment Design Basis, and Project Scope....................105

4.2.1 Common Parameters for Case Studies .......................................................... 105

4.2.2 Additional Design Bases Used for Case-2 ……............................................... 108

4.2.3 Project Scope ........................................................................................ 110

4.3 Case-1: Existing CFB Power Plant, Air Fired without $\mathrm{CO}_{2}$ Capture (Base

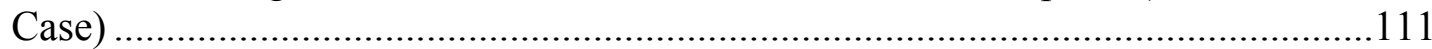

4.3.1 Case-1: Development of CFB Boiler Computer Model ........................................ 111

4.3.2 Case-1: Boiler Island Process Description, Performance, and Equipment.......... 112

4.3.3 Case-1: Boiler Performance Summary ………….......................................... 115

4.3.4 Case-1: Steam Cycle Performance Summary ................................................... 115

4.3.5 Case-1: Overall Plant Performance and $\mathrm{CO}_{2}$ Emissions Summary..................... 116

4.4 Case-2: Existing CFB Power Plant Retrofit with Oxygen Firing and $\mathrm{CO}_{2}$

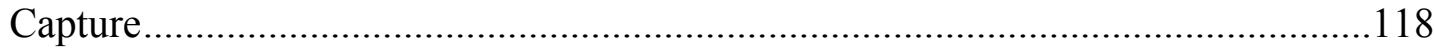

4.4.1 Case-2: Existing Power Plant Modifications...................................................... 118

4.4.2 Case-2: Oxygen Fired CFB Boiler Computer Model.......................................... 130

4.4.3 Case-2: Boiler Island Process Description, Performance, and Equipment.......... 131

4.4.4 Case-2: Gas Processing System (GPS): Process Description, Performance,

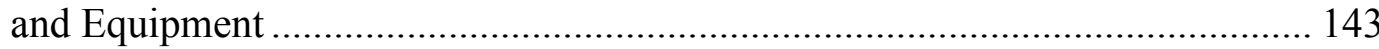

4.4.5 Case-2: Air Separation Unit (ASU): Process Description, Performance, and

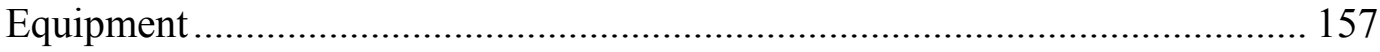

4.4.6 Case-2: Balance of Plant Equipment and Performance..................................... 162

4.4.7 Case-2: Overall Plant Performance and $\mathrm{CO}_{2}$ Emissions Summary ...................... 165

4.5 Retrofit Cost Analysis.......................................................................................171

4.5.1 Cost Estimation Basis:................................................................................. 171

4.5.2 Plant Investment Cost and Operating and Maintenance Cost Summary:............ 175

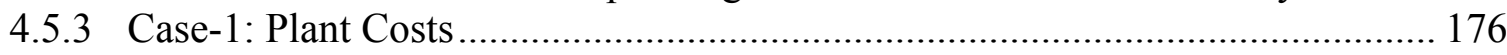

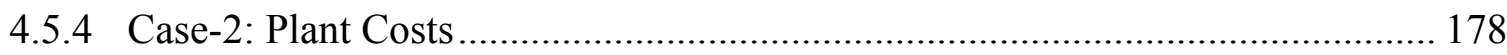

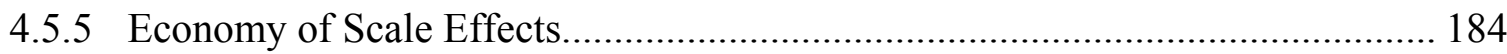

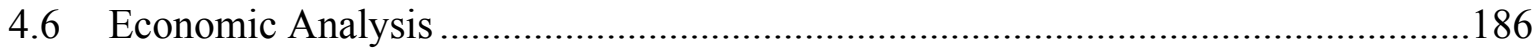

4.6.1 Economic Analysis Assumptions: ............................................................... 186

4.6.2 Economic Analysis Results Summary …………......................................... 188

4.6.3 Economic Analysis Sensitivity Study Results:................................................... 189

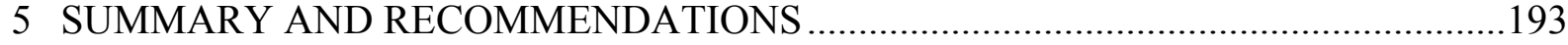

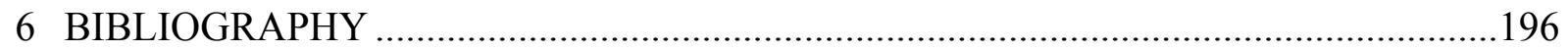




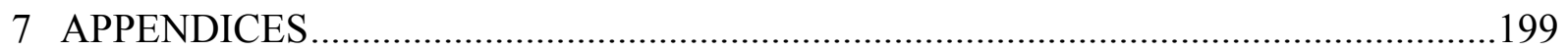

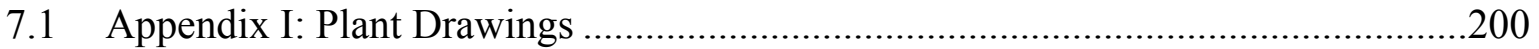

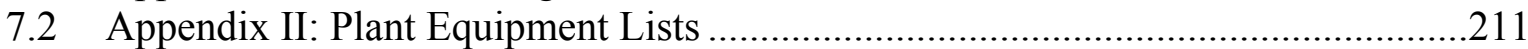

7.2.1 Case-2: Modified CFB Boiler Equipment ........................................................ 212

7.2.2 Case-2: New Gas Processing System Equipment ............................................. 214

7.2.3 Case-2: New Air Separation Unit Equipment ............................................. 215 


\section{LIST OF FIGURES}

Figure 2.1: Oxygen-Fired CFB Technology Development Horizon....................................... 9

Figure 2.2: Schematic of Vattenfall's Oxyfuel Demonstration Pilot Plant ..................... 28

Figure 3.1: Equilibrium Temperature for Calcination ............................................ 31

Figure 3.2: Boiler Heat Absorption Comparison - Air and 70\% $\mathrm{O}_{2}$ Firing .................... 33

Figure 3.3: Schematic of the Multi-use Test Facility (MFT) ....................................... 34

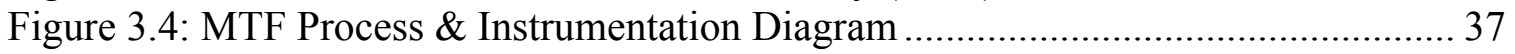

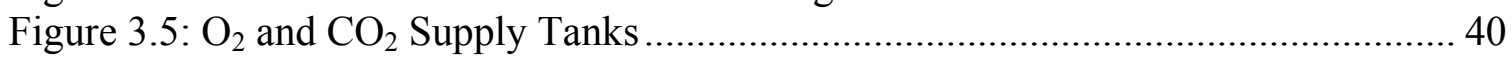

Figure 3.6: Schematic of Oxygen and Carbon Dioxide Flows to the MTF ..................... 41

Figure 3.7: Modified Fluidized Bed Heat Exchanger Showing Air Vent........................ 42

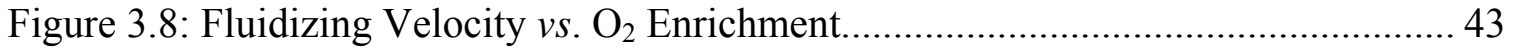

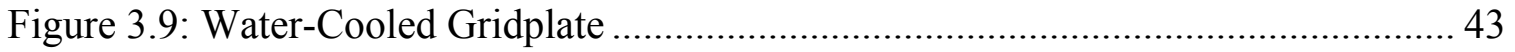

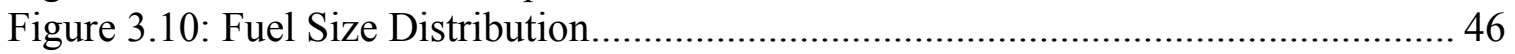

Figure 3.11: Limestone and Sand Screen Size Distribution ........................................ 50

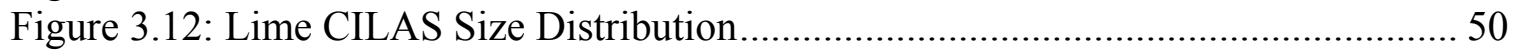

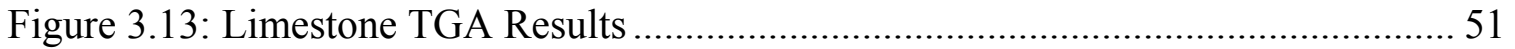

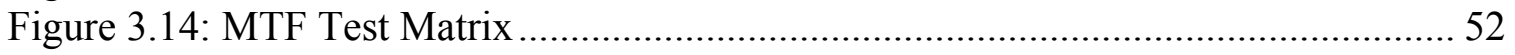

Figure 3.15: MTF Test Summary Figure .................................................................. 54

Figure 3.16: Calcium-to-Inert Ratio of Ash Samples ................................................. 57

Figure 3.17: Key for Temperature and Pressure Locations ............................................ 58

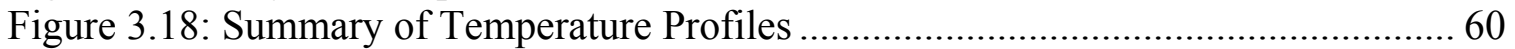

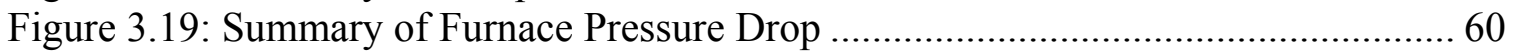

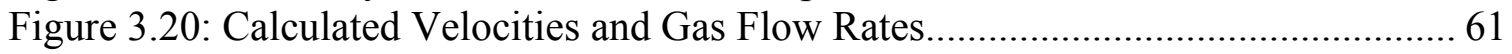

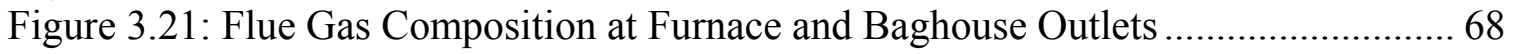

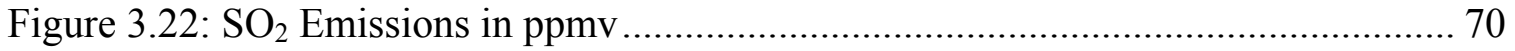

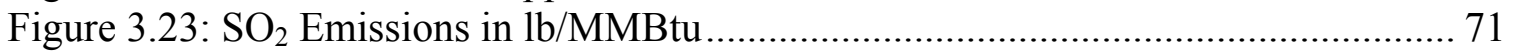

Figure 3.24: Summary of $\mathrm{SO}_{2}$ Emissions ............................................................... 72

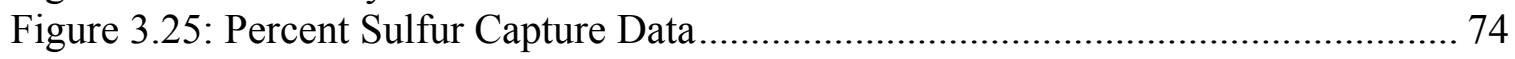

Figure 3.26: Calcium Utilization of Ash Samples ................................................... 75

Figure 3.27: Recarbonation of Solids Samples .................................................... 76

Figure 3.28: $\mathrm{NO}_{\mathrm{x}}$ Emissions vs. Mid Furnace Temperature ......................................... 77

Figure 3.29: SNCR test with Bituminous and Oxygen Firing ....................................... 78

Figure 3.30: SNCR Test with Pet Coke and Oxygen Firing .......................................... 78

Figure 3.31: CO Emissions vs. Upper Furnace Temperature ........................................ 80

Figure 3.32: $\mathrm{N}_{2} \mathrm{O}$ Emissions vs. Upper Furnace Temperature.................................... 81

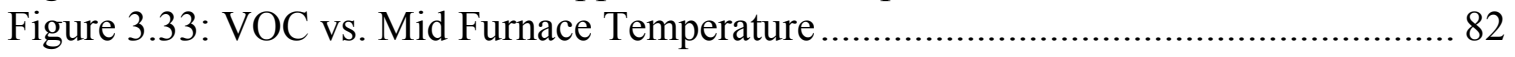

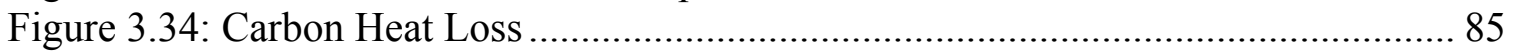

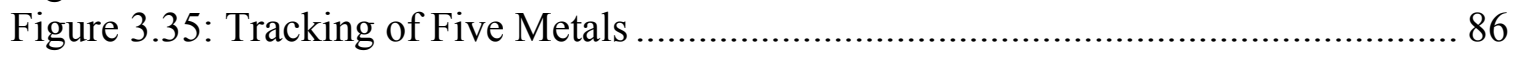

Figure 3.36: Calculated Metals Concentration on Dust............................................... 87

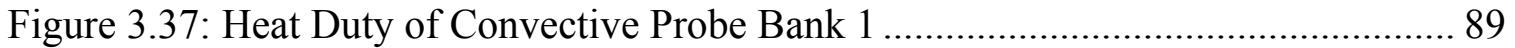

Figure 3.38: Heat Duty of Convective Probe Bank 2 ................................................. 90

Figure 3.39: Moving Bed Heat Exchanger Sectional Views ...................................... 95

Figure 3.40: Moving Bed Heat Exchanger ................................................................. 96

Figure 3.41: Moving Bed Heat Exchanger Average Solids Temperatures..................... 96

Figure 3.42: Moving Bed Heat Exchanger Solids and Heat Flows ................................ 97 
Figure 4.1: Study Unit (Existing CFB Steam Generator) Sectional Side Elevation Drawing...

Figure 4.2: Case-1 (Base Case) Simplified Boiler Island Gas Side Process Flow Diagram

Figure 4.3: Case-1 Simplified Steam Cycle Diagram and Performance ....................... 116

Figure 4.4: Case-1 Steam Cycle State Points Shown on T-S and H-S Coordinates...... 116

Figure 4.5: Simplified $\mathrm{O}_{2}$ Fired Concept Diagram ................................................... 118

Figure 4.6: New Gas Recirculation and Oxygen Supply Ductwork Sketch.................. 121

Figure 4.7: Case-2 New Ductwork Arrangement Drawing ......................................... 122

Figure 4.8: Case-2 New Duct and Damper P\&ID Schematic...................................... 126

Figure 4.9: Flash Dryer Absorber (FDA) System Schematic Diagram (simplified) ..... 128

Figure 4.10: Case-2 New Flash Dryer Absorber (FDA) System General Arrangement

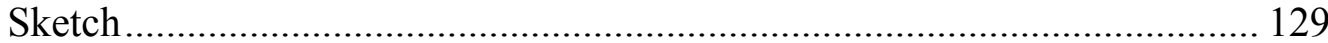

Figure 4.11: Case-2 Low Level Heat Recovery System Schematic ............................. 130

Figure 4.12: Calcination Temperature of Calcium Carbonate..................................... 133

Figure 4.13: Case-2 Simplified Boiler Island Gas Side Process Flow Diagram ........... 136

Figure 4.14: CFB Boiler Heat Absorption Comparison (Air and $\mathrm{O}_{2}$ Firing)................. 140

Figure 4.15: Convective Heat Transfer Rate Comparison .......................................... 141

Figure 4.16: Non-Luminous Radiant Heat Transfer Rate Comparison .......................... 141

Figure 4.17: Total Heat Transfer Rate Comparison.................................................... 142

Figure 4.18: Case-2 Process Flow Diagram for Flue Gas Quenching ........................... 149

Figure 4.19: Case-2 Process Flow Diagram for Flue Gas Compression ....................... 150

Figure 4.20: Case-2 Process Flow Diagram for Distillation........................................ 151

Figure 4.21: Case-2 Process Flow Diagram for Propane Refrigeration ........................ 152

Figure 4.22: Case-2 Air Separation Unit Process Flow Diagram................................. 159

Figure 4.23: Case-2 Steam Cycle Schematic and Performance................................... 163

Figure 4.24: Case-2 Steam Cycle State Points Shown on T-S and H-S Coordinates ..... 163

Figure 4.25: Boiler Efficiency Comparison.............................................................. 167

Figure 4.26: Steam Cycle Efficiency Comparison .................................................... 168

Figure 4.27: Auxiliary Power Comparison between Air-Fired and Oxygen Fired CFB

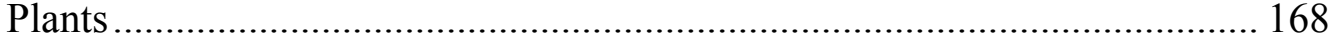

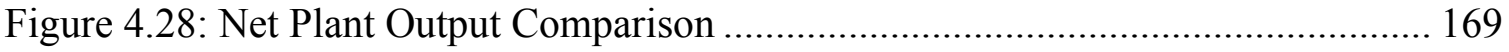

Figure 4.29: Net Plant Thermal Efficiency Comparison ........................................... 170

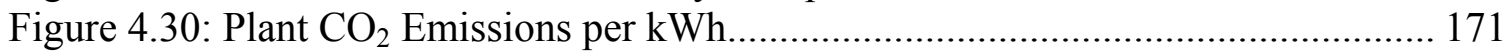

Figure 4.31: Gas Processing System Specific Cost Comparison.................................. 185

Figure 4.32: Incremental Cost of Electricity for Case-2 ......................................... 189

Figure 4.33: Economic Sensitivity Analysis Results for Case 2 ................................. 190

Figure 7.1: Case 1 - Existing Site Plot Plan Drawing Identifying Selected Major

Equipment Locations ......................................................................... 201

Figure 7.2: Case-1 - General Arrangement Boiler Side Elevation Drawing (existing CFB

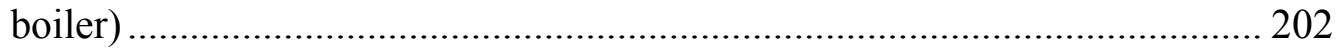

Figure 7.3: Case-1 - General Arrangement Boiler Plot Plan Drawing (existing CFB

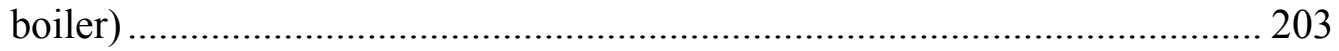

Figure 7.4: Side Elevation Drawing of Existing Baghouse and ID Fan ....................... 204

Figure 7.5: Plan View of Existing Baghouse and ID Fan........................................ 205 
Figure 7.6: Case-2 - General Arrangement of New Ductwork for Gas Recirculation and Oxygen Supply................................................................................... 206

Figure 7.7: Case-2 - Section Views of New Ductwork for Gas Recirculation and Oxygen Supply ............................................................................................... 207

Figure 7.8: Case-2 - New Gas Cooler and Gas Processing System Layout Drawing .... 208

Figure 7.9: Case 2 - New Air Separation Unit Layout Drawing .................................. 209

Figure 7.10: Case 2 - Modified Site Plot Plan Drawing Showing Locations of Existing Boiler and Major New Equipment ........................................................... 210 
COMMERCIALIZATION DEVELOPMENT OF OXYGEN FIRED CFB

FOR GREENHOUSE GAS CONTROL

\section{LIST OF TABLES}

Table 2.1: Performance Analyses for Various Power Plant Concepts............................ 16

Table 2.2: Cost Analyses for Various Power Plant Concepts........................................ 17

Table 2.3: Cost of Electricity and Avoided Cost for Various Power Plant Concepts ...... 18

Table 2.4: Summary of Bench-Scale FBC Testing........................................................ 19

Table 2.5: Summary of Previous Pilot-Scale Test Results ........................................... 20

Table 2.6: Techno-Economic Analysis Results of Oxy Combustion of Coal for $\mathrm{CO}_{2}$ Capture (from Dillon, et al., 2005)........................................................... 22

Table 2.7: Summary of Techno-Economic Studies of Coal Power Plant (From Tan, et al, 2005)

Table 2.8: List of Pilot-Scale Studies (from Tan, et al., 2005; Wall, et al., 2004) .......... 24

Table 2.9: Demonstration Plant Studies (from Tan, et al., 2005; Wall, et al., 2004) ....... 25

Table 2.10: Summary of $\mathrm{NO}_{\mathrm{x}}$ Emissions Results (From Tan, et al., 2005).................... 26

Table 2.11: Summary of $\mathrm{SO}_{2}$ Emissions Results (From Tan, et al., 2005) ...................... 27

Table 3.1: Typical Flue Gas Composition - Air vs. Oxygen Fired ................................. 32

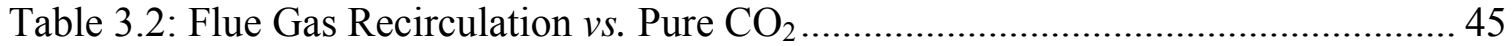

Table 3.3: Analysis and Size Distribution of Fuel Samples ........................................ 47

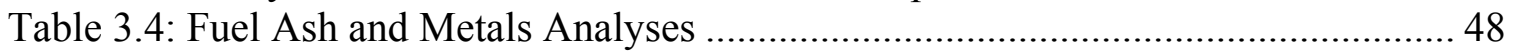

Table 3.5: PSD and Chemical Analysis of Lime and Limestones ................................. 49

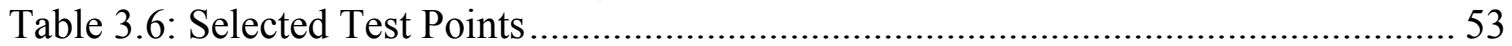

Table 3.7: Summary of Temperature and Pressure Profiles ........................................... 59

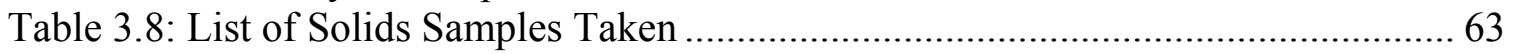

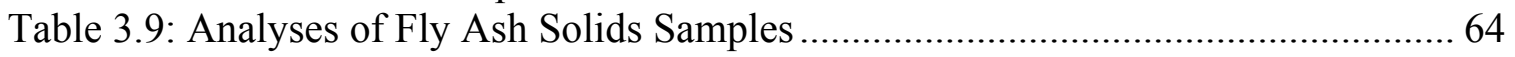

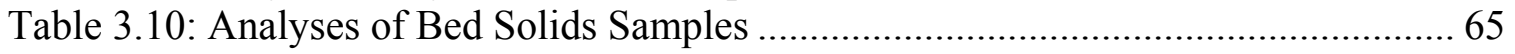

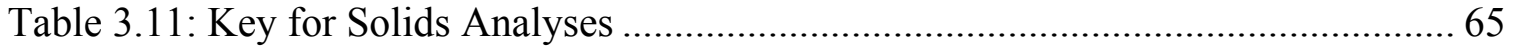

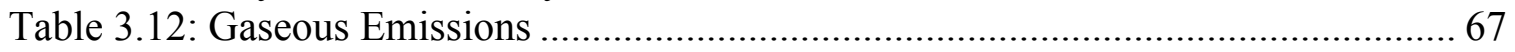

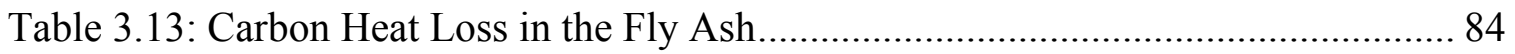

Table 3.14: Metals Data.......................................................................................... 88

Table 3.15: Moving Bed Heat Exchanger (MBHE) Test Data Summary ....................... 94

Table 4.1: Design Coal Analysis (Medium Volatile Bituminous) ................................ 105

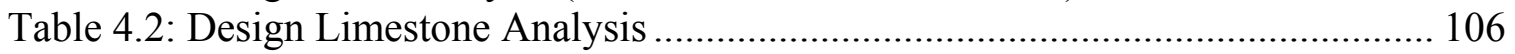

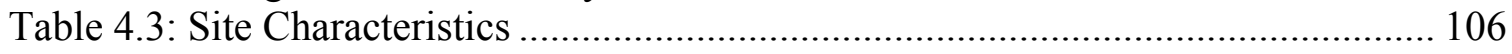

Table 4.4: Dakota Gasification Project's $\mathrm{CO}_{2}$ Product Specification for EOR .............. 108

Table 4.5: Case-1 (Base Case) Boiler Island Gas Side Material and Energy Balance ... 114

Table 4.6: Case-1 (Base Case) Boiler/Turbine Steam Flows and Conditions ............... 115

Table 4.7: Case-1 Overall Plant Performance Summary (Base Case).......................... 117

Table 4.8: Case-2 Ductwork Design Requirements................................................... 120

Table 4.9: Air and Oxygen Fired Flue Gas Comparison ............................................ 130

Table 4.10: Issues for Sulfur Capture in Oxygen Fired CFB ...................................... 134

Table 4.11: Case-2: Boiler Island Gas Side Material and Energy Balance ................... 138

Table 4.12: Case-2 (Base Case) Boiler/Turbine Steam Flows and Conditions .............. 139

Table 4.13: Dakota Gasification Project's $\mathrm{CO}_{2}$ Specification for EOR and the Calculated

Product Stream Purity .................................................................... 144

Table 4.14: Gas Processing System Material \& Energy Balance .................................. 154 
Table 4.15: Case-2 Gas Processing System Cooling Water and Fuel Gas Requirements

Table 4.16: Case-2 Gas Processing System Electrical Requirements ........................... 156

Table 4.17: Ambient Conditions Used for ASU Design................................................ 157

Table 4.18: ASU Oxygen Production and Purity......................................................... 158

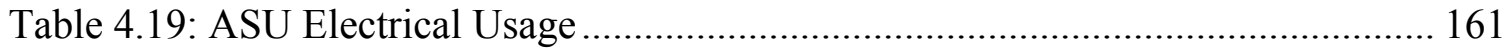

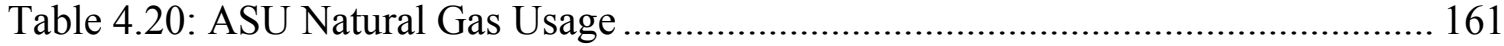

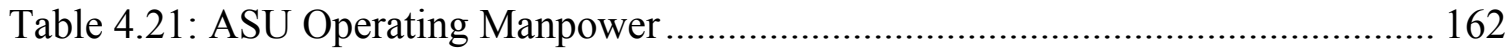

Table 4.22: Plant Performance and $\mathrm{CO}_{2}$ Emissions Summary and Comparison............ 166

Table 4.23: Plant Investment Costs (EPC basis) and O\&M Costs Summary.................. 175

Table 4.24: Case-1: Total Plant Operating and Maintenance Costs ................................ 177

Table 4.25: Case-2 Plant Retrofit Investment Cost Summary ...................................... 178

Table 4.26: Case-2: Total Plant Operating and Maintenance Cost Summary ................. 179

Table 4.27: Case-2: Modified Boiler \& BOP Annual Operating and Maintenance Costs

Table 4.28: Case-2 Gas Processing System Investment Costs ..................................... 182

Table 4.29: Case-2 Gas Processing System Annual Operating and Maintenance Costs 183

Table 4.30: Case-2 ASU Annual Operating Costs...................................................... 184

Table 4.31: Comparison of Gas Processing System Costs ............................................. 185

Table 4.32: Economic Evaluation Study Assumptions.................................................. 187

Table 4.33: Economic Sensitivity Study Parameters and Parameter Values................... 189

Table 4.34: Economic Sensitivity Analysis Results for Case 2 - Oxygen-Fired CFB with

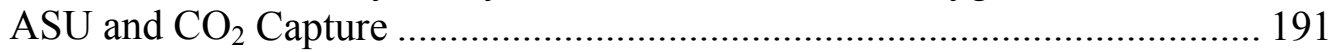




\section{LIST OF ACRONYMS AND ABBREVIATIONS}

\begin{tabular}{|c|c|c|c|}
\hline ABMA & American Boiler Manufacturers Association & $\mathrm{kV}$ & Kilovolt \\
\hline ACFM & Actual cubic feet per minute & kWe & Kilowatts electric \\
\hline ACMM & Actual cubic meters per minute & kWh & Kilowatt-hour \\
\hline ANSI & American National Standards Institute & $\mathrm{lbm}$ & Pound mass \\
\hline ASFH & Air Suction Filter House & LHV & Lower Heating Value \\
\hline ASME & American Society of Mechanical Engineers & LLHR & Low Level Heat Recovery \\
\hline ASU & Air Separation Unit & LMTD & Log Mean Temperature Difference \\
\hline Bara & Bar, absolute & LP & Low Pressure \\
\hline Barg & Bar, gauge & Ipm & Liters per minute \\
\hline $\mathrm{BI}$ & Boiler Island & MAC & Main Air Compressor \\
\hline BFP & Boiler Feedwater Pump & MBHE & Moving Bed Heat Exchanger \\
\hline BOP & Balance of Plant & MCR & Maximum Continuous Rating \\
\hline BSR & Beaven Sulfur Removal & MDEA & Methyl Diethanolamine \\
\hline Btu & British Thermal Unit & MEA & Monoethanolamine \\
\hline CFB & Circulating Fluidized Bed & $\mathrm{mm} \mathrm{H}_{2} \mathrm{O}$ & Millimeters of Water \\
\hline CFM & Cubic Feet per Minute & $\mathrm{mm} \mathrm{Hga}$ & Millimeters of Mercury, Absolute \\
\hline $\mathrm{CHL}$ & Carbon Heat Loss & MTF & Multi-use Test Facility \\
\hline CMM & Cubic Meters per Minute & MTP & Metal Temperature Program \\
\hline $\mathrm{CO}_{2}$ & Carbon Dioxide & MTPD & Metric Tonne Per Day \\
\hline COE & Cost of Electricity & MTPH & Metric Tonne Per Hour \\
\hline $\mathrm{CP}$ & Condensate Pump & MWe & Megawatt Electric \\
\hline CS & Carbon Steel & $\mathrm{MW}_{\text {th }}$ & Megawatt Thermal \\
\hline $\mathrm{dB}$ & Decibel & $\mathrm{N}_{2}$ & Nitrogen Gas \\
\hline DCA & Direct Contact Aftercooler & & \\
\hline DCS & Distributed Control System & NPHR & Net Plant Heat Rate \\
\hline DGC & Dakota Gasification Company & $\mathrm{O}_{2}$ & Oxygen Gas \\
\hline DOE/NETL & Department of Energy/National Energy Technology Laboratory & O\&M & Operation \& Maintenance \\
\hline ECBM & Enhanced Coal Bed Methane & OTM & Oxygen Transport Membrane \\
\hline EGR & Enhanced Gas Recovery & P\&ID & Process \& Instrumentation Diagram \\
\hline EHE & External Heat Exchanger & PA & Primary Air \\
\hline EOR & Enhanced Oil Recovery & $\mathrm{PC}$ & Pulverized Coal \\
\hline EPC & Engineered, Procured and Constructed (cost basis) & PFD & Process Flow Diagram \\
\hline FBC & Fluidized Bed Combustion & PFWH & Parallel Feedwater Heater \\
\hline FBHE & Fluidized Bed Heat Exchanger & $\mathrm{PHX}$ & Primary Heat Exchanger \\
\hline FD & Forced Draft & ppm & Parts per million \\
\hline FDA & Flash Drier Absorber & ppmv & Parts per million (by volume) \\
\hline FGD & Flue Gas Desulfurization & ppmw & Parts per million (by weight) \\
\hline FGR & Flue Gas Recirculation & psia & Pound per square inch, absolute \\
\hline FF & Fabric Filter & psig & Pound per square inch, gauge \\
\hline FOM & Fixed Operation \& Maintenance & RHBP & Reheat Boiler Program \\
\hline gpm & Gallons per minute & & \\
\hline GPS & Gas Processing System & SA & Secondary Air \\
\hline GWe & Gigawatt electric & SNCR & Selective Non Catalytic Reduction \\
\hline $\mathrm{HHV}$ & Higher Heating Value & TGA & Thermo-Gravimetric Analysis \\
\hline $\mathrm{HP}$ & High Pressure & TPD & Ton Per Day \\
\hline hp & Horse Power & $\mathrm{TPH}$ & Ton Per Hour \\
\hline $\mathrm{hr}$ & Hour & TSA & Temperature Swing Adsorption \\
\hline ID & Induced Draft & UBC & Unburned Carbon \\
\hline IP & Intermediate Pressure & UCT & Upper Column Turbine \\
\hline in. $\mathrm{H}_{2} \mathrm{O}$ & Inches of Water & V & Volt \\
\hline in. $\mathrm{Hga}$ & Inches of Mercury, Absolute & VOC & Volatile Organic Compounds \\
\hline $\mathrm{kg}$ & Kilogram & VOM & Variable Operation \& Maintenance \\
\hline $\mathrm{kJ}$ & Kilojoule & & \\
\hline
\end{tabular}




\section{EXECUTIVE SUMMARY}

\section{Background}

Because fossil fuel fired power plants are among the largest and most concentrated producers of $\mathrm{CO}_{2}$ emissions, recovery and sequestration of $\mathrm{CO}_{2}$ from the flue gas of such plants has been identified as one of the primary means for reducing anthropogenic $\mathrm{CO}_{2}$ emissions. In this study, ALSTOM Power Inc. (ALSTOM) has investigated one promising near-term coal fired power plant configuration designed to capture $\mathrm{CO}_{2}$ from effluent gas streams for sequestration.

Burning fossil fuels in mixtures of oxygen and recirculated flue gas (principally $\mathrm{CO}_{2}$ ) see schematic below - essentially eliminates the atmospheric nitrogen in the flue gas. The resulting flue gas comprises primarily $\mathrm{CO}_{2}$, along with some moisture, nitrogen, oxygen, and trace gases like $\mathrm{SO}_{2}$ and NOx. Thus, this flue gas can be processed relatively easily to enrich the $\mathrm{CO}_{2}$ content to $96-99^{+}$percent for use in enhanced oil or gas recovery (EOR or EGR) or simply dried for sequestration.

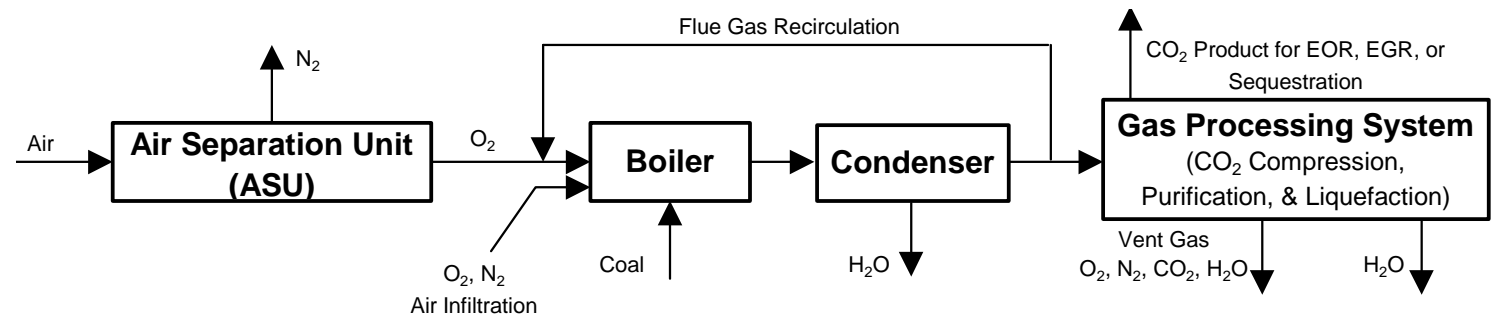

Oxygen firing in utility scale Pulverized Coal (PC) fired boilers has been shown to be a more economical method for $\mathrm{CO}_{2}$ capture than scrubbing with Kerr-McGee-Lummus Crest monoethanolamine (MEA), which is a currently available technology (Bozzuto, et al., 2001). Additionally, oxygen firing in new Circulating Fluid Bed Boilers (CFB's) can be more economical than in PC or Stoker firing, because recirculated gas flow can be reduced significantly. Oxygen-fired PC and Stoker units require large quantities of recirculated flue gas to maintain acceptable furnace temperatures. New oxygen-fired CFB units, on the other hand, can accomplish this by additional cooling of recirculated solids. The reduced recirculated gas flow with new CFB plants results in significant Boiler Island cost savings resulting from reduced component sizes (Marion, et al., 2003).

\section{Project Objective}

The objective of this work is to help prepare the oxygen fired CFB technology for largescale demonstration, especially for an enhanced oil or gas recovery (EOR or EGR) application. This was accomplished through the performance of two major milestones in this project:

\section{Pilot Scale Testing}

A pilot plant test of the oxygen-fired CFB concept was carried out in ALSTOM's 3.0 MWth (9.9 MMBtu/hr) Multi-use Test Facility (MTF). The specifically targeted objectives of this testing include:

- Demonstration of $\mathrm{SO}_{2}$ polishing, specifically ALSTOM's Flash Dryer Absorber (FDA) process for reducing $\mathrm{SO}_{2}$ emissions from the flue gas, which is concentrated to 
high $\mathrm{CO}_{2}, \mathrm{H}_{2} \mathrm{O}$, and $\mathrm{SO}_{2}$ levels due to oxygen firing (i.e., no nitrogen dilution)

- Assessment of volatile organic compounds (VOC's), mercury, and other trace elements emission potentials

- Determination of back-pass convective section heat transfer performance

- Demonstration of the suitability and performance of a moving bed heat exchanger (MBHE) in place of a fluidized bed heat exchanger (FBHE).

\section{Commercial Design Implications}

A conceptual retrofit design study to convert an existing 90-MWe (nominal) air fired CFB plant to oxygen firing for $\mathrm{CO}_{2}$ capture for an EOR application was carried out. This study was developed on the basis of ALSTOM's commercial CFB boiler design and performance standards as well as the technical information obtained from previous and current $\mathrm{O}_{2}$ fired MTF test campaigns. Results from the testing were used in this design study. The design study scope included development of the retrofit design, calculation of overall plant performance and $\mathrm{CO}_{2}$ emissions (Base Case and Retrofit Case), estimation of incremental retrofit costs, and economic analysis. This work sets the stage for developing a first of a kind large-scale demonstration of an oxygen fired CFB project in North America.

\section{Project Results Summary}

The MTF operated successfully with $\mathrm{O}_{2}$ firing with both coal and petroleum coke, consistent with the two test campaigns conducted in 2004 (Nsakala, Liljedahl, and Turek, 2004). No technical barriers to continued development of the $\mathrm{O}_{2}$ fired technology were found. Specific results and conclusions from the 2005 MTF pilot-scale testing are summarized here.

- There were no operational problems due to recarbonation or any other issues due to the oxygen firing over the range of CFB conditions tested.

- The sulfur capture with lime only to the back-end baghouse/FDA system was slightly lower with oxygen firing compared to air firing. There is evidence of some $\mathrm{CO}_{2}$ being captured in the FDA, along with the $\mathrm{SO}_{2}$.

- The sulfur capture in the furnace with limestone addition was higher with oxygen firing than with air firing. This was likely due in part to lower velocity with oxyfiring (longer residence time) and in part to more calcium in the furnace inventory during the oxygen fired tests.

- However, because of the higher capture in the furnace, the $\mathrm{SO}_{2}$ entering the FDA was lower with oxygen firing. The percentage sulfur reduction across the FDA was similar for air and oxygen firing.

- As expected, the $\mathrm{NO}_{\mathrm{x}}$ emissions were low with oxygen firing. Ammonia addition further reduced the $\mathrm{NO}_{\mathrm{x}}$ emissions. When the base $\mathrm{NO}_{\mathrm{x}}$ level was very low (50 ppmv), high stoichiometric ratios were required, which could lead to high ammonia slip. When $\mathrm{NO}_{\mathrm{x}}$ emissions were somewhat higher (100 ppmv), more reasonable amounts of ammonia achieved about $50 \%$ reduction. 
- $\mathrm{CO}$ emissions from bituminous coal were higher with oxygen firing than with air firing. This is likely due to the high $\mathrm{CO}_{2}$ partial pressure in the flue gas suppressing the oxidation of $\mathrm{CO}$. The $\mathrm{CO}$ emissions from pet coke were also low with oxygen firing.

- The $\mathrm{N}_{2} \mathrm{O}$ and VOC emissions were low over the range of CFB conditions tested.

- The heat loss due to unburned carbon in the fly ash was slightly less with oxygen firing compared to air firing.

- The emissions of mercury and other trace metals when oxy-firing were at least as low as with air firing.

- The MBHE performed as expected in terms of heat transfer. The performance did not deteriorate or change due to changes in firing conditions of the test campaign: load, fuel, limestone, or air vs. $\mathrm{O}_{2}$.

- The MBHE was opened for inspection after the test campaign and the surfaces were found to be clean with no evidence of solids accumulation over the brief test period.

The techno-economic study results are summarized in terms of the impact of retrofitting a small $(90 \mathrm{MWe}) \mathrm{CFB}$ plant with $\mathrm{O}_{2}$ firing and $\mathrm{CO}_{2}$ capture technology. The most important impacts include plant overall thermal efficiency reduction, plant net power output reduction, plant avoided $\mathrm{CO}_{2}$ emissions, area requirements for locating new equipment, the incremental investment cost, the incremental levelized cost of electricity $(\mathrm{COE})$, and $\mathrm{CO}_{2}$ mitigation cost results. These impacts are quantified in the following list:

- Plant Overall Thermal Efficiency Reduction $\sim 12.0$ percentage points

- Plant Net Power Output $\sim 69$ percent of air fired net output

- Plant $\mathrm{CO}_{2}$ Capture $\sim 94$ percent

- Plant Avoided $\mathrm{CO}_{2}$ Emissions $\sim 0.80 \mathrm{~kg} / \mathrm{kWhr}(\sim 1.77 \mathrm{lbm} / \mathrm{kWhr})$

- Product $\mathrm{CO}_{2}$ Content $\sim 99.8$ percent by volume (EOR application was assumed)

- Area Required for the ASU and GPS $\sim 10,100 \mathrm{~m}^{2}$ ( 2.5 acres total)

- Incremental Investment Cost $\sim 1,545 \$ / \mathrm{kW}$-new, $\sim 1,060 \$ / \mathrm{kW}$-original

- Incremental COE $\sim 3.1$ cents/kWhr

- $\mathrm{CO}_{2}$ Mitigation Cost $\sim 38.8 \$$ /tonne $\mathrm{CO}_{2}$ avoided ( 35.3 \$/ton)

It should be emphasized that because of the small size of this unit ( $~ 90 \mathrm{MWe}$-original, $62 \mathrm{MWe}-\mathrm{new}$ - after retrofit) some of the impacts listed above are strongly influenced by economy of scale effects. The retrofit costs required and the resulting economic impacts are significantly greater than would be expected with more typically sized CFB based power plants. The relatively low steam conditions for this existing unit contribute to the large impact on efficiency and a smaller impact on the economics. 


\section{Remarks and Recommendations}

Oxyfuel combustion is one of the promising near-term clean coal technologies being developed by the power industry. Firing coal with pure oxygen plus recycled flue gas (which is mainly $\mathrm{CO}_{2}$ ) produces a product flue gas, which is highly $\mathrm{CO}_{2}$-concentrated. This product flue gas can be simply dried and compressed for sequestration, leading to a near zero emissions power plant, or further processed into a high purity $\mathrm{CO}_{2}$ product for various uses, such as enhanced oil recovery (EOR) or enhanced gas recovery (EGR).

Results by ALSTOM and others indicate that this is an attractive option for coal combustion, for the following reasons:

- It uses proven and reliable commercially available pulverized coal (PC) or circulating fluidized bed (CFB) boiler technology

- It uses commercially available $\mathrm{CO}_{2}$ capture enabling technologies:

$>$ Oxygen production by cryogenic air separation

$>\mathrm{CO}_{2}$ purification, compression, and liquefaction

- There appear to be no show-stoppers in terms of:

$>$ Furnace operation

$>$ Heat transfer

$>$ Emissions of major gas species and trace elements

The development of this technology has proceeded to a level where it is now ready for large-scale demonstration. To prepare for demonstration of the oxygen-fired CFB concept, ALSTOM is now actively seeking partners for this important next step. Following a successful large-scale demonstration of the $\mathrm{O}_{2}$ fired technology, commercial offerings would be possible. Based on these results, it is recommended that this technology be demonstrated.

ALSTOM also identified a need to investigate the design of the $\mathrm{CO}_{2}$ capture ready oxygen-fired CFB power plant concept, which is the subject of Volume-II of this report. 


\section{INTRODUCTION}

The greenhouse effect is created by the presence of a number of gases in the atmosphere, with $\mathrm{CO}_{2}$ accounting for about 50 percent of this effect. Large quantities of $\mathrm{CO}_{2}$ are produced from fossil fuel combustion. Coal fired power plants represent some of the largest point sources for $\mathrm{CO}_{2}$ emissions and therefore these units will likely be early targets for conversion to $\mathrm{CO}_{2}$ capture and sequestration if the US decides to regulate $\mathrm{CO}_{2}$ emissions.

Previous studies (e.g., Bozzuto, et al., 2001) have shown that $\mathrm{CO}_{2}$ capture from existing coal fired plants utilizing Lummus-Kerr/McGee's commercial monoethanolamine-based (MEA) flue gas scrubbing systems would reduce plant output and efficiency by about 40 percent and increase cost of electricity by almost 6.2 cents/kWh. More recently, advanced amine technologies by Fluor (Econamine FG Plus) and MHI (KS-I) show, on paper, marked improvements in energy penalty and decreases in cost of electricity for Greenfield power plants (International Energy Agency, 2004). The respective values for the Econamine FG Plus were found to be 21 percent and 1.8 cents $/ \mathrm{kWh}$, and the corresponding numbers for the KS-1 were 19 percent and 2.0 cents $/ \mathrm{kWh}$.

An alternative method for $\mathrm{CO}_{2}$ capture is to burn fossil fuels in a mixture of oxygen and recycled flue gas (see schematic below). This concept eliminates almost all atmospheric nitrogen in the flue gas, thereby resulting in a flue gas stream that is composed primarily of $\mathrm{CO}_{2}$, along with small quantities of moisture, oxygen, nitrogen, and trace gases like $\mathrm{SO}_{2}$ and $\mathrm{NO}_{\mathrm{x}}$. This stream can be easily further processed into a high purity $\mathrm{CO}_{2}$ product for various uses such as EOR (as was assumed in this study), EGR, or simply dried and compressed for sequestration.

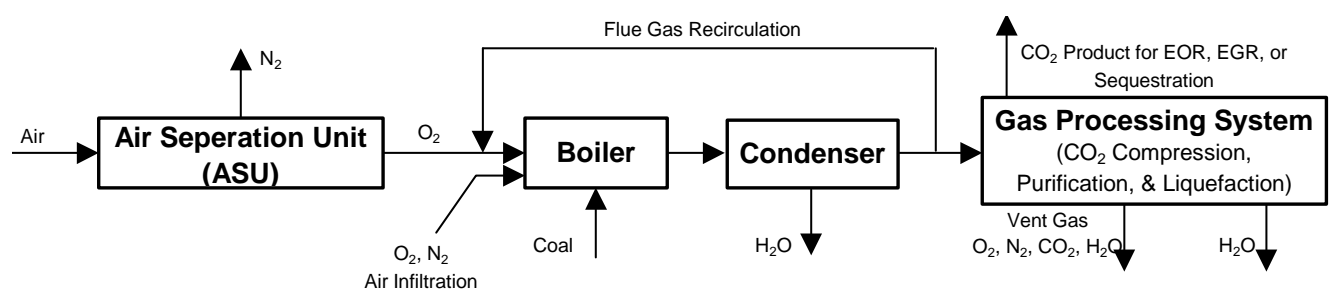

The combination of recycled flue gas/oxygen mixtures in concert with combustion in a circulating fluidized bed (CFB) boiler offers unique advantages compared to alternative methods of firing fossil fuels with oxygen. Unlike pulverized coal (PC) combustion or Stoker firing, circulating fluidized bed combustion has the advantage of controlling combustion chamber temperatures by modulating the recycle rate of cooled solids. This unique feature of a circulating fluidized bed combustor means that much higher percentages of oxygen can potentially be used in the combustion process than would be possible in alternate firing applications.

Though the primary motivation for using oxygen is to facilitate $\mathrm{CO}_{2}$ capture, newly constructed CFB combustors will be able to capitalize on the use of high oxygen content firing. Specifically, the use of higher oxygen content will allow a more compact, less expensive CFB boiler and improve overall system thermal efficiency.

To investigate the feasibility of various carbon capture technologies, including the oxygen-fired CFB concept, the US Department of Energy's National Energy Technology 
Laboratory (DOE) sponsored a two-phase program under a Cooperative Agreement DEFC26-01NT41146. This work was executed from September 28, 2001 to October 27, 2004.

Phase I entailed a comprehensive study evaluating the technical feasibility and economics of alternate $\mathrm{CO}_{2}$ capture technologies applied to Greenfield US coal-fired electric generation power plants. Thirteen cases, representing various levels of technology development, were evaluated. Seven cases represent coal combustion in CFB type equipment. Four cases represent Integrated Gasification Combined Cycle (IGCC) systems. Two cases represent advanced Chemical Looping systems. Marion, et al. reported the details of this work in 2003.

One of the thirteen cases studied was an oxygen-fired CFB boiler plant. In this concept, the fuel is fired with oxygen plus recirculated flue gas (mainly $\mathrm{CO}_{2}$ ), yielding a flue gas containing over 80 percent $\mathrm{CO}_{2}$. This flue gas can be easily processed to capture over 93 percent of the $\mathrm{CO}_{2}$ for sequestration or use in enhanced oil or gas recovery (EOR or EGR). The Phase I study identified the $\mathrm{O}_{2}$-fired CFB as having a near term development potential, because it uses conventional commercial CFB technology and commercially available enabling technologies such as cryogenic air separation and simple rectification or distillation based gas processing systems.

Phase II consisted of pilot-scale testing followed by a refined performance and economic evaluation of the oxygen-fired CFB concept. As a part of this workscope, ALSTOM modified its $3.0 \mathrm{MW}_{\text {th }}(9.9 \mathrm{MMBtu} / \mathrm{hr})$ Multiuse Test Facility (MTF) pilot plant to operate with $\mathrm{O}_{2} / \mathrm{CO}_{2}$ mixtures of up to 70 percent $\mathrm{O}_{2}$ by volume. Tests were conducted with coal and petroleum coke fuels. The test objectives were to determine the impacts of oxygen firing on heat transfer, bed dynamics, potential agglomeration, and gaseous and particulate emissions. The test data was used to refine the design, performance, costs, and economic models developed in Phase-I for an $\mathrm{O}_{2}$-fired CFB with $\mathrm{CO}_{2}$ capture. Results from the Phase II study have been reported by Nsakala, Liljedahl, and Turek in 2004.

In 2004, ALSTOM identified several additional items needing investigation in preparation for large-scale demonstration of the oxygen-fired CFB concept, namely:

- Operation and performance of the moving bed heat exchanger (MBHE) to avoid recarbonation and also for cost savings compared to the standard bubbling fluid bed heat exchanger (FBHE).

- Performance of the back-end flash dryer absorber (FDA) for sulfur capture under high $\mathrm{CO}_{2}$ / high moisture flue gas environment using calcined limestone in the fly ash and using fresh commercial lime directly in the FDA.

- Determination of the effect of recarbonation on fouling in the convective pass.

- Determination of back-pass convective section heat transfer performance.

- Assessment of the impact of oxygen firing on the mercury, other trace elements, and volatile organic compound (VOC) emissions.

- Development of a proposal-level retrofit design for an existing small utility scale CFB boiler retrofit with $\mathrm{O}_{2}$ firing and $\mathrm{CO}_{2}$ capture. Results and lessons learned 
from this study would then be applicable to a future large scale demonstration of the $\mathrm{O}_{2}$ fired CFB concept.

Hence, ALSTOM responded to a DOE Solicitation to address all these issues with further MTF pilot testing and a subsequent retrofit design study of oxygen firing and $\mathrm{CO}_{2}$ capture on a relatively small, existing air-fired CFB plant. A relatively small CFB was selected as the study unit such that the analysis results would be closely applicable to a large-scale demonstration of this $\mathrm{O}_{2}$ fired technology (ALSTOM's next major step in the development of this technology). ALSTOM received a contract award from the DOE to conduct a project entitled "Commercialization Development of Oxygen Fired CFB for Greenhouse Gas Control," under Cooperative Agreement DE-FC26-04NT42205.

Results from this study are discussed herein. 


\section{OXYGEN-FIRING TECHNOLOGY READINESS}

This section presents a summary of the work on oxygen-fired CFB technology that ALSTOM Power Inc. (ALSTOM) has been developing under the sponsorship of the US Department of Energy/National Energy Technology Laboratory (DOE). A very brief summary of the oxygen-fired Pulverized Fuel technology that ALSTOM and others have been developing is also provided for sake of completeness. The basic message is that oxygen-firing technology for $\mathrm{CO}_{2}$ capture uses existing commercial air-fired PC or CFB technologies and commercially available $\mathrm{CO}_{2}$ capture enabling technologies, such as oxygen production through cryogenic air separation, and product gas processing. The technology is also applicable to existing PC or CFB units. Hence, as will be shown below, this technology is now ready for demonstration at a large scale.

\section{$2.1 \mathrm{O}_{2}$ Fired CFB Technology Development by ALSTOM}

This section briefly describes the work on oxygen-fired CFB technology development by ALSTOM in Windsor, CT, USA, under the sponsorship of the DOE. Not discussed here is additional oxygen-fired development carried out by ALSTOM in Europe.

\subsubsection{ALSTOM's Development Roadmap}

Figure 2.1 is a roadmap showing the major steps ALSTOM has taken and proposes to take in developing the oxygen-fired CFB technology for $\mathrm{CO}_{2}$ capture from concept inception to commercial deployment. 


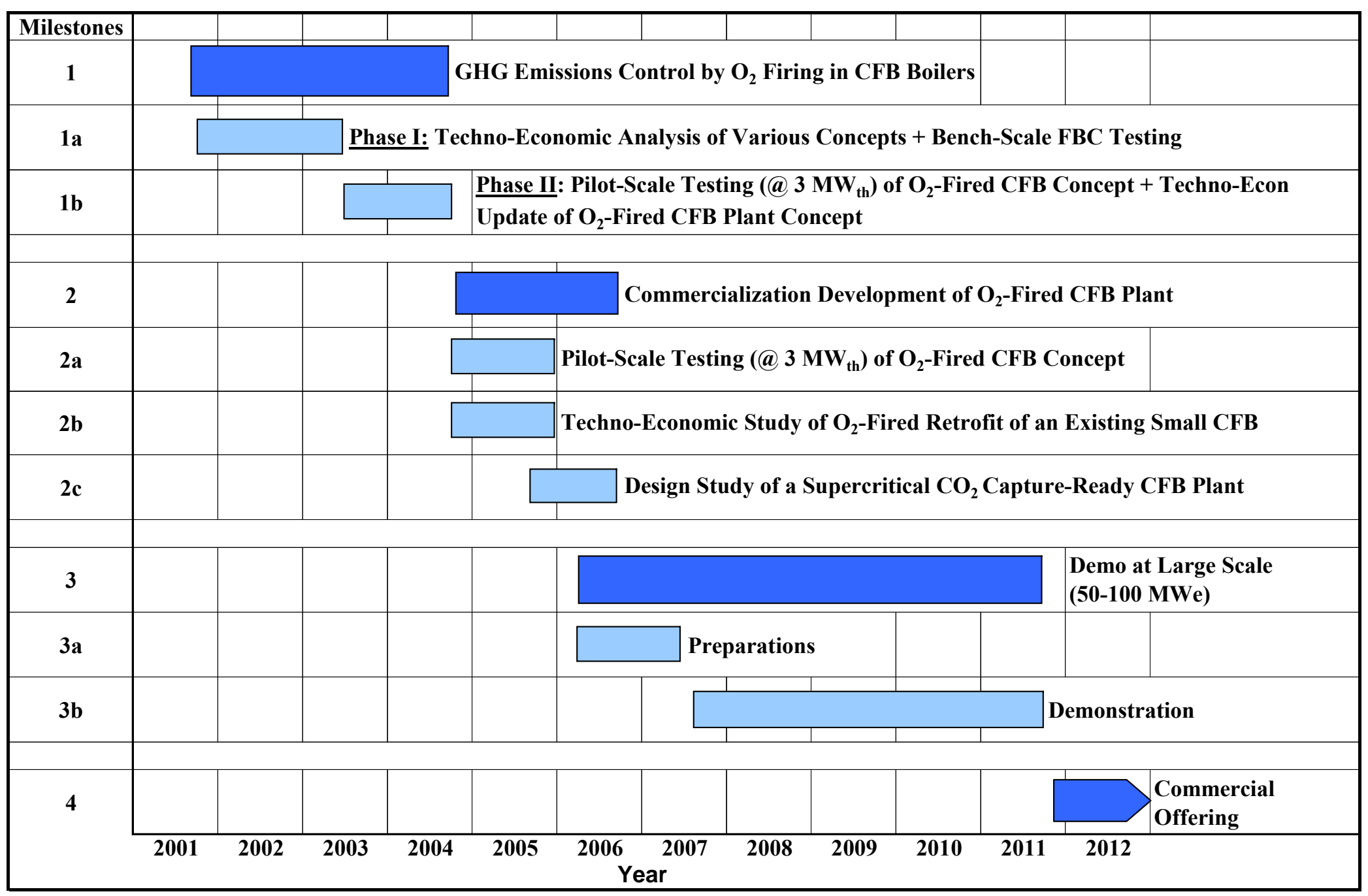

Figure 2.1: Oxygen-Fired CFB Technology Development Horizon 
The roadmap steps are summarized as follows:

- Techno-economic analysis and Bench scale FBC testing (Milestone 1a)

$>$ Concept screening

$\square$ Conceptual designs of various concepts

$\square$ Performance analyses of various concepts

$\square$ Cost estimates

$\square \mathrm{CO}_{2}$ emissions

$\square$ Economic analysis (levelized COE, Mitigation costs)

$\square$ Results: Small boiler for Greenfield $\mathrm{O}_{2}$ fired application $\rightarrow \sim 30 \%$ cost savings on Boiler Island as compared to air firing

$>$ Bench-Scale FBC Testing

$\square$ Two coals and two petroleum coke samples

$\square$ Two limestone samples

$\square \mathrm{O}_{2} / \mathrm{CO}_{2}$ mediums ranging from 21 to $70 \% \mathrm{O}_{2}$ globally

$>$ Selection of $\mathrm{O}_{2}$ fired $\mathrm{CFB}$ as a near term development technology

$\square$ Uses conventional commercial CFB technology

$\square$ Uses commercially available enabling technologies (ASU to supply the $\mathrm{O}_{2}$ to the combustion medium \& GPS to upgrade the $\mathrm{CO}_{2}$ concentrated flue gas into a $\mathrm{CO}_{2}$ product, suitable for sequestration or use in EOR or EGR)

- $\mathrm{O}_{2}$-Fired CFB Concept Evaluation (Milestone 1b)

$>$ Multi-use Test Facility (MTF) pilot-scale testing

$\square$ One coal and one petroleum coke

$\square$ Two limestone-types

$\square \mathrm{O}_{2} / \mathrm{CO}_{2}$ mediums ranging from 21 to $\& 70 \% \mathrm{O}_{2}$ locally \& to $55 \%$ globally.

$>\mathrm{O}_{2}$-Fired CFB Plant Design, Performance, and Economic Analysis Refinement

- Comercialization Development of $\mathrm{O}_{2}$ Fired CFB Plant (Milestone 2)

$>$ MTF testing (Milestone 2a)

$\square$ One coal and one petroleum coke

$\square$ Two limestone-types

$\square \mathrm{O}_{2} / \mathrm{CO}_{2}$ combustion medium of $30 \% \mathrm{O}_{2} / 70 \% \mathrm{CO}_{2}$

$>$ Study of a retrofit design of a 90-MWe air fired CFB to $\mathrm{O}_{2}$ firing for $\mathrm{CO}_{2}$ capture (Milestone $2 \mathrm{~b}$ )

$>$ Design study of a $\mathrm{CO}_{2}$ Capture Ready CFB Power Plant (supercritical steam conditions) (Milestone 2c)

- Remaining Technical Gaps

$>$ Limited number of fuel-types tested

$>$ Controls study (Startup/transition, trips, etc.)

$>$ Needs 50-100 MWe demonstration to show commercial readiness 
- Next steps

$>$ Technology demonstration at a larger scale (50-100 MWe) (Milestone 3).

$>$ Commercial deployment (Milestone 4)

$>$ Future Advanced $\mathrm{O}_{2}$ Production Technologies to improve the net plant efficiency and economics.

Each of the major steps on the roadmap is briefly described in the following sections.

\subsubsection{Brief Project Descriptions}

In 2001, ALSTOM began a two-phase program to investigate the feasibility of various carbon capture technologies. This program was sponsored under a Cooperative Agreement from the US Department of Energy's National Energy Technology Laboratory. Details of this work have been reported by Marion, et al., 2003.

\section{Phase I Project Description}

The Phase I workscope consisted of two major tasks, specifically:

- Task 1: Conceptual Technical and Economic Analyses of Thirteen Study Cases

- Task 2: Bench-Scale Fluidized Bed Combustion (FBC) Testing

ALSTOM was to make a recommendation to the DOE on next steps (i.e., whether or not to proceed to Phase II workscope), based on the results from the Phase I technoeconomic analysis and bench-scale testing.

Task 1: Technical and Economic Analyses:

Work entailed a comprehensive study evaluating the technical feasibility and economics of alternate $\mathrm{CO}_{2}$ capture technologies applied to Greenfield US coal-fired electric generation power plants. Thirteen cases, representing various levels of technology development, were evaluated. Seven cases represent coal combustion in CFB type equipment. Four cases represent Integrated Gasification Combined Cycle (IGCC) systems. Two cases represent advanced Chemical Looping systems. The key goals were to evaluate the impacts on the plant output, efficiency, and $\mathrm{CO}_{2}$ emissions, resulting from the addition of various $\mathrm{CO}_{2}$ capture systems to an array of $\mathrm{CFB}$ combustion based, IGCC based, and advanced Chemical Looping based power plants. Cost estimates were developed for these power plants and the impact of $\mathrm{CO}_{2}$ capture on the levelized cost of electricity $(\mathrm{COE})$ and on the mitigation cost for $\mathrm{CO}_{2}(\$ /$ tonne of $\mathrm{CO}_{2}$ avoided) were also evaluated. The thirteen study cases are briefly defined below.

Combustion Cases:

- Case-1: Air Fired Circulating Fluidized Bed (CFB) without $\mathrm{CO}_{2}$ Capture (Base Case for Comparison to Case-2 through Case-7)

- Case-2: Oxygen Fired CFB with $\mathrm{CO}_{2}$ Capture

- Case-3: Oxygen Fired CFB with $\mathrm{CO}_{2}$ Capture (sequestration only option)

- Case-4: Oxygen Fired Circulating Moving Bed (CMB) with $\mathrm{CO}_{2}$ Capture (advanced boiler concept) 
- Case-5: Air Fired CMB with $\mathrm{CO}_{2}$ Capture utilizing Regenerative Carbonate Process

- Case-6: Oxygen Fired CMB with Oxygen Transport Membrane (OTM) and $\mathrm{CO}_{2}$ Capture

- Case-7: Indirect Combustion of Coal via Chemical Looping and $\mathrm{CO}_{2}$ Capture IGCC Cases:

- Case-8: Built and Operating Present Day IGCC without $\mathrm{CO}_{2}$ Capture (Base Case for Comparison with Case-9)

- Case-9: Built and Operating Present Day IGCC with shift reaction and $\mathrm{CO}_{2}$ Capture

- Case-10: Commercially Offered Future IGCC without $\mathrm{CO}_{2}$ Capture (Base Case for Comparison with Case-11)

- Case-11: Commercially Offered Future IGCC with shift reaction and $\mathrm{CO}_{2}$ Capture

Advanced Chemical Looping Cases:

- Case-12: Indirect Gasification of Coal via Chemical Looping (Base Case for comparison to Case-13)

- Case-13: Indirect Gasification of Coal and $\mathrm{CO}_{2}$ Capture via Chemical Looping

\section{Task 2: Bench-Scale Fluidized Bed Combustion (FBC) Testing:}

The bench-scale FBC combustion testing supported the Task 1 case studies. The objective of Task 2 was to derive pertinent combustion performance and bed dynamic information under highly controlled operating conditions in a 102-mm (4-inch) inner diameter bubbling fluidized bed test facility. Results from oxy-fuel firing of three fuels, two coals and one delayed petroleum coke, were compared to those results obtained similarly from air firing.

Conclusion and Recommendation:

The results from the Phase I analysis led to the conclusion that further development work on the Oxygen-Fired CFB (Case-2) was justified. This recommendation was made to the DOE, based on the following rationale:

- This technology is the most near-term solution for $\mathrm{CO}_{2}$ capture as it uses:

$>$ Commercial air-fired CFB technology

$>$ Commercially available $\mathrm{CO}_{2}$ capture enabling technologies, specifically: $\square$ Oxygen production by cryogenic air separation $\square \mathrm{CO}_{2}$ capture, purification, compression, and liquefaction

- Oxygen firing produces a flue gas with high $\mathrm{CO}_{2}$ concentration $(>80 \%)$, which can be simply dried and compressed for sequestration or further processed into a high purity $\mathrm{CO}_{2}$ product for varied uses, such as enhanced oil recovery (EOR) or enhanced gas recovery (EGR). 
- The economics appear viable for a niche situation, such as enhanced oil recovery (EOR), whereby the $\mathrm{CO}_{2}$ production cost is balanced by the revenue streams from the sale of electricity, $\mathrm{CO}_{2}$ (for $\mathrm{EOR}$ ) and $\mathrm{N}_{2}$ (for oil reservoir pressure maintenance).

The DOE concurred with ALSTOM's recommendation of developing the $\mathrm{O}_{2}$ fired CFB technology for capturing $\mathrm{CO}_{2}$ and, hence, authorized the implementation of Phase-II workscope, as briefly described below.

\section{Phase II Project Description}

Phase II workscope consisted of pilot-scale testing followed by a refined performance and economic evaluation of the oxygen-fired CFB concept. As a part of this workscope, ALSTOM modified its 3.0 MWth (9.9 MMBtu/hr) Multiuse Test Facility (MTF) pilot plant to operate with $\mathrm{O}_{2} / \mathrm{CO}_{2}$ mixtures of up to $70 \% \mathrm{O}_{2}$ by volume. Tests with coal and petroleum coke were conducted. The test objectives were to determine the impacts of oxygen firing on heat transfer, bed dynamics, potential agglomeration, and major gaseous $\left(\mathrm{NO}_{\mathrm{x}}, \mathrm{N}_{2} \mathrm{O}, \mathrm{SO}_{2}\right.$, and $\left.\mathrm{CO}\right)$ and particulate emissions. The test data was used to refine the design, performance, costs, and economic models developed in Phase-I for an $\mathrm{O}_{2}$-fired $\mathrm{CFB}$ with $\mathrm{CO}_{2}$ capture (Case 2).

While carrying out the Phase II workscope, ALSTOM identified several items needing investigation in preparation for large-scale demonstration of the oxygen-fired CFB concept. They consisted of additional MTF pilot testing and a subsequent retrofit design study of oxygen firing and $\mathrm{CO}_{2}$ capture on a relatively small existing air-fired CFB plant. Hence, ALSTOM responded to a DOE Solicitation to address the identified technical gaps. ALSTOM received a contract award from the DOE conduct a project entitled "Commercialization Development of Oxygen Fired CFB for Greenhouse Gas Control," under Cooperative Agreement DE-FC26-04NT42205, as briefly described in the following section

\section{Commercialization Development of Oxygen-Fired CFB Plant}

The objective of this work was to prepare the oxygen fired CFB technology for large scale demonstration, especially for an enhanced oil or gas recovery (EOR or EGR) application. This was accomplished through the performance of three major tasks:

\section{MTF Testing}

A pilot plant test of the oxygen-fired CFB concept was carried out in ALSTOM's (3.0 $\mathrm{MW}_{\text {th }}(9.9 \mathrm{MMBtu} / \mathrm{hr}$ ) Multi-use Test Facility (MTF). The specifically targeted objectives of this testing include:

- Performance of the back-end flash dryer absorber (FDA) for sulfur capture under high $\mathrm{CO}_{2}$ / high moisture flue gas environment using calcined limestone in the fly ash and using fresh commercial lime directly in the FDA.

- Operation and performance of the moving bed heat exchanger (MBHE) to avoid recarbonation $\left(\mathrm{CaO}+\mathrm{CO}_{2} \rightarrow \mathrm{CaCO}_{3}\right)$ and also for cost savings compared to the standard fluidized bed heat exchanger (FBHE).

- Determination of the effect of recarbonation on fouling in the convective pass. 
- Assessment of the impact of oxygen firing on the mercury, other trace elements, and volatile organic compound (VOC) emissions.

\section{Commercial Design Implications}

A conceptual retrofit design study to oxyfuel firing for $\mathrm{CO}_{2}$ capture was carried out on an existing nominally 90 -MWe CFB boiler. This study was developed on the basis of ALSTOM's commercial CFB design and performance rules as well as the technical information from previous and current MTF test campaigns. Results were used to calculate incremental costs required for retrofit and conduct economic analysis. This work sets the stage for developing a first of a kind demonstration of an oxygen-fired CFB project in North America.

\section{$\mathrm{CO}_{2}$ Capture-Ready Supercritical CFB Plant Design Study}

An ongoing design study of a greenfield supercritical CFB plant with provisions for conversion to $\mathrm{CO}_{2}$ capture at a later time.

\subsubsection{Summary of Results}

Results from Phases I and II have been reported elsewhere (Marion, et al., 2003; Nsakala, Liljedahl, and Turek, 2004). These reports define in detail the premises and assumptions used for technical and economic analyses of various power plant concepts evaluated, and test fuels, sorbents, and conditions used in the bench-scale FBC and pilot-scale MTF facilities. The results from these reports and from the present study are summarized comprehensively in Table 2.1 through Table 2.5. Key results:

- All the technologies evaluated would be capable of reducing $\mathrm{CO}_{2}$ emissions by $90-99 \%$

- Capturing $\mathrm{CO}_{2}$ with any of these technologies would cause very significant impacts on power plant costs of electricity $(\mathrm{COE})$ and $\mathrm{CO}_{2}$ mitigation costs:

$>$ Incremental COE range: $\sim 1.0-4.0 \phi / \mathrm{kWh}$ over a respective reference power plant without $\mathrm{CO}_{2}$ capture, equivalent to an increase of $20-80 \%$.

$>\mathrm{CO}_{2}$ mitigation costs range: $12-47 \$ /$ tonne $\mathrm{CO}_{2}$ avoided (11- $43 \$ /$ ton)

- Oxygen-fired CFB technology, which has been evaluated in more detail, indicates the following:

$>$ Cost competitiveness remains an important issue, as is the case with all other technologies, with incremental $\mathrm{COE}$ and $\mathrm{CO}_{2}$ mitigation cost of about $3.4 \phi / \mathrm{kWh}$ and $41 \$ /$ tonne ( $37 \$ /$ ton) $\mathrm{CO}_{2}$ avoided, respectively

$>$ This technology is, nevertheless attractive for the following reasons:

a It is the most near-term development technology, because it uses proven commercial air-fired CFB technology and commercially available $\mathrm{CO}_{2}$ capture enabling technologies, such as oxygen production by cryogenic air separation (ASU), and gas processing (i.e., $\mathrm{CO}_{2}$ cleanup, compression, and liquefaction)

- Economic analysis looks viable for commercial EOR application, whereby electricity is sold to the power grid and $\mathrm{CO}_{2}$ and $\mathrm{N}_{2}$ (from the ASU) are sold to the oil field for stimulation and pressure maintenance, respectively. 
- Advancements in $\mathrm{O}_{2}$ production technology promise to significantly reduce costs and improve efficiency and economics.

$>$ Testing of coal and petroleum coke in bench-scale $\mathrm{O}_{2}$ fired FBC and pilot-scale CFB facilities indicate no technical barriers

a CFB operation with oxidant streams containing high oxygen concentration (up to $70 \%$ by volume) has been successfully demonstrated. This allows significant savings $(\sim 30 \%)$ on Greenfield CFB boiler investment costs

- The tests also produced important data on heat transfer coefficients, combustion efficiency, emissions of major pollutants (carbon monoxide, sulfur dioxide, and nitrogen oxides), and trace emissions (volatile organic compounds, mercury, and other metals). This test data forms the design basis for scale-up of an oxyfuel fired CFB demonstration plant.

- Test results indicate oxyfuel firing would have minimal impact on the boiler performance and emissions of major and trace pollutants (other than $\mathrm{CO}$ ) were equal to or lower than with air firing.

- Oxygen-fired CFB technology is ready for large scale demonstration. 
Table 2.1: Performance Analyses for Various Power Plant Concepts

\begin{tabular}{|c|c|c|c|c|c|c|c|c|c|c|c|c|c|}
\hline \multirow{2}{*}{ Project } & \multicolumn{2}{|r|}{ Study Case } & \multicolumn{2}{|c|}{ Fuel Feed Rate } & \multicolumn{3}{|c|}{ Oxygen Feed Rate } & \multicolumn{2}{|c|}{ Net Plant Heat Rate } & \multicolumn{2}{|c|}{$\begin{array}{l}\text { Net Plant } \\
\text { Efficiency }\end{array}$} & \multirow{2}{*}{\begin{tabular}{|c|}
$\begin{array}{c}\text { Energy } \\
\text { Penalty }\end{array}$ \\
$\%$ \\
\end{tabular}} & \multirow{2}{*}{$\begin{array}{c}\begin{array}{c}\text { Net Plant } \\
\text { Output, } \\
\text { kW }\end{array} \\
\text { kW } \\
\end{array}$} \\
\hline & \# & Description & $\mathrm{lbm} / \mathrm{hr}$ & $\begin{array}{c}\text { Tonne/ } \\
\text { Day }\end{array}$ & Source & $\mathrm{lbm} / \mathrm{hr}$ & $\begin{array}{c}\text { Tonne/ } \\
\text { Day }\end{array}$ & $\begin{array}{c}\begin{array}{c}\text { Btu/kWh, } \\
\text { HHV }\end{array} \\
\end{array}$ & $\begin{array}{c}\mathrm{kJ} / \mathrm{kWh}, \\
\mathrm{HHV}\end{array}$ & $\% \mathrm{HHV}$ & $\%$ LHV & & \\
\hline \multirow{13}{*}{$\begin{array}{l}\text { Greenhouse Gas } \\
\text { (GHG) Phase I }\end{array}$} & Case 1 & Air-fired CFB w/o CO2 Capture & 167,509 & 1,824 & Air & 383,856 & 4,180 & 9,611 & 10,140 & 35.51 & 36.93 & -- & 193,037 \\
\hline & Case 2 & $\begin{array}{l}\text { O2-Fired CFB w/ASU \& CO2 } \\
\text { Capture }\end{array}$ & 163,085 & 1,776 & ASU & 328,546 & 3,578 & 13,546 & 14,291 & 25.20 & 26.21 & 29.0 & 134,514 \\
\hline & Case 3 & $\begin{array}{l}\text { O2-Fired CFB w/ASU \& Flue Gas } \\
\text { Sequestration }\end{array}$ & 163,085 & 1,776 & ASU & 328,546 & 3,578 & 13,492 & 14,234 & 25.30 & 26.31 & 28.8 & 135,351 \\
\hline & Case 4 & $\begin{array}{l}\text { O2-Fired CMB w/ASU \& CO2 } \\
\text { Capture }\end{array}$ & 164,349 & 1,790 & ASU & 329,930 & 3,593 & 13,894 & 14,658 & 24.56 & 25.55 & 30.8 & 132,168 \\
\hline & Case 5 & $\begin{array}{l}\text { Air-Fired CFB w/Carbonate Reg. } \\
\text { Process \& CO2 Capture }\end{array}$ & 163,897 & 1,785 & Air & 384,361 & 4,185 & 11,307 & 11,929 & 30.18 & 31.39 & 15.0 & 161,184 \\
\hline & Case 6 & $\begin{array}{l}\text { O2-Fired CMB w/OTM \& CO2 } \\
\text { Capture }\end{array}$ & 202,456 & 2,205 & OTM & 407,722 & 4,440 & 11,380 & 12,006 & 29.99 & 31.19 & 15.5 & 197,435 \\
\hline & Case 7 & $\begin{array}{l}\text { CMB Chemical Looping } \\
\text { Combustion w/CO2 Capture }\end{array}$ & 163,446 & 1,780 & Air & 373,240 & 4,064 & 11,051 & 11,659 & 30.88 & 32.12 & 13.0 & 164,484 \\
\hline & Case 8 & $\begin{array}{l}\text { Built \& Operating IGCC w/o CO2 } \\
\text { Capture }\end{array}$ & 215,454 & 2,346 & ASU & 183,333 & 1,996 & 9,069 & 9,568 & 37.63 & 39.14 & --- & 263,087 \\
\hline & Case 9 & $\begin{array}{l}\text { Built \& Operating IGCC w/ CO2 } \\
\text { Capture }\end{array}$ & 238,694 & 2,599 & ASU & 204,167 & 2,223 & 11,467 & 12,098 & 29.76 & 30.95 & 20.9 & 230,515 \\
\hline & Case 10 & $\begin{array}{l}\text { Commercially Offered IGCC w/o } \\
\text { CO2 Capture }\end{array}$ & 210,010 & 2,287 & ASU & 174,309 & 1,898 & 9,884 & 10,428 & 34.53 & 35.91 & --- & 235,294 \\
\hline & Case 11 & $\begin{array}{l}\text { Commercially Offered IGCC } \\
\text { w/CO2 Capture }\end{array}$ & 225,822 & 2,459 & ASU & 187,431 & 2,041 & 12,441 & 13,125 & 27.43 & 28.53 & 20.6 & 201,004 \\
\hline & Case 12 & $\begin{array}{l}\text { Chemical Looping Gasification w/o } \\
\text { CO2 Capture }\end{array}$ & 197,428 & 2,150 & Air & 150,935 & 1,644 & 8,248 & 8,702 & 41.38 & 43.03 & --- & 265,146 \\
\hline & Case 13 & $\begin{array}{l}\text { Chemical Looping Gasification w/ } \\
\text { CO2 Capture }\end{array}$ & 213,582 & 2,326 & Air & 164,043 & 1,786 & 9,249 & 9,758 & 36.90 & 38.38 & 10.8 & 256,830 \\
\hline GHG Phase II & Case 2 & $\begin{array}{l}\text { O2 -Fired CFB w/ASU \& CO2 } \\
\text { Capture (updated from Phase I) }\end{array}$ & 162,894 & 1,774 & ASU & 328,342 & 3,575 & 13,152 & 13,875 & 25.95 & 26.99 & 26.9 & 138,402 \\
\hline \multirow{2}{*}{$\begin{array}{c}\text { Commercialization } \\
\text { Development of } \mathrm{O}_{2^{-}} \\
\text {Fired CFB Plant } \\
\text { (present study) }\end{array}$} & Case-1 & Air fired CFB w/o CO2 Capture & 75,111 & 818 & Air & 168,811 & 1,838 & 9,328 & 9,841 & 36.59 & 38.05 & --- & 90,427 \\
\hline & Case-2 & $\begin{array}{l}\text { CFB Retrofit with O2 Firing and } \\
\text { CO2 Capture }\end{array}$ & 74,562 & 812 & ASU & 168,180 & 1,831 & 13,716 & 14,470 & 24.88 & 25.88 & 32.0 & 62,144 \\
\hline
\end{tabular}

GHG Phase I: Greenfield plants; GHG Phase III: Update of Case 2 from Phase I; Present Study: Case-2 is a retrofit of existing plant Case-1.

Energy Penalty is relative to the appropriate base case. 
Table 2.2: Cost Analyses for Various Power Plant Concepts

\begin{tabular}{|c|c|c|c|c|c|c|c|c|c|c|c|}
\hline \multirow{3}{*}{ Project } & \multicolumn{2}{|r|}{ Study Case } & \multirow{3}{*}{\begin{tabular}{|c|}
$\begin{array}{c}\text { Net Plant } \\
\text { Output }\end{array}$ \\
kW \\
\end{tabular}} & \multicolumn{2}{|c|}{$\begin{array}{l}\text { Total Investment } \\
\text { Cost, EPC Basis }\end{array}$} & \multicolumn{5}{|c|}{ Operating \& Maintenance (O\&M) Costs } & \multirow{3}{*}{$\begin{array}{c}\text { Total O\&M } \\
\$ / k W h\end{array}$} \\
\hline & \multirow[t]{2}{*}{ \# } & \multirow{2}{*}{ Description } & & \multirow[t]{2}{*}{$\mathrm{k} \$$} & \multirow{2}{*}{$\$ / \mathrm{kW}$} & \multicolumn{2}{|c|}{ Fixed } & \multicolumn{2}{|c|}{$\begin{array}{l}\text { Variable @ 80\% } \\
\text { Capacity Factor }\end{array}$} & \multirow{2}{*}{ Total, $\mathrm{k} \$$} & \\
\hline & & & & & & $\mathrm{k} \$$ & $\$ / \mathrm{kW}$ & $\mathrm{k} \$$ & $\$ / \mathrm{kWh}$ & & \\
\hline \multirow{13}{*}{$\begin{array}{l}\text { Greenhouse Gas } \\
\text { (GHG) Phase I }\end{array}$} & Case 1 & Air-fired CFB w/o CO2 Capture & 193,037 & 251,804 & 1,304 & 5,658 & 29.31 & 5,587 & 0.0041 & 11,245 & 0.83 \\
\hline & Case 2 & $\begin{array}{l}\text { O2-Fired CFB w/ASU \& CO2 } \\
\text { Capture }\end{array}$ & 134,514 & 328,589 & 2,443 & 7,854 & 58.39 & 8,820 & 0.0094 & 16,674 & 1.77 \\
\hline & Case 3 & $\begin{array}{l}\text { O2-Fired CFB w/ASU \& Flue Gas } \\
\text { Sequestration }\end{array}$ & 135,351 & 320,638 & 2,369 & 8,061 & 59.55 & 8,654 & 0.0091 & 16,715 & 1.76 \\
\hline & Case 4 & $\begin{array}{l}\text { O2-Fired CMB w/ASU \& CO2 } \\
\text { Capture }\end{array}$ & 132,168 & 337,402 & 2,553 & 7,899 & 59.77 & 8,889 & 0.0096 & 16,788 & 1.81 \\
\hline & Case 5 & $\begin{array}{l}\text { Air-Fired CFB w/Carbonate Reg. } \\
\text { Process \& CO2 Capture }\end{array}$ & 161,184 & 270,232 & 1,677 & 5,799 & 35.98 & 8,264 & 0.0073 & 14,064 & 1.25 \\
\hline & Case 6 & $\begin{array}{l}\text { O2-Fired CMB w/OTM \& CO2 } \\
\text { Capture }\end{array}$ & 197,435 & 468,919 & 2,375 & 6,538 & 33.11 & 10,134 & 0.0073 & 16,671 & 1.20 \\
\hline & Case 7 & $\begin{array}{l}\text { CMB Chemical Looping } \\
\text { Combustion w/CO2 Capture }\end{array}$ & 164,484 & 273,568 & 1,663 & 5,797 & 35.25 & 8,015 & 0.0070 & 13,812 & 1.20 \\
\hline & Case 8 & $\begin{array}{l}\text { Built \& Operating IGCC w/o CO2 } \\
\text { Capture }\end{array}$ & 263,087 & 411,731 & 1,565 & 10,180 & 38.70 & 7,746 & 0.0042 & 17,926 & 0.97 \\
\hline & Case 9 & $\begin{array}{l}\text { Built \& Operating IGCC w/ CO2 } \\
\text { Capture }\end{array}$ & 230,515 & 502,330 & 2,179 & 12,139 & 52.66 & 9,202 & 0.0057 & 21,341 & 1.32 \\
\hline & Case 10 & $\begin{array}{l}\text { Commercially Offered IGCC w/o } \\
\text { CO2 Capture }\end{array}$ & 235,294 & 341,468 & 1,451 & 9,344 & 39.71 & 6,900 & 0.0042 & 16,244 & 0.99 \\
\hline & Case 11 & $\begin{array}{l}\text { Commercially Offered IGCC } \\
\text { w/CO2 Capture }\end{array}$ & 201,004 & 412,377 & 2,052 & 11,068 & 55.06 & 9,111 & 0.0065 & 20,178 & 1.43 \\
\hline & Case 12 & $\begin{array}{l}\text { Chemical Looping Gasification w/o } \\
\text { CO2 Capture }\end{array}$ & 265,146 & 296,991 & 1,120 & 8,814 & 24.47 & 8,223 & 0.0044 & 12,478 & 0.92 \\
\hline & Case 13 & $\begin{array}{l}\text { Chemical Looping Gasification w/ } \\
\text { CO2 Capture }\end{array}$ & 256,830 & 355,132 & 1,383 & 9,920 & 30.82 & 11,812 & 0.0066 & 17,804 & 1.21 \\
\hline GHG Phase II & Case 2 & $\begin{array}{l}\text { O2 -Fired CFB w/ASU \& CO2 } \\
\text { Capture (updated from Phase I) }\end{array}$ & 138,402 & 329,610 & 2,382 & 7,859 & 56.78 & 8,835 & 0.0091 & 16,694 & 0.99 \\
\hline \multirow{2}{*}{$\begin{array}{l}\text { Commercialization } \\
\text { Development of } \mathrm{O}_{2-} \\
\text { Fired CFB Plant } \\
\text { (present study) }\end{array}$} & Case-1 & Air fired CFB w/o CO2 Capture & 90,427 & -- & --- & 3,529 & 39.03 & 2,763 & 0.00436 & 6,293 & 0.99 \\
\hline & Case-2 & $\begin{array}{l}\text { CFB Retrofit with O2 Firing and } \\
\text { CO2 Capture }\end{array}$ & 62,144 & 96,024 & 1,545 & 5,330 & 85.77 & 6,115 & 0.01404 & 11,445 & 2.63 \\
\hline
\end{tabular}

Cost Bases: GHG Phase I : 2003 Dollars; GHS Phase II: 2004 Dollars; Commercialization Devel. Of O2-Fired CFB Plant : 2005 Dollars Present Study: Case-1 is an existing unit, no investment cost considered; Case-2 investment costs are for retrofit of the existing unit. 
Table 2.3: Cost of Electricity and Avoided Cost for Various Power Plant Concepts

\begin{tabular}{|c|c|c|c|c|c|c|c|c|c|c|c|c|c|}
\hline \multirow{2}{*}{ Project } & \multicolumn{2}{|r|}{ Study Case } & \multirow{2}{*}{\begin{tabular}{|c|}
$\begin{array}{c}\text { Net } \\
\text { Plant } \\
\text { Output }\end{array}$ \\
kW \\
\end{tabular}} & \multicolumn{6}{|c|}{ Levelized Cost of Electricity (Cents/kWh) } & \multicolumn{2}{|c|}{$\mathrm{CO}_{2}$ Emissions } & \multicolumn{2}{|c|}{ Avoided $\mathrm{CO}_{2}$ Cost } \\
\hline & \# & Description & & Financial & $\begin{array}{l}\text { Fixed } \\
\text { O\&M }\end{array}$ & $\begin{array}{c}\text { Variable } \\
\text { O\&M }\end{array}$ & Fuel & Total & $\begin{array}{l}\text { Incre- } \\
\text { mental } \\
\text { COE }\end{array}$ & $\mathrm{lbm} / \mathrm{kWh}$ & $\mathrm{g} / \mathrm{kWh}$ & $\$ /$ ton & \$/tonne \\
\hline \multirow{13}{*}{$\begin{array}{l}\text { Greenhouse Gas } \\
\text { (GHG) Phase I }\end{array}$} & Case 1 & Air-fired CFB w/o CO2 Capture & 193,037 & 2.49 & 0.42 & 0.41 & 1.20 & 4.53 & --- & 2.00 & 907 & --- & --- \\
\hline & Case 2 & $\begin{array}{l}\text { O2-Fired CFB w/ASU \& CO2 } \\
\text { Capture }\end{array}$ & 134,514 & 4.73 & 0.85 & 0.95 & 1.72 & 8.25 & 3.72 & 0.18 & 82 & 41 & 45 \\
\hline & Case 3 & $\begin{array}{l}\text { O2-Fired CFB w/ASU \& Flue Gas } \\
\text { Sequestration }\end{array}$ & 135,351 & 4.53 & 0.85 & 0.91 & 1.69 & 7.98 & 3.45 & 0.02 & 9 & 35 & 38 \\
\hline & Case 4 & $\begin{array}{l}\text { O2-Fired CMB w/ASU \& CO2 } \\
\text { Capture }\end{array}$ & 132,168 & 4.86 & 0.85 & 0.96 & 1.74 & 8.41 & 3.88 & 0.21 & 95 & 43 & 48 \\
\hline & Case 5 & $\begin{array}{l}\text { Air-Fired CFB w/Carbonate Reg. } \\
\text { Process \& CO2 Capture }\end{array}$ & 161,184 & 3.29 & 0.51 & 0.73 & 1.41 & 5.95 & 1.42 & 0.01 & 5 & 14 & 16 \\
\hline & Case 6 & $\begin{array}{l}\text { O2-Fired CMB w/OTM \& CO2 } \\
\text { Capture }\end{array}$ & 197,435 & 4.43 & 0.47 & 0.73 & 1.42 & 7.05 & 2.53 & 0.15 & 68 & 27 & 30 \\
\hline & Case 7 & $\begin{array}{l}\text { CMB Chemical Looping } \\
\text { Combustion w/CO2 Capture }\end{array}$ & 164,484 & 3.26 & 0.50 & 0.70 & 1.38 & 5.84 & 1.32 & 0.07 & 32 & 13 & 15 \\
\hline & Case 8 & $\begin{array}{l}\text { Built \& Operating IGCC w/o CO2 } \\
\text { Capture }\end{array}$ & 263,087 & 3.20 & 0.55 & 0.42 & 1.13 & 5.30 & --- & 1.81 & 821 & --- & --- \\
\hline & Case 9 & $\begin{array}{l}\text { Built \& Operating IGCC w/ CO2 } \\
\text { Capture }\end{array}$ & 230,515 & 4.40 & 0.75 & 0.57 & 1.43 & 7.15 & 1.85 & 0.23 & 104 & 23 & 26 \\
\hline & Case 10 & $\begin{array}{l}\text { Commercially Offered IGCC w/o } \\
\text { CO2 Capture }\end{array}$ & 235,294 & 3.00 & 0.57 & 0.42 & 1.24 & 5.22 & --- & 1.98 & 898 & --- & --- \\
\hline & Case 11 & $\begin{array}{l}\text { Commercially Offered IGCC } \\
\text { w/CO2 Capture }\end{array}$ & 201,004 & 4.19 & 0.79 & 0.65 & 1.56 & 7.18 & 1.95 & 0.15 & 68 & 23 & 25 \\
\hline & Case 12 & $\begin{array}{l}\text { Chemical Looping Gasification w/o } \\
\text { CO2 Capture }\end{array}$ & 265,146 & 2.34 & 0.47 & 0.44 & 1.03 & 4.28 & --- & 1.71 & 776 & --- & --- \\
\hline & Case 13 & \begin{tabular}{|l|} 
Chemical Looping Gasification w/ \\
CO2 Capture
\end{tabular} & 256,830 & 2.85 & 0.55 & 0.66 & 1.16 & 5.22 & 0.93 & 0.09 & 41 & 11 & 12 \\
\hline GHG Phase II & Case 2 & $\begin{array}{l}\text { O2 -Fired CFB w/ASU \& CO2 } \\
\text { Capture (updated from Phase I) }\end{array}$ & 138,402 & 4.5 & 0.8 & 0.9 & 1.6 & 7.9 & 3.4 & .17 & 77 & 37 & 41 \\
\hline \multirow{2}{*}{$\begin{array}{l}\text { Commercialization } \\
\text { Development of } \mathrm{O}_{2^{-}} \\
\text {Fired CFB Plant } \\
\text { (present study) }\end{array}$} & Case-1 & Air fired CFB w/o CO2 Capture & 90,427 & --- & --- & --- & --- & --- & --- & 1.94 & 880 & --- & --- \\
\hline & Case-2 & $\begin{array}{l}\text { CFB Retrofit with O2 Firing and } \\
\text { CO2 Capture }\end{array}$ & 62,144 & 2.86 & 0.67 & 0.97 & 0.57 & 3.12 & 3.12 & 0.17 & 77 & 35 & 39 \\
\hline
\end{tabular}

Cost Bases: GHG Phase I : 2003 Dollars; GHS Phase II: 2004 Dollars; Commercialization Devel. Of O2-Fired CFB Plant : 2005 Dollars.

Phase I and Phase II: Incremental COE and $\mathrm{CO}_{2}$ avoided costs are relative to the appropriate base case.

Present Study: All Case-2 COE components and $\mathrm{CO}_{2}$ avoided cost are incremental relative to Case- 1 . Total COE includes a $\$ 15 /$ ton credit for $\mathrm{CO}_{2}$ product (equivalent to $1.95 \$ / \mathrm{kWh})$. 
Table 2.4: Summary of Bench-Scale FBC Testing

\begin{tabular}{|c|c|c|c|c|c|c|c|c|c|c|c|c|c|c|c|c|}
\hline \multirow{3}{*}{ Fuel } & \multirow{3}{*}{$\begin{array}{l}\text { Test } \\
\text { No. }\end{array}$} & \multirow{3}{*}{$\begin{array}{c}\text { Combustion Gas } \\
\text { Medium }\end{array}$} & \multicolumn{2}{|c|}{ Gas Velocity } & \multirow{3}{*}{ Stoich } & \multirow{3}{*}{$\begin{array}{l}\mathrm{Ca} / \mathrm{S} \\
\text { Mole } \\
\text { Ratio }\end{array}$} & \multicolumn{2}{|c|}{$\begin{array}{c}\text { Bed } \\
\text { Temperature }\end{array}$} & \multicolumn{6}{|c|}{ Gaseous Emissions } & \multirow{2}{*}{$\begin{array}{c}\text { Fuel } \\
\text { Combustion }\end{array}$} & \multirow{2}{*}{$\begin{array}{l}\text { Unburned } \\
\text { Carbon in } \\
\text { Fly Ash }\end{array}$} \\
\hline & & & \multirow{2}{*}{$\mathrm{ft} / \mathrm{sec}$} & \multirow{2}{*}{$\mathrm{m} / \mathrm{sec}$} & & & \multirow{2}{*}{${ }^{\circ} \mathrm{F}$} & \multirow{2}{*}{${ }^{\circ} \mathrm{C}$} & \multicolumn{2}{|c|}{ NOx } & \multicolumn{2}{|l|}{$\mathrm{SO}_{2}$} & \multicolumn{2}{|l|}{$\mathrm{CO}$} & & \\
\hline & & & & & & & & & Ib/MMBtu & $\mathrm{kg} / \mathrm{GJ}$ & Ib/MMBtu & $\mathrm{kg} / \mathrm{GJ}$ & Ib/MMBtu & $\mathrm{kg} / \mathrm{GJ}$ & \%DAF Basis & \% Dry Basis \\
\hline \multirow{9}{*}{$\begin{array}{c}\text { Case CFB } \\
\text { Coal }\end{array}$} & $\mathrm{BCCa}$ & Air & 3.27 & 1.00 & 2.10 & --- & 1676 & 913 & 1.06 & 0.46 & 2.26 & 0.97 & 0.12 & 0.05 & 88.0 & 25.8 \\
\hline & BCCa1 & $21 \% \mathrm{O}_{2} / 79 \% \mathrm{CO}_{2}$ & 3.18 & 0.97 & 2.02 & --- & 1635 & 890 & 0.93 & 0.40 & 2.21 & 0.95 & 0.38 & 0.16 & 89.0 & 20.7 \\
\hline & $\mathrm{BCCb}$ & $30 \% \mathrm{O}_{2} / 70 \% \mathrm{CO}_{2}$ & 1.77 & 0.54 & 2.11 & --.- & 1683 & 917 & 0.90 & 0.39 & 2.42 & 1.04 & 0.32 & 0.14 & 90.8 & 20.7 \\
\hline & $\mathrm{BCCC}$ & $40 \% \mathrm{O}_{2} / 60 \% \mathrm{CO}_{2}$ & 2.77 & 0.84 & 2.95 & --- & 1681 & 916 & 1.01 & 0.44 & 2.70 & 1.16 & 0.30 & 0.13 & 95.1 & 10.3 \\
\hline & BCCd & $50 \% \mathrm{O}_{2} / 50 \% \mathrm{CO}_{2}$ & 2.69 & 0.82 & 2.59 & $-\cdots$ & 1871 & 1022 & 0.84 & 0.36 & 2.73 & 1.17 & 0.21 & 0.09 & --- & --- \\
\hline & BCCd1 & $50 \% \mathrm{O}_{2} / 50 \% \mathrm{CO}_{2}$ & 2.74 & 0.83 & 2.57 & --- & 1908 & 1042 & 0.83 & 0.36 & 2.78 & 1.19 & 0.23 & 0.10 & 95.0 & 12.2 \\
\hline & $\mathrm{BCCe}$ & $70 \% \mathrm{O}_{2} / 30 \% \mathrm{CO}_{2}$ & 2.89 & 0.88 & 3.67 & --- & 1805 & 985 & 0.82 & 0.35 & 2.96 & 1.27 & 0.48 & 0.21 & 95.3 & 10.3 \\
\hline & BCCf & Air & 2.78 & 0.85 & 2.51 & 3.5 & 1669 & 909 & 1.32 & 0.57 & 0.42 & 0.18 & 0.21 & 0.09 & 91.0 & 20.6 \\
\hline & $\mathrm{BCCg}$ & $30 \% \mathrm{O}_{2} / 70 \% \mathrm{CO}_{2}$ & 2.72 & 0.83 & 2.73 & 3.5 & 1708 & 931 & 1.27 & 0.55 & 1.61 & 0.69 & 0.35 & 0.15 & 90.7 & 21.1 \\
\hline \multirow{6}{*}{$\begin{array}{l}\text { Illinois \#6 } \\
\text { hvCb Coal }\end{array}$} & IIII\#6a & Air & 2.73 & 0.83 & 2.86 & --- & 1632 & 889 & 1.42 & 0.61 & 5.96 & 2.56 & 0.23 & 0.10 & 98.9 & 5.7 \\
\hline & III\#6b & $30 \% \mathrm{O}_{2} / 70 \% \mathrm{CO}_{2}$ & 2.58 & 0.79 & 3.93 & --- & 1591 & 866 & 1.63 & 0.70 & 5.59 & 2.40 & 0.48 & 0.21 & 99.1 & 5.8 \\
\hline & IIl\#6b1 & $30 \% \mathrm{O}_{2} / 70 \% \mathrm{CO}_{3}$ & 2.68 & 0.82 & 2.85 & --- & 1674 & 912 & 1.35 & 0.58 & 5.45 & 2.34 & 0.38 & 0.16 & --- & 4 \\
\hline & III\#6c & $50 \% \mathrm{O}_{2} / 50 \% \mathrm{CO}_{2}$ & 2.69 & 0.82 & 4.74 & -- & 1674 & 912 & 1.32 & 0.57 & 5.53 & 2.38 & 0.32 & 0.14 & 99.2 & 4.5 \\
\hline & III\#6d & Air & 2.80 & 0.85 & 3.14 & 3.5 & 1683 & 917 & 1.21 & 0.52 & 0.67 & 0.29 & 0.16 & 0.07 & 98.9 & 5.8 \\
\hline & $111 \# 6 \mathrm{e}$ & $30 \% \mathrm{O}_{2} / 70 \% \mathrm{CO}_{2}$ & 2.70 & 0.82 & 2.80 & 3.5 & 1691 & 922 & 1.32 & 0.57 & 1.83 & 0.79 & 0.38 & 0.16 & 98.5 & 6.8 \\
\hline \multirow{5}{*}{$\begin{array}{c}\text { Delayed } \\
\text { Petroleum } \\
\text { Coke }\end{array}$} & DPCa & Air & 2.77 & 0.84 & 2.80 & -- & 1662 & 905 & 2.15 & 0.92 & 1.37 & 0.59 & 0.09 & 0.04 & 99.9 & 28.3 \\
\hline & $\mathrm{DPCb}$ & $30 \% \mathrm{O}_{2} / 70 \% \mathrm{CO}_{3}$ & 2.79 & 0.85 & 2.70 & --- & 1759 & 959 & 1.79 & 0.77 & 1.33 & 0.57 & 0.26 & 0.11 & 99.8 & 38.9 \\
\hline & DPCb1 & $30 \% \mathrm{O}_{2} / 70 \% \mathrm{CO}_{2}$ & 2.59 & 0.79 & 3.81 & --- & 1603 & 873 & 1.86 & 0.80 & 1.26 & 0.54 & 0.33 & 0.14 & --- & $\cdots$ \\
\hline & DPCc & Air & 2.74 & 0.83 & 2.96 & 3.50 & 1657 & 903 & 1.75 & 0.75 & 0.56 & 0.24 & 0.08 & 0.04 & 99.8 & 39.9 \\
\hline & DPCd & $30 \% \mathrm{O}_{2} / 70 \% \mathrm{CO}_{3}$ & 2.82 & 0.86 & 2.83 & 3.50 & 1784 & 973 & 1.33 & 0.57 & 0.55 & 0.24 & 0.25 & 0.11 & \begin{tabular}{ll|}
99.9 \\
\end{tabular} & 34.9 \\
\hline
\end{tabular}

(From Marion et al., 2003) 
Table 2.5: Summary of Previous Pilot-Scale Test Results

\begin{tabular}{|c|c|c|c|c|c|c|c|c|c|c|c|c|c|c|c|c|c|c|c|}
\hline \multirow{2}{*}{$\begin{array}{l}\text { Test } \\
\text { Point }\end{array}$} & \multirow{2}{*}{ Fuel } & \multirow{2}{*}{ Comb. Medium } & \multirow{2}{*}{ Sorbent-Type } & \multirow{2}{*}{$\begin{array}{c}\text { Global } \mathrm{O}_{2} \\
\%\end{array}$} & \multirow{2}{*}{\begin{tabular}{|c|} 
Local $\mathrm{O}_{2}$ \\
$\%$
\end{tabular}} & \multicolumn{2}{|c|}{ Fuel Firing Rate } & \multirow{2}{*}{$\begin{array}{l}\mathrm{Ca} / \mathrm{S} \\
\mathrm{Mole} \\
\mathrm{R} \text { atio }\end{array}$} & \multirow{2}{*}{\begin{tabular}{|l|}
$\mathrm{O}_{2}$ \\
$\%$
\end{tabular}} & \multirow{2}{*}{$\begin{array}{l}\mathrm{N}_{2} \\
\%\end{array}$} & \multicolumn{2}{|c|}{$\mathrm{SO}_{2}$} & \multicolumn{2}{|c|}{$\mathrm{CO}$} & \multicolumn{2}{|c|}{$\mathrm{NO}_{\mathrm{x}}$} & \multicolumn{2}{|c|}{$\mathrm{N}_{2} \mathrm{O}$} & \multirow{2}{*}{$\begin{array}{c}\begin{array}{c}\text { Sulfur } \\
\text { Captur }\end{array} \\
\%\end{array}$} \\
\hline & & & & & & M M B tu/hr & $\mathrm{GJ} / \mathrm{hr}$ & & & & $\begin{array}{c}1 \mathrm{~b} / \mathrm{MM} \\
\mathrm{Btu}\end{array}$ & $\mathrm{kg} / \mathrm{G} \mathrm{J}$ & $\begin{array}{c}\mathrm{lb} / \mathrm{MMB} B \\
\mathrm{tu}\end{array}$ & $\mathrm{kg} / \mathrm{G} \mathrm{J}$ & $\begin{array}{c}1 \mathrm{~b} / \mathrm{Mm} \\
\mathrm{Btu}\end{array}$ & $\mathrm{kg} / \mathrm{G} \mathrm{J}$ & $\begin{array}{c}\text { 1b/M M } \\
\text { Btu }\end{array}$ & $\mathrm{kg} / \mathrm{G} \mathrm{J}$ & \\
\hline A 1 & $\begin{array}{c}\text { Tri-Star mvb } \\
\text { Coal }\end{array}$ & A ir & Chemstone & 21 & 21 & 3.96 & 4.18 & 2.0 & 3.9 & 80.0 & 0.07 & $\mid 0.03$ & 0.09 & 0.04 & 0.32 & 0.15 & -- & & 98 \\
\hline B 1 & \multirow{4}{*}{$\begin{array}{c}\text { Tri-Star mvb } \\
\text { Coal }\end{array}$} & \multirow{4}{*}{$\begin{array}{c}\mathrm{O}_{2} / \mathrm{CO}_{2} \text { (Low } \\
\text { Enrichment) }\end{array}$} & \multirow{4}{*}{ Chemstrone } & 21 & 26 & 4.07 & 4.29 & 2.0 & 3.2 & 8.0 & 0.58 & \begin{tabular}{|l|}
0.28 \\
\end{tabular} & 0.10 & 0.05 & 0.14 & 0.07 & -- & & 82 \\
\hline B2 & & & & 20 & 26 & 3.81 & 4.02 & 2.1 & 3.4 & 5.0 & 0.68 & 0.33 & 0.15 & 0.07 & 0.07 & 0.03 & 0.10 & 0.05 & 79 \\
\hline B 4 & & & & 31 & 40 & 4.78 & 5.04 & 2.0 & 2.8 & 13.0 & 0.71 & 0.34 & 0.11 & 0.05 & 0.05 & 0.02 & 0.07 & 0.03 & 78 \\
\hline B 5 & & & & 30 & 40 & 3.94 & 4.16 & 2.0 & 4.3 & 13.0 & 0.36 & 0.17 & 0.08 & 0.04 & 0.06 & 0.03 & 0.05 & 0.03 & 89 \\
\hline $\mathrm{C} 1$ & \multirow{7}{*}{$\begin{array}{c}\text { Tri-Star mvb } \\
\text { Coal }\end{array}$} & \multirow{7}{*}{$\begin{array}{c}\mathrm{O}_{2} / \mathrm{CO}_{2} \text { ( } \mathrm{High} \\
\text { Enrichment) }\end{array}$} & \multirow{7}{*}{ Aragonite } & 36 & 49 & 4.24 & 4.47 & 1.6 & 9.3 & 16.7 & 1.07 & $\mid 0.51$ & 0.18 & 0.09 & 0.14 & 0.07 & -- & & 66 \\
\hline $\mathrm{C} 2$ & & & & 37 & 50 & 5.69 & 6.00 & 2.0 & 4.2 & 16.5 & 0.52 & \begin{tabular}{|l|}
0.25 \\
\end{tabular} & 0.37 & 0.18 & 0.05 & 0.02 & -- & & 84 \\
\hline $\mathrm{C} 3$ & & & & 43 & 60 & 6.57 & 6.93 & 2.0 & 3.5 & 13.0 & 0.42 & \begin{tabular}{|l|}
0.20 \\
\end{tabular} & 0.18 & 0.09 & 0.06 & 0.03 & -- & & 87 \\
\hline $\mathrm{C} 4$ & & & & 49 & 67 & 7.87 & 8.30 & 2.0 & 3.4 & 11.0 & 0.44 & \begin{tabular}{|l|}
0.21 \\
\end{tabular} & 0.15 & 0.07 & 0.05 & 0.02 & 0.05 & 0.02 & 86 \\
\hline $\mathrm{C} 5$ & & & & 50 & 70 & 7.57 & 7.99 & 2.1 & 4.9 & 19.0 & 0.36 & \begin{tabular}{|l|l}
0.17 \\
\end{tabular} & 0.15 & 0.07 & 0.09 & 0.04 & 0.07 & 0.03 & 89 \\
\hline $\mathrm{C} 6$ & & & & 50 & 70 & 7.56 & 7.98 & 2.1 & 3.9 & 17.0 & 0.79 & \begin{tabular}{|l|l}
0.38 \\
\end{tabular} & 0.16 & 0.08 & 0.06 & 0.03 & 0.04 & 0.02 & 75 \\
\hline $\mathrm{C} 7$ & & & & 50 & 70 & 7.57 & 7.99 & 2.1 & 4.4 & 17.3 & 0.91 & \begin{tabular}{|l|l} 
& 0.44
\end{tabular} & 0.22 & 0.11 & 0.05 & 0.02 & 0.05 & 0.02 & 71 \\
\hline D 1 & \multirow{5}{*}{$\begin{array}{l}\text { Delayed Pet. } \\
\text { Coke }\end{array}$} & \multirow{5}{*}{$\begin{array}{c}\mathrm{O}_{2} / \mathrm{CO}_{2} \text { (High } \\
\text { Enrichment) }\end{array}$} & \multirow{5}{*}{ Aragonite } & 43 & 61 & 6.28 & 6.63 & 2.0 & 2.9 & 17.4 & 0.38 & \begin{tabular}{|l|l} 
\\
0.18
\end{tabular} & 0.09 & 0.04 & 0.07 & 0.04 & 0.04 & 0.02 & 94.7 \\
\hline D2 & & & & 49 & 70 & 7.08 & 7.47 & 1.9 & 3.1 & 17.4 & 0.05 & 0.02 & 0.04 & 0.02 & 0.11 & 0.05 & 0.02 & 0.01 & 99.3 \\
\hline D3 & & & & 49 & 70 & 7.92 & 8.36 & 1.7 & 3.3 & 17.4 & 0.30 & 0.14 & 0.05 & 0.02 & 0.08 & 0.04 & 0.01 & 0.00 & 95.9 \\
\hline D4 & & & & 49 & 70 & 7.92 & 8.36 & 1.7 & 2.9 & 17.4 & 0.44 & 0.21 & 0.05 & 0.02 & 0.07 & 0.03 & 0.00 & 0.00 & 93.8 \\
\hline D5 & & & & 49 & 70 & 7.62 & 8.04 & 1.8 & 2.7 & 12.0 & 0.08 & \begin{tabular}{|l|l}
0.04 \\
\end{tabular} & 0.05 & 0.02 & 0.09 & 0.04 & 0.01 & 0.00 & 98.8 \\
\hline
\end{tabular}

(From Nsakala, Liljedahl, Turek, 2004) 


\section{2 $\mathrm{O}_{2}$ Fired Pulverized Fuel Technology Development}

Other research teams are also making considerable progress on oxy-combustion technology development for $\mathrm{CO}_{2}$ capture. Based on information in the open literature, it appears that ALSTOM is the only one developing this technology for both pulverized coal (PC) and circulating fluidized bed (CFB) boiler applications. Others are developing this technology solely for PC application. Below is a brief summary of the advances that have been made over the years in the areas of techno-economic analysis, combustion testing, and pilot-scale demonstration.

\subsubsection{Techno-Economic Analysis}

Table 2.6 summarizes recent results by IEA Greenhouse Gas R\&D Program on $\mathrm{CO}_{2}$ capture from an advanced supercritical PC plant (Dillon, et al., 2005). This study shows the following techno-economic impacts for capturing $90 \%$ of the $\mathrm{CO}_{2}$ from this Oxycombustion plant, compared to a reference air-fired plant without $\mathrm{CO}_{2}$.

- Energy penalty: $8.9 \%$ point, is equivalent to $20 \%$

- Incremental cost of electricity (COE): $2.3 \notin / \mathrm{kWh}$, is equivalent to $46 \%$

- $\mathrm{CO}_{2}$ mitigation cost: 40 \$/tonne of $\mathrm{CO}_{2}$ avoided (36 \$/ton)

The International Flame Research Foundation (IFRF) also recently published a report summarizing the results of a literature survey on the subject of oxy-combustion with recycled flue gas (Tan, et al., 2005). The objective of the study was to provide an overview of the current state-of-the art technology from a techno-economic standpoint.

It appears that the only common thread to the studies reported by IFRF is that everyone used a cryogenic air separation unit (ASU) as a means of supplying oxygen to the boiler. Virtually all other parameters (plant size, fuel-type, steam conditions, etc.) are different. Hence, it is difficult to draw conclusions based on consistent comparison criteria. Suffice it to say that the techno-economic impact values reported by IEA are within the ranges reported here (see Table 2.6), namely:

- Significant $\mathrm{CO}_{2}$ reductions (80-100\%) are achievable

- Energy penalty ranges from about 15 - 31\% compared to respective reference plant without $\mathrm{CO}_{2}$ capture.

- $\mathrm{CO}_{2}$ mitigation costs range from about 21 to more than $44 \$ /$ tonne of $\mathrm{CO}_{2}$ avoided (40\$/ton)

The cryogenic air separation process bears a major responsibility in the energy penalty and high cost associated with the oxy-combustion process. It is anticipated that advanced oxygen production technologies such as oxygen transport membrane will be helpful in the future in reducing the energy penalty and the specific cost of oxygen production. 
Table 2.6: Techno-Economic Analysis Results of Oxy Combustion of Coal for $\mathrm{CO}_{2}$ Capture (from Dillon, et al., 2005)

\begin{tabular}{|c|c|c|c|}
\hline Parameter & Physical Units & $\begin{array}{c}\text { ASC PC Air Fired } \\
\text { Power Pant Without } \\
\mathrm{CO}_{2} \text { Capture } \\
\end{array}$ & $\begin{array}{c}\text { ASC PC Oxy- } \\
\text { Combustion Power } \\
\text { Plant With } \mathrm{CO}_{2} \text { Capture }\end{array}$ \\
\hline Steam Cycle & bara $/{ }^{\circ} \mathrm{C} /{ }^{\circ} \mathrm{C}$ & $290 / 600 / 620$ & $290 / 600 / 620$ \\
\hline Fuel Input & $\mathrm{kg} / \mathrm{s}$ & 59.19 & 58.09 \\
\hline Fuel Heating Value & $\mathrm{MJ} / \mathrm{kg}(\mathrm{LHV})$ & 25.86 & 25.86 \\
\hline Fuel Heat Input & $\mathrm{MW}_{\text {th }}(\mathrm{LHV})$ & 1530.8 & 1502.2 \\
\hline $\mathrm{O}_{2}$ Input & tonne/day & --- & 10373 \\
\hline Gross Power Output & MWe & 740 & 737 \\
\hline ASU Power & MWe & --- & 87 \\
\hline $\mathrm{CO}_{2}$ Compression \& Purification & MWe & --- & 65 \\
\hline Power Plant Auxiliaries & MWe & 63 & 54 \\
\hline Net Power Output & MWe & 677 & 532 \\
\hline Gross Efficiency & $\%$ LHV & 48.3 & 49.1 \\
\hline Net Efficiency & $\%$ LHV & 44.3 & 35.4 \\
\hline $\mathrm{CO}_{2}$ Capture Energy Penalty & $\%$ points & --- & 8.9 \\
\hline Specific Investment Costs & US\$/kWe (net) & 1513 & 2342 \\
\hline Fuel Cost & US\$/GJ & 1.5 & 1.5 \\
\hline Cost of Electricity, COE & US $\$ / k W h$ & 4.98 & 7.28 \\
\hline $\mathrm{CO}_{2}$ Emissions & $\mathrm{t} / \mathrm{h}$ & 489 & 45 \\
\hline $\mathrm{CO}_{2}$ Captured & $\mathrm{g} / \mathrm{kWh}$ & --- & 831 \\
\hline $\mathrm{CO}_{2}$ Mitigation Cost & US\$/tonne & --- & 36 \\
\hline
\end{tabular}


Table 2.7: Summary of Techno-Economic Studies of Coal Power Plant (From Tan, et al, 2005)

\begin{tabular}{|c|c|c|c|c|c|}
\hline Author(s) & Description & $\begin{array}{c}\text { Economic Analysis } \\
\text { Results } \\
\end{array}$ & $\begin{array}{c}\text { Plant } \\
\text { Efficiency } \\
(\%) \\
\end{array}$ & $\begin{array}{l}\text { Efficiency } \\
\text { Relative to } \\
\text { Base Case } \\
\end{array}$ & $\begin{array}{c}\text { Relative } \\
\mathrm{CO}_{2} \\
\text { Reduction } \\
\end{array}$ \\
\hline $\begin{array}{l}\text { McPhail et } \\
\text { al. (1997) }\end{array}$ & $\begin{array}{l}660 \mathrm{MW} \text { power plant } \\
\text { retrofitted with different heat } \\
\text { integration configurations: } \\
\text { net output reduced to } 446- \\
513 \mathrm{MW}\end{array}$ & $\begin{array}{l}\text { Optimal cost of } \\
\text { power is } 55 \% \text { higher } \\
\text { than in base case; } \\
\text { capital cost increases } \\
\text { by } 50 \%\end{array}$ & $28.5-32.7$ & $0.692-0.794$ & $95-100 \%$ \\
\hline $\begin{array}{l}\text { Okawa } \\
\text { et al. } \\
(1997)\end{array}$ & $\begin{array}{l}1000 \mathrm{MW} \text { power plant with } \\
\text { power from ASU and } \mathrm{CO}_{2} \\
\text { capture supplied by original } \\
\text { plant }\end{array}$ & $\begin{array}{l}\text { Retrofit cost is } 3.8 \\
\text { billion yen per year }\end{array}$ & 29.1 & 0.735 & -- \\
\hline $\begin{array}{l}\text { Nsakala et } \\
\text { al. }(2001)\end{array}$ & $\begin{array}{l}433 \mathrm{MW} \text { baseline plant with } \\
\text { power for ASU and } \mathrm{CO}_{2} \\
\text { capture supplied by original } \\
\text { plant; net power after retrofit } \\
\text { is } 280 \mathrm{MW} \text {. }\end{array}$ & $\begin{array}{l}\mathrm{CO}_{2} \text { capture cost of } \\
\mathrm{US} \$ 42 \text { per ton }\end{array}$ & 24.1 & 0.657 & $82.3 \%$ \\
\hline $\begin{array}{l}\text { Simbeck } \\
(2001)\end{array}$ & $\begin{array}{l}300 \mathrm{MW} \text { power plant fired } \\
\text { with sub-bituminous coal; } \\
\text { power for ASU and } \mathrm{CO}_{2} \\
\text { capture supplied by auxiliary } \\
\text { NGCC plant. }\end{array}$ & $\begin{array}{l}\text { Total cost relative to } \\
\text { baseline plant is } 2.98 \text {; } \\
\mathrm{CO}_{2} \text { capture cost is } \\
\text { US } \$ 28 \text { per ton. }\end{array}$ & 29.2 & 0.807 & $87.2 \%$ \\
\hline $\begin{array}{l}\text { Andersson } \\
\text { and } \\
\text { Maksinen } \\
(2002)\end{array}$ & $\begin{array}{l}865 \mathrm{MW} \text { lignite-fired } \\
\text { baseline plant with power } \\
\text { ASU and } \mathrm{CO}_{2} \text { capture } \\
\text { supplied by original plant; } \\
\text { net power after retrofit is } 623 \\
-697 \mathrm{MW} \text {. }\end{array}$ & $\begin{array}{l}\text { Total cost relative to } \\
\text { baseline plant is } 0.96\end{array}$ & $30.7-34.3$ & $0.721-0.805$ & -- \\
\hline $\begin{array}{l}\text { Singh et al. } \\
(2003)\end{array}$ & $\begin{array}{l}400 \mathrm{MW} \text { power plant fired } \\
\text { with sub-bituminous coal; } \\
\text { power for ASU and } \mathrm{CO}_{2} \\
\text { capture supplied by auxiliary } \\
\text { NGCC plant. }\end{array}$ & $\begin{array}{l}\text { Retrofit cost is } \\
\text { US } \$ 76.4 \text { million, } \\
\text { resulting in a } 20 \% \\
\text { increase in power } \\
\text { cost. } \mathrm{CO}_{2} \text { capture } \\
\text { cost is US } \$ 35 \text { per ton }\end{array}$ & --- & --- & --- \\
\hline $\begin{array}{l}\text { Kakaras et } \\
\text { al. }(2004)\end{array}$ & $\begin{array}{l}280 \mathrm{MW} \text { baseline power } \\
\text { plant; net output after retrofit } \\
184 \mathrm{MW}\end{array}$ & --- & 23.8 & 0.649 & $79 \%$ \\
\hline $\begin{array}{l}\text { Varagani et } \\
\text { al. }(2004)\end{array}$ & $\begin{array}{l}500 \mathrm{MW} \text { baseline power } \\
\text { plant; net power after retrofit } \\
405-409 \mathrm{MW}\end{array}$ & $\begin{array}{l}\text { Power cost } 33 \% \\
\text { higher than baseline; } \\
\mathrm{CO}_{2} \text { capture cost is } \\
\text { US } \$ 19-21 \text { per ton }\end{array}$ & $29.9-31.4$ & $0.808-0.849$ & $99 \%$ \\
\hline
\end{tabular}

\subsubsection{Combustion Testing in Pilot-Scale and Demonstration Plant}

Table 2.8 and Table 2.9 list the major test work carried out by various research organizations in $\mathrm{O}_{2}$ fired pilot-scale and demonstration plants (Wall, et al. 2004). The studies focused on pulverized fuel (PC) firing in oxygen with recycled flue gas. The 
pilot-scale facilities ranged in firing rate from 0.3 to $3.0_{\mathrm{MWth}}$; the demonstration plant was an $88 \mathrm{MW}_{\text {th }}$ facility. A variety of combustion performance issues were evaluated including heat transfer, gaseous emissions $\left(\mathrm{NO}_{\mathrm{x}}, \mathrm{SO}_{2}\right)$, particulate emissions, etc. In summary:

- Flue Gas Recycle Ratio (R), defined as: $\boldsymbol{R}=\frac{M r f g}{M r f g+M p f g}$,

where $\boldsymbol{M}$ is flue gas mass flow rate

rfg: recycled flue gas

pfg: product flue gas

This parameter is important to optimize, because it influences adiabatic flame temperature and heat transfer.

Table 2.8: List of Pilot-Scale Studies (from Tan, et al., 2005; Wall, et al., 2004)

\begin{tabular}{|c|c|c|}
\hline Organization & Furnace used & Focus of Study \\
\hline $\begin{array}{l}\text { EERC and } \\
\text { ANL }\end{array}$ & $\begin{array}{l}10 \text { million BTU/hr. }(\sim 3.0 \\
\left.\mathrm{MW}_{\mathrm{th}}\right) \text { tower furnace with } \\
\text { internal square furnace cross } \\
\text { section of } 1 \mathrm{x} 1 \mathrm{~m} \text { and } 6 \mathrm{~m} \\
\text { long - using a single swirl } \\
\text { burner }\end{array}$ & $\begin{array}{l}\text { - Demonstrating the technical feasibility of the } \mathrm{CO}_{2} \\
\text { recycle boiler } \\
\text { Demonstrating the ratio of recycle gas to } \mathrm{O}_{2} \text { for } \\
\text { achieving similar performance to air fired system } \\
\text { Q } \\
\text { Quantifying the observable operational changes in } \\
\text { - Prome stability, pollution emissions and burnout } \\
\text { Providing as basis for scaling experimental results to } \\
\text { commercial scale }\end{array}$ \\
\hline IFRF & $\begin{array}{l}\text { IFRF Furnace } \# 1: 2.5 \mathrm{MWth} \\
\text { horizontal furnace with } \\
\text { internal square cross section } \\
\text { of } 2 \times 2 \mathrm{~m} \text { and } 6.25 \mathrm{~m} \text { long - } \\
\text { using an air staged swirl } \\
\text { burner }\end{array}$ & $\begin{array}{l}\text { Optimizing } \mathrm{O}_{2}-\mathrm{RFG} \text { firing conditions to yield } \\
\text { similar heat transfer performance to air fired system } \\
\text { Evaluating the impact of } \mathrm{O}_{2}-\mathrm{RFG} \text { process on furnace } \\
\text { performance, including flame ignition and stability, } \\
\text { heat transfer, combustion efficiency and pollutant } \\
\text { emissions as compared to air fired system }\end{array}$ \\
\hline IHI & $\begin{array}{l}\text { IHI's } 1.2 \text { MWth combustion } \\
\text { test furnace: a horizontal } \\
\text { cylinder furnace with } 1.3 \mathrm{~m} \\
\text { inner diameter and } 7.5 \mathrm{~m} \text { in } \\
\text { length - using a swirl burner }\end{array}$ & $\begin{array}{l}\text { - Combustion characteristic of pulverized coal } \mathrm{O}_{2} / \mathrm{CO}_{2} \\
\text { mixture } \\
\text { Evaluation of the effect of wet or dry recycled flue } \\
\text { gas on the combustion process }\end{array}$ \\
\hline $\begin{array}{c}\text { Air Liquide and } \\
\text { B\&W }\end{array}$ & $\begin{array}{l}1.5 \mathrm{MWth} \text { pilot scale boiler } \\
\text { with air staged combustion } \\
\text { system }\end{array}$ & $\begin{array}{l}\text { - Demonstrating the technical feasibility of conversion } \\
\text { from air firing to O2-RFG firing for large scale boiler } \\
\text { Highlighting the impact of O2-RFG process on } \\
\text { emissions and boiler efficiency }\end{array}$ \\
\hline CANMET & $\begin{array}{l}\text { Vertical Combustor } \\
\text { Research Facility }(0.3 \\
\text { MWth): A cylindrical down- } \\
\text { fired and adiabatic vertical } \\
\text { combustor with an inner } \\
\text { diameter of } 0.60 \mathrm{~m} \text { and a } \\
\text { length of } 6.7 \mathrm{~m} \text { - using a } \\
\text { swirl burner }\end{array}$ & $\begin{array}{l}\text { - Pulverized coal combustion behavior in various O2- } \\
\text { RFG mixtures compared with air fired system } \\
\text { Demonstrating the technical factors on the } \\
\text { combustion performance }\end{array}$ \\
\hline
\end{tabular}


Table 2.9: Demonstration Plant Studies (from Tan, et al., 2005; Wall, et al., 2004)

\begin{tabular}{|l|l|ll|}
\hline \multicolumn{1}{|c|}{ Organization } & \multicolumn{1}{|c|}{ Furnace Used } & \multicolumn{1}{c|}{ Focus of Study } \\
\hline Rolls Royce & $\begin{array}{l}\text { 88 MWth Combustion test } \\
\text { International } \\
\text { Combustion }\end{array}$ & $\begin{array}{l}\text { rig with } 5.5 . \mathrm{m}^{2} \times 21 \mathrm{~m} \text { long } \\
\text { using a conventional }\end{array}$ & $\begin{array}{l}\text { To assess the feasibility of adopting flue gas } \\
\text { recirculation and oxygen injection on an existing coal } \\
\text { fired thermal power plant }\end{array}$ \\
& 35MWth low $\mathrm{NO}_{\mathrm{x}}$ burner & $\begin{array}{l}\text { To gain experience in the operation of oxy-coal with } \\
\text { RFG burner }\end{array}$ \\
\hline
\end{tabular}

Wet or Dry flue Gas Recycle: Wet flue gas recycle was found to be more advantageous than dry flue gas recycle from the standpoints of capital investment and operating cost.

$N O_{x}$ Emissions: $\mathrm{NO}_{\mathrm{x}}$ emissions were found to be much lower in oxy-combustion as compared to air firing (see Table 2.10). This is due primarily to:

- Elimination of thermal $\mathrm{NO}_{\mathrm{x}}$

- Conversion of some of the $\mathrm{NO}_{\mathrm{x}}$ in the recycle leg to molecular nitrogen $\left(\mathrm{N}_{2}\right)$

$\mathrm{SO}_{2}$ Emissions: There is a substantial reduction of $\mathrm{SO}_{2}$ formation in oxy-combustion compared to air firing, presumably due to some sulfur retention in the fly ash/particulates (see Table 2.11). 
Table 2.10: Summary of $\mathrm{NO}_{x}$ Emissions Results (From Tan, et al., 2005)

\begin{tabular}{|c|c|c|c|}
\hline Author(s) & $\begin{array}{c}\text { Emission } \\
(\mathrm{mg} / \mathrm{MJ})\end{array}$ & $\begin{array}{l}\text { Conversion } \\
\text { Ratio } \\
\end{array}$ & Conclusion \\
\hline $\begin{array}{l}\text { Croiset and } \\
\text { Thambimuthu } \\
\text { (2001) }\end{array}$ & $\begin{array}{l}\text { Air: } 340 \\
\text { RFG }\left(28 \% \mathrm{O}_{2}\right) \text { : } \\
100 \\
\text { RFG }\left(42 \% \mathrm{O}_{2}\right) \text { : } \\
210\end{array}$ & $\begin{array}{l}\text { Air: } 35 \% 1 \\
\text { RFG }\left(28 \% \mathrm{O}_{2}\right): \\
10 \% \operatorname{RFG}(42 \% \\
\left.\mathrm{O}_{2)}\right): 22 \%\end{array}$ & $\begin{array}{l}\text { High } \mathrm{NO}_{\mathrm{x}} \text { concentration inside the furnace but lower } \\
\mathrm{NO}_{\mathrm{x}} \text { emissions in flue gas than baseline case }\end{array}$ \\
\hline Chui et al. (2003) & $\begin{array}{l}\text { Air: } 110 \\
\text { RFG: } 140- \\
150\end{array}$ & $\begin{array}{l}\text { Air: } 14 \% \\
\text { RFG: } 18-19 \%\end{array}$ & $\begin{array}{l}\mathrm{NO}_{\mathrm{x}} \text { production strongly dependent on swirl number. } \\
\mathrm{RFG} \text { mode can produce the same or even higher amount } \\
\text { of } \mathrm{NO}_{\mathrm{x}} \text { within the combustor than in baseline case. The } \\
\text { observed reduction of } \mathrm{NO}_{\mathrm{x}} \text { in exhaust gas is due } \\
\text { primarily to the fraction of } \mathrm{NO}_{\mathrm{x}} \text { removed with the } \\
\text { recycle stream. }\end{array}$ \\
\hline Kiga et al. (1997) & $\begin{array}{l}\text { Air: } 75-370 \\
\text { RFG: }<53\end{array}$ & $\begin{array}{l}\text { Air: } 7-35 \% \\
\text { RFG: }<5 \%\end{array}$ & $\begin{array}{l}\text { The conversion ratio of fuel nitrogen into } \mathrm{NO}_{\mathrm{x}} \text { is much } \\
\text { higher in baseline case than with oxy-coal FRG } \\
\text { combustion. }\end{array}$ \\
\hline $\begin{array}{l}\text { Nozsaki et al. } \\
\text { (1997) }\end{array}$ & --- & --- & $\begin{array}{l}\text { The recycled } \mathrm{NO}_{\mathrm{x}} \text { is rapidly reduced to } \mathrm{HCN} \text { or } \mathrm{NH}_{3} \text { in } \\
\text { the combustion zone and } \mathrm{NO}_{\mathrm{x}} \text { formation for } \mathrm{O}_{2} / \mathrm{CO}_{2} \\
\text { combustion is lower than for air combustion }\end{array}$ \\
\hline $\begin{array}{l}\text { Kimura et al. } \\
(1995)\end{array}$ & $\begin{array}{l}\text { Air: } 340 \\
\text { RFG: }<90\end{array}$ & $\begin{array}{l}\text { Air: } 30-33 \% \\
\text { RFG: }<8 \%\end{array}$ & $\begin{array}{l}\mathrm{NO}_{\mathrm{x}} \text { conversion ratio in } \mathrm{O}_{2} / \mathrm{CO}_{2} \text { combustion is very } \\
\text { much lower than that in normal air combustion because } \\
\text { of the higher reduction in the combustion zone. }\end{array}$ \\
\hline Hu et al. (2000) & --- & $\begin{array}{l}\text { Air: } 28 \%^{2} \\
\text { Oxy-coal: } 14 \%\end{array}$ & $\begin{array}{l}\mathrm{NO}_{\mathrm{x}} \text { emission is strongly dependent on the } \mathrm{O}_{2} \\
\text { concentration. Peak value of } \mathrm{NO}_{\mathrm{x}} \text { emission in air } \\
\text { combustion is double the value in } \mathrm{O}_{2}+\mathrm{CO}_{2} \text { combustion. }\end{array}$ \\
\hline $\begin{array}{l}\text { Woycenko } \\
\text { et al. (1994) }\end{array}$ & $\begin{array}{l}\text { Air: } 320 \\
\text { RFG: } 50-150\end{array}$ & $\begin{array}{l}\text { Air: } 30 \%^{3} \\
\text { RFG: } 5-14 \%\end{array}$ & $\begin{array}{l}\mathrm{NO}_{\mathrm{x}} \text { formation is much lower in oxy-coal with RFG } \\
\text { combustion than in baseline case. }\end{array}$ \\
\hline $\begin{array}{l}\text { Zheng and } \\
\text { Furimsky (2003) }\end{array}$ & --- & $\begin{array}{l}\text { Air: } \\
\text { RFG: up to } 2 \%\end{array}$ & $\begin{array}{l}\mathrm{NO}_{\mathrm{x}} \text { formation in } \mathrm{O}_{2} / \mathrm{CO}_{2} \text { atmosphere predicted to be } \\
\text { reduced by a factor of at least } 15 \text { relative to air } \\
\text { combustion based on chemical equilibrium calculations. }\end{array}$ \\
\hline $\begin{array}{l}\text { Liu and Okazaki } \\
\text { (2003) }\end{array}$ & --- & $\begin{array}{l}\text { Air: } 30 \% \\
\text { ARFG: } 4-8 \%\end{array}$ & $\begin{array}{l}\text { Very high flue gas recycle ratios are possible through } \\
\text { heat recirculation. Stable flames at } 15 \% \mathrm{O}_{2} \text { allows } \\
\text { reduction in fuel-N conversion by a factor of } 7 \text {. }\end{array}$ \\
\hline $\begin{array}{l}\text { Chatel-Pelage et } \\
\text { al. (2003) }\end{array}$ & $\begin{array}{l}\text { Air: } 120-190 \\
\text { RFG: } 35-90\end{array}$ & --- & $\begin{array}{l}\text { 1.5 MAW Pilot-scale demonstration of potential for } \\
\text { drastic } \mathrm{NO}_{\mathrm{x}} \text { reduction. }\end{array}$ \\
\hline
\end{tabular}

${ }^{\mathrm{T}}$ Conversion made using coal HHV.

${ }^{2}$ Both values are at $1273 \mathrm{~K}$ temperature and at the stoichiometric point. The oxy-coal value is with $80 \% \mathrm{CO}_{2}$ in inlet gas.

${ }^{3}$ Conversion made using coal LCV 
Table 2.11: Summary of $\mathrm{SO}_{2}$ Emissions Results (From Tan, et al., 2005)

\begin{tabular}{|c|c|c|c|}
\hline \multirow{2}{*}{ Author(s) } & \multicolumn{2}{|c|}{ Conversion (\%) } & \multirow{2}{*}{ Experimental Conditions } \\
\hline & $\begin{array}{c}\text { Air } \\
\text { Combustion }\end{array}$ & $\begin{array}{c}\text { Oxy-Fuel } \\
\text { Combustion }\end{array}$ & \\
\hline $\begin{array}{l}\text { Woycenko et al. } \\
\text { (1994) }\end{array}$ & 96 & $60-75$ & $\begin{array}{l}\text { Experimental results using Göttelborn coal with } \\
1.02 \% \text { sulfur. }\end{array}$ \\
\hline Kiga et al. (1997) & $70-78$ & $37-41$ & $\begin{array}{l}\text { Experimental results using } 3 \text { different bituminous } \\
\text { coals with } 0.38-0.96 \% \text { sulfur. }\end{array}$ \\
\hline Hu et al. (2000) & $6-12 *$ & $5-12 *$ & $\begin{array}{l}20-100 \% \mathrm{O}_{2} \text { mixed with } \mathrm{N}_{2} \text { or } \mathrm{CO}_{2} \text { at temperature } \\
\text { of } 1123-1573 \mathrm{~K} \text { and equivalence ratios } 0.4-1.4 \text {. }\end{array}$ \\
\hline $\begin{array}{l}\text { Croiset and } \\
\text { Thambimuthu } \\
(2001)\end{array}$ & 91 & $56-66$ & $\begin{array}{l}\text { Experimental results using US eastern bituminous } \\
\text { coal with } 0.96 \% \text { sulfur; } 28-42 \% \text { oxygen in } \mathrm{O}_{2} / \mathrm{RFG} \\
\text { mixture using oxygen feed of } 90-100 \% \text { purity. }\end{array}$ \\
\hline $\begin{array}{l}\text { Zheng and } \\
\text { Furimsky (2003) }\end{array}$ & $91-100$ & $90-100$ & $\begin{array}{l}\text { Computations based on chemical equilibrium using } \\
\mathrm{F}^{*} \mathrm{~A}^{*} \mathrm{C}^{*} \mathrm{~T}\end{array}$ \\
\hline
\end{tabular}

* In mg SO 2 (as S) per g coal

\subsubsection{Vattenfall Demonstration Project}

German electricity company Vattenfall Europe, a subsidiary of a Swedish electricity group Vattenfall, has proposed to build a first of a kind 30 MWth pilot plant next to the Schwarze Pumpe coal-fired power station in Brandeburg, Germany. This facility, which will burn German lignite, will be oxyfuel fired. In this case, pulverized fuel will be burned in pure oxygen plus recirculated flue gas (mainly carbon dioxide). The carbon dioxide formed in the combustion process can be easily separated and sequestered in rock formations, leading to zero-emissions into the atmosphere. The primary objective of the 30 MWth Vattenfall project is to demonstrate the oxyfuel process for carbon dioxide capture. ALSTOM has supported Vattenfall in the development of the oxyfuel concept, depicted in Figure 2.2.

The next step will be to design and build a 250 MWe demonstration power plant for commercial operation by 2015 . Vattenfall estimates that this demonstration plant will cost $\sim € 40$ million and will take three years to build, with commissioning in 2008. ALSTOM has been selected to supply the boiler for this demonstration project.

More details are given on the following Webpage:

(http://www.thelocal.se/article.php?ID=1459\&date=20050519). 


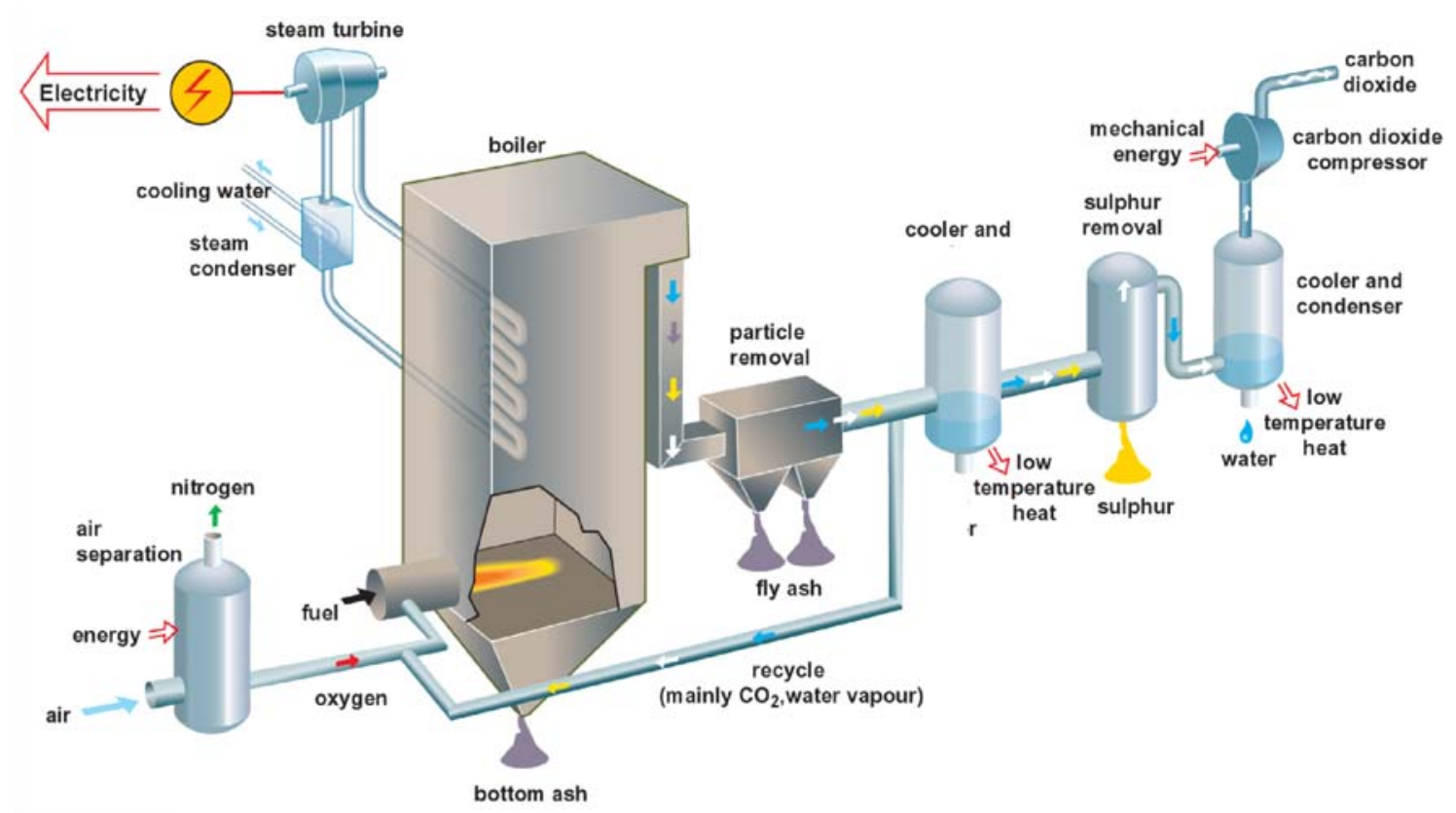

Figure 2.2: Schematic of Vattenfall's Oxyfuel Demonstration Pilot Plant

\subsection{Concluding Remarks}

Oxyfuel combustion is one of the promising clean coal technologies being developed by the power industry. Firing coal with pure oxygen plus recycled flue gas (which is mainly $\mathrm{CO}_{2}$ ) produces a product flue gas, which is highly $\mathrm{CO}_{2}$-concentrated. This product flue gas can be simply dried and compressed for sequestration, leading to a near zero emissions power plant, or further processed into a high purity $\mathrm{CO}_{2}$ product for various uses, such as enhanced oil recovery (EOR) or enhanced gas recovery (EGR).

Results by ALSTOM and others indicate that this is an attractive option for coal combustion, because:

- It uses proven and reliable commercially available pulverized coal (PC) or circulating fluidized bed (CFB) boiler technology

- It uses commercially available $\mathrm{CO}_{2}$ capture enabling technologies:

$>$ Oxygen production by cryogenic air separation

$>\mathrm{CO}_{2}$ purification, compression, and liquefaction

- There appear to be no show-stoppers in terms of:

$>$ Furnace operation

$>$ Heat transfer

$>$ Emissions of major gas species and trace elements

The development of this technology has proceeded to a level where it is now ready for large scale demonstration, after which commercial offerings would be possible. 


\section{$3 \quad$ PILOT SCALE TEST RESULTS AND DATA ANALYSIS}

The objective of the pilot-scale testing was to generate detailed technical data needed to establish advanced CFB design requirements and performance when firing coal and delayed petroleum coke in $\mathrm{O}_{2} / \mathrm{CO}_{2}$ mixtures. Pilot-scale testing was performed at ALSTOM's Multi-use Test Facility (MTF), located in Windsor, Connecticut.

Results from the test data analysis will be available for the design of systems to retrofit existing CFB units for oxygen firing and for the design of new oxygen-fired CFB boilers. Test data analysis results were also used in this project for the plant retrofit task. The results of the retrofit task are discussed in Section 4 of this report where the retrofit design, performance calculations, costs and economic impacts are shown for Case 2 (CFB retrofit to $\mathrm{O}_{2}$-firing with $\mathrm{CO}_{2}$ Capture, Purification, Compression, and Liquefaction).

\subsection{Background and Objectives}

A major task of the Phase II program was to conduct a pilot plant test in ALSTOM's 3.0 $\mathrm{MW}_{\text {th }}(9.9 \mathrm{MMBtu} / \mathrm{hr})$ pilot plant. The objective of the pilot testing was to simulate an oxygen-fired commercial plant and demonstrate successful operation. The testing also generated data on the following aspects of oxygen-fired combustion.

- Flue Gas Quality

- Bed Dynamics

- Heat Transfer (Waterwalls, Convection Pass Sections, Bubbling Bed Sections, and Moving Bed Sections)

- Flue Gas Desulfurization

- $\mathrm{NO}_{\mathrm{x}}$ Emissions Reduction

- Other Pollutants' Emissions $\left(\mathrm{N}_{2} \mathrm{O}, \mathrm{CO}, \mathrm{VOC}, \mathrm{Hg}\right.$, and other trace elements)

- Bed and Ash Characteristics (e.g., Potential Bed Agglomeration)

This information was used for the retrofit design study of commercial sized units

\subsubsection{MTF Pilot Tests Conducted in Year 2004}

Phase II workscope consisted of pilot-scale testing followed by a refined performance and economic evaluation of the oxygen-fired CFB concept. As a part of this workscope, ALSTOM modified its 3.0 MWth (9.9 MMBtu/hr) Multiuse Test Facility (MTF) pilot plant to operate with $\mathrm{O}_{2} / \mathrm{CO}_{2}$ mixtures of up to $70 \% \mathrm{O}_{2}$ by volume. Tests with coal and petroleum coke were conducted in two phases totaling approximately two hundred (200) hours. The test objectives were to determine the impacts of oxygen firing on heat transfer, bed dynamics, potential agglomeration, and major gaseous $\left(\mathrm{NOx}, \mathrm{N}_{2} \mathrm{O}, \mathrm{SO}_{2}\right.$, and $\mathrm{CO}$ ) and particulate emissions. The test data was used to refine the design, performance, costs, and economic models developed in Phase-I for an $\mathrm{O}_{2}$-fired CFB with $\mathrm{CO}_{2}$ capture (Case-2).

While carrying out the Phase II workscope, ALSTOM identified several items needing investigation in preparation for large-scale demonstration of the oxygen-fired CFB 
concept. They consisted of additional MTF pilot testing and a subsequent retrofit design study of oxygen firing and $\mathrm{CO}_{2}$ capture on a relatively small existing air-fired CFB plant. Hence, ALSTOM responded to a DOE Solicitation to address the identified technical gaps. ALSTOM received a contract award from the DOE to conduct a project entitled "Commercialization Development of Oxygen Fired CFB for Greenhouse Gas Control," under Cooperative Agreement DE-FC26-04NT42205, as briefly described in the following section.

\subsubsection{Objectives of the 2005 MTF Pilot Tests}

The specifically targeted objectives for testing the oxygen-fired CFB concept the MTF included:

- Back-end sulfur capture. That is, demonstration of $\mathrm{SO}_{2}$ polishing, specifically ALSTOM's Flash Dryer Absorber (FDA) process for reducing $\mathrm{SO}_{2}$ emissions from the flue gas, which is concentrated to high $\mathrm{CO}_{2}, \mathrm{H}_{2} \mathrm{O}$, and $\mathrm{SO}_{2}$ levels due to oxygen firing (i.e., no nitrogen dilution);

- Demonstration of the suitability and performance of a Moving Bed Heat Exchanger in place of a Fluidized Bed Heat Exchanger.

- Determination of the effect of combustion staging and ammonia injection on $\mathrm{NO}_{\mathrm{x}}$ emissions reduction

- Assessment of volatile organic compounds (VOC's), mercury, and other trace elements emission potentials

- Determination of back-pass convection section heat transfer performance

These issues are briefly discussed in the following sub-sections.

\subsubsection{Backend Sulfur Capture}

One of the major benefits of fluidized bed combustion is the ability to capture $\mathrm{SO}_{2}$ from the flue gas by the addition of limestone to the combustor. The sulfur capture occurs in two steps:

1. The calcium carbonate in the limestone is calcined to calcium oxide.

$$
\text { Calcination: } \quad \mathrm{CaCO}_{3}+\text { heat } \rightarrow \mathrm{CaO}+\mathrm{CO}_{2}
$$

2. The calcium oxide reacts with $\mathrm{SO}_{2}$ to form calcium sulfate.

$$
\text { Sulfation: } \quad \mathrm{CaO}+\mathrm{SO}_{2}+1 / 2 \mathrm{O}_{2} \rightarrow \mathrm{CaSO}_{4}
$$

Calcination occurs when the limestone is heated to above the calcination temperature, which depends on the $\mathrm{CO}_{2}$ content of the surrounding gas - see Figure 3.1. 


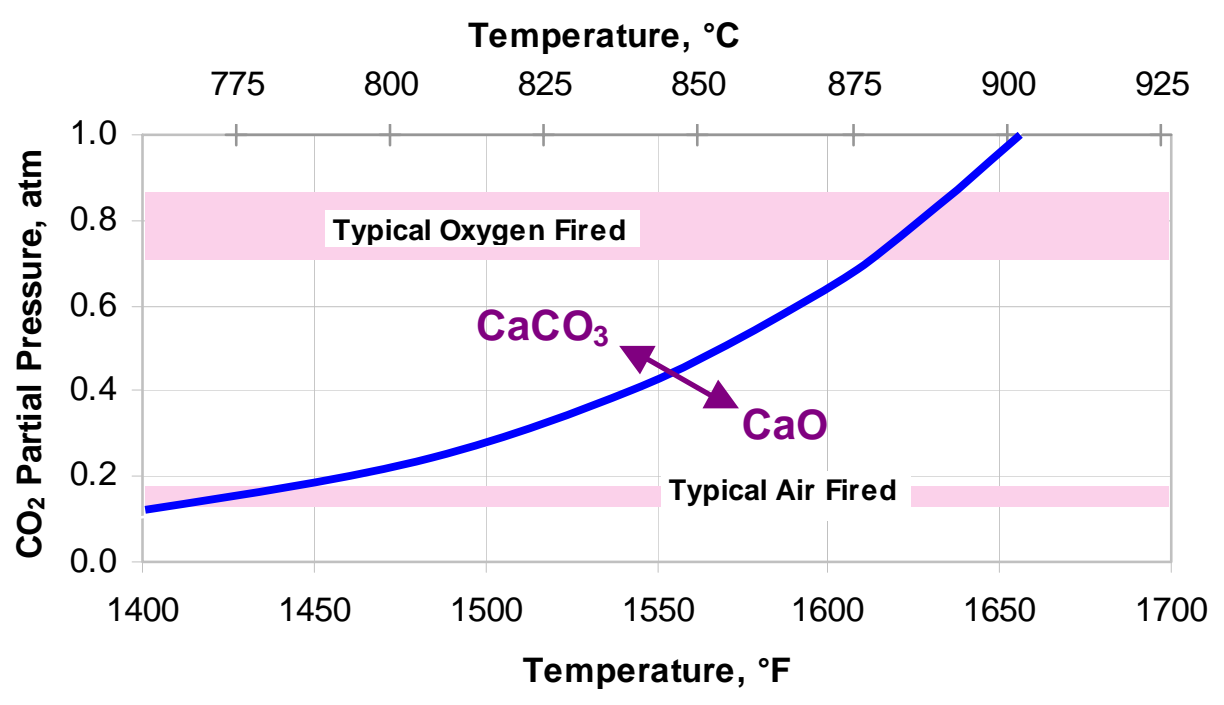

Figure 3.1: Equilibrium Temperature for Calcination

With air firing, the $\mathrm{CO}_{2}$ content of the flue gas is under $20 \%$. Limestone will calcine at about $760{ }^{\circ} \mathrm{C}\left(1400^{\circ} \mathrm{F}\right)$, which is well below the typical CFB operating temperature of 815 to $900{ }^{\circ} \mathrm{C}\left(1500\right.$ to $\left.1650^{\circ} \mathrm{F}\right)$.

With oxygen firing, however, the $\mathrm{CO}_{2}$ content is above $70 \%$. This requires a temperature above $885^{\circ} \mathrm{C}\left(1625^{\circ} \mathrm{F}\right)$ for calcination to occur. There are two consequences of this:

1. The combustor needs to operate at a high temperature to ensure calcination. This can generally be designed for - anthracites and petroleum cokes are typically combusted at above $885^{\circ} \mathrm{C}\left(1,625^{\circ} \mathrm{F}\right)$ in $\mathrm{CFB}$ combustors. For some fuels, there may be concerns for ash fusion and sulfur capture in the furnace may suffer at high temperature, as shown previously (Nsakala, et al. 2004)

2. Where the ash cools to below the calcination temperature while exposed to the high $\mathrm{CO}_{2}$ content, recarbonation (the reverse of calcination) may occur.

Recarbonation: $\quad \mathrm{CaO}+\mathrm{CO}_{2} \rightarrow \mathrm{CaCO}_{3}+$ heat [3]

Recarbonation is a concern in those locations where the temperature drops below the calcination temperature: fluidized bed or moving bed heat exchanger and the convective pass. 
Table 3.1: Typical Flue Gas Composition - Air vs. Oxygen Fired

\begin{tabular}{|c|c|c|c|}
\hline Constituent & Air & $\begin{array}{c}\text { A. } 30 \% \mathrm{O}_{2} / \text { Recycled } \\
\text { Flue Gas } \\
\text { (Retrofit Scenario) }\end{array}$ & $\begin{array}{c}\text { B. } 70 \% \mathrm{O}_{2} / \text { Recycled } \\
\text { Flue Gas } \\
\text { (Greenfield Scenario) }\end{array}$ \\
\hline $\mathrm{N}_{2}(\%)$ & 74.78 & 0.81 & 0.74 \\
\hline $\mathrm{CO}_{2}(\%)$ & 14.49 & 82.78 & 74.91 \\
\hline $\mathrm{H}_{2} \mathrm{O}(\%)$ & 7.40 & 13.05 & 20.97 \\
\hline $\mathrm{O}_{2}(\%)$ & 3.31 & 3.31 & 3.31 \\
\hline $\mathrm{SO}_{2}, \mathrm{ppmv}$ & 199 & 469 & 764 \\
\hline
\end{tabular}

Hence, two options were evaluated during the test campaign for dealing with the issues of sulfur capture and recarbonation:

1. Backend Sulfur Capture with FDA/Lime. This test entailed using a sand bed instead of injecting limestone in the furnace, and injecting commercially prepared lime $(\mathrm{CaO})$ into the FDA to capture $\mathrm{SO}_{2}$. Testing was conducted while firing the medium volatile bituminous coal in both air and $\mathrm{O}_{2} / \mathrm{CO}_{2}$ mixture (Case A in Table 3-1). This scenario implies that in commercial operation, the FBHE can be fluidized with recycled flue gas (mainly $\mathrm{CO}_{2}$ ) without the danger of recarbonation.

2. Limestone Injection in the Furnace with a Backend Polishing System (FDA). This test entailed using the FDA in a classical manner. That is, limestone was fed to the furnace, and the FDA was used as a secondary $\mathrm{SO}_{2}$ polishing system. Testing was also conducted while firing the medium volatile bituminous coal in both air and $\mathrm{O}_{2} / \mathrm{CO}_{2}$ mixture (Case $\mathrm{A}$ in Table 3.1). This scenario implies that in commercial operation, the FBHE should be fluidized with air or inert gas (e.g., $\mathrm{N}_{2}$ from the ASU) in order to avoid recarbonation. Under this scenario, the fluidizing gas would have to be vented off into a heat recovery system before it is exhausted to the atmosphere.

\subsubsection{MBHE Demonstration}

The MBHE, which was demonstrated in this testing, is located in a parallel solids stream with the fluid bed heat exchanger (FBHE), as shown in Figure 3.3. This device was tested while firing the medium volatile bituminous coal in air and in an $\mathrm{O}_{2} / \mathrm{CO}_{2}$ mixture (Case A in Table 3.1) and petcoke in the same $\mathrm{O}_{2} / \mathrm{CO}_{2}$ mixture.

The moving bed external heat exchanger design provides several advantages over a bubbling fluidized bed. One significant advantage of the moving bed is that a higher temperature differential is obtained between the bed material and the steam cycle working fluid. This reduces the surface area and weight requirements for the heat exchanger pressure parts. The higher temperature differential occurs because the moving bed can be designed as a counterflow heat exchanger. The bubbling fluid bed on the other hand is more of a "stirred" heat exchanger where the bed material is at a "stirred temperature". The "stirred temperature" is much lower than the inlet solids temperature in the moving bed. Additionally, the moving bed does not require any fluidizing medium, fluidizing blower, fluidizing nozzles, and fluidizing gas piping thus providing a 
much simpler system. With these advantages, the moving bed allows for a much more compact and less expensive design than a bubbling bed design.

The savings of MBHE design are further magnified for $\mathrm{O}_{2}$ firing due to the greater external heat exchanger duty. Figure 3.2 shows the distribution of the heat duty between the combustor, convective pass, and external heat exchanger when firing coal in air and an $\mathrm{O}_{2} / \mathrm{CO}_{2}$ medium (Nsakala, Liljedahl, and Turek, 2004).

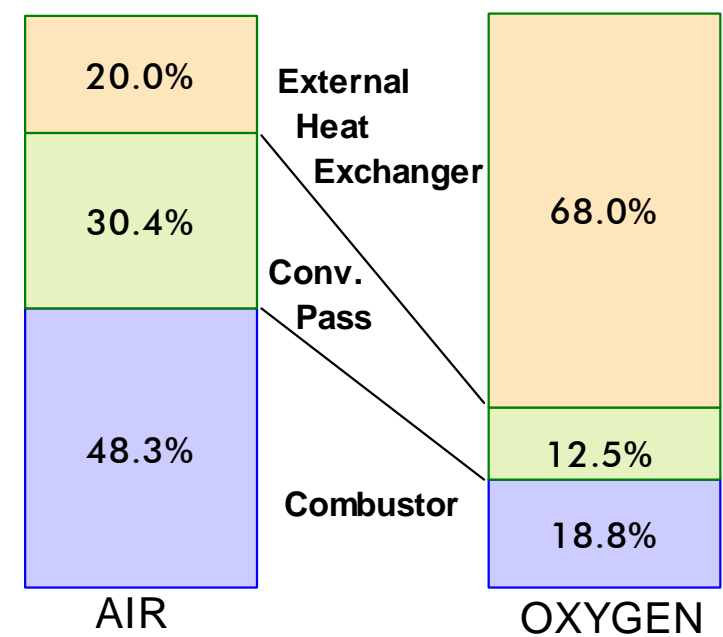

Figure 3.2: Boiler Heat Absorption Comparison - Air and $70 \% \mathrm{O}_{2}$ Firing

The ability of the MBHE to operate without fluidizing media is very significant for $\mathrm{O}_{2}$ firing, as the potential for recarbonation is avoided altogether.

\subsection{5 $\quad \mathrm{NO}_{\mathrm{x}}$ Emissions}

$\mathrm{NO}_{\mathrm{x}}$ emissions with oxygen firing are lower than with air firing due to the elimination of nitrogen from the air. This was the case in the 2004 pilot testing. In the 2005 tests, ammonia was injected to investigate the potential for further reduction by selective noncatalytic reduction (SNCR).

\subsubsection{Mercury and Trace Elements Analysis}

Mercury and other trace elements were not reported in previous studies. The present study addressed this issue.

\subsubsection{Convective Pass Fouling and Heat Transfer}

In a conventional CFB, the flue gas leaving the cyclone is cooled in the convective pass followed by an air preheater. In the convective pass, fly ash typically deposits on the tube banks. If necessary, steam soot blowers periodically clean the tubes. As the gas cools to below about $760{ }^{\circ} \mathrm{C}\left(1400^{\circ} \mathrm{F}\right.$ ) (see Figure 3.1), there is the potential for $\mathrm{CO}_{2}$ in the flue gas to recombine with calcium oxide in the deposits to form calcium carbonate (per Eq. 3 above). This can increase the hardness of the deposits, making them difficult to remove. With oxygen firing, the $\mathrm{CO}_{2}$ content is higher, so the recarbonation occurs in a broader temperature range and at a higher rate.

Two convective tubes were installed downstream of the MTF cyclone (Figure 3.3) to 
investigate the effect of oxygen firing on both tube fouling and heart transfer

\subsection{MTF Pilot Plant}

ALSTOM Power Inc.'s “Multi-Use Combustion Test Facility” (MTF) was developed by its US Power Plant Laboratories to support the Power Generation Businesses strategic development needs. This facility (Figure 3.3) provides the flexibility to perform pilotscale testing with conventional pulverized-coal firing, fluidized bed combustion, and gasification firing conditions. The test facility is located in ALSTOM Power Inc.'s Combustion Research Complex at its US Power Plant Laboratories facilities in Windsor, Connecticut, USA.

The MTF also allows testing with both circulating and bubbling fluidized bed conditions, as well as various other conditions being considered for advanced processes. Capabilities for testing under FBC modes provide detailed data on heat transfer, hydrodynamics, combustion, sulfur capture and process control.

Investigations can be conducted with test fuels including coal, oil, and gas as well as various alternative fuels such as petroleum coke and biomass. Complete solid fuel and sorbent handling systems, a flue gas scrubbing system and a Fabric Filter Test Facility are also incorporated into the MTF.

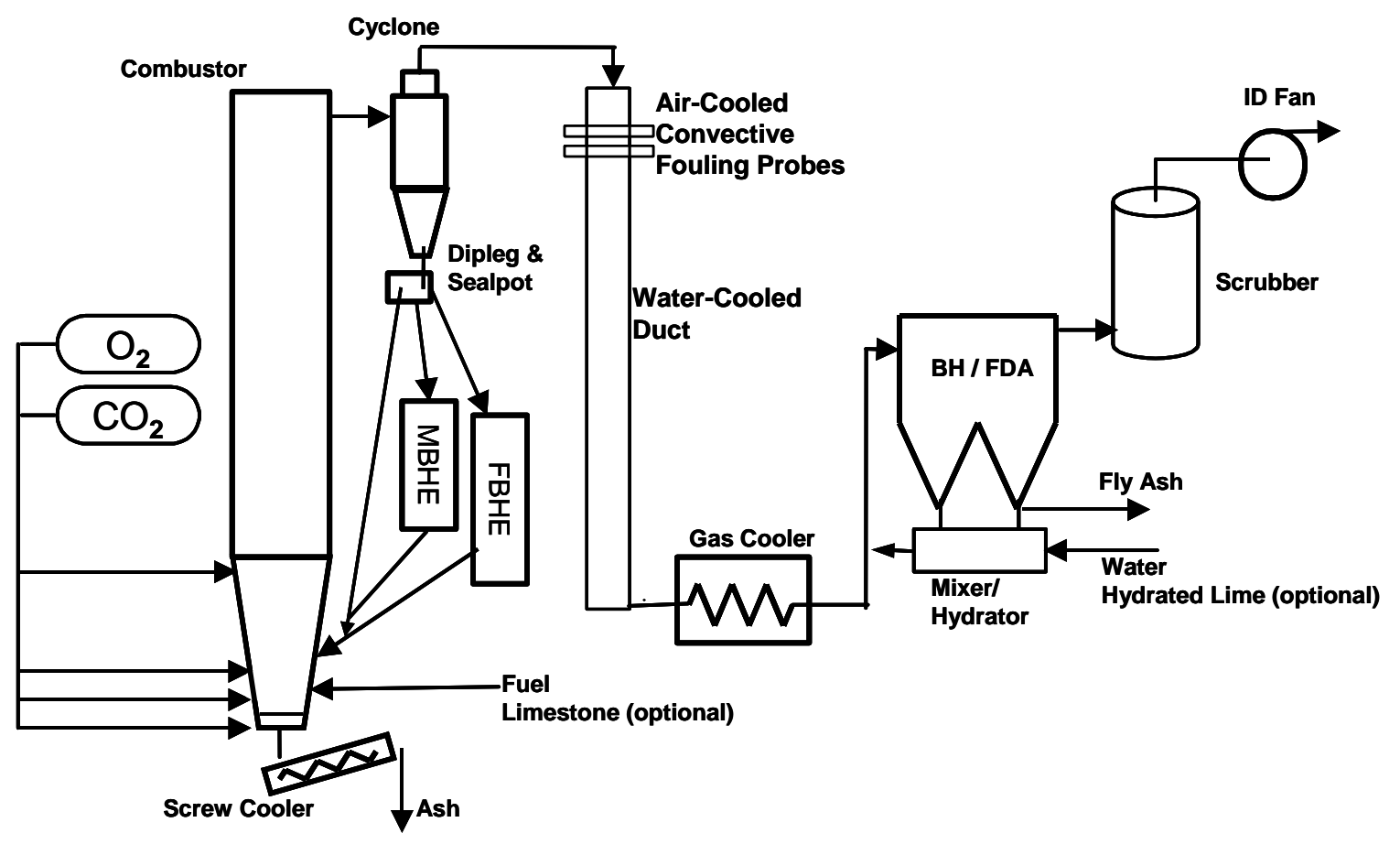

Figure 3.3: Schematic of the Multi-use Test Facility (MFT)

\subsubsection{General Facility Description}

This section gives a description on the MTF in its basic CFB configuration. The modifications made for the oxygen-fired testing are also described in this section

The MTF can be operated under atmospheric conditions at firing capacities up to 3.0 $\mathrm{MW}_{\text {th }}(9.9$ million Btu per hour). The combustor has an overall height of more than $18 \mathrm{~m}$ 
(60 feet $\mathrm{m}$ ). The inside diameter is $1 \mathrm{~m}$ (40 inches) in the upper furnace; in the bottom nine feet it tapers to $0.66 \mathrm{~m}$ (26 inches) diameter. The area of the fluidizing grid is $42 \%$ of the upper furnace area $\left(26^{2} / 40^{2} \times 100\right)$. The furnace is equipped with extensive instrumentation and control systems and is housed in an enclosed building with supporting ancillary equipment.

Combustion air is supplied through a Spencer forced draft fan. The combustion air stream is split into underbed and overfire air streams. The underbed air passes through an electric heater, where it can be preheated up to $540^{\circ} \mathrm{C}\left(100{ }^{\circ} \mathrm{F}\right)$. The underbed air then enters a plenum, before passing through the air distributor.

Overfire air is injected into the furnace at one or more locations. A large number of ports are available for evaluating the effect of overfire air location. The overfire air is connected to the combustor ports with high temperature flexible tubing, which makes the relocation of overfire air locations a rapid and easy process.

The combustor is made of several modular sections. The upper combustor sections are lined with 254-mm (10-inch) thick refractory. This refractory liner consists of a composite of three layers: 102-mm (4-inch) of refractory brick on the interior surface followed by $102 \mathrm{~mm}$ (4 inches) of low density insulating refractory and $51 \mathrm{~mm}$ ( 2 inches) of mineral wool board against the facility housing.

At two elevations along the combustor, there are $305 \mathrm{~mm}$ ( 1 foot) wide by $1,730 \mathrm{~mm}$ (68 inches) tall openings to accommodate water-wall test sections for heat transfer measurements. When the water-wall panels are not used, the openings are fitted with flat water-cooled panels with a thin refractory covering.

Additional heat transfer surface can also be installed in the upper furnace if desired - e.g., horizontal tube bundles or vertical wing walls.

The hot combustion gases and solids exit the top of the combustor and enter a refractorylined cyclone, where the circulating solids are separated from the hot gases. The separated solids drop through a dipleg into a sealpot. The dipleg can be water-cooled, steam cooled, or uncooled. When the dipleg is cooled, the solids recirculation rate through the combustor can be estimated from a heat balance across the dipleg. The hot solids in the sealpot either return directly to the combustor through an insulated stainless steel solids return pipe, or a portion of the solids may be diverted to one of two watercooled heat exchangers before returning back to the combustor. The main heat exchanger is a fluid bed heat exchanger, similar to that used in current commercial designs. The second heat exchanger has at different times been configured as a fluid bed heat exchanger, a moving bed heat exchanger, and a falling solids heat exchanger. The heat exchangers are used to cool the recirculating solids and thus control the combustor bed temperature. They provide the test facility with a great deal of flexibility in operating the combustor over a wide range of process conditions.

Circulating ash can be drained from the FBHE into 55-gallon drums as needed to help control furnace inventory. This ash can be added back into the furnace if necessary to increase inventory. Otherwise it may be saved as startup material for future tests.

The hot flue gas leaving the cyclone flows through a water-cooled heat exchanger. The cooled gases then flows though a fabric filter and a wet caustic scrubber for final $\mathrm{SO}_{2}$ and 
particulate control. The baghouse can be bypassed if desired - e.g., during warm-up. The induced draft fan and the stack follow the wet scrubber.

The baghouse has been modified into a Flash Dry Absorber (FDA) test system. The FDA system is a dry process based on the reaction between $\mathrm{SO}_{2}$ and $\mathrm{Ca}(\mathrm{OH})_{2}$ in humid conditions. Additional equipment for the FDA test system include a FDA mixer/hydrator, additive feed system, FDA reaction duct, modification of the flue gas ducting, and additional gas analyzers, instrumentation, and controls systems. The fly ash collected in the baghouse is discharged through a screw into 55-gallon drums, which are weighed then saved or disposed of as required.

The combustor is warmed up with a natural gas igniter, which is sized for a maximum heat input of 3.0 $\mathrm{MW}_{\text {th }}$ (9.9 million Btu/hour). The igniter is located 1,372 mm (4.5 feet) above the air distributor, with the flame directed downward toward the bed at a $55^{\circ}$ angle. Crushed coal and sized limestone are supplied to the combustor through the fuel feed system. Coal and limestone are metered from the storage silos by gravimetric feeders and are then lifted up to the feed inlet chute by a drag chain conveyor. The fuel and sorbent drop through a rotary valve either directly into the furnace at one of two elevations or into the return pipe that carries the hot recycle solids back to the fluidized bed.

A drain port is located on the opposite side of the bed for removing large rocks and for maintaining bed level. The hot ash removed in the bed drain system passes through a water-cooled screw into 55-gallon drums, which are weighed then saved or disposed of.

The Multi-Use Combustion Test Facility uses an ABB Advant 460 distributed control system for the process control and data acquisition needs of this facility, and for the other major combustion facilities in the Combustion System Development Complex. The MTF is very well instrumented, with over 500 temperature, pressure, and flow measurements throughout the facility.

Figure 3.4 is a simplified Process and Instrumentation Diagram (P\&ID) for the main furnace system as set up for the oxygen-fired tests in 2004. The only significant differences between

Figure 3.4 and how the MTF was set up for these tests in 2005 are (1) the cooling coil shown at the top of the furnace was not installed and (2) the MBHE (not shown) was used in parallel with the FBHE as shown in Figure 3.3.

A LabView data acquisition system is used to collect these measurements and process calculations from the Advant system. The LabView program provides on-line trend analysis, data archival, and data analysis.

Ports are located at 16 different elevations along the height and around the circumference of the combustor. They provide a great deal of flexibility for detailed in-furnace measurements, overfire air location, and observation ports. Test probes are used to measure process conditions both radially and axially within the furnace. Typical test measurements across the combustor profile can include solids loading and composition, 
local solid fluxes, gas composition and temperature, and local heat flux. The gas analysis system allows measurement of important species, including $\mathrm{O}_{2}, \mathrm{CO}, \mathrm{CO}_{2}, \mathrm{SO}_{2}, \mathrm{NO}_{\mathrm{x}}$, $\mathrm{N}_{2} \mathrm{O}$, and THC (total hydrocarbons). Gas samples can also be collected for more detailed species analysis in a gas chromatograph 


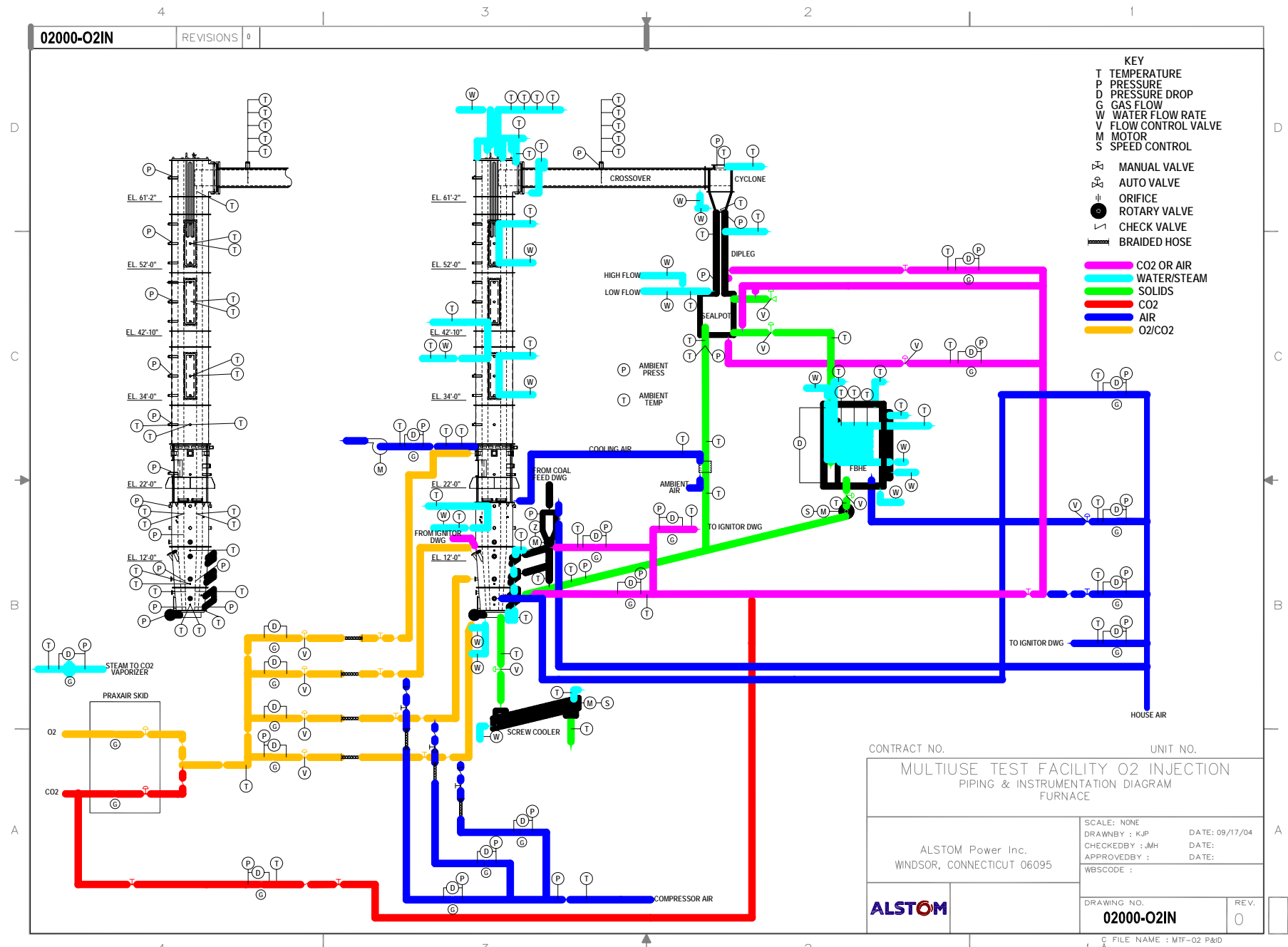

Figure 3.4: MTF Process \& Instrumentation Diagram 


\section{Logged Data}

Hundreds of data points are monitored and logged by the Advant and LabView systems.

- Over 150 Type-K thermocouples are installed on the MTF to measure air, flue gas, water, combustor, and refractory temperatures.

- Over 40 pressure cells are installed on the furnace and gas ducts.

- Water flows are measured with turbine flow meters.

- Coal and limestone belt feeder rates are logged. These feeders are calibrated before each test and may be checked periodically during each test by collecting material off the belt for $1 / 2$ to 2 minutes.

- Additional pressure differential cells are used (along with pressure and temperature) to calculate air, natural gas, and steam flows.

- An in-situ Rosemount $\mathrm{O}_{2}$ analyzer, located downstream of the heat exchanger, measures the wet oxygen content of the flue gas.

- At the same point, a gas sample is extracted, filtered, drawn through a heated sample line to the control room, and dried. Analyzers measure $\mathrm{O}_{2}, \mathrm{CO}_{2}, \mathrm{CO}, \mathrm{NO}$, $\mathrm{NO}_{2}, \mathrm{~N}_{2} \mathrm{O}, \mathrm{NO}_{\mathrm{x}}$, total hydrocarbons (THC), and $\mathrm{SO}_{2}$. The analyzers usually operate continuously with purges every hour or so as the filter pressure drop increases. The analyzers are calibrated twice per day.

- The gas analyzers in the control room can be switched over to analyze in-furnace gas samples, which are extracted and filtered using a water-cooled gas-sampling probe.

- After the baghouse, a gas sample is extracted, filtered, drawn through a heated sample line to a control room, and dried. Analyzers measure $\mathrm{O}_{2}, \mathrm{CO}_{2}, \mathrm{CO}, \mathrm{NO}_{\mathrm{x}}$, and $\mathrm{SO}_{2}$. The analyzers usually operate continuously with purges every hour or so as the filter pressure drop increases. The analyzers are calibrated twice per day.

- Waterwall panels or single tubes can be installed in the furnace to obtain heat transfer data. Two single-tube test sections were installed for this test.

- Water-cooled heat transfer probes can be used for measuring local total and radiation heat flux throughout the furnace. This data is not logged to the normal data system. These probes were not used in these tests.

\section{Solids Samples}

Solids samples are taken at several locations.

- Coal and limestone samples are taken off the feed belts periodically and mixed together for a composite each 8 or 12-hour shift.

- Bed drain material from the water-cooled screw outlet is regularly sampled.

- FBHE drain material is usually taken for analysis of the circulating material. There are also ports in the heat exchanger box for directly withdrawing samples. 
- Samples of fly ash are collected from the baghouse drain.

- There are several water-cooled solids probes for collecting samples from the furnace. These probes can also measure the local solids flux. There were no infurnace solids samples taken during these tests.

- Crossover solids at the cyclone inlet are sampled at the calculated average isokinetic conditions with the water-cooled solids probe to determine the rate of solids circulation and the size distribution of the solids entering the cyclone. This sampling can be done at different locations horizontally and vertically across the cyclone inlet. The solid loading is higher at the top and lower at the bottom of the duct. The profile is roughly linear so a single sample at the midpoint can be used to estimate the solids loading.

- Isokinetic dust load can be measured according to EPA Method 5 in the down flow water-cooled duct after the cyclone. No Method 5 sampling was done during these tests by ALSTOM; TRC Environmental Corporation (TRC) did Method 5 sampling of particulate as described below.

- A High Volume technique is used to collect a larger fly ash sample at the calculated average isokinetic conditions of the duct at 4 points along one axis. The original purpose of this method was to get a reasonably unbiased sample for size and composition analysis. It turns out that the measured dust load is often quite accurate and compares favorably with Method 5 measurements.

Selected solids samples are analyzed as required. Samples not analyzed are retained for future use as needed.

\section{Additional Sampling for these MTF Tests}

- $\quad$ TRC sampled at the cyclone outlet and the baghouse inlet at three test conditions EPA Method 5 for particulate and EPA Method 29 for metals.

\subsubsection{Facility Modification for Oxygen Firing}

The $\mathrm{O}_{2} / \mathrm{CO}_{2}$ supply and control infrastructure and other modifications made to the MTF furnace and ancillary equipment are discussed below.

Oxygen and Carbon Dioxide Supply Infrastructure. In the commercial design for oxygenfired boilers, pure oxygen is delivered to the plant and is mixed with recirculated dried flue gas in order to achieve the desired oxygen content of the net oxidant. For the pilot plant testing, mixtures of oxygen and pure carbon dioxide were used, with each supplied by purchased liquefied gases. This approach is more cost effective for the short term testing and allows additional flexibility of control not afforded by recirculating flue gas.

An $\mathrm{O}_{2} / \mathrm{CO}_{2}$ supply and control infrastructure, designed and supplied by Praxair, Inc. was integrated into the MTF facility to enable the combustion of fuels in various $\mathrm{O}_{2} / \mathrm{CO}_{2}$ mixtures (Figure 3.5). An oil-fired steam boiler was rented to supply steam to the $\mathrm{CO}_{2}$ vaporizer. 


\section{Discussion of Global and Local $\mathrm{O}_{2}$ Enrichments.}

Oxygen and carbon dioxide are blended to simulate the mixture of pure oxygen and recirculated flue gas used for the oxidant in the combustor. In addition, some pure $\mathrm{CO}_{2}$ bypasses the mixing skid to be used for various purposes where high oxygen mixtures were not desired, e. g.,

- coal assist "air"

- igniter cooling "air"

There is also air introduced into the system through leakage as well as air used to fluidize the sealpot. Figure 3.6 indicates the various flows.

As a result, there are several definitions of the oxygen content of the oxidant.

Global $\mathrm{O}_{2}$ - The concentration of $\mathrm{O}_{2}$ in the overall $\mathrm{O}_{2} / \mathrm{CO}_{2}$ mixture from the tanks, which includes the bypass $\mathrm{CO}_{2}$. There is no actual gas mixture at this concentration. This mixture represents the overall ratio of $\mathrm{O}_{2}$ and $\mathrm{CO}_{2}$ entering the system and is used for normalizing the emissions, and other analyses.

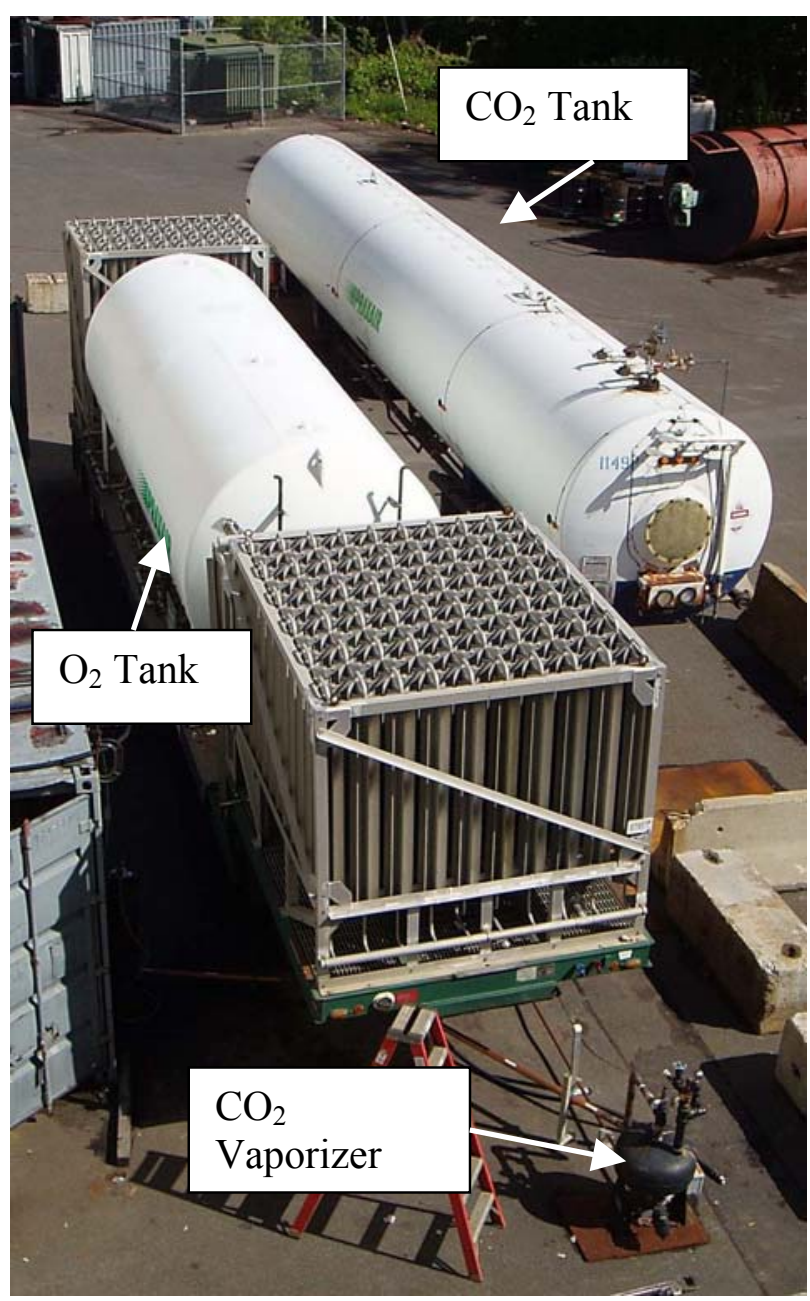

Figure 3.5: $\mathrm{O}_{2}$ and $\mathrm{CO}_{2}$ Supply Tanks

Local $\mathrm{O}_{2}$ - The actual combustion mixture of $\mathrm{O}_{2} / \mathrm{CO}_{2}$ as it comes from the mixing skid. This has a higher $\mathrm{O}_{2}$ content than the global mixture. This is the oxidant mixture which enters at the bottom of the furnace and first sees the coal in the fluid bed. This is the relevant mixture for materials of construction of the fluidizing nozzles and for concerns regarding high oxygen concentrations resulting in elevated combustion temperatures at the coal surface, which might lead to agglomeration.

Overall $\mathrm{O}_{2}$ - The oxygen concentration of the overall oxidant, including the air leakage. This value is not used much in the analysis of the results. 


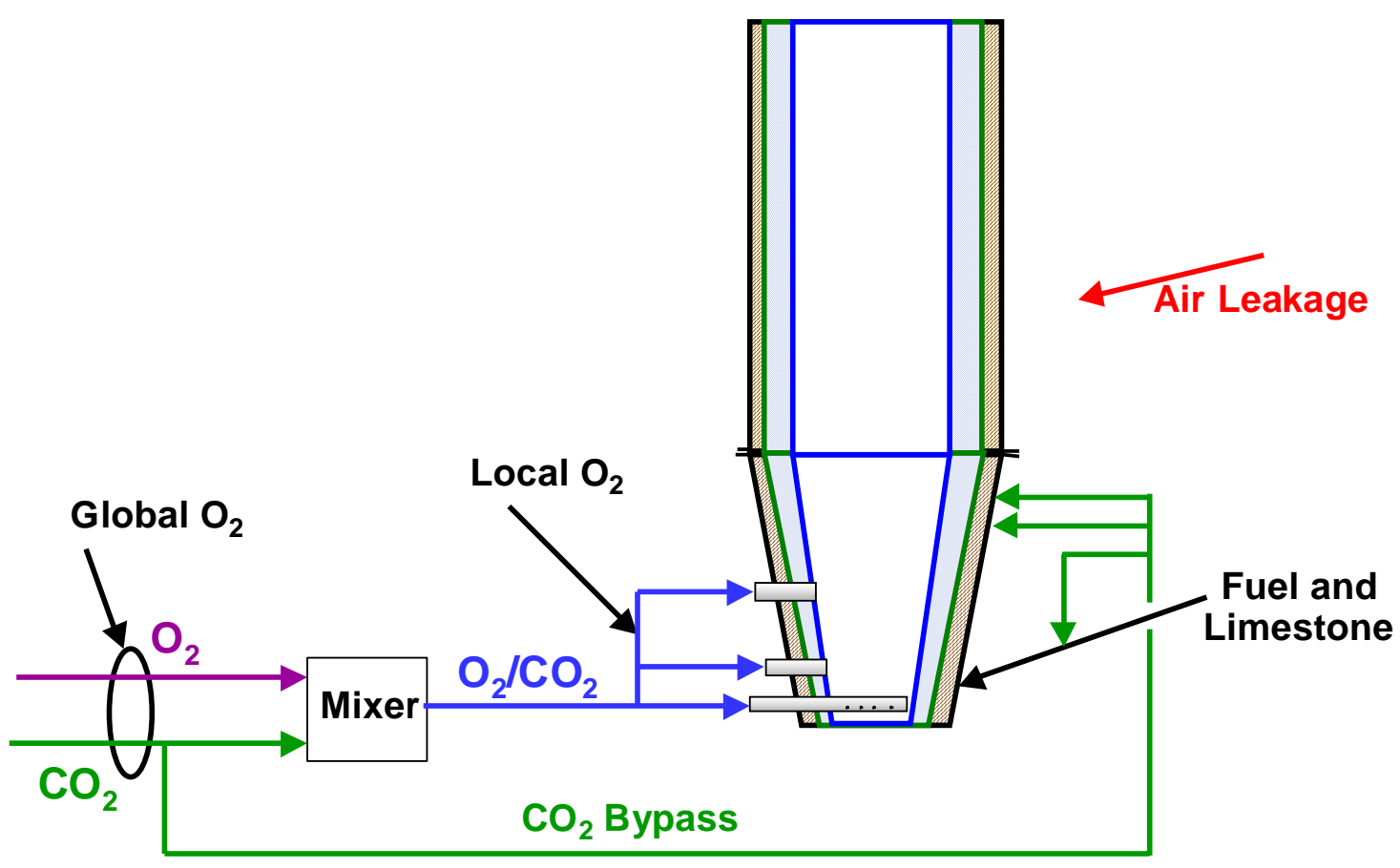

Figure 3.6: Schematic of Oxygen and Carbon Dioxide Flows to the MTF

The same definitions can apply to a commercial unit, which would use recirculated flue gas in place of the pure $\mathrm{CO}_{2}$. Because of the small scale of the pilot plant, the bypass $\mathrm{CO}_{2}$ requirements and the amount of air leakage are relatively large, so the differences between the three mixture definitions are larger than they would be in a full-scale commercial unit.

\section{Venting of the FBHE}

In order to avoid recarbonation, the MTF's fluidized bed heat exchanger (FBHE) was fluidized with air. The FBHE was modified as shown in Figure 3.7 such that the fluidizing air was vented off to the I.D. Fan. In this manner, the cooled solids could be recirculated into the furnace with only a small entrainment of air. 


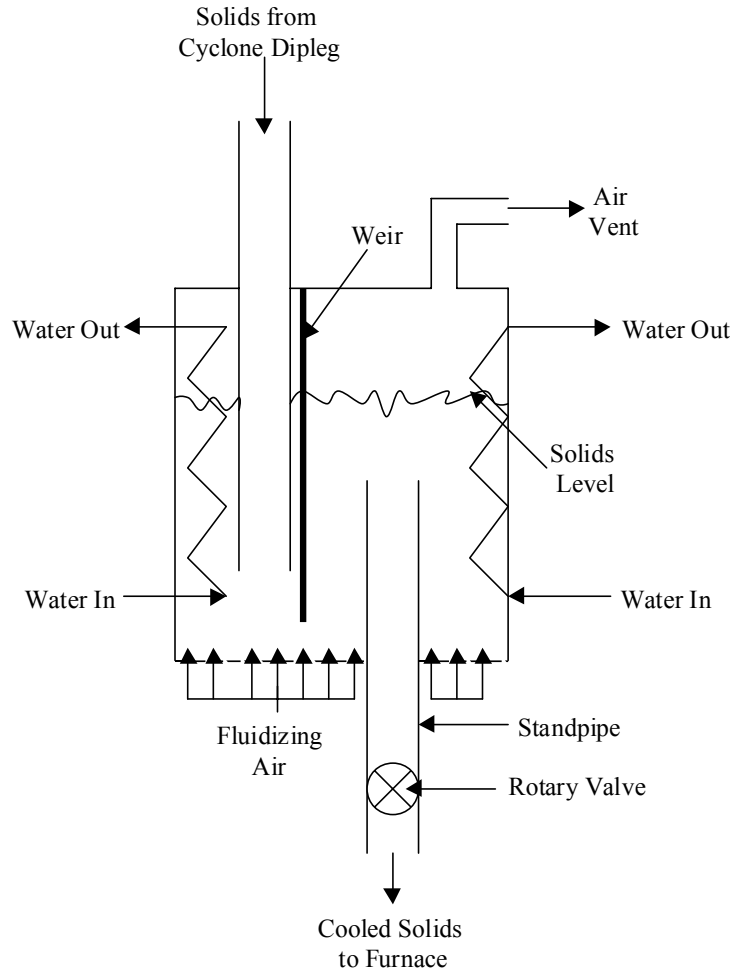

Figure 3.7: Modified Fluidized Bed Heat Exchanger Showing Air Vent

\section{Instrumentation and Control System}

The materials and instrumentation for the oxygen supply and distribution were specified for service in high oxygen environment. Most of the existing instrumentation on the facility was suitable for the oxygen testing, since the combustion reduces the oxygen content in the furnace to the typical range of $3-4 \%$.

A furnace of this size burning gas and coal - even with air - does have some risks. The control system has been programmed to handle such situations as loss of fuel and temperature or pressure excursions.

With oxygen firing, there is the additional concern of avoiding high $\mathrm{O}_{2}$ concentrations where they aren't wanted. If the fuel trips or plugs while firing high oxygen mixture, the furnace and backend systems would see the high $\mathrm{O}_{2}$ levels. If

the $\mathrm{CO}_{2}$ supply should stop, pure oxygen would enter the furnace, which would be highly undesirable.

The MTF control system logic was modified to detect and respond to these situations.

\subsubsection{Differences Between 2004 and 2005 Pilot Plant Modifications}

\section{Reduced Furnace Diameter.}

For the 2004 MTF tests, the diameter of the upper furnace was reduced from $1 \mathrm{~m} \mathrm{(40}$ inches) to $530 \mathrm{~mm}$ ( 21 inches) by adding a refractory liner. The liner reduced the diameter at the bottom of the furnace from $660 \mathrm{~mm}$ (26 inches) to $360 \mathrm{~mm}$ (14 inches). This was done to maintain a high fluidizing velocity in the furnace even at global oxygen enrichments of up to $70 \%$ while keeping the firing rate below the MTF's operating permit level of 3.0 $\mathrm{MW}_{\text {th }}(9.9 \mathrm{MMBtu} / \mathrm{hr})$. After last year's tests, the refractory liner was removed.

For this 2005 test series, no liner was used. In the air-fired tests, the firing rate and velocities were as they normally are. For the oxygen-fired tests, the global $\mathrm{O}_{2}$ content was 30\%, which resulted in lower velocities in the furnace (see Figure 3.8). 


\section{Grid Plate}

With the reduced furnace diameter in 2004, the normal grid plate was replaced with a smaller design using spargers for air/oxidant at the furnace bottom. In 2005 tests, a normal, full-size grid plate with fluidizing nozzles was used (shown in Figure 3.9).

\section{Air Firing}

In 2004, compressed air was used for the air fired test conditions. In 2005, because of the higher firing rate on air and the lower pressure drop through the nozzles, the normal forced draft fan was used.

\section{Cyclone}

The water-cooled cyclone and inlet duct used in 2004 were replaced with uncooled sections. There is now (in 2005) less of a

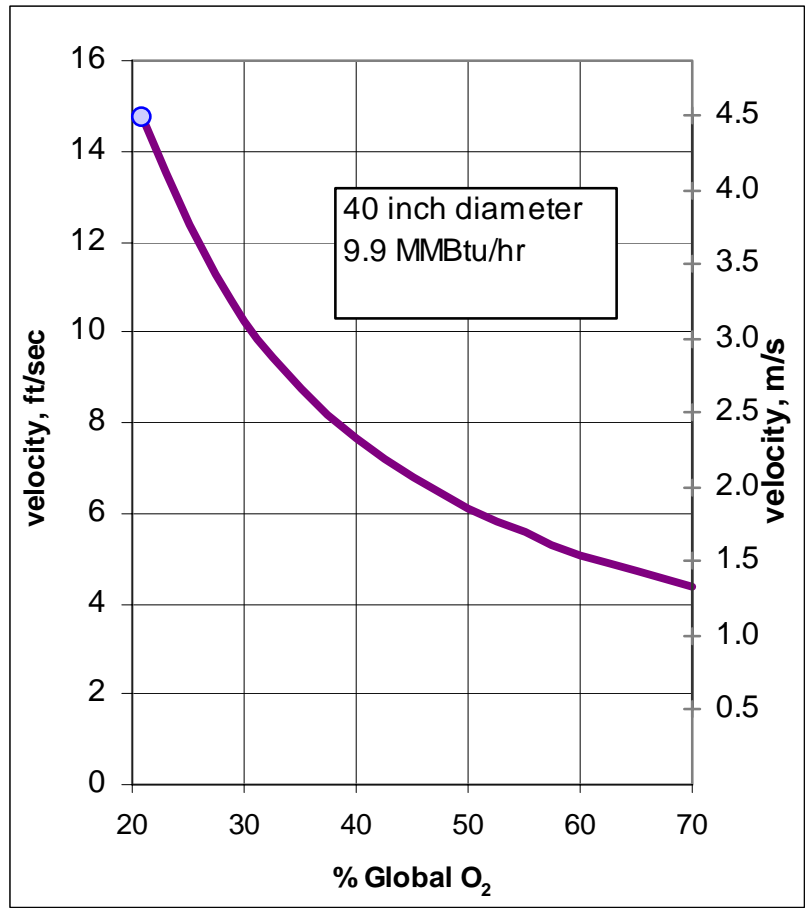

Figure 3.8: Fluidizing Velocity vs. $\mathrm{O}_{2}$ Enrichment temperature drop for solids and gas through the cyclone.

\section{Sealpot}

To avoid unnecessary air leakage, it is desirable to fluidize the sealpot with $\mathrm{CO}_{2}$. But in the pilot plant, the sealpot temperature can be below the recarbonation temperature, so in 2004 the sealpot was re-plumbed to allow fluidization with $\mathrm{CO}_{2}$, air, or a mixture of the two. In 2005, the sealpot was simply fluidized with air.

\subsubsection{Differences Between Pilot Plant and Commercial Unit}

The MTF pilot plant is a good model of a commercial CFB boiler - it comprises most of the components of

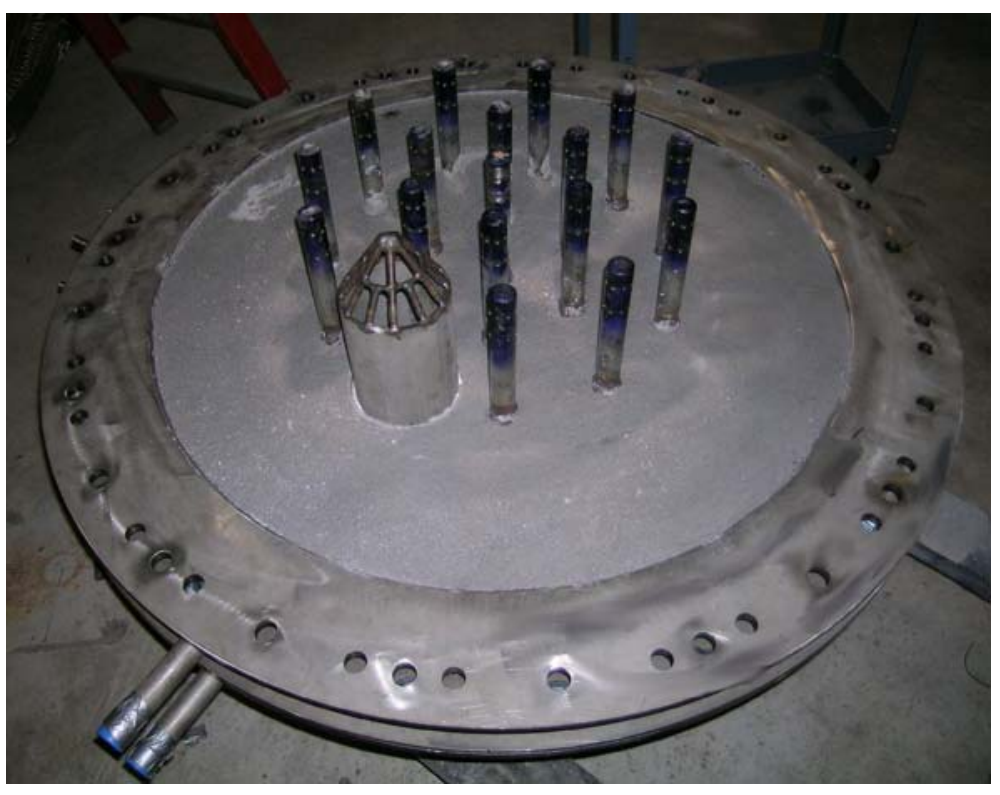

Figure 3.9: Water-Cooled Gridplate the commercial system and is large enough to simulate the process without gross distortions due to scale. There are, however, several differences, which must be kept in mind when evaluating the test results.

The most obvious is the difference in scale, especially the smaller cross sectional area. 
This has several impacts. One is that everything is much more uniform across the cross section. The MTF has an inner diameter of $1.0 \mathrm{~m}$ (40 inches). A large commercial unit may, for example, have dimensions of $7.6 \mathrm{~m}$ x 24m (25' x 80'). Even smaller commercial units have shown strong maldistributions: for example, a plume of nearly zero oxygen may extend up the entire furnace height above the fuel feed locations, while at the opposite wall the oxygen content may be $10 \%$. We have seen maldistributions in the MTF, but they are much less severe and do not extend the whole height of the unit. As a consequence, pilot plants in general have lower $\mathrm{CO}$ and $\mathrm{SO}_{2}$ emissions, which benefit from improved mixing. On the other hand, $\mathrm{NO}_{\mathrm{x}}$ emissions tend to be higher in a pilot plant, since the better mixing reduces the beneficial effect of horizontally staged combustion.

Another consequence of the reduced scale is the much greater surface-to-volume ratio in the pilot plant. If the pilot furnace were of waterwall construction, the heat removal would be much too large to sustain coal combustion conditions. The pilot plant is refractory lined with the possibility for some heat transfer sections along the height of the furnace. The heat removal profile along the height is therefore different. The large internal refluxing of solids along the height of the furnace does tend to smooth out the temperature profile, but it is not perfectly uniform in either the pilot or commercial units.

A typical commercial unit has a furnace height of over $30 \mathrm{~m}(100 \mathrm{ft})$ while the MTF furnace is about $19 \mathrm{~m}(62 \mathrm{ft})$ tall. This affects the gas residence time in the furnace. This impact is somewhat lessened by the fact that the furnace operates with a superficial velocity slightly lower than current commercial designs $\sim 4.5 \mathrm{vs} .5 .5 \mathrm{~m} / \mathrm{s}(15 \mathrm{ft} / \mathrm{sec} \mathrm{vs} .18$ $\mathrm{ft} / \mathrm{sec}$ ) or higher.

There are other features of the small-scale pilot that may matter. For example, as a practical matter, the sealpot is proportionally large compared to the scale of the furnace, so the fluidizing airflow to the seal pot is relatively large.

The dipleg can operate water-cooled, steam cooled, or uncooled. This cooling of the dipleg reduces the temperature of the solids in the sealpot, possibly to below the recarbonation temperature. This was especially relevant to this oxygen fired test program, since the sealpot operated below the calcination temperature. In 2004, the sealpot could not operate with $\mathrm{CO}_{2}$ fluidizing only (the calcium oxide in the ash reacted with the $\mathrm{CO}_{2}$ to form $\mathrm{CaCO}_{3}$, leaving no fluidizing gas). For these tests, the sealpot was fluidized with air, which introduced additional air leakage into the system.

Another difference relevant to the oxygen-fired tests was the use of pure $\mathrm{CO}_{2}$ for mixing with the oxygen, rather than recirculated flue gas. Table 3.2 shows an example of the differences in flue gas composition leaving the combustor between firing with pure $\mathrm{O}_{2} / \mathrm{CO}_{2}$ mixtures and with recirculated flue gas (FGR).

When firing with recirculated flue gas, sulfur and moisture are returned back to the combustor resulting in higher concentrations in the flue gas (recirculation loop). The consequence of using pure $\mathrm{CO}_{2}$ is a higher $\mathrm{CO}_{2}$ content in the flue gas with other components somewhat lowered. Compared to the major difference in gas composition going from air-fired to oxygen-fired, the changes due to using pure $\mathrm{CO}_{2}$ were not considered significant for these tests. 
Table 3.2: Flue Gas Recirculation vs. Pure $\mathrm{CO}_{2}$

\begin{tabular}{|c|c|c|c|}
\hline & \multirow{2}{*}{ Air Firing } & \multicolumn{2}{|c|}{$30 \%$ Oxygen } \\
\hline & & FGR & Pure $\mathrm{CO}_{2}$ \\
\hline $\mathrm{N}_{2}(\%)$ & 74.78 & 0.81 & 0.22 \\
\hline $\mathrm{CO}_{2}(\%)$ & 14.49 & 82.78 & 88.2 \\
\hline $\mathrm{H}_{2} \mathrm{O}(\%)$ & 7.40 & 13.05 & 8.24 \\
\hline $\mathrm{O}_{2}(\%)$ & 3.31 & 3.31 & 3.31 \\
\hline $\mathrm{SO}_{2}, \mathrm{ppmv}$ & 199 & 469 & 302 \\
\hline $\mathrm{SO}_{2}$, dry & 215 & 540 & 329 \\
\hline \multicolumn{4}{|c|}{$\begin{array}{l}\text { Based on Bituminous coal with } 2.3 \% \mathrm{~S} \text { fired to a constant } \\
\text { excess oxygen } \\
90 \% \text { S Capture in Boiler, } 80 \% \text { in backend for } 98 \% \text { total } \\
\text { capture } \\
\text { Flue Gas dried to } 7 \% \mathrm{H}_{2} \mathrm{O} \text { Before Flue Gas Recirculation }\end{array}$} \\
\hline
\end{tabular}

\subsection{Fuels and Limestones}

This section describes the fuels and limestones that were consumed during the MTF testing.

\subsubsection{Fuels}

One coal and one petroleum coke were burned in these tests. The coal is a medium volatile bituminous (mvb) coal obtained from Tri-Star Mining, Inc. This coal (referred to as Tri-Star coal) is a 50/50 weight \% blend of Big Vein and Morantown coal seams from Garrett County in Maryland. The shot petroleum coke was acquired from ConocoPhillips VENCO plant in Moundsville, West Virginia. Tri-Star mvb coal and ConocoPhillips petcoke were sampled from the MTF belt feeder throughout the testing. The proximate and ultimate analyses and higher heating values along with the screen size distributions for selected fuel samples are given in Table 3.3. The analyses of the mvb coal and petcoke are consistent with the analyses obtained from the samples studied in 2004 (Nsakala, Liljedahl, and Turek, 2004). The fuel size distributions are plotted Figure 3.10. 
COMMERCIALIZATION DEVELOPMENT OF OXYGEN FIRED CFB

FOR GREENHOUSE GAS CONTROL

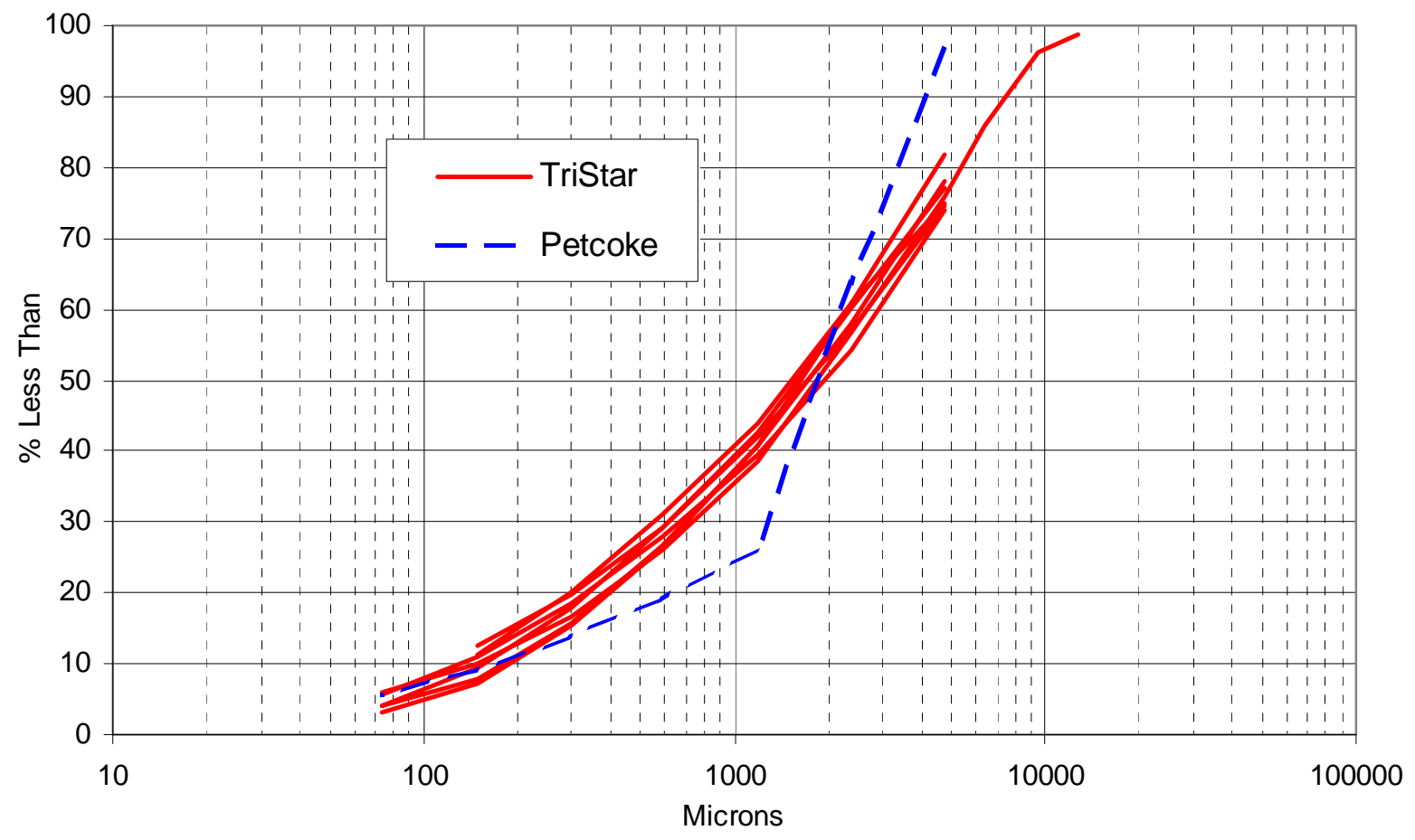

Figure 3.10: Fuel Size Distribution 


\section{Table 3.3: Analysis and Size Distribution of Fuel Samples}

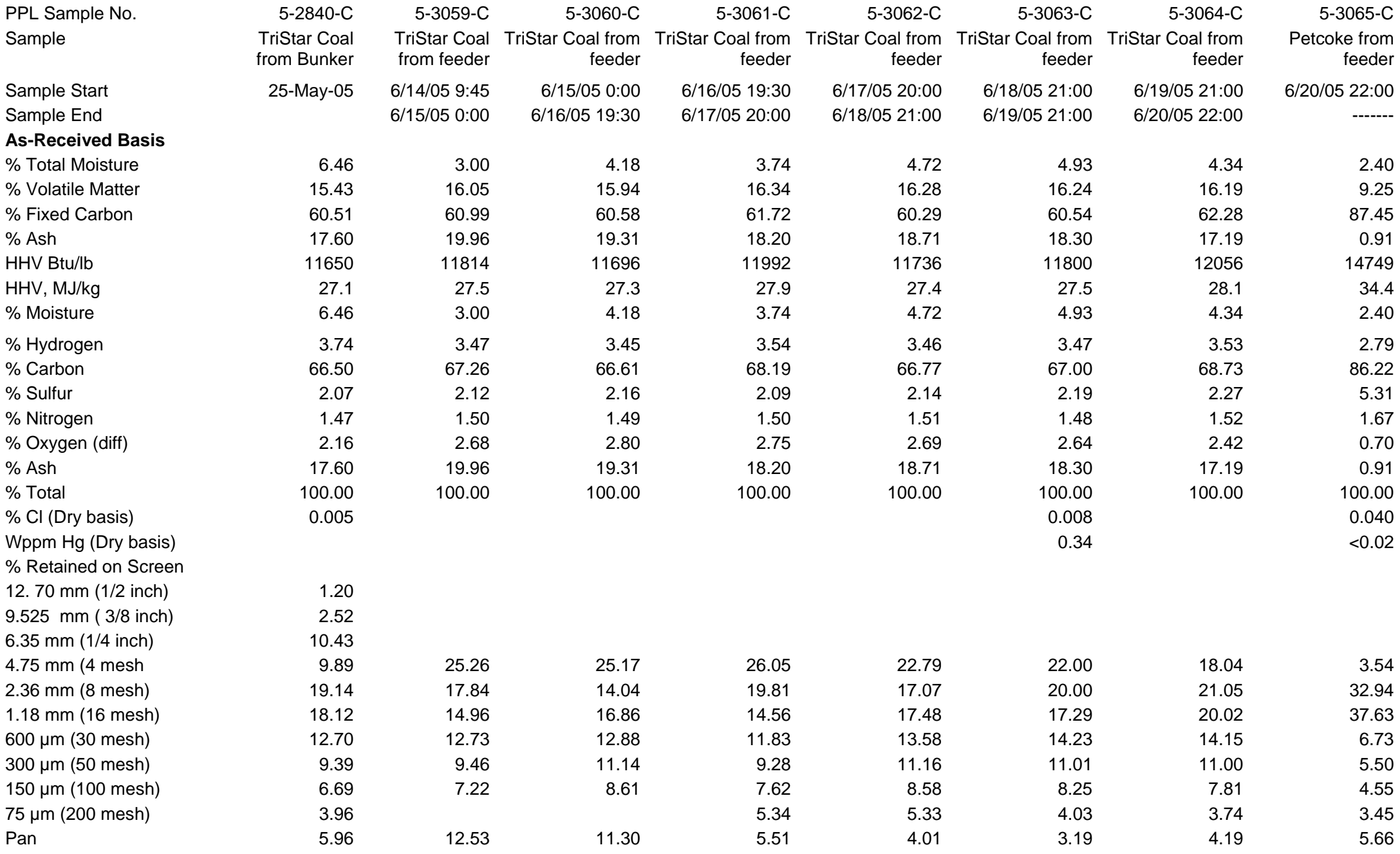


The ash composition of the Tri-Star Coal and the metals content of the coal and pet coke are presented in Table 3.4.

Table 3.4: Fuel Ash and Metals Analyses

\begin{tabular}{|c|c|c|c|c|}
\hline \multicolumn{2}{|c|}{$\begin{array}{c}\text { Coal Ash Composition } \\
\text { weight } \% \text { (as oxide) in ash }\end{array}$} & \multicolumn{3}{|c|}{$\begin{array}{c}\text { Minor/Trace Elements } \\
\text { weight ppm (as element) in dry coal) }\end{array}$} \\
\hline & $\begin{array}{l}\text { Coal } \\
5-3063-\mathrm{C}\end{array}$ & & $\begin{array}{l}\text { Coal } \\
5-3063-C\end{array}$ & $\begin{array}{l}\text { Pet Coke } \\
5-3065-C\end{array}$ \\
\hline SiO2 & 53.86 & Arsenic & 8.2 & 0.9 \\
\hline $\mathrm{Al} 2 \mathrm{O} 3$ & 24.13 & Barium & 207 & 7.8 \\
\hline $\mathrm{Fe} 2 \mathrm{O} 3$ & 11.44 & Beryllium & 2.3 & 0.1 \\
\hline $\mathrm{CaO}$ & 2.26 & Cadmium & 0.3 & 0.0 \\
\hline $\mathrm{MgO}$ & 0.86 & Chromium & 32.3 & 4.4 \\
\hline $\mathrm{Na2O}$ & 0.24 & Cobalt & 7.4 & 1.1 \\
\hline K2O & 2.37 & Copper & 12.4 & 3.1 \\
\hline TiO2 & 1.18 & Iron & 15397 & 744 \\
\hline P2O5 & 0.48 & Lead & 10.0 & 0.7 \\
\hline SO3 & 2.43 & Manganese & 56.2 & 7.1 \\
\hline $\mathrm{MnO}$ & 0.06 & Mercury & 0.34 & $<0.02$ \\
\hline $\mathrm{BaO}$ & 0.12 & Molybdenum & 6.8 & 36.7 \\
\hline SrO & 0.07 & Nickel & 25.9 & 236 \\
\hline \multirow[t]{4}{*}{ Total } & 99.50 & Strontium & 114 & 5.1 \\
\hline & & Titanium & 1361 & 32.8 \\
\hline & & Vanadium & 53.6 & 653 \\
\hline & & Zinc & 27.7 & 6.8 \\
\hline
\end{tabular}

\subsubsection{Sorbents}

Three sorbents were used in the MTF tests:

Hydrated Lime A hydrated lime was fed directly to the FDA/baghouse for backend sulfur capture without limestone injection into the furnace. This is attractive because it avoids the recarbonation issues in the furnace and heat exchangers altogether.

ATF40 Limestones The ATF40 limestone, from Specialty Minerals in North Adams, MA, was fed into the furnace for combined furnace/FDA sulfur capture. This limestone was selected because it was conveniently available in a fine size, which was expected to circulate well in the combustor even at the reduced velocity of the $\mathrm{O}_{2}$-fired test conditions. This limestone has very low sulfation reactivity; lower even than Chemstone, which was used in 2004 (see Figure 3.13).

Aragonite To see the impact of the limestone reactivity, we switched from ATF40 limestone to high-reactivity Aragonite during oxygen firing with the Tri-Star coal and continued with Aragonite for the oxygen firing with pet coke.

The chemical analyses of the sorbents are given in Table 3.5 along with the size distribution of the limestones. 


\section{Table 3.5: PSD and Chemical Analysis of Lime and Limestones}

\begin{tabular}{|c|c|c|c|c|c|}
\hline $\begin{array}{l}\text { PPL Sample No. } \\
\text { Sample I.D. }\end{array}$ & $\begin{array}{l}\text { 5-3066-L } \\
\text { Hydrated } \\
\text { Lime from } \\
\text { Feeder }\end{array}$ & $\begin{array}{l}\text { 5-2730-LS } \\
\text { ATF } 40 \\
\text { from } \\
\text { Bunker }\end{array}$ & $\begin{array}{l}\text { 5-3067-LS } \\
\text { ATF } 40 \text { from } \\
\text { Feeder }\end{array}$ & $\begin{array}{l}\text { 5-3068-LS } \\
\text { ATF } 40 \text { from } \\
\text { Feeder }\end{array}$ & $\begin{array}{l}\text { 5-3069-LS } \\
\text { Aragonite } \\
\text { from Feeder }\end{array}$ \\
\hline Sample Start & 6/16/05 19:30 & $4 / 28 / 05$ & 6/18/05 11:45 & 6/19/05 21:00 & 6/20/05 16:00 \\
\hline Sample End & 6/18/05 11:45 & & 6/19/05 21:00 & 6/20/05 16:00 & ------ \\
\hline$\%$ Total Moisture & 1.34 & 0.01 & 0.14 & 0.07 & 0.58 \\
\hline \multicolumn{6}{|l|}{ Dry Basis } \\
\hline$\%$ as $\mathrm{CaCO}_{3}$ & 9.5 & 94.4 & 92.9 & 93.9 & 95.0 \\
\hline$\%$ as $\mathrm{MgCO}_{3}$ & 1.8 & 1.5 & 1.2 & 1.2 & 0.7 \\
\hline$\%$ Inerts (difference) & 4.9 & 4.1 & 5.9 & 4.9 & 4.3 \\
\hline Active Lime as $\mathrm{Ca}(\mathrm{OH})_{2}$ & 83.9 & & & & \\
\hline \multicolumn{6}{|l|}{ Wt \% Retained on } \\
\hline $1.18 \mathrm{~mm}$ (16 Mesh) & & & 0 & 0.15 & 0.81 \\
\hline $600 \mu \mathrm{m}$ (30 Mesh) & & 0.06 & 0.06 & 0.59 & 8.92 \\
\hline $300 \mu \mathrm{m}$ (50 Mesh) & & 11.21 & 11.42 & 13.60 & 27.23 \\
\hline $212 \mu \mathrm{m}$ (70 Mesh) & & 21.03 & & & \\
\hline $150 \mu \mathrm{m}$ (100 Mesh) & & 26.24 & 47.59 & 48.23 & 52.87 \\
\hline $75 \mu \mathrm{m}$ (200 Mesh) & & & 28.70 & 25.43 & 9.00 \\
\hline Pan & & 41.46 & 12.23 & 12.00 & 1.17 \\
\hline
\end{tabular}

The limestone sizes are plotted in Figure 3.11. The lime size distribution according to CiLas laser measurement is shown in Figure 3.12.

The results of thermo-gravimetric analysis (TGA) tests of limestone reactivity are shown in Figure 3.13 for ATF40, Aragonite, and Chemstone (used in 2004). 


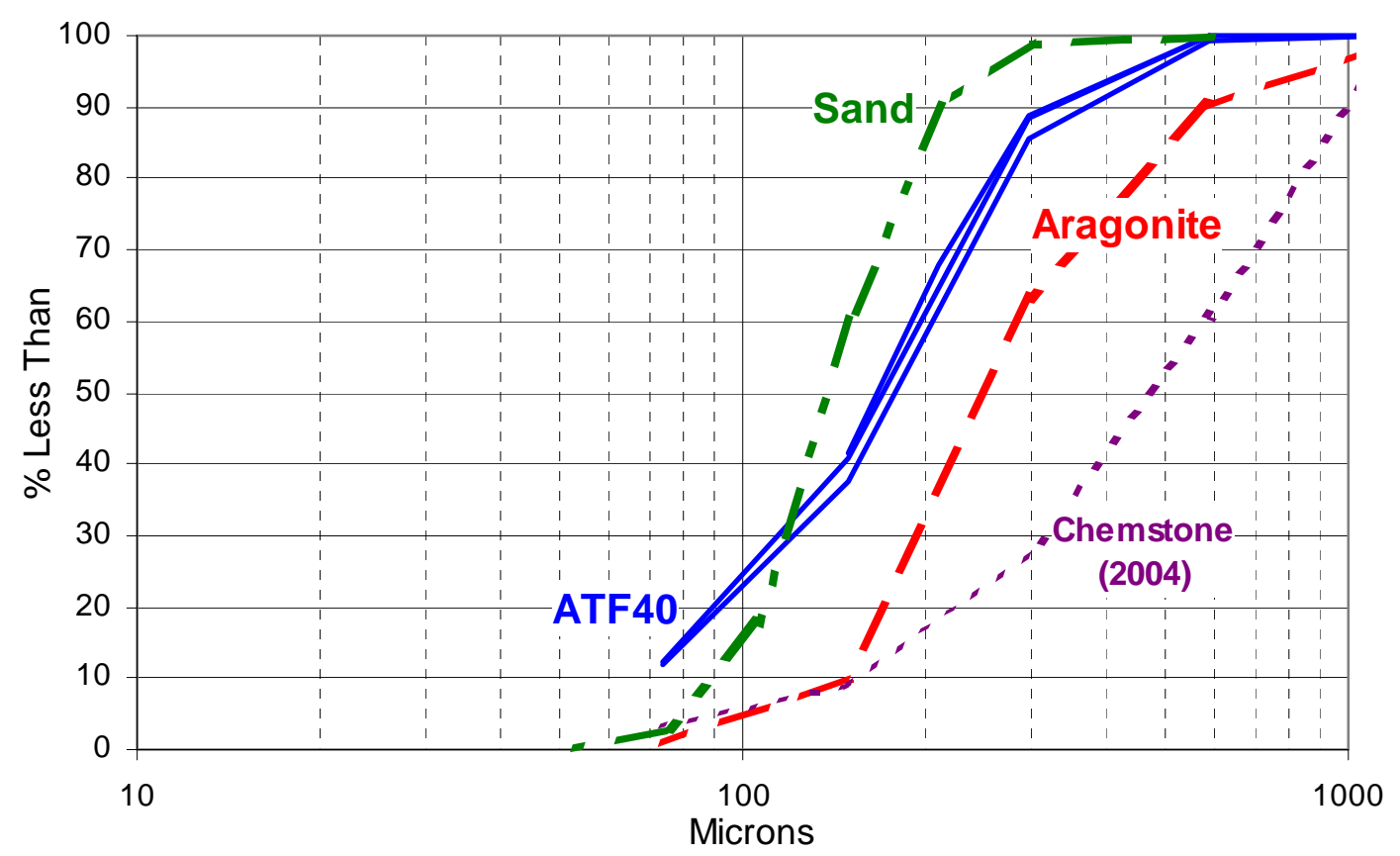

Figure 3.11: Limestone and Sand Screen Size Distribution

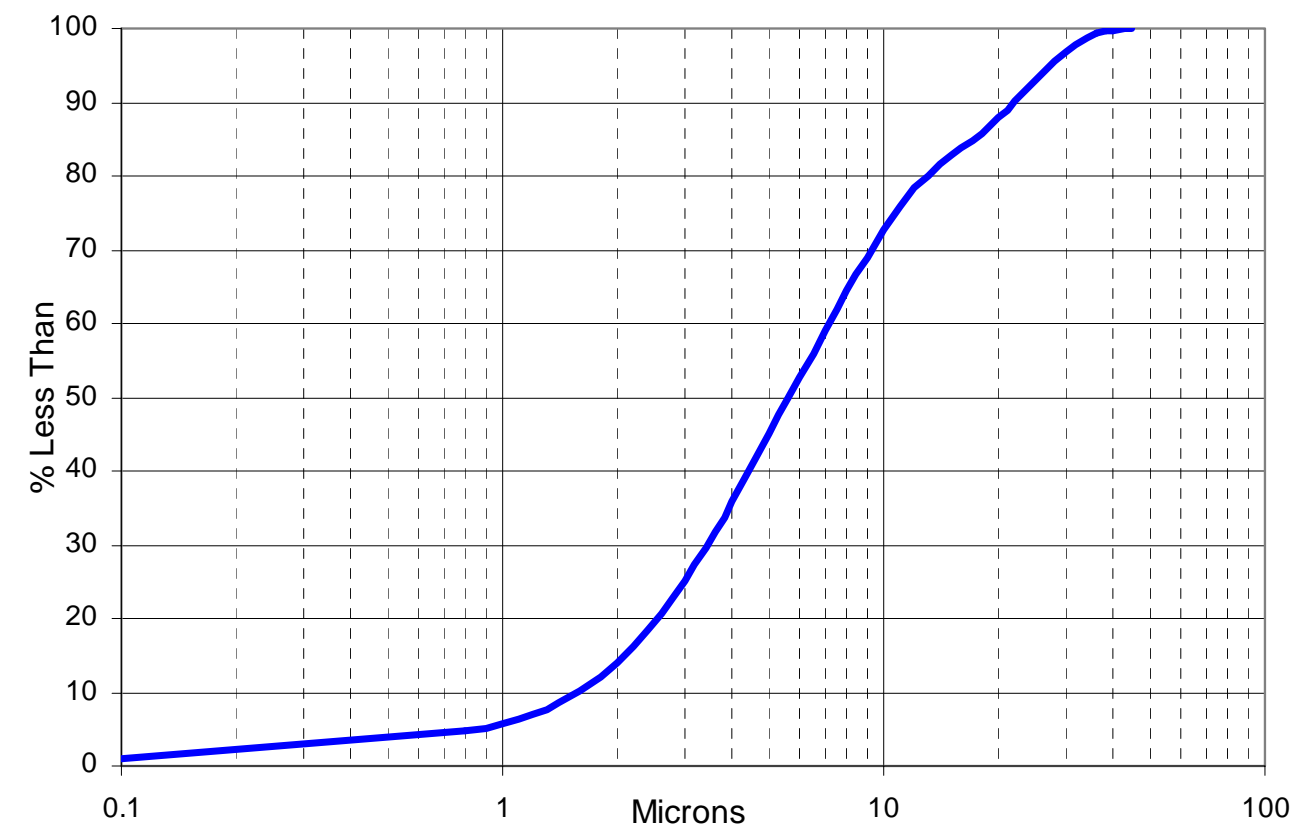

Figure 3.12: Lime CILAS Size Distribution 


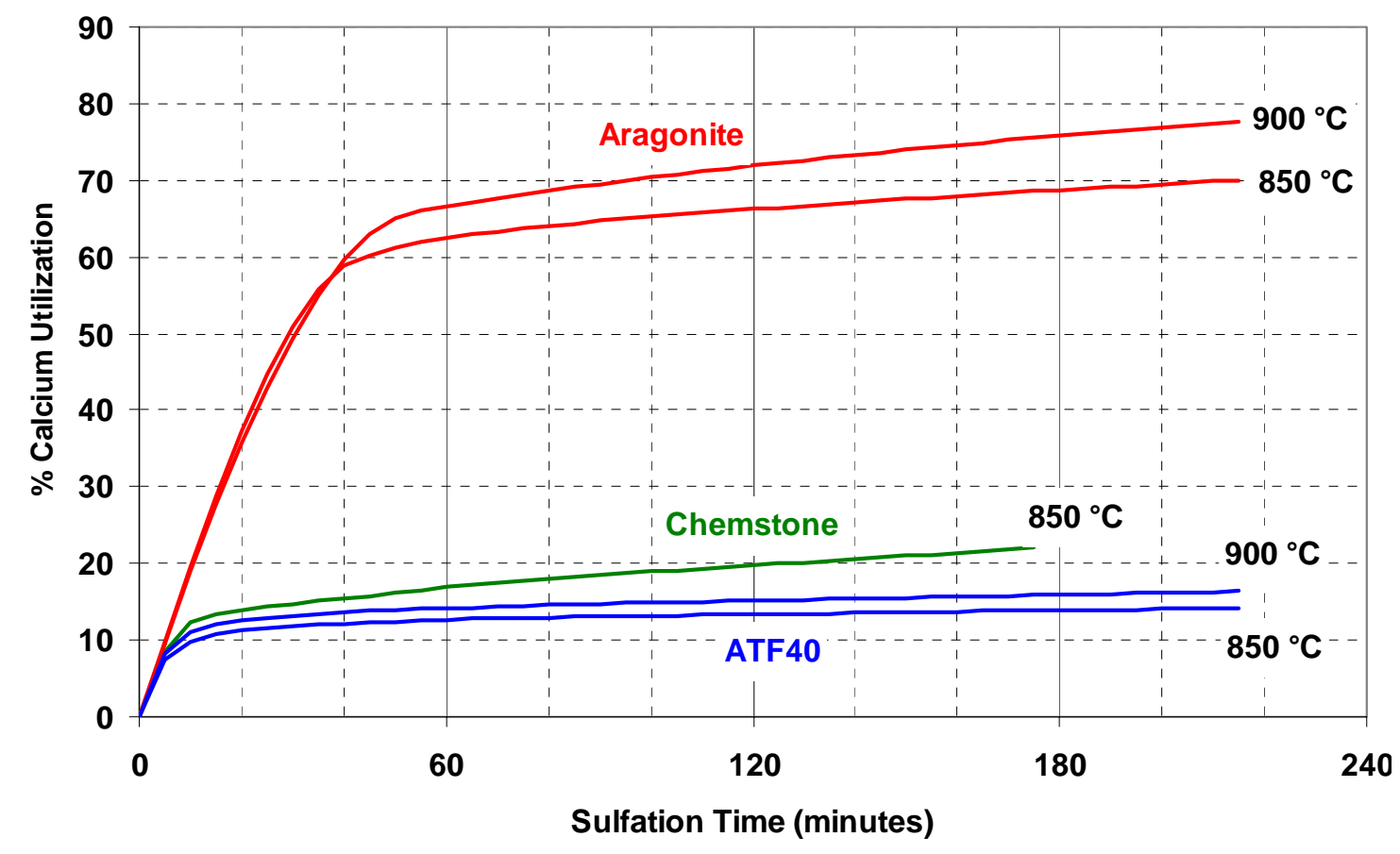

Figure 3.13: Limestone TGA Results

\subsubsection{Sand}

The starting material for the combustor was an inert silica sand, supplied by U. S. Silica. The typical size distribution of the F-95 sand from the product data sheet was shown in Figure 3.11. The sand is reported to be $99.8 \% \mathrm{SiO}_{2}$.

\subsection{Test Description and Conditions}

\subsubsection{Test Matrix and Objectives.}

The objectives for the test week (Figure 3.14) were

- Run with the Tri-Star coal air-fired, with hydrated lime fed to the backend FDA

- Run with the Tri-Star coal on $30 \% \mathrm{O}_{2}$ in $\mathrm{CO}_{2}$ balance, with hydrated lime fed to the backend FDA

- Run with the Tri-Star coal air-fired with limestone to the furnace and backend FDA capture with fly ash.

- Run with the Tri-Star coal on $30 \% \mathrm{O}_{2}$ in $\mathrm{CO}_{2}$ balance, with limestone to the furnace and backend FDA capture with fly ash.

- Run with the petcoke on $30 \% \mathrm{O}_{2}$ in $\mathrm{CO}_{2}$ balance, with limestone to the furnace and backend FDA capture with fly ash. 


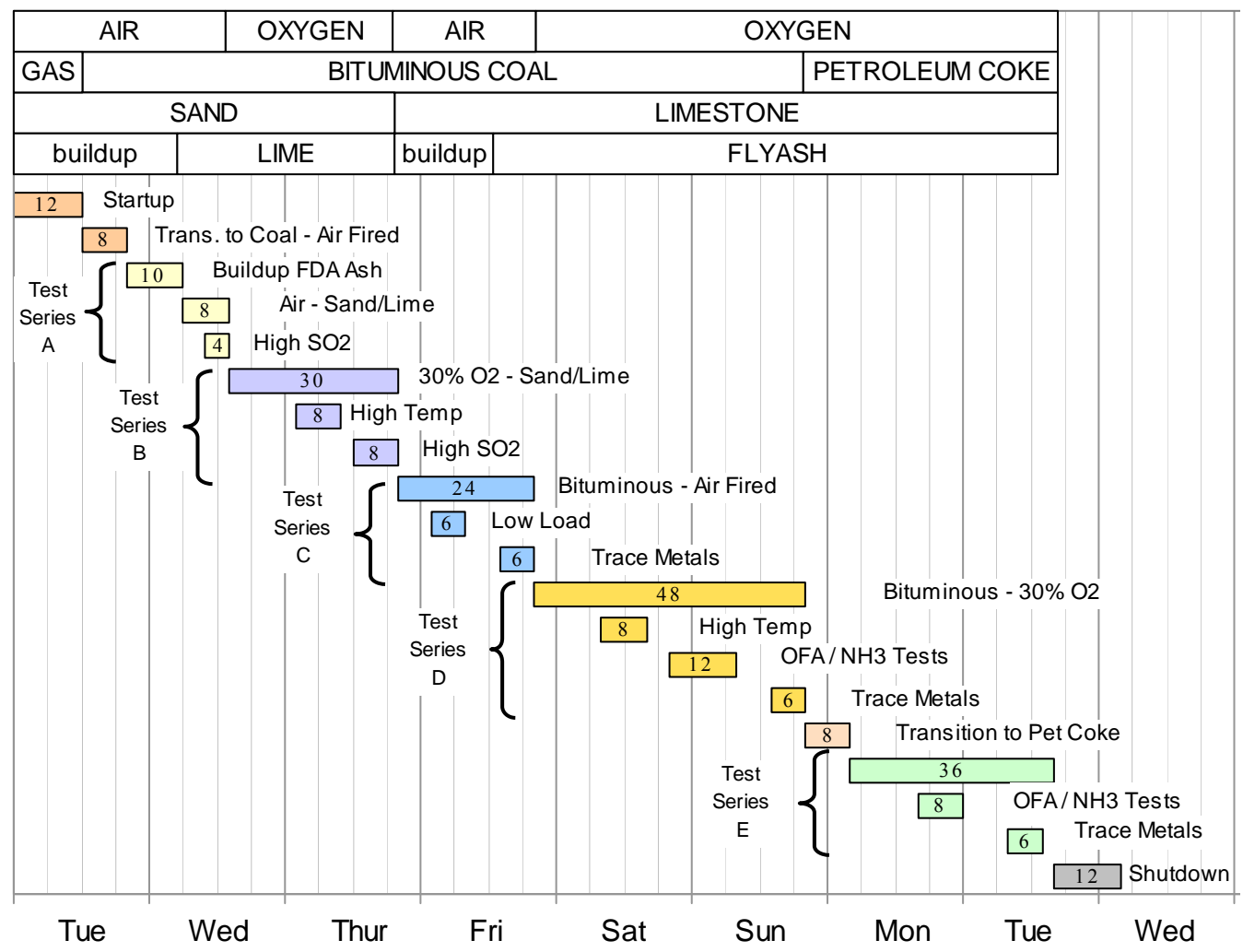

Figure 3.14: MTF Test Matrix

\section{Test Points}

From the nine days testing, several test points have been defined when the furnace was at certain specified conditions - see Table 3.6 and Figure 3.15. The time duration for these test points ranges between 33 minutes and eight hours. They are not necessarily considered to be steady state points.

A brief discussion of each test point follows. The test week started on Monday, June 13, 2005 with air firing. The furnace and external heat exchangers were initially charged with sand. The baghouse was empty. The facility reached full coal firing on Tuesday morning, June 14. Most of Tuesday was used to accumulate fly ash inventory in the baghouse in preparation for lime fed to the baghouse.

Test Point A1 - A six-hour period with air firing after achieving full temperature. This is before lime feed to the baghouse.

Test Point A2 - At 22:00 on June 14 we began lime feed to the baghouse. Point A2 is the final 4 hours of this condition.

Test Point A3 - At 06:00 on June 15 we added sulfur to the furnace and increased the lime flow to the baghouse proportionally. This was to match the $\mathrm{SO}_{2}$ concentration of the oxygen-fired tests.

At 11:30 on June 15 we transitioned to oxygen firing, but were forced to shut down 3 hours later due to a bearing failure in the I.D. fan. 


\section{Table 3.6: Selected Test Points}

\begin{tabular}{|c|c|c|c|c|c|c|c|c|c|c|c|}
\hline \multirow[b]{2}{*}{ Test Point } & \multicolumn{3}{|c|}{ Testing Time } & \multirow[b]{2}{*}{ Fuel } & \multicolumn{2}{|c|}{ Sorbent Injection } & \multirow[b]{2}{*}{ Combustion Medium } & \multirow{2}{*}{$\begin{array}{c}\text { Special } \\
\text { Measurements }\end{array}$} & \multirow{2}{*}{\begin{tabular}{|c} 
Relative \\
Humidity in \\
FDA (\%)
\end{tabular}} & \multicolumn{2}{|c|}{ Firing Rate } \\
\hline & Start & End & Duration & & $\begin{array}{c}\text { Lime into FDA } \\
(\mathrm{Ca} / \mathrm{S})\end{array}$ & $\begin{array}{l}\text { Limestone into } \\
\text { Furnace }(\mathrm{Ca} / \mathrm{S})\end{array}$ & & & & $\mathrm{MW}_{\text {th }}$ & MMBtu/hr \\
\hline $\mathrm{A} 1$ & $6 / 1416: 00$ & 6/14 22:00 & $6: 00$ & \multirow{3}{*}{$\begin{array}{c}\text { Tri-Star mvb } \\
\text { Coal }\end{array}$} & 0.1 & \multirow{3}{*}{ None } & \multirow{3}{*}{ Air } & & 0 & 2.80 & 9.57 \\
\hline A2 & 6/15 02:00 & 6/15 06:00 & 4:00 & & 1.3 & & & & & 2.79 & 9.55 \\
\hline A3 & $6 / 1508: 30$ & $6 / 15 \quad 10: 30$ & $2: 00$ & & 1.3 & & & & & 2.85 & 9.71 \\
\hline B1 & $6 / 1622: 00$ & 6/17 02:00 & 4:00 & \multirow{6}{*}{$\begin{array}{c}\text { Tri- Star mvb } \\
\text { Coal }\end{array}$} & 1.0 & \multirow{6}{*}{ None } & \multirow{6}{*}{$30 \% \mathrm{O}_{2} / 70 \% \mathrm{CO}_{2}$} & & & 2.78 & 9.51 \\
\hline B2 & 6/17 12:00 & $6 / 17$ 14:00 & 2:00 & & 0.0 & & & & & 2.85 & 9.74 \\
\hline B3 & $6 / 1712: 00$ & $6 / 1717: 30$ & $1: 30$ & & 1.3 & & & & 30 & 2.86 & 9.75 \\
\hline B4 & $6 / 17$ 19:00 & $6 / 1721: 00$ & $2: 00$ & & 1.4 & & & & 50 & 2.86 & 9.75 \\
\hline B5 & $6 / 1721: 30$ & $6 / 1723: 30$ & $1: 30$ & & 1.1 & & & & 70 & 2.85 & 9.74 \\
\hline B6 & 6/17 23:45 & 6/18 01:20 & $1: 35$ & & 1.4 & & & & 70 & 2.85 & 9.74 \\
\hline $\mathrm{C} 1$ & 6/18 06:00 & 6/18 08:00 & 2:00 & \multirow{5}{*}{$\begin{array}{c}\text { Tri-Star mvb } \\
\text { Coal }\end{array}$} & \multirow{5}{*}{ None } & $\begin{array}{c}\text { ATF40 } \\
\mathrm{Ca} / \mathrm{S}=1.8\end{array}$ & \multirow{5}{*}{ Air } & & 0 & 2.82 & 9.63 \\
\hline $\mathrm{C} 2$ & $6 / 18$ 10:00 & 6/18 13:00 & 3:00 & & & \multirow{4}{*}{$\begin{array}{c}\mathrm{ATF} 40 \\
\mathrm{Ca} / \mathrm{S}=2.00\end{array}$} & & & 50 & 2.82 & 9.64 \\
\hline $\mathrm{C} 3$ & $6 / 1816: 00$ & $6 / 1817: 30$ & $1: 30$ & & & & & & 70 & 2.83 & 9.65 \\
\hline $\mathrm{C} 4$ & $6 / 1818: 30$ & $6 / 1823: 00$ & $4: 30$ & & & & & $\begin{array}{l}\text { Hg \& Other Trace } \\
\text { Elements }\end{array}$ & 50 & 2.82 & 9.64 \\
\hline $\mathrm{C} 5$ & 6/19 00:00 & $6 / 1922: 15$ & $5: 00$ & & & & & & 50 & 2.22 & 7.58 \\
\hline D1 & 6/19 09:00 & 6/19 15:00 & 6:00 & \multirow{4}{*}{$\begin{array}{c}\text { Tri-Star mvb } \\
\text { Coal }\end{array}$} & \multirow{4}{*}{ None } & \multirow{3}{*}{$\begin{array}{c}\mathrm{ATF} 40 \\
\mathrm{Ca} / \mathrm{S}=2.00\end{array}$} & \multirow{4}{*}{$30 \% \mathrm{O}_{2} / 70 \% \mathrm{CO}_{2}$} & & 55 & 2.84 & 9.70 \\
\hline D2 & $6 / 18$ 18:00 & $6 / 1920: 00$ & $2: 00$ & & & & & & 75 & 2.85 & 9.71 \\
\hline D3 & 6/20 08:00 & $6 / 2016: 00$ & 8:00 & & & & & $\begin{array}{l}\mathrm{Hg} \& \text { Other Trace } \\
\text { Elements; } \mathrm{NH}_{3} \\
\text { Injection }\end{array}$ & 70 & 2.84 & 9.70 \\
\hline D4 & $6 / 2020: 00$ & 6/20 22:01 & 2:00 & & & $\begin{array}{l}\text { Aragonite } \\
\mathrm{Ca} / \mathrm{S}=2.0\end{array}$ & & & 70 & 2.85 & 9.71 \\
\hline E1 & $6 / 2106: 00$ & 6/21 11:00 & $5: 00$ & \multirow{3}{*}{$\begin{array}{l}\text { Petroleum } \\
\text { Coke }\end{array}$} & \multirow{3}{*}{ None } & $\begin{array}{l}\text { Aragonite } \\
\mathrm{Ca} / \mathrm{S}=1.4\end{array}$ & \multirow{3}{*}{$30 \% \mathrm{O}_{2} / 70 \% \mathrm{CO}_{2}$} & $\begin{array}{c}\mathrm{Hg} \& \text { Other Trace } \\
\text { Elements; } \mathrm{NH}_{3} \\
\text { Injection } \\
\end{array}$ & 70 & 2.92 & 9.98 \\
\hline E2 & $6 / 2116: 50$ & 6/21 19:40 & $2: 50$ & & & $\begin{array}{l}\text { Aragonite } \\
\mathrm{Ca} / \mathrm{S}=1.3\end{array}$ & & & 70 & 2.93 & 10.01 \\
\hline E3 & $6 / 2120: 40$ & $6 / 2121: 13$ & $0: 33$ & & & $\begin{array}{l}\text { Aragonite } \\
\mathrm{Ca} / \mathrm{S}=1.4\end{array}$ & & & 50 & 2.93 & 10.01 \\
\hline
\end{tabular}




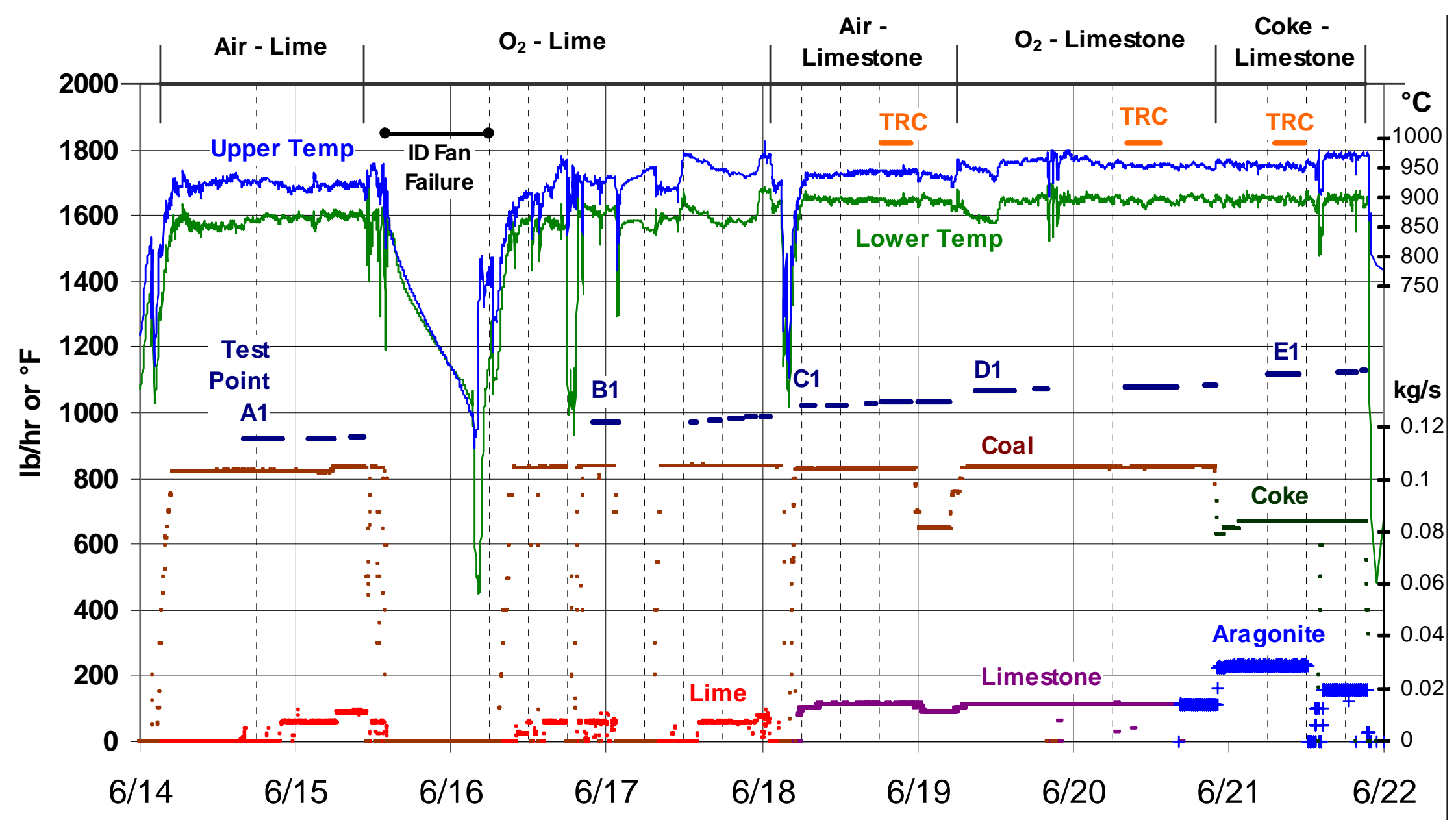

Note: The bars for Test Points, ID Fan Failure, and TRC Testing indicate times only; their "y-axis" values are arbitrary

Figure 3.15: MTF Test Summary Figure 
Test Point B1 - At about 22:00 on June 16 we were at full coal with oxygen firing - 30\% Global $\mathrm{O}_{2}$. At 02:00 the next morning we ran out of $\mathrm{CO}_{2}$ due to delivery problems. We switched to air firing through the night.

Test Point B2 - At midday on June 17 we were back at base conditions with $30 \% \mathrm{O}_{2}$ firing with no limestone to the furnace and no lime to the baghouse.

Test Point B3 - At about 15:00 we started lime feed to the baghouse and water to bring the relative humidity to about $30 \%$.

Test Point B4 - Increased the relative humidity out of the baghouse to about 50\%.

Test Point B5 - Increased the relative humidity out of the baghouse to about $70 \%$.

Test Point B6 - Increased the furnace temperature.

Again overnight delivery problems caused us to run out of $\mathrm{CO}_{2}$, so we ended Test $\mathrm{B}$ and moved on to the air-fired Test $\mathrm{C}$. We shut off lime and water flow to the baghouse and began feeding the ATF40 limestone to the furnace.

Test Point C1 - Air-fired test point with limestone to the furnace and no lime to the baghouse as the fly ash inventory starts to turn over.

Test Point C2 - Increased the limestone flow to the furnace to a Calcium-to-Sulfur ratio $(\mathrm{Ca} / \mathrm{S})$ of 2.0 and began water flow to the baghouse for backend sulfur capture at a relative humidity of $50 \%$.

Test Point C3 - Increased relative humidity to $70 \%$.

Test Point C4 - Returned to 50\% relative humidity. Increased the overfire (and total) airflow slightly. During this test period, TRC took duplicate samples at the baghouse inlet and outlet.

Test Point C5 - Reduced the load from 9.6 to 7.4 MMBtu/hr. Reduced the overfire air to maintain the fluidizing velocity at the grid.

At about 06:00 on June 19 we ended the air-fired test and switched to oxygen firing with $30 \%$ global $\mathrm{O}_{2}$.

Test Point D1 - The initial test period with ATF40 limestone and oxygen firing. The relative humidity at the baghouse outlet is about $55 \%$.

Test Point D2 - A short test period with the relative humidity increased to about $75 \%$.

At this point we began some high temperature tests, but the control logic repeatedly tripped the unit at the higher temperatures. These test points were abandoned.

Test Point D3 - A longer steady test period at about 70\% relative humidity. During this test period, TRC took duplicate samples at the baghouse inlet and outlet.

Test Point D4 - At about 16:30 on June 20, we switched from the low reactivity ATF40 limestone to the high reactivity aragonite. The $\mathrm{SO}_{2}$ emission from the furnace quickly dropped due to the more reactive sorbent. This short test point was at the end of the bituminous firing. 
Test Point E1 - At about 22:00 on June 20 we switched to petroleum coke firing. The aragonite feed rate was increased to maintain a $\mathrm{Ca} / \mathrm{S}$ ratio of 2.0. During this initial test period, TRC took duplicate samples at the baghouse inlet and outlet.

Test Point E2 - At about noon on June 21 we shut off the limestone for an hour then reestablished at a reduced $\mathrm{Ca} / \mathrm{S}$ ratio of about 1.35 .

Test Point E3 - The water flow to the baghouse was reduced to drop the relative humidity from $70 \%$ to about $50 \%$.

After a very short test point E3, a solids leak in the rotary valve below the FBHE became worse, at which point we terminated the test.

\subsection{Test Results and Analysis}

This section provides test data analysis results for the testing described previously in Section 3.4.

\subsubsection{Operability}

Throughout the test week, there were no operational problems attributable to the oxygen firing. In the 2004 tests, there was operational evidence of recarbonation problems in the sealpot and in the cyclone hopper (with pet coke). In 2005, the sealpot was fluidized with air to avoid operational problems (with the tradeoff of higher $\mathrm{N}_{2}$ in the flue gas). Also the cyclone temperature was maintained above the recarbonation temperature. One way to avoid recarbonation problems commercially is to add no limestone to the furnace - as tested here in Test Series A and B (see Figure 3.14). Even with limestone added to the furnace, the cyclone and sealpot stay hotter in a commercial plant than the smaller MTF pilot, so recarbonation will be less of an issue.

\subsubsection{Approaches to Steady State}

Some things can change and respond to changes rapidly in a CFB. For example, $\mathrm{NO}_{\mathrm{x}}$ emissions will quickly respond to a change in air staging and a change in furnace temperature will quickly affect the $\mathrm{CO}$ emissions. Changes in ash composition can take much longer - the solids inventory is large compared to the feed rate. $\mathrm{SO}_{2}$ emissions, for example, will change quickly if the limestone feedrate is changed, but there is a longer term effect as the composition of the bed inventory reaches a new steady state value.

Figure 3.16 shows one measure of bed ash composition - the mass ratio of calcium to inert (Ca:I) in the ash. Figure 3.16 shows the value for selected samples of different ashes as well as the calculated steady state value based on the feed rates and compositions of the fuel and limestone. 


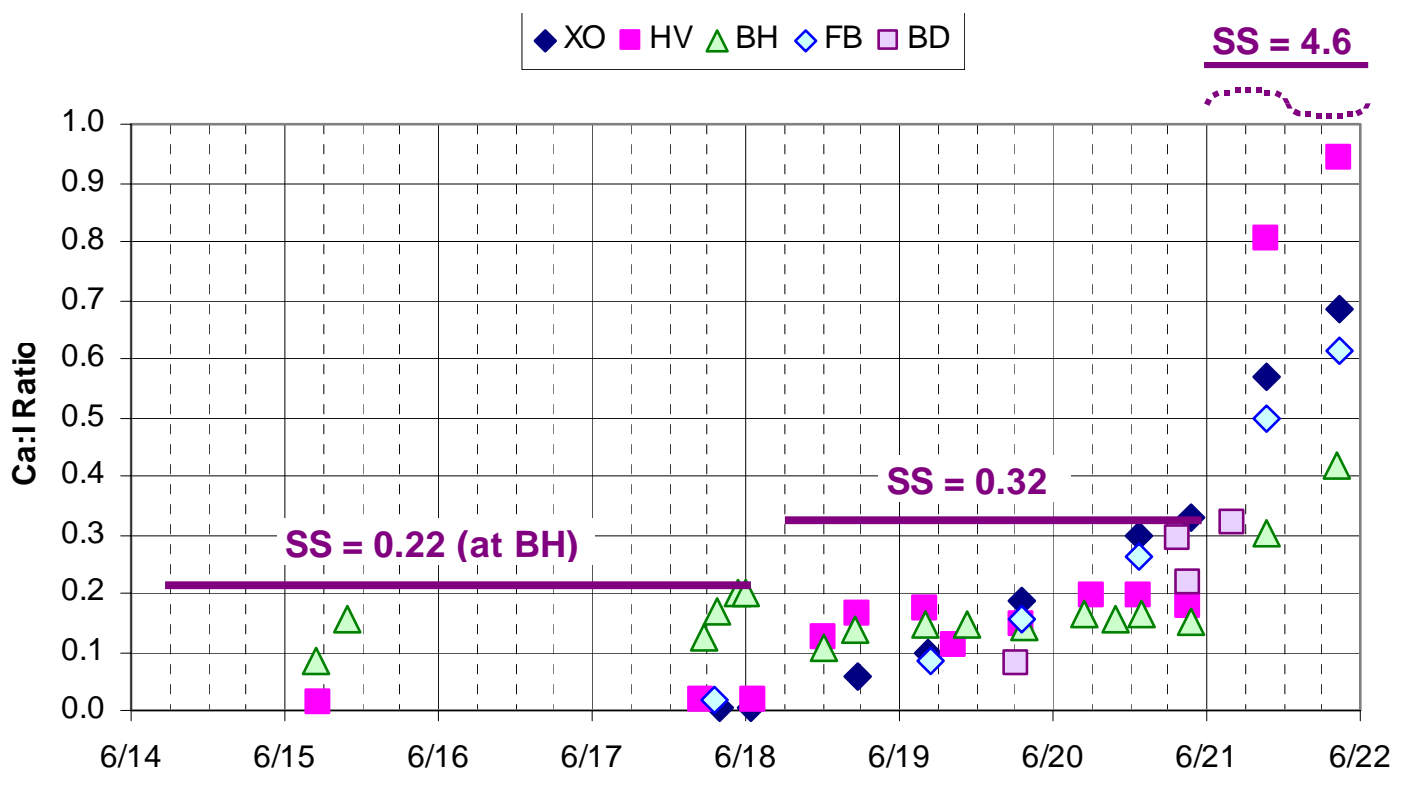

Figure 3.16: Calcium-to-Inert Ratio of Ash Samples

For the first four days of testing, the Ca:I ratio in the furnace is about zero, since no limestone was added. At the baghouse (where lime was added) the calculated ratio is 0.22 . The baghouse samples $(\mathrm{BH})$ approached this value.

For the next three days, with bituminous coal and limestone at a $\mathrm{Ca}: \mathrm{S}$ ratio of about $2: 1$, the calculated overall Ca:I ratio is about 0.32. The samples of bed drain (BD) and circulating material ( $\mathrm{XO}$ and $\mathrm{FB}$ ) reached this value at the end of the three days. The fly ash ratio more quickly approached a steady value that is lower ( $\mathrm{HV}$ and $\mathrm{BH}$ ). It is often the case that the ash in the coal is finer than the added limestone (i.e., not a lot of rocks in the coal). In this case, the fly ash will reach a steady Ca:I ratio lower than the calculated overall value; the bed drain should have a higher ratio to maintain the mass balance.

For the last day with pet coke, the calculated Ca:I ratio is about 4.6; much higher due to the very low fuel ash and high sulfur. The measured values jumped markedly, but did not approach steady state in the one day of pet coke firing. Note that the fly ash at the baghouse drain $(\mathrm{BH})$ changed more slowly than fly ash at the furnace outlet (HV). This is expected, due to the additional inventory in the baghouse.

\subsubsection{Furnace Temperature and Pressure Profiles}

Temperature profiles along the furnace height and pressure profiles along the primary recirculation loop are useful indications of the furnace conditions. Figure 3.17 gives a key to the temperature and pressure locations in the MTF. 


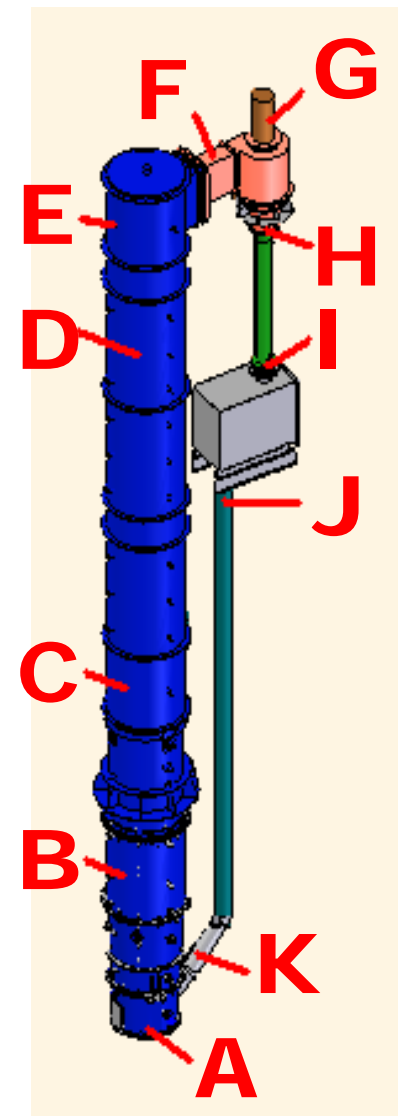

Figure 3.17: Key for Temperature and Pressure Locations

Average data from these temperature and pressure profiles are summarized in Table 3.7. The furnace temperatures are averaged at four elevations and the pressure drop is split into two sections. This summary data is plotted in Figure 3.18 and Figure 3.19. 
Table 3.7: Summary of Temperature and Pressure Profiles

\begin{tabular}{|c|c|c|c|c|c|c|c|c|c|c|c|c|c|c|c|c|c|c|c|c|c|c|}
\hline \multirow{3}{*}{$\begin{array}{l}\text { Test } \\
\text { Point }\end{array}$} & \multicolumn{10}{|c|}{ Temperatures } & \multicolumn{8}{|c|}{ Pressures } & \multicolumn{4}{|c|}{ Velocities } \\
\hline & \multicolumn{2}{|c|}{ Bottom } & \multicolumn{2}{|c|}{ Mid 1} & \multicolumn{2}{|c|}{ Mid 2} & \multicolumn{2}{|c|}{ Upper } & \multicolumn{2}{|c|}{ Sealpot } & \multicolumn{2}{|c|}{ Total } & \multicolumn{2}{|c|}{ Upper } & \multicolumn{2}{|c|}{ Lower } & \multicolumn{2}{|c|}{ Grid } & \multicolumn{2}{|c|}{ Grid } & \multicolumn{2}{|c|}{ Upper } \\
\hline & ${ }^{\circ} \mathrm{C}$ & ${ }^{\circ} \mathrm{F}$ & ${ }^{\circ} \mathrm{C}$ & ${ }^{\circ} \mathrm{F}$ & ${ }^{\circ} \mathrm{C}$ & ${ }^{\circ} \mathrm{F}$ & ${ }^{\circ} \mathrm{C}$ & ${ }^{\circ} \mathrm{F}$ & ${ }^{\circ} \mathrm{C}$ & ${ }^{\circ} \mathrm{F}$ & cm.w.g & in.w.g. & cm.w.g & in.w.g. & cm.w.g & in.w.g. & cm.w.g & in.w.g. & $\mathrm{m} / \mathrm{s}$ & $\mathrm{ft} / \mathrm{sec}$ & $\mathrm{m} / \mathrm{s}$ & $\mathrm{ft} / \mathrm{sec}$ \\
\hline $\mathrm{A} 1$ & 871 & 1600 & 900 & 1651 & 917 & 1682 & 928 & 1702 & 892 & 1637 & 34.2 & 13.5 & 12.9 & 5.1 & 21.4 & 8.4 & 95.1 & 37.4 & 5.2 & 17.0 & 4.3 & 14.2 \\
\hline $\mathrm{A} 2$ & 868 & 1594 & 894 & 1641 & 909 & 1668 & 920 & \begin{tabular}{|l|}
1689 \\
\end{tabular} & 881 & 1618 & 52.0 & 20.5 & 12.6 & 5.0 & 39.3 & 15.5 & 91.7 & 36.1 & 5.1 & 16.8 & 4.4 & 14.5 \\
\hline $\mathrm{A} 3$ & 873 & 1603 & 897 & 1647 & 912 & 1674 & 924 & 1696 & 882 & 1620 & 61.2 & 24.1 & 11.0 & 4.3 & 50.5 & 19.9 & 89.3 & 35.2 & 5.1 & 16.7 & 4.4 & 14.5 \\
\hline & & & & & & & & & & & & & & & & & & & & & & \\
\hline B1 & 877 & \begin{tabular}{|l|}
1611 \\
\end{tabular} & 892 & 1638 & 914 & 1678 & 929 & 1704 & 853 & 1567 & 119.0 & 46.8 & 9.4 & 3.7 & 109.9 & 43.3 & 41.9 & 16.5 & 4.5 & 14.6 & 3.2 & 10.4 \\
\hline B2 & 882 & 1620 & 913 & 1675 & 950 & 1742 & 969 & \begin{tabular}{|l|}
1777 \\
\end{tabular} & 845 & 1553 & 73.0 & 28.8 & 3.7 & 1.4 & 70.1 & 27.6 & 57.3 & 22.6 & 4.5 & 14.8 & 3.3 & 10.7 \\
\hline B3 & 861 & 1581 & 889 & 1633 & 927 & 1701 & 949 & 1739 & 850 & 1561 & 87.2 & 34.3 & 4.8 & 1.9 & 82.2 & 32.3 & 51.6 & 20.3 & 4.5 & 14.7 & 3.2 & 10.5 \\
\hline B4 & 863 & 1586 & 887 & 1628 & 920 & 1687 & 940 & \begin{tabular}{|l|}
1724 \\
\end{tabular} & 844 & 1552 & 102.4 & 40.3 & 5.5 & 2.2 & 97.4 & 38.3 & 43.2 & 17.0 & 4.5 & 14.7 & 3.2 & 10.4 \\
\hline B5 & 865 & 1590 & 886 & 1627 & 917 & 1683 & 937 & \begin{tabular}{|l|}
1719 \\
\end{tabular} & 843 & 1550 & 103.5 & 40.8 & 5.9 & 2.3 & 98.0 & 38.6 & 43.2 & 17.0 & 4.6 & 15.0 & 3.2 & 10.4 \\
\hline B6 & 914 & \begin{tabular}{|l|}
1677 \\
\end{tabular} & 932 & 1709 & 957 & 1755 & 973 & \begin{tabular}{|l|}
1783 \\
\end{tabular} & 870 & 1598 & 101.9 & 40.1 & 6.4 & 2.5 & 95.0 & 37.4 & 46.0 & 18.1 & 4.8 & 15.7 & 3.3 & 10.7 \\
\hline C1 & 902 & \begin{tabular}{|l|}
1656 \\
\end{tabular} & 917 & 1683 & 927 & 1700 & 936 & 1717 & 901 & 1653 & 59.6 & 23.5 & 20.4 & 8.0 & 39.8 & 15.7 & 100.7 & 39.6 & 5.1 & 16.9 & 4.3 & 14.0 \\
\hline $\mathrm{C} 2$ & 899 & \begin{tabular}{|l|}
1651 \\
\end{tabular} & 919 & 1686 & 930 & 1707 & 940 & \begin{tabular}{|l|}
1724 \\
\end{tabular} & 903 & 1658 & 51.6 & 20.3 & 17.3 & 6.8 & 34.5 & 13.6 & 101.4 & 39.9 & 5.1 & 16.8 & 4.2 & 13.8 \\
\hline $\mathrm{C} 3$ & 900 & 1652 & 922 & 1692 & 935 & 1715 & 945 & \begin{tabular}{|l|}
1734 \\
\end{tabular} & 909 & 1668 & 43.0 & 16.9 & 15.9 & 6.3 & 27.0 & 10.6 & 108.4 & 42.7 & 5.2 & 17.2 & 4.3 & 14.1 \\
\hline $\mathrm{C} 4$ & 897 & 1646 & 920 & 1688 & 934 & 1713 & 944 & \begin{tabular}{|l|}
1732 \\
\end{tabular} & 908 & 1666 & 39.5 & 15.6 & 14.7 & 5.8 & 24.4 & 9.6 & 110.1 & 43.4 & 5.3 & 17.2 & 4.4 & 14.5 \\
\hline $\mathrm{C} 5$ & 897 & \begin{tabular}{|l|}
1646 \\
\end{tabular} & 915 & 1679 & 927 & 1701 & 939 & \begin{tabular}{|l|}
1721 \\
\end{tabular} & 869 & 1596 & 59.6 & 23.5 & 9.3 & 3.7 & 50.4 & 19.8 & 105.3 & 41.5 & 5.1 & 16.9 & 3.6 & 11.9 \\
\hline & & & & & & & & & & & & & & & & & & & & & & \\
\hline D1 & 878 & \begin{tabular}{|l|}
1612 \\
\end{tabular} & 899 & 1651 & 930 & 1706 & 950 & \begin{tabular}{|l|}
1741 \\
\end{tabular} & 843 & 1549 & 102.7 & 40.4 & 4.8 & 1.9 & 98.3 & 38.7 & 43.7 & 17.2 & 4.5 & 14.7 & 3.2 & 10.5 \\
\hline $\mathrm{D} 2$ & 903 & \begin{tabular}{|l|}
1657 \\
\end{tabular} & 922 & 1692 & 950 & 1741 & 966 & \begin{tabular}{|l|}
1771 \\
\end{tabular} & 880 & 1616 & 76.6 & 30.1 & 6.8 & 2.7 & 70.0 & 27.6 & 50.2 & 19.8 & 4.6 & 15.1 & 3.2 & 10.6 \\
\hline $\mathrm{D} 3$ & 898 & \begin{tabular}{|l|}
1648 \\
\end{tabular} & 915 & 1679 & 939 & 1722 & 955 & \begin{tabular}{|l|}
1751 \\
\end{tabular} & 878 & 1613 & 104.0 & 40.9 & 8.2 & 3.2 & 95.9 & 37.7 & 42.0 & 16.5 & 4.5 & 14.9 & 3.2 & 10.6 \\
\hline $\mathrm{D} 4$ & 898 & 1648 & 914 & 1678 & 937 & 1718 & 952 & \begin{tabular}{|l|}
1746 \\
\end{tabular} & 880 & 1616 & 107.6 & 42.3 & 7.7 & 3.0 & 99.4 & 39.1 & 40.1 & 15.8 & 4.5 & 14.8 & 3.2 & 10.6 \\
\hline & & & & & & & & & & & & & & & & & & & & & & \\
\hline E1 & 901 & \begin{tabular}{|l|}
1654 \\
\end{tabular} & 917 & 1682 & 941 & 1725 & 956 & \begin{tabular}{|l|}
1752 \\
\end{tabular} & 881 & 1618 & 102.3 & 40.3 & 9.6 & 3.8 & 92.6 & 36.4 & 44.1 & 17.4 & 4.7 & 15.3 & 3.2 & 10.5 \\
\hline$E 2$ & 901 & \begin{tabular}{|c|}
1653 \\
\end{tabular} & 925 & 1697 & 959 & 1757 & 975 & \begin{tabular}{|l|}
1787 \\
\end{tabular} & 873 & 1603 & 80.0 & 31.5 & 5.1 & 2.0 & 74.8 & 29.5 & 53.2 & 20.9 & 4.6 & 14.9 & 3.2 & 10.5 \\
\hline E3 & 892 & 1637 & 919 & 1686 & 956 & 1753 & 976 & 1788 & 885 & 1625 & 92.7 & 36.5 & & 1.8 & 88.0 & 34.7 & 47.8 & 18.8 & 4.5 & 14.6 & 3.1 & 10.3 \\
\hline & $\begin{array}{l}\text { Botto } \\
\text { Mid } 1 \\
\text { Mid } 2 \\
\text { Uppe } \\
\text { Sealp } \\
\text { Total } \\
\text { Lowe } \\
\text { Uppe }\end{array}$ & $\begin{array}{l}\text { avera } \\
\text { - avera } \\
\text { t - tem } \\
\text { ressur } \\
\text { Pressu } \\
\text { Press }\end{array}$ & $\begin{array}{l}\text { ge o } \\
\text { perat } \\
\text { e Drc }\end{array}$ & $\begin{array}{l}\text { e lea } \\
\text { - Poi } \\
p-P c\end{array}$ & $\begin{array}{l}\text { nper } \\
\text { mpe } \\
\text { ng tl } \\
\text { A to } \\
\text { tt A }\end{array}$ & $\begin{array}{l}\text { atures } \\
\text { atures } \\
\text { rature } \\
\text { e sea } \\
\text { Point } \\
\text { o Poir }\end{array}$ & $\begin{array}{l}\text { at loc } \\
\text { at loc } \\
\text { at lo } \\
\text { pot } \\
\text { E } \\
\text { B }\end{array}$ & $\begin{array}{l}\text { tion } \mathrm{B} \\
\text { tion } \mathrm{C} \\
\text { ation } \mathrm{C}\end{array}$ & the & $2 \mathrm{Al}$ & $\begin{array}{l}\text { el up } \\
\text { el don }\end{array}$ & & & & & & & & & & & \\
\hline
\end{tabular}




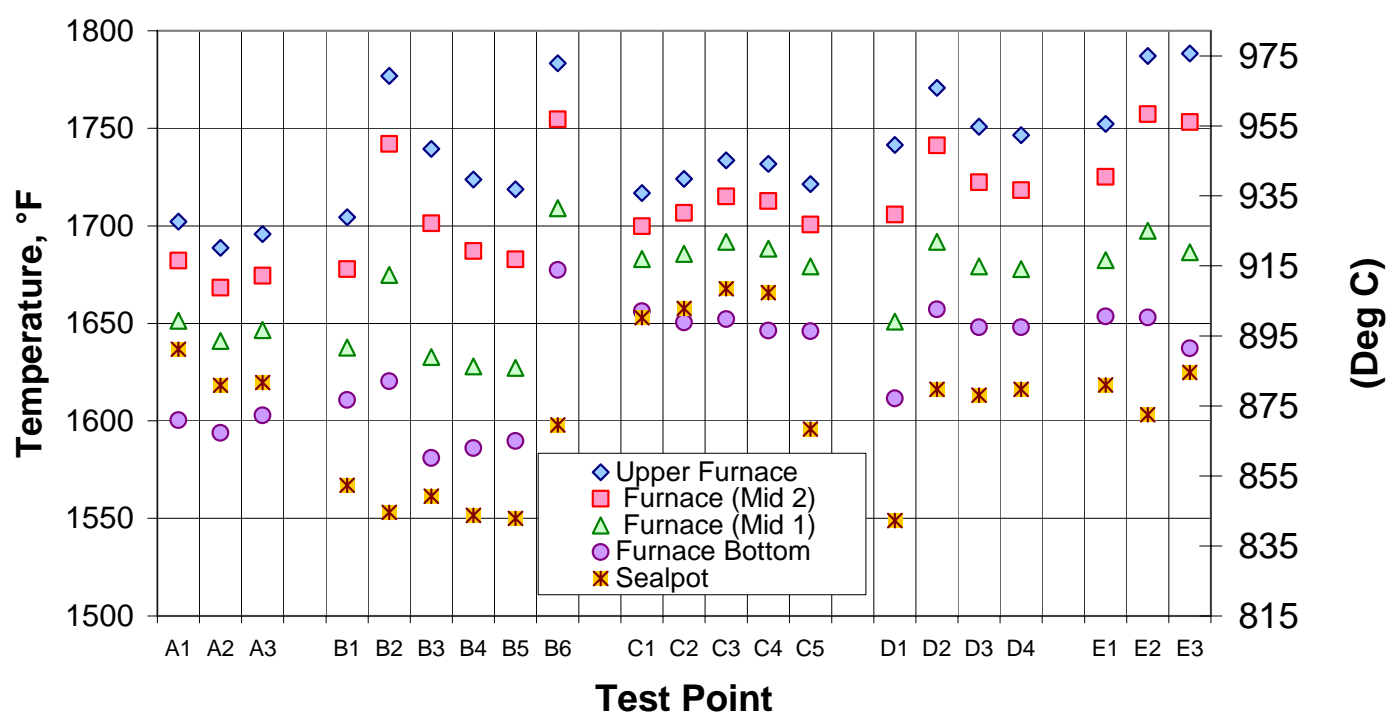

Figure 3.18: Summary of Temperature Profiles

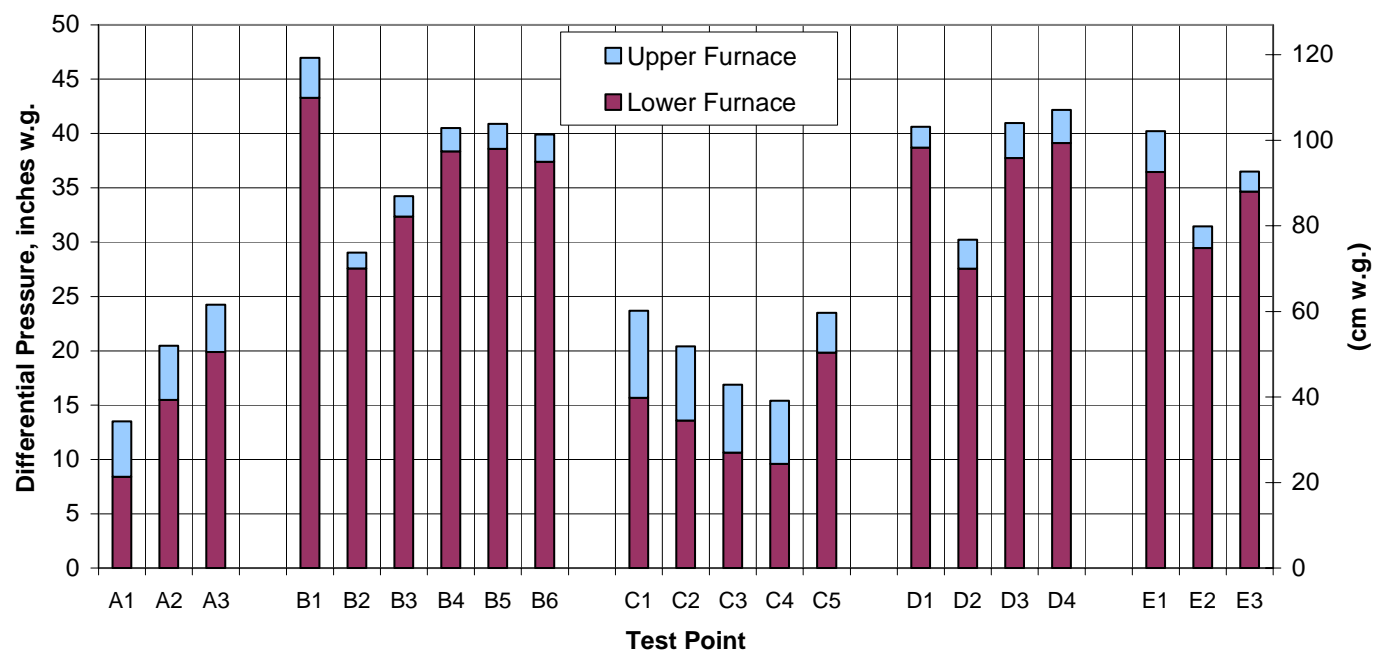

Figure 3.19: Summary of Furnace Pressure Drop

The calculated velocities in the upper furnace and at the grid are plotted in Figure 3.20. 

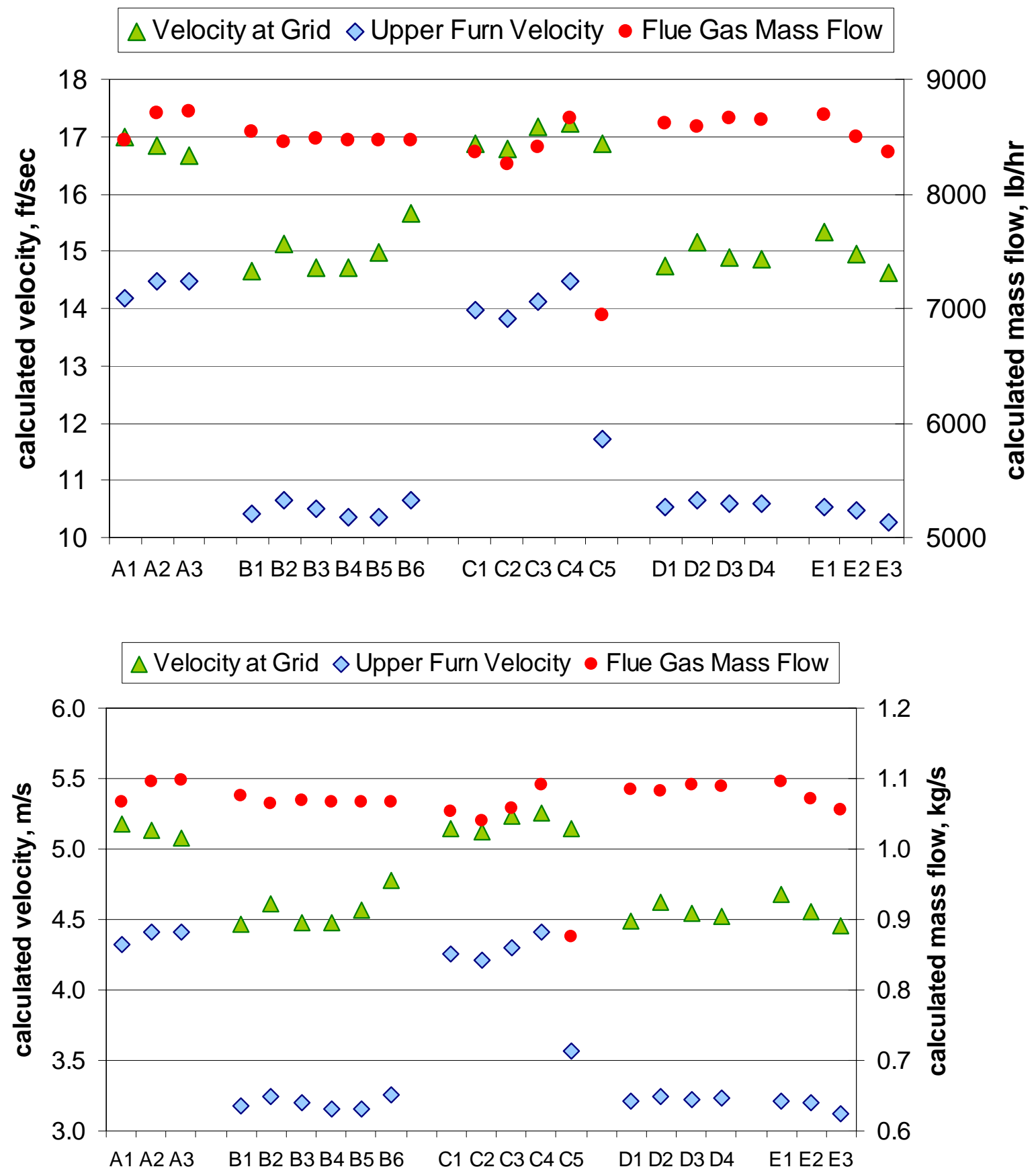

Figure 3.20: Calculated Velocities and Gas Flow Rates

The velocity at the grid plate is calculated based on the primary oxidant flow through the grid plate. The velocity in the upper furnace is based on the calculated flue gas flow rate which includes all the oxidant plus the gaseous products of coal combustion. The flue gas flow is also plotted in Figure 3.20. At the 30\% global oxygen content of the oxidant, the mass flow rate of flue gas is similar to that of air firing. The velocity is lower with oxygen firing because the molecular weight of $\mathrm{CO}_{2}$ is greater than $\mathrm{N}_{2}$. 


\subsubsection{Solids Samples}

A list of all the solid samples taken during the test is given in Table 3.8. The sample types given in Table 3.8 through Table 3.10 have the following key:

hv - hi volume pseudo-isokinetic sample taken at the cyclone outlet

xo - pseudo-isokinetic sample taken at the crossover duct (cyclone inlet)

bd - sample of bed drain material

bh - sample of baghouse fly ash

fb - sample drained from fluid bed heat exchanger

fp - deposit from convective heat transfer / fouling probes

The results of chemical analyses of selected solids samples are given in Table 3.9 through Table 3.11 
Table 3.8: List of Solids Samples Taken

\begin{tabular}{|c|c|c|c|c|c|}
\hline $\begin{array}{c}\overleftarrow{\mathscr{E}} \\
\stackrel{-}{*}\end{array}$ & 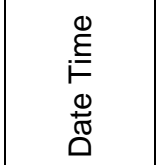 & $\begin{array}{l}\frac{0}{0} \\
\frac{0}{E} \\
\text { ஸे }\end{array}$ & $\begin{array}{l}\stackrel{\varpi}{\varrho} \\
\stackrel{-}{-}\end{array}$ & 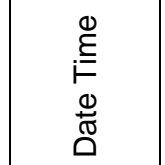 & 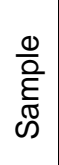 \\
\hline & 6/14 10:30 & hv & & $6 / 16$ 15:43 & bh \\
\hline & 6/14 14:10 & bh & & $6 / 16$ 16:45 & bh \\
\hline & 6/14 14:25 & bh & & $6 / 16$ 17:50 & bh \\
\hline & 6/14 22:30 & bh & & $6 / 16$ 19:45 & bh \\
\hline & 6/15 00:00 & $\mathrm{bh}$ & & $6 / 16$ 21:40 & $\mathrm{bh}$ \\
\hline & 6/15 01:00 & bh & B1 & $6 / 16$ 22:50 & bh \\
\hline & 6/15 01:45 & bh & B1 & $6 / 17$ 00:00 & bh \\
\hline A2 & 6/15 03:20 & bh & $\mathrm{B} 2$ & $6 / 17$ 12:58 & bh \\
\hline A2 & 6/15 04:20 & bh & & $6 / 17$ 14:33 & bh \\
\hline A2 & 6/15 05:00 & bh & & $6 / 17$ 15:25 & bh \\
\hline A2 & 6/15 05:20 & hv & B3 & $6 / 17$ 16:15 & bh \\
\hline & 6/15 06:15 & bh & B3 & $6 / 17$ 17:00 & hv \\
\hline & 6/15 06:57 & bh & B3 & $6 / 17$ 17:19 & bh \\
\hline & $6 / 15$ 07:29 & $\mathrm{bh}$ & & $6 / 17$ 18:24 & $\mathrm{bh}$ \\
\hline & 6/15 08:12 & bh & B4 & 6/17 19:06 & $\mathrm{fb}$ \\
\hline A3 & 6/15 08:57 & $\mathrm{bh}$ & B4 & $6 / 17$ 19:29 & bh \\
\hline A3 & 6/15 09:43 & bh & B4 & $6 / 17$ 19:45 & $x O$ \\
\hline A3 & 6/15 10:28 & bh & B4 & $6 / 17$ 20:30 & bh \\
\hline & 6/15 11:10 & bh & B5 & 6/17 21:41 & $\mathrm{bh}$ \\
\hline & 6/15 11:54 & bh & B5 & $6 / 17$ 22:55 & bh \\
\hline & 6/15 12:44 & bh & & $6 / 17$ 23:30 & hv \\
\hline & 6/15 13:32 & bh & & $6 / 1723: 30$ & $x O$ \\
\hline & $6 / 15$ 14:20 & bh & B6 & $6 / 17$ 23:55 & bh \\
\hline & 6/16 12:10 & bh & B6 & $6 / 18$ 01:10 & hv \\
\hline & 6/16 13:00 & $\mathrm{bh}$ & B6 & $6 / 18$ 01:10 & $x O$ \\
\hline & 6/16 13:50 & bh & & $6 / 18$ 02:10 & bh \\
\hline & 6/16 14:42 & bh & & 6/18 03:00 & bh \\
\hline
\end{tabular}

\begin{tabular}{|c|c|c|}
\hline 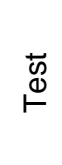 & 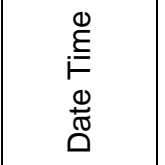 & 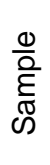 \\
\hline & 6/18 04:05 & bh \\
\hline & 6/18 05:20 & bh \\
\hline C1 & 6/18 06:49 & bh \\
\hline $\mathrm{C} 1$ & $6 / 18$ 07:40 & $\mathrm{fb}$ \\
\hline C1 & 6/18 07:40 & $x O$ \\
\hline $\mathrm{C} 1$ & $6 / 18$ 07:40 & $x O$ \\
\hline & 6/18 08:03 & bh \\
\hline & 6/18 09:09 & bh \\
\hline $\mathrm{C} 2$ & 6/18 10:00 & hv \\
\hline $\mathrm{C} 2$ & 6/18 10:00 & $x O$ \\
\hline $\mathrm{C} 2$ & 6/18 10:00 & bh \\
\hline $\mathrm{C} 2$ & 6/18 11:05 & $\mathrm{bh}$ \\
\hline $\mathrm{C} 2$ & 6/18 12:05 & bh \\
\hline C2 & 6/18 12:15 & hv \\
\hline $\mathrm{C} 2$ & 6/18 12:30 & xo \\
\hline & 6/18 13:05 & bh \\
\hline & 6/18 13:17 & bh \\
\hline & 6/18 14:35 & xo \\
\hline & 6/18 14:36 & bh \\
\hline & $6 / 18$ 14:40 & hv \\
\hline & $6 / 18$ 15:40 & $\mathrm{bh}$ \\
\hline $\mathrm{C} 3$ & 6/18 17:06 & bh \\
\hline C3 & 6/18 17:20 & hv \\
\hline $\mathrm{C} 3$ & 6/18 17:25 & xo \\
\hline $\mathrm{C} 4$ & 6/18 19:46 & bh \\
\hline $\mathrm{C} 4$ & 6/18 21:08 & bh \\
\hline
\end{tabular}

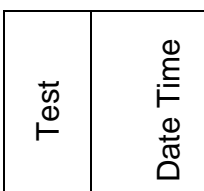

C4 $6 / 1822: 33$ bh 6/18 23:35 bh

C5 6/19 01:00 bh

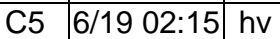

C5 $6 / 19$ 02:15 xo

C5 $6 / 19$ 02:30 bh

C5 $6 / 19$ 02:40 fb

C5 $6 / 19$ 04:15 bh

C5 6/19 04:15 bh

C5 $6 / 19$ 04:46 fb

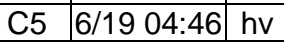

C5 6/19 04:46 xo 6/19 06:00 bh 6/19 07:57 bh $6 / 19$ 08:34 fb 6/19 08:30 hv 6/19 08:34 xo

D1 6/19 10:30 bh

D1 $6 / 19$ 12:28 bh

D1 $6 / 19$ 12:41 bd

D1 $6 / 1912: 50 \mathrm{fb}$

D1 $6 / 19$ 12:50 $\mathrm{hv}$

D1 $6 / 19$ 12:50 xo

D1 $6 / 19$ 13:40 bh

D1 $6 / 19$ 14:58 bh 6/19 16:45 bd

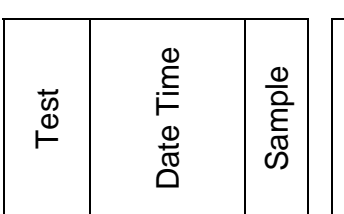

6/19 17:00 bh D2 $6 / 19$ 18:07 bh D2 6/19 18:35 bh D2 $6 / 19$ 19:00 bd D2 $6 / 19$ 19:00 $\mathrm{fb}$ D2 6/19 19:00 hv D2 6/19 19:00 xo D2 6/19 19:43 bh 6/19 21:23 bh 6/19 22:00 bd 6/19 23:40 bh 6/20 01:40 bh $6 / 2002: 30$ hv $6 / 2002: 45 \mathrm{fb}$ 6/20 03:20 bh $6 / 2004: 50$ bh 6/20 06:00 xo $6 / 2006: 10$ hv $6 / 2006: 45$ bh D3 6/20 08:12 bh D3 6/20 09:34 bh D3 $6 / 2010: 49$ bh D3 6/20 12:15 bh D3 $6 / 2013: 30 \mathrm{fb}$ D3 $6 / 20$ 13:30 $\mathrm{hv}$

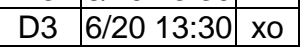

$$
\begin{array}{|l|l|}
\hline \multirow{2}{*}{} & \\
\hline &
\end{array}
$$

D3 $6 / 20$ 13:45 bh D3 6/20 15:04 bh 6/20 16:30 bh 6/20 16:40 bh 6/20 17:44 bd 6/20 19:45 xo $6 / 2019: 47$ bh 6/20 19:43 bd D4 $6 / 2020: 00 \mathrm{fb}$ D4 6/20 20:00 hv D4 6/20 21:15 bd D4 $6 / 20$ 21:20 hv D4 6/20 21:15 bh D4 6/20 21:30 xo

D4 6/20 21:40 bh 6/20 23:00 bd 6/21 00:40 bd $6 / 2100: 40 \mathrm{fb}$ 6/21 00:40 bh 6/21 00:40 bh $6 / 2101: 00$ hv 6/21 01:15 xo 6/21 02:45 bh $6 / 2102: 45$ bh 6/21 04:10 bd \begin{tabular}{|l|l|}
\hline $6 / 2104: 10$ & $\mathrm{fb}$ \\
\hline
\end{tabular}

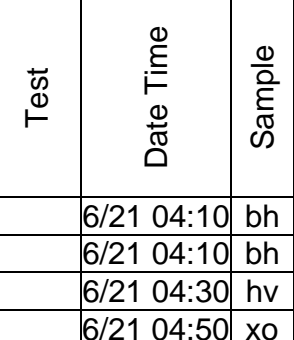

E1 6/21 06:14 bd

E1 6/21 07:20 bh

E1 6/21 08:50 bd

E1 6/21 09:10 fb

E1 6/21 09:10 hv

E1 6/21 09:10 xo

E1 6/21 09:10 bh $6 / 2112: 00 \mathrm{fb}$

6/21 12:00 hv 6/21 12:00 xo $6 / 2113: 45$ bd 6/21 16:39 bh E2 6/21 18:00 fb E2 6/21 18:10 hv E2 6/21 18:10 bh E2 $6 / 2118: 40 \mathrm{fb}$ E2 6/21 18:40 xo 6/21 20:30 bh E3 6/21 20:45 fb E3 6/21 20:45 hv E3 6/21 20:45 xo 6/21 21:32 bh \begin{tabular}{l|l|} 
post-test & $\mathrm{fp}$ \\
\hline
\end{tabular} 
Table 3.9: Analyses of Fly Ash Solids Samples

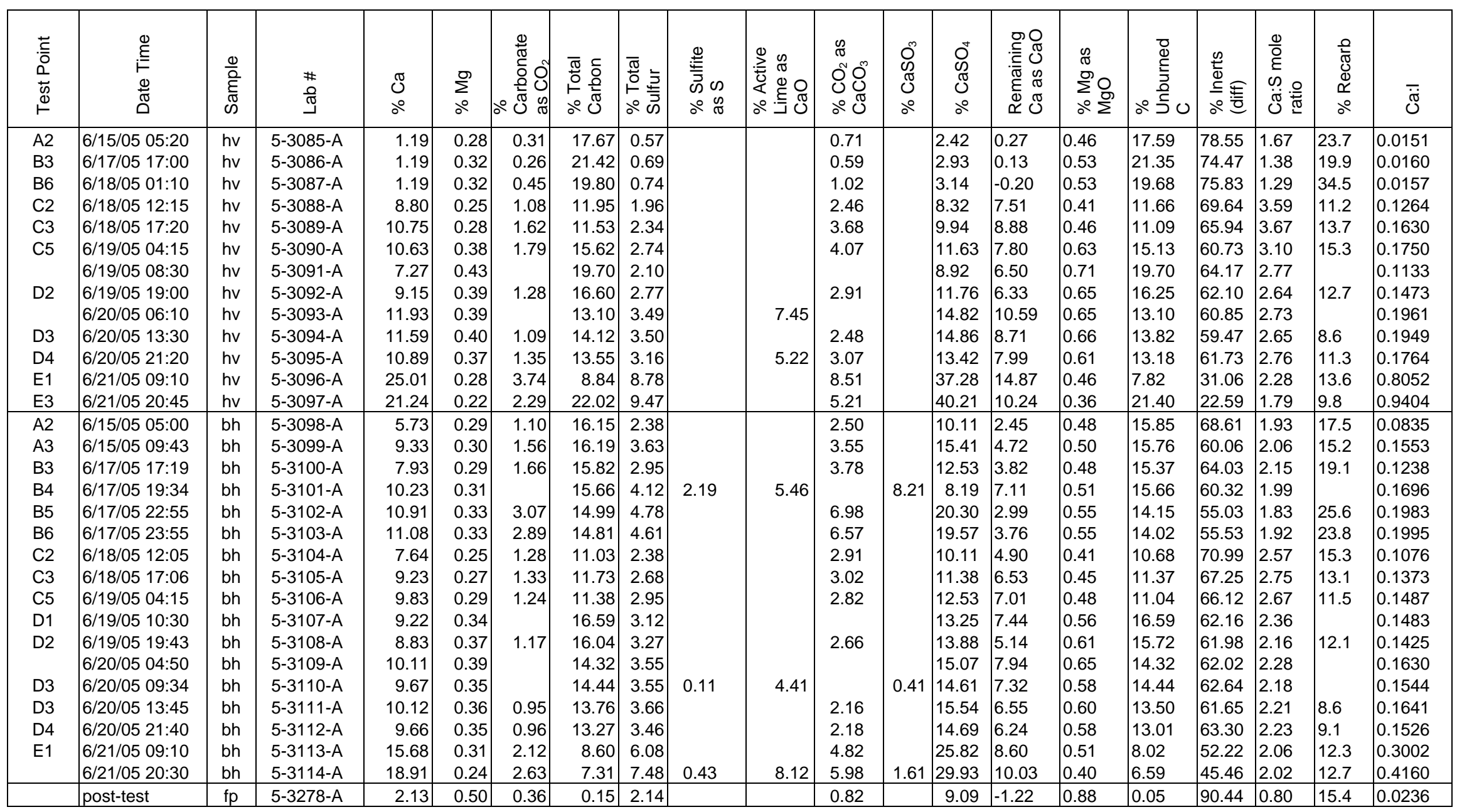


Table 3.10: Analyses of Bed Solids Samples

\begin{tabular}{|c|c|c|c|c|c|c|c|c|c|c|c|c|c|c|c|c|c|c|c|c|}
\hline 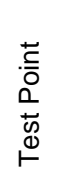 & 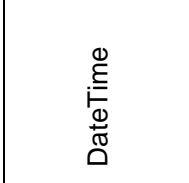 & 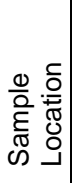 & $\begin{array}{l}\# \\
\frac{\overrightarrow{0}}{\alpha}\end{array}$ & $\begin{array}{l}U^{\sigma} \\
0^{\circ}\end{array}$ & $\sum_{0}^{0}$ & 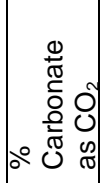 & 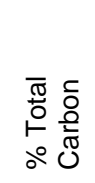 & 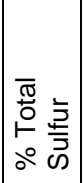 & 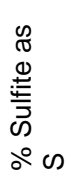 & 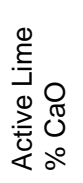 & 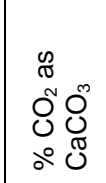 & $\begin{array}{l}0^{\infty} \\
\text { U } \\
0 \\
0\end{array}$ & $\begin{array}{l}0^{+} \\
0 \\
0 \\
0 \\
0\end{array}$ & 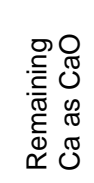 & $\begin{array}{l}0 \\
\sum_{0}^{0} \\
\pi \\
0 \\
0\end{array}$ & 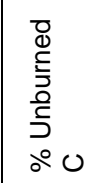 & 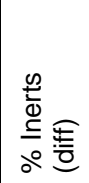 & 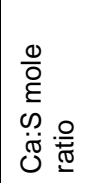 & 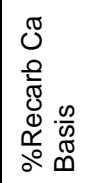 & $\overline{\tilde{\sigma}}$ \\
\hline B4 & 6/17/05 19:45 & xo & $5-3076-A$ & 0.43 & 0.04 & 0.11 & 0.19 & 0.13 & & & 0.25 & & 0.55 & 0.23 & 0.07 & 0.16 & 98.74 & 2.65 & 23.3 & 0.0044 \\
\hline B6 & 6/18/05 01:00 & xo & 5-3077-A & 0.46 & 0.04 & 0.06 & 0.23 & 0.14 & & & 0.14 & & 0.59 & 0.32 & 0.07 & 0.21 & 98.67 & 2.63 & 11.9 & 0.0047 \\
\hline C3 & 6/18/05 17:25 & xo & 5-3078-A & 5.05 & 0.08 & 0.14 & 0.30 & 0.85 & & & 0.32 & & 3.61 & 5.40 & 0.13 & 0.26 & 90.28 & 4.75 & 2.5 & 0.0559 \\
\hline C5 & 6/19/05 04:40 & xo & 5-3079-A & 8.25 & 0.11 & 0.15 & 0.17 & 1.63 & & & 0.34 & & 6.92 & 8.50 & 0.18 & 0.13 & 83.93 & 4.05 & 1.7 & 0.0983 \\
\hline D2 & 6/19/05 19:00 & xo & $5-3080-A$ & 13.45 & 0.18 & 0.39 & 0.31 & 3.17 & & & 0.89 & & 13.46 & 12.78 & 0.30 & 0.20 & 72.37 & 3.39 & 2.6 & 0.1858 \\
\hline D3 & $6 / 20 / 05$ 13:30 & xo & $5-3081-A$ & 18.29 & 0.22 & 0.28 & 0.28 & 4.81 & & & 0.64 & & 20.42 & 16.82 & 0.36 & 0.20 & 61.55 & 3.04 & 1.4 & 0.2972 \\
\hline D4 & 6/20/05 21:30 & xo & 5-3082-A & 19.43 & 0.22 & & 0.33 & 5.08 & & & & & 21.57 & 18.30 & 0.36 & 0.33 & 59.43 & 3.06 & & 0.3269 \\
\hline E1 & 6/21/05 09:10 & xo & 5-3083-A & 25.44 & 0.22 & 0.69 & 0.45 & 7.42 & & & 1.57 & & 31.50 & 21.74 & 0.36 & 0.26 & 44.56 & 2.74 & 2.5 & 0.5709 \\
\hline E3 & $6 / 21 / 05$ 20:45 & xo & 5-3084-A & 26 & 0.19 & & 0.49 & 9.95 & & & & & 42.25 & 18.98 & 0.32 & 0.49 & 37.97 & 2.09 & & 0.6847 \\
\hline B4 & 6/17/05 19:06 & $\mathrm{fb}$ & $5-3115-A$ & 1.74 & 0.11 & & 0.15 & 0.34 & & & & & 1.44 & 1.84 & 0.17 & 0.15 & 96.39 & 4.09 & & 0.0181 \\
\hline C5 & 6/19/05 04:46 & $\mathrm{fb}$ & 5-3116-A & 7.42 & 0.09 & & 0.16 & 1.38 & & & & & 5.86 & 7.97 & 0.15 & 0.16 & 85.86 & 4.30 & & 0.0864 \\
\hline D2 & 6/19/05 19:00 & $\mathrm{fb}$ & 5-3117-A & 11.90 & 0.13 & 0.51 & 0.25 & 2.63 & & & 1.16 & & 11.17 & 11.40 & 0.22 & 0.11 & 75.94 & 3.62 & 3.9 & 0.1567 \\
\hline D3 & 6/20/05 13:30 & $\mathrm{fb}$ & 5-3118-A & 17.06 & 0.19 & 0.44 & 0.22 & 4.19 & & & 1.00 & & 17.79 & 15.98 & 0.31 & 0.10 & 64.82 & 3.26 & 2.3 & 0.2632 \\
\hline E1 & 6/21/05 09:15 & $\mathrm{fb}$ & 5-3119-A & 23.66 & 0.19 & 0.34 & 0.65 & 7.26 & & & 0.77 & & 30.83 & 19.97 & 0.31 & 0.56 & 47.56 & 2.61 & 1.3 & 0.4975 \\
\hline E3 & $6 / 21 / 05$ 20:45 & $\mathrm{fb}$ & 5-3120-A & 25.00 & 0.18 & & 0.43 & 9.43 & & & & & 40.04 & 18.49 & 0.30 & 0.43 & 40.74 & 2.12 & & 0.6136 \\
\hline \multirow[t]{2}{*}{ D2 } & 6/19/05 18:30 & bd & 5-3121-A & 6.71 & 0.09 & & 0.80 & 1.38 & & & & & 5.86 & 6.98 & 0.15 & 0.80 & 86.22 & 3.89 & & 0.0778 \\
\hline & 6/20/05 19:43 & bd & $5-3275-A$ & 18.01 & 0.20 & 1.29 & 0.43 & 4.67 & & & 2.93 & & 19.83 & 15.39 & 0.33 & 0.08 & 61.44 & 3.08 & 6.5 & 0.2931 \\
\hline \multirow[t]{2}{*}{ D4 } & $6 / 20 / 05$ 21:15 & bd & $5-3122-A$ & 14.70 & 0.15 & 1.25 & 0.71 & 3.76 & & & 2.84 & & 15.96 & 12.40 & 0.25 & 0.37 & 68.18 & 3.13 & 7.7 & 0.2156 \\
\hline & 6/21/05 04:10 & bd & 5-3276-A & 18.28 & 0.17 & 1.21 & 1.74 & 5.85 & & & 2.75 & & 24.84 & 13.80 & 0.28 & 1.41 & 56.91 & 2.50 & 6.0 & .3212 \\
\hline
\end{tabular}

Table 3.11: Key for Solids Analyses

\begin{tabular}{|l|l|}
\hline Test Point & \\
\hline Date Time & When Sample Taken \\
\hline Sample & Type of sample \\
\hline Lab \# & ALSTOM Lab ID \# \\
\hline$\% \mathrm{Ca}$ & Measured Calcium \\
\hline$\% \mathrm{Mg}$ & Measured Magnesium \\
\hline$\%$ Carbonate as $\mathrm{CO}_{2}$ & Measured $\mathrm{CO}_{2}$ released from Carbonate \\
\hline$\%$ Total Carbon & Measured Total Carbon \\
\hline$\%$ Total Sulfur & Measured Total Sulfur \\
\hline$\%$ Sulfite as S & Measured Sulfite \\
\hline$\%$ Active Lime as CaO & Measurement of "Lime Reactivity" \\
\hline
\end{tabular}

\begin{tabular}{|l|l|}
\hline$\% \mathrm{CO}_{2}$ as $\mathrm{CaCO}_{3}$ & Calculated Assuming all $\mathrm{CO}_{2}$ is as $\mathrm{CaCO}_{3}$ \\
\hline$\% \mathrm{CaSO}_{3}$ & Calculated Assuming all Sulfite is as $\mathrm{CaSO}_{3}$ \\
\hline$\% \mathrm{CaSO}_{4}$ & Calculated Assuming Remaining Sulfur is as $\mathrm{CaSO}_{4}$ \\
\hline Remaining $\mathrm{Ca}$ as $\mathrm{CaO}$ & Calculated Assuming Remaining Calcium is as $\mathrm{CaO}$ \\
\hline$\% \mathrm{Mg}$ as $\mathrm{MgO}$ & Calculated Assuming all Magnesium is as $\mathrm{MgO}$ \\
\hline$\%$ Unburned C & Calculated From Total Carbon minus $\mathrm{CO}_{2}$ \\
\hline$\%$ Inerts (diff) & Calculated by Difference \\
\hline Ca:S mole ratio & Calculated From Total Calcium and Total Sulfur \\
\hline$\%$ Recarb & Calculated CaCO $\mathrm{Ca}_{3}$ as of Total Calcium (mole basis) \\
\hline Ca:I & Mass Ratio of Calcium (as Ca) to Inert \\
\hline & \\
\hline
\end{tabular}




\subsubsection{Gaseous Emissions}

Summary of Emissions

The average emission levels for each defined test period are given in Table 3.12. The flue gas concentrations into and out of the baghouse are shown in

Figure 3.21 . With oxy-firing there is some air in-leakage, which brings the $\mathrm{N}_{2}$ content to about $10 \%$ leaving the furnace. It is higher leaving the baghouse since there is additional air introduced there. 
Table 3.12: Gaseous Emissions

\begin{tabular}{|c|c|c|c|c|c|c|c|c|c|c|c|c|c|c|c|c|c|c|c|c|}
\hline \multirow[t]{2}{*}{$\begin{array}{l}\text { Test } \\
\text { Point }\end{array}$} & $\mathrm{O} 2$ & $\mathrm{O} 2 \mathrm{bh}$ & $\mathrm{SO} 2$ & $\begin{array}{c}\mathrm{SO} 2 \\
\mathrm{bh}\end{array}$ & $\mathrm{CO}$ & NOx & $\mathrm{N} 2 \mathrm{O}$ & $\mathrm{THC}$ & $\mathrm{SO} 2$ & $\begin{array}{c}\mathrm{SO} 2 \\
\mathrm{bh}\end{array}$ & $\mathrm{CO}$ & NOx & $\mathrm{N} 2 \mathrm{O}$ & THC & $\mathrm{SO} 2$ & $\begin{array}{c}\mathrm{SO} 2 \\
\text { bh }\end{array}$ & $\mathrm{CO}$ & NOx & $\mathrm{N} 2 \mathrm{O}$ & THC \\
\hline & \multicolumn{2}{|c|}{$\%$ dry } & \multicolumn{6}{|c|}{ ppm dry } & \multicolumn{6}{|c|}{ Ib/MMBtu } & \multicolumn{6}{|c|}{ gm/GJ } \\
\hline A1 & 3.45 & 6.72 & 1816 & 1333 & 72 & 70 & 39 & 3 & 3.53 & 3.18 & 0.061 & 0.098 & 0.051 & 0.0012 & 1517 & 1368 & 26 & 42 & 22 & 0.5 \\
\hline A2 & 4.47 & 7.75 & 1656 & 140 & 77 & 80 & 73 & 2 & 3.41 & 0.36 & 0.069 & 0.119 & 0.100 & 0.0013 & 1468 & 156 & 30 & 51 & 43 & 0.5 \\
\hline A3 & 4.15 & 7.69 & 2569 & 634 & 91 & 82 & 50 & 7 & 5.19 & 1.63 & 0.081 & 0.121 & 0.068 & 0.0035 & 2230 & 700 & 35 & 52 & 29 & 1.5 \\
\hline B1 & 4.37 & 8.73 & 2347 & 892 & 173 & 18 & 21 & 7 & 3.34 & 1.74 & 0.113 & 0.028 & 0.026 & 0.0042 & 1437 & 747 & 49 & 12 & 11 & 1.8 \\
\hline B2 & 4.54 & 9.14 & 2350 & 1633 & 123 & 25 & 0 & 2 & 3.23 & 3.22 & 0.074 & 0.025 & 0.000 & 0.0006 & 1387 & 1383 & 32 & 11 & 0 & 0.3 \\
\hline B3 & 4.24 & 8.90 & 2316 & 527 & 145 & 17 & 0 & 1 & 3.17 & 1.03 & 0.087 & 0.017 & 0.000 & 0.0004 & 1363 & 442 & 37 & 7 & 0 & 0.2 \\
\hline B4 & 3.98 & 9.00 & 2376 & 372 & 168 & 14 & 1 & 1 & 3.21 & 0.74 & 0.099 & 0.014 & 0.001 & 0.0005 & 1380 & 317 & 43 & 6 & 0 & 0.2 \\
\hline B5 & 3.85 & 8.91 & 2426 & 257 & 173 & 14 & 2 & 1 & 3.27 & 0.51 & 0.102 & 0.014 & 0.002 & 0.0004 & 1405 & 217 & 44 & 6 & 1 & 0.2 \\
\hline B6 & 4.02 & 9.08 & 2461 & 278 & 149 & 24 & 0 & 2 & 3.34 & 0.55 & 0.088 & 0.024 & 0.000 & 0.0006 & 1438 & 238 & 38 & 10 & 0 & 0.3 \\
\hline C1 & 3.48 & 7.46 & 1060 & 785 & 79 & 110 & 58 & 2 & 2.06 & 1.98 & 0.067 & 0.155 & 0.075 & 0.0009 & 887 & 850 & 29 & 67 & 32 & 0.4 \\
\hline $\mathrm{C} 2$ & 3.12 & 7.37 & 900 & 517 & 75 & 113 & 55 & 2 & 1.72 & 1.29 & 0.063 & 0.155 & 0.069 & 0.0008 & 738 & 556 & 27 & 67 & 30 & 0.3 \\
\hline C3 & 2.60 & 7.33 & 811 & 458 & 75 & 120 & 37 & 2 & 1.50 & 1.14 & 0.061 & 0.161 & 0.045 & 0.0007 & 644 & 490 & 26 & 69 & 20 & 0.3 \\
\hline $\mathrm{C} 4$ & 3.24 & 7.68 & 713 & 430 & 71 & 130 & 38 & 2 & 1.37 & 1.10 & 0.063 & 0.222 & 0.047 & 0.0011 & 589 & 472 & 27 & 95 & 20 & 0.5 \\
\hline C5 & 3.79 & 8.61 & 664 & 367 & 63 & 107 & 37 & 1 & 1.31 & 1.01 & 0.055 & 0.153 & 0.049 & 0.0005 & 565 & 434 & 24 & 66 & 21 & 0.2 \\
\hline D1 & 3.60 & 9.11 & 756 & 377 & 138 & 26 & 12 & 2 & 1.02 & 0.75 & 0.081 & 0.026 & 0.011 & 0.0006 & 437 & 323 & 35 & 11 & 5 & 0.3 \\
\hline D2 & 3.46 & 8.80 & 775 & 422 & 115 & 46 & 0 & 1 & 1.03 & 0.82 & 0.067 & 0.044 & 0.000 & 0.0005 & 444 & 352 & 29 & 19 & 0 & 0.2 \\
\hline D3 & 3.56 & 8.72 & 536 & 293 & 113 & 50 & 16 & 1 & 0.72 & 0.56 & 0.067 & 0.048 & 0.014 & 0.0004 & 310 & 242 & 29 & 21 & 6 & 0.2 \\
\hline D4 & 4.02 & 8.48 & 112 & 31 & 125 & 92 & 25 & 1 & 0.15 & 0.06 & 0.075 & 0.091 & 0.022 & 0.0004 & 66 & 25 & 32 & 39 & 10 & 0.2 \\
\hline E1 & 4.23 & 8.58 & 107 & 6 & 57 & 104 & 19 & 2 & 0.15 & 0.01 & 0.036 & 0.105 & 0.017 & 0.0007 & 64 & 5 & 15 & 45 & 7 & 0.3 \\
\hline E2 & 4.34 & 8.59 & 416 & 130 & 0 & 60 & 0 & 1 & 0.58 & 0.25 & 0.000 & 0.061 & 0.000 & 0.0004 & 251 & 108 & 0 & 26 & 0 & 0.2 \\
\hline E3 & 2.54 & 7.29 & 536 & 245 & 1 & 23 & 0 & 1 & 0.74 & 0.45 & 0.000 & 0.022 & 0.000 & 0.0004 & 316 & 194 & 0 & 10 & 0 & 0.2 \\
\hline
\end{tabular}



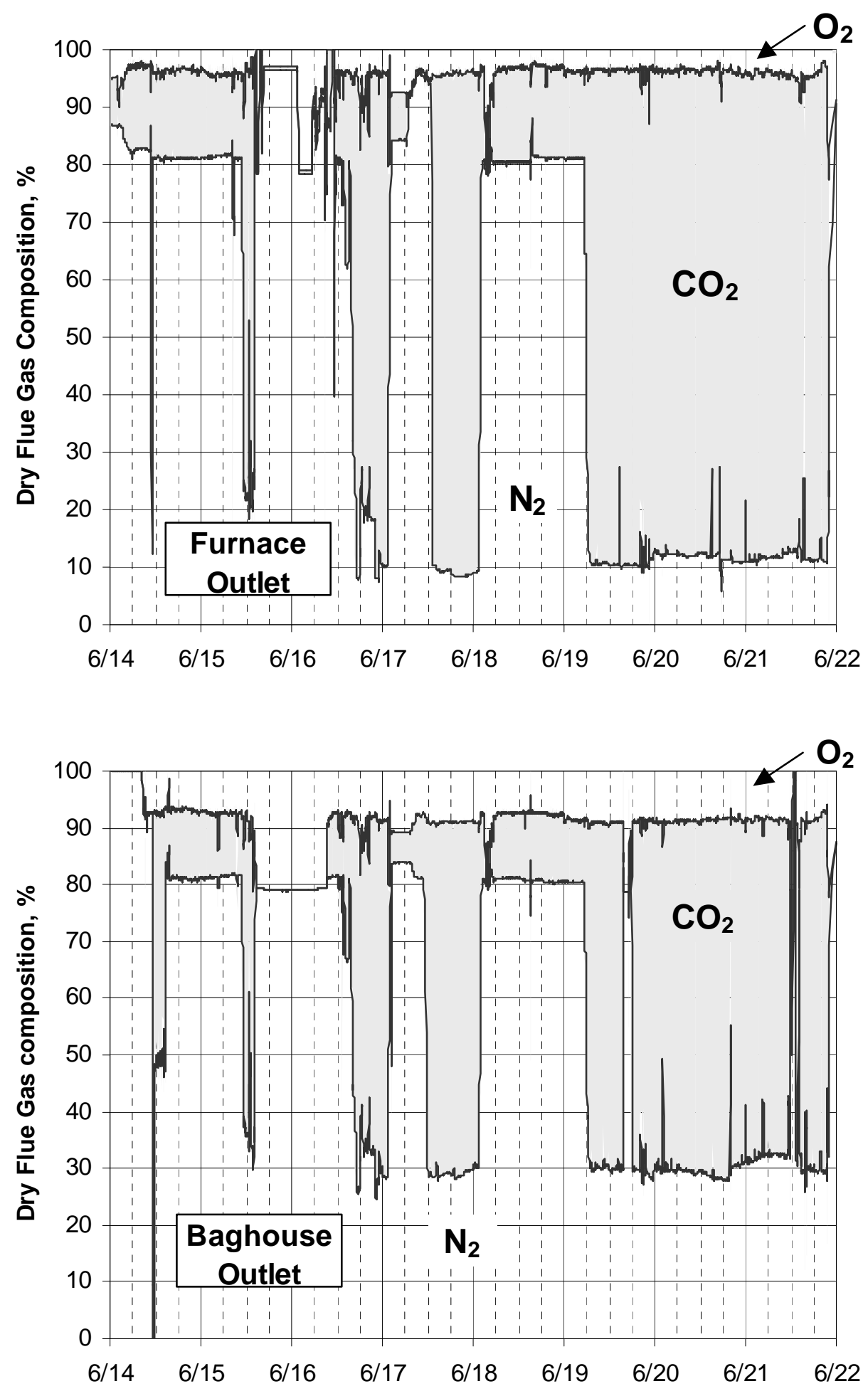

Figure 3.21: Flue Gas Composition at Furnace and Baghouse Outlets 


\section{Correcting for Excess Oxygen and Air Leakage}

The gaseous pollutants $\mathrm{SO}_{2}, \mathrm{CO}, \mathrm{NO}_{\mathrm{x}}, \mathrm{N}_{2} \mathrm{O}$, and $\mathrm{THC}$ are measured as volume (or molar) concentration in a dried flue gas. Obviously the concentration depends upon any change in the volume of the flue gas due to excess combustion air or air in-leakage. It is common to normalize the measured concentration to a fixed level of excess air - that is, a fixed level of oxygen in the flue gas. It is typical in the U.S. to express the concentration as parts per million (ppmv) at 3\% oxygen in the flue gas on a dry basis. The conversion factor is based on the fact that the excess air contains $21 \%$ oxygen:

ppmv@3\% $\mathrm{O}_{2}=$ ppmv measured*(21 - 3)/ (21 - \% $\mathrm{O}_{2}$ measured $)$

For example, if we measure 100 ppmv $\mathrm{CO}$ at $5 \% \mathrm{O}_{2}$ in the flue gas, the value normalized to $3 \% \mathrm{O}_{2}$ is $100 *(18) /(21-5)=112.5 \mathrm{ppmv}$. Other common bases are $6 \% \mathrm{O}_{2}$ and $15 \%$ $\mathrm{O}_{2}$ - the latter used for gas turbines which operate with high excess air.

It is sometimes useful to relate the emission level to the energy content of the fuel - e.g., the pounds of pollutant emitted per million Btu of fuel heating value fired (lb/MMBtu). The conversion to this unit is a two step process:

3. Normalize the concentration value to zero percent oxygen - stoichiometric combustion with no excess air,

4. Convert to $\mathrm{lb} / \mathrm{MMBtu}$ using the calculated volume of stoichiometric flue gas generated per MMBtu fired.

The stoichiometric flue gas per MMBtu can be calculated from the fuel analysis or standard values may be used.

The situation with oxygen firing is more complicated. Excess oxygen, which is in the flue gas, may have come from excess oxidant (pure oxygen or a mixture of $\mathrm{O}_{2}$ and $\mathrm{CO}_{2}$ ) or it may have come from air in-leakage. Since the two sources have different oxygen contents, there are two different normalizations needed. It is necessary to know how much of each source there is.

This was done by determining the nitrogen content of the flue gas. In 2004, the $\mathrm{N}_{2}$ was measured with a gas chromatograph. These results confirmed a good match with nitrogen calculated as $\% \mathrm{~N}_{2}=100-\% \mathrm{CO}_{2}-\% \mathrm{O}_{2}$, so no gas chromatograph was used in these tests. The fuel burned in $\mathrm{O}_{2} / \mathrm{CO}_{2}$ with no excess oxidant and no air leakage will have a small expected nitrogen content from the fuel nitrogen. Any additional $\mathrm{N}_{2}$ in the flue gas is assumed to come from air leakage. Knowing the air leakage and its oxygen content $(21 \%)$ allows us to determine how much additional oxygen is in the flue gas from excess $\mathrm{O}_{2} / \mathrm{CO}_{2}$ oxidant.

Table 3.12 includes the conversion to $\mathrm{lb} / \mathrm{MMBtu}$ for the average of each test condition and the similar conversion for gm/GJ. Per customary usage, MMBtu is based on a higher heating value and GJ on lower heating value.

To compare emission rates with air and oxygen firing, the heat input bases are most useful - lb/MMBtu or $\mathrm{g} / \mathrm{GJ}$. This may be especially relevant for non-condensables such as $\mathrm{CO}$ and $\mathrm{NO}_{\mathrm{x}}$, which may be vented from the high- $\mathrm{CO}_{2}$ gas produced. In the case of $\mathrm{SO}_{2}$, which may be retained in the $\mathrm{CO}_{2}$ product, the product specification may in fact be in ppmv. 


\subsubsection{Sulfur Emissions and Backend Capture}

The level of sulfur capture and the resultant emissions depend on many factors, including

- fuel - sulfur content, ash content, calcium in the ash, and fuel rank/reactivity.

- $\quad$ sorbent - feed rate ( $\mathrm{Ca}: \mathrm{S}$ ratio), reactivity, and size.

- furnace design and operating conditions - especially temperature, solids inventory, and extent of "air" staging.

The $\mathrm{SO}_{2}$ emissions seen in the pilot plant or in a commercial unit do respond quickly to changes in any of these parameters. The composition of the furnace solids inventory is also important; this changes much more slowly so it can take many hours to reach a new steady state point after a change. None of the results from these short pilot tests can be assumed to quantitatively apply to long-term commercial operation.

Figure 3.22 shows the ppmv $\mathrm{SO}_{2}$ into and out of the baghouse, along with the sorbent being fed.

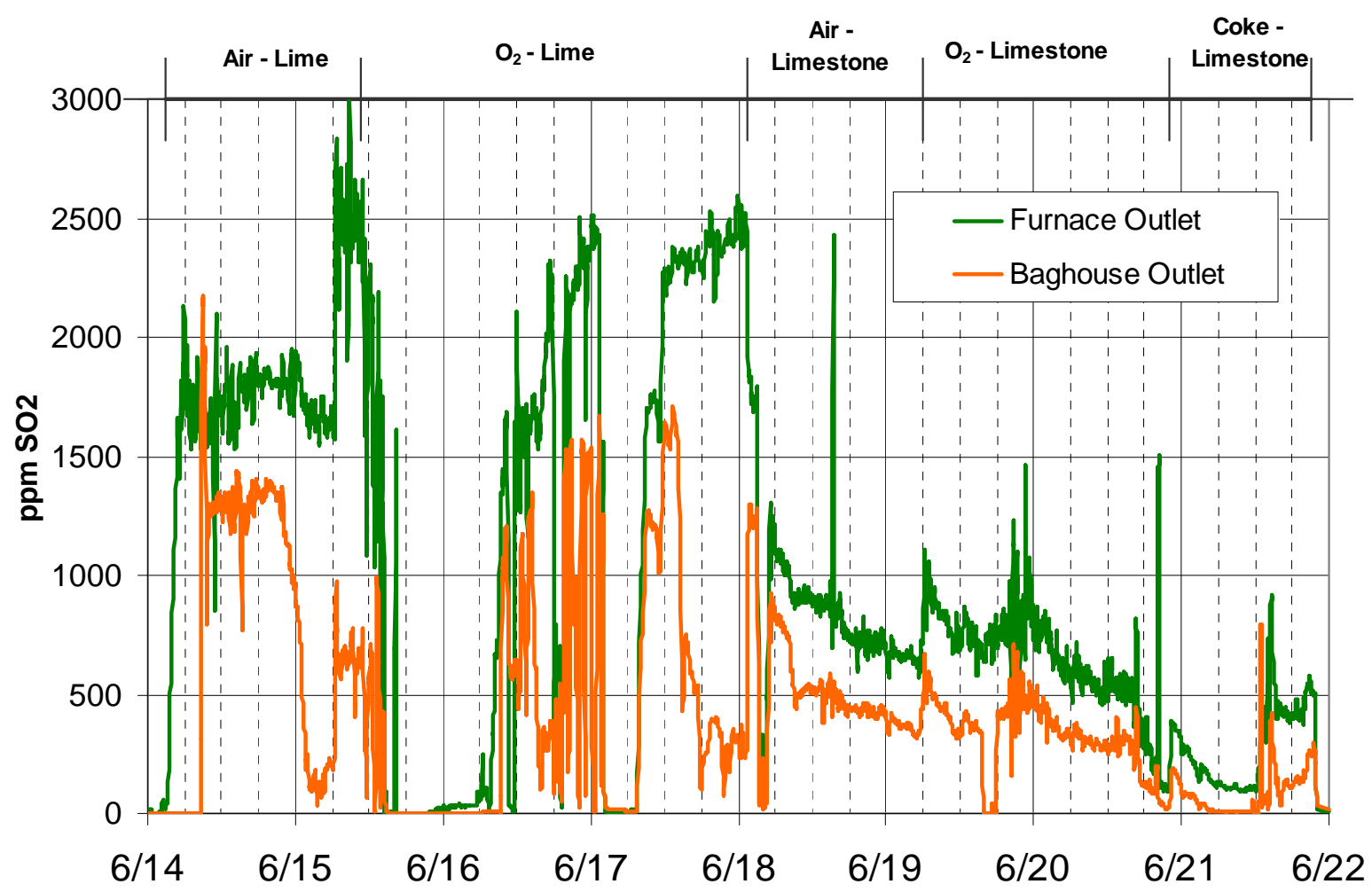

Figure 3.22: $\mathrm{SO}_{2}$ Emissions in ppmv

As discussed in the preceding section, the ppmv changes when oxygen firing. For example, at 6:00 AM on 6/19 we switched from air to oxy-firing. The ppmv $\mathrm{SO}_{2}$ jumped up. Not because of more sulfur emitted, but rather because of less dilution $\left(30 \% \mathrm{O}_{2}\right.$ in $\mathrm{CO}_{2}$ vs $21 \% \mathrm{O}_{2}$ in $\mathrm{N}_{2}$ ). Figure 3.23, which shows the emissions in lb/MMBtu, eliminates this effect. 


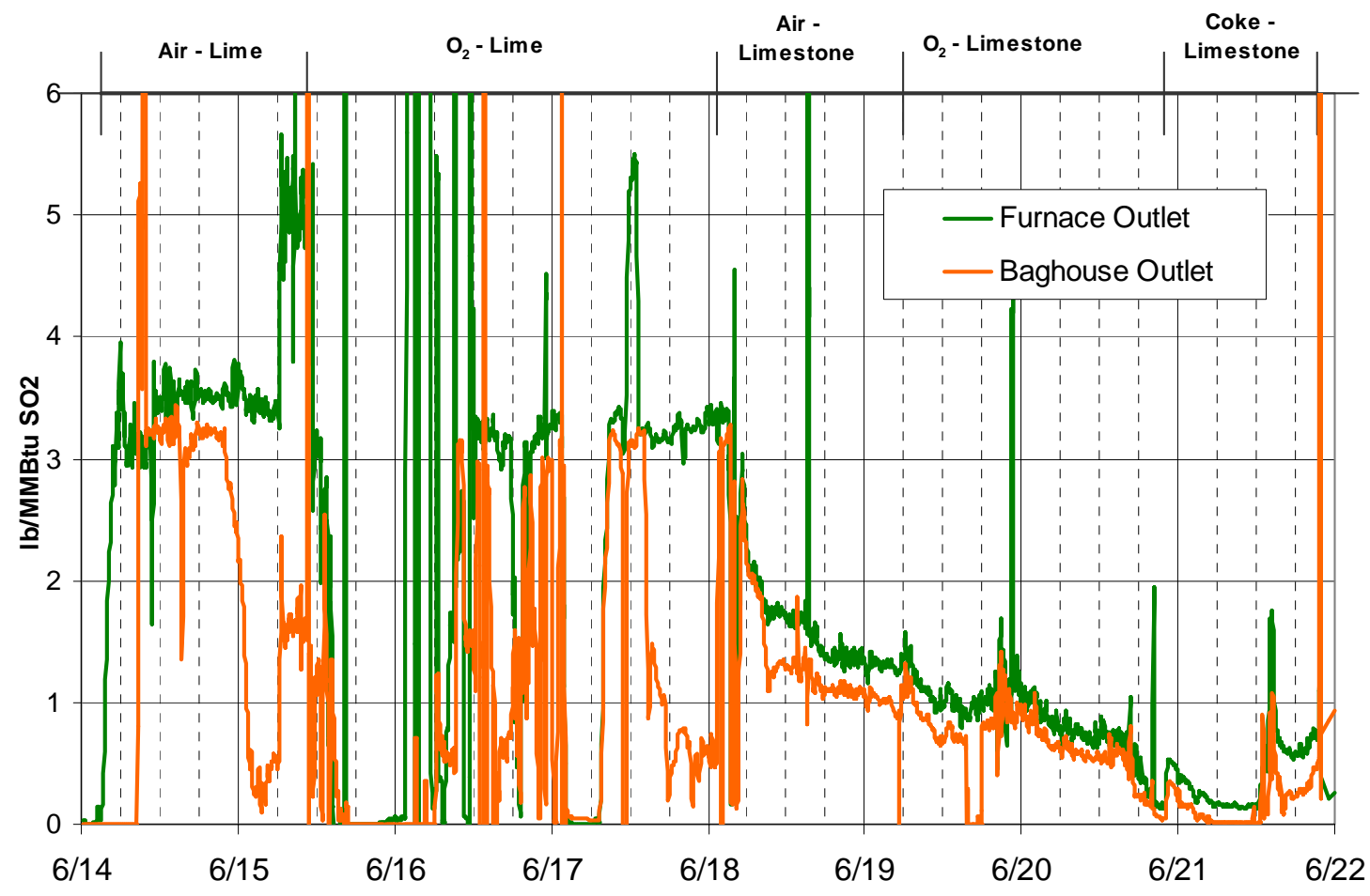

Figure 3.23: $\mathrm{SO}_{2}$ Emissions in Ib/MMBtu

Figure 3.24 gives a summary of the $\mathrm{SO}_{2}$ emissions from the furnace and the baghouse for each defined test point. 

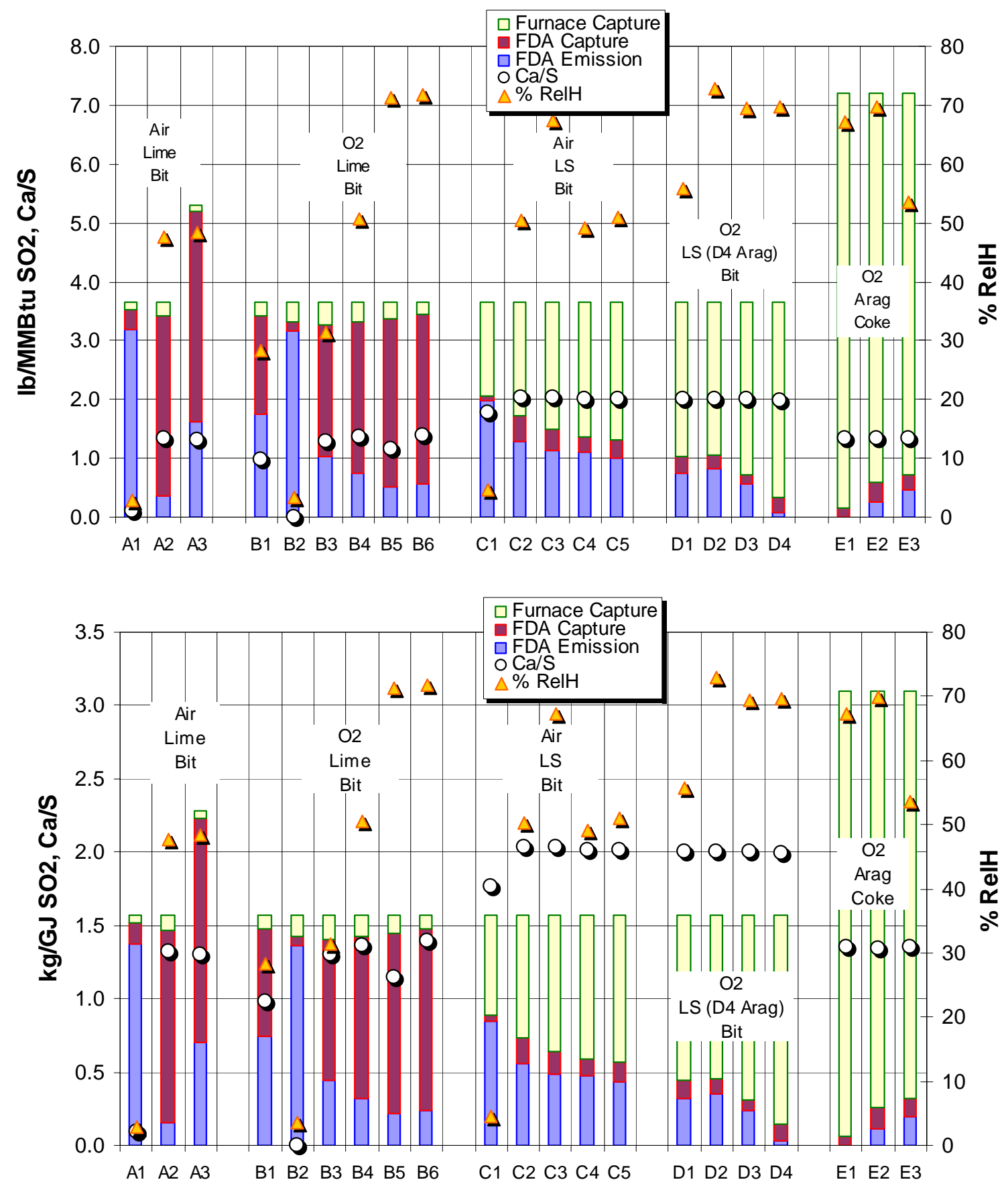

Figure 3.24: Summary of $\mathrm{SO}_{2}$ Emissions

The overall height of each bar is the uncontrolled $\mathrm{SO}_{2}$ emissions (based on the sulfur in the fuel). The top, yellow, bar represents the sulfur capture in the furnace; the middle, red, bar is the sulfur capture in the FDA.

Test Points A1-A3 were obtained while firing Tri-Star medium volatile bituminous coal in air. No limestone was fed to the furnace, hydrated lime was injected into the FDA at the $\mathrm{Ca} / \mathrm{S}$ molar ratios of 1.0 to 1.4 . Test Points B1-B6 were obtained similarly to Test 
Points A1-A-3, except that the combustion medium was $\mathrm{O}_{2} / \mathrm{CO}_{2}$, instead of air. The purpose of these two test series was to capture sulfur only in the baghouse/FDA. Results from these two test series indicate the following (see Figure 3.25):

- In-furnace sulfur captures were very low (about $2 \%$ to $13 \%$ ). The inherent $\mathrm{Ca} / \mathrm{S}$ mole ratio of the bituminous coal is roughly 0.1 , which may acccount for some sulfur capture by the coal ash in the furnace.

- In Test Series B, the sulfur capture in the FDA increased as the relative humidity increased from 30 to 50 to $70 \%$.

- Comparing Test Point A2 and B4, which were at approximately the same relative humidity in the FDA, one sees that overall sulfur capture was better for air firing than for $\mathrm{O}_{2} / \mathrm{CO}_{2}$ firing ( $90 \%$ vs. $80 \%$ ), respectively. However, increasing the relative humidity from about $50 \%$ to $70 \%$ yielded sulfur capture of almost $90 \%$ for $\mathrm{O}_{2} / \mathrm{CO}_{2}$ firing.

Test Points C1-C5 were obtained while firing Tri-Star medium volatile bituminous coal in air. ATF40 limestone was injected into the furnace at a $\mathrm{Ca} / \mathrm{S}$ mole ratio of 1.8-2.0, and the FDA was operated in a classical manner (i.e., water was injected into it to set the relative humidity at a given value). Test Points D1-D3 were obtained similarly to Test Points C1-C5, except that the combustion medium was $\mathrm{O}_{2} / \mathrm{CO}_{2}$, instead of air. Test Point D4 was run consistent with Test Points D1-D3, but with Aragonite, instead of ATF40 limestone. The purpose of these two test series was to evaluate sulfur capture in-furnace and across the FDA. Figure 3.25 shows:

- In-furnace sulfur capture was better for $\mathrm{O}_{2} / \mathrm{CO}_{2}$ firing than for air firing. This may be partly due to the lower velocity - thus longer gas residence time - with oxyfiring (see Figure 3.20). It may also be a continuation of the trend of increasing sulfur capture as calcium accumulates in the bed inventory.

- Sulfur capture across the baghouse/FDA for $\mathrm{O}_{2} / \mathrm{CO}_{2}$ firing was similar to that for air firing. Because of the better capture in the furnace, the $\mathrm{SO}_{2}$ concentration entering the baghouse was lower with oxy-firing. The percentage reduction across the baghouse was similar (Figure 3.25), though the absolute sulfur retention was lower with oxy-firing.

- With either air or oxygen firing, the sulfur capture in the FDA with limestone did not appear to be higher at $70 \%$ relative humidity compared to $50 \%$.

- Because of the increased capture in the furnace, overall sulfur capture was better for $\mathrm{O}_{2} / \mathrm{CO}_{2}$ firing that for air firing.

- Over 95\% overall sulfur capture was achieved with the more reactive Aragonite.

Test Points E1-E3 were obtained while firing the petcoke in $\mathrm{O}_{2} / \mathrm{CO}_{2}$. Aragonite was injected into the furnace at a $\mathrm{Ca} / \mathrm{S}$ mole ratio of 2 and 1.4. Overall sulfur capture was better than for bituminous coal firing under similar circumstances: the capture was $94 \%$ and $97-100 \%$ at relative humidities of $50 \%$ and $70 \%$, respectively. 

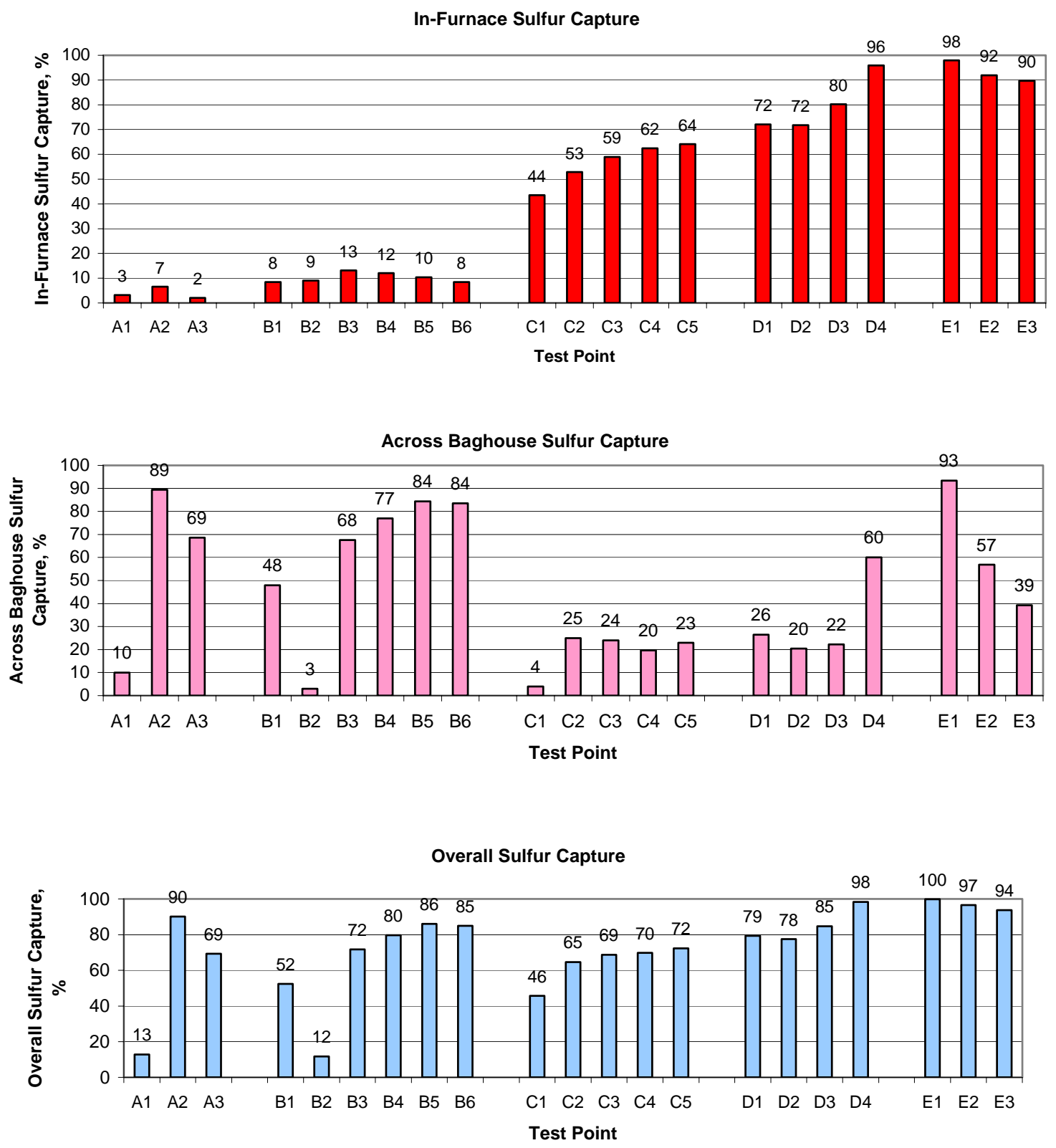

Figure 3.25: Percent Sulfur Capture Data 


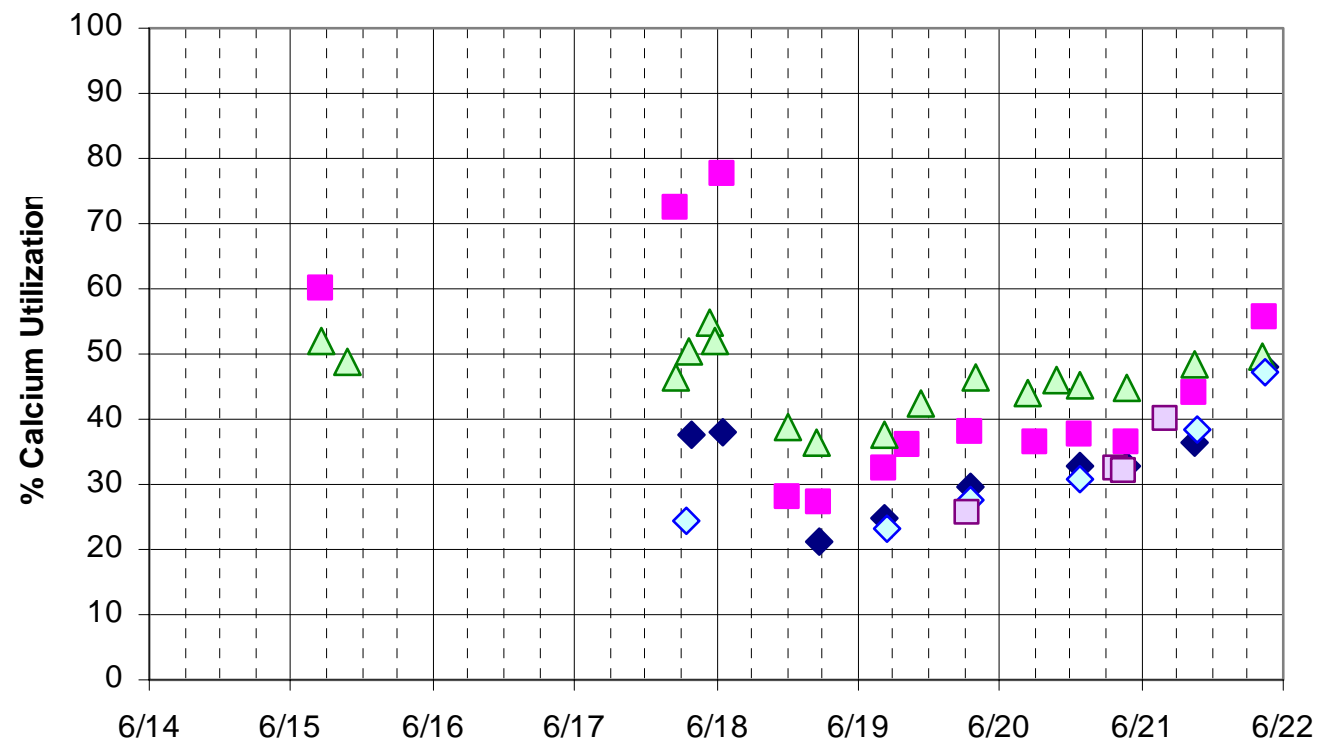

Figure 3.26: Calcium Utilization of Ash Samples

The calcium utilization of selected ash samples is shown in Figure 3.26.

Prior to about 3:00 AM on 6/18 there was no limestone to the furnace, so utilization of the samples taken at the cyclone outlet (HV), the cyclone inlet (XO) and fluid bed heat exchanger (FB) is based only on the small amount of inherent calcium in the coal ash. The calcium in the lime fed to the baghouse was about $50 \%$ utilized, with both air firing (6/15) and oxygen firing (6/17-18).

Once limestone was fed to the furnace, the utilization of the baghouse ash is greater than the ash entering the baghouse. This is expected - the FDA is making use of calcium in the fly ash. The exception is the last point in the utilization chart. When we switched to pet coke at 23:00 on 6/20, the utilization in the furnace went up. This shows up quickly in the high volume ash. The FDA still captures additional sulfur (see Figure 3.24), but the baghouse drain sample utilization lags behind because of the large inventory of baghouse ash.

\subsubsection{Recarbonation}

Many of the solids samples from the pilot tests were analyzed for $\mathrm{CO}_{2}$, which is assumed to have been present as $\mathrm{CaCO}_{3}$. The amount of calcium carbonate as a percentage of the total calcium in each sample is shown as \% Recarbonation in Table 3.9 and Table 3.10. This is shown in Figure 3.27. The crossover (XO) and fluid bed heat exchanger (FB) samples are circulating material, which stays in the furnace generally above the calcination temperature; they have a low level of carbonate in the ash. The bed drain material (BD) has a higher level of recarbonation. This is likely due to some of the limestone feed being drained from the bottom of the furnace before it has a chance to completely calcine. 
$\bullet \mathrm{XO} \square \mathrm{HV} \triangle \mathrm{BH} \diamond \mathrm{FB} \square \mathrm{BD}$

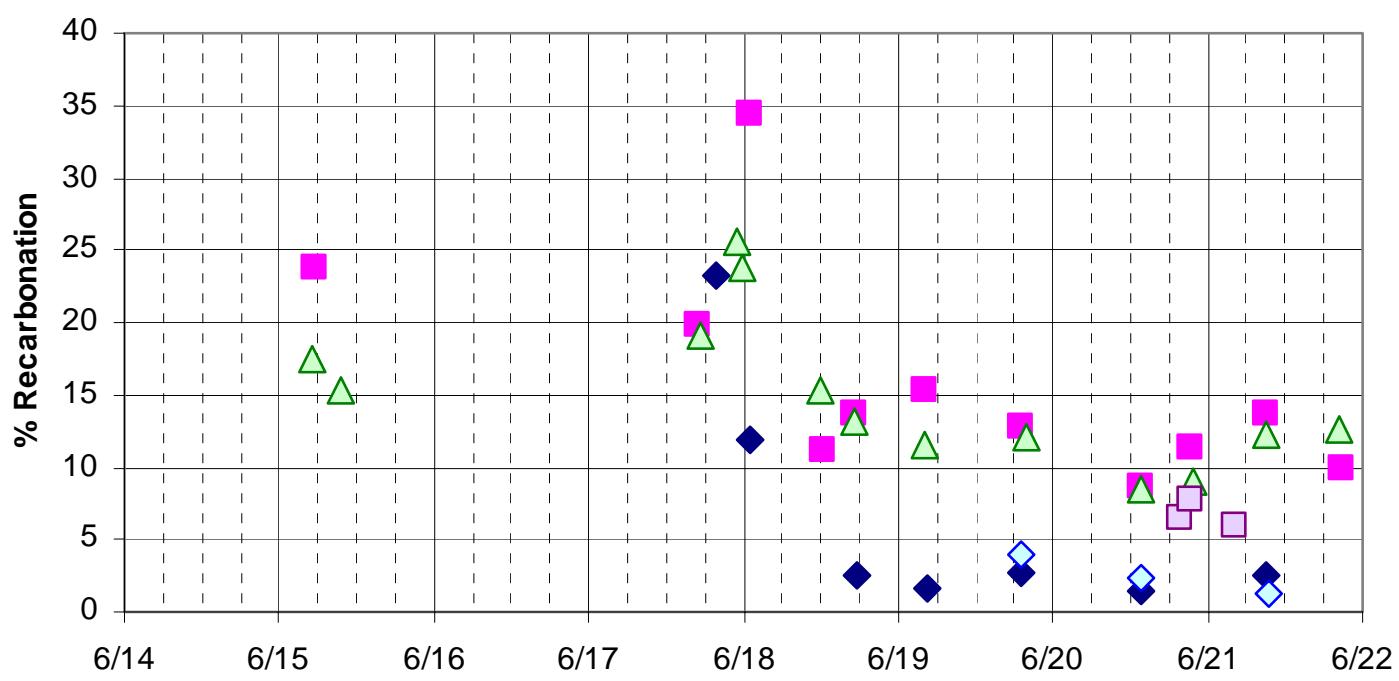

Figure 3.27: Recarbonation of Solids Samples

The high volume fly ash samples (HV) were taken at a point where the flue gas had cooled to below the calcination temperature - generally $540-600^{\circ} \mathrm{C}\left(1000\right.$ to $\left.1100^{\circ} \mathrm{F}\right)$. These samples show a higher level of recarbonation. Fly ash samples taken from the baghouse have similar levels of recarbonation during the second part of the test week with limestone fed to the furnace. This implies that no further recarbonation is taking place in the baghouse. That is, $\mathrm{CO}_{2}$ is not competing with $\mathrm{SO}_{2}$ for reacting with calcium in the FDA system.

Earlier in the week with lime fed to the baghouse, this lime had a higher level of recarbonation. According to the feed analysis (Table 3.5), the hydrated lime has about $10 \%$ carbonation expressed a percent of total calcium. So an additional 5 to $15 \%$ of the calcium is recarbonated in the baghouse. With lime, there does seem to be the potential for $\mathrm{CO}_{2}$ competing with $\mathrm{SO}_{2}$ for the calcium in the FDA system.

It should be noted that recarbonation of the fly ash is possible in air-fired boilers as well, where recarbonation levels of up to $10 \%$ have been seen.

\subsection{8 $\quad \mathrm{NO}_{\mathrm{x}}$ Emissions}

Typical $\mathrm{NO}_{\mathrm{x}}$ emissions from air-fired tests in the MTF pilot plant are in the range of 30 to $65 \mathrm{~g} / \mathrm{GJ}$ (0.07 to $0.15 \mathrm{lb} / \mathrm{MMBtu})$ fired. Results from air firing and $\mathrm{O}_{2} / \mathrm{CO}_{2}$ firing were as follows (see Figure 3.28):

- During Tri-Star medium volatile bituminous coal firing in air, without injecting limestone into the furnace (Test Point Series A): 43-52 g/GJ (0.1-0.12 lb/MMBtu)

- During Tri-Star medium volatile bituminous coal firing in $\mathrm{O}_{2} / \mathrm{CO}_{2}$, without injecting limestone into the furnace (Test Point Series B): 6-12 g/GJ (0.014-0.028 $\mathrm{lb} / \mathrm{MMBtu})$

- During Tri-Star medium volatile bituminous coal firing in air, while injecting 
limestone into the furnace (Test Point Series C): 64-95 g/GJ (0.15-0.22 lb/MMBtu)

- During Tri-Star medium volatile bituminous coal firing in $\mathrm{O}_{2} / \mathrm{CO}_{2}$, while injecting limestone into the furnace (Test Point Series D): 11-39 g/GJ (0.026-0.091 lb/MMBtu)

- During petcoke firing in $\mathrm{O}_{2} / \mathrm{CO}_{2}$, while injecting limestone into the furnace (Test Point Series E): 9-47 g/GJ (0.022-0.11 lb/MMBtu)

These results underscore important information, namely:

- $\mathrm{NO}_{\mathrm{x}}$ emissions under oxygen firing were consistently more than $60 \%$ lower than during air firing of the bituminous coal

- $\mathrm{NO}_{\mathrm{x}}$ emissions under either air firing or oxygen firing were higher while injecting limestone into the furnace than while not injecting limestone into the furnace. This is due to the known catalytic effect of calcined limestone on $\mathrm{NO}_{\mathrm{x}}$ emissions.

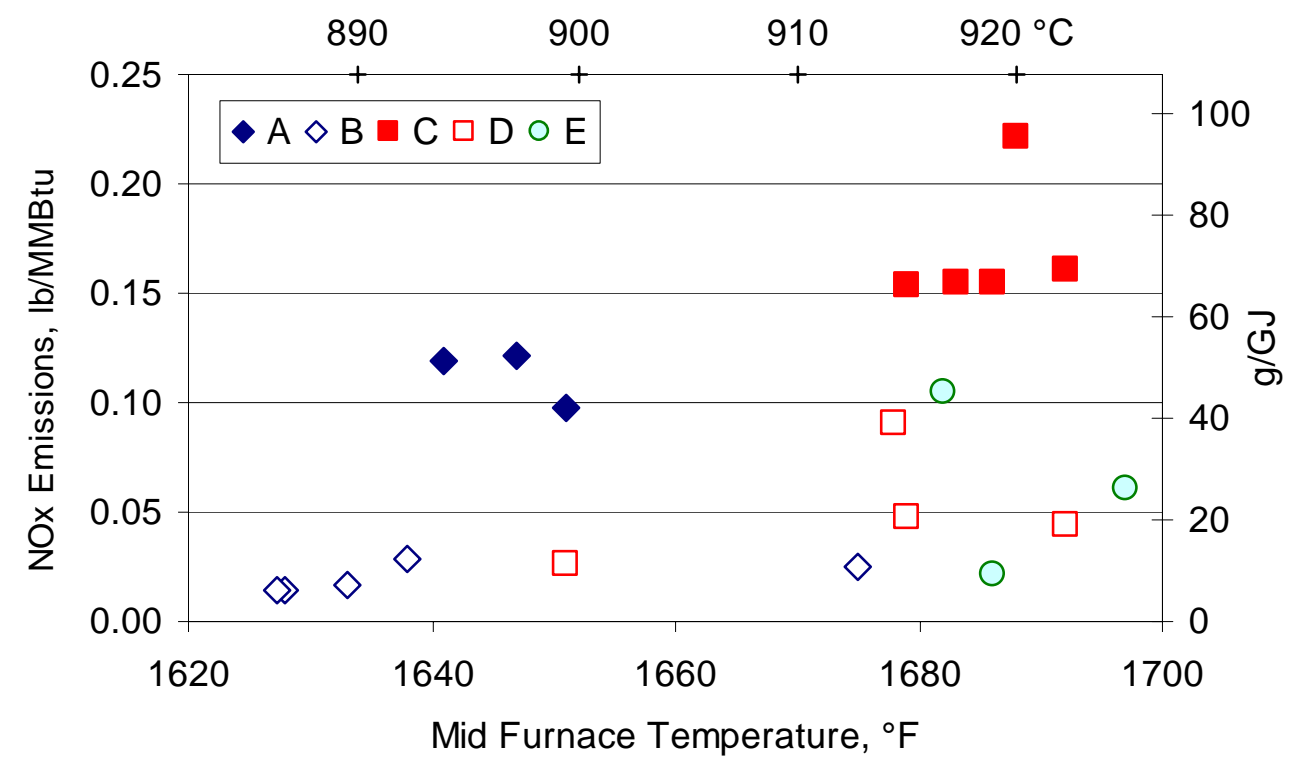

Figure 3.28: $\mathrm{NO}_{\mathrm{x}}$ Emissions vs. Mid Furnace Temperature

\section{SNCR with Ammonia Addition}

Although the $\mathrm{NO}_{\mathrm{x}}$ emissions are low with $\mathrm{O}_{2}$ firing, we did two tests with ammonia injection into the furnace outlet.

The first test was the morning of June 20 firing Tri-Star mvb coal (Figure 3.29). Before injecting ammonia, the $\mathrm{NO}_{\mathrm{x}}$ level was about $50 \mathrm{ppmv}(0.05 \mathrm{lb} / \mathrm{MMBtu})$. At this low $\mathrm{NO}_{\mathrm{x}}$ level, the lowest ammonia feed rate we could get was an NSR of about 3. (NSR is the normal stoichiometric ratio of ammonia to NOx.) Over the course of three hours, the ammonia feed was increased to as high as NSR of 14 . The $\mathrm{NO}_{\mathrm{x}}$ dropped by about $40 \%$ to 30 ppmv. The NSR of 14 is much higher than typically used commercially and may have led to high ammonia slip (which was not measured at the MTF). 


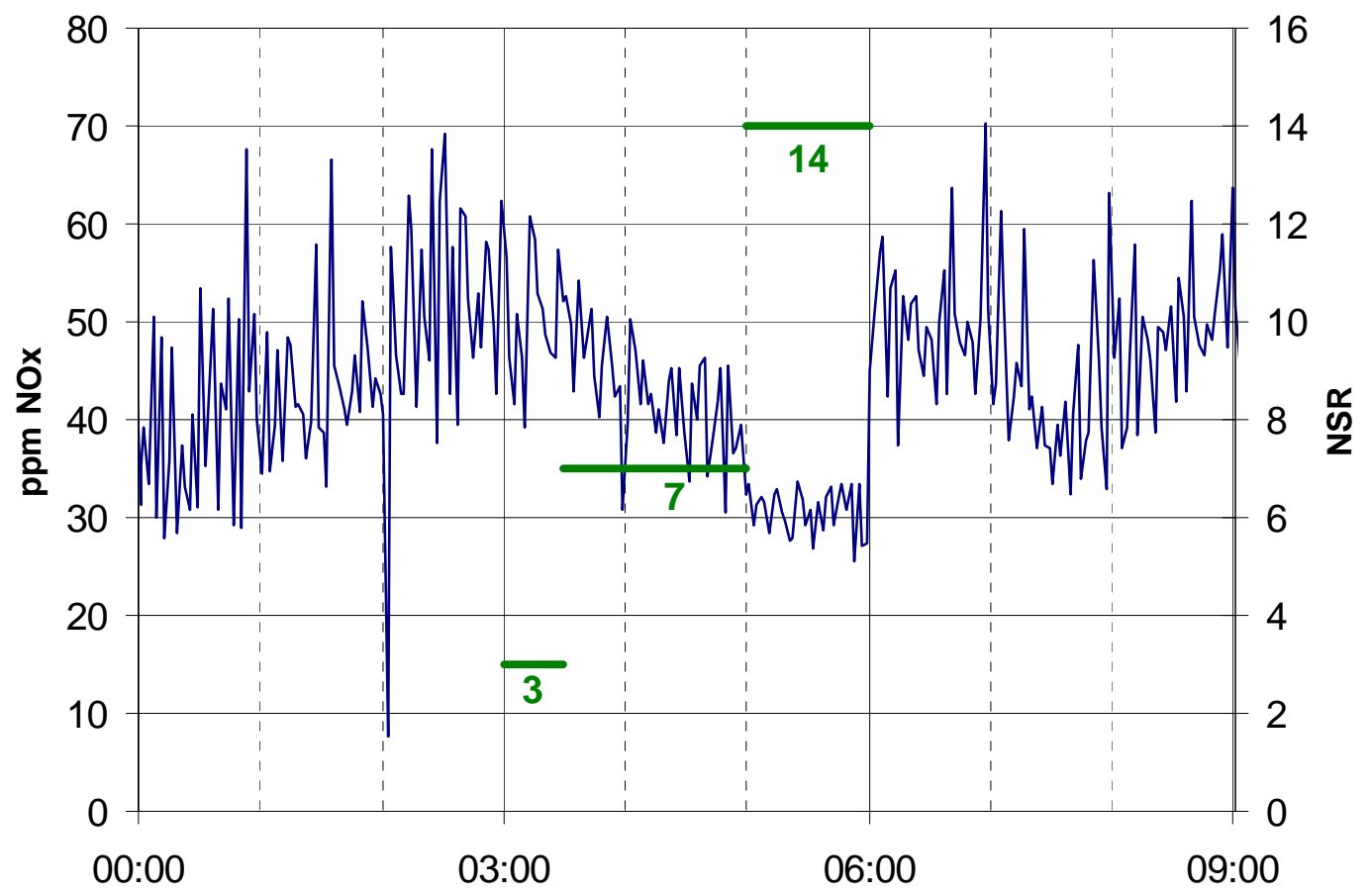

Figure 3.29: SNCR test with Bituminous and Oxygen Firing

The second test was early in the pet coke firing when the $\mathrm{NO}_{\mathrm{x}}$ level was about 100 ppmv $(0.1 \mathrm{lb} / \mathrm{MMBtu})$. With this higher baseline $\mathrm{NO}_{\mathrm{x}}$, a reduction of about $50 \%$ was achieved at an NSR of 3.4 (Figure 3.30).

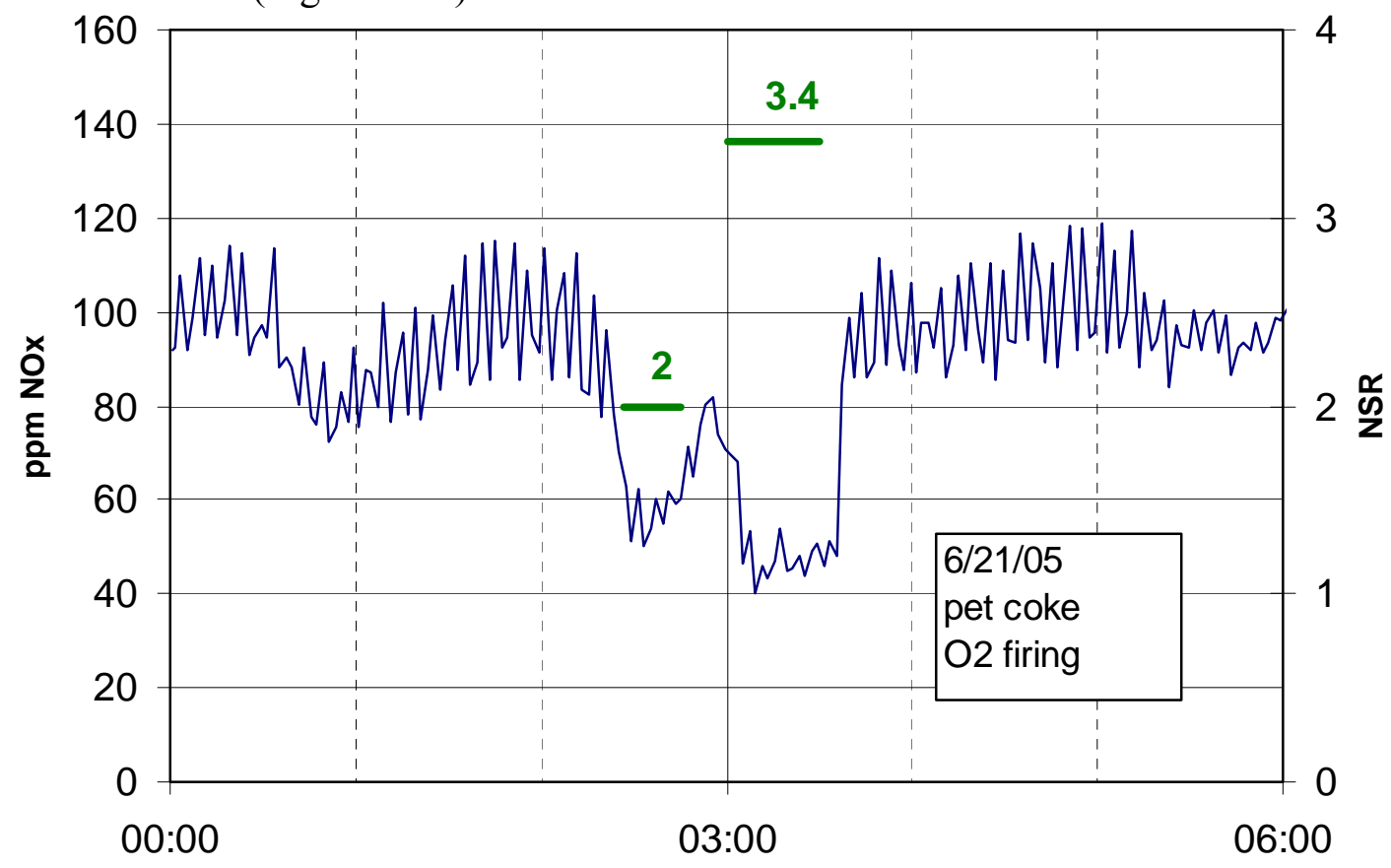

Figure 3.30: SNCR Test with Pet Coke and Oxygen Firing 
These results indicate that ammonia injection into the top of the furnace can achieve $\mathrm{NO}_{\mathrm{x}}$ reductions in the high $\mathrm{CO}_{2}$ environment. When the base emissions are already low, high ammonia flows may be needed to obtain meaningful reductions. Ammonia slip will be a concern - this was not measured. SNCR may be more useful with somewhat higher base emissions.

\subsubsection{CO Emissions}

Carbon monoxide emissions depend strongly on fuel type and on furnace temperature. A medium volatile coal like the Tri-Star would typically be expected to have a $\mathrm{CO}$ emission rate of less than $43 \mathrm{~g} / \mathrm{GJ}(0.1 \mathrm{lb} / \mathrm{MMBtu})$. Petroleum coke generally has lower $\mathrm{CO}$ emissions than coal.

$\mathrm{CO}$ results from air firing and $\mathrm{O}_{2} / \mathrm{CO}_{2}$ firing in the present study were as follows (see Figure 3.31):

- During Tri-Star medium volatile bituminous coal firing in air, without injecting limestone into the furnace (Test Point Series A): 26-35 g/GJ (0.061-0.081 lb/MMBtu)

- During Tri-Star medium volatile bituminous coal firing in $\mathrm{O}_{2} / \mathrm{CO}_{2}$, without injecting limestone into the furnace (Test Point Series B): 39-47 g/GJ (0.09-0.11 $\mathrm{lb} / \mathrm{MMBtu})$

- During Tri-Star medium volatile bituminous coal firing in air, while injecting limestone into the furnace (Test Point Series C): 24-29 g/GJ (0.055-0.067 lb/MMBtu)

- During Tri-Star medium volatile bituminous coal firing in $\mathrm{O}_{2} / \mathrm{CO}_{2}$, while injecting limestone into the furnace (Test Point Series D): 29-35 g/GJ (00.067-.081 lb/MMBtu)

- During petcoke firing in $\mathrm{O}_{2} / \mathrm{CO}_{2}$, while injecting limestone into the furnace (Test Point Series E): 0-15 g/GJ (0.0-0.036 lb/MMBtu)

These results underscore important information, namely:

- $\mathrm{CO}$ emissions under oxygen firing were 25 to $45 \%$ higher during oxygen firing than during air firing of the bituminous coal. This is believed to be due to the high $\mathrm{CO}_{2}$ partial pressure (i.e., the reaction $\mathrm{CO}+\mathrm{O}_{2} \rightarrow \mathrm{CO}_{2}$ is suppressed). 


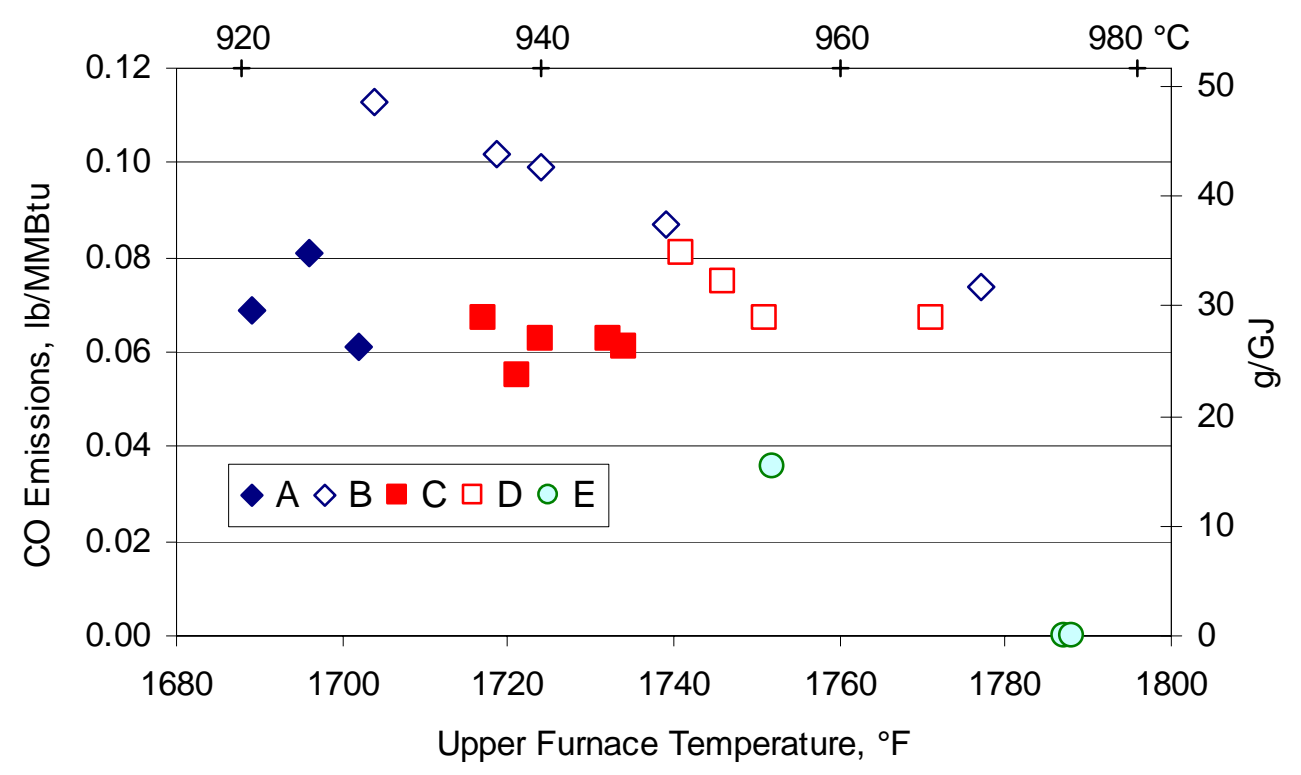

Figure 3.31: CO Emissions vs. Upper Furnace Temperature

\subsubsection{0 $\quad \mathrm{N}_{2} \mathrm{O}$ Emissions}

Nitrous oxide $\left(\mathrm{N}_{2} \mathrm{O}\right)$ is a greenhouse gas which is currently not regulated. Although $\mathrm{N}_{2} \mathrm{O}$ is released in much smaller quantities than $\mathrm{CO}_{2}$, it is a more potent greenhouse gas. $\mathrm{N}_{2} \mathrm{O}$ has roughly 300 times the global warming potential (GWP) of an equal mass of $\mathrm{CO}_{2}$.

$\mathrm{N}_{2} \mathrm{O}$ emissions are strongly dependent on temperature. Pulverized coal furnaces usually have well less than $4 \mathrm{~g} / \mathrm{GJ}(10 \mathrm{ppmv}) \mathrm{N}_{2} \mathrm{O}$ (normalized to $3 \% \mathrm{O}_{2}$ ). Fluid bed combustors, which operate much cooler, typically have from 18 to $36 \mathrm{~g} / \mathrm{GJ}$ (50 to $100 \mathrm{ppmv}$ ) (@3\% $\left.\mathrm{O}_{2}\right)$.

In previous MTF tests, ALSTOM has seen from 25 to $36 \mathrm{~g} / \mathrm{GJ}$ (70 to 100 ppmv) @3\% $3 \% \mathrm{O}_{2}$ when the upper furnace temperature is about $900^{\circ} \mathrm{C}\left(1650^{\circ} \mathrm{F}\right)$. This range is equal to about 43 to $56 \mathrm{~g} / \mathrm{GJ}(0.1$ to $0.13 \mathrm{lb} / \mathrm{MMBtu})$. The emissions in this study were generally lower (see Figure 3.32):

$\mathrm{N}_{2} \mathrm{O}$ results from air firing and $\mathrm{O}_{2} / \mathrm{CO}_{2}$ firing in the present study were as follows (see Figure 3-30):

- During Tri-Star medium volatile bituminous coal firing in air, without injecting limestone into the furnace (Test Point Series A): 22-29 g/GJ (.051-.068 lb/MMBtu)

- During Tri-Star medium volatile bituminous coal firing in $\mathrm{O}_{2} / \mathrm{CO}_{2}$, without injecting limestone into the furnace (Test Point Series B): 0.5-11 g/GJ (0.001-.026 lb/MMBtu)

- During Tri-Star medium volatile bituminous coal firing in air, while injecting limestone into the furnace (Test Point Series C): 19-32 g/GJ (0.045-0.075 $\mathrm{lb} / \mathrm{MMBtu})$

- During Tri-Star medium volatile bituminous coal firing in $\mathrm{O}_{2} / \mathrm{CO}_{2}$, while injecting 
limestone into the furnace (Test Point Series D): 0-9 g/GJ (00.0-0.022 lb/MMBtu)

- During petcoke firing in $\mathrm{O}_{2} / \mathrm{CO}_{2}$, while injecting limestone into the furnace (Test Point Series E): 0-7 g/GJ (0.0-0.017 lb/MMBtu)

In conclusion, $\mathrm{N}_{2} \mathrm{O}$ emissions were lower for $\mathrm{O}_{2}$ firing than for air firng.

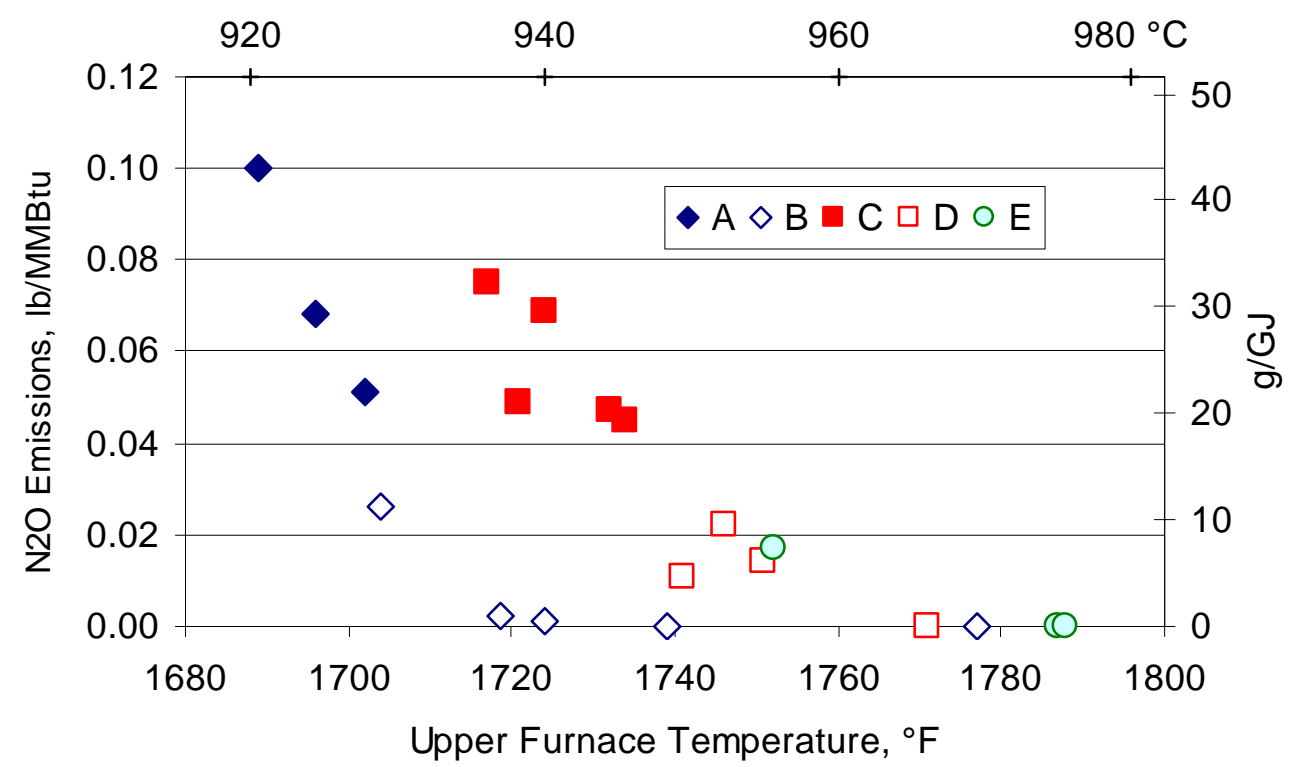

Figure 3.32: $\mathrm{N}_{2} \mathrm{O}$ Emissions vs. Upper Furnace Temperature

\subsubsection{VOC Emissions}

VOC results, expressed as total hydrocarbon (as methane) from air firing and $\mathrm{O}_{2} / \mathrm{CO}_{2}$ firing in the present study were as follows (see Figure 3.33):

- During Tri-Star medium volatile bituminous coal firing in air, without injecting limestone into the furnace (Test Point Series A): 0.5-1.5 g/GJ (0.0012-.0035 lb/MM Btu)

- During Tri-Star medium volatile bituminous coal firing in $\mathrm{O}_{2} / \mathrm{CO}_{2}$, without injecting limestone into the furnace (Test Point Series B): $<0.5 \mathrm{~g} / \mathrm{GJ}(0.0004-$ $0.0006 \mathrm{lb} / \mathrm{MMBtu})$

- During Tri-Star medium volatile bituminous coal firing in air, while injecting limestone into the furnace (Test Point Series C): $<0.5 \mathrm{~g} / \mathrm{GJ}(0.0005-0.0011$ lb/MMBtu)

- During Tri-Star medium volatile bituminous coal firing in $\mathrm{O}_{2} / \mathrm{CO}_{2}$, while injecting limestone into the furnace (Test Point Series D): $<0.5 \mathrm{~g} / \mathrm{GJ}(0.0004-0.0006$ lb/MMBtu)

- During petcoke firing in $\mathrm{O}_{2} / \mathrm{CO}_{2}$, while injecting limestone into the furnace (Test Point Series E): $<0.5 \mathrm{~g} / \mathrm{GJ}(.0004-0.0007 \mathrm{lb} / \mathrm{MMBtu})$. 
These results indicate that the VOC emissions during both air and $\mathrm{O}_{2} / \mathrm{CO}_{2}$ firing of the Tri-Star mvb coal and $\mathrm{O}_{2} / \mathrm{CO}_{2}$ firing of the petcoke were negligibly small.

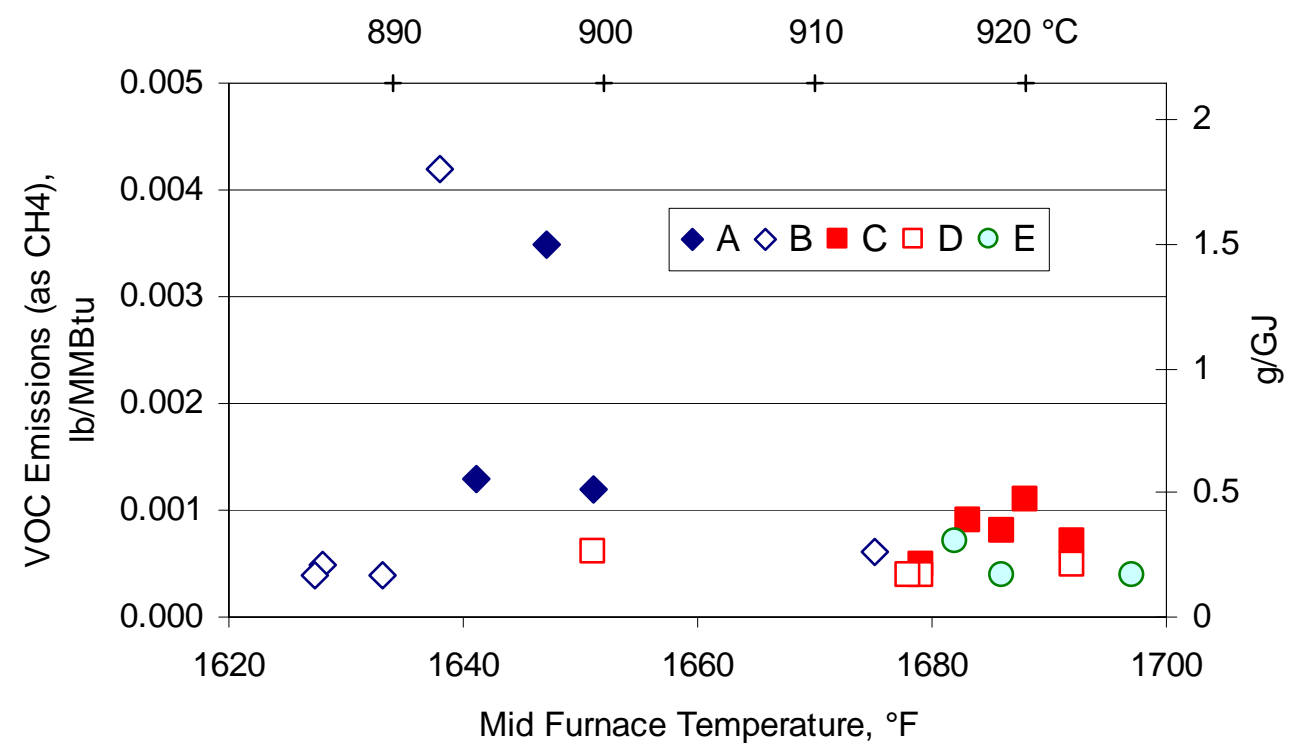

Figure 3.33: VOC vs. Mid Furnace Temperature

\subsubsection{Combustion Efficiencies/Unburned Carbon (UBC) Emissions}

The ash which results from the CFB combustion process usually contains some unburned carbon. This unburned carbon represents a heat loss, expressed as Carbon Heat Loss (CHL) which is the heating value of the unburned carbon as a percentage of the heating value of the parent fuel. Typical values for commercial CFB's are in the range of 1 to $2 \%$ of the heat input lost as unburned carbon. High and low reactivity fuels can deviate significantly from this range. Furnace temperature, excess air level, and cyclone capture efficiency also have large impacts on CHL.

The two main ash streams from the combustor are the bed drain and the fly ash, each of which contain some unburned carbon. The CHL in the fly ash is usually much larger than that in the bed drain.

The CHL in the fly ash is calculated by

$\mathrm{CHL}=\mathrm{UBC} *$ Flow $* 14,500 / \mathrm{Q}$ (percent of coal HHV)

Where:

$\mathrm{UBC}=\%$ unburned carbon in the fly ash

Flow $=$ fly ash flow rate, $(\mathrm{lb} / \mathrm{hr})$

$14,500=$ the heating value of the unburned carbon, $(\mathrm{Btu} / \mathrm{lb})$

$\mathrm{Q}=$ fuel firing rate, $(\mathrm{Btu} / \mathrm{hr}-\mathrm{HHV})$

The estimated values of carbon heat loss are given in Table 3.13 and Figure 3.34 for each of the fly ash and bed drain samples analyzed. The total carbon in the ash is corrected by 
deducting the carbon analyzed as $\mathrm{CO}_{2}$; this gives the unburned carbon. For several of the samples, the $\mathrm{CO}_{2}$ was not analyzed (note in Table 3.9 and Table 3.10). In these cases we estimated the $\mathrm{CO}_{2}$ correction to get the unburned carbon in Table 3.13. The fly ash flow rate was estimated by the High Volume sample readings (see Section 3.2.1) and the baghouse drain rate. The bed drain flow rate was estimated from the rate of filling the drums. 
Table 3.13: Carbon Heat Loss in the Fly Ash

\begin{tabular}{|c|c|c|c|c|c|c|c|c|c|c|c|c|}
\hline \multirow[t]{2}{*}{$\begin{array}{l}\text { Test } \\
\text { Point }\end{array}$} & \multirow[t]{2}{*}{$\begin{array}{c}\text { Sample } \\
\text { Location }\end{array}$} & \multirow[t]{2}{*}{ Date Time } & \multirow{2}{*}{$\begin{array}{c}\text { Unburned } \\
\text { Carbon in } \\
\text { Fly Ash } \\
\% \\
\end{array}$} & \multicolumn{2}{|c|}{ Ash flow } & \multicolumn{2}{|c|}{ Carbon Flow } & \multicolumn{2}{|c|}{ Heat Loss } & \multicolumn{2}{|c|}{ Fuel firing Rate } & \multirow{2}{*}{$\begin{array}{c}\text { Carbon Heat } \\
\text { Loss (CHL) in } \\
\text { Fly Ash } \\
\%\end{array}$} \\
\hline & & & & $\mathrm{kg} / \mathrm{hr}$ & $\mathrm{lb} / \mathrm{hr}$ & $\mathrm{kg} / \mathrm{hr}$ & $\mathrm{lb} / \mathrm{hr}$ & MWth & MMBtu/hr & MWth & MMBtu/hr & \\
\hline A2 & hv & $6 / 15 / 2005$ 5:20 & 17.59 & 91 & 200 & 16.0 & 35.2 & 0.1495 & 0.510 & 2.8 & 9.6 & 5.31 \\
\hline B3 & hv & $6 / 17 / 2005$ 17:00 & 21.35 & 68 & 150 & 14.5 & 32.0 & 0.1361 & 0.464 & 2.8 & 9.7 & 4.79 \\
\hline B6 & hv & 6/18/2005 1:10 & 19.68 & 54 & 120 & 10.7 & 23.6 & 0.1003 & 0.342 & 2.8 & 9.7 & 3.53 \\
\hline $\mathrm{C} 2$ & hv & $6 / 18 / 2005$ 12:15 & 11.66 & 136 & 300 & 15.9 & 35.0 & 0.1486 & 0.507 & 2.8 & 9.6 & 5.28 \\
\hline \multirow[t]{3}{*}{$\mathrm{C} 3$} & hv & $6 / 18 / 2005$ 17:20 & 11.09 & 113 & 250 & 12.6 & 27.7 & 0.1178 & 0.402 & 2.8 & 9.6 & 4.19 \\
\hline & hv & 6/19/2005 4:15 & 15.13 & 68 & 150 & 10.3 & 22.7 & 0.0964 & 0.329 & 2.2 & 7.6 & 4.33 \\
\hline & hv & 6/19/2005 8:30 & $19.29^{*}$ & 54 & 120 & 10.5 & 23.1 & 0.0983 & 0.336 & 2.8 & 9.7 & 3.46 \\
\hline \multirow[t]{2}{*}{$\mathrm{D} 2$} & hv & 6/19/2005 19:00 & 16.25 & 91 & 200 & 14.7 & 32.5 & 0.1381 & 0.471 & 2.8 & 9.7 & 4.86 \\
\hline & hv & $6 / 20 / 20056: 10$ & $12.69^{*}$ & 82 & 180 & 10.4 & 22.8 & 0.0970 & 0.331 & 2.8 & 9.7 & 3.41 \\
\hline D3 & hv & 6/20/2005 13:30 & 13.82 & 91 & 200 & 12.5 & 27.6 & 0.1174 & 0.401 & 2.8 & 9.7 & 4.13 \\
\hline D4 & hv & $6 / 20 / 2005$ 21:20 & 13.18 & 91 & 200 & 12.0 & 26.4 & 0.1120 & 0.382 & 2.8 & 9.7 & 3.94 \\
\hline E1 & hv & $6 / 21 / 20059: 10$ & 7.82 & 23 & 50 & 1.8 & 3.9 & 0.0166 & 0.057 & 2.9 & 10 & 0.57 \\
\hline E3 & hv & $6 / 21 / 200520: 45$ & 21.4 & 23 & 50 & 4.9 & 10.7 & 0.0455 & 0.155 & 2.9 & 10 & 1.55 \\
\hline A2 & bh & 6/15/2005 5:00 & 15.85 & 91 & 200 & 14.4 & 31.7 & 0.1347 & 0.460 & 2.8 & 9.6 & 4.79 \\
\hline A3 & bh & 6/15/2005 9:43 & 15.76 & 91 & 200 & 14.3 & 31.5 & 0.1339 & 0.457 & 2.8 & 9.7 & 4.71 \\
\hline B3 & bh & $6 / 17 / 200517: 19$ & 15.37 & 68 & 150 & 10.5 & 23.1 & 0.0979 & 0.334 & 2.8 & 9.7 & 3.45 \\
\hline B4 & bh & 6/17/2005 19:34 & $15.25^{*}$ & 68 & 150 & 10.4 & 22.9 & 0.0972 & 0.332 & 2.8 & 9.7 & 3.42 \\
\hline B5 & bh & $6 / 17 / 200522: 55$ & 14.15 & 68 & 150 & 9.6 & 21.2 & 0.0902 & 0.308 & 2.8 & 9.7 & 3.17 \\
\hline B6 & bh & $6 / 17 / 200523: 55$ & 14.02 & 68 & 150 & 9.5 & 21.0 & 0.0893 & 0.305 & 2.8 & 9.7 & 3.14 \\
\hline $\mathrm{C} 2$ & bh & $6 / 18 / 2005$ 12:05 & 10.68 & 136 & 300 & 14.5 & 32.0 & 0.1361 & 0.465 & 2.8 & 9.6 & 4.84 \\
\hline $\mathrm{C} 3$ & bh & $6 / 18 / 2005$ 17:06 & 11.37 & 113 & 250 & 12.9 & 28.4 & 0.1208 & 0.412 & 2.8 & 9.6 & 4.29 \\
\hline C5 & bh & 6/19/2005 4:15 & 11.04 & 68 & 150 & 7.5 & 16.6 & 0.0704 & 0.240 & 2.2 & 7.6 & 3.16 \\
\hline D1 & bh & $6 / 19 / 2005$ 10:30 & $16.26^{*}$ & 54 & 120 & 8.9 & 19.5 & 0.0829 & 0.283 & 2.8 & 9.7 & 2.92 \\
\hline \multirow[t]{2}{*}{$\mathrm{D} 2$} & bh & 6/19/2005 19:43 & 15.72 & 91 & 200 & 14.3 & 31.4 & 0.1336 & 0.456 & 2.8 & 9.7 & 4.70 \\
\hline & bh & $6 / 20 / 20054: 50$ & $13.99^{*}$ & 82 & 180 & 11.4 & 25.2 & 0.1070 & 0.365 & 2.8 & 9.7 & 3.76 \\
\hline D3 & bh & $6 / 20 / 20059: 34$ & $14.11^{*}$ & 91 & 200 & 12.8 & 28.2 & 0.1199 & 0.409 & 2.8 & 9.7 & 4.22 \\
\hline D3 & bh & $6 / 20 / 2005$ 13:45 & 13.5 & 91 & 200 & 12.2 & 27.0 & 0.1147 & 0.392 & 2.8 & 9.7 & 4.04 \\
\hline D4 & bh & $6 / 20 / 2005$ 21:40 & 13.01 & 91 & 200 & 11.8 & 26.0 & 0.1105 & 0.377 & 2.8 & 9.7 & 3.89 \\
\hline \multirow[t]{2}{*}{ E1 } & bh & 6/21/2005 9:10 & 8.02 & 23 & 50 & 1.8 & 4.0 & 0.0170 & 0.058 & 2.9 & 10 & 0.58 \\
\hline & bh & $6 / 21 / 200520: 30$ & 6.59 & 23 & 50 & 1.5 & 3.3 & 0.0140 & 0.048 & 2.9 & 10 & 0.48 \\
\hline \multirow[t]{2}{*}{$\mathrm{D} 2$} & bd & $6 / 19 / 2005$ 18:30 & $0.47^{*}$ & 68 & 150 & 0.3 & 0.7 & 0.0030 & 0.010 & 2.8 & 9.7 & 0.11 \\
\hline & bd & $6 / 20 / 2005$ 19:43 & 0.08 & 54 & 120 & 0.0 & 0.1 & 0.0004 & 0.001 & 2.8 & 9.7 & 0.01 \\
\hline \multirow[t]{2}{*}{ D4 } & bd & 6/20/2005 21:15 & 0.37 & 54 & 120 & 0.2 & 0.4 & 0.0019 & 0.006 & 2.8 & 9.7 & 0.07 \\
\hline & bd & $6 / 21 / 20054: 10$ & 1.41 & 45 & 100 & 0.6 & 1.4 & 0.0060 & 0.020 & 2.9 & 10 & 0.20 \\
\hline
\end{tabular}




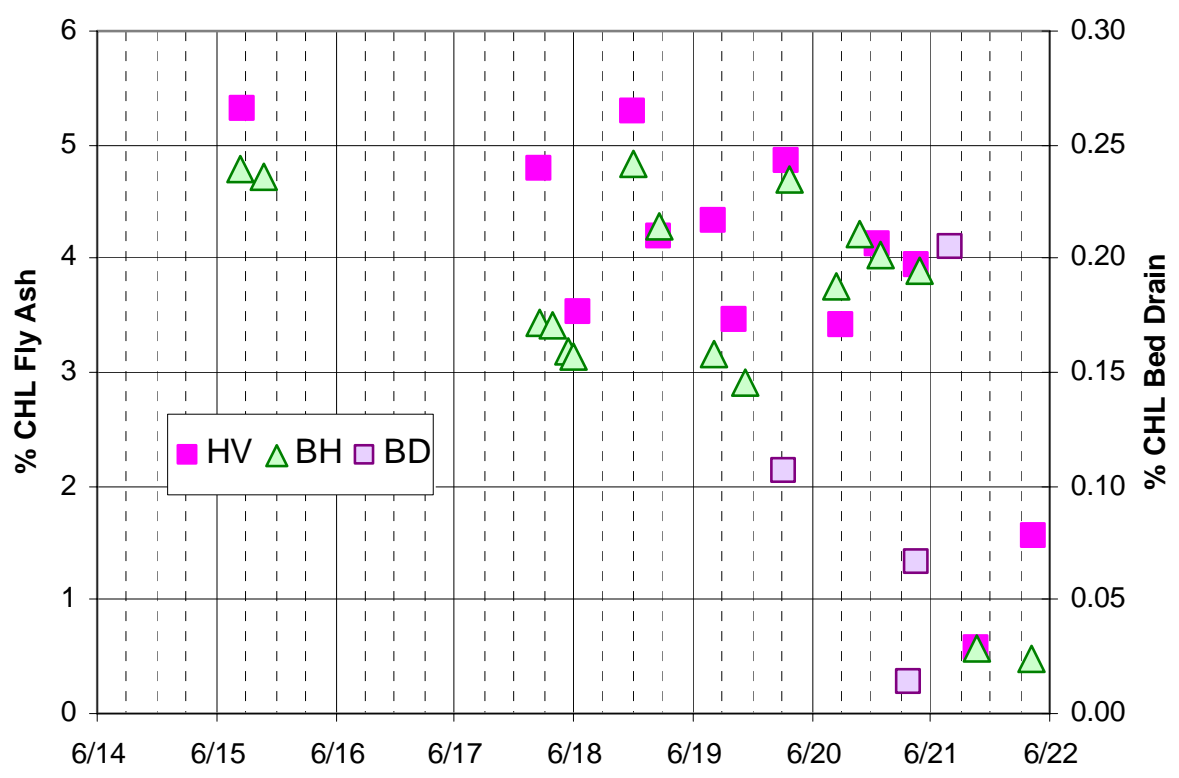

Figure 3.34: Carbon Heat Loss

The carbon heat loss in the fly ash is $3-5 \%$ of the higher heating value heat input for the bituminous coal. The heat loss in the fly ash seems to be lower with oxygen firing compared to air firing. The carbon heat loss is much lower with the pet coke, which is typical. The carbon heat loss in the bed drain is less than $1 / 4 \%$.

\subsubsection{Mercury and Other Trace Metals}

TRC Environmental Corporation (TRC) conducted emissions sampling for particulate matter (EPA Method 5) and Metals (EPA Method 29). Tests were done at three test conditions:

- C4 - Air Fired, TriStar Bituminous, ATF40 limestone

- D3 - $\mathrm{O}_{2}$ Fired, TriStar Bituminous, ATF40 limestone

- $\quad \mathrm{E} 1-\mathrm{O}_{2}$ Fired, Pet Coke, Aragonite

At each test condition, TRC took duplicate samples at the furnace outlet and at the baghouse outlet. TRC's results for particulate load and for 15 metals are given in Table 3.14. A summary of the fate of 5 metals is shown in Figure 3.35. The drop in metals emissions across the baghouse ("out" vs. "in") is greater for the two oxygen fired cases. However, both air-fired tests had a greater dust load out of the baghouse (see Table 3.14), perhaps due to a filter bag not seated well.

Figure 3.36 expresses the emission rate as parts per million (by mass) relative to the measured dust flow rates. 

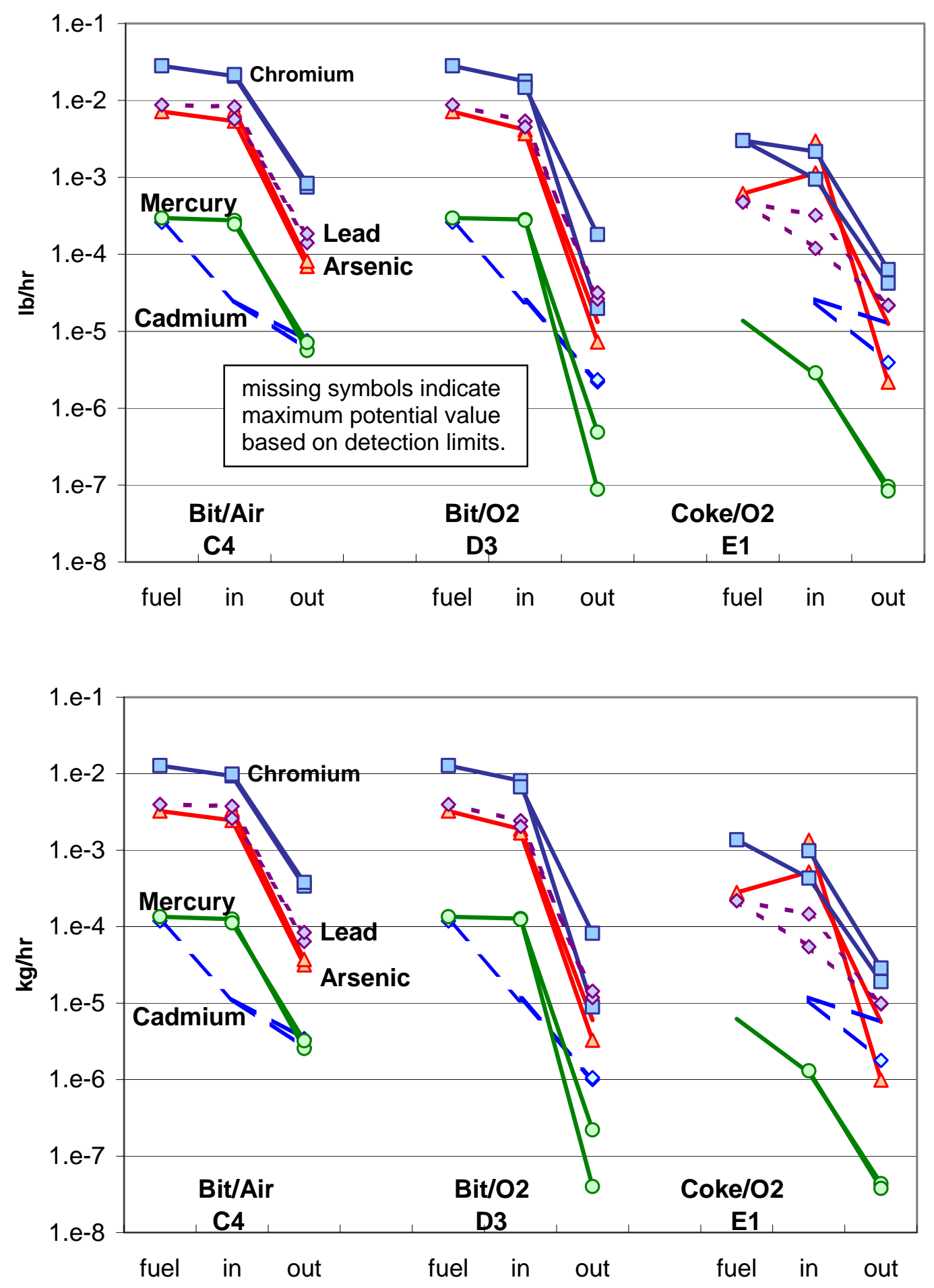

Figure 3.35: Tracking of Five Metals 
COMMERCIALIZATION DEVELOPMENT OF OXYGEN FIRED CFB FOR GREENHOUSE GAS CONTROL

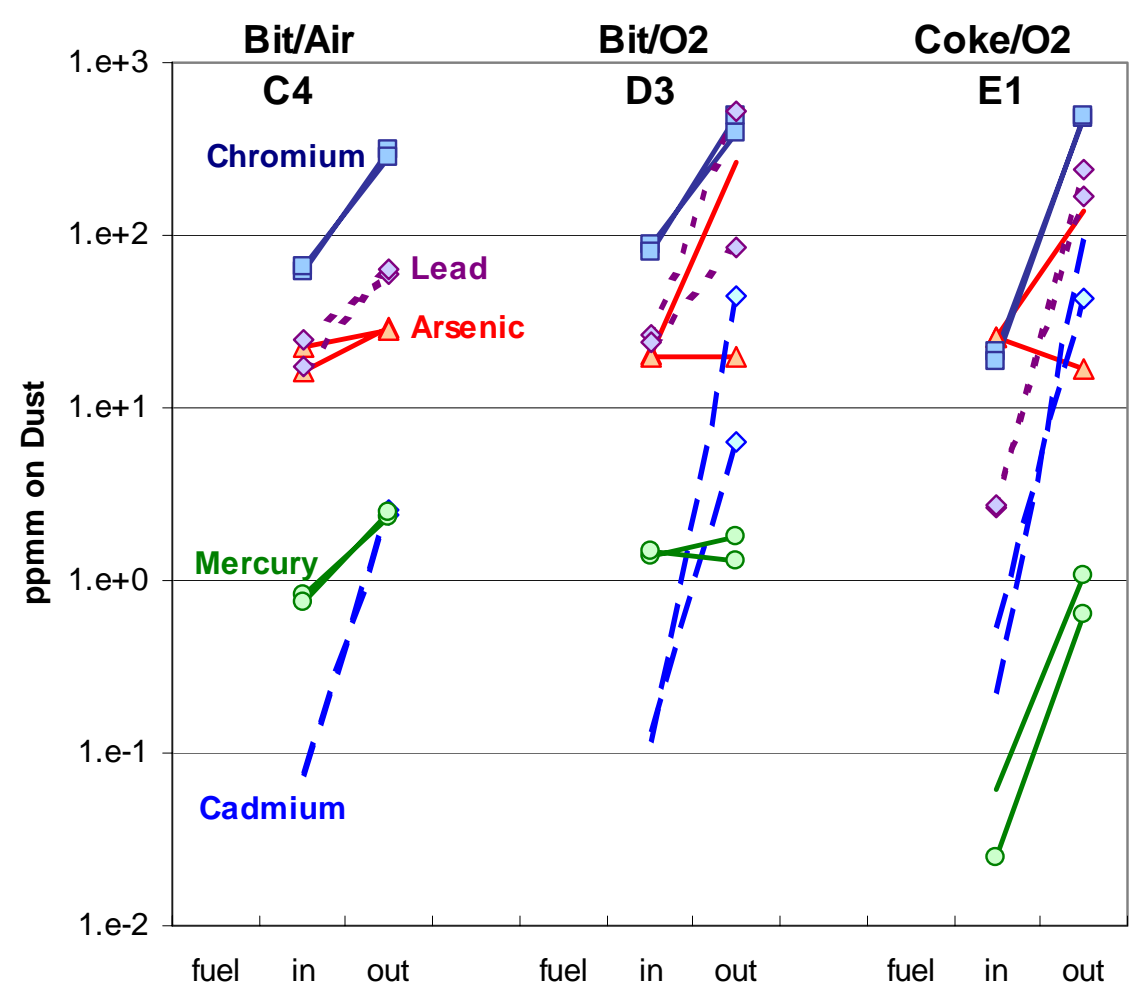

Figure 3.36: Calculated Metals Concentration on Dust 
Table 3.14: Metals Data

\begin{tabular}{|c|c|c|c|c|c|c|c|c|c|c|c|c|c|c|c|c|c|c|c|}
\hline \multicolumn{2}{|l|}{$\begin{array}{l}\text { DATE } \\
\text { TIME } \\
\end{array}$} & $\begin{array}{r}\text { 6/18/05 } \\
18: 20- \\
20: 25 \\
\mathrm{Fu}\end{array}$ & $\begin{array}{r}\text { 6/18/05 } \\
20: 50- \\
22: 56 \\
\text { urnace Outle }\end{array}$ & $\begin{array}{l}\text { Average } \\
\text { et }\end{array}$ & $\begin{array}{r}\text { 6/18/05 } \\
18: 20- \\
20: 25 \\
\text { Bag }\end{array}$ & $\begin{array}{r}6 / 18 / 05 \\
20: 50- \\
22: 56 \\
\text { ghouse Outl }\end{array}$ & $\begin{array}{l}\text { Average } \\
\text { et }\end{array}$ & $\begin{array}{c}\text { 6/20/05 } \\
08: 25- \\
10: 27 \\
\text { Fu }\end{array}$ & $\begin{array}{r}\text { 6/20/05 } \\
11: 20- \\
13: 23 \\
\text { Irnace Outle }\end{array}$ & Average & $\begin{array}{c}6 / 20 / 05 \\
08: 25- \\
10: 27 \\
\text { Bag }\end{array}$ & $\begin{array}{c}6 / 20 / 05 \\
11: 20- \\
13: 23 \\
\text { ghouse Outl }\end{array}$ & $\begin{array}{l}\text { Average } \\
\text { let }\end{array}$ & $\begin{array}{r}\text { 6/21/05 } \\
07: 05- \\
09: 08 \\
\mathrm{Fu}\end{array}$ & $\begin{array}{rr}5 / 21 / 05 \\
- & 09: 45- \\
3 & 11: 50 \\
\text { urnace Outle }\end{array}$ & Average & $\begin{array}{r}\text { 6/21/05 } \\
07: 05- \\
09: 08 \\
\text { Bag }\end{array}$ & $\begin{array}{r}6 / 21 / 05 \\
09: 45- \\
11: 50 \\
\text { ghouse Out }\end{array}$ & Average \\
\hline Temperature & ${ }^{\circ} \mathrm{F}$ & 1041 & 1033 & 1037 & \multicolumn{3}{|c|}{$\begin{array}{c}\text { Baghouse Outlet } \\
128 \quad 128\end{array}$} & \multicolumn{3}{|c|}{\begin{tabular}{cc}
\multicolumn{2}{c}{ Furnace Outlet } \\
$1093 \quad 1089$
\end{tabular}} & 117 & & 1048 & $3 \quad 1073$ & 1061 & 126 & 126 & 126 \\
\hline $\mathrm{CO} 2$ & $\%$ & 15 & 15 & 15 & 15 & 15 & 15 & 85 & 85 & 85 & 85 & 85 & 85 & 85 & 85 & 85 & 85 & 85 & 85 \\
\hline $\mathrm{O} 2$ & $\%$ & 3 & 3 & & 3 & 3 & 3 & 4.5 & 4.5 & 4.5 & 4.5 & 4.5 & 4.5 & 4 & 4 & 4 & 4 & 4 & \\
\hline Moisture & $\%$ & 7.6 & 7.3 & 7.5 & 10.3 & 9.7 & 10.0 & 10.8 & 9.7 & 10.2 & 10.7 & 11.0 & 10.8 & 4.3 & 11.7 & 8.0 & 11.4 & 11.6 & 11.5 \\
\hline Volumetric Flowrate, Actu & $\mathrm{acfm}^{1}$ & 7247 & 7205 & 7226 & 3614 & 3624 & 3619 & 5211 & 5312 & 5261 & 2508 & 2845 & 2676 & 5117 & 5369 & 5243 & 2842 & 2917 & 2880 \\
\hline Volumetric Flowrate & $\mathrm{dscfm}^{2}$ & 2352 & 2355 & 2353 & 2813 & 2843 & 2828 & 1577 & 1633 & 1605 & 2047 & 2298 & 2172 & 1706 & 1626 & 1666 & 2258 & 2312 & 2285 \\
\hline Volumetric Flowrate, Dry Std. & $\mathrm{dscm} / \mathrm{hr}$ & 3996 & 4001 & 3999 & 4780 & 4831 & 4805 & 2680 & 2775 & 2728 & 3478 & 3904 & 3691 & 2898 & 2763 & 2830 & 3836 & 3929 & 3883 \\
\hline Sample Catch & & & & & & & & & & & & & & & & & & & \\
\hline Particula & $\mathrm{mg}$ & 39829 & 39483 & & $\begin{array}{r}321.30 \\
7.1\end{array}$ & 384.10 & & 25372 & 22230 & & 10.30 & 84.30 & & 5625 & 13346 & & 20.60 & 31.40 & \\
\hline Ag - silver & ug & 358 & $<3.00$ & & 7.41 & 31.19 & & $<3.00$ & $<3.00$ & & 4.40 & 9.03 & & $<3.00$ & $<3.00$ & & $\begin{array}{r}6.49 \\
3.300\end{array}$ & 1.13 & \\
\hline As -arsenic & ug & 642 & 887 & & 9.16 & 10.79 & & 517 & 437 & & $<3.00$ & 1.64 & & 143 & 340 & & $<3.00$ & 0.52 & \\
\hline Ba -barium & ug & 13400 & 11640 & & 244.24 & $\begin{array}{r}305.00 \\
5.07\end{array}$ & & 12040 & 9211 & & 10.40 & 45.60 & & $\begin{array}{r}276 \\
<180\end{array}$ & 523 & & $\begin{array}{r}13.10 \\
<180\end{array}$ & $\begin{array}{r}9.05 \\
<180\end{array}$ & \\
\hline Be - beryllium & ug & 198 & 129 & & 4.62 & 5.97 & & 197 & 159 & & $<1.80$ & $<1.80$ & & $<1.80$ & $\begin{array}{r}2.02 \\
<300-10-10\end{array}$ & & $<1.80$ & $<1.80$ & \\
\hline Cd - cadmium & ug & $<3.00$ & $<3.00$ & & 0.76 & 1.00 & & $<3.00$ & $<3.00$ & & 0.50 & 0.53 & & $<3.00$ & $<3.00$ & & 0.94 & $<3.00$ & \\
\hline Cr-chromium & ug & 2453 & 2588 & & 98.00 & 110.00 & & 2226 & 1749 & & 4.48 & 40.90 & & 119 & $\begin{array}{r}248 \\
\end{array}$ & & $\begin{array}{r}10.10 \\
\end{array}$ & 15.10 & \\
\hline $\mathrm{Fe}$ - iron & ug & 1279061 & 1320019 & & 18624.0 & 21054.2 & & 1529044 & 1194022 & & 629.40 & 16162.30 & & 21490 & 46738 & & 2307.60 & 8256.20 & \\
\hline $\mathrm{Hg}$ - mercury & ug & 32.86 & 29.51 & & 0.74 & 0.94 & & 35.18 & 32.49 & & 0.02 & 0.11 & & $<0.34$ & 0.33 & & 0.02 & 0.02 & \\
\hline $\mathrm{Ni}$ - nickel & ug & 1877 & 1788 & & 57.28 & 63.30 & & 1575 & 1335 & & 6.28 & 27.50 & & 2701 & 9493 & & 12.10 & 20.40 & \\
\hline $\mathrm{Pb}$ - lead & ug & 986 & 681 & & 18.62 & 24.55 & & 670 & 533 & & 5.91 & 7.15 & & 15.07 & 36.80 & & 5.16 & 5.22 & \\
\hline Sb - antimony & ug & 37.30 & 117 & & 3.05 & 3.23 & & 73.75 & 68.80 & & $<3.00$ & 1.38 & & 5.83 & $<3.00$ & & $<3.00$ & $<3.00$ & \\
\hline Sr - stron & ug & 10600 & 9774 & & 200.32 & 236.00 & & 9028 & 6971 & & 7.81 & 27.40 & & 3200 & 9388 & & 0.76 & 6.18 & \\
\hline Ti - titanium & ug & 120000 & 119000 & & 2344.90 & 2710.00 & & 99500 & 77900 & & 57.70 & 185.00 & & 8926 & 18300 & & 39.50 & 25.80 & \\
\hline $\mathrm{TI}$ - thallium & ug & $<3.00$ & $<3.00$ & & $<3.00$ & $<3.00$ & & $<3.00$ & $<3.00$ & & $<3.00$ & $<3.00$ & & $<3.00$ & $<3.00$ & & $<5.00$ & $<5.00$ & \\
\hline -vanadium & ug & 4264 & 4899 & & 93.36 & 107.00 & & 4058 & 3362 & & 3.20 & $\begin{array}{l}7.92 \\
\end{array}$ & & 5752 & 19550 & & 7.64 & 2.91 & \\
\hline Sample V & $\mathrm{dscn}$ & 1.050 & 1.052 & & 1.388 & 1.406 & & 0.737 & 0.722 & & 1.739 & 1.949 & & 0.800 & 0.697 & & 2.028 & 2.072 & \\
\hline Isokinetic Rat & $\%$ & 98.3 & 98.4 & & 108.7 & 108.9 & & 102.9 & 97.4 & & 102.5 & 102.3 & & 103.3 & 94.4 & & 108.3 & 108.1 & \\
\hline CONCENTR & & & & & & & & & & & & & & & & & & & \\
\hline Particulate (t & $\mathrm{g} / \mathrm{dscm}$ & $\begin{array}{r}37925 \\
340.88\end{array}$ & $\begin{array}{l}37527 \\
<2.85\end{array}$ & $\begin{array}{r}37726 \\
<171.87\end{array}$ & $\begin{array}{r}231.41 \\
5.34\end{array}$ & $\begin{array}{r}273.20 \\
22.18\end{array}$ & $\begin{array}{r}252.30 \\
13.76\end{array}$ & $\begin{array}{r}34421.77 \\
<4.07\end{array}$ & $\begin{array}{r}30778.26 \\
<4.15\end{array}$ & $\begin{array}{r}32600.02 \\
<4.11\end{array}$ & 5.92 & $\begin{array}{r}43.26 \\
4.63\end{array}$ & $\begin{array}{r}24.59 \\
3.58\end{array}$ & $\begin{array}{r}7033.33 \\
<3.75\end{array}$ & $\begin{array}{ll}3 & 19155.19\end{array}$ & 13094.26 & $\begin{array}{r}10.16 \\
3.20\end{array}$ & $\begin{array}{r}15.16 \\
0.55\end{array}$ & $\begin{array}{r}12.66 \\
1.87\end{array}$ \\
\hline $\begin{array}{l}\text { Ag - silver } \\
\text { As -arsenic }\end{array}$ & & $\begin{array}{l}340.88 \\
611.31\end{array}$ & $\begin{array}{l}<2.85 \\
843.07\end{array}$ & $\begin{array}{r}<171.87 \\
727.19\end{array}$ & $\begin{array}{l}5.34 \\
6.60\end{array}$ & $\begin{array}{r}22.18 \\
7.67\end{array}$ & $\begin{array}{r}13.76 \\
7.14\end{array}$ & $\begin{array}{l}<4.07 \\
701.40\end{array}$ & $\begin{array}{l}<4.15 \\
605.05\end{array}$ & $\begin{array}{l}<4.11 \\
653.23\end{array}$ & $\begin{array}{r}2.53 \\
<1.72\end{array}$ & $\begin{array}{l}4.63 \\
0.84\end{array}$ & $\begin{array}{r}3.58 \\
<1.28\end{array}$ & $\begin{array}{l}<3.75 \\
178.81\end{array}$ & $\begin{array}{ll}5 & <4.31 \\
1 & 48799\end{array}$ & $\begin{array}{r}<4.03 \\
333.40\end{array}$ & $\begin{array}{r}3.20 \\
<1.48\end{array}$ & 0.55 & $\begin{array}{r}1.87 \\
<0.86\end{array}$ \\
\hline $\begin{array}{l}\text { As -arsenic } \\
\text { Ba -barium }\end{array}$ & $\begin{array}{l}\text { ug/dscm } \\
u g / d s c m\end{array}$ & \begin{tabular}{|r|}
611.31 \\
12759.38
\end{tabular} & $\begin{array}{r}843.07 \\
11063.57\end{array}$ & 11911.47 & $\begin{array}{r}0.00 \\
175.91\end{array}$ & $\begin{array}{l}1.01 \\
216.94\end{array}$ & $\begin{array}{r}7.14 \\
196.42\end{array}$ & $\begin{array}{r}101.40 \\
16334.41\end{array}$ & $\begin{array}{r}6053.05 \\
1275.14\end{array}$ & $\begin{array}{r}653.23 \\
14543.77\end{array}$ & $\begin{array}{r}<1.72 \\
5.98\end{array}$ & $\begin{array}{r}0.84 \\
23.40\end{array}$ & $\begin{array}{l}<1.28 \\
14.69\end{array}$ & $\begin{array}{l}178.81 \\
345.11\end{array}$ & $\begin{array}{l}487.99 \\
750.64\end{array}$ & $\begin{array}{l}333.40 \\
547.88\end{array}$ & $\begin{array}{r}1.48 \\
6.46\end{array}$ & $\begin{array}{l}0.25 \\
4.37\end{array}$ & $\begin{array}{r}<0.86 \\
5.41\end{array}$ \\
\hline Be - beryllium & $\mathrm{ug} / \mathrm{dscm}$ & \begin{tabular}{|l}
188.53 \\
\end{tabular} & 122.61 & 155.57 & 3.33 & 4.25 & $\begin{array}{r}3.79 \\
\end{array}$ & 267.27 & 220.14 & 243.70 & $<1.03$ & $<0.92$ & $<0.98$ & $<2.25$ & 2.90 & $<2.57$ & $<0.89$ & $<0.87$ & $<0.88$ \\
\hline $\mathrm{Cd}$ - cadmium & & $<2.86$ & $<2.85$ & $<2.85$ & 0.55 & 0.71 & 0.63 & $<4.07$ & $<4.15$ & $<4.11$ & 0.29 & 0.27 & 0.28 & $<3.75$ & $<4.31$ & $<4.03$ & 0.46 & $<1.45$ & $<0.96$ \\
\hline $\mathrm{Cr}$-chromium & & 2335.73 & 2459.84 & 2397.78 & 70.58 & 78.24 & 74.41 & 3019.97 & 2421.59 & 2720.78 & 2.58 & 20 & 11.78 & 148.80 & 355.94 & 252.37 & 4.98 & 7.29 & 6.13 \\
\hline $\mathrm{Fe}$ - ir & & 1217912 & 1254650 & 1236281 & 13413.61 & 14975.20 & 14194.40 & 2074420 & 1653190 & 1863805 & 362 & & 4328 & 26872 & 67081 & 46976 & 1138 & & 2562 \\
\hline $\mathrm{Hg}-\mathrm{m}$ & & 31.29 & 28.05 & $\begin{array}{r}29.67 \\
\end{array}$ & 0.53 & 0.67 & $\begin{array}{r}1410.40 \\
0.60\end{array}$ & 47.73 & 44.98 & $\begin{array}{r}46.36 \\
\end{array}$ & 0.01 & 0.06 & 0.03 & $<0.43$ & 0.47 & $<0.45$ & 0.01 & 0.01 & 0.01 \\
\hline $\mathrm{Ni}-\mathrm{ni}$ & & 1787.27 & 1699.46 & 1743.36 & 41.25 & 45.02 & 43.14 & 2136.77 & 1848.38 & 1992.58 & 3.61 & 14 & 8.86 & 3377.37 & $7 \quad 13624.87$ & 8501.12 & 5.97 & 9.85 & 7.91 \\
\hline & & 938.86 & & 793.07 & 13.41 & 17.46 & 15.44 & 908.97 & 737.97 & & & & & 18.84 & & 35.83 & & & 2.5 \\
\hline & & & & & & & & 06 & & 91. & $<1$. & & $<1$ & & & & & & $<1.4$ \\
\hline & & \begin{tabular}{|l|}
10093.24 \\
\end{tabular} & 928 & 9691.61 & 144.28 & 167 & 56.07 & 12248.09 & 9651.74 & 1094 & 4. & 14 & 9. & 400 & $\begin{array}{ll}3134 \\
\end{array}$ & 873 & & & \\
\hline & & & & 113 & & & & & & & & & & & & & & & 15 \\
\hline & & & & & & & & & & & & $<1$ & $<1$ & & & & & & $<2$ \\
\hline V-vana & ug/as & 4060.15 & 4656.39 & 4358.27 & 67.24 & 76.11 & 71.67 & 5505.40 & 4654.88 & 5080.14 & 1.84 & 4.06 & 2.95 & 7192.39 & $9 \quad 28059.23$ & 17625.8 & 3.77 & 1.40 & $2.5 \mathrm{c}$ \\
\hline EMIS & & & & & & & & & & & & & & & & & & & \\
\hline Parti & $\mathrm{bs} / \mathrm{h}$ & $\begin{array}{r}334.11 \\
3.00 \mathrm{e}-3\end{array}$ & $\begin{array}{r}331.03 \\
\end{array}$ & $\begin{array}{r}332.57 \\
\end{array}$ & $\begin{array}{r}2.44 \\
62 e-5\end{array}$ & & $\begin{array}{r}2.67 \\
146 \mathrm{e}-4\end{array}$ & 203.39 & 188.30 & 195.84 & 0.05 & $\begin{array}{r}0.37 \\
399 \mathrm{e}-5\end{array}$ & & $\begin{array}{r}44.94 \\
\end{array}$ & $4 \quad 116.66$ & 80.80 & 0.09 & & $\begin{array}{r}0.11 \\
1.59 e-5\end{array}$ \\
\hline & & & & $<1.51 \mathrm{e}-3$ & $\begin{array}{l}5.62 \mathrm{e}-5 \\
6.95 \mathrm{e}-\mathrm{s}\end{array}$ & $\begin{array}{l}2.36 \mathrm{e}-4 \\
8.17 \mathrm{e}-5\end{array}$ & $\begin{array}{l}1.46 \mathrm{e}-4 \\
756 \mathrm{e}-5\end{array}$ & $<2.40 \mathrm{e}-5$ & & $<2.47 \mathrm{e}-5$ & & $3.99 \mathrm{e}-5$ & $\begin{array}{r}2.96 \mathrm{e}-5 \\
\end{array}$ & $<2.40 \mathrm{e}-5$ & & & & $4.72 \mathrm{e}-6$ & $\begin{array}{l}1.59 \mathrm{e}-5 \\
7.34 \mathrm{e}-6\end{array}$ \\
\hline $\begin{array}{l}\text { As -arsenic } \\
\text { Ba -barium }\end{array}$ & $\begin{array}{l}\mathrm{l} b \mathrm{bSh} / \mathrm{hr} \\
\mathrm{lbs} / \mathrm{hr}\end{array}$ & $\begin{array}{l}5.39 \mathrm{e}-3 \\
1.12 \mathrm{e}-1\end{array}$ & $\begin{array}{l}7.44 \mathrm{e}-3 \\
9.76 \mathrm{e}-2\end{array}$ & & $\begin{array}{l}6.95 e-5 \\
1.85 e-3\end{array}$ & $\begin{array}{l}8.17 \mathrm{e}-5 \\
2.31 \mathrm{e}-3\end{array}$ & $\begin{array}{l}7.56 e-5 \\
2.08 e-3\end{array}$ & $\begin{array}{l}4.14 \mathrm{e}-3 \\
9.65 \mathrm{e}-2\end{array}$ & $\begin{array}{l}3.70 \mathrm{e}-3 \\
7.80 \mathrm{e}-2\end{array}$ & $\begin{array}{l}3.92 \mathrm{e}-3 \\
8.73 \mathrm{e}-2\end{array}$ & $\mid \begin{array}{r}<1.32 \mathrm{e}-5 \\
4.58 \mathrm{e}-5\end{array}$ & $\begin{array}{l}7.24 \mathrm{e}-6 \\
2.01 \mathrm{e}-4\end{array}$ & $\begin{array}{r}<1.02 \mathrm{e}-5 \\
1.24 \mathrm{e}-4\end{array}$ & & $\begin{array}{ll}3 & 2.97 \mathrm{e}-3 \\
3 & 4.57 \mathrm{e}-3\end{array}$ & $\begin{array}{l}2.06 \mathrm{e}-3 \\
3.39 \mathrm{e}-3\end{array}$ & $\begin{array}{r}1.25 \mathrm{e}-5 \\
5.46 \mathrm{e}-5\end{array}$ & $\begin{array}{l}2.17 \mathrm{e}-6 \\
3.78 \mathrm{e}-5\end{array}$ & $\begin{array}{r}\quad 7.34 \mathrm{e}-6 \\
4.62 \mathrm{e}-5\end{array}$ \\
\hline $\begin{array}{l}\text { Ba-barium } \\
\text { Be - beryllium }\end{array}$ & Ibs/ & $1.66 \mathrm{e}-3$ & $\begin{array}{l}9.16 \mathrm{e}-2 \\
1.08 \mathrm{e}-3\end{array}$ & $\begin{array}{l}1.05 \mathrm{e}-1 \\
1.37 \mathrm{e}-3\end{array}$ & $3.51 \mathrm{e}-5$ & $4.52 \mathrm{e}-5$ & $\begin{array}{l}2.08 \mathrm{e}-3 \\
4.01 \mathrm{e}-5\end{array}$ & $\begin{array}{l}9.65 \mathrm{e}-2 \\
1.58 \mathrm{e}-3\end{array}$ & $1.35 \mathrm{e}-3$ & $\begin{array}{l}8.13 \mathrm{e}-2 \\
1.46 \mathrm{e}-3\end{array}$ & $<7.94 \mathrm{e}-6$ & $<7.95 \mathrm{e}-6$ & $<7.94 \mathrm{e}-6$ & $\begin{array}{l}<.21 \mathrm{e}-3 \\
<1.44 \mathrm{e}-5\end{array}$ & $\begin{array}{ll}3 & 4.5 / \mathrm{e}-3 \\
5 & 1.77 \mathrm{e}-5\end{array}$ & $\begin{array}{l}3.60 \mathrm{e}-5 \\
<\end{array}$ & $\begin{array}{l}5.40 e^{-5} \\
-7.51 e^{-6}\end{array}$ & $<7.53 \mathrm{e}-6$ & $<7.52 \mathrm{e}-6$ \\
\hline $\mathrm{Cd}$ - cadmium & $\mathrm{lbs} / \mathrm{hr}$ & $<2.52 \mathrm{e}-5$ & $<2.52 \mathrm{e}-5$ & $<2.52 \mathrm{e}-5$ & $5.77 \mathrm{e}-6$ & $7.57 \mathrm{e}-6$ & $6.67 e-6$ & $<2.40 \mathrm{e}-5$ & $<2.54 \mathrm{e}-5$ & $<2.47 \mathrm{e}-5$ & $2.20 \mathrm{e}-6$ & $2.34 \mathrm{e}-6$ & $2.27 \mathrm{e}-6$ & $<2.40 \mathrm{e}-5$ & $5<2.62 e-5$ & $<2.51 \mathrm{e}-5$ & $3.92 \mathrm{e}-6$ & $<1.25 \mathrm{e}-5$ & $<8.23 \mathrm{e}-6$ \\
\hline $\mathrm{Cr}$-chromium & $\mathrm{lbs} / \mathrm{hr}$ & \begin{tabular}{|l|}
$2.06 \mathrm{e}-2$ \\
\end{tabular} & $2.17 \mathrm{e}-2$ & $2.11 \mathrm{e}-2$ & $7.44 \mathrm{e}-4$ & $8.33 \mathrm{e}-4$ & $7.89 \mathrm{e}-4$ & $1.78 \mathrm{e}-2$ & $1.48 \mathrm{e}-2$ & $1.63 \mathrm{e}-2$ & $1.97 \mathrm{e}-5$ & $1.81 \mathrm{e}-4$ & $1.00 \mathrm{e}-4$ & $9.51 \mathrm{e}-4$ & $\begin{array}{ll}4 & 2.17 \mathrm{e}-3\end{array}$ & $1.56 \mathrm{e}-3$ & $4.21 \mathrm{e}-5$ & $6.31 \mathrm{e}-5$ & $5.26 \mathrm{e}-5$ \\
\hline Co _ in & Ibs/hr & $1.07 e+1$ & 1.11e+1 & $1.09 e+1$ & $1.41 \mathrm{e}-1$ & $1.59 \mathrm{e}-1$ & $1.50 \mathrm{e}-1$ & 1.23e+1 & $1.01 e+1$ & 1.12e+1 & $2.77 \mathrm{e}-3$ & $7.14 \mathrm{e}-2$ & $3.71 \mathrm{e}-2$ & $1.72 \mathrm{e}-1$ & $1 \quad 4.09 \mathrm{e}-1$ & $2.90 \mathrm{e}-1$ & $9.62 \mathrm{e}-3$ & $3.45 \mathrm{e}-2$ & $2.21 \mathrm{e}-2$ \\
\hline & & & 2.4 & 2.62 & & & 6.37 & & & & & $4.86 \mathrm{e}-7$ & -7 & $<2.72 \mathrm{e}-6$ & $\begin{array}{ll}6 \quad 2.88 \\
6\end{array}$ & $=2.80 e-6$ & & & $8.98 \mathrm{e}$ \\
\hline & & & 1.5 & 1.5 & & & & & 1.3 & & & & & 2.1 & & & & & \\
\hline & & & 5.7 & 6.9 & & & & & & & & & & & & & & & \\
\hline & & & 9.8 & & & & & & & & & & & & & & & & \\
\hline & & & 8. & & & & & & & & & & & & & & & & \\
\hline & & $1.01 \mathrm{e}+0$ & $9.98 \mathrm{e}-1$ & 1.00 & 1. & 2.0 & & & & & & & & & & & & & \\
\hline & & & 25 & & & & & & & & & & & & & & & & \\
\hline V-vana & Ibs & $e-2$ & e-2 & & e-4 & $8.10 \mathrm{e}-4$ & $7.60 e-4$ & $3.25 \mathrm{e}-2$ & $2.85 \mathrm{e}-2$ & 3. & $1 \mathrm{e}-5$ & $50 e-5$ & $45 e-5$ & $4.60 \mathrm{e}-2$ & $1.71 \mathrm{e}-1$ & $1.08 \mathrm{e}-1$ & $3.19 \mathrm{e}-5$ & $1.22 \mathrm{e}-5$ & $2.20 \mathrm{e}$ \\
\hline
\end{tabular}




\subsubsection{Convective Pass Heat Transfer and Fouling}

\section{Heat Transfer to the Convective Probes}

The convective/fouling probes are air-cooled banks installed in the water-cooled duct downstream of the cyclone (see Figure 3.3). The heat duty to each of the two banks of probes is calculated by the flow rate and temperature increase of the cooling air.

It is expected that the convective heat transfer will be higher with oxygen firing due to the higher non-luminous radiative heat transfer with high $\mathrm{CO}_{2}$ and $\mathrm{H}_{2} \mathrm{O}$ content of the flue gas.

The gas velocity over the tube banks drops when $\mathrm{O}_{2}$ firing, but mass flow stays about constant (see Figure 3.20). Mass flow is the more relevant to heat transfer, so this effect is minimal.

The local gas-side thermocouple was not reading during the test, but the temperature is estimated to be between 700 and $815^{\circ} \mathrm{C}$ (about 1,300 to $1,500{ }^{\circ} \mathrm{F}$ ). The temperature upstream of the probes in the water-cooled duct gives a qualitative indication of the changing gas-side temperature.

The heat duties to the two probe banks as functions of this upstream temperature are given in Figure 3.37 and Figure 3.38. All of the logged data points during each Test Series are plotted in the figures.

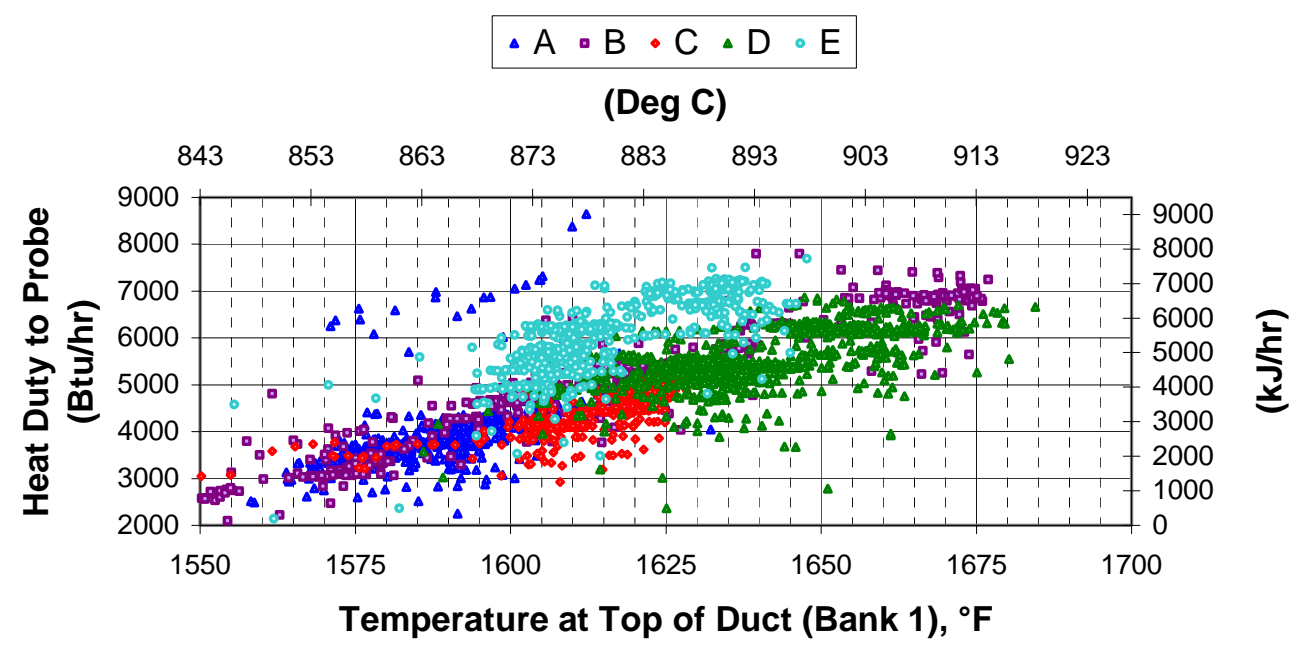

Figure 3.37: Heat Duty of Convective Probe Bank 1 


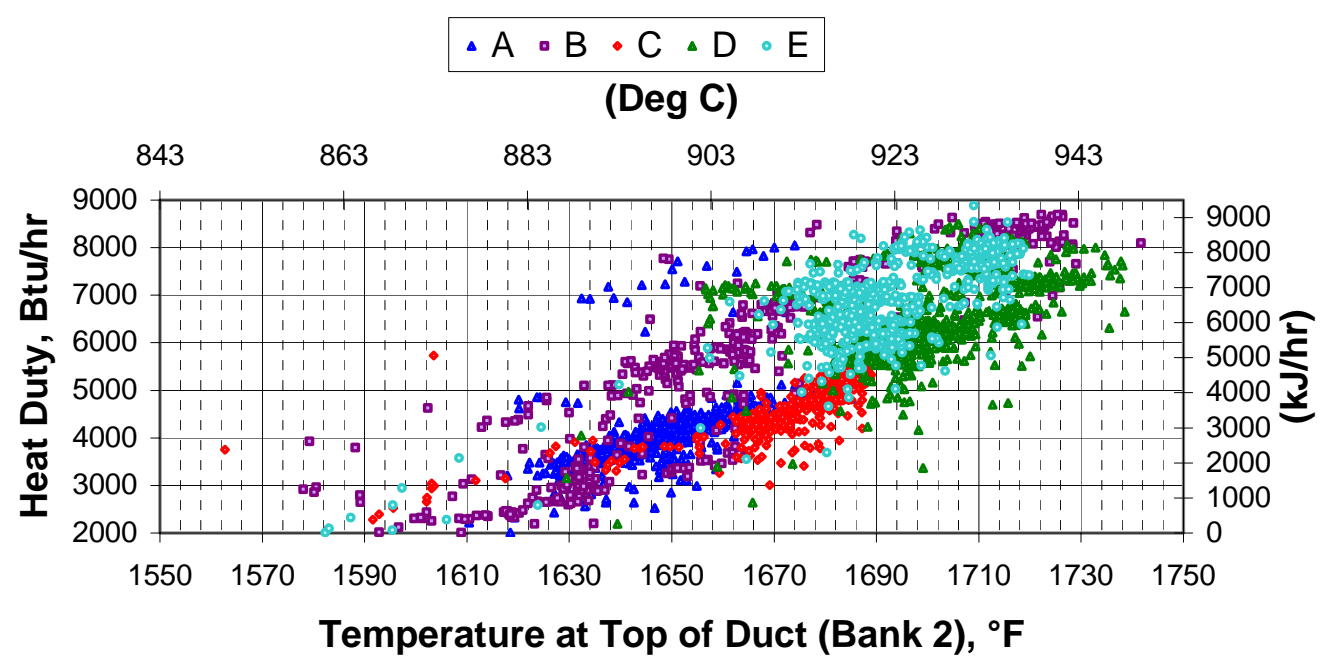

Figure 3.38: Heat Duty of Convective Probe Bank 2

Comparing the lime-only tests, we see that the heat duty is higher with oxygen firing for a comparable temperature (Test Series B vs. A). The increase is less marked with limestone added to the furnace (C vs. D), but there seems to be some increase. The heat duty clearly increases with pet coke firing, but there is no air-fired test for comparison.

\section{Fouling of the Convective Probes}

Throughout the test week, the convective pass fouling probes were observed - no severe buildup was seen. At the end of the test, the weakly bonded deposit that was present was easily removed.

The deposit was analyzed (see Table 3.9). The deposit was 90\% inert, probably mostly from fine clay in the ash. The calcium in the deposit was about $15 \% \mathrm{CaCO}_{3}$ and the rest $\mathrm{CaSO}_{4}$.

\subsubsection{Moving Bed Heat Exchanger}

The use of a moving bed heat exchanger (MBHE) instead of a conventional FBHE provides a number of significant advantages. A FBHE would need to be fluidized with either high-pressure flue gas or with fluidizing air. The use of flue gas would require a high-pressure recirculation fan that would be expensive, and require maintenance. The presence of $\mathrm{CO}_{2}$ in the fluidizing gas would also increase the potential for recarbonation and agglomeration in the FBHE. Using fluidizing air would eliminate the potential for recarbonation, but would add additional requirements for ash separation, cleaning, and cooling of the air since it cannot be combined with the concentrated $\mathrm{CO}_{2}$ stream leaving the CFB. In either case, the FBHE will have higher auxiliary power requirements and will present arrangement issues for units with a large number of cyclones and FBHEs.

The use of the MBHE mitigates these issues. Solids flow through the MBHE by gravity. It does not require any high pressure fluidizing air or gas. This eliminates the potential for recarbonation or the need for fluidizing air cleanup and cooling. It also results in a much lower auxiliary power requirement than a FBHE. The MBHEs can be designed for 
larger heat duties than FBHEs. Large $\mathrm{O}_{2}$-fired CFB can therefore be designed with a fewer number of MBHEs than FBHEs, which results in a more compact and less expensive plant arrangement.

A moving bed heat exchanger (MBHE) was installed in the MTF to cool re-circulated ash. Solids flow by gravity through a horizontal tube bundle consisting of spiral-finned tubes. A seal leg and a flow control device that prevent air or flue gas permeation through the solids control the solids flow rate. This reduces the potential for recarbonation $\left(\mathrm{CaO}+\mathrm{CO}_{2} \rightarrow \mathrm{CaCO}_{3}\right)$ in the re-circulated ash as it is cooled before being returned to the combustion chamber. There is also an operating cost advantage for the facility in that relatively expensive steam, $\mathrm{N}_{2}$, or $\mathrm{CO}_{2}$ gases are not required for fluidization.

The MBHE tube bundle arrangement is a multi-pass layout which may have counter flow and parallel flow sections. In commercial applications, the coolant would be superheated or reheated steam. The counter flow arrangement reduces the amount of tubing pressure parts because the higher log-mean temperature difference between the solids and coolant. A parallel arrangement may be used in finishing sections to minimize the metal temperature-stress requirements at the coolant outlet end.

Heat is transferred directly from particles in contact with the tube-fin surface. Particles are mixed as they travel from one pass to another giving good heat transfer. While this holds for conventional CFB coal fired ash solids, there was some question whether the heat transfer would be affected by variations in fuel ash properties or CFB inert bed material, particularly with $\mathrm{O}_{2}$ firing. The test results reported here are of interest for this reason.

The MBHE used for this test is shown in Figure 3.39. It was installed in parallel with a fluidized bed heat exchanger used for conventional MTF CFB firing. Solids were supplied to the top nozzle of the MBHE by a side slip stream from the MTF cyclone seal pot. A rotary valve at the bottom controlled solids flow through the MBHE. The MBHE was previously fabricated and installed in the MTF to evaluate heat transfer performance for earlier projects.

The MBHE consisted of two tube bundles shown in Figure 3.39, the upper having 4 tubes in depth and the lower having 6 tubes in depth. Each bundle was seven tubes wide. The bundles consisted of $38.1 \mathrm{~mm}$ (1.5") OD tubes with $12.7 \mathrm{~mm}\left(0.5^{\prime \prime}\right)$ high by $1.52 \mathrm{~mm}$ (0.06") thick circumferential fins on $38.1 \mathrm{~mm}\left(0.5^{\prime \prime}\right)$ spacing. The tubes were T22 alloy and the fins were Armco 409 alloy. Tube spacing was offset with $\mathrm{S}_{\mathrm{T}}=63.5 \mathrm{~mm}\left(2.5^{\prime \prime}\right)$ and $\mathrm{S}_{\mathrm{L}}=47.63 \mathrm{~mm}\left(1.875^{\prime \prime}\right)$, where $\mathrm{S}_{\mathrm{T}}$ is center-to-center spacing in the transverse direction and $\mathrm{S}_{\mathrm{L}}$ is center-to-center spacing in the longitudinal direction.

A photograph of the MBHE installation in the MTF is shown in Figure 3.40. The main metal enclosure containing refractory insulation and the tube bundles are shown. Also, the uninsulated coolant inlet headers and insulated coolant outlet headers are shown on the right. Solids are admitted to the top of the MBHE from the deck above, and exit below the deck supporting the MBHE. A 55-gallon metal drum in the background indicates the scale of the MBHE.

Instruments were installed on the MBHE to measure its performance. The primary 
instruments were type $\mathrm{K}$ thermocouples to measure solids inlet and outlet temperatures and the tube bundle coolant inlet and outlet temperatures. In addition, two turbine meters measured cooling water flow in each bundle. All instruments were read by the MTF LabView data acquisition system and stored on the PPL server network for later analysis.

The tube bundles were cooled by local Metropolitan District Commissions (MDC) water of high purity. A precision turbine meter measured the water flow rate. The MBHE heat transfer rate was determined for each bundle, using the cooling water as a heat flow medium. The inlet temperature of the coolant was measured by two inlet header thermocouples. The outlet temperature of each pass of a tube bundle was measured by a thermocouple inserted axially through the header into the outlet of the tube to a depth of $203.2 \mathrm{~mm}$ (8 inches). A boundary layer trip ring was installed in each tube outlet upstream from the thermocouple to provide a mixed fluid temperature. The average heat flow to a bundle was calculated from the average inlet-outlet temperature difference, coolant flow rate, and coolant specific heat.

The solids flow rate through the heat exchanger was calculated from the solids average inlet-outlet temperature difference, MBHE heat flow, and solids specific heat. The rotary valve could also have been used as a solids flow meter, but it was un-calibrated. Also, rotary valves are volumetric devices and the pockets in the valve may not be full under some circumstances. The heat balance method of calculating solids flow rates was preferred because of this.

An intermediate solids temperature between tube bundles was calculated from the average solids inlet temperature, top tube bundle heat transfer, calculated solids flow rate, and solids specific heat. This solids temperature was calculated because the spacing between top and bottom bundles was too small for an accurate temperature measurement by thermocouples.

The average inlet $\left(\mathrm{T}_{\mathrm{si} \text { avg }}\right)$ and outlet solids temperatures $\left(\mathrm{T}_{\mathrm{so} \text { avg }}\right)$ for this test campaign are shown in Figure 3.41. The solids inlet temperatures ranged from 760 to $870{ }^{\circ} \mathrm{C}$ (1400 to $1600{ }^{\circ} \mathrm{F}$ ) during the test campaign, depending on the combustion test conditions of the project. Both tube bundles were in service during the test. The average measured solids outlet temperature was very low and approached the cooling water inlet temperature in some cases. Because there were no solids thermocouples between the tube bundles as explained previously, an intermediate solids temperature between the upper and lower tube bundles $\left(\mathrm{T}_{\text {smu calc }}\right)$ was calculated. This temperature was determined using a solids flow, tube bundle heat transfer, and solids inlet temperature as shown. Measured test data is indicated by lines on these figures. Predicted conditions are indicated by the symbols. A calculation design procedure was used to predict the solids outlet temperature for each tube bundle and the results are shown as symbols at selected times for each tube bundle. There is good agreement between predicted and measured temperatures except for those low load tests where the lower bundle outlet solids temperature approaches the coolant temperature.

The heat transfer to the coolant in the upper $\left(\mathrm{Q}_{\mathrm{u} \text { avg }}\right)$ and lower tube bundles $\left(\mathrm{Q}_{1 \text { avg }}\right)$ is shown in Figure 3.42. The solids flow rate $\left(\mathrm{W}_{\mathrm{s} \text { avg }}\right)$ through the MBHE is also shown. The heat transfer in the MBHE is governed by the log-mean temperature difference (LMTD) between solids and coolant, surface area, fin effectiveness, solids velocity, and 
solids thermal properties. MBHE heat transfer does not significantly change with anything other than the LMTD. The LMTD does change with the solids flow rate. The results of Figure 3.42 show the close relationship between solids flow rate and heat transfer. A calculation design procedure was used to predict the coolant heat flow for each tube bundle and the results are shown as symbols at selected times for each tube bundle. There is good agreement between predicted and measured heat transfer.

Also shown in Figure 3.42 are bars indicating operating conditions in the MTF. Comparisons of differences between measured and predicted heat transfer do not show a significant influence of operating conditions.

The solids flow was selected from the test matrix of the $\mathrm{O}_{2}$ firing test program. This program was designed primarily for analysis of the combustion and emission characteristics of $\mathrm{O}_{2}$ firing and not for MBHE performance. The solids flow through the MBHE was changed as determined by the firing requirements, not MBHE requirements.

The difference between measured and calculated heat transfer does not significantly vary from test to test. This indicates that neither $\mathrm{O}_{2}$ vs. air firing, coal vs. pet coke firing, nor limestone variation have a significant influence MBHE heat transfer performance.

The heat transfer calculation procedure for the MBHE is similar to a convective pass section of a conventional boiler. However, the spiral fin heat transfer calculation procedure was refined for the MBHE application. The calculation procedure is complicated by the heat transfer performance being affected by both the fin effectiveness and by the solids-coolant log mean temperature difference. Fin effectiveness is governed by the surface heat transfer coefficient. The surface heat transfer coefficient is governed by solids transport properties, particle size, and solids flow distribution. At the same time, the solids and coolant specific heats are temperature dependant. For this reason, the heat transfer calculation procedure is iterative and gives correct results when the heat transfer for both coolant and solids converge. This procedure has been developed from a series of previous tests on MBHE performance and the conditions of this campaign confirm its validity for $\mathrm{O}_{2}$ firing as well as other applications.

In summary

- The MBHE performed as expected in terms of heat transfer. Also, the performance did not deteriorate or change due to changes in firing conditions of the test campaign; load, fuel, limestone, or air vs. $\mathrm{O}_{2}$.

- The MBHE performance did not change with time due to fouling of the heat transfer surface, or experience loss of solids flow due to agglomeration

- The MBHE was opened for inspection after the test campaign and the surfaces were found to be clean with no evidence of solids accumulation. 
Table 3.15: Moving Bed Heat Exchanger (MBHE) Test Data Summary

\begin{tabular}{|c|c|c|c|c|c|}
\hline \multirow[t]{2}{*}{ Date } & \multirow[t]{2}{*}{ Condition } & \multicolumn{2}{|c|}{$\mathrm{Qu}_{\text {measured }}$} & \multicolumn{2}{|c|}{$\mathrm{QI}_{\text {measured }}$} \\
\hline & & Btu/h & $\mathrm{kJ} / \mathrm{h}$ & Btu/h & $\mathrm{kJ} / \mathrm{h}$ \\
\hline 6/19 00:02 & Bit Coal/Air/ATF40 & $4.09 E+05$ & $4.31 E+05$ & $9.70 \mathrm{E}+04$ & $1.02 \mathrm{E}+05$ \\
\hline 6/19 06:32 & $\begin{array}{l}\text { Bit Coal/Air/ATF40/ } \\
\text { Low Load }\end{array}$ & $2.64 \mathrm{E}+05$ & $2.79 E+05$ & $4.32 E+04$ & $4.56 \mathrm{E}+04$ \\
\hline 6/19 20:02 & Bit Coal/O $/ \mathrm{O}_{2} / \mathrm{ATF} 40$ & $4.89 E+05$ & $5.16 \mathrm{E}+05$ & $1.67 \mathrm{E}+05$ & $1.76 \mathrm{E}+05$ \\
\hline 6/20 01:07 & Bit Coal/O $/ \mathrm{O}_{2} / \mathrm{ATF} 40$ & $7.71 E+05$ & $8.13 E+05$ & $4.34 \mathrm{E}+05$ & $4.58 E+05$ \\
\hline $6 / 2019: 03$ & Bit Coal/O $/$ /Aragonite & $7.73 E+05$ & $8.16 \mathrm{E}+05$ & $4.38 \mathrm{E}+05$ & $4.62 E+05$ \\
\hline $6 / 2112: 01$ & Petcoke/ $\mathrm{O}_{2} /$ Aragonite & $7.59 \mathrm{E}+05$ & $8.01 E+05$ & $4.00 \mathrm{E}+05$ & $4.22 E+05$ \\
\hline
\end{tabular}


COMMERCIALIZATION DEVELOPMENT OF OXYGEN FIRED CFB
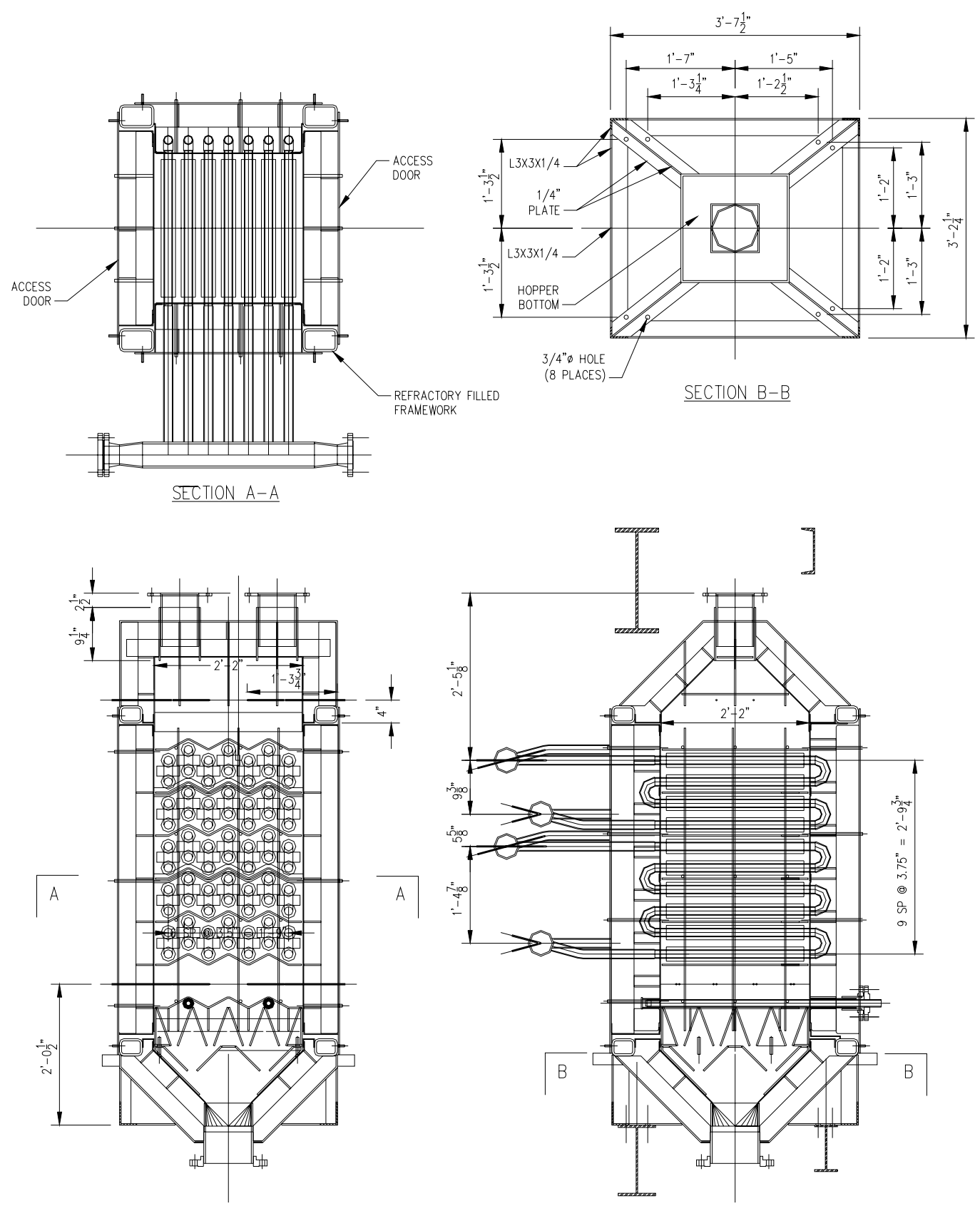

Figure 3.39: Moving Bed Heat Exchanger Sectional Views 


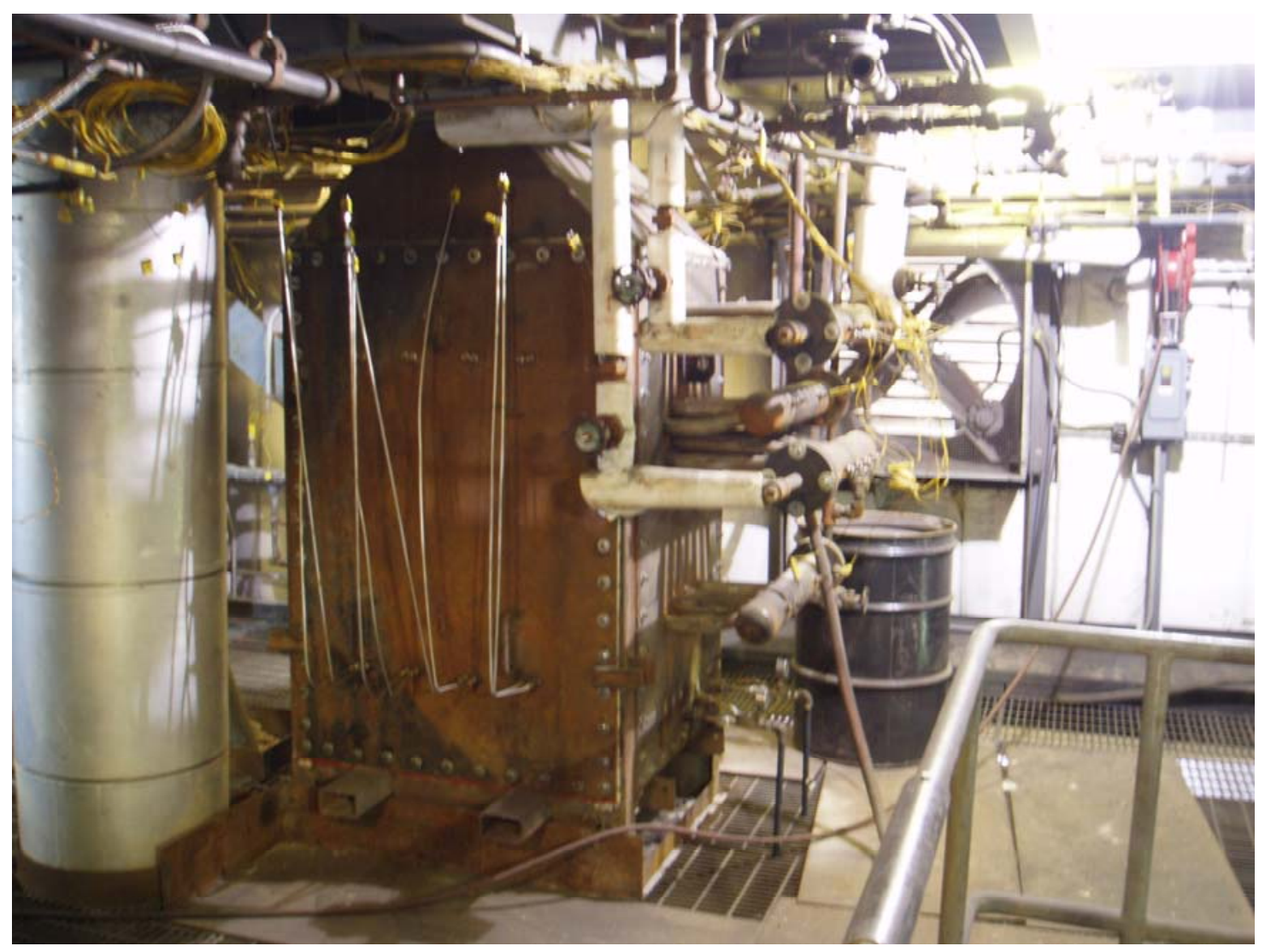

Figure 3.40: Moving Bed Heat Exchanger

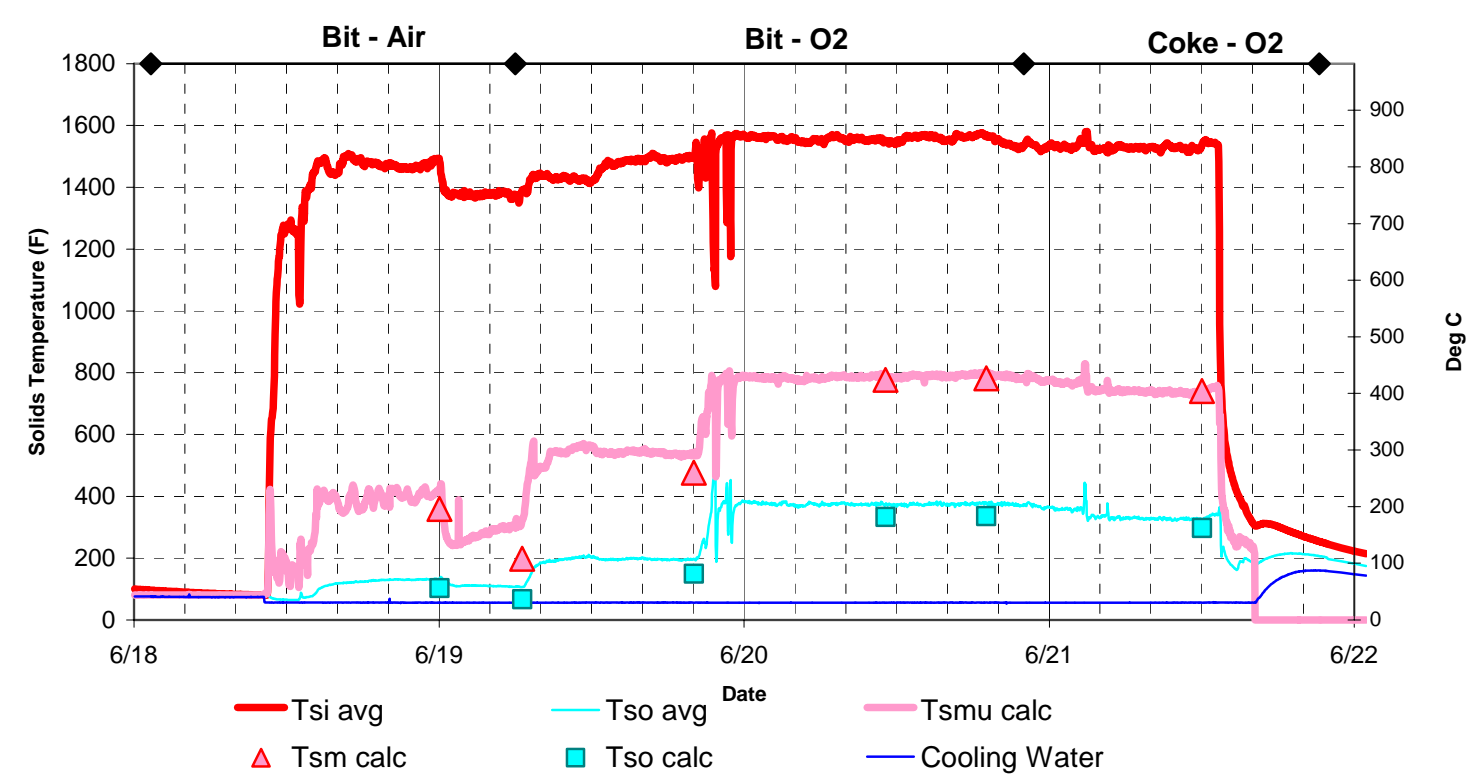

Figure 3.41: Moving Bed Heat Exchanger Average Solids Temperatures 

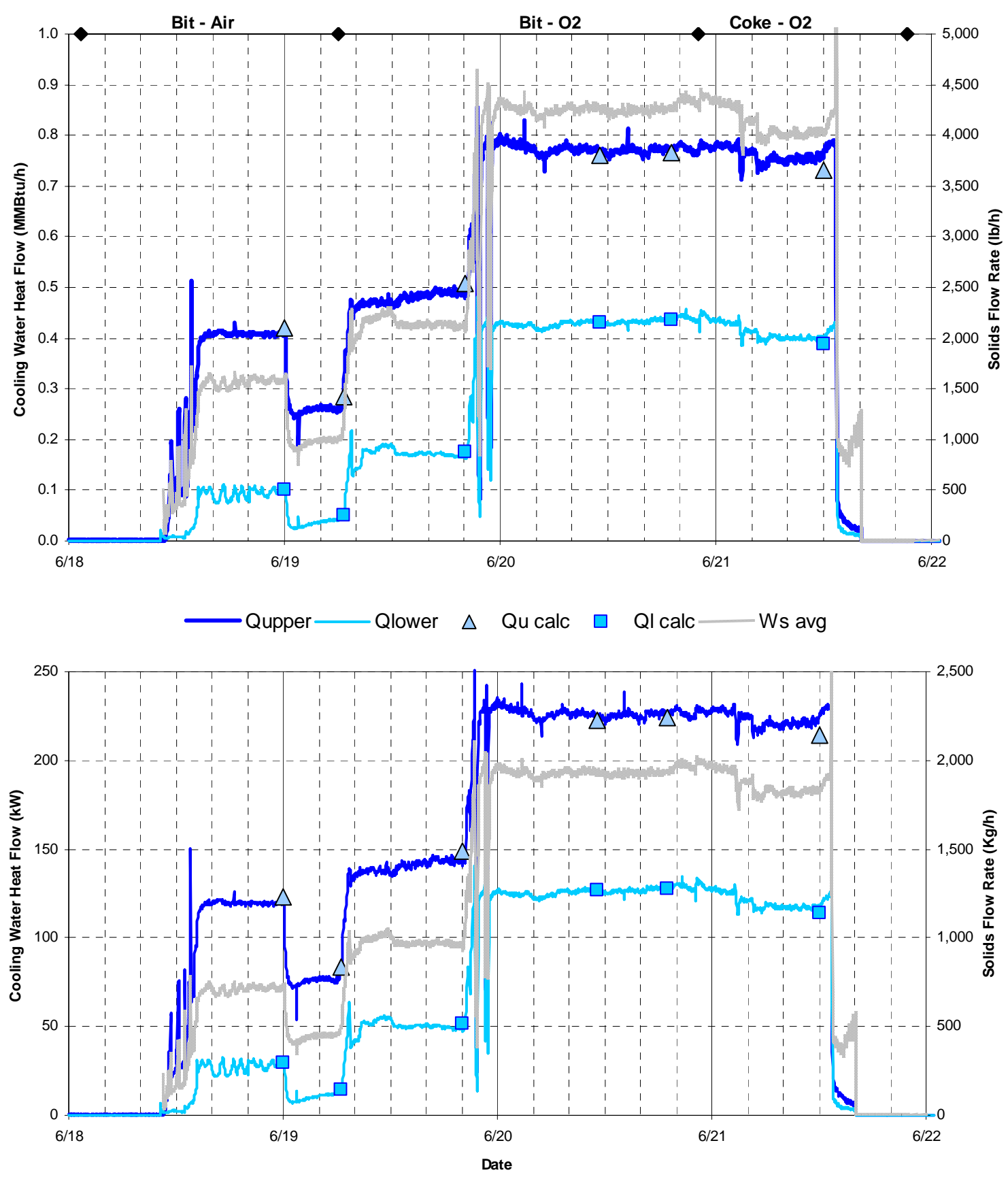

Figure 3.42: Moving Bed Heat Exchanger Solids and Heat Flows 


\subsection{Summary of Pilot Scale Test Results}

The main results from the 2005 pilot scale testing are summarized here.

- There were no operational problems due to recarbonation or any other issues due to the oxygen firing.

- The sulfur capture with lime only to the back-end baghouse/FDA system was slightly lower with oxygen firing compared to air firing. There is evidence of some $\mathrm{CO}_{2}$ being captured in the FDA, along with the $\mathrm{SO}_{2}$.

- The sulfur capture in the furnace with limestone addition was higher with oxygen firing than with air firing. This was likely due in part to lower velocity with oxyfiring (longer residence time) and in part to more calcium in the furnace inventory during the oxygen fired tests.

- Because of the higher capture in the furnace, the $\mathrm{SO}_{2}$ entering the FDA was lower with oxygen firing. The percentage sulfur reduction across the FDA was similar for air and oxygen firing.

- As expected, the $\mathrm{NO}_{\mathrm{x}}$ emissions were low with oxygen firing. Ammonia addition further reduced the $\mathrm{NO}_{\mathrm{x}}$ emissions. When the base $\mathrm{NO}_{\mathrm{x}}$ level was very low (50 ppmv), high stoichiometric ratios were required, which could lead to high ammonia slip. When $\mathrm{NO}_{\mathrm{x}}$ emissions were somewhat higher (100 ppmv), more reasonable amounts of ammonia achieved about $50 \%$ reduction.

- $\mathrm{CO}$ emissions from bituminous were higher with oxygen firing than with air firing. This is likely due to the high $\mathrm{CO}_{2}$ partial pressure in the flue gas suppressing the oxidation of $\mathrm{CO}$. The $\mathrm{CO}$ emissions from pet coke were quite low with oxygen firing. (No air firing was done with pet coke for comparison, but $\mathrm{CO}$ is typically low.)

- The $\mathrm{N}_{2} \mathrm{O}$ and VOC emissions were low under all circumstances.

- The heat loss due to unburned carbon in the fly ash is slightly less with oxygen firing compared to air firing.

- The emissions of mercury and other trace metals when oxy-firing were at least as low as with air firing.

- The MBHE performed as expected in terms of heat transfer. Also, the performance did not deteriorate or change due to changes in firing conditions of the test campaign; load, fuel, limestone, or air vs. $\mathrm{O}_{2}$.

- The MBHE performance did not change with time due to fouling of the heat transfer surface, or experience loss of solids flow due to agglomeration

- The MBHE was opened for inspection after the test campaign and the surfaces were found to be clean with no evidence of solids accumulation. 


\section{TECHNO-ECONOMIC EVALUATIONS}

This section describes the technical and economic evaluation results, which come from the two related case studies that are defined in this report. The two cases studied include Case-1: an existing air fired CFB steam plant base case and Case-2: a retrofit of the existing air fired CFB steam plant with oxygen firing and $\mathrm{CO}_{2}$ capture. The selected existing study unit is described in Section 4.1 including the criteria used for selection while the performance and design basis for the study is defined in Section 4.2.

The results of this techno-economic evaluation are presented in terms of several categories including plant performance, investment cost requirements, and economic analyses. Descriptions of the major processes and of the major equipment used for these processes are also provided. The performance of the power plant both before and after retrofit to $\mathrm{CO}_{2}$ capture is presented in terms of the associated energy and material balances as well as various plant performance summary tables and comparison graphs.

The performance results for the "business as usual" Case- 1 is shown in Section 4.3 and is used primarily for comparison with Case-2. The performance results for Case-2 with $\mathrm{O}_{2}$ firing and $\mathrm{CO}_{2}$ capture are shown in Section 4.4. Retrofit modifications are described with major equipment shown on general arrangement drawings. Retrofit investment cost estimates and operating and maintenance costs are shown in Section 4.5. Finally, economic evaluation results are shown in Section 4.6, which fully quantifies the economic impacts of retrofitting this unit to $\mathrm{O}_{2}$ firing and $\mathrm{CO}_{2}$ capture.

Brief descriptions of the two study cases (Case-1 and Case-2) are presented below with more detailed descriptions provided later in Sections 4.3 and 4.4, respectively.

Case-1: Existing CFB steam power plant without $\mathrm{CO}_{2}$ Capture (Base Case).

Conventional existing air-fired CFB based steam power plant ( $90 \mathrm{MWe}-\mathrm{net})$ without $\mathrm{CO}_{2}$ capture using a subcritical pressure steam cycle with the following steam conditions: 138 bara $/ 538^{\circ} \mathrm{C} / 538^{\circ} \mathrm{C}, 7.6 \mathrm{~cm} \mathrm{Hga}\left(2,000 \mathrm{psia} / 1,000^{\circ} \mathrm{F} / 1,000^{\circ} \mathrm{F}, 3.0 \mathrm{in} . \mathrm{Hga}\right)$.

Implication: Provides a reference point for comparison of performance \& economic analyses. Provides the existing plant to which the retrofit technology for $\mathrm{O}_{2}$ firing and $\mathrm{CO}_{2}$ capture are applied in Case-2.

Case-2: Retrofit of the Case- 1 existing power plant to oxygen firing with $\mathrm{CO}_{2}$ Capture, Purification, Compression and Liquefaction.

Oxygen is provided from a Cryogenic Air Separation Unit (ASU). The CFB Boiler Island provides a concentrated $\mathrm{CO}_{2}$ flue gas product stream to the Gas Processing System (GPS) where it is further purified, compressed and liquefied to meet a specification for an Enhanced Oil Recovery (EOR) application.

Implication: A near term $\mathrm{CO}_{2}$ capture concept. Cost savings for the Gas Processing System equipment as compared to current commercially available amine scrubbing systems. Improved plant thermal efficiency and lower net plant output reduction as compared to current commercialy available amine based $\mathrm{CO}_{2}$ capture systems (reduced energy penalty). 
The major new equipment for the Case- 2 retrofit concept in this study include:

- An Air Separation Unit with a nominal capacity of about 1,640 tonne (1,800 tons) of $\mathrm{O}_{2}$ per day.

- A Gas Processing System with a nominal capacity of about 1,910 tonne $(2,100$ tons) of $\mathrm{CO}_{2}$ per day including $\mathrm{CO}_{2}$ purification, compression, and liquefaction.

- Other equipment as required by the existing boiler and balance of plant systems to accommodate the retrofit to $\mathrm{O}_{2}$ firing and $\mathrm{CO}_{2}$ capture. The added equipment consists of primarily a new gas recirculation system, new $\mathrm{O}_{2}$ supply piping, a new FDA $\mathrm{SO}_{2}$ removal system, controls/instrumentation for the $\mathrm{O}_{2}$ firing and gas recirculation systems, and integration of a new low level heat recovery system into the existing steam cycle.

\subsection{Study Unit Selection and Description}

This section of the report provides a description of the selected study unit and includes the criteria used for selection of the existing unit. The selection criteria were developed such that the results of this study would be helpful when an actual large scale technology demonstration was undertaken.

\subsubsection{Study Unit Selection Criteria}

The study unit selected for this conceptual retrofit design study (retrofit to $\mathrm{O}_{2}$ firing and $\mathrm{CO}_{2}$ capture) was chosen on the basis of the following criteria:

1. An existing CFB unit of ALSTOM design, thus ensuring that all original boiler design and performance information are available

2. A unit encompassing all major conventional features of a commercial CFB plant:

- Boiler Island - furnace, cyclone, external fluidized bed heat exchanger, convective pass, baghouse, and ID/FD fans

- Balance of Plant - Fuel and sorbent preparation and conveyance infrastructure, steam turbine, and generator

3. A unit ranging in size from 50-100 MWe. This represents an appropriate size for a technology demonstration project, from both a technical and project cost standpoint. The size of the selected existing unit is small relative to today's capabilities, so that the results of this study would be applicable for a future technology demonstration. It was recognized however that selection of a small unit would cause greater retrofit specific cost $(\$ / \mathrm{kW})$ and economic impacts (incremental $\mathrm{COE}, \mathrm{CO}_{2}$ mitigation cost), as compared to studies using much larger study units, due to "economy of scale" effects.

4. A unit located in the United States, which should facilitate the actual search in the future for a unit to demonstrate the $\mathrm{O}_{2}$ firing technology at large scale in North America

5. A unit burning coal, petroleum coke or a mixture thereof.

Based on the preceding criteria, the unit described in Section 4.1.2 below was selected for 
the current conceptual retrofit design study. The selected unit met all the above selection criteria.

\subsubsection{Study Unit Description}

The power plant analyzed in this study is an existing coal burning steam power plant. The coal is combusted in a relatively small CFB steam generator unit of ALSTOM design. A general arrangement side elevation drawing of the study unit CFB boiler is shown in Figure 4.1. (Additional drawings are shown in Section 7.1.) This boiler is a nominal 90 MWe-net CFB unit, which supplies steam to a subcritical pressure steam cycle. The CFB boiler is one of four identical units at the site. The four boilers supply steam to two steam turbines. The furnace of the selected unit is a single cell design that fires medium volatile bituminous coal. The unit has two cyclones and two external fluidized bed heat exchangers (FBHE's). This unit is representative in many ways of a large number of coal fired CFB units in use today. The unit is designed to generate about $284,401 \mathrm{~kg} / \mathrm{hr}(627,000 \mathrm{lbm} / \mathrm{hr})$ of steam at full load at $138 \mathrm{bara}(2,000 \mathrm{psia})$ and $538^{\circ} \mathrm{C}$ $\left(1005^{\circ} \mathrm{F}\right)$ with reheat also to $538^{\circ} \mathrm{C}\left(1005^{\circ} \mathrm{F}\right)$. These are fairly common steam cycle operating conditions for utility scale CFB based power generation systems in operation today.

\section{Combustor:}

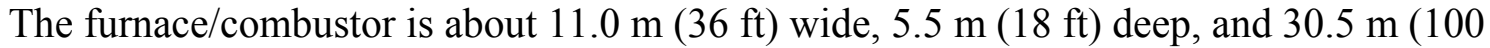
$\mathrm{ft}$ ) high. Crushed coal, limestone and preheated air are supplied to the furnace where combustion occurs. Injection of limestone into the furnace is provided to remove sulfur dioxide from the flue gas by converting it to $\mathrm{CaSO}_{4}$. Bed material $\left(\mathrm{CaSO}_{4}\right.$, unreacted lime, ash, and small amounts of unburned carbon) is continuously drained to remove captured sulfur and ash and to control furnace solids inventory.

\section{Cyclones, Seal Pots and Solids Control Valves:}

A mixture of hot flue gas and entrained solids leaves the furnace and enters two $6.4 \mathrm{~m}$ (21 $\mathrm{ft}$ ) diameter cyclones that separate the flue gas from the solids. The hot solids separated in the cyclone flow through a seal pot and a solids control valve. The seal pot provides a pressure seal to prevent gas flowing from the combustor through the solids piping system into the cyclone bottom, which is at a lower pressure. The solids control valve is used to control steam outlet temperatures by biasing hot solids either directly back to the furnace or through the FBHE's that are used to cool the solids by heating steam.

\section{Fluid Bed Heat Exchangers:}

The FBHE's contain tube banks (superheater, reheater and evaporator sections), which exchange heat with the hot solids from the cyclones. The FBHE's are fluidized with air such that the solids continuously move through the FBHE's and back to the furnace. The air used for fluidization is supplied from the fluidizing air blowers. Outlet steam temperature is controlled by adjusting the solids flow through the FBHE's and with desuperheating spray.

\section{Backpass:}

The flue gas leaving the cyclones enters the rear pass, which includes a low temperature superheater, a low temperature reheater, and an economizer section, which preheats the feedwater prior to evaporation. 


\begin{abstract}
Air Heater:
Flue gas leaving the rear pass economizer section enters an air heater. The air heater used in this unit is a Heat Pipe (Q-Pipe) type regenerative air heater, which cools the flue gas by ultimately providing heat to both the primary and secondary air streams. The heat is transferred from the flue gas to the air within the air heater via a separate fluid contained within sloped tubes. The fluid within the tubes evaporates on the hot flue gas side, flows up to the cold air side where it is condensed and then flows back to the hot side to complete its cycle. Because of its design, this type of air heater does not leak any of the relatively high-pressure air into the relatively low-pressure flue gas stream.
\end{abstract}

\title{
Baghouse:
}

Particulate matter is removed from the cooled flue gas leaving the air heater in a fabric filter (baghouse). The flue gas is drawn through the unit with the induced draft fan (located downstream of the baghouse) and is then exhausted to the atmosphere through the common stack (common to the four boilers). The induced draft fan and forced draft system (primary air fan, secondary air fan, and fluidizing air blowers) are controlled to operate the unit in a balanced draft mode with the cyclone outlet maintained at a slightly negative pressure, typically about $-1.3 \mathrm{~cm} \mathrm{wg}(-0.5 \mathrm{in} \mathrm{wg)}$.

\section{Water/Steam Circuit:}

The water/steam circuit within the CFB boiler starts with the economizer where warm feedwater is provided from the final extraction feedwater heater. Water leaving the economizer enters the steam drum. This water mixes with recirculated water within the drum and the mixture is circulated through the furnace walls and evaporator bank located within one of the FBHE's where evaporation takes place. The steam/water mixture leaving these evaporator sections is returned to the steam drum where the steam and water are separated. The water is recirculated through the evaporator sections as described above and the separated steam flows to the superheater circuit.

The superheater is divided into two major sections. Saturated steam leaving the steam drum first cools the roof and rear pass walls before supplying the low temperature superheater section. The low temperature superheater section is located in the rear pass of the unit and is a horizontal section. Steam leaving the low temperature superheater section first flows through the de-superheater spray station which is used for final steam temperature control and then to the finishing superheater sections located in one of two external FBHE's. Steam leaving the finishing superheater is piped to the high-pressure turbine where it is expanded to reheat pressure.

The steam exits the HP turbine exhaust flange and is piped to the reheater circuit. The reheater circuit starts with the reheat de-superheating spray station. Steam leaving the spray station flows to two reheater sections in series, a low temperature section followed by a finishing section. The low temperature reheater section is located in the rear pass of the unit. Steam leaving the low temperature reheater is piped to the finishing reheat section, which is located in one of the two external FBHE's.

The steam leaving the finishing reheater section is returned to the intermediate pressure turbine where it continues its expansion through the intermediate and low-pressure turbines for power generation before being exhausted to the condenser. The steam turbine generator produces about $100 \mathrm{MWe}$ at Maximum Continuous Rating (MCR). The steam 
cycle has six feedwater heaters (three low-pressure heaters, a deaerator, and two highpressure heaters) where the feedwater is preheated to about $237.8^{\circ} \mathrm{C}\left(460{ }^{\circ} \mathrm{F}\right)$ before entering the economizer of the CFB steam generator unit. The boiler feed pump is electric motor driven. 


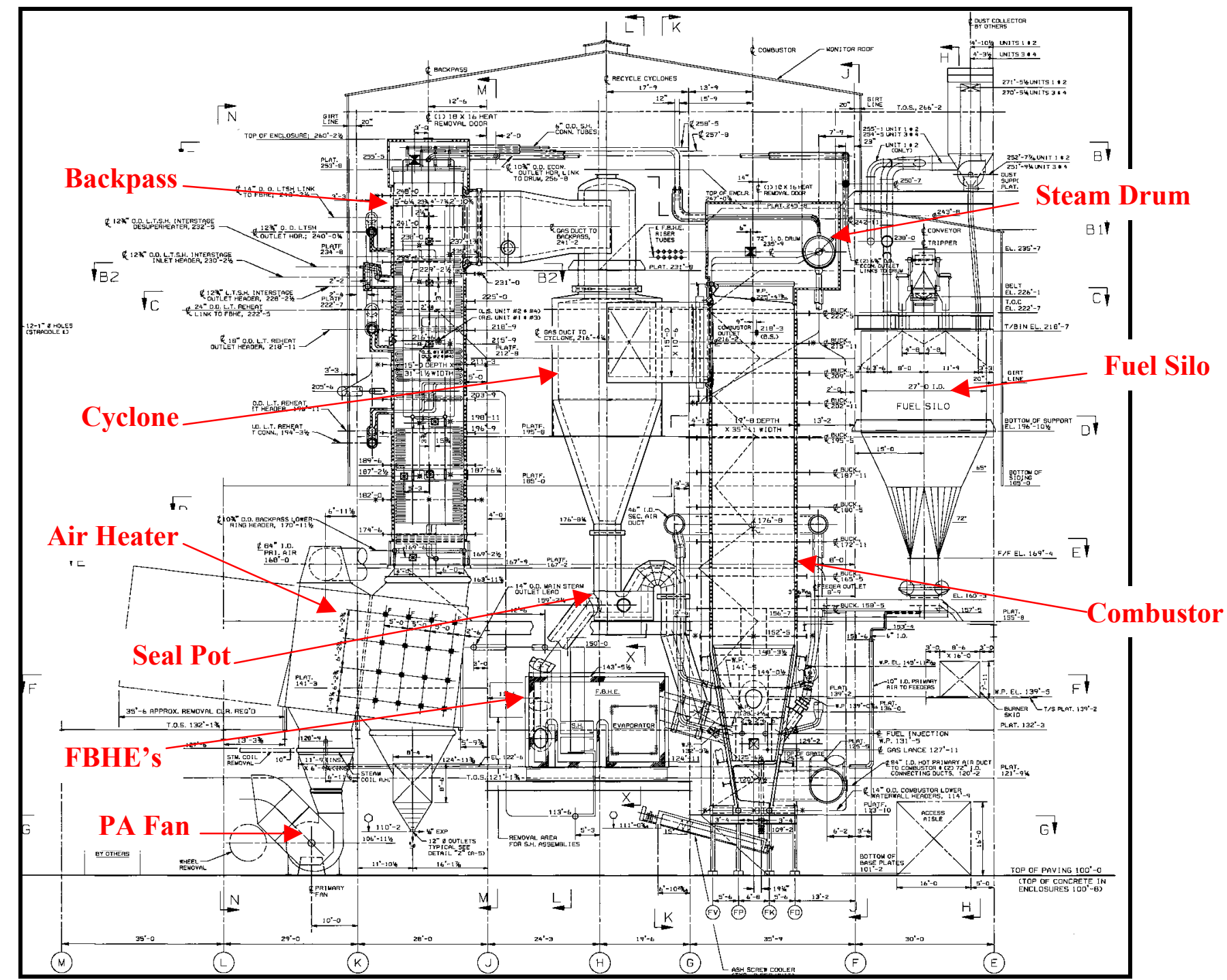

Figure 4.1: Study Unit (Existing CFB Steam Generator) Sectional Side Elevation Drawing 


\subsection{Plant Performance Basis, Equipment Design Basis, and Project Scope}

This section describes the basis for plant performance calculations and equipment design for each of the two cases analyzed in this study. Included are descriptions of various common parameters for the two cases, the $\mathrm{CO}_{2}$ product specification used for the $\mathrm{CO}_{2}$ capture case (Case-2) and other design and performance bases used throughout the study. Additionally, the overall project scope is defined in this section.

The equipment design basis and the basis for plant performance calculations used in this study are similar to what was used in two previous studies (Marion, et al., 2003 and Nsakala, Liljedahl, and Turek, 2004).

\subsubsection{Common Parameters for Case Studies}

Plant performance calculations and retrofit equipment designs were based on many parameters that were common to both study cases including identical coal and limestone analyses, ambient conditions, site conditions, etc. In this manner, the impacts for the $\mathrm{O}_{2}$ fired $\mathrm{CO}_{2}$ capture technology are clearly quantified and fully attributable to the application of the $\mathrm{CO}_{2}$ capture technology and not shifted due to assumption differences between the cases. The common items between the two cases are described in this section.

\section{Consumables:}

Table 4.1 shows the design coal analysis which was used for both cases in this study. The coal is classified as a medium volatile bituminous coal and is representative of the range of coals that are currently used at this site. Table 4.2 shows the limestone analysis that was added to the furnace for $\mathrm{SO}_{2}$ capture in Case-1 only.

Table 4.1: Design Coal Analysis (Medium Volatile Bituminous)

\begin{tabular}{|l|c||c|}
\hline Constituent & (Units) & \\
\hline \hline $\mathrm{O}_{2}$ & (wt. frac.) & 0.0218 \\
$\mathrm{~N}_{2}$ & $"$ & 0.0123 \\
$\mathrm{H}_{2} \mathrm{O}$ & $"$ & 0.0417 \\
$\mathrm{H}_{2}$ & $"$ & 0.0293 \\
Carbon & $"$ & 0.6217 \\
Sulfur & $"$ & 0.0251 \\
Ash & $"$ & 0.2481 \\
\hline \hline Total & $"$ & 1.0000 \\
\hline \hline & & \\
HHV Coal & $(\mathrm{Btu} / \mathrm{lbm})$ & 11,103 \\
& $(\mathrm{~kJ} / \mathrm{kg})$ & 23,201 \\
\hline
\end{tabular}


Table 4.2: Design Limestone Analysis

\begin{tabular}{|l||c|c|}
\hline Constituent & (Units) & \\
\hline \hline $\mathrm{CaCO}_{3}$ & (wt. frac.) & $\mathbf{0 . 9 8 3 0}$ \\
Moisture & $"$ & 0.0000 \\
Ash & $"$ & 0.0170 \\
\hline \hline Total & $"$ & 1.0000 \\
\hline
\end{tabular}

In Case-2, instead of limestone, a mixture of lime $(\mathrm{CaO})$ and water was added in the new Flash Dryer Absorber system for $\mathrm{SO}_{2}$ capture. Limestone was not added to the furnace in Case-2, due to concerns regarding recarbonation. For the purpose of this study, the lime was assumed to be pure Calcium Oxide $(\mathrm{CaO})$.

Additionally, a small quantity of natural gas is used in Case-2 for desiccant drying in both the Gas Processing System and Air Separation Unit. For the purpose of this study, the natural gas was assumed to be pure Methane $\left(\mathrm{CH}_{4}\right)$ with a higher Heating Value (HHV) of $55,578 \mathrm{~kJ} / \mathrm{kg}(23,896 \mathrm{Btu} / \mathrm{lbm})$.

\section{Plant Ambient Design Conditions and Site Characteristics:}

The two plants included in this conceptual level study are both assumed to be located on a common existing site, and are assumed to be operated under common conditions of fuel, limestone, utility, and environmental standards. This section describes the existing host site conditions, which are used as a design basis for retrofitting the existing plant to $\mathrm{O}_{2}$ firing and $\mathrm{CO}_{2}$ capture.

Table 4.3 lists ambient and other relevant characteristic assumptions for this site. The ambient conditions used for all material and energy balances were based on the standard American Boiler Manufacturers Association (ABMA) atmospheric conditions (i.e., $26.7^{\circ} \mathrm{C}, 80^{\circ} \mathrm{F} ; 1.01$ bara, 14.7 psia; 60 percent relative humidity). Steam cycle calculations for both cases use a condenser pressure of 7.6 centimeters of mercury absolute (3.0 in Hga) as shown in Table 4.3. For equipment sizing the maximum dry bulb temperature is $35.0^{\circ} \mathrm{C}\left(95^{\circ} \mathrm{F}\right)$ and the minimum dry bulb temperature for mechanical design is $-6.7^{\circ} \mathrm{C}\left(20^{\circ} \mathrm{F}\right)$.

Table 4.3: Site Characteristics

\begin{tabular}{|l|c|c|c|}
\hline Design Parameter & Units & \multicolumn{2}{|c|}{ Value } \\
\hline Ash Disposal & & \multicolumn{2}{|c|}{ Off Site } \\
Water Source & & \multicolumn{2}{|c|}{ River } \\
Design Relative Humidity & percent & \multicolumn{2}{|c|}{60.0} \\
Elevation & $\mathrm{ft}, \mathrm{m}$ & 500 & 152.40 \\
Design Atmospheric Pressure & psia, bara & 14.7 & 1.01 \\
Design Temperature, dry bulb & ${ }^{\circ} \mathrm{F},{ }^{\circ} \mathrm{C}$ & 80 & 26.7 \\
Design Temperature, wet bulb & ${ }^{\circ} \mathrm{F},{ }^{\circ} \mathrm{C}$ & 52 & 11.1 \\
Design Condenser Pressure & in, $\mathrm{cm} \mathrm{Hga}$ & 3 & 7.62 \\
\hline
\end{tabular}


For costing purposes, the existing plant site is assumed to be located in the Gulf Coast region of southeastern Texas. The site consists of approximately $2.5 \mathrm{~km}^{2}$ (300 acres) usable within $24 \mathrm{~km}$ (15 miles) of a medium-sized metropolitan area, with a wellestablished infrastructure capable of supporting the required construction work force. The area immediately surrounding the site has a mixture of agricultural and light industrial uses. The site is served by a river of adequate quantity for use as makeup cooling water with minimal pretreatment and for the receipt of cooling system blowdown discharges.

A railroad line suitable for unit coal trains passes within $4 \mathrm{~km}(2-1 / 2$ miles $)$ of the site boundary. A well-developed road network serves the site, capable of carrying AASHTO H-20 S-16 loads and with overhead restriction of not less than 4.9 meters (16 feet) (Interstate Standard).

The site is on relatively flat land with a maximum difference in elevation within the site of about 9 meters (30 feet). The topography of the area surrounding the site is rolling hills, with elevations within 1,800 meters (2,000 yards) not more than 90 meters (300 feet) above the site elevation. The site is within Seismic Zone 1, as defined by the Uniform Building Code.

The following list further describes the assumed existing site characteristics available for the addition of the new ASU and GPS systems as well as other equipment added to the Boiler Island.

- The site is relatively clear and level with no characteristics that would cause any unusual construction problems.

- The structural strength of the soil is adequate for spread footings (no piling is required) at this site.

- No rock excavation is required on this site.

- An abundant sub-surface water supply is assumed available on this site.

Additionally, the following utilities are assumed to be available at the existing site.

- Communication lines

- Electrical power for plant retrofit construction

- Potable water and sanitary sewer connections

\section{Steam Cycle}

The steam cycle represents another common basis for both plants. It is nearly identical for Cases $1 \& 2$ differing only by the addition of a low-level heat recovery system for Case-2, which is used for recovery of heat rejected from the ASU. The steam turbine for the existing plant is a single reheat machine $\left(138 \mathrm{bara}, 2,000 \mathrm{psia} / 538{ }^{\circ} \mathrm{C}, 1,000^{\circ} \mathrm{F} / 538\right.$ $\left.{ }^{\circ} \mathrm{C}, 1,000{ }^{\circ} \mathrm{F}\right)$ with a main steam flow of $284,401 \mathrm{~kg} / \mathrm{hr}(627,000 \mathrm{lbm} / \mathrm{hr})$ and a condenser pressure of $7.6 \mathrm{~cm} \mathrm{Hga} \mathrm{(3.0} \mathrm{in} \mathrm{Hga).} \mathrm{The} \mathrm{cold} \mathrm{reheat} \mathrm{flow} \mathrm{is} 257,375 \mathrm{~kg} / \mathrm{hr}(567,416$ $\mathrm{lbm} / \mathrm{hr}$ ). The main steam flow and cold reheat steam flow is identical for Cases $1 \& 2$. Six extraction feedwater heaters are used to preheat the feedwater to $237.8^{\circ} \mathrm{C}\left(460{ }^{\circ} \mathrm{F}\right)$ 
for Case-1. In Case-2, the first two low-pressure feedwater heaters are partially bypassed by some of the condensate leaving the condensate pump, which supplies the new low level heat recovery system for heat recovery in the air separation unit. The heated condensate for Case- 2 is returned to existing extraction heater \#3 followed by the deaerator and the high-pressure extraction feedwater heaters where it is also heated to $237.8^{\circ} \mathrm{C}\left(460^{\circ} \mathrm{F}\right)$.

\subsubsection{Additional Design Bases Used for Case-2}

Several additional design bases were used which were specific to the retrofit case (Case2) only. These additional design bases included the $\mathrm{CO}_{2}$ product specification, the assumed available plant services, and the basis used for the design of added structures and foundations that are part of the plant retrofit.

\section{$\mathrm{CO}_{2}$ Product Specification}

The $\mathrm{CO}_{2}$ capture system for Case- 2 was designed for a minimum of 94 percent $\mathrm{CO}_{2}$ capture from the boiler flue gas stream. Table 4.4 shows the Dakota Gasification Project's $\mathrm{CO}_{2}$ Product Specification achieved for EOR (Dakota, 2005). This purity specification was used as a guideline for the Gas Processing System (GPS) design in this study. It should be understood that product purity specifications for the $\mathrm{CO}_{2}$ are very dependent on the individual oil field being flooded.

\section{Table 4.4: Dakota Gasification Project's $\mathrm{CO}_{2}$ Product Specification for EOR}

\begin{tabular}{|l|l|c|}
\hline Component & (units) & Value \\
\hline $\mathrm{CO}_{2}$ & $($ vol \%) & $\mathbf{9 6}$ \\
$\mathrm{H}_{2} \mathrm{~S}$ & $($ vol \%) & 1 \\
$\mathrm{CH}_{4}$ & $($ vol \%) & $\mathbf{0 . 3}$ \\
$\mathrm{C}_{2}+\mathrm{HC}^{\prime} \mathrm{S}$ & $($ vol \%) & 2 \\
$\mathrm{CO}$ & $($ vol \%) &.-- \\
$\mathrm{N}_{2}$ & $($ (ppm by vol.) & $\mathbf{6 0 0 0}$ \\
$\mathrm{H}_{2} \mathrm{O}$ & $($ (ppm by vol.) & 2 \\
$\mathrm{O}_{2}$ & $($ ppm by vol.) & $\mathbf{1 0 0}$ \\
Mercaptans and other Sulfides & (vol \%) & $\mathbf{0 . 0 3}$ \\
\hline
\end{tabular}

The nitrogen concentration in Table 4.4 is 6000 ppmv. It should be noted that according to Charles Fox of Kinder Morgan (Fox, 2002), a maximum nitrogen concentration of 4 percent (by volume) would be required to control the minimum miscibility pressure.

The $\mathrm{CO}_{2}$ product is provided in a liquid state at the plant boundary at 138 barg $(2,000$ psig). 


\section{Plant Services:}

The following services and support systems are assumed to be available at the plant as part of the existing balance-of-plant systems for use in the retrofit of the existing plant.

Auxiliary Power Systems:

- $7,200 \mathrm{~V}$ system for motors above $2,240 \mathrm{~kW}(3,000 \mathrm{hp})$.

- 4,160 V system for motors from 190 to $2,240 \mathrm{~kW}$ (250 to 3,000 hp).

- $480 \mathrm{~V}$ system for motors from 0 to $190 \mathrm{~kW}$ (0 to $250 \mathrm{hp}$ ) and miscellaneous loads.

- Emergency diesel generator (480 V) to supply loads required for safe and orderly plant shutdown. Instruments and controls and other loads requiring regulated (1percent) 208/120 Vac power are supplied from this source.

- $250 \mathrm{Vdc}$ system motors and, via static inverters, uninterruptible ac power for the integrated control and monitoring system intercommunication.

- 125 Vdc system for dc controls, emergency lighting, and critical tripping circuits including the plant shutdown system.

Cooling Water:

- Cooling water (from the cooling towers) is available at between 1.4 and 2.1 barg (20 and $30 \mathrm{psig}), 32.2^{\circ} \mathrm{C}\left(90^{\circ} \mathrm{F}\right)$ maximum temperature. The water is periodically chlorinated, and $\mathrm{pH}$ is maintained at 6.5 to 7.5 . The cooling towers receive makeup water from the river.

- Auxiliary cooling water, which uses de-mineralized water treated for corrosion control, at 4.1 to $5.5 \mathrm{barg}$ ( 60 to $80 \mathrm{psig})$ and $40.6^{\circ} \mathrm{C}\left(105^{\circ} \mathrm{F}\right)$, is available for small heat loads (e.g., control oil coolers). The $\mathrm{pH}$ is maintained at about 8.5.

Compressed Air:

- Instrument air filtered and dried to $-40^{\circ} \mathrm{C}\left(-40^{\circ} \mathrm{F}\right)$ dew point at 5.5 to 6.9 barg $(80$ $-100 \mathrm{psig})$ and $43^{\circ} \mathrm{C}\left(110^{\circ} \mathrm{F}\right)$ maximum.

- Service air at 5.5 to 6.9 barg (80 -100 psig) and $43^{\circ} \mathrm{C}\left(110^{\circ} \mathrm{F}\right)$ maximum.

Lube Oil:

- Lube oil from the conditioning system, with particulate matter removed to $10 \mu \mathrm{m}$ or lower.

Hydrogen and Carbon Dioxide:

- $\mathrm{H}_{2}$ and $\mathrm{CO}_{2}$ for generator cooling and purging from storage.

Nitrogen:

- $\mathrm{N}_{2}$ for equipment blanketing against corrosion during shutdown and lay-up.

Raw Water:

- Filtered river water. Additional water treatment will be included for potable water, etc. 


\section{Structures and Foundations:}

Structures are provided to support and permit access to all plant retrofit components requiring support to conform to the site criteria. The structure(s) are enclosed if deemed necessary to conform to the environmental conditions.

Foundations are provided for the support structures, pumps, tanks, and other plant components. A soil-bearing load of $24,400 \mathrm{~kg} / \mathrm{m}^{2}\left(5,000 \mathrm{lbm} / \mathrm{ft}^{2}\right)$ is used for foundation design.

\subsubsection{Project Scope}

The boundary limit for these plants includes the complete plant facility within the "fence line." It encompasses all equipment from the coal pile to the busbar and includes the coal receiving and water supply systems and terminates at the high-voltage side of the main power transformers. For the Case- 2 with $\mathrm{CO}_{2}$ capture, the boundary also includes the gas processing system and air separation unit and terminates at the outlet flange of the $\mathrm{CO}_{2}$ product pipe. It does not include the $\mathrm{CO}_{2}$ pipeline to the $\mathrm{EOR}$ site or the $\mathrm{CO}_{2}$ injection well. The scope of supply for the retrofit case (Case-2) is further defined by the following list.

- Oxygen supply system (cryogenic ASU)

- Gas processing system to produce the $\mathrm{CO}_{2}$ product gas (Distillation type system)

- Existing boiler modifications to accommodate $\mathrm{O}_{2}$ firing and $\mathrm{CO}_{2}$ capture

- Site preparation and site improvements as required for added equipment

- Foundations, buildings, and structures required for all added plant equipment and facilities

- General support facilities for administration, maintenance and storage

- Plant electrical distribution, lighting, and communication systems

- Instruments and controls

- Miscellaneous power plant equipment

The electrical facilities within the retrofit scope include all control equipment, service equipment, conduit and cable trays, all wire and cable. 


\subsection{Case-1: Existing CFB Power Plant, Air Fired without $\mathrm{CO}_{2}$ Capture (Base Case)}

Case- 1 represents the Base Case for this study. This case was included to provide a reference point for the comparison of performance $\&$ economic analyses results and also provides the existing plant definition to which the retrofit technology for $\mathrm{O}_{2}$ firing and $\mathrm{CO}_{2}$ capture are applied in Case- 2 .

Case-1 for this study is defined as the selected existing unit firing coal at full load, utilizing air as the oxidant, without capturing $\mathrm{CO}_{2}$ from the flue gas. This existing plant utilizes a subcritical steam cycle with reheat $\left(138\right.$ bara, 2,000 psia / $538{ }^{\circ} \mathrm{C}, 1,000{ }^{\circ} \mathrm{F} / 538$ ${ }^{\circ} \mathrm{C}, 1,000{ }^{\circ} \mathrm{F}$; $7.6 \mathrm{~cm} \mathrm{Hga,} 3.0$ in Hga). This represents the "business as usual" operating scenario and is used as the basis of comparison for the retrofit $\mathrm{CO}_{2}$ removal option investigated in this study (i.e., Case-2).

A brief performance summary for the Case-1 plant reveals the following information. The Case- 1 plant produces a net plant output of $90,427 \mathrm{~kW}$. The net plant heat rate and thermal efficiency are calculated to be $9,839 \mathrm{~kJ} / \mathrm{kWh}(9,328 \mathrm{Btu} / \mathrm{kWh})$ and 36.59 percent, respectively (HHV basis) for this case. Specific carbon dioxide emissions are about 0.88 $\mathrm{kg} / \mathrm{kWh}(1.94 \mathrm{lbm} / \mathrm{kWh})$.

\subsubsection{Case-1: Development of CFB Boiler Computer Model}

The first step in the development of a Base Case was to set up a computer simulation model of the existing CFB boiler. Using test data from the existing unit, the computer model was then calibrated. The calibrated boiler model was then used first for analysis of Case-1 (the Base Case) and then later the model was modified for analysis of Case-2 (the $\mathrm{CO}_{2}$ removal concept).

A proprietary in-house computer model was used to simulate the performance of this existing CFB boiler. The first step in the calculation of unit performance is to set up a steady state performance computer model of the existing CFB steam generator unit. This involves calculating or obtaining all the geometric information for the steam generator unit as required by the Reheat Boiler Program (RHBP) as input data. The RHBP provides an integrated, steady state performance model of the Boiler Island including the steam generator unit, the air heater, and steam temperature control logic. The RHBP is used to size components and/or predict performance of existing components. In this study, since the existing boiler island component sizes are known, the RHBP was used exclusively for calculating unit performance.

The next step was to calibrate the RHBP model of the unit. This involves obtaining test data (with air firing) from the existing unit and "adjusting" the un-calibrated performance model with "calibration factors" to exactly match the test data. The test data required for calibration includes steam temperatures entering and leaving each major heat exchanger section in the unit, steam pressures, coal analysis, flue gas oxygen content, ambient conditions, etc. The "adjustments or calibration factors" for the model are in the form of "surface effectiveness factors" for the various heat exchanger sections throughout the unit.

Once calibrated, the boiler performance model (RHBP) can be provided with a variety of new inputs or boundary conditions such as new steam side requirements (mass flows, 
temperatures, and pressures from the agreed upon MCR steam turbine material and energy balance). The RHBP is then run to predict new performance for the CFB steam generator unit. After completing the calibration process, the model was run and performance was calculated for Case-1 (the Base Case). Case-1 was run to match the MCR steam turbine heat balance.

\subsubsection{Case-1: Boiler Island Process Description, Performance, and Equipment}

The simplified gas side process flow diagram for the Case-1 (Base Case) Boiler Island is shown in Figure 4.2. The process description provided below briefly describes the function of the major equipment and systems included within the existing Boiler Island. Complete data for all streams shown in Figure 4.2 and the associated material and energy balance for this case are provided in Table 4.5.

CFB Steam Generator Unit

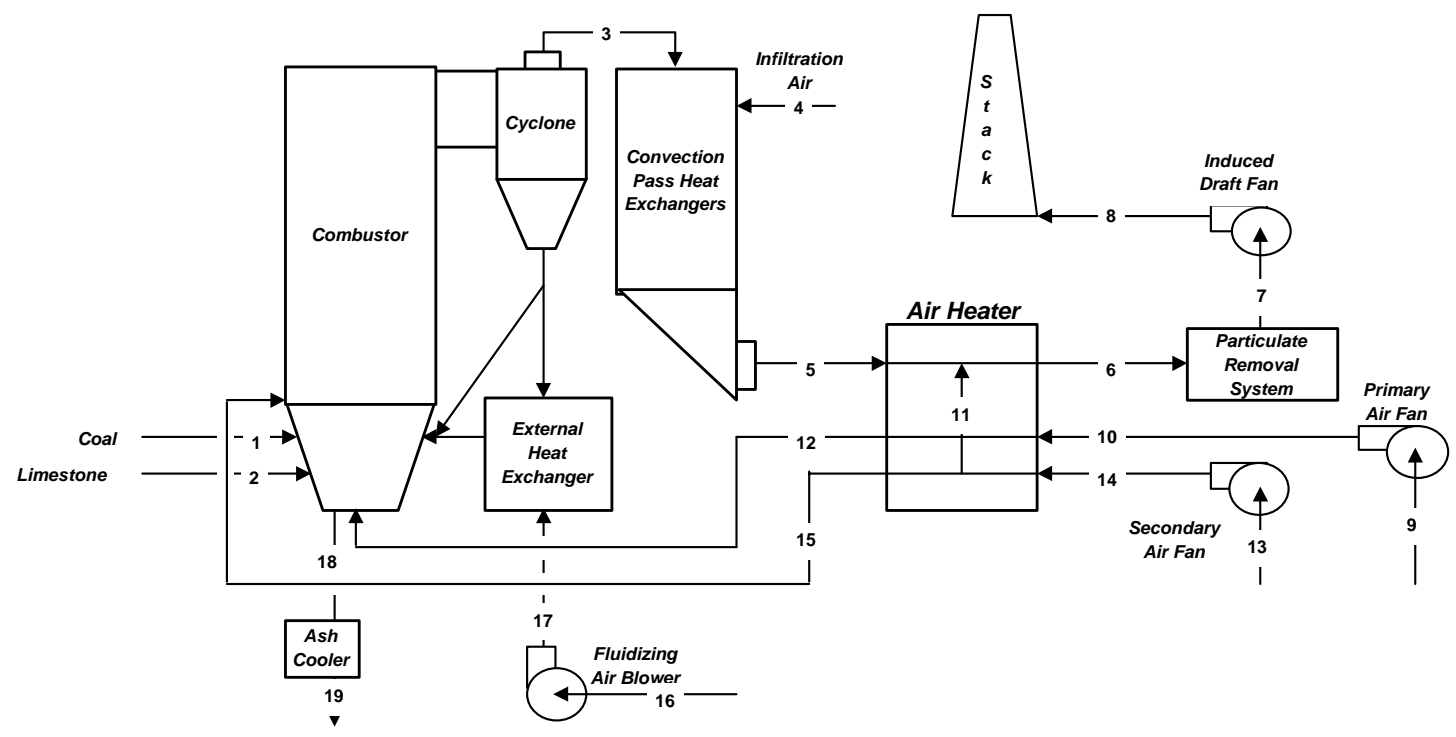

Figure 4.2: Case-1 (Base Case) Simplified Boiler Island Gas Side Process Flow Diagram

In this concept coal (Stream 1) and limestone (Stream 2) are reacted with preheated air (Streams 12,15) in the combustor section of the existing Circulating Fluidized Bed (CFB) system. The combustor is a water-cooled refractory lined vessel designed to combust the fuel, capture $\mathrm{SO}_{2}$ and to evaporate high-pressure steam. The air that flows to the combustor (Streams 12,15, 17) is supplied from a primary air fan, a secondary air fan, and fluidizing air blowers. The products of combustion leaving the combustor flow through two cyclones where most of the entrained hot solids are removed and recirculated to the combustor. The solid stream leaving the bottom of each cyclone is split into two streams. Both streams ultimately are returned to the combustor. The first solids stream is an uncooled stream, which flows directly back to the combustor. The second solids stream flows through External Heat Exchangers (EHE's - 1 EHE per cyclone) where the solids are cooled before returning to the combustor. The External Heat Exchangers provide evaporator, superheat and reheat duty to the steam cycle. 
Draining hot solids from the combustor through water-cooled ash coolers (Stream 18) controls solids inventory in the system while recovering heat from the hot ash. The cooling water used for the ash coolers is feedwater from the final extraction feedwater heater of the steam cycle.

The combustor temperature is $1580^{\circ} \mathrm{F} / 860^{\circ} \mathrm{C}$. The temperature of Stream 3 is $1680^{\circ} \mathrm{F} /$ $916^{\circ} \mathrm{C}$ based on a $100^{\circ} \mathrm{F}$ increase due to afterburning in the cyclone.

The flue gas leaving the cyclones (Stream 3) is cooled in heat exchanger sections (superheater, reheater, economizer) located in the convection pass of the system, also by exchanging heat with the power cycle working fluid. The flue gas leaving the convection pass heat exchanger sections (Stream 5) is further cooled in the air heater. The flue gas leaving the air heater (Stream 6) is cleaned of fine particulate matter in a baghouse and enters the induced draft (ID) fan (Stream 7). The flue gas leaving the ID fan (Stream 8) is then discharged to the atmosphere through a common stack (shared by the three other identical units located on the existing site). 
Table 4.5: Case-1 (Base Case) Boiler Island Gas Side Material and Energy Balance

\begin{tabular}{|c|c|c|c|c|c|c|c|c|c|c|c|c|c|c|c|c|c|c|c|c|}
\hline SI Units & & & & & & & & & & & & & & & & & & & & \\
\hline \begin{tabular}{|l} 
Constituent \\
\end{tabular} & (Units) & 1 & 2 & 3 & 4 & 5 & 6 & 7 & 8 & 9 & 10 & 11 & 12 & 13 & 14 & 15 & 16 & 17 & 18 & 19 \\
\hline 02 & $(\mathrm{Kg} / \mathrm{hr})$ & 751 & & 12219 & 774 & 12993 & 12993 & 12993 & 12993 & 50220 & 50220 & 0 & 50220 & 18708 & 18708 & 18708 & 7744 & 7744 & & \\
\hline N2 & & 424 & & 254422 & 2566 & 256987 & 256987 & 256987 & 256987 & 166369 & 166369 & 0 & 166369 & 61975 & 61975 & 61975 & 25654 & 25654 & & \\
\hline $\begin{array}{ll}1 \mathrm{~N} 2 \\
\mathrm{H} 2 \mathrm{O}\end{array}$ & " & 1437 & & 14747 & 43 & 14790 & 14790 & 14790 & 14790 & 2808 & 2808 & 0 & 2808 & 1046 & 1046 & 1046 & 433 & 433 & & \\
\hline $\mathrm{CO} 2$ & $"$ & & & 79605 & & 79605 & 79605 & 79605 & 79605 & & & & & & & & & & & \\
\hline SO2 & " & & & 173 & & 173 & 173 & 173 & 173 & & & & & & & & & & & \\
\hline $\mathrm{H} 2$ & " & 1010 & & & & & & & & & & & & & & & & & & \\
\hline $\begin{array}{l}\text { Carbon } \\
\text { Sulfur }\end{array}$ & $"$ & 21423 & & & & & & & & & & & & & & & & & 428 & 428 \\
\hline $\begin{array}{l}\text { Sulfur } \\
\text { CaO }\end{array}$ & $"$ & 865 & & & & & & & & & & & & & & & & & 0 & 0 \\
\hline \begin{tabular}{|l}
$\mathrm{CaO}$ \\
CaSO4
\end{tabular} & $"$ & & & & & & & & & & & & & & & & & & $\begin{array}{l}2042 \\
3306\end{array}$ & $\begin{array}{l}2042 \\
3306 \\
-1006\end{array}$ \\
\hline $\mathrm{CaCO} 3$ & " & & 6076 & & & & & & & & & & & & & & & & 0 & \\
\hline Ash & $"$ & 8549 & 105 & & & & & & & & & & & & & & & & 8654 & 8654 \\
\hline & & Coal & LLimestone & ine Gas to BHI & thnfitration Air & ilue Gas to $\mathrm{Al}$ & Flue Gas to PF & Filue Gas to II & IFFGas from ID & D Primary Air & Primary Air & AH Lkg Air & Primary Air & ondary $\mathrm{Ail}$ & ondary $\mathrm{Ail}$ & ondary $\mathrm{Ai}$ & dizing Air & idizing Air & Ir Ash Drain & Ash Drain \\
\hline \begin{tabular}{|l} 
Total Gas \\
\end{tabular} & $(\mathrm{Kg} / \mathrm{hr})$ & $\begin{array}{r}0.00 \\
3449\end{array}$ & 0.00 & 361166 & 3383 & 364549 & 9. 364549 & 364549 & $\begin{array}{l}9 \quad 364549 \\
\text { 9. }\end{array}$ & 3. 219397 & 219397 & & 219397 & 81730 & 81730 & 81730 & 33831 & 33831 & & \\
\hline $\begin{array}{l}\text { Total Solids } \\
\text { Total Flow }\end{array}$ & " & $\begin{array}{l}34459 \\
3459\end{array}$ & $\begin{array}{l}56181 \\
6181 \\
\end{array}$ & 361166 & 3383 & 364549 & 364549 & 364549 & 364549 & 219397 & 219397 & 0 & 219397 & 81730 & 81730 & 81730 & 33831 & 33831 & $\frac{14431}{14431}$ & $\frac{14431}{14431}$ \\
\hline Temperature & (Peg C) & 267 & 267 & 9156 & 267 & 278.9 & & & 1557 & 267 & 452 & 452 & 2090 & 267 & 416 & 2090 & 267 & & 8600 & 7655 \\
\hline $\begin{array}{l}\text { Temperature } \\
\text { Pressure }\end{array}$ & (Deg C) & 1014 & $\begin{array}{l}26.7 \\
1014\end{array}$ & $\begin{array}{r}915.6 \\
1014\end{array}$ & $\begin{array}{l}26.7 \\
1014\end{array}$ & $\begin{array}{l}27.9 \\
1004\end{array}$ & $\begin{array}{l}148.3 \\
0.994\end{array}$ & $\begin{array}{l}148.3 \\
0.963\end{array}$ & $\begin{array}{l}155.7 \\
1014\end{array}$ & $\begin{array}{r}26.7 \\
1014\end{array}$ & $\begin{array}{r}45.2 \\
1.201\end{array}$ & $\begin{array}{r}45.2 \\
1201\end{array}$ & $\begin{array}{l}209.0 \\
1.188\end{array}$ & $\begin{array}{l}26.7 \\
1014\end{array}$ & $\begin{array}{r}41.6 \\
1.163 \\
\end{array}$ & $\begin{array}{l}209.0 \\
1.150\end{array}$ & $\begin{array}{l}26.7 \\
1014\end{array}$ & $\begin{array}{r}81.3 \\
1.634 \\
\end{array}$ & $\begin{array}{l}860.0 \\
1014 \\
\end{array}$ & $\begin{array}{l}265.5 \\
1014 \\
\end{array}$ \\
\hline h-sensible & $(\mathrm{kJ} / \mathrm{kg})$ & 0.000 & 0.000 & $\begin{array}{r}912.712 \\
\end{array}$ & 0.000 & 238.962 & 113.294 & 113.294 & $\begin{array}{ll}4 & 120.269 \\
\end{array}$ & 0.000 & 16.933 & 16.933 & 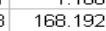 & 0.000 & 13.704 & 168.192 & 0.000 & $\begin{array}{r}1.634 \\
50.084\end{array}$ & 838.229 & 194.033 \\
\hline Energy & & & & & & & & & & & & & & & & & & & & \\
\hline Chemical & $\left(10^{6} \mathrm{~kJ} / \mathrm{hr}\right)$ & 799.470 & & & & & & & & & & & & & & & & & 12.618 & 12.618 \\
\hline Sensible & $\left(10^{6} \mathrm{~kJ} / \mathrm{hr}\right)$ & 0.000 & 0.000 & 329.640 & & 87.113 & 41.301 & 41.301 & 43.844 & 0.000 & 3.715 & 0.000 & 36.901 & 0.000 & 1.120 & 13.746 & 0.000 & 1.694 & 12.096 & 2.800 \\
\hline Latent & $\left(10^{6} \mathrm{~kJ} / / \mathrm{hr}\right)$ & 0.000 & 0.000 & 32.356 & 0.095 & 32.451 & 32.451 & 32.451 & 32.451 & 6.162 & 6.162 & 0.000 & 6.162 & 2.295 & 2.295 & 2.295 & 0.950 & 0.950 & 0.000 & 0.000 \\
\hline Total Energy & $\left(10^{6} \mathrm{~kJ} / \mathrm{hr}\right)$ & 799.470 & 0.000 & 361.996 & 0.095 & 119.564 & 73.752 & 73.752 & 76.295 & 6.162 & 9.877 & 0.000 & 43.062 & 2.295 & 3.415 & 16.042 & 0.950 & 2.644 & 24.714 & 15.418 \\
\hline
\end{tabular}

\begin{tabular}{|c|c|c|c|c|c|c|c|c|c|c|c|c|c|c|c|c|c|c|c|c|}
\hline English Units & & & & & & & & & & & & & & & & & & & & \\
\hline Constituent & (Units) & 1 & 2 & 3 & 4 & 5 & 6 & 7 & 8 & 9 & 10 & 11 & 12 & 13 & 14 & 15 & 16 & 17 & 18 & 19 \\
\hline $\mathrm{O} 2$ & $(\mathrm{Lbm} / \mathrm{hr})$ & 1656 & & 26938 & 1707 & 28645 & 28645 & 28645 & 28645 & 110717 & 110717 & 0 & 110717 & 41244 & 41244 & 41244 & 17072 & 17072 & & \\
\hline N2 & & 934 & & 560907 & 5656 & 566563 & 566563 & 566563 & 566563 & 366782 & 366782 & 0 & 366782 & 136633 & 136633 & 136633 & 56557 & 56557 & & \\
\hline $\mathrm{H} 2 \mathrm{O}$ & " & 3168 & & 32512 & 95 & 32607 & 32607 & 32607 & 32607 & 6191 & 6191 & 0 & 6191 & 2306 & 2306 & 2306 & 955 & 955 & & \\
\hline $\mathrm{CO} 2$ & " & 0 & & 175501 & & 175501 & 175501 & 175501 & 175501 & & & & & & & & & & & \\
\hline SO2 & " & 0 & & 381 & & 381 & 381 & 381 & 381 & & & & & & & & & & & \\
\hline $\mathrm{H} 2$ & " & 2226 & & & & & & & & & & & & & & & & & & \\
\hline Carbon & " & 47230 & & & & & & & & & & & & & & & & & 945 & 945 \\
\hline Sulfur & $"$ & 1907 & & & & & & & & & & & & & & & & & 0 & \\
\hline $\begin{array}{l}\text { aaO } \\
\text { CaSO4 }\end{array}$ & $"$ & 0 & & & & & & & & & & & & & & & & & $\begin{array}{l}4503 \\
7287\end{array}$ & $\begin{array}{l}4503 \\
7228 \\
\end{array}$ \\
\hline CaCO3 & 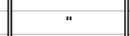 & 0 & 13394 & & & & & & & & & & & & & & & & 0 & \\
\hline Ash & & 18848 & 232 & & & & & & & & & & & & & & & & 19080 & 19080 \\
\hline & (Lbm/hr) & $\begin{array}{l}\text { Coal } \\
75969\end{array}$ & \begin{tabular}{|r|} 
Limestone \\
13626
\end{tabular} & 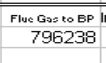 & $\begin{array}{r}\text { Infiltration Air } \\
7459 \\
0\end{array}$ & $\begin{array}{r}\text { Flue Gas to AH } \\
803698\end{array}$ & \begin{tabular}{|c|} 
Flue Gos to PR \\
803698
\end{tabular} & 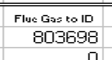 & \begin{tabular}{|l|} 
Fas fortomin \\
803698 \\
\end{tabular} & \begin{tabular}{|l|} 
Primary Air \\
483690 \\
\end{tabular} & $\begin{array}{r}\text { Primary Air } \\
483690\end{array}$ & $\begin{array}{r}\text { AHLkg Air } \\
\text { D }\end{array}$ & \begin{tabular}{|l|} 
Primary Air \\
483690
\end{tabular} & $\begin{array}{l}\text { cendaray, Ait } \\
180184\end{array}$ & $\begin{array}{l}\text { condary A, } \\
180184 \\
1804\end{array}$ & 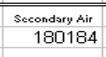 & $\begin{array}{l}\text { idizing sair } \\
74584\end{array}$ & \begin{tabular}{r|} 
Fluidizing g Air \\
74584 \\
\end{tabular} & Ash brain & Ash Drain \\
\hline $\begin{array}{l}\text { Total Solids } \\
\text { Total Flow }\end{array}$ & " & $\frac{75569}{75969}$ & $\frac{13626}{13626}$ & 796238 & $\begin{array}{r}0 \\
7459\end{array}$ & $\begin{array}{r}0 \\
803698\end{array}$ & \begin{tabular}{|r}
0 \\
803698 \\
\end{tabular} & $\begin{array}{r}0 \\
803698\end{array}$ & $\begin{array}{r}0 \\
803698 \\
\end{array}$ & 483690 & 483690 & 0 & 483690 & 180184 & 180184 & 180184 & 74584 & 74584 & $\begin{array}{l}31815 \\
31815\end{array}$ & $\frac{31815}{31815}$ \\
\hline Temnerature & (Deg F & & & & & & & & & & 113 & 113 & 108 & 80 & 107 & 408 & 80 & & $1580 \mathrm{P}>$ & \\
\hline $\begin{array}{l}\text { Pressure } \\
\text { Preste }\end{array}$ & (Psia) & $\begin{array}{r}80 \\
14.7\end{array}$ & $\begin{array}{r}80 \\
14.7\end{array}$ & $\begin{array}{l}1680 \\
14.7\end{array}$ & $\begin{array}{r}80 \\
14.7\end{array}$ & $\begin{array}{l}544 \\
14.6\end{array}$ & $\begin{array}{r}299 \\
14.4\end{array}$ & $\begin{array}{r}299 \\
14.0\end{array}$ & $\begin{array}{r}312 \\
14.7\end{array}$ & $\begin{array}{l}80 \\
14.7\end{array}$ & $\begin{array}{r}113 \\
17.4075\end{array}$ & $\begin{array}{r}113 \\
17.4\end{array}$ & $\begin{array}{r}408 \\
17.2\end{array}$ & $\begin{array}{c}80 \\
14.7\end{array}$ & $\begin{array}{r}107 \\
16.9\end{array}$ & $\begin{array}{l}468 \\
167\end{array}$ & $\begin{array}{r}80 \\
14.7\end{array}$ & $\begin{array}{l}188 \\
237\end{array}$ & $\begin{array}{r}1580 \\
14.7\end{array}$ & $\begin{array}{l}510 \\
14.7 \\
\end{array}$ \\
\hline hsensible & (Btu/lbm) & 0.000 & 0.000 & 436.792 & 0.000 & 114.359 & 54.219 & 54.219 & 57.557 & 0.000 & 8.104 & 8.104 & 80.491 & 0.000 & 6.558 & 80.491 & 0.000 & 23.968 & 401.147 & 92.858 \\
\hline Energy & & & & & & & & & & & & & & & & & & & & \\
\hline Chemical & $\left(10^{6} \mathrm{Btu} / \mathrm{hr}\right)$ & 843.488 & & & & & & & & & & & & & & & & & 13.312 & 13.312 \\
\hline Sensible & {$\left[10^{6} \mathrm{Btu} / \mathrm{hr} r\right.$} & 0.000 & 0.000 & 347790 & 0.000 & 91910 & 43.575 & 43.575 & 46.258 & 0.000 & 3.920 & 0.000 & 38.933 & 0.000 & 1182 & 14.503 & 0.000 & 1788 & 12762 & 2954 \\
\hline Latent & $11^{6}$ Btushro & 0000 & 0000 & 34138 & 0 & 34238 & 34238 & 34238 & 34238 & 6501 & 6501 & 0000 & 6501 & 2042 & 2020 & 2422 & 1000 & 1002 & 0000 & 0.000 \\
\hline Total Energy $y^{(1)}$ & $\left(10^{6} \mathrm{Btu} / \mathrm{hr}\right)$ & 843.488 & 0.000 & 381.928 & 0.100 & 126.148 & 77.813 & 77.813 & 80.496 & 6.501 & 0.001 & 0.000 & 45.433 & $\frac{2.422}{2.422}$ & $\frac{2.422}{3.603}$ & $\frac{2.22}{16.925}$ & $\frac{1.002}{1.002}$ & 2790 & 26.075 & 0.267 \\
\hline
\end{tabular}




\subsubsection{Case-1: Boiler Performance Summary}

The main steam flow used for Case- 1 is $284,401 \mathrm{~kg} / \mathrm{hr}(627,000 \mathrm{lbm} / \mathrm{hr})$. This represents the maximum continuous rating (MCR) for the unit. The cold reheat flow leaving the high-pressure turbine for this case is $257,375 \mathrm{~kg} / \mathrm{hr}(567,418 \mathrm{lbm} / \mathrm{hr})$. The hot reheat flow, returning to the intermediate pressure turbine, for this case is also $257,375 \mathrm{~kg} / \mathrm{hr}$ $(567,418 \mathrm{lbm} / \mathrm{hr})$. The inlet and outlet steam/water conditions supplied to and produced by the existing CFB steam generator unit are shown in Table 4.6 below.

Table 4.6: Case-1 (Base Case) Boiler/Turbine Steam Flows and Conditions

\begin{tabular}{|c|rrrr|}
\hline & SHO & FWI & RHO & RHI \\
\hline (lbm/hr) & 627000 & 627000 & 567418 & 567418 \\
(kg/hr) & 284401 & 284401 & 257375 & 257375 \\
\hline (psia) & 2095 & 2500 & 451 & 481.7 \\
(bara) & 144.5 & 172.4 & 31.1 & 33.2 \\
\hline (deg F) & 1005 & 460 & 1001 & 635 \\
(deg C) & 540 & 238 & 539 & 335 \\
\hline (Btu/lbm) & 1474 & 443 & 1522 & 1322 \\
(kJ/kg) & 3080.3 & 924.6 & 3181.4 & 2761.8 \\
\hline Notes: & SHO = Superheater Outlet & & \\
& FWI = Feedwater Inlet & & \\
& RHO = Reheater Outlet & & \\
& RHI = Reheater Inlet
\end{tabular}

Neither the superheat nor reheat circuits require any de-superheating spray to maintain required steam outlet temperatures. The outlet steam temperatures are kept at required levels via solids flow control through the external heat exchangers with the desuperheating spray being used only for transients. The boiler was fired with about 20 percent excess air and the resulting boiler efficiency calculated for this case was about 89.46 percent (HHV basis) with an air heater exit gas temperature of $148^{\circ} \mathrm{C}\left(299^{\circ} \mathrm{F}\right)$.

\subsubsection{Case-1: Steam Cycle Performance Summary}

This section quantifies the existing steam cycle performance for this study. It is important to quantify the steam cycle performance for the Base Case because there will be some changes in the steam cycle performance for Case- $2\left(\mathrm{O}_{2}\right.$ firing \& $\mathrm{CO}_{2}$ capture $)$ where there is some low-level heat integration involved.

The steam cycle for Case-1 (Base Case) is shown schematically in Figure 4.3. The highpressure turbine expands about $284,401 \mathrm{~kg} / \mathrm{hr}(627,000 \mathrm{lbm} / \mathrm{hr})$ of steam at $138 \mathrm{bara}$ $(2,000 \mathrm{psia})$ and $538 \mathrm{C}(1,000 \mathrm{~F})$. Reheat steam is returned to the intermediate pressure turbine at 29.5 bara $(428 \mathrm{psia})$ and $538 \mathrm{C}(1,000 \mathrm{~F})$. These steam conditions (temperatures, pressures) represent common steam cycle operating conditions for existing utility scale CFB power generation systems in use today. The condenser pressure used in this study was $7.6 \mathrm{~cm} \mathrm{Hga} \mathrm{(3.0} \mathrm{in} \mathrm{Hga).} \mathrm{The} \mathrm{steam} \mathrm{turbine} \mathrm{performance} \mathrm{analysis} \mathrm{results}$ show the generator produces $97,758 \mathrm{~kW}$ output and the steam turbine heat rate is about $8,362 \mathrm{~kJ} / \mathrm{kWh}(7,928 \mathrm{Btu} / \mathrm{kWh})$. Figure 4.4 shows the associated T-S and H-S diagrams 
for the existing steam cycle state points. More details are given in Section 4.4.6.

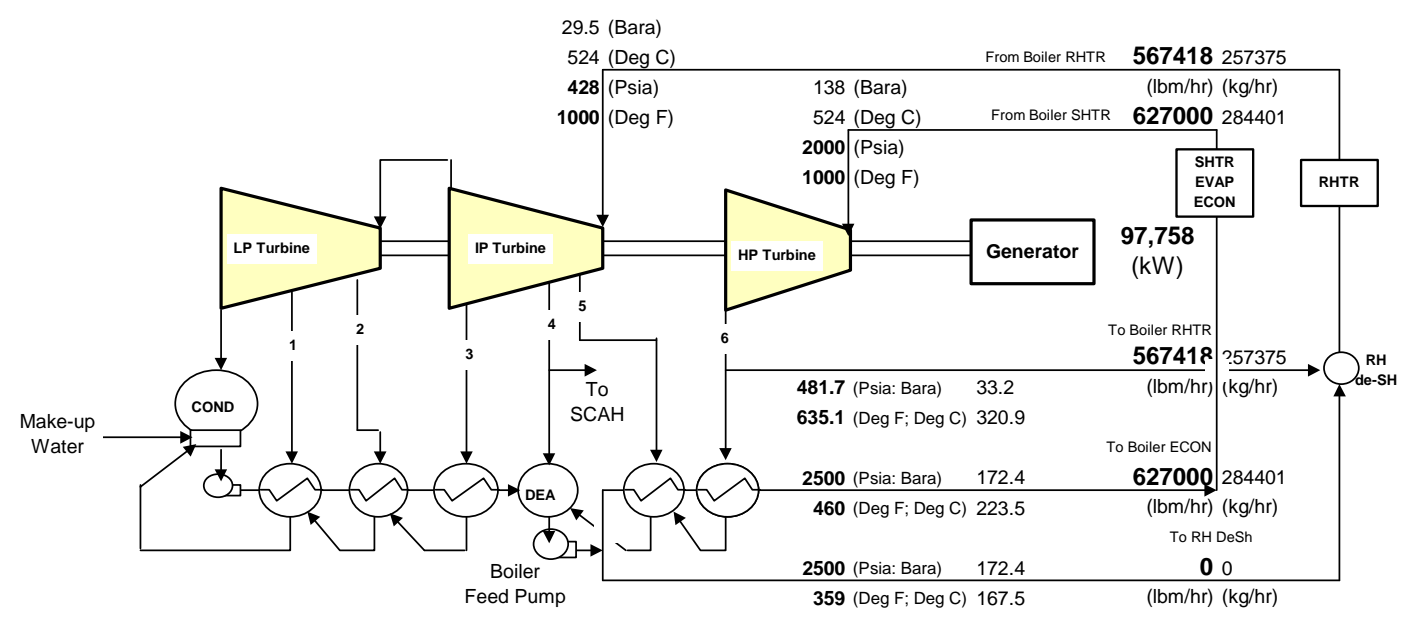

\begin{tabular}{|c|c|c|c|c|c|c|}
\hline Energy Outputs & $\overline{\left(10^{6} \mathrm{Btu} / \mathrm{hr}\right)}$ & $\left(110^{6} \mathrm{KJ} / \mathrm{hr}\right)$ & Energy Inputs & $\left(10^{6} \mathrm{Btu} / \mathrm{hr}\right)$ & $\left(10^{6} \mathrm{KJ} / \mathrm{hr}\right)$ & Turbine Heat Rate \\
\hline Steam Turbine Power Output & 340.1 & 358.7 & Boiler Heat Input & 760.8 & $802.4 \|$ & 7928 (Btu/kwhr) \\
\hline SCAH Heat Output & 0.0 & 0.0 & BFP \& CP Input & 6.2 & 6.5 & 8362 (KJ/kwhr) \\
\hline Condenser Loss & 426.8 & 450.2 & Total Energy Input & 766.9 & 809.0 & \\
\hline Total Energy Output & 766.9 & 809.0 & In - Out & 0.0 & 0.0 & \\
\hline
\end{tabular}

Figure 4.3: Case-1 Simplified Steam Cycle Diagram and Performance
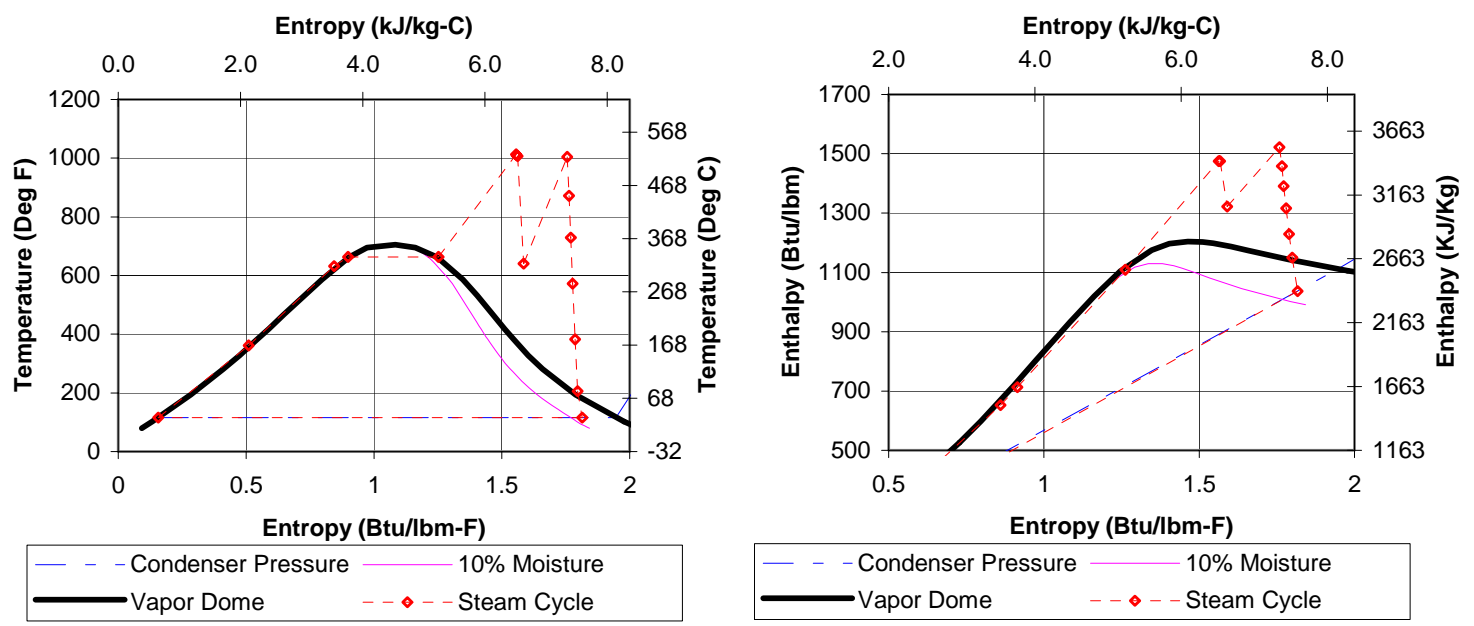

Figure 4.4: Case-1 Steam Cycle State Points Shown on T-S and H-S Coordinates

\subsubsection{Case-1: Overall Plant Performance and $\mathrm{CO}_{2}$ Emissions Summary}

A brief performance summary for this existing plant is summarized in Table 4.7 and reveals the following information. The Case-1 plant produces a net plant output of about 90.4 MWe. The boiler efficiency is about 89.5 percent (HHV basis) and the steam cycle efficiency is about 43.1 percent. The net plant heat rate and thermal efficiency (HHV basis) are calculated to be about $9,800 \mathrm{~kJ} / \mathrm{kWh}(9,300 \mathrm{Btu} / \mathrm{kWh})$ and 36.6 percent, 
respectively for this case. Specific carbon dioxide emissions are about $0.88 \mathrm{~kg} / \mathrm{kWh}(1.94$ $\mathrm{lbm} / \mathrm{kWh})$.

\section{Table 4.7: Case-1 Overall Plant Performance Summary (Base Case)}

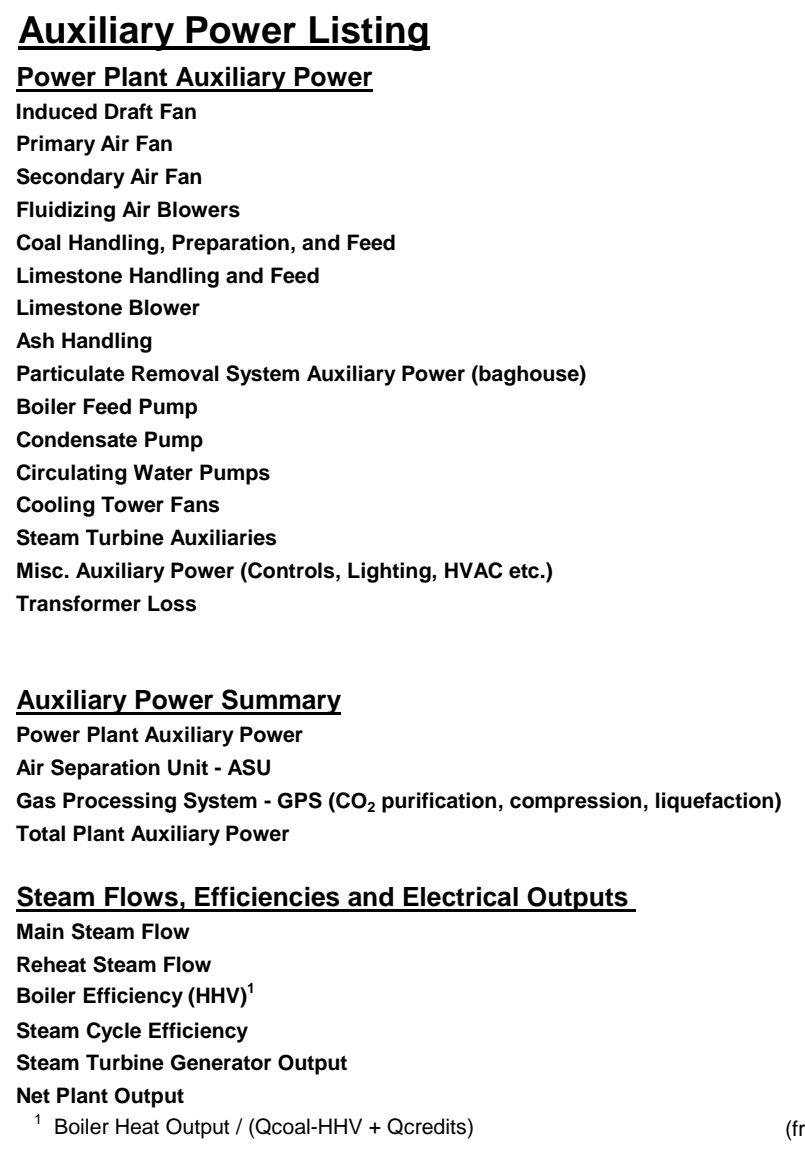

Fuel Heat Inputs

Coal Heat Input (HHV)

Natural Gas Heat Input (HHV) ${ }^{2}$

Total Fuel Heat Input (HHV)

${ }^{2}$ Required for GPS \& ASU Desiccant Regeneration in Case 2

\section{Overall Plant Efficiency}

Net Plant Heat Rate (HHV)

Net Plant Thermal Efficiency (HHV)

Normalized Thermal Efficiency (HHV; Relative to Base Case)

Energy Penalty

\section{$\mathrm{CO}_{2}$ Emissions}

$\mathrm{CO}_{2}$ Produced

$\mathrm{CO}_{2}$ Captured

Fraction of $\mathrm{CO}_{2}$ Captured

$\mathrm{CO}_{2}$ Emitted

Specific $\mathrm{CO}_{2}$ Emissions

Normalized Specific $\mathrm{CO}_{2}$ Emissions (Relative to Base Case) Avoided $\mathrm{CO}_{2}$ Emissions (as compared to Base Case)

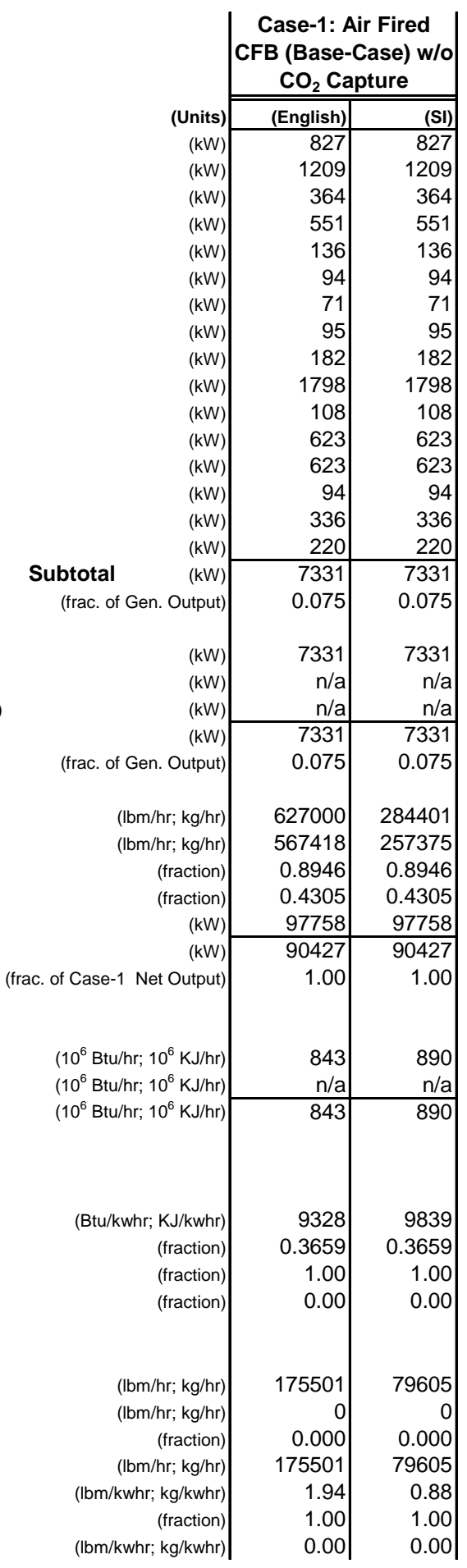




\subsection{Case-2: Existing CFB Power Plant Retrofit with Oxygen Firing and $\mathrm{CO}_{2}$ Capture}

The basic $\mathrm{CO}_{2}$ capture concept behind Case- 2 is to replace combustion air with a mixture of oxygen and recycled flue gas thereby creating a high $\mathrm{CO}_{2}$ content flue gas stream as shown in Figure 4.5. Using relatively pure oxygen and recirculated flue gas as an oxidant stream instead of air eliminates most of the atmospheric nitrogen and therefore the flue gas consists of primarily $\mathrm{CO}_{2}$ and $\mathrm{H}_{2} \mathrm{O}$. The flue gas stream can be further processed, (i.e., through rectification or distillation, depending on the $\mathrm{CO}_{2}$ product specification) into a high purity $\mathrm{CO}_{2}$ end product for various uses such as EOR, as was assumed in this study, EGR, or simply dried and compressed for sequestration.

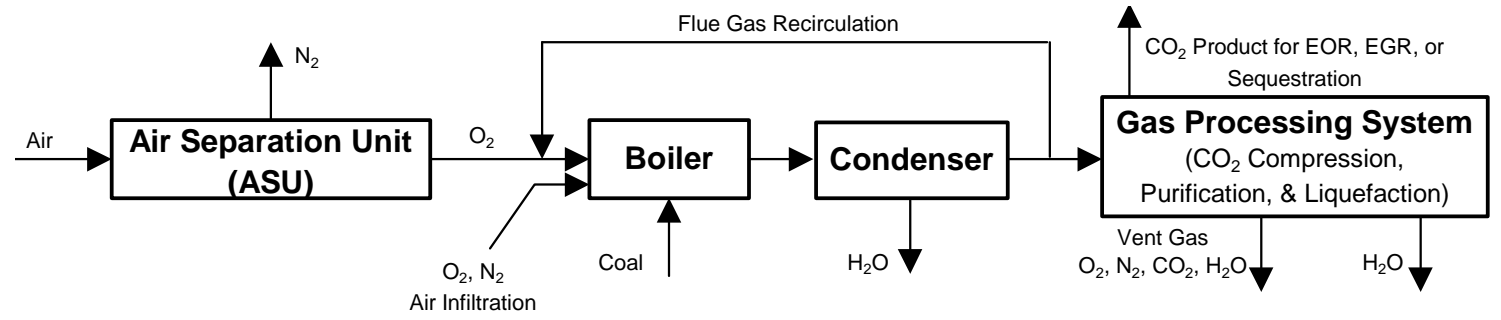

Figure 4.5: Simplified $\mathrm{O}_{2}$ Fired Concept Diagram

A brief performance summary for Case-2 plant reveals the following information. The Case-2 plant produces a net plant output of about 62.1 MWe. The boiler efficiency is about 88.8 percent (HHV basis) and the steam cycle efficiency is about 41.2 percent. The net plant heat rate and thermal efficiency are calculated to be about $14,600 \mathrm{~kJ} / \mathrm{kWh}$ $(13,900 \mathrm{Btu} / \mathrm{kWh})$ and 24.6 percent respectively (HHV basis) for this case. Specific carbon dioxide emissions are about $0.08 \mathrm{~kg} / \mathrm{kWh}(0.17 \mathrm{lbm} / \mathrm{kWh})$.

\subsubsection{Case-2: Existing Power Plant Modifications}

This section provides a review of the equipment changes made to the existing air fired CFB power plant (Case-1) in order to accommodate the retrofit of the unit to oxygen firing for the purpose of $\mathrm{CO}_{2}$ capture (Case-2). This retrofit represents a power plant consisting of the following major equipment groups:

- An existing Circulating Fluidized Bed (CFB) boiler modified to accommodate oxygen-firing

- A new cryogenic type Air Separation Unit (ASU) to provide $\mathrm{O}_{2}$ to the CFB boiler for combustion of the fuel

- An existing subcritical steam cycle with reheat [ 100 MWe-gross: 138 bara $(2,000$ psia $) / 538^{\circ} \mathrm{C}\left(1,000^{\circ} \mathrm{F}\right) / 538^{\circ} \mathrm{C}\left(1,000^{\circ} \mathrm{F}\right) / 7.6 \mathrm{~cm} \mathrm{Hga}(3.0 \mathrm{in}$. Hga $\left.)\right]$ modified to accommodate low level heat recovery from the new ASU.

- A new Gas Processing System (GPS) designed to purify, compress, and liquefy the high $\mathrm{CO}_{2}$ content flue gas produced by the CFB boiler to conditions acceptable for an EOR application.

- Balance of plant equipment (existing) including coal, sorbent and ash handling, cooling water system, electrical systems, etc. 
The following two subsections describe the modifications to the boiler island and steam cycle for Case-2 to accommodate this retrofit.

\section{Boiler Island Equipment Modifications and Additions:}

The CFB boiler performance and retrofit equipment design is based on current CFB equipment design practices and on new information obtained from the pilot scale testing and data analysis discussed previously in Section 3. Boiler island modifications to the existing CFB unit to accommodate $\mathrm{O}_{2}$ firing and $\mathrm{CO}_{2}$ capture involve relatively minor modifications to the boiler, draft system, desulfurization system, and controls and instrumentation. The basic modifications required in these areas are discussed below.

\section{Modified Boiler:}

The Boiler Island should be inspected for potential air leaks into the system and should be sealed to minimize any air infiltration. Special attention should be given to all penetrations including seal boxes for convective surfaces, access doors, fuel piping, sootblowers, ductwork, dampers, expansion joints, and fans. Modifications to the existing boiler pressure parts are not required.

\section{Modified Draft System:}

The draft system comprises all the fans and blowers (primary air fan, secondary air fan, fluidizing air blowers, and induced draft fan), ductwork, dampers, expansion joints, etc., that supply air to and remove flue gas from the unit. This system must be modified such that the boiler can operate in the air-fired mode for start-up and in the new oxygen-fired mode with gas recirculation. The system also must be flexible enough to allow the on line transition from air to oxygen firing.

Vendors for the existing fans and blowers were contacted regarding the capability of this equipment to operate satisfactorily with the different gas analyses and other conditions expected with $\mathrm{O}_{2}$ firing.

Fans and Blowers:

The forced draft system (PA \& SA fans, FA Blowers) will be handling recirculated flue gas rather than air during $\mathrm{O}_{2}$ fired operations. The recirculated flue gas has a higher molecular weight (more $\mathrm{CO}_{2}$ and less $\mathrm{N}_{2}$ ) and a higher inlet temperature to the fans and blowers than air. The recirculated flue gas even with the higher inlet temperature to the fans has an increased density. Taking all these differences into consideration, the vendors have stated that the existing primary air fan, secondary air fan, and fluidizing air blowers (FBHE and Seal Pot blowers) will easily accommodate the new operating conditions expected with $\mathrm{O}_{2}$ firing.

Although the ID fan will also be handling the increased density flue gas, it must now additionally accommodate a larger pressure rise across the fan. The increased system draft loss is due primarily to the addition of the flash dryer absorber (FDA) system for $\mathrm{SO}_{2}$ removal. Because of the increased draft losses, a new ID fan and motor are required.

An additional benefit of the higher molecular weight gas is that the draft system fans and blowers will consume less power ( $\sim 22$ percent less in total) as compared to the equivalent MCR operating condition with air firing. Some of this reduction results from introducing the oxygen from the ASU downstream of the PA and SA fans and some results from the reduction in inlet temperature for the ID fan. Even though the ID fan must handle more 
mass flow and a higher pressure rise with $\mathrm{O}_{2}$ firing, because the inlet temperature with $\mathrm{O}_{2}$ firing is so much lower than with air firing, the power requirement is significantly lower with $\mathrm{O}_{2}$ firing as compared to air firing. Partially offsetting these reductions is the slightly higher inlet temperatures to the PA, SA, and fluidizing air blowers.

New and Modified Ductwork:

Significant modifications and additions were required to the existing plant ductwork system in order to accommodate the new gas recirculation system, FDA system, and the addition of $\mathrm{O}_{2}$ firing capability as described below. New ductwork is required in several areas of the Boiler Island. Oxygen supply control valves and piping from the new ASU to the existing primary and secondary air fan outlet ducts is required. New ductwork with control and isolation dampers are also required for the recycle flue gas streams that feed the primary and secondary air fans and the existing fluidizing air blowers. Ductwork is also modified to accommodate the new FDA system. Additionally, new ductwork and dampers are required to supply product gas (primarily $\mathrm{CO}_{2}$ ) to the new Gas Processing System. Various isolation dampers are also required. Provisions in the new ductwork system to accommodate startup with air firing (air inlet duct with associated isolation dampers) are also required.

Refer to Table 4.8 for the associated cross-sectional areas and other ductwork design requirements for this system. Figure 4.6 shows a rough sketch of the new gas recirculation and oxygen supply ductwork and where it is located with respect to the existing boilers. Figure 4.7 shows the new Ductwork Arrangement Drawing for the new gas recirculation system and the $\mathrm{O}_{2}$ supply system to the boiler. Additional drawings for the retrofit case are given in Section 7.1.

Table 4.8: Case-2 Ductwork Design Requirements

\begin{tabular}{|c|c|c|c|c|c|c|c|c|c|c|c|c|c|c|c|c|}
\hline \multirow{3}{*}{ Description } & \multirow{3}{*}{ Item } & \multirow{3}{*}{ Qty } & \multirow{2}{*}{\multicolumn{2}{|c|}{ Design Velocity }} & \multirow{2}{*}{\multicolumn{2}{|c|}{$\begin{array}{c}\text { Req'd Area } \\
\text { Each }\end{array}$}} & \multirow{2}{*}{\multicolumn{2}{|c|}{$\begin{array}{l}\text { Operating } \\
\text { Temperature }\end{array}$}} & \multirow{2}{*}{\multicolumn{2}{|c|}{$\begin{array}{c}\text { Design } \\
\text { Temperature }\end{array}$}} & \multicolumn{6}{|c|}{ Duct Pressures } \\
\hline & & & & & & & & & & & \multicolumn{2}{|c|}{ Normal } & \multicolumn{2}{|c|}{ Design (positive) } & \multicolumn{2}{|c|}{$\begin{array}{c}\text { Design } \\
\text { (negative) }\end{array}$} \\
\hline & & & $(\mathrm{ft} / \mathrm{min})$ & $(\mathrm{m} / \mathrm{min})$ & (ft2) & (m2) & (Deg F) & $(\operatorname{Deg} C)$ & (Deg F) & (Deg C) & (in wg) & $(\mathrm{cm} \mathrm{wg)}$ & (in wg) & $(\mathrm{cm} \mathrm{wg})$ & (in wg) & $(\mathrm{cm} \mathrm{wg)}$ \\
\hline \multicolumn{17}{|l|}{ Recirculated Gas } \\
\hline GR duct from stack duct & A1 & 1 & 2500 & 762 & 52.7 & 4.90 & 112 & 44 & 150 & 66 & 2 & 5 & 8 & 20 & 8 & 20 \\
\hline Duct to PA Inlet & $\mathrm{A} 2$ & 1 & 2500 & 762 & 32.4 & 3.01 & 112 & 44 & 150 & 66 & 0 & 0 & 8 & 20 & 8 & 20 \\
\hline Duct to SA Inlet & $\mathrm{A} 3$ & 1 & 2500 & 762 & 12.9 & 1.20 & 112 & 44 & 150 & 66 & 0 & 0 & 8 & 20 & 8 & 20 \\
\hline Blower Header Duct & A4 & 1 & 2500 & 762 & 7.9 & 0.73 & 112 & 44 & 150 & 66 & -1 & -3 & 8 & 20 & 8 & 20 \\
\hline Header to FBHE Blower Inlets & A5 & 1 & 2500 & 762 & 5.4 & 0.50 & 112 & 44 & 150 & 66 & -2 & -5 & 8 & 20 & 8 & 20 \\
\hline Header to FBHE Blower Inlet & A6 & 2 & 2500 & 762 & 5.4 & 0.50 & 112 & 44 & 150 & 66 & -3 & -8 & 8 & 20 & 8 & 20 \\
\hline Header to Sealpot Blower Inlets & A7 & 1 & 2500 & 762 & 2.9 & 0.27 & 112 & 44 & 150 & 66 & -4 & -10 & 8 & 20 & 8 & 20 \\
\hline Header to Sealpot Blower Inlet & A8 & 2 & 2500 & 762 & 1.4 & 0.13 & 112 & 44 & 150 & 66 & -4 & -10 & 8 & 20 & 8 & 20 \\
\hline \multicolumn{17}{|l|}{ Air } \\
\hline Startup air inlet duct & B1 & 1 & 2500 & 762 & 75 & 6.97 & 100 & 38 & 150 & 66 & -2 & -5 & 8 & 20 & 8 & 20 \\
\hline \multicolumn{17}{|l|}{ Oxygen } \\
\hline Oxygen from $\mathrm{O} 2$ plant & $\mathrm{C} 1$ & 1 & 2500 & 762 & 9.3 & 0.86 & 65 & 18 & 100 & 38 & 110 & 279 & 90 & 229 & 8 & 20 \\
\hline Oxygen to PA fan outlet & $\mathrm{C} 2$ & 1 & 2500 & 762 & 6.7 & 0.62 & 65 & 18 & 100 & 38 & 85 & 216 & 70 & 178 & 8 & 20 \\
\hline Oxygen to SA fan outlet & $\mathrm{C} 3$ & 1 & 2500 & 762 & 2.7 & 0.25 & 65 & 18 & 100 & 38 & 85 & 216 & 60 & 152 & 8 & 20 \\
\hline
\end{tabular}




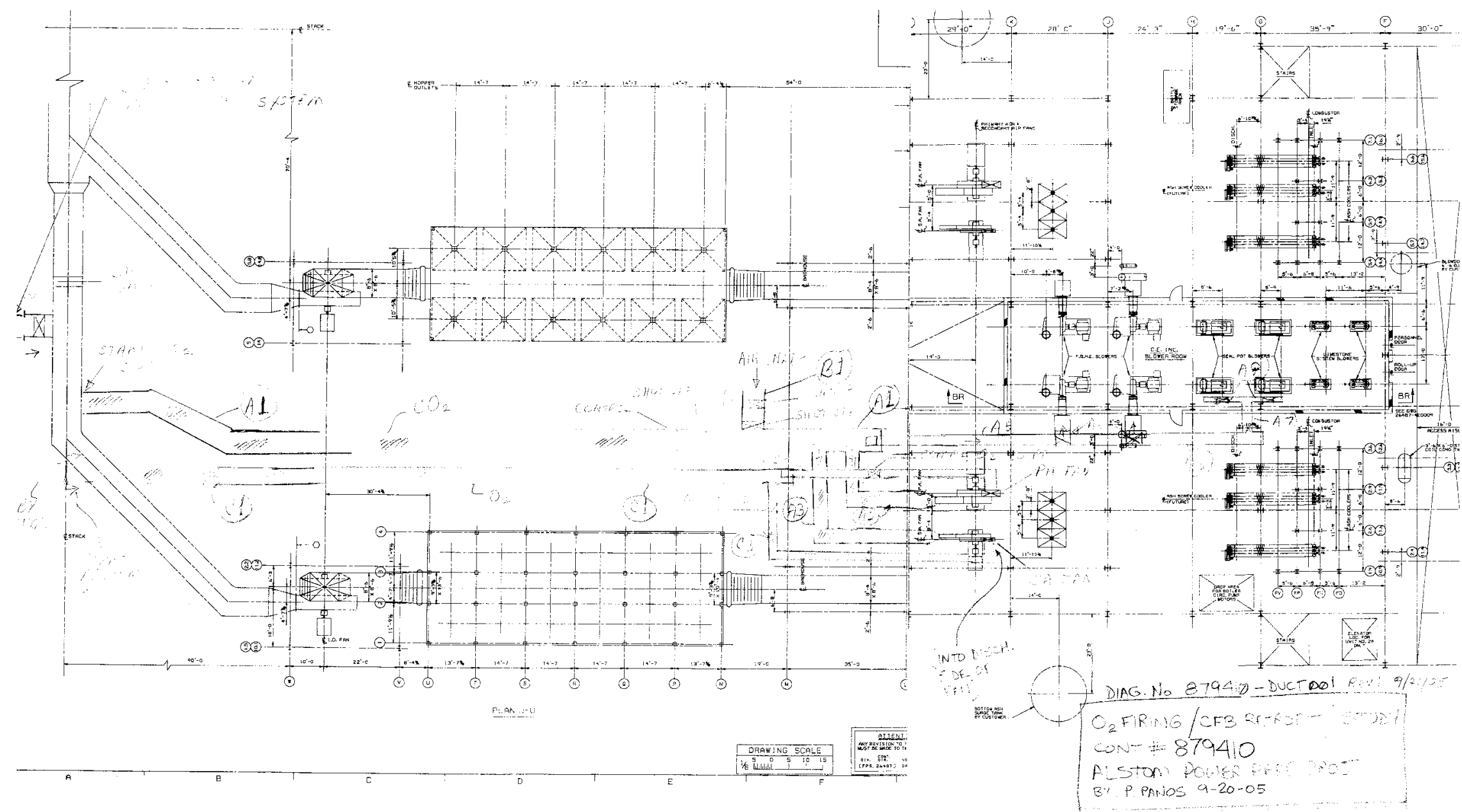

Figure 4.6: New Gas Recirculation and Oxygen Supply Ductwork Sketch 


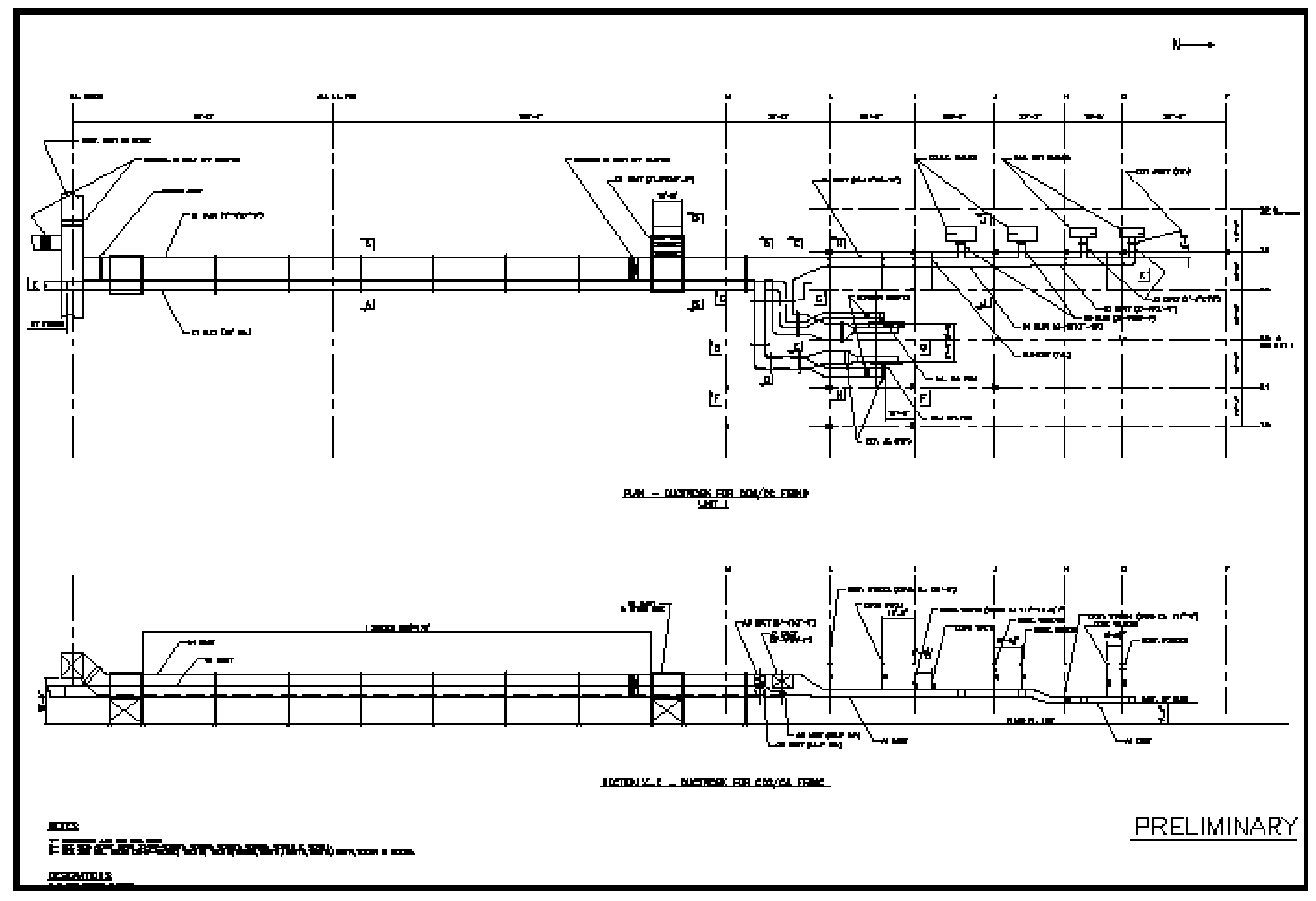

Figure 4.7: Case-2 New Ductwork Arrangement Drawing 


\section{Modified Controls and Instrumentation for the Boiler:}

Additional controls and instrumentation will be required for the new components and systems. The transition between air firing and oxygen firing as well as additional safety precautions associated with oxygen use in this type of setting needs careful consideration.

The following is a description of the process controls required to start up, increase and reduce load, and shut down a circulating $\mathrm{CFB}$ that has been converted to $\mathrm{O}_{2}$ firing and $\mathrm{CO}_{2}$ capture.

In general terms, the unit will be started up on air firing as it normally is, with the exception that all flue gas desulfurization will take place at the outlet of the boiler in the new FDA system. The unit will be switched to oxygen firing at any point between the minimum load on $\mathrm{O}_{2}$ firing and $100 \%$ load. It will operate on oxygen firing at high loads. The exact minimum load capability with $\mathrm{O}_{2}$ firing was not determined for the study unit since it was beyond the scope of the current study but it is expected to be in the $50-75 \%$ range. As the unit is brought down in load, a load hold will be initiated and the unit will be switched back to air firing above the minimum $\mathrm{O}_{2}$ fired load.

Please refer to the Duct and Damper P\&ID Schematic (Figure 4.8) for the location of control and shutoff dampers as well as the locations for various sensors identified in the following description. The thick red lines on this figure indicate the new ductwork, dampers, equipment, and instrumentation required for this retrofit.

The following are new ducts that make up the oxygen firing system

1. Short duct section to convey the $\mathrm{CO}_{2}$ flue gas to the Gas Processing System (GPS) from the duct that connects ID fan outlet to the stack

2. Fan Header duct for $\mathrm{CO}_{2}$ rich flue gas from duct that connects ID fan outlet to the stack to the inlet of the fans and blowers (A-1)

3. Short duct section for air from atmosphere to the new header duct, with inlet silencer (B-1).

4. Duct for oxygen from the Air Separation Unit (ASU) to the PA Fan outlet, upstream of the air heater $(\mathrm{C}-2)$.

5. Duct for oxygen from air separation unit to the SA fan outlet, upstream of the air heater $(\mathrm{C}-3)$.

The following new dampers make up the oxygen firing control system:

1. One isolation (V-9) and one control damper (V-10) in duct between ID Fan and Stack, to isolate stack from ID fan and Gas Processing System

2. One isolation (V-12) and one control damper (V-11) in the duct to the Gas Processing System (GPS), to isolate, control, or connect the boiler flue gas to the GPS

3. One isolation ( $\mathrm{V}-1)$ and one control damper ( $\mathrm{V}-2)$ in the header duct from the ID fanto-Stack duct, upstream of the atmospheric dampers.

4. One isolation damper (V-6) and control damper (V-5) in the atmospheric air duct to the header duct, to control the air to the boiler during air firing and combination air and oxygen firing. 
5. One control damper ( $\mathrm{V}-7)$ in the duct from the air separation unit (ASU) to the PA fan outlet, to provide and control oxygen content to the PA during oxygen firing

6. One control damper (V-8) in the duct from Air Separation Unit (ASU) to the SA fan outlet, to provide and control oxygen content to the SA during oxygen firing

7. One isolation damper each $(\mathrm{V}-3$ and $\mathrm{V}-4)$ to the two external heat exchanger blowers, to isolate either blower when not in use.

The following is new instrumentation required for the control of the oxygen firing system:

1. An $\mathrm{O}_{2}$ meter in the PA duct downstream of the air heater in order to control the oxygen in the PA duct.

2. An $\mathrm{O}_{2}$ meter in the SA duct downstream of the air heater in order to control the oxygen in the SA duct.

3. A pressure sensor in the $\mathrm{CO}_{2}$ header duct, downstream of the isolation and control campers (V-1 and V-2), in order to control the pressure in the header duct as the atmospheric dampers are closed or opened

4. A $\mathrm{CO}_{2}$ and an $\mathrm{O}_{2}$ measurement device in the duct to the FBHE and sealpot blowers, to provide compensation for the use of $\mathrm{CO}_{2}$ and oxygen versus air to the blower flow measurement device

The following steps are to be taken for start-up and switching to oxygen firing:

1. Start-up boiler on air firing. The oxygen firing dampers are lined up as follows for air firing:

- Isolation and control dampers to Gas Processing System are shut (V-11 \& V-12)

- Isolation damper and control dampers from atmosphere to main header duct are open (V-5 \& V-6)

- Isolation and control dampers between the ID fan-to-Stack duct and the Air fan inlets are shut (V-9 \& V-10)

- Control dampers for oxygen from Air Separation Unit (ASU) to PA and SA fan outlets are both closed (V-7 \& V-8)

- The Isolation damper to either one or both of the FBHE blowers (V-3 or V-4) are opened

2. Start the boiler as usual and bring the boiler to near full load (90\% to $100 \%)$.

3. Switching over to $\mathrm{O}_{2}$ firing is accomplished as follows:

- Assure that oxygen from the air separation unit is available

- Release oxygen control dampers V-7 and V-8 to control oxygen in the PA and SA ducts to the furnace at $24 \%$

- Open isolation damper V-1 to permit flow of flue gas to the boiler, and release V-2 to control header duct pressure $\mathrm{P}_{\mathrm{h}}$ to the same value it was (about a negative 0.5 in wg). 
- Begin slowly closing atmospheric air control damper V-5. As V-5 closes, V-2 will begin to open to control $\mathrm{P}_{\mathrm{h}}$. At the same time, $\mathrm{V}-7$ and $\mathrm{V}-8$ will begin to control oxygen in the PA and SA ducts. Boiler $\mathrm{O}_{2}$ at the economizer outlet will control the $\mathrm{SA}$ fan, and the ratio controller will control the PA to SA ratio to remain the same as it was at the beginning of the switchover to oxygen firing.

- The flue gas will become richer in $\mathrm{CO}_{2}$ and leaner in nitrogen as the atmospheric damper is closing. When the atmospheric air control camper (V-5) is closed, shut the atmospheric air isolation damper, V-6. A this point the unit is switched to oxygen firing, and the PA to SA ratio controller can be released or held as desired. The header pressure, $\mathrm{P}_{\mathrm{h}}$, setpoint can also be changed.

- As the boiler is switching to oxygen firing and the composition of the gas used for fluidizing the FBHE changes, the controls will provide compensation to the flow setpoints of the FBHE and sealpot fluidizing air blowers. This is done in order to maintain the fluidizing velocity constant, by measuring the $\mathrm{CO}_{2}$ and $\mathrm{O}_{2}$ in the header duct.

4. The flue gas is now ready to be switched from the stack to the GPS for $\mathrm{CO}_{2}$ capture. This switch is accomplished as follows:

- Open the isolation damper to the GPS, V-12.

- Slowly open the control damper to the GPS, V-11.

- After V-11 is fully open, begin slowly closing V-10.

- When V-10 is shut, close the stack isolation damper V-9

- The unit is now fully on oxygen firing and providing $\mathrm{CO}_{2}$ rich flue gas to the Gas Processing System.

To switch back to air firing, reverse this procedure with the following exception: during the switch from $\mathrm{CO}_{2}$ recycle to air firing, air control damper V-5 will control header duct pressure, $\mathrm{P}_{\mathrm{h}}$, and flue gas recycle damper $\mathrm{V}-2$ will be set to open gradually. 


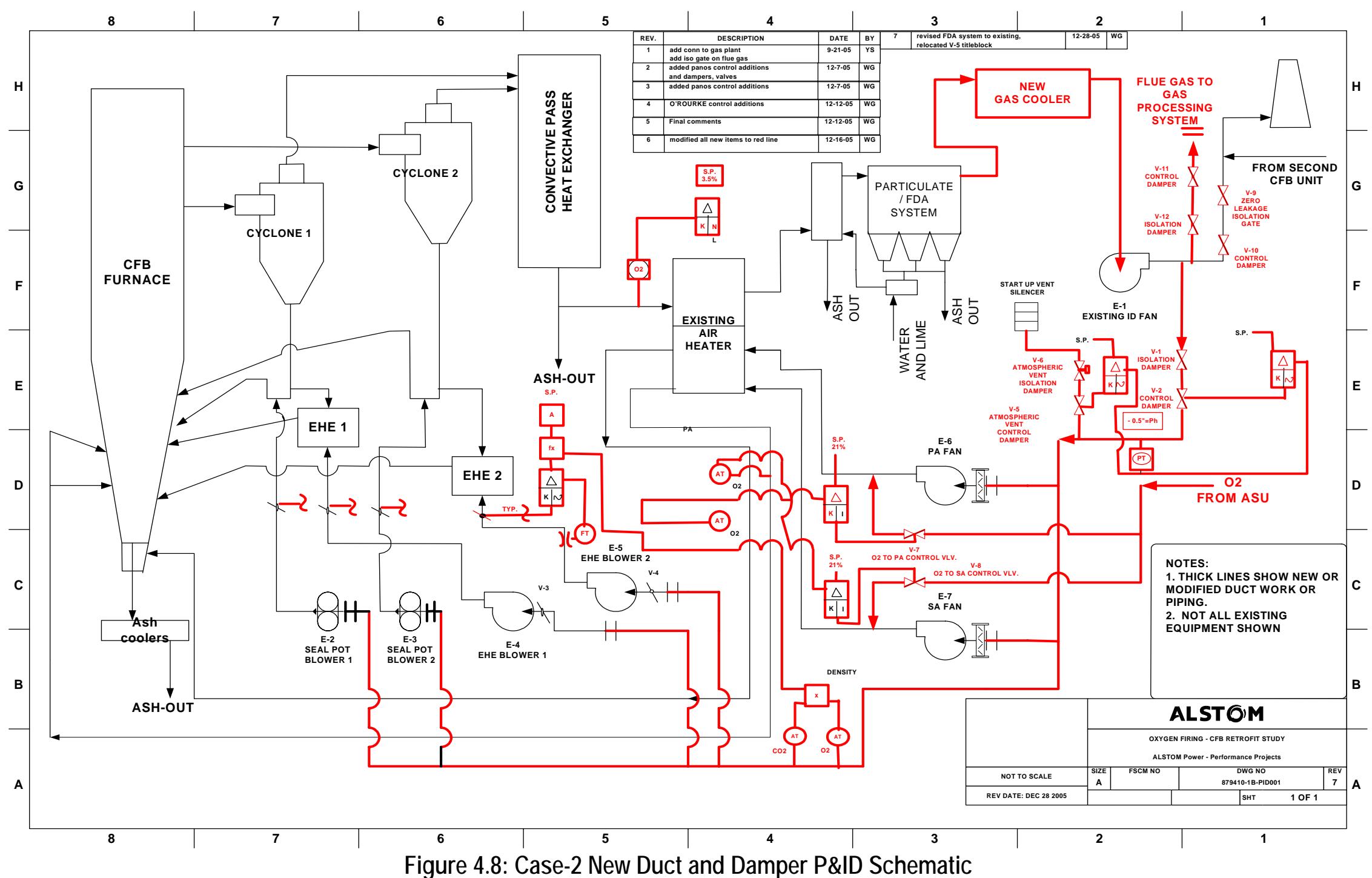




\section{Modified Desulfurization System:}

The existing unit, Case-1, a traditional furnace limestone injection system is used to remove about 90 percent of the $\mathrm{SO}_{2}$ produced. For the oxygen fired Case-2, limestone is not added to the furnace. Rather, sulfur capture is done in a backend Flash Dryer Absorber (FDA) system with lime injection. The issues and options for sulfur capture with oxygen firing are discussed in Section 4.4.3.

The FDA system is a dry $\mathrm{SO}_{2}$ removal process, which operates in a humid flue gas condition. The heart of the FDA system is the patented mixer/humidifier. The equilibrium moisture content in the ash received from the fabric filter is increased a few percent by the addition of water. The mixer uniformly distributes the water into the entire collected ash stream prior to re-injection into the flue gas. The humidified solids in the mixer continue to behave as a free-flowing powder, without clumping, enabling even distribution of the moist powder into the flue gas for $\mathrm{SO}_{2}$ absorption. The blending of the fresh lime, water, and recycle product is done externally from the flue gas. This ensures a homogeneous mixture prior to injection back into the flue gas stream.

The typical end product is a dry powder consisting of a mixture of fly ash, calcium sulfite/sulfate, hydroxide, carbonate, chloride, etc.

Figure 4.9 shows a simplified schematic process diagram of the FDA system. In the current application the existing baghouse is used with modifications as required for the addition of the FDA system.

Flue gas leaving the existing air heater, with a high $\mathrm{SO}_{2}$ content enters the reactor section prior to entering the fabric filter. Here, a mixture of recirculated ash, fresh lime and water are injected into the flue gas stream and most of the $\mathrm{SO}_{2}$ reacts with the lime to form $\mathrm{CaSO}_{3} \cdot 1 / 2 \mathrm{H}_{2} \mathrm{O}$. Some $\mathrm{CaSO}_{4} \cdot 2 \mathrm{H}_{2} \mathrm{O}$ is formed and a small amount of $\mathrm{CaCO}_{3}$ is also formed. The particulate matter is collected in the modified existing fabric filter. A portion of the collected particulate is removed as the waste product stream with the remainder of the particulate matter being recirculated as described previously. Water is added to control the humidity of the flue gas stream leaving the fabric filter to a proper level. Fresh lime is also added. FDA systems are commercial products that ALSTOM has supplied for both air-fired CFB and pulverized coal fired units.

Because of the high $\mathrm{CO}_{2}$ content in the flue gas with oxygen firing, there is less confidence in the FDA performance predictions for Case-2 than for air firing. Various performance assumptions were made based on test results that were developed as a part of this project (refer to Section 3) and these assumptions used to develop the FDA system performance used for Case-2. 


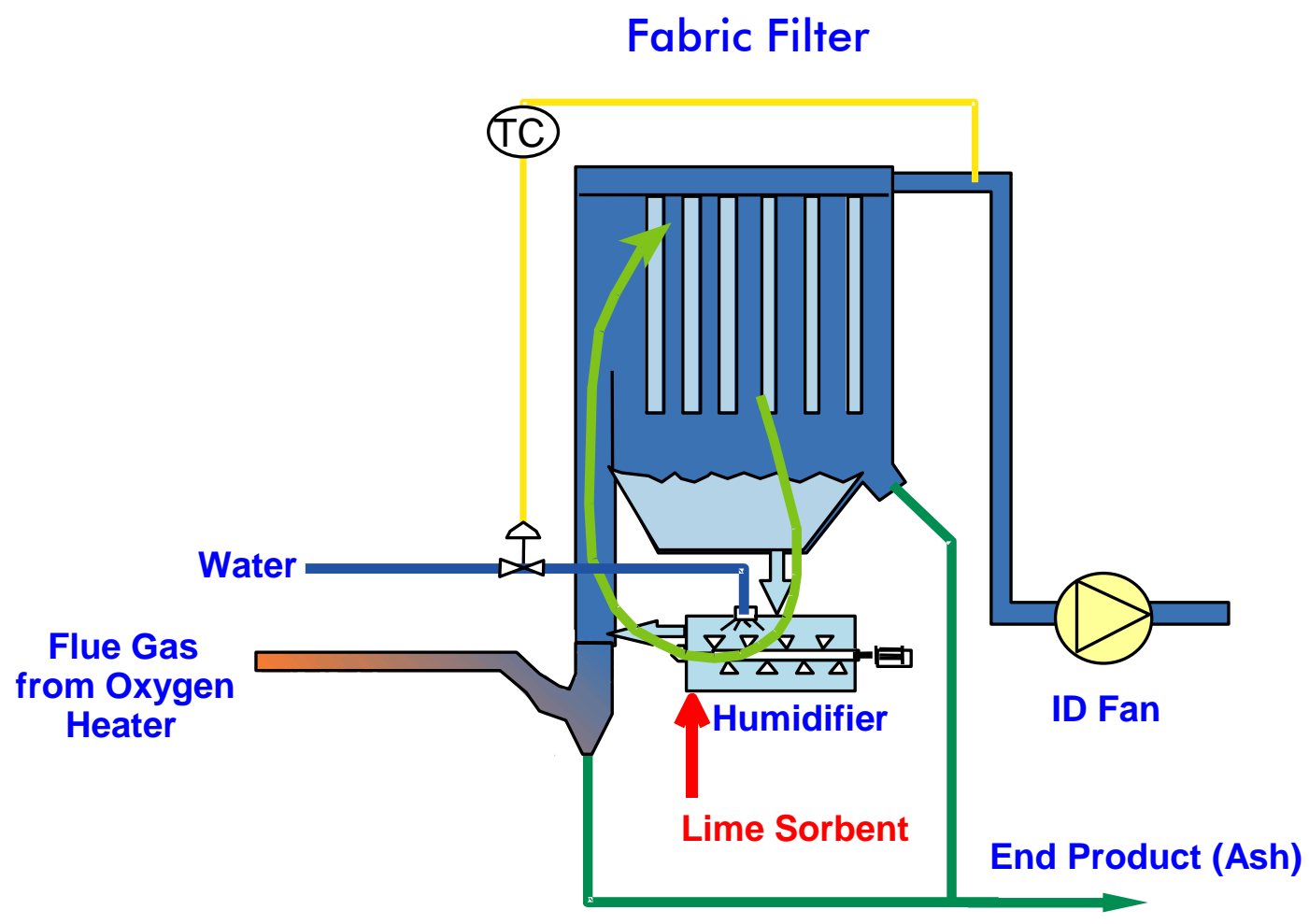

Figure 4.9: Flash Dryer Absorber (FDA) System Schematic Diagram (simplified)

Addition of the new FDA system will require the following basic modifications:

- Modifications to the existing Fabric Filter (FF) hoppers for airslide attachments

- Elevation of the FF to accommodate the FDA system and its components

- Modification of the existing FF inlet duct for connection to the FDA outlet

- Modification of the existing duct leaving the air heater for connection to the FDA system

- Internal coating of the FF outlet duct and tube sheet to mitigate moisture corrosion

- Modification to the ash handling system

A general arrangement sketch (not to scale) of the FDA system design is shown in Figure 4.10. The dimensions shown on the drawing are in units of feet and the major components are identified on this sketch. 


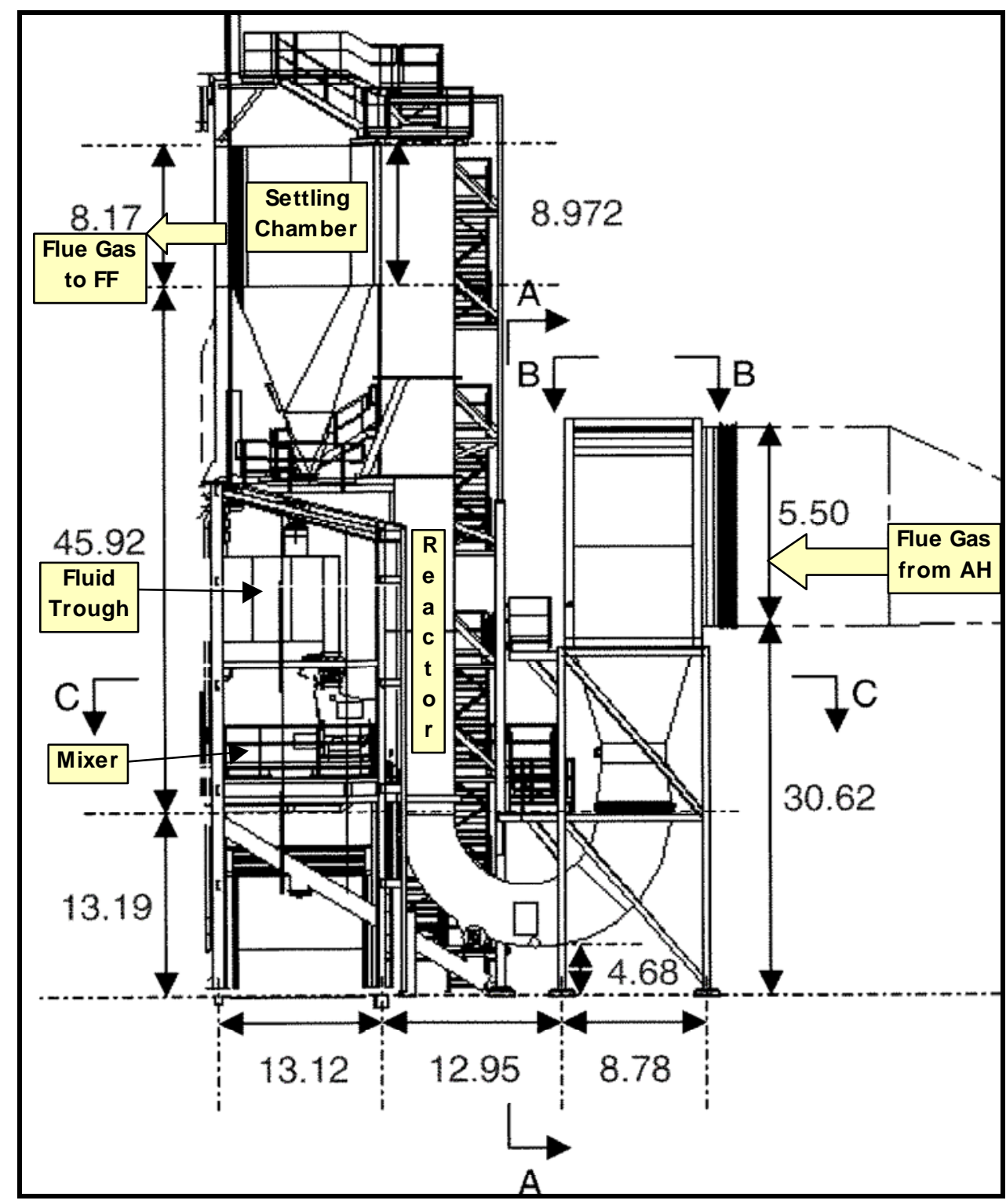

Figure 4.10: Case-2 New Flash Dryer Absorber (FDA) System General Arrangement Sketch

(not to scale - dimensions in $\mathrm{ft}$ )

\section{General Arrangement Drawings:}

Complete general arrangement drawings of the modified Case-2 CFB boiler were not developed for this project since the only modifications to the boiler were the addition of and modifications to boiler ductwork (i.e., new gas recirculation system, new $\mathrm{O}_{2}$ supply piping, new product gas supply system to GPS, etc). Drawings of the new ductwork are contained in Appendix I: Plant Drawings (Section 7.1). These drawings highlight the new ductwork required for the existing unit to accommodate $\mathrm{O}_{2}$ firing and $\mathrm{CO}_{2}$ capture Case-2 Steam Cycle Equipment Modifications and Additions:

In Case-2, a low level heat recovery system is integrated with the existing steam cycle. 
Most of the low-pressure condensate stream leaving the existing condensate pump bypasses the existing extraction feedwater heaters \#1 and \#2 as shown in Figure 4.11 below. The heat added to the condensate stream is provided through the recovery of low level heat rejected from the three ASU main air compressor aftercoolers. This heat integration allows the existing steam turbine to generate additional power output since extractions to the existing feedwater heaters are reduced and more steam flows through the low pressure stages of the existing turbine. Consequently, the condenser also rejects more heat.

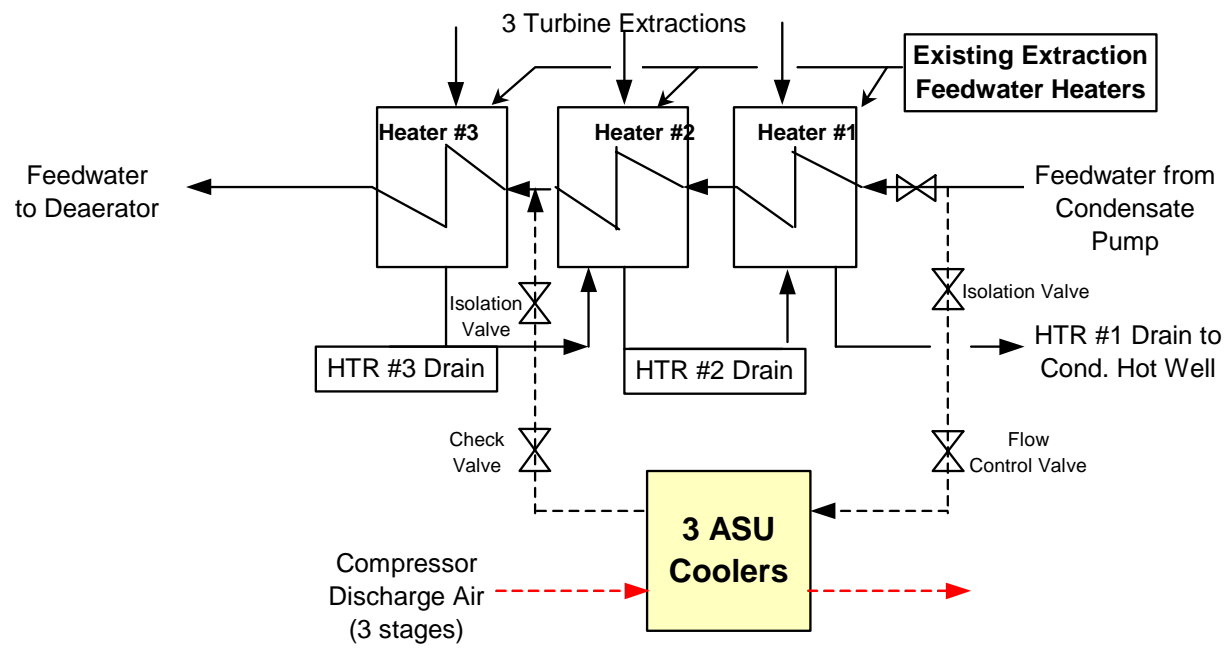

Figure 4.11: Case-2 Low Level Heat Recovery System Schematic

\subsubsection{Case-2: Oxygen Fired CFB Boiler Computer Model}

The boiler system computer model (RHBP; see Section 4.3.1) developed and calibrated for Case- 1 was checked for applicability with $\mathrm{O}_{2}$ firing and used, with modified input data, to simulate the $\mathrm{O}_{2}$ fired boiler performance of Case-2. With oxygen firing, a high carbon dioxide content flue gas is produced. Table 4.9 shows a comparison between the air and $\mathrm{O}_{2}$ fired flue gases leaving the cyclones and entering the convective pass from this study.

\section{Table 4.9: Air and Oxygen Fired Flue Gas Comparison}

\begin{tabular}{|l|c||c||c|}
\hline Constituent & (Units) & Air & Oxygen \\
\hline \hline $\mathbf{O}_{2}$ & (vol. frac.) & 0.0316 & 0.0316 \\
$\mathrm{~N}_{2}$ & $"$ & 0.7509 & 0.0471 \\
$\mathrm{H}_{2} \mathrm{O}$ & $"$ & 0.0677 & 0.1070 \\
$\mathrm{CO}_{2}$ & $"$ & 0.1496 & 0.8108 \\
$\mathrm{SO}_{2}$ & $"$ & 0.0002 & 0.0035 \\
\hline
\end{tabular}

The $\mathrm{O}_{2}$ fired flue gas has significantly higher $\mathrm{CO}_{2}$ and $\mathrm{H}_{2} \mathrm{O}$ contents and much lower $\mathrm{N}_{2}$ content than the air fired flue gas. The $\mathrm{SO}_{2}$ content while small is also increased 
significantly with $\mathrm{O}_{2}$ firing. These differences cause the $\mathrm{O}_{2}$ fired flue gas to have significantly different physical and thermal properties as compared to the air fired flue gas. These gas property differences cause considerable differences in the heat transfer processes, which occur within the steam generator unit.

The CFB boiler computer model (RHBP) accounts for two modes of heat transfer in the convective pass of the unit (non-luminous radiation and convection). Investigation of the non-luminous radiation formulations within the RHBP indicated that current equations, based on the "Hottel curves," (Hottel and Sarofim, 1967) would be accurate and formulation modifications to the RHBP would not be required. The convection formulations used in the RHBP were also checked and were found to also have the capability of accurately analyzing convective heat transfer for flue gases of the analyses typical with $\mathrm{O}_{2}$ firing. After checking these heat transfer items and providing the RHBP with the proper input data for this $\mathrm{O}_{2}$ fired case, the model was run to simulate the boiler performance for Case-2.

With the increased heat transfer rates typically associated with oxygen firing and with similar steam temperature profiles (as compared to air firing), there is potential for high metal temperatures especially within rear pass heat exchangers of the study unit. Another proprietary in-house computer program, the Metal Temperature Program (MTP), was utilized to investigate this issue. The MTP, using thermal inputs from the RHBP, calculates steam and metal temperatures at any selected point along the length of a tube. All tubes or selected tubes of any given heat exchanger bank can be modeled. This program was used to insure no design limits were exceeded.

\subsubsection{Case-2: Boiler Island Process Description, Performance, and Equipment}

This section describes the Boiler Island processes for Case- 2 and includes a simplified process flow diagram (PFD), and material and energy balance.

The basic $\mathrm{CO}_{2}$ capture concept behind Case-2 is to replace combustion air with oxygen thereby creating a high $\mathrm{CO}_{2}$ content flue gas stream that can be further processed into a high purity $\mathrm{CO}_{2}$ end product for various uses such as EOR as was assumed for this study or sequestration. To accommodate this concept in an existing CFB unit, the basic idea is to provide the proper amount of flue gas recirculation such that the $\mathrm{O}_{2}$ fired CFB unit operates as similar as possible to the air firing mode.

\section{Specific Assumptions implemented for Case-2:}

The following four subsections describe areas where key assumptions were made for the analysis of the oxygen fired CFB power plant study (Case-2). The key assumptions can be categorized as either assumed process variable values or as assumed process equipment arrangements. These subsections discuss the values used for these assumed process variables or the modified system arrangements used. Additionally, the rationale for the use of these process values or modified system arrangements is also discussed.

\section{Oxygen Content in Oxidant Stream to Furnace:}

The oxygen fired Case-2 performance simulations were done with local oxygen content in the oxidant streams for combustion (Streams 16 and 20 in Figure 4.13) of about 24 percent by volume with the remainder as recirculated flue gas. This quantity of 
recirculated flue gas provides a superficial gas velocity in the combustor that is slightly lower than what was used in Case-1 with air firing. However, because of the higher density of the flue gas (due to the high $\mathrm{CO}_{2}$ content and reduced $\mathrm{N}_{2}$ content) the bed dynamics are expected to be similar to air firing. The mass flow rate of oxygen from the ASU is modulated to provide about 3 percent by volume of oxygen in the flue gas stream leaving the combustor (the same as was used in the air fired Case-1).

\section{Furnace Heat Transfer Rate:}

The furnace flue gas composition with oxygen firing has much higher $\mathrm{CO}_{2}$ and $\mathrm{H}_{2} \mathrm{O}$ concentrations, as compared to air firing, which would tend to increase the non-luminous radiation component of the heat transfer rate from the gas to the walls. However, the heat transfer rate in the furnace is dominated by solids heat transfer phenomenon (conduction, convection and radiation).

Analysis of heat transfer data from the MTF testing showed that there was no discernible difference in the furnace wall heat transfer coefficient between air firing and $\mathrm{O}_{2}$ firing. Therefore, for Case- 2 calculations, furnace wall heat transfer coefficients were assumed to be identical to those used for air firing.

\section{Low Level Heat Recovery System:}

In $\mathrm{O}_{2}$ fired Case-2, part of the low-pressure feedwater stream leaving the existing condensate pump bypasses the existing extraction feedwater heaters \#1 and \#2. The additional heat added to the feedwater is provided through the recovery of low level heat rejected by the Air Separation Unit (ASU) main air compressor aftercoolers. This results in an increase in steam turbine generator output of about $1.6 \mathrm{MWe}$ and an increase in condenser heat rejection of about $44.8 \times 10^{6} \mathrm{~kJ} / \mathrm{hr}\left(42.5 \times 10^{6} \mathrm{Btu} / \mathrm{hr}\right)$ or about 10 percent as compared to the Case-1 analysis.

\section{Sulfur Capture:}

In conventional, air fired CFBs, limestone is added to the combustor to capture much of the sulfur in the fuel. A backend sulfur capture system, such as ALSTOM's FDA, may be used for additional sulfur capture.

With oxygen firing, limestone can also be used in the combustor, but a high combustor temperature would be required to ensure calcination of the limestone (see Section 3.1.3).

Figure 4.12 shows the calcination temperature of calcium carbonate as a function of temperature and $\mathrm{CO}_{2}$ partial pressure. For typical $\mathrm{CO}_{2}$ content with oxygen firing, a temperature of about $885^{\circ} \mathrm{C} / 1625^{\circ} \mathrm{F}$ would be required. Recarbonation $\left(\mathrm{CaO}+\mathrm{CO}_{2} \rightarrow\right.$ $\left.\mathrm{CaCO}_{3}\right)$ can occur where the temperature drops lower:

- In the backpass the gas and fly ash cool; the fly ash may recarbonate.

- In the External Heat Exchanger the circulating solids cool to below the calcination temperature. 


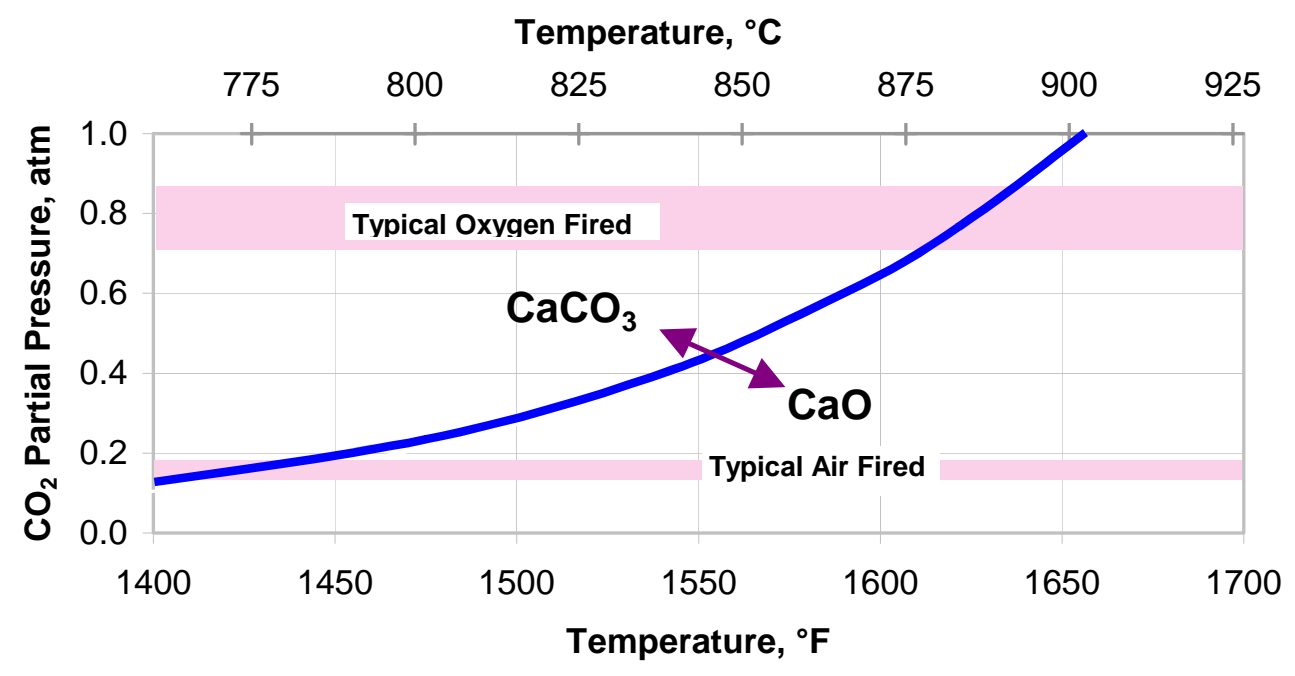

Figure 4.12: Calcination Temperature of Calcium Carbonate

If a FBHE is fluidized with recirculated flue gas, the large amount of unreacted $\mathrm{CaO}$ in the solids will "capture" most of the $\mathrm{CO}_{2}$ in the fluidizing gas. This leaves the small amount of water vapor and oxygen, which will be unable to fluidize the heat exchanger (unless a very large excess of flue gas is used).

This was demonstrated in the 2004 pilot plant tests (Nsakala, Liljedahl, and Turek, 2004). The sealpot operated below the calcination point during those tests - the cyclone and dipleg were cooled. When the sealpot was fluidized with pure $\mathrm{CO}_{2}$, it would not operate. It was necessary to fluidize with air for those tests. In a commercial unit, the sealpot would likely remain above the calcination temperature; the problem will be in the FBHE.

Some of the implications for sulfur capture are summarized in Table 4.10, for both retrofit and greenfield plants, each with or without limestone added to the furnace.

When retrofitting an air fired CFB to oxygen firing, the oxygen will be blended with recirculating flue gas to about $30 \% \mathrm{O}_{2}$ in the oxidant stream. This will approximately maintain the performance of the existing equipment as designed for air firing. A new greenfield unit can be designed for a richer oxidant - up to $70 \% \mathrm{O}_{2}$. This allows a smaller unit due to the reduced gas flow. With reduced gas flow, there is less heat removal in the furnace and convective pass. Thus a larger External Heat Exchanger is required to control the combustor temperature and provide heat to the steam cycle (see Nsakala, Liljedahl, and Turek, 2004).

With limestone added to the combustor, the temperature should be high to ensure good calcination. A high temperature may not be appropriate for low rank fuels, which are generally burned at lower combustor temperatures. Anthracite and petroleum coke will be best suited for high temperatures, especially with limestone in the combustor.

One way to avoid recarbonation is to fluidize the FBHE with air or with nitrogen from the air separation plant. To avoid contaminating the flue gas, the fluidizing gas must be vented separately, with heat recovery and particulate removal from the hot vented gas. 
Table 4.10: Issues for Sulfur Capture in Oxygen Fired CFB

\begin{tabular}{|c|c|c|c|c|}
\hline & \multicolumn{2}{|c|}{ Greenfield } & \multicolumn{2}{|c|}{ Retrofit } \\
\hline Oxygen Dilution with Recirculated Flue Gas & \multicolumn{2}{|c|}{ Up to $70 \% \mathrm{O}_{2}$ with a large External Heat Exchanger } & \multicolumn{2}{|c|}{ About $30 \% \mathrm{O}_{2}$ to match air fired conditions } \\
\hline Limestone to Furnace & Yes & No & Yes & No \\
\hline \multicolumn{5}{|l|}{ Furnace Temperature for: } \\
\hline Calcination (all fuels) & $\begin{array}{l}\text { High temperature desirable } \\
\quad\left(>1625^{\circ} \mathrm{F} / 885^{\circ} \mathrm{C}\right)\end{array}$ & No Restriction & High temperature desirable & No Restriction \\
\hline Low Rank Fuel & $\begin{array}{l}\text { High temperature not a good } \\
\text { match }\end{array}$ & $\begin{array}{c}\text { Low temperature } \\
\left(<1550^{\circ} \mathrm{F} / 840^{\circ} \mathrm{C}^{1}\right)\end{array}$ & $\begin{array}{c}\text { Redesign to high } \\
\text { temperature not a good } \\
\text { match } \\
\end{array}$ & $\begin{array}{l}\text { As designed (low } \\
\text { temperature) }\end{array}$ \\
\hline Bituminous Coal & $\begin{array}{c}\text { Sulfur capture in the furnace } \\
\text { may suffer at high furnace } \\
\text { temperature }\end{array}$ & Medium temperature & $\begin{array}{l}\text { Sulfur capture in the furnace } \\
\text { may suffer with redesign to } \\
\text { high temperature }\end{array}$ & $\begin{array}{l}\text { As designed (medium } \\
\text { temperature) }\end{array}$ \\
\hline Anthracite and Petroleum Coke & $\begin{array}{l}\text { High temperature a good } \\
\text { match }\end{array}$ & $\begin{array}{l}\text { High temperature } \\
\left(>1600^{\circ} \mathrm{F} / 870^{\circ} \mathrm{C}^{1}\right)\end{array}$ & $\begin{array}{c}\text { As designed (high } \\
\text { temperature) a good match }\end{array}$ & $\begin{array}{l}\text { As designed (high } \\
\text { temperature) }\end{array}$ \\
\hline Sorbent in Backend FDA & $\begin{array}{l}\mathrm{CaO} \text { in fly ash from the } \\
\text { furnace }\end{array}$ & $\begin{array}{c}\text { Lime or hydrated lime } \\
\text { added to FDA }\end{array}$ & $\begin{array}{l}\mathrm{CaO} \text { in fly ash from the } \\
\text { furnace }\end{array}$ & $\begin{array}{c}\text { Lime or hydrated lime } \\
\text { added to FDA }\end{array}$ \\
\hline FBHE Fluidizing Gas & $\begin{array}{c}\text { Air, } \mathrm{N}_{2} \text {, other - } \\
\text { requires vent system }\end{array}$ & Recirculated Flue Gas OK & $\begin{array}{c}\text { Air, } \mathrm{N}_{2} \text {, other - } \\
\text { requires vent system }\end{array}$ & Recirculated Flue Gas OK \\
\hline MBHE & $\begin{array}{c}\text { OK - will avoid } \\
\text { recarbonation with limestone }\end{array}$ & $\begin{array}{c}\text { OK - benefits even } \\
\text { without added limestone }\end{array}$ & Not likely economical & eplace existing FBHE \\
\hline
\end{tabular}

\footnotetext{
${ }^{1}$ These temperature ranges are very approximate
} 
Another approach is to feed no limestone in the combustor. Recirculated flue gas can then be used to fluidize the FBHE. The sulfur capture is done entirely in the backend FDA system fed with fresh lime (or hydrated lime). Most commercial installations of FDA to date are on pulverized coal units and incinerators with added lime or hydrated lime (no limestone added to the combustor).

One of the advantages of a MBHE is that it needs no fluidizing gas, so it could operate even with the $\mathrm{CaO}$ in the solids cooling to below the calcination temperature. Even without limestone in the furnace and the potential for recarbonation, an MBHE will have additional benefits (see Section 3.5.15).

Note there is one possible scenario for oxygen firing which would require no sulfur capture - the $\mathrm{CO}_{2}$-rich flue gas is dried, then directly sequestered, including the $\mathrm{SO}_{2}$ and other pollutants. This scenario is not considered in here; sulfur capture is necessary to meet a $\mathrm{CO}_{2}$ product specification for enhanced oil recovery.

For the present study - a retrofit with medium volatile bituminous coal - the options considered are limestone to the furnace with air fluidizing a vented FBHE vs. lime only to the FDA. A rough operating cost comparison shows that using limestone has about 15\% lower combined total annual sorbent cost and solid waste disposal costs. This lower operating cost is equivalent to a decrease in incremental COE of about 0.05 cents $/ \mathrm{kWh}$ or about a 1.2 percent. This decrease would be offset by the additional investment costs for the vented FBHE with heat recovery and dust cleanup. The level of this additional invetment cost was not estimated, but was thought to be high enough that the lime-only option was selected for this $\mathrm{O}_{2}$ fired retrofit application.

For petroleum coke and other fuels with less than about $15 \%$ ash, limestone added to the combustor also serves to maintain sufficient bed inventory. Without limestone, additional inert materials, such as sand or bottom ash from a pulverized coal boiler, would need to be continually added to the combustor.

\section{Process Description, Process Flow Diagram and Equipment:}

Figure 4.13 shows a simplified process flow diagram for the Boiler Island of the Case-2 oxygen-fired CFB retrofit concept. This process description briefly describes the function of the major equipment and systems included within the Boiler Island. 


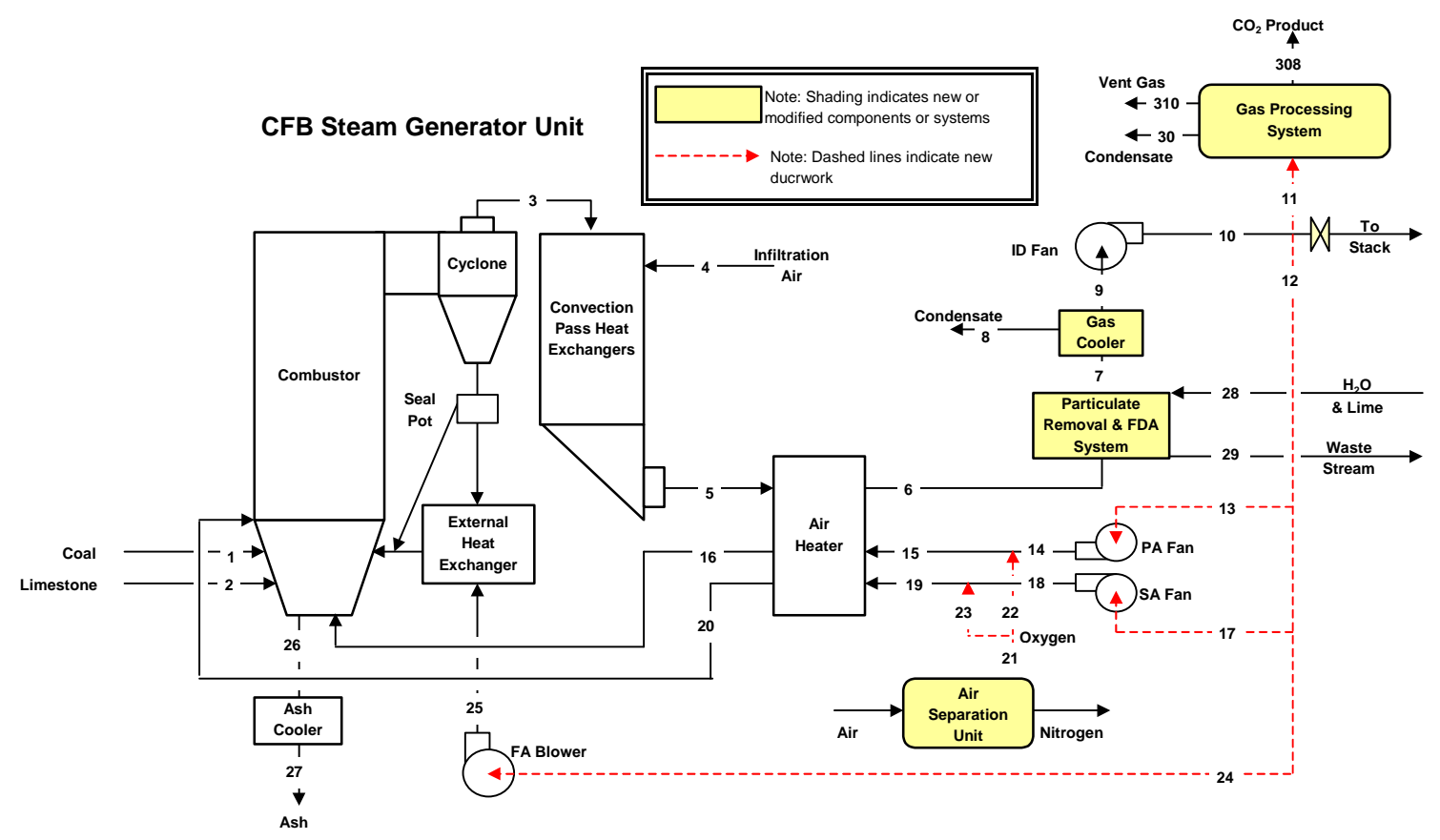

Figure 4.13: Case-2 Simplified Boiler Island Gas Side Process Flow Diagram

Complete data for all streams are shown in the material and energy balance shown in Table 4.11. In this concept coal or another high carbon content fuel (Stream 1) is reacted with a preheated mixture of substantially pure oxygen and recirculated flue gas (Streams 16 and 20) in the Combustor section of the Circulating Fluidized Bed (CFB) system. The oxygen supply (Streams 21, 22, and 23) is provided from a new cryogenic Air Separation Unit (ASU).

Flue gas (mainly $\mathrm{CO}_{2}$ and $\mathrm{H}_{2} \mathrm{O}$ ) and ash enter the two existing cyclones (Stream 3). Most of the solids are removed in the cyclone. The hot solids are recirculated to the combustor through two parallel paths: (1) an uncooled stream, which flows directly back to the combustor, and (2) a stream flowing through the existing two Fluid Bed Heat Exchangers where the solids are cooled before returning to the combustor. The Fluid Bed Heat Exchangers provide evaporator, superheat, and reheat duty.

Draining hot solids through the existing water-cooled ash coolers (Streams 26 and 27) controls solids inventory in the system while effectively recovering heat from the hot ash. The cooling water used for the ash coolers is provided from the feedwater stream leaving the final extraction feedwater heater of the steam cycle.

The combustor temperature is $1580^{\circ} \mathrm{F} / 860^{\circ} \mathrm{C}$. The temperature of Stream 3 is $1680^{\circ} \mathrm{F} /$ $916^{\circ} \mathrm{C}$ based on a $100^{\circ} \mathrm{F}$ increase due to afterburning in the cyclone. This is the same as in the Base Case.

The flue gas leaving the cyclones (Stream 3) is cooled in existing heat exchanger sections (Superheater, Reheater, and Economizer) located in the convection pass (back pass) of the system, also by exchanging heat with the power cycle working fluid. The flue gas leaving the convection pass heat exchanger sections (Stream 5) is further cooled in an 
existing air heater. The oxygen stream leaving the new Air Separation Unit (Stream 21) is split and mixed with primary and secondary streams of recirculated flue gas (Streams 14 and 18) and the mixtures are preheated in the air heater. The quantity of recirculated flue gas used (Stream 12) is adjusted to provide proper fluidization for the bed and other equipment in the CFB system requiring a fluidizing medium.

The flue gas leaving the existing air heater (Stream 6) is cleaned of fine particulate matter and $\mathrm{SO}_{2}$ in the modified Particulate Removal and Flash Dryer Absorber (FDA) system. Finally, a new Gas Cooler is used to cool the gas before the flue gas enters the Induced Draft (ID) Fan (Stream 9). The Gas Cooler is used to cool the flue gas to as low a temperature as is possible (using a direct contact water system) before recycling. This is done to minimize the power requirements for the draft system (induced draft fan, fluidizing air blowers, primary air and secondary air fans) and the product gas compression system, which is part of the Gas Processing System. Some $\mathrm{H}_{2} \mathrm{O}$ vapor is condensed out of the flue gas in the Gas Cooler. The flue gas leaving the ID Fan (Stream 10), comprised of mostly $\mathrm{CO}_{2}$, is split with about 20 percent of the flue gas going to the product stream (Stream 11) for further processing for an EOR application. The remainder of the flue gas (about 80 percent) is recirculated to the CFB system (Stream 12).

\section{Material and Energy Balance:}

Table 4.11 shows the Boiler Island material and energy balance for Case-2. The stream numbers shown at the top of each column of the table refer to stream numbers shown in Figure 4.13. The performance shown was calculated with $\mathrm{O}_{2}$ firing at MCR conditions for this unit and at ambient conditions as defined in the design basis.

The MCR condition is defined as high-pressure turbine inlet conditions of $284,401 \mathrm{~kg} / \mathrm{hr}$ $(627,000 \mathrm{lbm} / \mathrm{hr}), 138 \mathrm{bara}(2,000 \mathrm{psia}), 538^{\circ} \mathrm{C}\left(1,000{ }^{\circ} \mathrm{F}\right)$ and intermediate-pressure turbine inlet conditions of $257,375 \mathrm{~kg} / \mathrm{hr}(567,418 \mathrm{lbm} / \mathrm{hr}), 29.5$ bara $(428 \mathrm{psia}), 538^{\circ} \mathrm{C}$ $\left(1,000^{\circ} \mathrm{F}\right)$. These steam conditions were also used for the Base Case (Case- 1$)$. The boiler was fired with enough oxygen to leave about 3 percent by volume of oxygen in the flue gas stream leaving the furnace (Stream 3), the same as was used for Case-1. This oxygen requirement results in a stoichiometry of about 1.04 for Case-2. 
Table 4.11: Case-2: Boiler Island Gas Side Material and Energy Balance

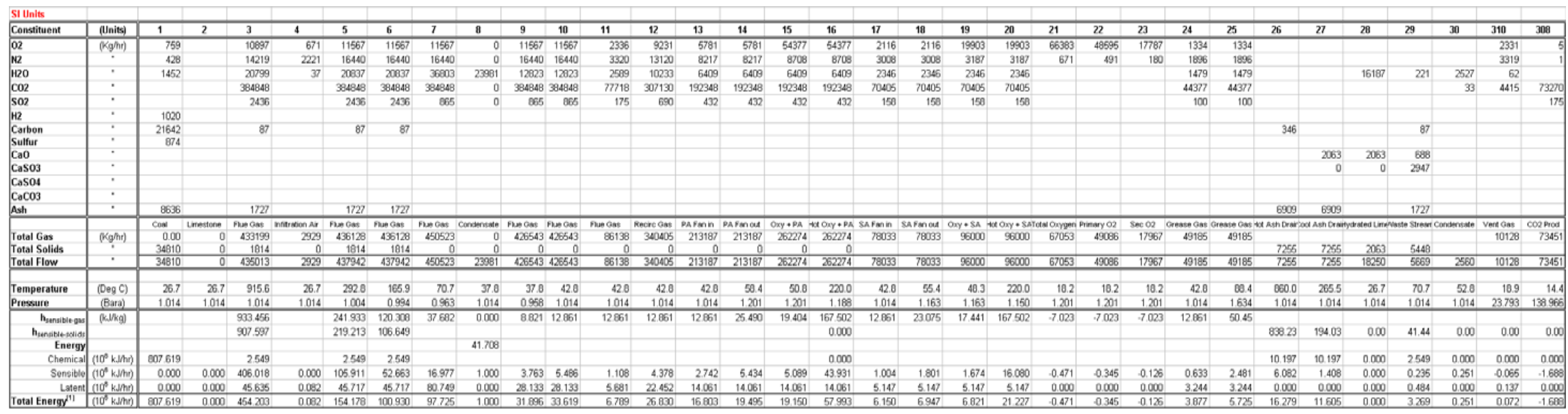

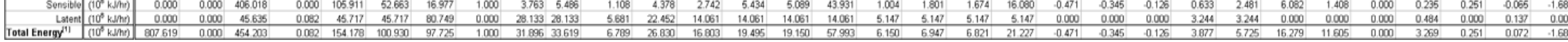
Notes:

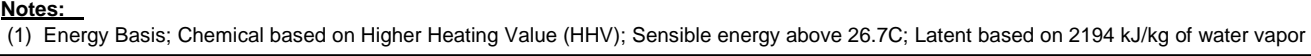

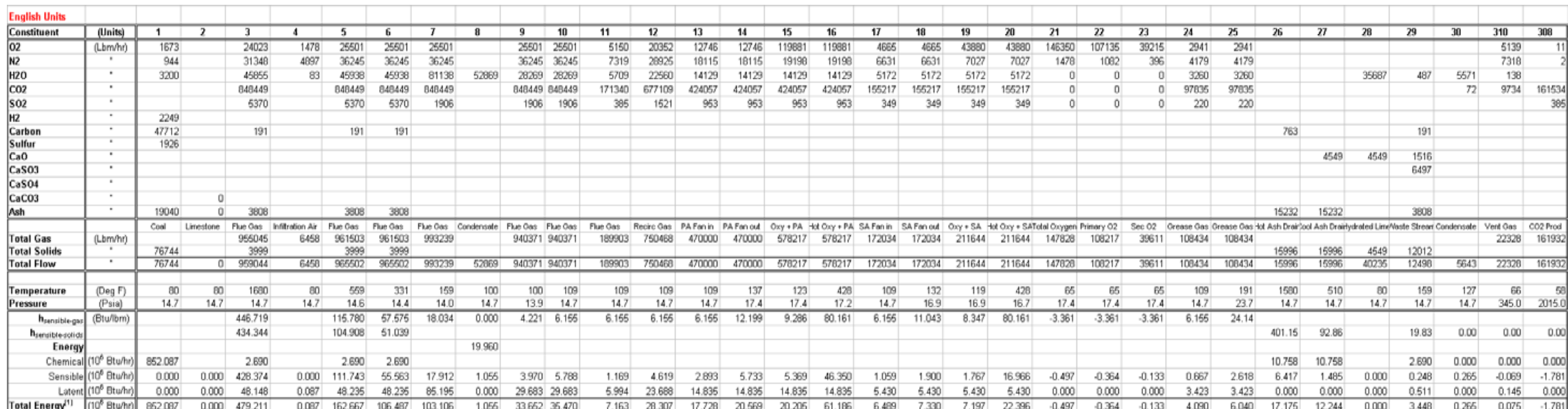

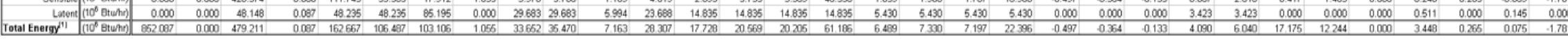

\begin{tabular}{ll}
\hline Notes: \\
(1) Energy Basis; Chemical based on Higher Heating Value (HHV); Sensible energy above 80F; Latent based on 1050 Btu/Lbm of water vapor
\end{tabular} 


\section{Case-2: Boiler Performance Summary:}

The main steam flow for this case is $284,401 \mathrm{~kg} / \mathrm{hr}(627,000 \mathrm{lbm} / \mathrm{hr})$. The cold reheat flow leaving the high-pressure turbine for this case is $257,375 \mathrm{~kg} / \mathrm{hr}(567,418 \mathrm{lbm} / \mathrm{hr})$. The hot reheat flow that is returned to the intermediate pressure turbine for this case is also $257,375 \mathrm{~kg} / \mathrm{hr}(567,418 \mathrm{lbm} / \mathrm{hr})$. The inlet and outlet steam/water conditions supplied to and produced by the modified $\mathrm{O}_{2}$ fired CFB steam generator unit is shown in Table 4.12 below. These steam/water conditions are identical to those in the air fired Case-1.

Table 4.12: Case-2 (Base Case) Boiler/Turbine Steam Flows and Conditions

\begin{tabular}{|c|rrrr|}
\hline & SHO & FWI & RHO & RHI \\
\hline (lbm/hr) & 627000 & 627000 & 567418 & 567418 \\
(kg/hr) & 284401 & 284401 & 257375 & 257375 \\
\hline (psia) & 2095 & 2500 & 451 & 481.7 \\
(bara) & 144.5 & 172.4 & 31.1 & 33.2 \\
\hline (deg F) & 1005 & 460 & 1001 & 635 \\
(deg C) & 540 & 238 & 539 & 335 \\
\hline (Btu/lbm) & 1474 & 443 & 1522 & 1322 \\
(kJ/kg) & 3080.3 & 924.6 & 3181.4 & 2761.8 \\
\hline Notes: & SHO = Superheater Outlet & \\
& FWI = Feedwater Inlet & & \\
& RHO = Reheater Outlet \\
& RHI = Reheater Inlet
\end{tabular}

To produce these steam outlet conditions, the superheat circuit requires about 1.2 percent de-superheating spray and the reheat circuit requires no spray. Biasing the flow of hot solids leaving the cyclones through or around the Reheat external heat exchanger controls the outlet steam temperature of the reheater to the required level. The Reheat desuperheating sprays are used only during transients if required. Solids flow is biased through or around the Superheat external heat exchanger to control the bed temperature. The Superheat de-superheating sprays are used to control superheater outlet temperature to the desired value.

The boiler was fired with enough oxygen such that there remains about 3 percent by volume $\mathrm{O}_{2}$ in the flue gas exiting the combustor (the same as in Case-1 with air firing). The resulting boiler efficiency calculated for this case was about 88.8 percent (HHV basis). The air heater exit gas temperature was $166^{\circ} \mathrm{C}\left(331^{\circ} \mathrm{F}\right)$ for this case.

\section{Boiler Heat Transfer Comparison:}

Figure 4.14 shows a general comparison of the boiler heat absorption distribution between the air firing of Case-1 and the oxygen firing of Case-2. The total heat absorption is exactly the same in both air fired Case- 1 and oxygen fired Case- 2 .

The combustor temperature is the same for both cases and the heat transfer coefficient in the Combustor was assumed to be the same, based upon the review and analysis of pilot plant test data (see Section 3). Thus the Combustor heat absorption is the same in both cases. Differences in heat absorption occur in the Convection Pass, the External Heat 
Exchanger and ash cooler. The Convection Pass heat absorption for $\mathrm{O}_{2}$ fired Case- 2 is about 24 percent higher than it was for air fired Case-1 due to the higher mass flow $(\sim 20$ percent higher) and higher specific heat of the flue gas in the convective pass with $\mathrm{O}_{2}$ firing. To compensate for the increased convective pass absorption, the External Heat Exchanger (EHE) heat absorption for $\mathrm{O}_{2}$ fired Case- 2 is reduced to about 79 percent of the Case-1 air fired value. This is accomplished by diverting a larger portion of the hot solids leaving the cyclones directly to the combustor thus reducing the hot solids flow through the EHE's. The heat transfer coefficient for the FBHE's was assumed to be the same for air and $\mathrm{O}_{2}$ firing based upon the review and analysis of test data from Section 3. The lower ash flow being removed from the combustor of Case- 2 accounts for the difference in ash cooler heat absorption. The ash flow is lower in Case- 2 since limestone is not added to the combustor in this case.

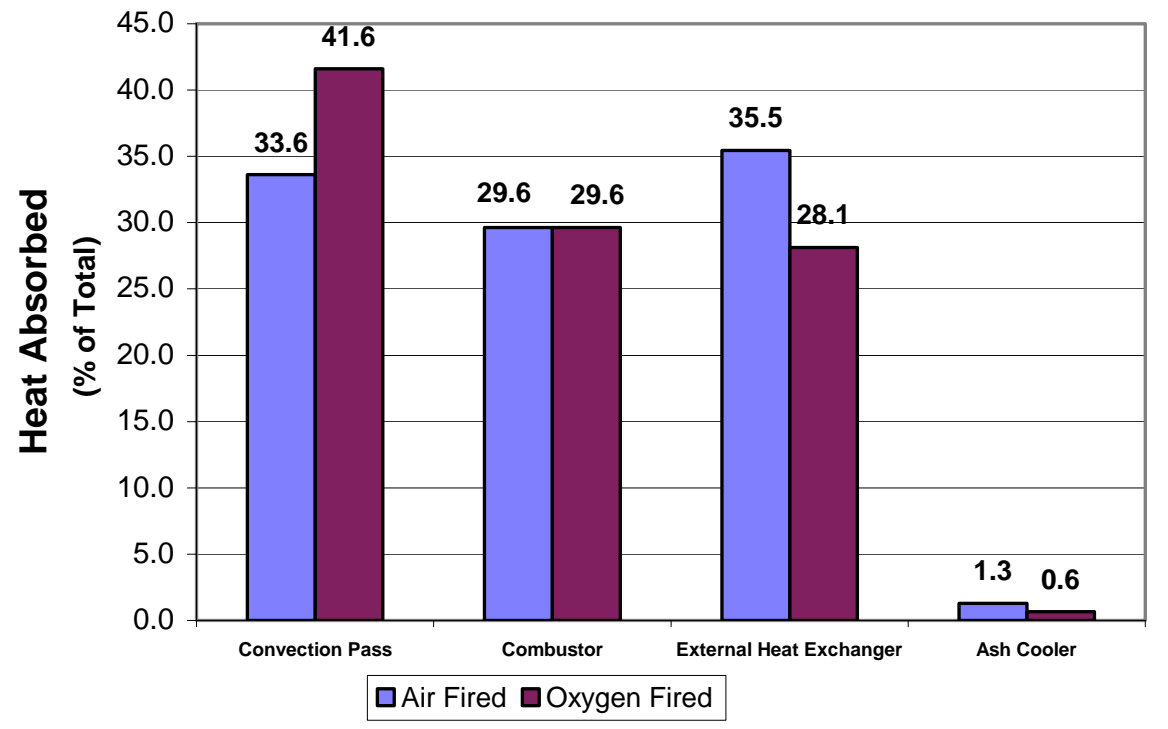

Figure 4.14: CFB Boiler Heat Absorption Comparison (Air and $\mathrm{O}_{2}$ Firing)

\section{Convection Pass Heat Transfer Comparison:}

Figure 4.15, Figure 4.16, and Figure 4.17 show the comparison of convective, nonluminous, and total heat transfer rates respectively between air firing and oxygen firing for all the major sections contained within the existing convective pass of the unit at full load (MCR) operating conditions.

Convective heat transfer in utility steam generator units is dependent upon many of the transport properties of the flue gas (viscosity, thermal conductivity, density, specific heat and others). Additionally, convection depends on Reynolds number where gas velocity is important. With the $\mathrm{O}_{2}$ fired system there are significant changes in the flue gas analysis as compared to the flue gas with air firing. These gas analysis changes cause both transport property changes and gas velocity changes throughout the unit. The resulting convective heat transfer rate enhancements with $\mathrm{O}_{2}$ firing as compared to air firing ranged from about 16 to 17 percent, as shown in Figure 4.15. 


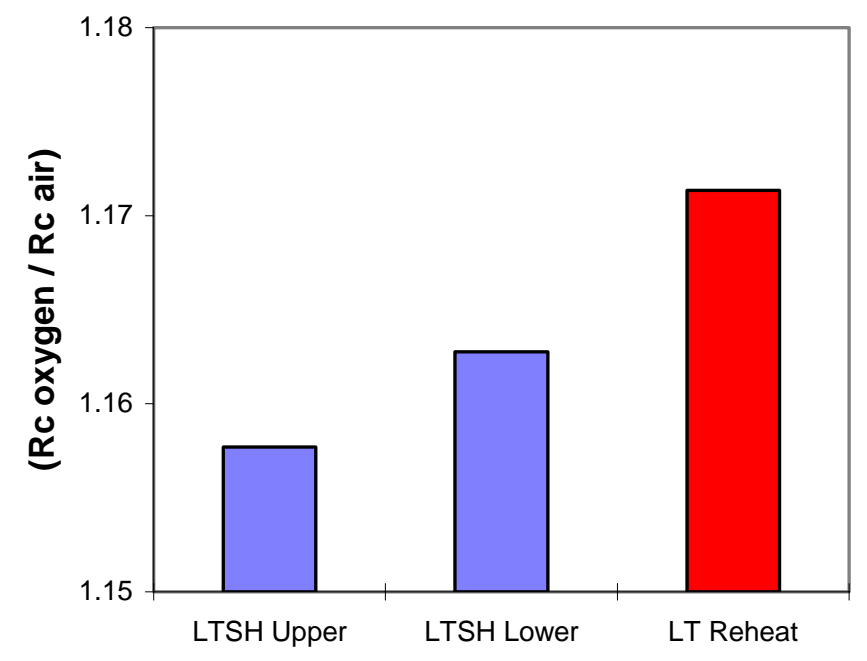

Figure 4.15: Convective Heat Transfer Rate Comparison

Significant differences in non-luminous radiant heat transfer are also expected when comparing air firing and $\mathrm{O}_{2}$ firing. Of the gases produced by the complete combustion of a fuel, only carbon dioxide, water vapor and sulfur dioxide emit radiation over a sufficiently wide band of wavelengths to warrant consideration. With this $\mathrm{O}_{2}$ fired system the primary change in the flue gas as compared to air firing is the large increase in the $\mathrm{CO}_{2}$ and $\mathrm{H}_{2} \mathrm{O}$ content and the decrease in $\mathrm{N}_{2}$ content. The resulting enhancement in non-luminous heat transfer rates with $\mathrm{O}_{2}$ firing as compared to air firing ranged from about 42 to 45 percent, as shown in Figure 4.16.

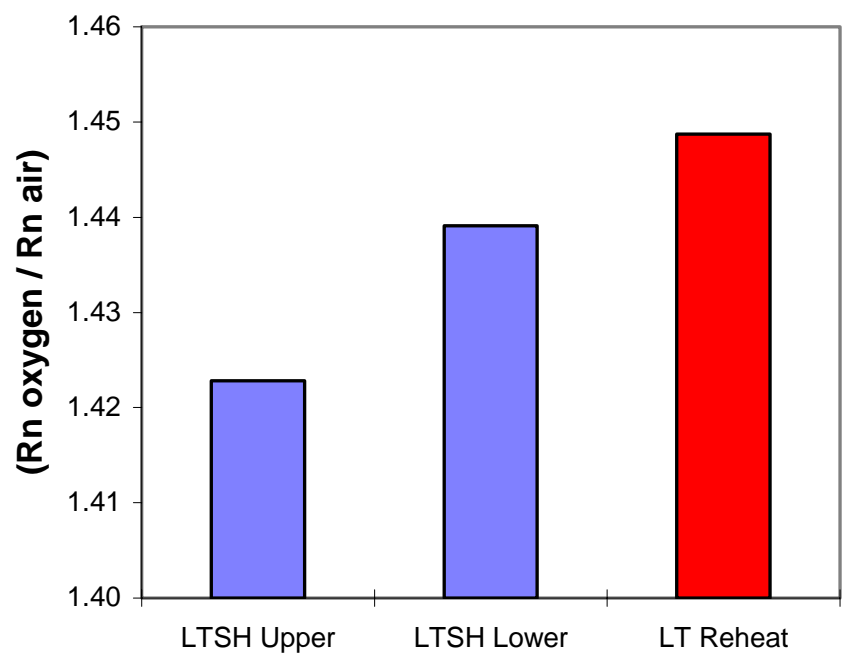

Figure 4.16: Non-Luminous Radiant Heat Transfer Rate Comparison

The total heat transfer rate enhancements with $\mathrm{O}_{2}$ firing as compared to air firing ranged from 14 to 23 percent, as shown in Figure 4.17. 


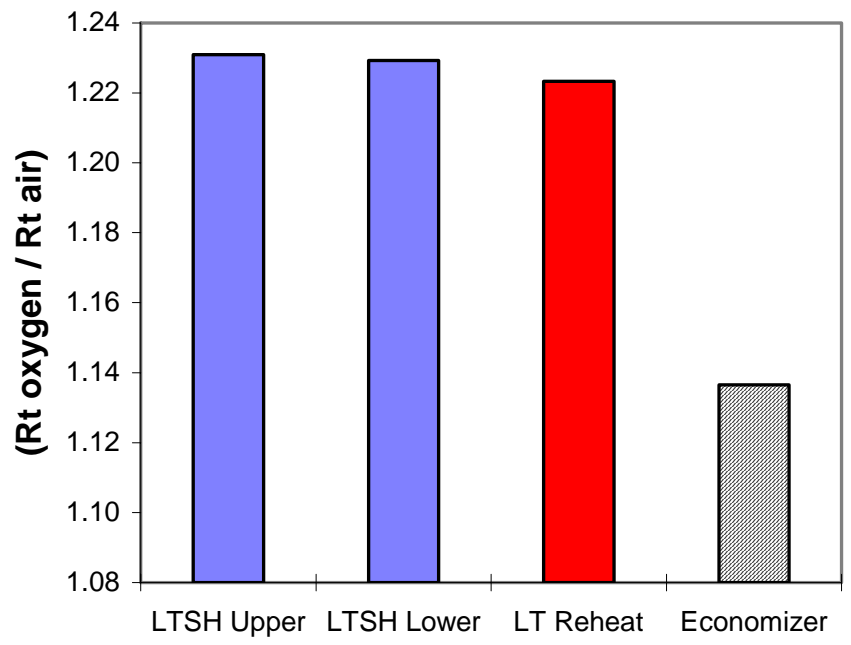

Figure 4.17: Total Heat Transfer Rate Comparison

\section{Boiler Pressure Part Materials Evaluation:}

With the increased heat transfer rates associated with oxygen firing and with similar steam temperature profiles (as compared to air firing), there was concern regarding the potential for high metal temperatures especially within rear pass heat exchangers of the study unit. The Metal Temperature Program (MTP) was utilized to investigate this issue. The MTP, using thermal inputs from the RHBP, calculates steam and metal temperatures along the length of a tube. This program was used in a preliminary analysis to insure no design limits were exceeded for the existing heat exchanger tubing.

A Circulating Fluid Bed (CFB) Boiler operates with only moderately less total air flow at low loads than at Maximum Continuous Rating (MCR). This is done in order to maintain proper fluidization and circulation of the bed. The combustor outlet temperature does not drop off proportionally with load because the lower airflow reduces the heat transfer rate in the combustor. As a consequence, the gas temperature entering the backpass during low loads is only moderately lower than at MCR. As a result of the relatively higher gas weight with only moderately less gas temperature, the pressure parts material selection in the backpass of a CFB is overwhelmingly governed by low load conditions and not the MCR operating condition. In other words, the backpass pressure part materials on CFBs are typically of better quality than they need to be at high loads.

With oxygen firing, for the present retrofit scenario, the gas weight is approximately 20 percent higher, and the backpass heat absorption is greater than for air firing at the same load. Metal Temperature Program analysis of the backpass pressure part materials using the calculated gas and steam conditions between 75 percent to MCR loads with oxygen firing indicate that the pressure parts temperatures operate within ASME allowable limits.

At lower loads, below about 75 percent, the unit would have to be switched back over to air firing. If it is essential to operate the unit at low loads on oxygen firing, then the pressure part materials will have to be upgraded. For the scope of the work in this study, it was assumed that the unit would either operate at high loads, or be permitted to operate 
on air firing at low loads.

The implication for oxygen firing is that for high load conditions, from approximately 75 percent to MCR, the existing pressure part materials will be sufficient. More detailed analyses would have to be made of low load operation on oxygen firing to determine exactly the lowest possible load the unit could be safely operated at, before the unit would have to be switched over to air firing.

One possible method to alleviate this limitation or at least extend the $\mathrm{O}_{2}$ firing load range is to force the combustor outlet temperature to be reduced at low loads. Since we are capturing sulfur in the baghouse with a lime based FDA system there would be no adverse effects on sulfur capture if this method were used. The reduced combustor outlet temperature could be obtained by biasing more of the solids leaving the cyclones through the FBHE's at loads below 75 percent. This method could be investigated in a more detailed analysis.

For the Fluid Bed Heat Exchanger (FBHE) surfaces, the materials are essentially unaffected by the gas weight increase of the backpass. There is some increase in the inlet steam temperatures with $\mathrm{O}_{2}$ firing, but since the temperature increase is at the cool end of the tubing for the FBHE's, where the materials selections are governed by the outlet steam temperatures, the materials are more than adequate. Therefore, no changes in pressure parts materials are necessary for the FBHE's.

\subsubsection{Case-2: Gas Processing System (GPS): Process Description, Performance, and Equipment}

The purpose of the Gas Processing System (GPS) for this project is to process the flue gas stream leaving the oxygen-fired Boiler Island to provide a liquid $\mathrm{CO}_{2}$ product stream of suitable conditions for an EOR application.

The Case- $2 \mathrm{CO}_{2}$ capture system is designed for more than 94 percent $\mathrm{CO}_{2}$ capture from the GPS feed stream. Process design, equipment selection, performance calculations and cost estimates were developed for all the systems and equipment required for cooling, purifying, compressing and liquefying of the $\mathrm{CO}_{2}$ rich flue gas stream to a product quality acceptable for pipeline transport. The Dakota Gasification Company's $\mathrm{CO}_{2}$ specification for EOR (Dakota Gasification Company, 2005) given in Table 4.13 was used as the basis for the $\mathrm{CO}_{2}$ capture system design. The calculated volume percent values for the product stream using the gas processing system described in this section are shown for comparison in the far right column of Table 4.13. As shown, the $\mathrm{CO}_{2}$ product meets or exceeds all of the specification values. 
Table 4.13: Dakota Gasification Project's $\mathrm{CO}_{2}$ Specification for EOR and the Calculated Product Stream Purity

\begin{tabular}{|l|l|c|c|}
\multicolumn{2}{l|}{} & Spec & Actual \\
Value & Value \\
\hline $\mathrm{CO}_{2}$ & $($ vol $\%)$ & 96 & 99.8 \\
$\mathrm{H}_{2} \mathrm{~S}$ & $($ vol $\%)$ & 1 & --- \\
$\mathrm{CH}_{4}$ & $($ vol $\%)$ & 0.3 & --- \\
$\mathrm{C}_{2}+\mathrm{HC}$ 's & $($ vol $\%)$ & 2 & --- \\
$\mathrm{CO}$ & $($ vol \%) & -- & --- \\
$\mathrm{N}_{2}$ & $($ ppm by vol. $)$ & 6000 & 19.0 \\
$\mathrm{H}_{2} \mathrm{O}$ & $($ ppm by vol. $)$ & 2 & 0.5 \\
$\mathrm{O}_{2}$ & $($ ppm by vol. $)$ & 100 & 95.0 \\
Mercaptans and other Sulfides & (vol \%) & 0.03 & --- \\
\hline
\end{tabular}

\section{GPS Process Description:}

The following subsections provide the process description for a $\mathrm{CO}_{2}$ recovery system that first cools and then compresses a $\mathrm{CO}_{2}$ rich flue gas stream from an oxygen-fired $\mathrm{CFB}$ boiler to a pressure high enough so $\mathrm{CO}_{2}$ can be liquefied. The resulting liquid $\mathrm{CO}_{2}$ is passed through a $\mathrm{CO}_{2}$ distillation column to reduce the $\mathrm{N}_{2}$ and $\mathrm{O}_{2}$ content to meet the stringent specification noted above. Then the liquid $\mathrm{CO}_{2}$ is pumped to a high pressure so it can be economically transported for usage or sequestration. The overhead gas from the $\mathrm{CO}_{2}$ distillation column condenser outlet is ultimately vented to atmosphere.

In this study it was assumed that the $\mathrm{CO}_{2}$ product was to be used for an enhanced oil recovery (EOR) application. Pressure in the transport pipeline must be maintained above the critical pressure of $\mathrm{CO}_{2}$ to avoid 2-phase flow. The transport line and $\mathrm{CO}_{2}$ injection well however are not included as part of the scope in this project.

A later subsection (Process Flow Diagrams) provides four process flow diagrams (PFD's) for the GPS. These PFD's are referred to throughout this process description.

Figure 4.18 shows the Flue Gas Quenching process flow diagram.

Figure 4.19,

Figure 4.20, and Figure 4.21 show the Flue Gas Compression, Distillation and Propane Refrigeration process flow diagrams, which make up the complete Gas Processing System.

The key process parameters (pressures, temperatures, duties etc.) are shown in the material and energy balance tables provided in a later subsection (Material and Energy Balance) and will not be repeated in this description except in selected instances. The following subsections describe the various processes used within the Case-2 Gas Processing System.

\section{Flue Gas Quenching:}

Please refer to

Figure 4.18 (Drawing Number: PFD - 100). 
The feed to the Gas Processing System is the flue gas stream that leaves the particulate and sulfur removal system of the Boiler Island. At this point, the flue gas is above the dew point of $\mathrm{H}_{2} \mathrm{O}$. All of the flue gas leaving the boiler is cooled to $37.8^{\circ} \mathrm{C}\left(100^{\circ} \mathrm{F}\right)$ in Gas Cooler DA-101 that operates slightly below atmospheric pressure. A significant amount of water condenses out in this cooler. Excess condensate is blown down to the cooling water system. A single vessel has been provided for this cooler.

The Gas Cooler is configured in a packed tower arrangement where the flue gas is contacted with cold water in countercurrent fashion. Warm water from the bottom of the contactor is recycled back to the top of the contactor by Water Pump GA-101 after first being cooled in an external water cooled heat exchanger, Water Cooler EB-101 (plate and frame exchanger). The cooling water for this exchanger comes from the existing cooling tower.

Because the flue gas may carry a small amount of fly ash, the circulating water is filtered in Water Filter FD-101A-C to prevent solids build-up in the circulating water. Condensate blowdown is filtered and is taken out downstream of the filter. However, the stream is not cooled and is split off before EB-101. Make-up water is added before EB-101.

From the Gas Cooler the gas stream is boosted in pressure by the ID fan (part of the boiler scope). The gas stream is then split into two streams. One stream is recirculated to the boiler and the other stream is the product feed stream. This design was developed to minimize the length of ducting operating at a slight vacuum and to minimize the temperature of the gas being recycled back to the boiler thus minimizing the power requirement of the existing boiler fans and blowers. The mass flow rate of the gas recirculation stream is about 4.2 times the mass flow rate of the product gas stream, which proceeds to the gas compression area. The recycle stream is sized to provide oxygen content of about 24 percent by volume in the oxidant streams supplying the existing boiler. The Gas Cooler also reduces the volumetric flow rate to, and the resulting power consumption of, the flue gas compression equipment located downstream.

\section{Gas Compression System:}

Please refer to

Figure 4.19 (Drawing Number: PFD - 200).

The flue gas compression section is where the $\mathrm{CO}_{2}$ rich flue gas stream leaving the Boiler Island is compressed to about 30.0 barg (435 psig) by a four-stage centrifugal compressor, Flue Gas Compressor GB-101. The volumetric flow to the compressor inlet is about 910 actual cubic meters per minute $(32,000$ ACFM) and only a single frame is required. The discharge pressures of the four stages have been balanced to give reasonable power distribution and discharge temperatures across the various stages. The discharge pressures following each stage are listed below:

- $1^{\text {st }}$ Stage $\quad 1.6$ barg (23 psig)

- $2^{\text {nd }}$ Stage $\quad 4.3$ barg $(63$ psig)

- $\quad 3^{\text {rd }}$ Stage $\quad 11.7$ barg (170 psig) 


$$
\text { - } 4^{\text {th }} \text { stage } \quad 30.0 \text { barg (435 psig) }
$$

Power consumption for this large compressor has been estimated using adiabatic efficiencies of about 82 percent for each stage as provided by the vendor.

Each flue gas compression stage has an aftercooler that utilizes cooling water for cooling the flue gas. In these aftercoolers the flue gas leaving each compressor stage is cooled to within $11.1^{\circ} \mathrm{C}\left(20^{\circ} \mathrm{F}\right)$ of the entering cooling water temperature which is $29.4^{\circ} \mathrm{C}\left(85^{\circ} \mathrm{F}\right)$.

Recovery of the aftercooler heat rejection with low temperature feedwater was considered. In theory this heat can be recovered in the condensate stream of the existing steam cycle and the overall power cycle can be made more efficient. However, this type of heat recovery system was not used in this case for several reasons. First, the temperature levels obtainable by the feedwater leaving the aftercoolers $(65-104 \mathrm{C} ; 150$ $220 \mathrm{~F}$ ) are relatively low. Second, minimal additional steam turbine power was calculated, and third, significant incremental costs are required for the larger heat exchangers and piping system, which would be required for the heat recovery system. Therefore, this type of low level heat recovery system was determined not to be economically justified in this situation.

As mentioned, the hot flue gas leaving each of the first three compressor stages is cooled with cooling water to $40.6^{\circ} \mathrm{C}\left(105^{\circ} \mathrm{F}\right)$ (Flue Gas Compressor $1^{\text {st }} / 2^{\text {nd }} / 3^{\text {rd }}$ Stage Aftercooler EA-101/2/3). The flue gas compressor $4^{\text {th }}$ stage aftercooler (EA-104) cools the flue gas to $65.0^{\circ} \mathrm{C}\left(149^{\circ} \mathrm{F}\right)$ against cooling water. The flue gas then performs the reboiling duty for the $\mathrm{CO}_{2}$ distillation column where the flue gas is further cooled to $26.7^{\circ} \mathrm{C}\left(80^{\circ} \mathrm{F}\right)$. This cooler gas allows additional water to be knocked out which decreases the size and fuel gas consumption of the product gas driers. Due to their large size, many of these heat exchangers consist of multiple shells. Because of highly corrosive conditions, the process side of the coolers must be stainless steel.

Experience has shown that above ambient heat exchangers with duties under $0.95 \times 10^{6}$ $\mathrm{kJ} / \mathrm{hr}\left(1 \times 10^{6} \mathrm{Btu} / \mathrm{hr}\right)$ have relatively poor cost to benefit ratios. Thus a trim cooler to further cool the flue gas leaving each aftercooler was not added for this relatively small plant size.

Because the flue gas stream leaving the direct contact flue gas cooler (DA-101) is saturated, some water condenses out in the three aftercoolers. The sour condensate is separated in knockout drums (FA-100/1/2/3/4) equipped with mist eliminator pads. Condensate from these drums is drained to the cooling tower or to waste water treatment. To prevent corrosion, these drums have stainless steel liners.

Flue gas leaving the 4th stage discharge knockout drum (FA-104) is fed to Flue Gas Drier FF-101 A/B where nearly all the remaining moisture is removed.

\section{Gas Drying:}

Please refer to

Figure 4.19 (Drawing Number: PFD - 200).

It is necessary to dry the $\mathrm{CO}_{2}$ stream to meet the product specification. A fixed bed alumina drier has been selected to provide this service. 
The performance of a fixed-bed drier improves as pressure increases. This favors locating the drier at the discharge of the compressor. However, as the operating pressure of the drier increases, so does the design pressure of the equipment. This favors lowpressure operation. But, at low pressure the diameter or number of the drier vessels grows, increasing the cost of the vessel. Having to process the recycle gas from the distillation column condenser cooling would also increase the diameter of the vessel. However, this is less than 13 percent of the forward flow. For this design the drier has been optimally located downstream of the 4th stage compressor. The $\mathrm{CO}_{2}$ Drier system consists of two vessels (FF-101 A/B). One vessel is on line while the other is being regenerated. Flow direction is down during operation and up during regeneration.

The drier is regenerated with the non-condensable vent gas from the distillation column after it exits heat exchanger EA-108 in a simple once through scheme. During regeneration, the non-condensable vent gas is heated in Regeneration Heater FH-101 before passing it through the exhausted drier. After regeneration, heating is stopped while the vent gas flow continues through the drier bed. This cools the bed down to the normal operating range. The regeneration gas and the impurities contained in it are vented to the atmosphere.

Regeneration of an alumina bed requires relatively high temperature and, because HP steam pressure may fluctuate, a gas-fired heater has been specified for this service.

A Flue Gas Filter (FD-102) has been provided at the drier outlet to remove any fines that the gas stream may pick up from the desiccant bed.

\section{$\mathrm{CO}_{2}$ Condensation and Stripping:}

Please refer to

Figure 4.20, and Figure 4.21 (Drawing Numbers: PFD - 300, PFD - 400).

From the $\mathrm{CO}_{2}$ Drier, the gas stream is cooled to $-24.4^{\circ} \mathrm{C}\left(-12^{\circ} \mathrm{F}\right)$ using propane refrigeration in a $\mathrm{CO}_{2}$ Feed Condenser (EA-105 A/B). From EA-105 the partially condensed flue gas stream continues on to $\mathrm{CO}_{2}$ Column DA-102. At the pressure and temperature leaving the $\mathrm{CO}_{2}$ Feed Condenser (EA-105), 28.8 bara (418 psia) and $-24.4^{\circ} \mathrm{C}$ $\left(-12^{\circ} \mathrm{F}\right)$, about 90 -mole percent of the stream is condensed. The flash vapors contain approximately 63-weight percent of the inlet oxygen and nitrogen, but also about 7.2weight percent of the $\mathrm{CO}_{2}$. Therefore, a distillation column with both a reboiler and condenser has been provided to reduce the loss of $\mathrm{CO}_{2}$ to an acceptable level (about 5.7weight percent) while simultaneously boiling out the inerts from the $\mathrm{CO}_{2}$ liquid in the bottom of the column. A simple rectifier column with only a condenser could not remove enough of the inerts to meet the stringent $\mathrm{CO}_{2}$ product specification. Upon leaving the distillation column sump the pressure of the liquid is boosted to 138 barg (2,000 psig) by $\mathrm{CO}_{2}$ Pipeline Pump GA-103. This stream is now available for usage or sequestration. In this study it was assumed that the $\mathrm{CO}_{2}$ product was used for an enhanced oil recovery (EOR) application.

The vapors in the feed to the distillation column contain the nitrogen and the oxygen that flashed from the feed as well as additional vapors generated in the reboiler. To keep the $\mathrm{CO}_{2}$ loss to the minimum, the distillation column also has an overhead condenser $\left(\mathrm{CO}_{2}\right.$ Column Condenser EA-107). This is a floodback type condenser installed on top of the 
distillation column. It cools the overhead vapor from the tower down to $-45{ }^{\circ} \mathrm{C}(-50$ ${ }^{\circ} \mathrm{F}$ ). The condensed $\mathrm{CO}_{2}$ acts as cold reflux in the $\mathrm{CO}_{2}$ Column.

Taking a slipstream from the inert-free liquid $\mathrm{CO}_{2}$ leaving the $\mathrm{CO}_{2}$ column bottoms and letting it down to the Flue Gas Compressor 3rd stage suction pressure cools EA-107. At this pressure, $\mathrm{CO}_{2}$ liquid boils at $-50{ }^{\circ} \mathrm{C}\left(-58^{\circ} \mathrm{F}\right)$ thus providing the refrigeration necessary to condense some of the $\mathrm{CO}_{2}$ from the distillation column overhead gas. The process has been designed to achieve more than 94 percent $\mathrm{CO}_{2}$ recovery. The vaporized $\mathrm{CO}_{2}$ from the cold side of EA-107 is fed to EA-109 and then to the suction of the Flue Gas Compressor 3rd stage.

Any system containing liquefied gas such as $\mathrm{CO}_{2}$ is potentially subject to very low temperatures if the system is depressurized to atmospheric pressure while the system contains cryogenic liquid. If the $\mathrm{CO}_{2}$ Column (and all other associated equipment that may contain liquid $\mathrm{CO}_{2}$ ) were to be designed for such a contingency, it would have to be made of stainless steel. However, through proper operating procedures and instrumentation such a scenario can be avoided and low temperature carbon steel (LTCS) can be used instead. Our choice here is LTCS. However, the condenser section will be made from stainless steel.

\section{$\mathrm{CO}_{2}$ Pumping and $\mathrm{CO}_{2}$ Pipeline:}

Please refer to

Figure 4.20 (Drawing Number: PFD - 300).

The $\mathrm{CO}_{2}$ product must be increased in pressure to 138 barg (2,000 psig). A multistage heavy-duty pump (GA-103) is required for this service. This is a highly reliable derivative of an API-class boiler feedwater pump.

It is important that the pipeline pressure be always maintained above the critical pressure of $\mathrm{CO}_{2}$ such that single-phase (dense-phase) flow is guaranteed. Therefore, the pressure in the line should be controlled with a pressure controller and the associated control valve located at the destination end of the line.

The $\mathrm{CO}_{2}$ transport line and $\mathrm{CO}_{2}$ injection well however are not included as part of the scope of supply in this project.

\section{Offgas:}

\section{Please refer to}

Figure 4.20 (Drawing Number: PFD - 300).

The vent gas from the $\mathrm{CO}_{2}$ Column overhead is at high pressure and there is an opportunity for power recovery using turbo-expanders. Because the gas cools down in the expansion process, there is also an opportunity for cold recovery. Power recovery from the stream after let down via an expander was examined and it was determined that the amount of power that could be recovered without freezing the carbon dioxide in the stream was small. Thus power recovery could not be economically justified. The offgas leaves the distillation column at $-45.6^{\circ} \mathrm{C}\left(-50^{\circ} \mathrm{F}\right)$ approximately. The refrigeration recovery to condense $\mathrm{CO}_{2}$ was the best use for this cold stream since it also produces a reasonable temperature regeneration gas for the dryers. 
COMMERCIALIZATION DEVELOPMENT OF OXYGEN FIRED CFB

FOR GREENHOUSE GAS CONTROL

\section{Process Flow Diagrams:}

Four process flow diagrams for the Gas Processing System (GPS) described above are listed and shown below:

- (Drawing Number: PFD - 100) Flue Gas Quenching

- (Drawing Number: PFD - 200) Flue Gas Compression

- (Drawing Number: PFD - 300) Distillation

- (Drawing Number: PFD - 400) Propane Refrigeration 


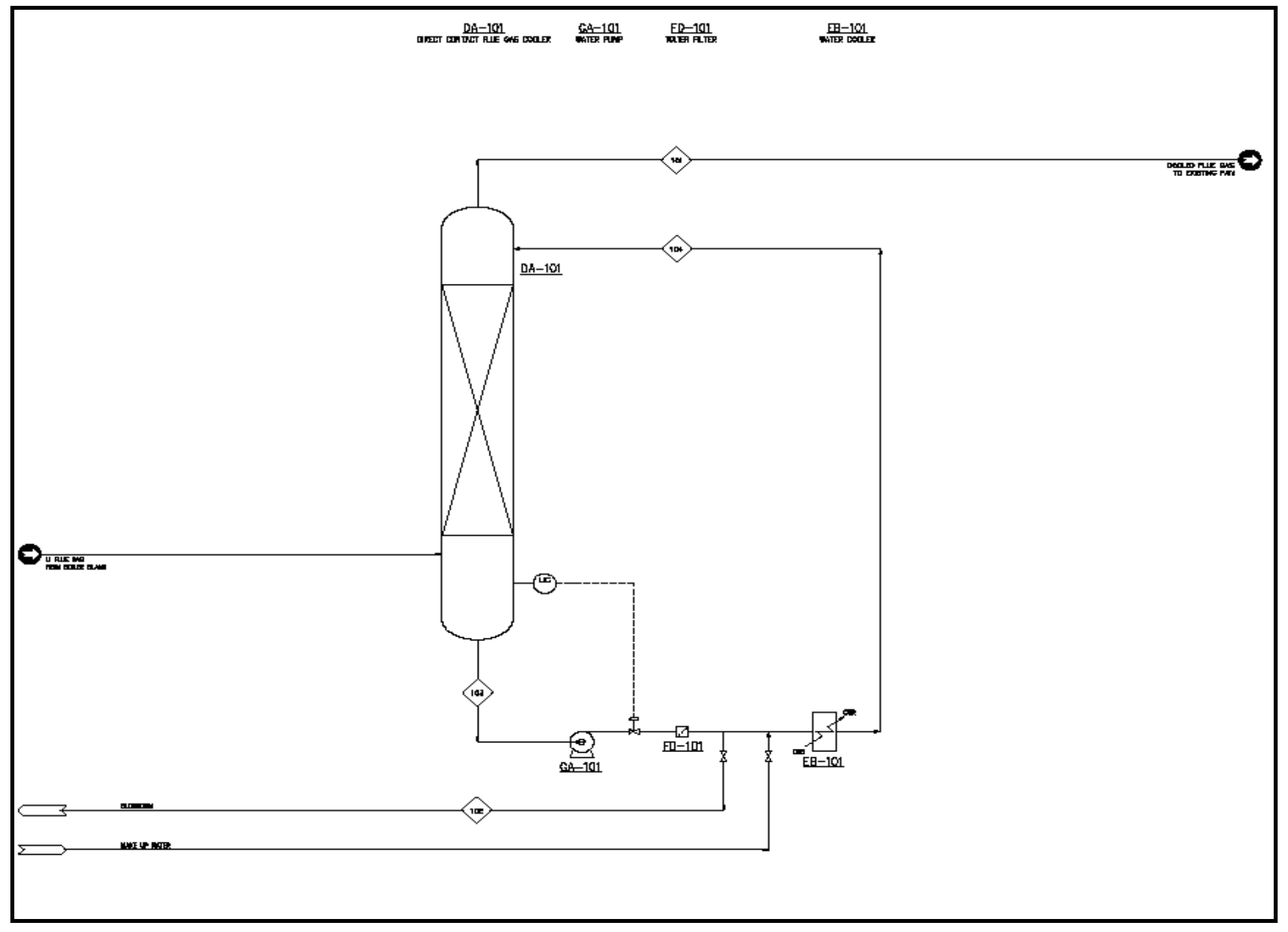

Figure 4.18: Case-2 Process Flow Diagram for Flue Gas Quenching 


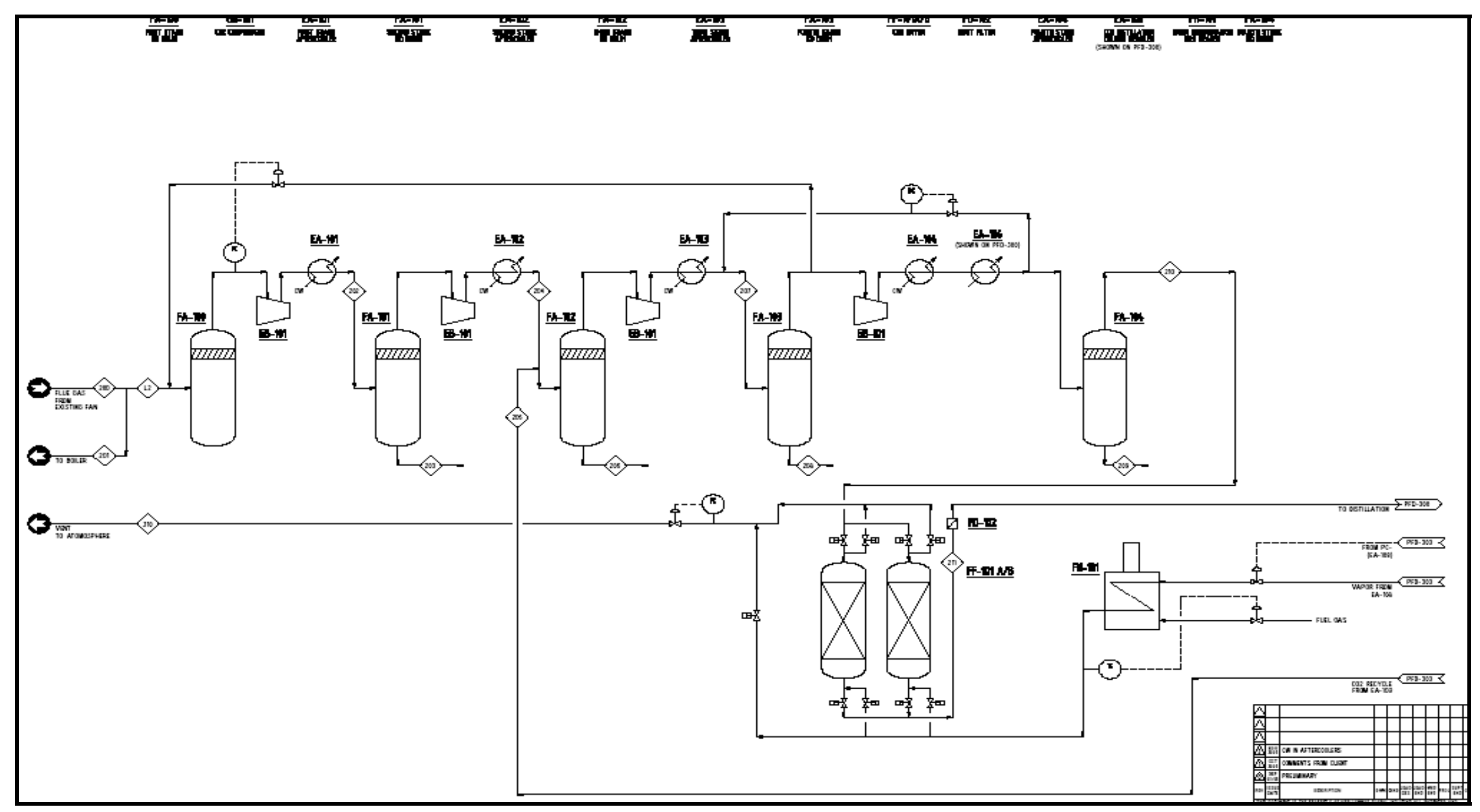

Figure 4.19: Case-2 Process Flow Diagram for Flue Gas Compression 


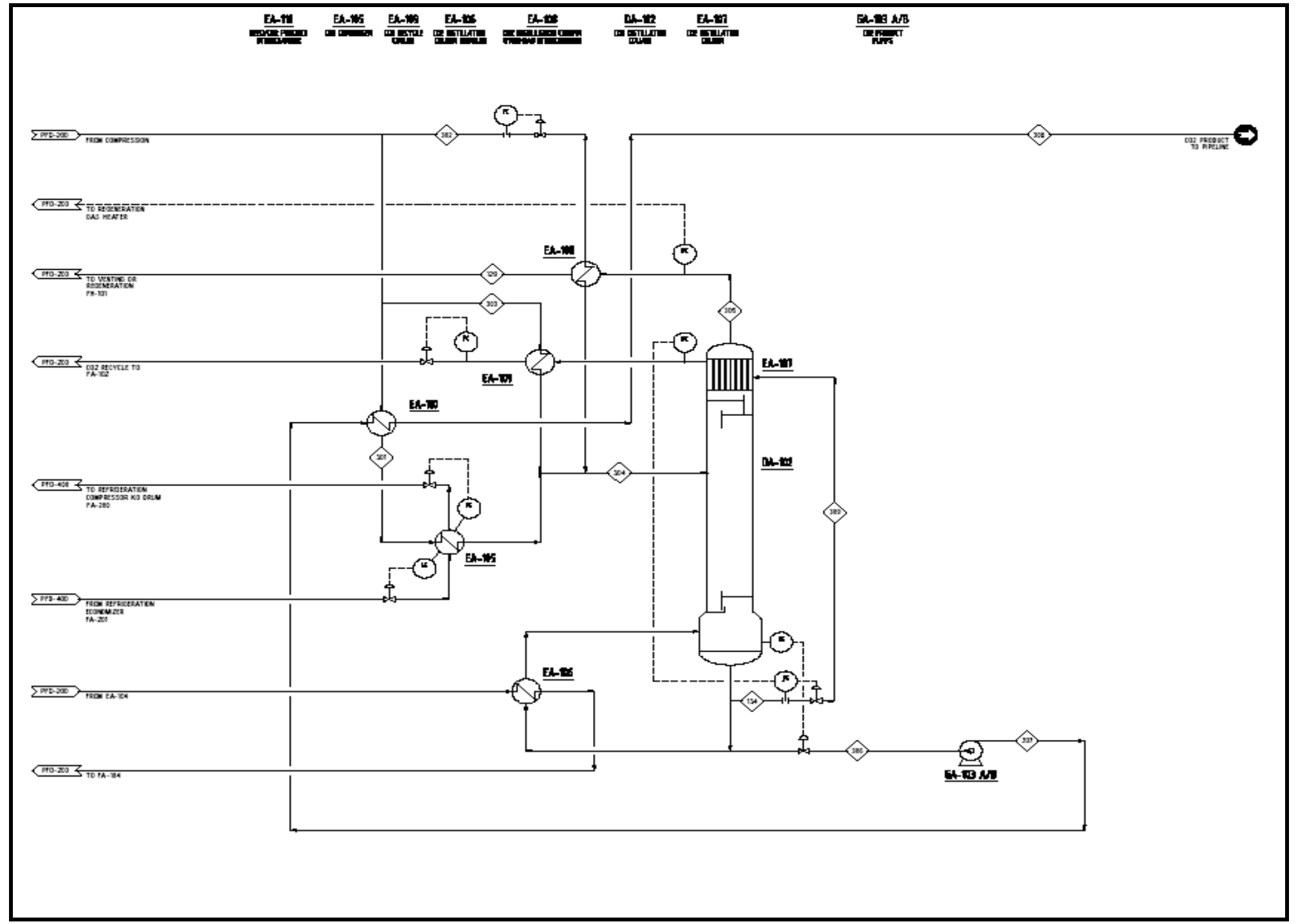

Figure 4.20: Case-2 Process Flow Diagram for Distillation 


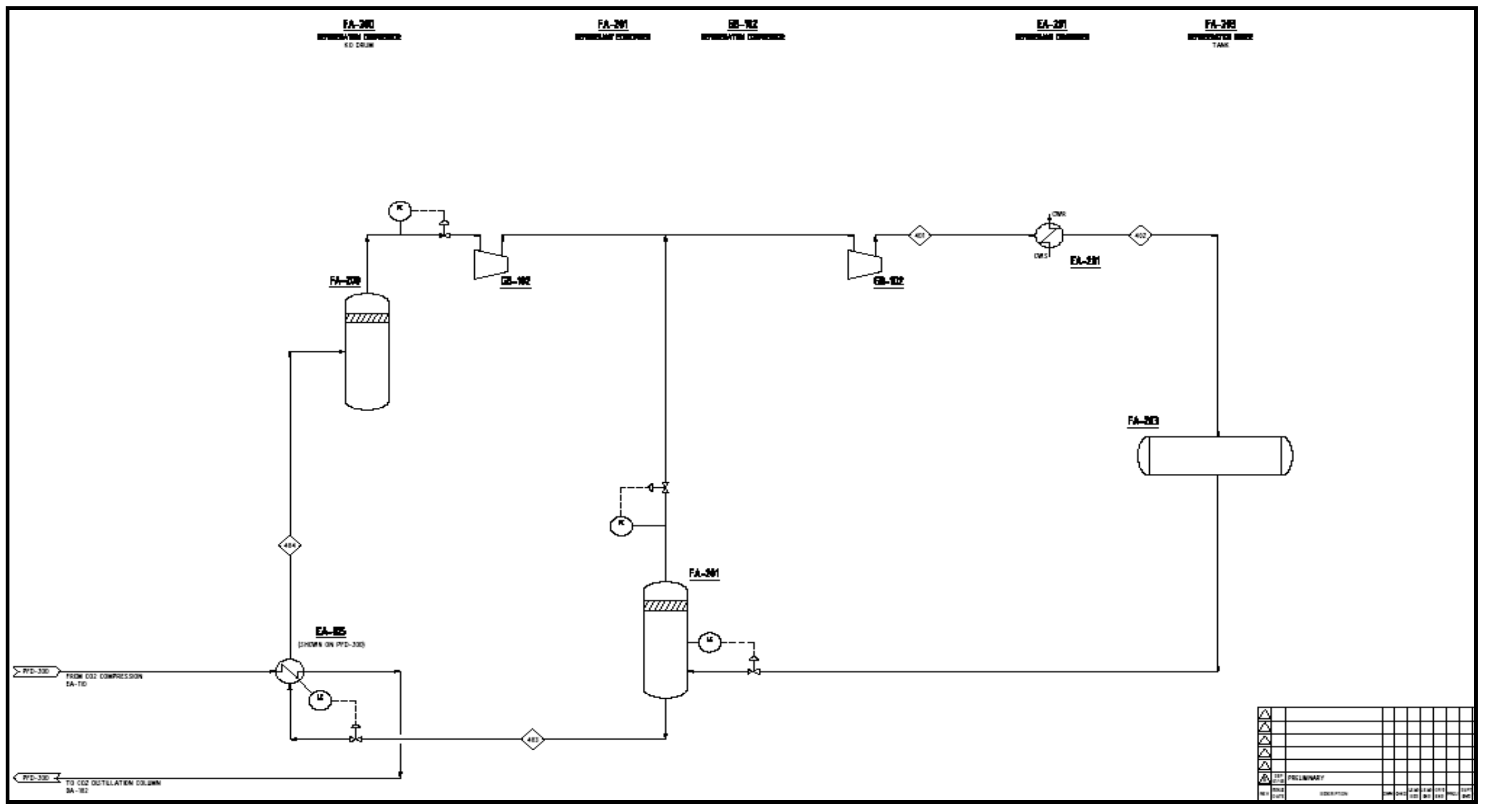

Figure 4.21: Case-2 Process Flow Diagram for Propane Refrigeration 


\section{Material and Energy Balance:}

Table 4.14 contains the overall material and energy balance for the Flue Gas Cooling System and the $\mathrm{CO}_{2}$ Compression, Distillation, and Liquefaction System described above. It is based on more than 94 percent recovery of $\mathrm{CO}_{2}$ from the feed stream. Please refer to the Process Flow Diagrams shown in the previous section for the stream numbers shown in this table.

It is important to note that the $\mathrm{CO}_{2}$ product to the pipeline (Stream 308 Table 4.14) meets the Dakota Gasification Specifications (Dakota Gasification Company, 2005) (Table 4.13) with respect to $\mathrm{CO}_{2}(99.8 \%$ vs. $>96 \%), \mathrm{O}_{2}\left(95\right.$ ppmv vs. 100 ppmv, $\mathrm{N}_{2}(19$ ppmv vs. 6,000 ppmv $)$, and $\mathrm{H}_{2} \mathrm{O}\left(0.5\right.$ ppmv vs. 2.0 ppmv). The concentration of $\mathrm{SO}_{2}$ in the $\mathrm{CO}_{2}$ product is $0.17 \%$, as it is not eliminated in the distillation column. There is no oxidized sulfur as $\mathrm{SO}_{2}$ in the Dakota product gas since it comes from a gasification process. There is no experience to indicate what an appropriate $\mathrm{SO}_{2}$ limit is. If it is less than can be achieved by CFB combined with FDA, then additional removal will be required. This could be done with a caustic scrubber just before the GPS. 


\section{Table 4.14: Gas Processing System Material \& Energy Balance}

\begin{tabular}{|c|c|c|c|c|c|c|c|c|c|c|c|c|c|c|c|c|c|c|c|c|c|}
\hline STREAM HAME & & 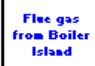 & 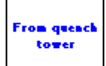 & blozdow. & $\begin{array}{l}\text { quesch water } \\
\text { out }\end{array}$ & queech soter & Froes blozer & $\begin{array}{l}\text { liquectaction } \\
\text { litrit } \\
\text { erait }\end{array}$ & to boiler & \begin{tabular}{|c} 
co secood \\
setage
\end{tabular} & $\underset{\mathbf{k 0}}{2.20 \text { ater }}$ & |io 3rd stage & 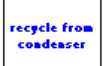 & $\begin{array}{c}\text { 3rd water } \\
\text { Ko }\end{array}$ & Co Ate stage & $\begin{array}{l}\text { Act - water } \\
\text { scrobber }\end{array}$ & Aet water k0 & To drier & Froes drier & $\begin{array}{l}\text { To reftig } \\
\text { ceiller }\end{array}$ & $\begin{array}{l}\text { To ieners } \\
\text { exaboseger }\end{array}$ \\
\hline PFD STREAM HO. & & L1 & 101 & 102 & 103 & 104 & 200 & $\mathrm{~L} 2$ & 201 & 202 & 203 & 204 & 205 & 206 & 207 & 208 & 209 & 210 & 211 & 301 & 302 \\
\hline VAPOR FRACTION & Molar & 1.000 & 1.000 & 0.000 & 0.000 & 0.000 & 1.000 & 1.000 & 1.000 & 0.962 & 0.000 & 0.980 & 1.000 & 0.000 & 0.997 & 0.000 & 0.000 & 1.000 & 1.000 & 1.000 & 1.000 \\
\hline \multirow{2}{*}{ TEMPERATURE } & ${ }^{\circ} \mathrm{F}$ & 159.0 & 100.0 & 126.6 & 126.3 & 90.0 & 109.0 & 109.0 & 109.0 & 105.0 & 105.0 & 105.0 & -30.1 & 88.8 & 105.0 & 105.0 & 36.4 & 36.4 & 45.0 & 40.0 & 44.3 \\
\hline & ${ }^{\circ} \mathrm{C}$ & 70.6 & 37.8 & 52.5 & 52.4 & 32.2 & 42.8 & 42.8 & 42.8 & 40.6 & 40.6 & 40.6 & -34.5 & 31.6 & 40.6 & 40.6 & 2.5 & 2.5 & 7.2 & 4.4 & 6.8 \\
\hline \multirow[t]{2}{*}{ PRESSURE } & PSIA & 14 & 14 & 60 & 14 & 18 & 15 & 15 & 15 & 35 & 35 & 97 & 94 & 94 & 299 & 299 & 440 & 440 & 433 & 423 & 428 \\
\hline & Bara & 0.96 & 0.96 & 4.14 & 0.96 & 1.24 & 1.01 & 1.01 & 1.01 & 2.44 & 2.44 & 6.70 & 6.47 & 6.47 & 20.59 & 20.59 & 30.34 & 30.34 & 29.86 & 29.17 & 29.52 \\
\hline \multirow{3}{*}{$\begin{array}{l}\text { MASS FLOWRATE } \\
\end{array}$} & libmolihr & 25,903 & 22,979 & 2,931 & 105,725 & 102,800 & 22,979 & 4,638 & 18,340 & 4,638 & 176 & 4,463 & 801 & 102 & 5,162 & 15 & 23 & 5,123 & 5,121 & 5,026 & 60 \\
\hline & $1 \mathrm{lb} / \mathrm{hr}$ & 993,239 & \begin{tabular}{ll|}
940,764 \\
\end{tabular} & 52,828 & $1,905,309$ & $1,852,834$ & \begin{tabular}{ll|l|}
940,764 \\
\end{tabular} & 189,903 & 750,861 & 189,903 & 3,168 & \begin{tabular}{l|l|l}
186,735 \\
\end{tabular} & \begin{tabular}{l|l|}
35,274 \\
\end{tabular} & \begin{tabular}{ll|l}
1,847 \\
\end{tabular} & 220,162 & 274 & \begin{tabular}{l|l|l}
437 \\
\end{tabular} & 219,450 & 219,408 & 215,358 & 2,550 \\
\hline & $\mathrm{kg} / \mathrm{hr}$ & 450,525 & 426,723 & 23,962 & 864,233 & 840,431 & 426,723 & 86,138 & 340,585 & 86,138 & 1,437 & 84,702 & 16,000 & 838 & 99,864 & 124 & 198 & 99,541 & 99,522 & 97,684 & 1,157 \\
\hline \multirow{2}{*}{ ENERGY } & Etuhr & $-3.72 \mathrm{E}+09$ & $-3.43 E+09$ & \begin{tabular}{|l|l|}
$-3.57 \mathrm{E}+08$ \\
\end{tabular} & $-1.29 \mathrm{E}+10$ & $-1.26 \mathrm{E}+10$ & $-3.43 E+09$ & $-6.92 E+08$ & $-2.73 E+09$ & \begin{tabular}{|l|}
$-6.95 E+08$ \\
\end{tabular} & $-2.15 E+07$ & $-6.76 E+08$ & \begin{tabular}{|l|l|}
$-1.36 E+08$ \\
\end{tabular} & \begin{tabular}{|l|}
$-1.25 E+07$ \\
\end{tabular} & $-8.00 \mathrm{E}+08$ & $-1.85 E+06$ & $-2.91 E+06$ & $-8.01 E+08$ & $-8.00 \mathrm{E}+08$ & $-7.85 \mathrm{E}+08$ & $-9.30 E+06$ \\
\hline & kJuhr & \begin{tabular}{|l|l}
$-3.92 E+09$ \\
\end{tabular} & $-3.62 E+09$ & \begin{tabular}{|l|}
$-3.77 \mathrm{E}+08$ \\
\end{tabular} & $-1.36 \mathrm{E}+10$ & $-1.33 \mathrm{E}+10$ & $-3.61 \mathrm{E}+09$ & $-7.30 E+08$ & $-2.88 \mathrm{E}+09$ & $-7.33 E+08$ & $-2.27 \mathrm{E}+07$ & \begin{tabular}{|c|}
$-7.13 E+08$ \\
\end{tabular} & \begin{tabular}{|l|}
$-1.44 E+08$ \\
\end{tabular} & $-1.32 \mathrm{E}+07$ & \begin{tabular}{|c|}
$8.44 E+08$ \\
\end{tabular} & $-1.95 E+06$ & \begin{tabular}{|c|}
$-3.07 E+06$ \\
\end{tabular} & $-8.45 E+08$ & 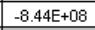 & $-8.29 \mathrm{E}+08$ & $-9.81 E+06$ \\
\hline \multirow{2}{*}{\multicolumn{2}{|c|}{ COMPOSITOH }} & & & & & & & & & & & & & & & & & & & & \\
\hline & & $74.43 \%$ & $83.92 \%$ & $0.02 \%$ & $0.02 \%$ & $0.03 \%$ & $83.92 \%$ & $83.92 \%$ & $83.92 \%$ & $83.92 \%$ & $0.07 \%$ & $87.22 \%$ & $99.82 \%$ & $0.24 \%$ & $90.90 \%$ & $0.62 \%$ & $2.41 \%$ & $91.57 \%$ & $91.61 \%$ & $91.61 \%$ & $91.61 \%$ \\
\hline Oxygen & & $3.08 \%$ & $3.47 \%$ & $0.00 \%$ & $0.00 \%$ & $0.00 \%$ & $3.47 \%$ & $3.47 \%$ & $3.47 \%$ & $3.47 \%$ & $0.00 \%$ & $3.60 \%$ & $0.01 \%$ & $0.00 \%$ & $3.12 \%$ & $0.00 \%$ & $0.00 \%$ & $3.14 \%$ & $3.14 \%$ & $3.14 \%$ & $3.14 \%$ \\
\hline Nitrogen & & $5.00 \%$ & $5.63 \%$ & $0.00 \%$ & $0.00 \%$ & $0.00 \%$ & $5.63 \%$ & $5.63 \%$ & $5.63 \%$ & $5.63 \%$ & $0.00 \%$ & $5.85 \%$ & $0.00 \%$ & $0.00 \%$ & $5.06 \%$ & $0.00 \%$ & $0.00 \%$ & $5.10 \%$ & $5.10 \%$ & $5.10 \%$ & $5.10 \%$ \\
\hline Argon & & $0.00 \%$ & $0.00 \%$ & $0.00 \%$ & $0.00 \%$ & $0.00 \%$ & $0.00 \%$ & $0.00 \%$ & $0.00 \%$ & $0.00 \%$ & $0.00 \%$ & $0.00 \%$ & $0.00 \%$ & $0.00 \%$ & $0.00 \%$ & $0.00 \%$ & $0.00 \%$ & $0.00 \%$ & $0.00 \%$ & $0.00 \%$ & $0.00 \%$ \\
\hline NO & & $0.00 \%$ & $0.00 \%$ & $0.00 \%$ & $0.00 \%$ & $0.00 \%$ & $0.00 \%$ & $0.00 \%$ & $0.00 \%$ & $0.00 \%$ & $0.00 \%$ & $0.00 \%$ & $0.00 \%$ & $0.00 \%$ & $0.00 \%$ & $0.00 \%$ & $0.00 \%$ & $0.00 \%$ & $0.00 \%$ & $0.00 \%$ & $0.00 \%$ \\
\hline $\mathrm{H} 2 \mathrm{O}$ & & $17.39 \%$ & $6.84 \%$ & $99.98 \%$ & $99.98 \%$ & $99.97 \%$ & $6.84 \%$ & $6.84 \%$ & $6.84 \%$ & $6.84 \%$ & $99.92 \%$ & $3.18 \%$ & $0.00 \%$ & $99.74 \%$ & $0.78 \%$ & $99.33 \%$ & $97.42 \%$ & $0.05 \%$ & $0.00 \%$ & $0.00 \%$ & $0.00 \%$ \\
\hline \multirow[t]{2}{*}{ SO2 } & & $0.11 \%$ & $0.14 \%$ & $0.00 \%$ & $0.00 \%$ & $0.00 \%$ & $0.14 \%$ & $0.14 \%$ & $0.14 \%$ & $0.14 \%$ & $0.01 \%$ & $0.14 \%$ & $0.17 \%$ & $0.02 \%$ & $0.15 \%$ & $0.05 \%$ & $0.17 \%$ & $0.15 \%$ & $0.15 \%$ & $0.15 \%$ & $0.15 \%$ \\
\hline \multirow{2}{*}{\multicolumn{22}{|c|}{ VAPOR }} \\
\hline & & & & & & & & & & & & & & & & & & & & & \\
\hline \multirow{3}{*}{$\begin{array}{l}\text { MOLAR FLOWRATE } \\
\text { MASS FLOWRATE }\end{array}$} & libmolihr & 25,903 & 22,979 & & & & 22,979 & 4,638 & 18,340 & 4,463 & & 4,374 & 801 & & \begin{tabular}{|l|l|}
5,147 \\
\end{tabular} & & & 5,123 & 5,121 & 5,026 & 60 \\
\hline & Ib $\mathrm{bhr}$ & 993,239 & 940,764 & & & & 940,764 & 189,903 & 750,861 & 186,735 & - & \begin{tabular}{|l|l|}
185,135 \\
\end{tabular} & \begin{tabular}{|c|}
35,274 \\
\end{tabular} & - & \begin{tabular}{|l|l|}
219,887 \\
\end{tabular} & - & - & 219,450 & 219,408 & 215,358 & 2,550 \\
\hline & $\mathrm{kg} / \mathrm{hr}$ & 450,525 & 426,723 & & & & 426,723 & 86,138 & 340,585 & 84,702 & & 83,976 & 16,000 & - & 99,739 & & - & 99,541 & 99,522 & 97,684 & 1,157 \\
\hline \multirow{2}{*}{ STD VOL. FLOW } & MMSCFD & 235.9 & 209.3 & & & & 209.3 & 42.2 & 167.0 & 40.6 & & 39.8 & 7.3 & & 46.9 & & & 46.7 & 46.6 & 45.8 & 0.5 \\
\hline & MMSCMD & 6.681 & 5.926 & & & & 5.926 & 1.196 & 4.730 & 1.151 & & 1.128 & 0.207 & & 1.327 & & & 1.321 & 1.321 & 1.296 & 0.015 \\
\hline \multirow{2}{*}{ ACTUAL VOL. FLOW } & ACFM & 204,329 & 164,837 & & & & 158,246 & 31,944 & 126,302 & 12,609 & & 4,414 & 609 & & 1,583 & & & 808 & 854 & 847 & 10 \\
\hline & ACMM & $5,785.98$ & $4,667.69$ & & & & $4,481.04$ & 904.54 & $3,576.50$ & 357.06 & & 124.99 & 17.23 & & 44.83 & & & 22.88 & 24.18 & 23.99 & 0.28 \\
\hline \multirow{3}{*}{$\begin{array}{l}\text { MOLECULAR WEIGHT } \\
\text { DENSITY }\end{array}$} & $M N$ & 38.34 & 40.94 & & & & 40.94 & 40.94 & 40.94 & 41.84 & & 42.32 & 44.04 & & 42.73 & & & 42.83 & 42.85 & 42.85 & 42.85 \\
\hline & $1 \mathrm{~b} / \mathrm{s}^{\mathrm{t}}$ & 0.08 & 0.10 & & & & 0.10 & 0.10 & 0.10 & 0.25 & & 0.70 & 0.97 & & 2.31 & & & 4.53 & 4.28 & 4.24 & 4.23 \\
\hline & $\mathrm{kg}^{\mathrm{mg} / \mathrm{m}^{3}}$ & 0.0010 & 0.0012 & & & & $\begin{array}{ll}0.0013 \\
\end{array}$ & 0.0013 & 0.0013 & 0.0032 & & 0.0090 & 0.0124 & & $\begin{array}{ll}0.0298 \\
\end{array}$ & & & 0.0582 & 0.0551 & 0.0545 & 0.0544 \\
\hline \multirow{2}{*}{\multicolumn{2}{|c|}{$\begin{array}{l}\text { VISCOSITY } \\
\text { HEAVY LIQUID }\end{array}$}} & 0.0153 & 0.0149 & & & & 0.0152 & 0.0152 & 0.0152 & 0.0156 & & 0.0160 & 0.0117 & & 0.0166 & & & 0.0153 & 0.0154 & 0.0153 & 0.0154 \\
\hline & & & & & & & & & & & & & & & & & & & & & \\
\hline MOLAR FLOW RATE & lbmol/hr & & & 2,931 & 105,725 & 102,800 & & & & 176 & 176 & 88 & & 102 & 15 & 15 & 23 & & & & \\
\hline \multirow{2}{*}{ MASS FLOWRATE } & lbshr & & & 52,828 & $1,905,309$ & $1,852,834$ & & & & 3,168 & 3,168 & 1,600 & & 1,847 & 274 & 274 & 437 & & & & \\
\hline & $\mathrm{kghhr}$ & & & $23,962.3$ & $864,233.0$ & $840,430.8$ & & & & 1,437 & $1,436.95$ & 726 & & 837.82 & 124 & 124.39 & 198.23 & & & & \\
\hline \multirow{2}{*}{ STD VOL. FLOW } & BPD & & & 3,625 & 130,737 & 127,138 & & & & 217 & 217 & 110 & & 127 & 19 & 19 & 30 & & & & \\
\hline & $M^{3}, 0$ & & & 432 & 15,589 & 15,160 & & & & 26 & 26 & 13 & & 15 & 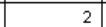 & 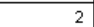 & 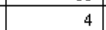 & & & & \\
\hline \multirow[t]{2}{*}{ ACTUAL VOL. FLOW } & GPM & & & 107 & 3,857 & 3,693 & & & & 6 & 6 & 3 & & 4 & 1 & 1 & 1 & & & & \\
\hline & $M^{3} M$ & & & 0.40 & 14.60 & 13.98 & & & & 0.02 & .02 & 01 & & 01 & 0.00 & 0.00 & 0.00 & & & & \\
\hline DENSITY & $\| b^{\prime} / \mathrm{t}^{\mathrm{t}}$ & & & 61.58 & 61.58 & 62.55 & & & & 62.17 & 62.17 & 62.22 & & \begin{tabular}{ll|}
62.66 \\
\end{tabular} & $\begin{array}{ll}62.36 \\
\end{array}$ & 62.36 & \begin{tabular}{ll|}
64.73 \\
\end{tabular} & & & & \\
\hline & $\mathrm{kgm}^{\mathrm{3}} \mathrm{s}$ & & & 0.7917 & 0.7917 & 0.8042 & & & & 0.7993 & 0.7993 & 0.7999 & & 0.8056 & 0.8017 & 0.8017 & 0.8321 & & & & \\
\hline VISCOSITY & $\mathrm{cP}$ & & & 0.5215 & 0.5229 & 0.76006 & & & & 0.6446 & 0.6446 & $\begin{array}{ll}0.6809 \\
\end{array}$ & & 0.07989 & 0.6730 & 0.6730 & 1.3485 & & & & \\
\hline SURFACE TENSION & Dyneicm & & & 67.27 & 67.30 & 70.83 & & & & 69.34 & 69.34 & 69.24 & & 70.78 & 68.94 & 68.94 & 74.24 & & & & \\
\hline
\end{tabular}

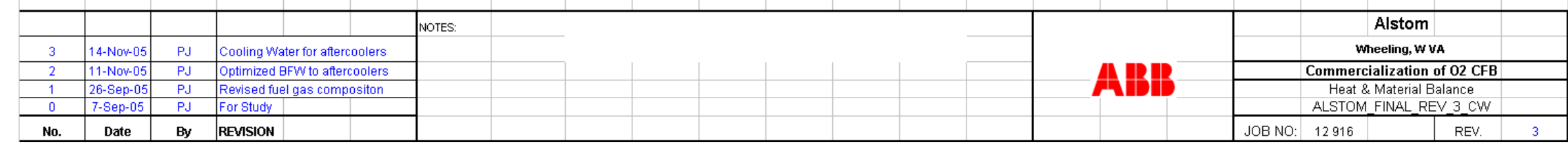




\section{Table 4.14 (Continued)}

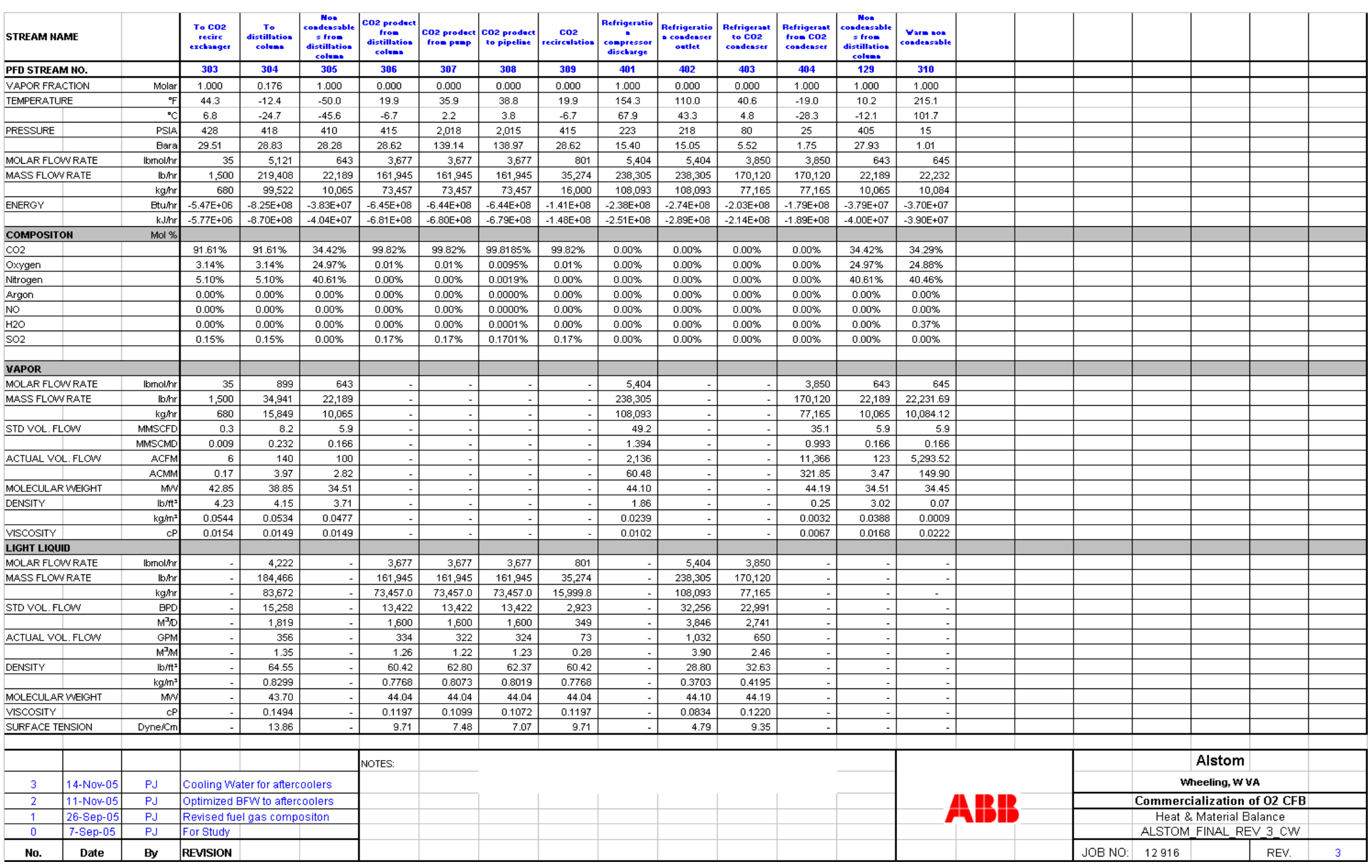




\section{Gas Processing System Utilities:}

The following tables define the cooling water, natural gas, and electrical requirements for the Gas Processing System described previously.

\section{Table 4.15: Case-2 Gas Processing System Cooling Water and Fuel Gas Requirements}

\begin{tabular}{|c|c|c|c|c|c|c|c|c|c|c|c|}
\hline \multirow[b]{2}{*}{ REV } & \multirow{2}{*}{$\begin{array}{c}\text { Equipment } \\
\text { TAG NO }\end{array}$} & \multirow[b]{2}{*}{ SERVICE } & \multirow{2}{*}{$\begin{array}{c}\text { No. } \\
\text { Installed }\end{array}$} & \multicolumn{2}{|c|}{ DUTY } & \multicolumn{2}{|c|}{ INLET TEMPERATURE } & \multicolumn{2}{|c|}{ OUTLET TEMPERATURE } & \multicolumn{2}{|c|}{ FLOWRATE } \\
\hline & & & & MMBTU/HR & $\mathrm{kJ} / \mathrm{HR}$ & DEG F & DEG C & DEG F & DEG C & LB/HR & KG/HR \\
\hline 3 & EA-101 & FG Comp 1 stg after cooler & 1 & 10.90 & 11.50 & 85 & 29 & 105 & 41 & 545,000 & 247,208 \\
\hline 3 & EA-102 & FG Comp 2 stg after cooler & 1 & 9.32 & 9.83 & 85 & 29 & 105 & 41 & 466,000 & 211,374 \\
\hline 3 & EA-103 & FG Comp 3 stg after cooler & 1 & 9.77 & 10.31 & 85 & 29 & 105 & 41 & 488,500 & 221,580 \\
\hline 3 & EA-104 & FG Comp 4 stg after cooler & 1 & 3.86 & 4.07 & 85 & 29 & 105 & 41 & 193,000 & 87,543 \\
\hline & & TOTALCOOLING WATER & & 33.85 & 35.70 & & & & & $1,692,500$ & 767,704 \\
\hline
\end{tabular}

\begin{tabular}{|c|c|c|c|c|c|c|c|c|c|c|c|}
\hline \multirow[b]{2}{*}{ REV } & \multirow{2}{*}{$\begin{array}{c}\text { Equipment } \\
\text { TAG NO }\end{array}$} & \multirow[b]{2}{*}{ SERVICE } & \multirow{2}{*}{$\begin{array}{c}\text { No. } \\
\text { Installed }\end{array}$} & \multicolumn{2}{|c|}{$\overline{\text { DUTY }}$} & \multicolumn{2}{|c|}{ INLET TEMPERATURE } & \multicolumn{2}{|c|}{ OUTLET TEMPERATURE } & \multicolumn{2}{|c|}{$\begin{array}{l}\text { FLOWRATE } \\
\end{array}$} \\
\hline & & & & MMBTU/HR & $\mathrm{kJ} / \mathrm{HR}$ & DEG F & DEG C & DEG F & DEG C & LB/HR & KG/HR \\
\hline 3 & EA-201 & Refrig Condenser & 1 & 37.00 & 39.03 & 85 & 29 & 100 & 38 & $2,466,667$ & $1,118,860$ \\
\hline 3 & EB-101 & Water Cooler & 1 & 67.60 & 71.30 & 85 & 29 & 105 & 41 & $3,380,000$ & $1,533,141$ \\
\hline & & TOTAL COOLING WATER & & 104.60 & 110.33 & & & & & $5,846,667$ & $2,652,001$ \\
\hline
\end{tabular}

\begin{tabular}{|c|c|c|c|c|c|c|c|c|c|c|c|c|}
\hline \multirow[t]{3}{*}{ FUEL GAS } & \multirow{3}{*}{$\begin{array}{c}\text { Equipment } \\
\text { TAG NO }\end{array}$} & FUEL GAS VALUE BASIS: & \multirow{3}{*}{$\begin{array}{c}930 \\
\text { ONLINE } \\
\text { FACTOR }\end{array}$} & \multicolumn{2}{|l|}{ BTU/SCF (LHV) } & \multirow{3}{*}{$\begin{array}{c}\text { EFFICIENCY } \\
\%\end{array}$} & \multirow{2}{*}{\multicolumn{4}{|c|}{ FLOWRATE (Peak) }} & \multirow{2}{*}{\multicolumn{2}{|c|}{ FLOW (Avg) }} \\
\hline & & & & & & & & & & & & \\
\hline & & SERVICE & & MMBTU/HR & $\mathrm{kJ} / \mathrm{HR}$ & & MMSCFD & MMSCMD & SCFH & SCMH & MMSCFD & MMSCMD \\
\hline 3 & $\mathrm{FH}-101$ & Alumina Drier Regeneration & $61 \%$ & 4.60 & 4.85 & $80 \%$ & 0.148 & 0.00420 & 6,183 & 175 & 0.091 & 0.0026 \\
\hline & & TOTAL FUEL GAS & & 4.60 & 4.85 & & 0.148 & 0.00420 & 6,183 & 175 & 0.091 & 0.0026 \\
\hline
\end{tabular}

Table 4.16: Case-2 Gas Processing System Electrical Requirements

\begin{tabular}{|c|c|c|c|c|c|}
\hline $\begin{array}{c}\text { Number of } \\
\text { trains }\end{array}$ & Item Number & Service & $\begin{array}{c}\text { Brake Power } \\
\text { (ea) }\end{array}$ & $\begin{array}{c}\text { motor } \\
\text { efficiency }\end{array}$ & Power \\
\hline & & & $(\mathrm{kW})$ & (frac) & $(\mathrm{kW})$ \\
\hline 1 & GB-100 & 1 Stage & 2,161 & 0.95 & 2,275 \\
\hline 1 & & 2 Stage & 2,171 & 0.95 & 2,285 \\
\hline 1 & & 3 Stage & 2,677 & 0.95 & 2,818 \\
\hline \multirow[t]{6}{*}{1} & & 4 Stage & 840 & 0.95 & 884 \\
\hline & & sub total & 7,849 & & 8,262 \\
\hline & & gear losses & & 0.02 & 165 \\
\hline & & Electric Motor Input & & & 8,427 \\
\hline & & 1.1 API Standard & & & 826 \\
\hline & & motor rating & & & 9,254 \\
\hline 1 & GB-101 & 1 Stage & 1,629 & 0.95 & 1,715 \\
\hline \multirow[t]{6}{*}{1} & & 2 Stage & 1,992 & 0.95 & 2,097 \\
\hline & & sub total & 3,621 & & 3,812 \\
\hline & & 1.02 gear losses & & 0.02 & 76 \\
\hline & & Electric Motor Input & & & 3,888 \\
\hline & & 1.1 API Standard & & & 381 \\
\hline & & motor rating & & & 4,269 \\
\hline 1 & GA-101 & Water pump & 159 & 0.95 & 167 \\
\hline \multirow[t]{2}{*}{1} & GA-103 & CO2 Pipeline pump & 311 & 0.95 & 327 \\
\hline & & Total Electrical Input & & & 12,810 \\
\hline
\end{tabular}




\section{Gas Processing System Equipment:}

A layout drawing showing a general arrangement plot plan for the GPS equipment is shown in Appendix I: Plant Drawings (Section 7.1). The equipment list for the Gas Processing System is provided in Appendix II: Plant Equipment Lists (Section 7.2.2).

\subsubsection{Case-2: Air Separation Unit (ASU): Process Description, Performance, and Equipment}

This section presents the process requirements for the warm end and cold box for the air separation plant. It will be designed to produce nominally 1,640 tonne (1,800 tons) per day (TPD) of oxygen.

The power requirements, utility requirements, staffing and other O\&M costs were prorated from ASU information (provided by Praxair) used in a previous study (Marion, et al., 2003). The following subsections are provided to summarize this information:

- Air Separation Unit Ambient Design Basis

- Air Separation Unit Production Rates and Purities

- Air Separation Unit Process Description, Process Flow Diagram and Equipment

- Air Separation Unit Utility Summary

- Air Separation Unit Chemical Requirements

- Air Separation Unit Operating Manpower

Air Separation Unit Ambient Design Basis:

The ambient conditions presented in Table 4.17 below were used to evaluate the ASU system performance and to generate the utility summary.

Table 4.17: Ambient Conditions Used for ASU Design

\begin{tabular}{|l|c|c|c|c|}
\hline \multirow{2}{*}{ Item } & \multicolumn{2}{|c|}{ SI Units } & \multicolumn{2}{c|}{ English Units } \\
\cline { 2 - 5 } & Value & Units & Value & Units \\
\hline Barometric Pressure & 1.013 & Bara & 14.7 & Psia \\
Dry Bulb Temperature & 26.7 & ${ }^{\circ} \mathrm{C}$ & 80 & ${ }^{\circ} \mathrm{F}$ \\
Hot Dry Bulb Temperature & 35 & ${ }^{\circ} \mathrm{C}$ & 95 & ${ }^{\circ} \mathrm{F}$ \\
Cold Day Temperature & -6.7 & ${ }^{\circ} \mathrm{C}$ & 20 & ${ }^{\circ} \mathrm{F}$ \\
Wet Bulb Temperature & 11.1 & ${ }^{\circ} \mathrm{C}$ & 52 & ${ }^{\circ} \mathrm{F}$ \\
Cooling Water Temperature & 32.2 & ${ }^{\circ} \mathrm{C}$ & 90 & ${ }^{\circ} \mathrm{F}$ \\
\hline
\end{tabular}

\section{Air Separation Unit Production Rates and Purities:}

The production rate indicated below in Table 4.18 shows the net mass flow-rate provided from the Air Separation Unit's Cold Box. 
Table 4.18: ASU Oxygen Production and Purity

\begin{tabular}{|c|c|c|c|c|c|}
\hline \multirow{2}{*}{ Plant Site } & \multicolumn{2}{|c|}{ Oxygen } & \multicolumn{2}{c|}{ Pressure } & Purity \\
\cline { 2 - 6 } & $\begin{array}{c}\text { tonne/day } \\
\left.\text { Contained } \mathrm{O}_{2}\right)\end{array}$ & $\begin{array}{c}\text { ton/day } \\
\text { Contained } \mathrm{O}_{2}\end{array}$ & bara & psia & $\left(\% \mathrm{O}_{2}\right)$ \\
\hline Southeast US & 1,590 & 1,750 & 1.24 & 18.0 & 99.0 \\
\hline
\end{tabular}

\section{Air Separation Unit Process Description, Process Flow Diagram and Equipment:}

The process and equipment description below refers to the Process Flow Diagram shown in Figure 4.22 below. A layout drawing showing a plot plan for the ASU equipment is shown in Appendix I: Plant Drawings (Section 7.1). The equipment list for this 1,600 tonne/day (1,800 ton/day) ASU is provided in Appendix II: Plant Equipment Lists (Section 7.2.3). 


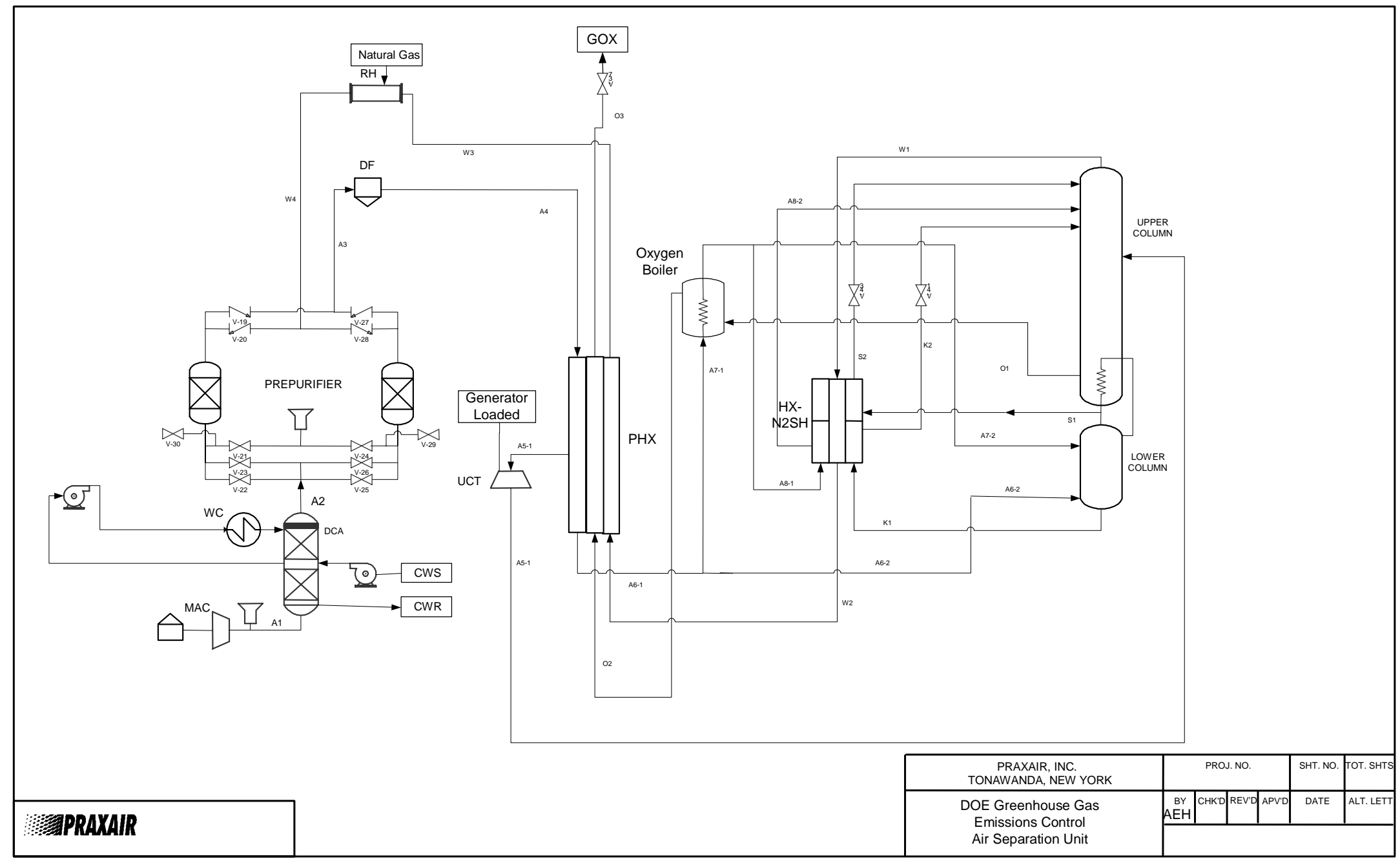

Figure 4.22: Case-2 Air Separation Unit Process Flow Diagram 


\section{Air Compression:}

Ambient air is drawn through the air suction filter house (ASFH) for the removal of large airborne particles prior to entering the main air compressor (MAC). The compressor is a 3 -stage high efficiency integral gear centrifugal compressor. Included with the compressor are adjustable inlet guide vanes, coupling with guard, lube oil system and two aftercoolers. The aftercoolers (shell and tube heat exchangers) are part of a low-level heat recovery system, which is integrated with the plant steam cycle. Additional aftercooling of the MAC is also accomplished with a two stage Direct Contact Aftercooler (DCA) that is located after the $3^{\text {rd }}$ stage shell and tube aftercooler. Air is cooled in the DCA by exchanging heat with cooling water in the first stage and with chilled water provided by a mechanical chiller in the second stage.

\section{Pre-purification:}

The after-cooled air is then passed through the pre-purification system. The prepurification system uses a two bed temperature-swing adsorption (TSA) process that allows continuous operation. One bed purifies the feed air while the other bed is being regenerated with first hot then cool waste nitrogen. A natural gas regeneration heater provides regeneration energy. The pre-purifier beds utilize a split adsorbent design (molecular sieve and alumina) to remove water, carbon dioxide, and most of the hydrocarbons from the air stream. After pre-purification, the air stream is passed through a dust filter to remove any solid particles.

\section{Air Feed Streams:}

The cold box requires one air feed stream. This stream is sent through the Primary Heat Exchanger (PHX) and then split into three streams. One stream is fed to the bottom of the lower column. The second air stream is fed to the oxygen boiler. The third air stream (turbine air) is cooled partially in the PHX and fed to the turbine. Adjusting the turbine airflow can modulate the total amount of refrigeration generated by the cold box.

\section{Cold Box:}

The air stream to the oxygen boiler is cooled and condensed against product oxygen and sent to both the upper and lower column.

The turbine air stream is cooled against warming nitrogen and oxygen streams. It is drawn from an intermediate location between the warm leg and the cold leg of the PHX. It is then expanded and cooled in the upper column turbine (UCT). The UCT stream enters two thirds of the way down the upper (low-pressure) distillation column.

The air entering the lower column is separated into nitrogen at the top and oxygenenriched air (kettle liquid) at the bottom. The nitrogen at the top of the column is condensed in the main condenser against boiling oxygen from the upper column. A portion of the condensed nitrogen from the main condenser is used as reflux for the lower column. The remainder is subcooled in the cross flow passages in the nitrogen superheater section of the PHX against warming gaseous nitrogen streams from the upper column. This subcooled liquid nitrogen stream then enters the top of the upper column as reflux. The kettle liquid is subcooled in the cross flow passes of the nitrogen superheater section of the PHX and then enters the upper about $2 / 3$ of the way down the column.

The upper column produces high purity liquid oxygen $\left(>99.0\right.$ percent $\left.\mathrm{O}_{2}\right)$ in the bottom. The upper column also produces waste nitrogen from the top. The gaseous nitrogen 
stream is warmed in all sections of the PHX to near-ambient temperatures. The product oxygen is boiled in the oxygen boiler against the condensing air stream and exits as product.

\section{Products:}

Gaseous oxygen is available at pressure directly from the cold box and delivered to the battery limit at 0.23 barg ( $3.3 \mathrm{psig})$.

\section{Air Separation Unit Utility Summary:}

The following tables show the expected electricity and natural gas usage for the ASU. The utilities presented here are for nominally 1,650 tonne/day (1,800 tons/day) of oxygen.

Table 4.19: ASU Electrical Usage

\begin{tabular}{|l|r|}
\hline \multirow{2}{*}{ Components } & 1756 T/D \\
\cline { 2 - 2 } BLAC & kW \\
Turbine & 16539 \\
Water Chiller & -201 \\
DCA Pumps & 633 \\
Misc. (Incl. Lube Oil) & 77 \\
\hline \multicolumn{2}{|c}{ Total } \\
\hline
\end{tabular}

Table 4.20: ASU Natural Gas Usage

\begin{tabular}{ll}
\hline Natural Gas used for $1 / 3$ of time \\
\hline Natural Gas Use - peak $(\mathrm{kg} / \mathrm{hr} ; \mathrm{lbm} / \mathrm{hr})$ & $328 ; 723$ \\
\hline
\end{tabular}

\section{Air Separation Unit Chemical Requirements:}

There are no major on-going chemical requirements, as follows:

- Cooling Water is supplied by others, thus major treatment chemicals are part of this supply.

- With a small closed loop cooling system, some minor treatment chemicals will be required.

- Minor consumable items such as analyzer zero span and fuel gas cylinders, as well as, lube oil top-off will be required.

- Pre-purifier adsorbent is included in plant pricing and is typically not replaced.

- To cover minor consumables, approximately $\$ 20,000 /$ year is estimated.

Air Separation Unit Operating Manpower:

- The operating staff is shown in Table 4.21. It is assumed that the existing power 
plant staffing covers the positions of Supervisor, Plant Engineering/Assistant Manager, and ASU Maintenance staff (Mechanical \& Instrumentation). Therefore only the ASU Operators (4 per shift) are included in the ASU Operating \& Maintenance fixed costs account shown in Section 4.5.

- Major maintenance would be staffed externally - either from the power plant staff or contractors.

Table 4.21: ASU Operating Manpower

\begin{tabular}{|l|l|}
\hline Supervisor & 1 \\
\hline Plant Engineering/Assistant Manager & 1 \\
\hline Operators & 4 \\
\hline $\begin{array}{l}\text { Maintenance (Mechanical \& } \\
\text { Instrumentation) }\end{array}$ & 2 \\
\hline
\end{tabular}

\subsubsection{Case-2: Balance of Plant Equipment and Performance}

The balance of plant equipment and performance description provided in this section discusses only areas where there are major differences relative to Case-1. Most of the existing balance of plant equipment is unchanged for Case-2. The primary change is the addition to the steam cycle of a system for the recovery of low-level heat from the ASU and GPS. The heat is recovered in the low temperature condensate stream discharged from the existing condensate pump.

\section{Case-2 Steam Cycle Performance and Equipment:}

This section describes the performance and equipment used in the Case- 2 steam cycle. Additionally, differences as compared to Case-1 are discussed.

\section{Case-2 Steam Cycle Performance:}

The steam cycle was modified somewhat for Case-2 with the integration of low level heat recovery from the ASU. The steam cycle for Case-2 is shown schematically in Figure 4.23. The steam cycle is nearly identical to that for Case-1 (see Figure 4.3), differing only in the integration of low-level heat recovery systems for Case-2. The existing steam turbine is a nominal $100 \mathrm{MWe}$ single reheat machine with steam conditions of 138 barg $538^{\circ} \mathrm{C} / 538^{\circ} \mathrm{C}\left(2.000 \mathrm{psig} 1,000{ }^{\circ} \mathrm{F} / 1,000{ }^{\circ} \mathrm{F}\right)$ and a condenser pressure of $7.6 \mathrm{~cm} \mathrm{Hga}$ (3.0 in Hga). The main steam flow $(284401 \mathrm{~kg} / \mathrm{hr}, 627,000 \mathrm{lbm} / \mathrm{hr}$ ) and cold reheat steam flow $(257,375 \mathrm{~kg} / \mathrm{hr}, 567,418 \mathrm{lbm} / \mathrm{hr})$ are identical for both cases. Six extraction feedwater heaters are used for each case. Case-2, however, partially bypasses condensate around the existing low-pressure extraction feedwater heaters \#1 and \#2. 


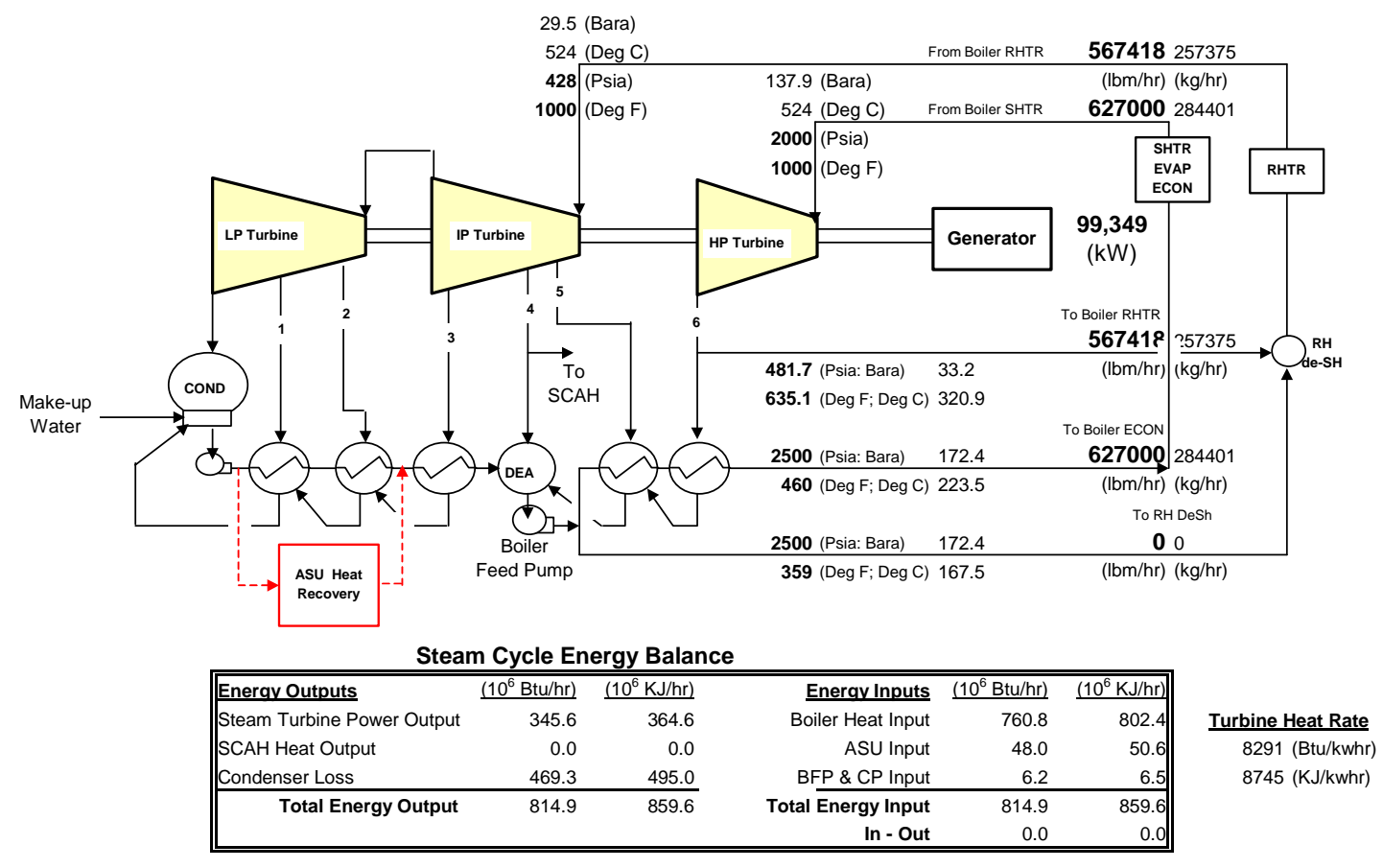

Note:

Extraction Feedwater heaters \#1 and \#2 are partially bypassed for Case-2.

Figure 4.23: Case-2 Steam Cycle Schematic and Performance

The condensate bypass is done for the purpose of low temperature heat recovery in the ASU system. The final feedwater temperature is $237.8^{\circ} \mathrm{C}\left(460{ }^{\circ} \mathrm{F}\right)$ for both cases. Figure 4.24 shows the associated T-S and H-S diagrams for the steam cycle state points of Case-2.
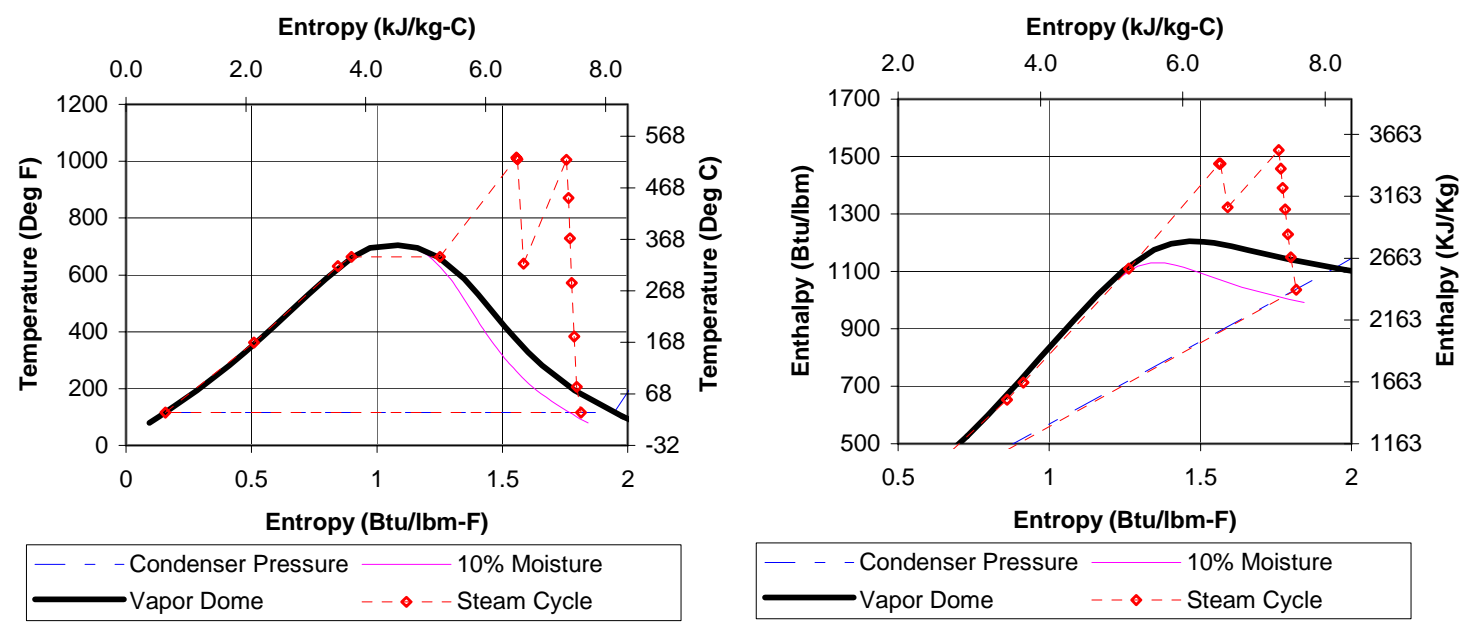

Figure 4.24: Case-2 Steam Cycle State Points Shown on T-S and H-S Coordinates

The steam turbine performance analysis results for Case- 2 show the generator produces 
about 99 MWe output and the steam turbine heat rate is about $8,745 \mathrm{~kJ} / \mathrm{kWh}(8,291$ $\mathrm{Btu} / \mathrm{kWh}$ ). The generator output, turbine heat rate and condenser losses are slightly higher for Case-2 than for Case-1. This is a result of the low level heat recovery system, which reduces extraction flows to the first two low-pressure extraction feedwater heaters and thus increases steam flow through the LP turbine and its associated power output.

\section{Case-2 Steam Cycle Equipment (existing and new):}

The steam cycle starts at the condenser hot well, which is a receptacle for the condensed steam from the exhaust of the steam turbine. The condensate flows to the suction of the condensate pumps (CP), which increase the pressure of the fluid by a nominal $10.3 \mathrm{bar}$ (150-psi) to transport it through the piping system and enable it to enter the open contact heater, or deaerator. The condensate passes through a gland steam condenser, followed by three low-pressure extraction feedwater heaters in series. The heaters successively increase the condensate temperature to a nominal $148.3^{\circ} \mathrm{C}\left(299^{\circ} \mathrm{F}\right)$ by condensing and partially sub-cooling steam extracted from the LP steam turbine section. Each heater receives extraction steam at successively higher pressure and temperature. The condensed steam (now referred to as heater drains) is progressively passed to the next lower pressure heater, with the drains from the lowest heater draining to the condenser.

The Case- 2 condensate heating system differs from Case 1 in that there are additional heat exchangers in parallel condensate streams with the two low-pressure extraction heaters as shown in Figure 4.23. The additional heat exchangers are shown schematically as a single component labeled "ASU Heat Recovery" located in the lower left corner of Figure 4.23. In reality, three parallel condensate streams are used to recover some of the heat rejected by the three ASU main air compressor aftercoolers.

This heat recovery system increases the generator output by about $1.6 \mathrm{MWe}$ or about 1.6 percent as compared to Case-1. The condenser heat rejection is also increased by about $44.8 \times 10^{6} \mathrm{~kJ} / \mathrm{hr}\left(42.5 \times 10^{6} \mathrm{Btu} / \mathrm{hr}\right)$ or about 10 percent as compared to Case- 1 .

The heated condensate streams leaving the ASU system are combined and mixed with condensate leaving the \#2 heater before entering the \# 3 heater. Condensate leaving the \#3 heater is piped to the deaerator where the condensate is heated and stripped of noncondensable gases by direct contact with steam extracted from the steam turbine. The extracted steam is condensed and mixes with the heated condensate, which flows by gravity to a deaerator storage tank. The boiler feedwater pumps (BFP) take suction from the storage tank and increase the fluid pressure to a nominal 172.4 bara (2,500 psia). Both the condensate pump and boiler feed pump are electric motor driven pumps. The high-pressure feedwater leaving the BFP flows through two more high-pressure feedwater heaters, increasing in temperature to $237.8^{\circ} \mathrm{C}\left(460^{\circ} \mathrm{F}\right)$ at the exit from the final feedwater heater (entrance to the boiler economizer section). Each feedwater heater receives a separate extraction steam stream at successively higher pressure and temperature. The condensed steam leaving the feedwater heaters (called drains) is progressively passed to the next lower pressure heater, with the drains from the lowest high pressure heater (heater \#5) draining to the deaerator.

Within the CFB boiler system the warm feedwater leaving the feedwater system is further heated in the economizer, evaporated and finally superheated. The high-pressure superheated steam leaving the finishing superheater, $284,401 \mathrm{~kg} / \mathrm{hr}(627,000 \mathrm{lbm} / \mathrm{hr})$ of 
steam at 138 bara $\left(2,000\right.$ psia) and $538^{\circ} \mathrm{C}\left(1,000^{\circ} \mathrm{F}\right)$, is expanded through the highpressure turbine. Reheat steam $(257,375 \mathrm{~kg} / \mathrm{hr}, 567,418 \mathrm{lbm} / \mathrm{hr})$ is heated and returned to the intermediate pressure turbine at 29.5 bara $\left(428\right.$ psia) and $538{ }^{\circ} \mathrm{C}\left(1,000{ }^{\circ} \mathrm{F}\right)$. These conditions represent common steam cycle operating conditions for current utility scale CFB power generation systems. The reheated steam expands through the intermediate and low-pressure turbines before exhausting to the condenser. The condenser pressure used for both cases in this study was 7.6 centimeters of mercury absolute (3.0 in Hga).

\section{Other Balance of Plant Equipment:}

Most of the other existing balance of plant systems and equipment for Case- 2 are not affected by the retrofit to $\mathrm{O}_{2}$ firing and $\mathrm{CO}_{2}$ capture and are therefore identical to the existing systems used for Case-1. This equipment includes coal and limestone handling equipment (Note: limestone is not used in Case-2), coal and limestone preparation and feed equipment, ash handling equipment, and electrical equipment.

The cooling water system for Case- 1 rejects heat primarily from the condenser and also small quantities from other equipment throughout the existing plant. For Case-2, this system is required to reject about 45 percent more heat than for Case-1. There are three factors that lead to the increase in the cooling water system heat rejection duty as listed below:

- Additional condenser heat rejection due to bypassing of the first two low-pressure feedwater heaters.

- Heat rejection from the Gas Processing System refrigeration condenser (EA-201), water cooler (EB-101), and compressor aftercoolers (EA-101 - EA-104).

- Heat rejection from the ASU stage \#3 direct contact aftercooler (DCA).

It was assumed that the existing plant cooling water system would be able to handle this increased duty. This assumption was made knowing that the existing study unit is one of four identical units located on the existing site, which share a common cooling water system. Therefore, an increase of 45 percent from one of the units represents only about a 11.25 percent increase for the total plant cooling water system. This level of increase is typically well within the design margin for these systems and as such no additional cooling system equipment was added.

\subsubsection{Case-2: Overall Plant Performance and $\mathrm{CO}_{2}$ Emissions Summary}

This section provides a summary and comparison of several important plant performance outputs from this study. Comparisons between Case- 2 and Case- 1 are provided.

Table 4.22 shows a fairly detailed comparison of plant performance and $\mathrm{CO}_{2}$ emissions for the $\mathrm{CO}_{2}$ recovery concept (Case-2) and the Base Case (Case-1) that employs no $\mathrm{CO}_{2}$ recovery system for comparison. Selected results from this table are illustrated and compared in Figure 4.25 - Figure 4.30. 


\section{Table 4.22: Plant Performance and $\mathrm{CO}_{2}$ Emissions Summary and Comparison}

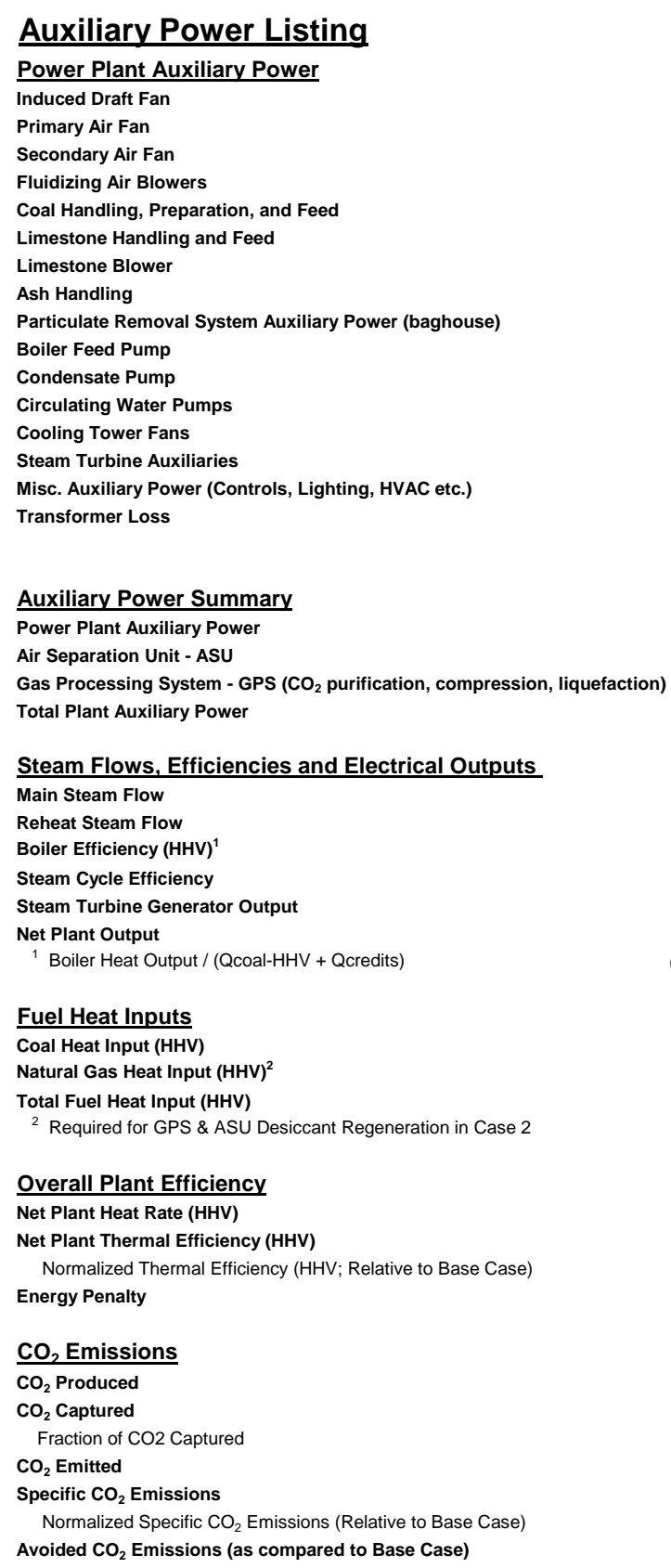

\begin{tabular}{|c|c|c|c|c|}
\hline \multirow[b]{2}{*}{ (Units) } & \multicolumn{2}{|c|}{$\begin{array}{c}\text { Case-1: Air Fired } \\
\text { CFB (Base-Case) w/o } \\
\mathrm{CO}_{2} \text { Capture } \\
\end{array}$} & \multicolumn{2}{|c|}{$\begin{array}{c}\text { Case-2: CFB Retrofit } \\
\text { with } \mathrm{O}_{2} \text { Firing } \\
\text { and } \mathrm{CO}_{2} \text { Capture }\end{array}$} \\
\hline & (English) & (SI) & (English) & (SI) \\
\hline$(\mathrm{kW})$ & 827 & 827 & 561 & 561 \\
\hline$(\mathrm{kW})$ & 1209 & 1209 & 876 & 876 \\
\hline$(\mathrm{kW})$ & 364 & 364 & 259 & 259 \\
\hline$(\mathrm{kW})$ & 551 & 551 & 602 & 602 \\
\hline$(\mathrm{kW})$ & 136 & 136 & 138 & 138 \\
\hline$(\mathrm{kW})$ & 94 & 94 & 0 & 0 \\
\hline$(\mathrm{kW})$ & 71 & 71 & 0 & 0 \\
\hline$(\mathrm{kW})$ & 95 & 95 & 48 & 48 \\
\hline$(\mathrm{kW})$ & 182 & 182 & 298 & 298 \\
\hline$(\mathrm{kW})$ & 1798 & 1798 & 1798 & 1798 \\
\hline$(\mathrm{kW})$ & 108 & 108 & 108 & 108 \\
\hline$(\mathrm{kW})$ & 623 & 623 & 902 & 902 \\
\hline$(\mathrm{kW})$ & 623 & 623 & 902 & 902 \\
\hline$(\mathrm{kW})$ & 94 & 94 & 94 & 94 \\
\hline$(\mathrm{kW})$ & 336 & 336 & 504 & 504 \\
\hline$(\mathrm{kW})$ & 220 & 220 & 223 & 223 \\
\hline Subtotal & 7331 & 7331 & 7313 & 7313 \\
\hline (frac. of Gen. Output) & 0.075 & 0.075 & 0.074 & 0.074 \\
\hline$(\mathrm{kW})$ & 7331 & 7331 & 7313 & 7313 \\
\hline$(\mathrm{kW})$ & $\mathrm{n} / \mathrm{a}$ & $\mathrm{n} / \mathrm{a}$ & 17081 & 17081 \\
\hline$(\mathrm{kW})$ & $\mathrm{n} / \mathrm{a}$ & $\mathrm{n} / \mathrm{a}$ & 12810 & 12810 \\
\hline$(\mathrm{kW})$ & 7331 & 7331 & 37204 & 37204 \\
\hline (frac. of Gen. Output) & 0.075 & 0.075 & 0.374 & 0.374 \\
\hline$(\mathrm{lbm} / \mathrm{hr} ; \mathrm{kg} / \mathrm{hr})$ & 627000 & 284401 & 627000 & 284401 \\
\hline$(\mathrm{lbm} / \mathrm{hr} ; \mathrm{kg} / \mathrm{hr})$ & 567418 & 257375 & 567418 & 257375 \\
\hline (fraction) & 0.8946 & 0.8946 & 0.8875 & 0.8875 \\
\hline (fraction) & 0.4305 & 0.4305 & 0.4117 & 0.4117 \\
\hline$(\mathrm{kW})$ & 97758 & 97758 & 99349 & 99349 \\
\hline$(\mathrm{kW})$ & 90427 & 90427 & 62144 & 62144 \\
\hline (frac. of Case-1 Net Output) & 1.00 & 1.00 & 0.69 & 0.69 \\
\hline$\left(10^{6} \mathrm{Btu} / \mathrm{hr} ; 0^{6} \mathrm{KJ} / \mathrm{hr}\right)$ & 843 & 890 & 852 & 899 \\
\hline$\left(10^{6} \mathrm{Btu} / \mathrm{hr} ; 10^{6} \mathrm{KJ} / \mathrm{hr}\right)$ & $\mathrm{n} / \mathrm{a}$ & $\mathrm{n} / \mathrm{a}$ & 9.3 & 9.8 \\
\hline$\left(10^{6} \mathrm{Btu} / \mathrm{hr} ; 10^{6} \mathrm{KJ} / \mathrm{hr}\right)$ & 843 & 890 & 861 & 909 \\
\hline (Btu/kwhr; KJ/kwhr) & 9328 & 9839 & 13861 & 14620 \\
\hline (fraction) & 0.3659 & 0.3659 & 0.2462 & 0.2462 \\
\hline (fraction) & 1.00 & 1.00 & 0.67 & 0.67 \\
\hline (fraction) & 0.00 & 0.00 & 0.33 & 0.33 \\
\hline$(\mathrm{lbm} / \mathrm{hr} ; \mathrm{kg} / \mathrm{hr})$ & 175501 & 79605 & 172405 & 78201 \\
\hline$(\mathrm{lbm} / \mathrm{hr} ; \mathrm{kg} / \mathrm{hr})$ & & 0 & 161534 & 73270 \\
\hline (fraction) & 0.000 & 0.000 & 0.937 & 0.937 \\
\hline$(\mathrm{lbm} / \mathrm{hr} ; \mathrm{kg} / \mathrm{hr})$ & 175501 & 79605 & 10871 & 4931 \\
\hline (lbm/kwhr; kg/kwhr) & 1.94 & 0.88 & 0.17 & 0.08 \\
\hline (fraction) & 1.00 & 1.00 & 0.09 & 0.09 \\
\hline $\mathrm{bm} / \mathrm{kwhr} ; \mathrm{kg} / \mathrm{kwhr}$ ] & 0.00 & 0.00 & 1.77 & 0.80 \\
\hline
\end{tabular}

\section{Boiler Efficiency:}

Figure 4.25 compares boiler efficiencies for the two cases. Case-1 (the air-fired Base Case) is slightly higher than the oxygen fired case primarily due to a lower dry gas loss. The lower dry gas loss is the result of lower flue gas flow (about 20 percent lower than for Case-2) and lower temperature exiting the air heater. The flue gas flow rate exiting the air heater is higher for Case-2 for a couple of reasons. Each case has approximately the same superficial gas velocity in the combustor. However, the $\mathrm{O}_{2}$ fired case has a flue 
gas composition with a high $\mathrm{CO}_{2}$ composition whereas the air fired case has a typical airfired flue gas composition with a high $\mathrm{N}_{2}$ composition. Therefore, with both cases using nearly the same superficial gas velocity in the combustor, the higher flue gas molecular weight of the $\mathrm{O}_{2}$ fired case causes a higher flue gas density and mass flow as compared to the air fired case. The higher air heater outlet temperature for the $\mathrm{O}_{2}$ fired case is the result of higher oxidant temperature entering the existing air heater and the higher mass flows as described above. The boiler efficiency decrease for this existing unit is about 0.8 percentage points for Case- 2 .

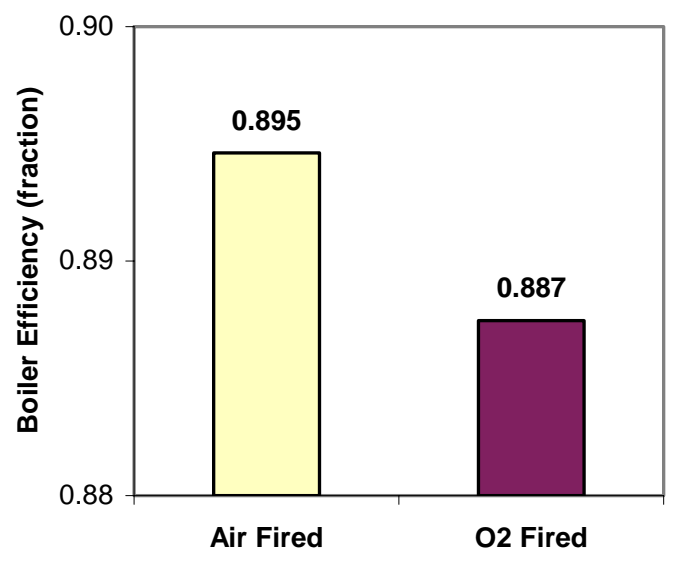

Figure 4.25: Boiler Efficiency Comparison

The boiler heat output is the same in each case since steam cycles that are nearly identical. The only difference in the steam cycles is the low-level heat recovery system for Case-2, described in the previous section, which has no impact on the required boiler heat output. Because of the slightly higher boiler efficiency, the air-fired Base Case has a slightly lower coal heat input (by about 1 percent) than the oxygen fired case.

\section{Steam Cycle Efficiency:}

Figure 4.26 compares steam cycle efficiency for the two cases. Case-1, the air-fired Base Case, has a higher steam cycle efficiency (by about 5 percent) than the oxygen fired Case 2. This is primarily due to the fact that in Case- 1 there is no low-level heat recovery system. The low level-heat recovery system used in Case- 2 provides heat (recovered from ASU) to the low-pressure condensate stream leaving the condenser, which for Case1 was heated with the traditional low-pressure extraction feedwater heaters (Heaters \#1 and \#2). 


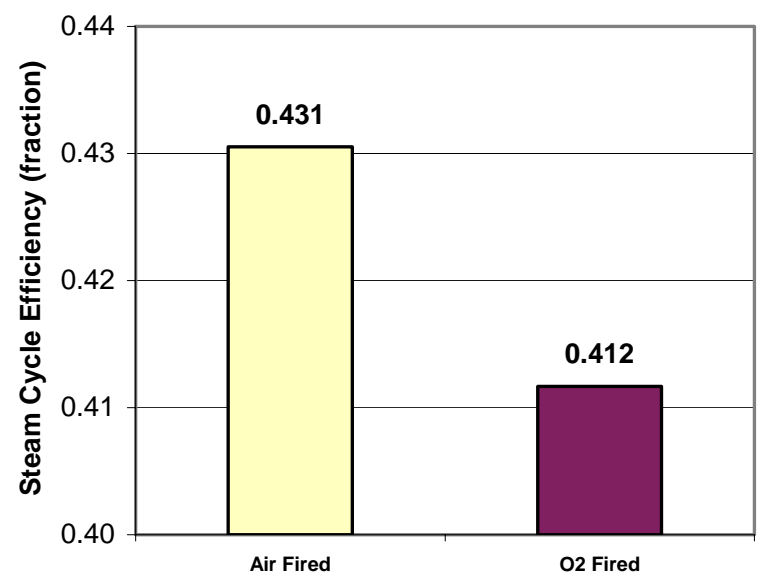

Figure 4.26: Steam Cycle Efficiency Comparison

\section{Gas Processing System Auxiliary Power:}

The $\mathrm{CO}_{2}$ capture case requires $\mathrm{CO}_{2}$ compression, purification and liquefaction within the Gas Processing Systems (GPS) in order to meet the product gas specification. The GPS power requirements were calculated to be about $145 \mathrm{kWh} /$ tonne $(160 \mathrm{kWh} /$ ton $)$ of $\mathrm{CO}_{2}$ captured for this case.

\section{Total Plant Auxiliary Power:}

There are three main categories that comprise the total plant auxiliary power. These are:

1. The Gas Processing System

2. The Air Separation Unit (ASU)

3. The traditional power plant auxiliaries associated with the draft system, cooling water system, material handling, etc.

Figure 4.27 compares total plant auxiliary power for the two cases.
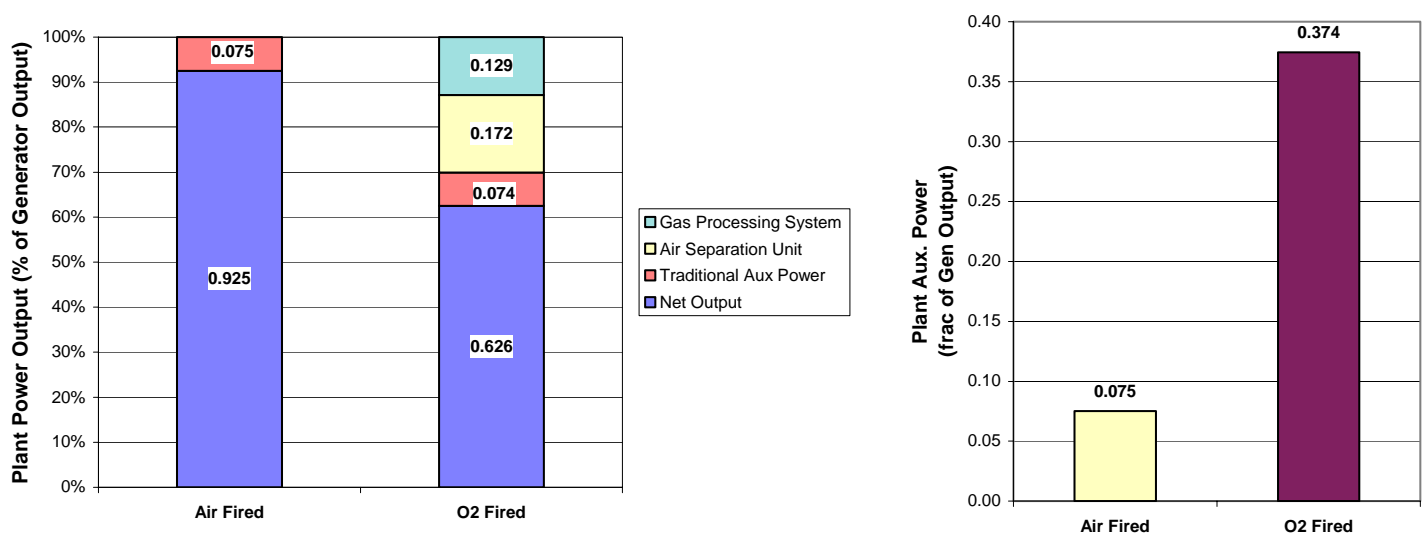

Figure 4.27: Auxiliary Power Comparison between Air-Fired and Oxygen Fired CFB Plants

Case-1, the air-fired Base Case without $\mathrm{CO}_{2}$ recovery, requires much less auxiliary power than Case-2, since it does not require an ASU for supply of oxidant or a Gas Processing 
System to compress and purify the $\mathrm{CO}_{2}$. The auxiliary power for Case- 1 is only that which is attributable to the traditional power plant equipment. This includes equipment for solids handling (coal, limestone, and ash), air and gas handling, water pumping for the steam cycle and cooling water systems, as well as other miscellaneous systems within the traditional power plant. This case requires slightly less than 8 percent of the generator output for auxiliary power. A detailed listing of plant auxiliary power is shown in Table 4.22 .

Case-2 includes the ASU and GPS which consume about 17.2 and 12.9 percent of the gross output, respectively, while the traditional auxiliary power consumption is reduced slightly to about 7.4 percent of the generator output (see Table 4.22).

The auxiliary power consumption for the draft system (fans \& blowers) is reduced by about 22 percent with $\mathrm{O}_{2}$ firing which is partially due to handling a higher molecular weight gas. Some of this reduction results from introducing the oxygen from the ASU downstream of the PA and SA fans and some results from the reduction in inlet gas temperature for the ID fan. Partially offsetting these draft system power reductions is the slightly higher inlet temperatures to the PA, SA, and fluidizing air blowers with $\mathrm{O}_{2}$ firing.

The traditional auxiliary power reduction for the draft system is partially offset by increases in the power requirements for the cooling water pumps, cooling tower fans, FDA system, and miscellaneous (controls, lighting, HVAC, etc.).

\section{Net Plant Power Output:}

Figure 4.28 compares the resulting net power output (MWe) for the cases. The net power output for Case-2 is reduced by about $28.3 \mathrm{MWe}$ as compared to Case- 1 . The new output is about 69 percent of the air fired base case net output. The output reduction is primarily a result of additional power requirements for the ASU and GPS systems.

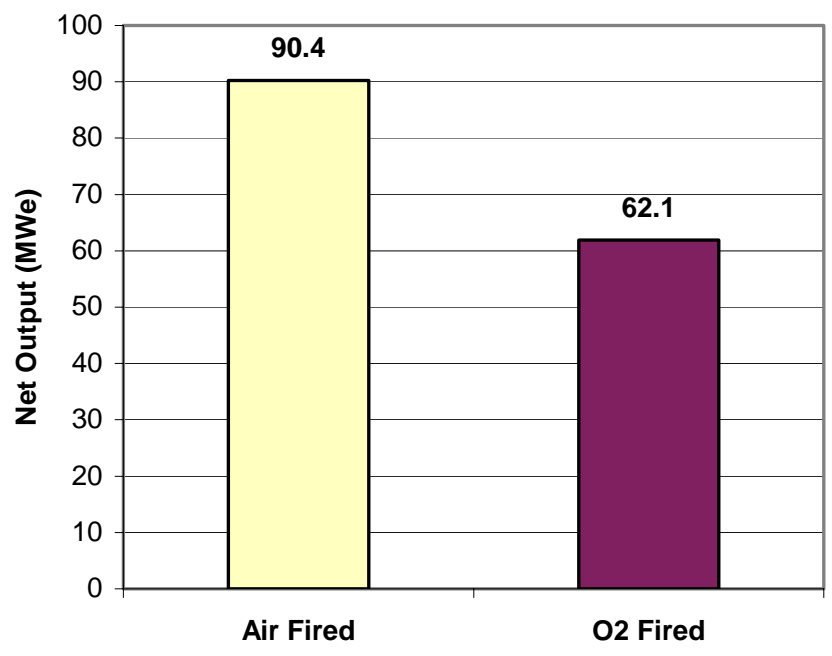

Figure 4.28: Net Plant Output Comparison

\section{Plant Thermal Efficiency:}

Figure 4.29 shows a comparison of Net Plant Thermal Efficiency between Case-1 and 
Case-2. These efficiency results reflect the combined impact of boiler efficiency, steam cycle efficiency, and plant auxiliary power on net plant thermal efficiency. As shown previously, the differences in plant auxiliary power represents the dominant factor for differences in overall net plant thermal efficiency for the cases studied.

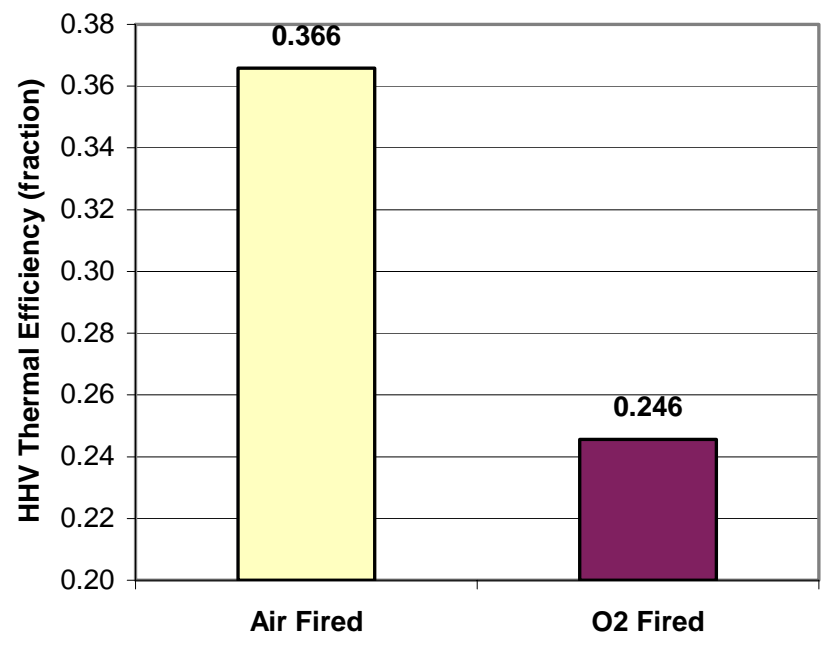

Figure 4.29: Net Plant Thermal Efficiency Comparison

The resulting energy penalty for Case-2 is about 32.7 percent as compared to Case-1. There are two primary reasons for the energy penalty associated with Case-2. First, the integration into the power plant of the Air Separation Unit (ASU) to provide combustion oxygen, and second, the Gas Processing System (GPS) to compress, purify, and liquefy the $\mathrm{CO}_{2}$ product. Both these systems (ASU and GPS) consume large quantities of auxiliary power as shown in Table 4.22. The oxygen-fired case utilizes a cryogenic based ASU system, which adds a significant load to the plant auxiliary power requirement. About $211 \mathrm{kWh} /$ tonne $(233 \mathrm{kWh} /$ ton $)$ of oxygen supplied or about 17.2 percent of the steam turbine generator output is attributable to the ASU. The GPS power requirements were calculated to be about $145 \mathrm{kWh} /$ tonne $(160 \mathrm{kWh} /$ ton $)$ of $\mathrm{CO}_{2}$ captured or about 12.9 percent of the steam turbine generator output.

\section{$\underline{\text { Plant } \mathrm{CO}_{2}} \underline{\text { Emissions: }}$}

Figure 4.30 compares the $\mathrm{CO}_{2}$ produced and emitted for each case. The Base Case air fired CFB produces - and emits $-1.94 \mathrm{lb} / \mathrm{kWh}(0.88 \mathrm{~kg} / \mathrm{kWh})$ of $\mathrm{CO}_{2}$. The $\mathrm{O}_{2}$ fired plant in Case-2 produces $2.77 \mathrm{lb} / \mathrm{kWh}(1.26 \mathrm{~kg} / \mathrm{kWh})$. Case-2 actually produces slightly less $\mathrm{CO}_{2}$ per hour than Case-1, due to not adding limestone. Because of the lower net power output, however, Case-2 produces more $\mathrm{CO}_{2}$ per $\mathrm{kWh}$.

The gas processing system in Case-2 recovers $2.60 \mathrm{lb} / \mathrm{kWh}(1.18 \mathrm{~kg} / \mathrm{kWh})$ of $\mathrm{CO}_{2}$ - a $94 \%$ reduction. The emissions are $0.17 \mathrm{lb} / \mathrm{kWh}(0.08 \mathrm{~kg} / \mathrm{kWh})$.

With respect to air firing, Case- 2 reduces the $\mathrm{CO}_{2}$ emissions by $1.77 \mathrm{lb} / \mathrm{kWh}$ $(0.80 \mathrm{~kg} / \mathrm{kWh})$. On this basis, the $\mathrm{CO}_{2}$ emissions are reduced by $91 \%$. 


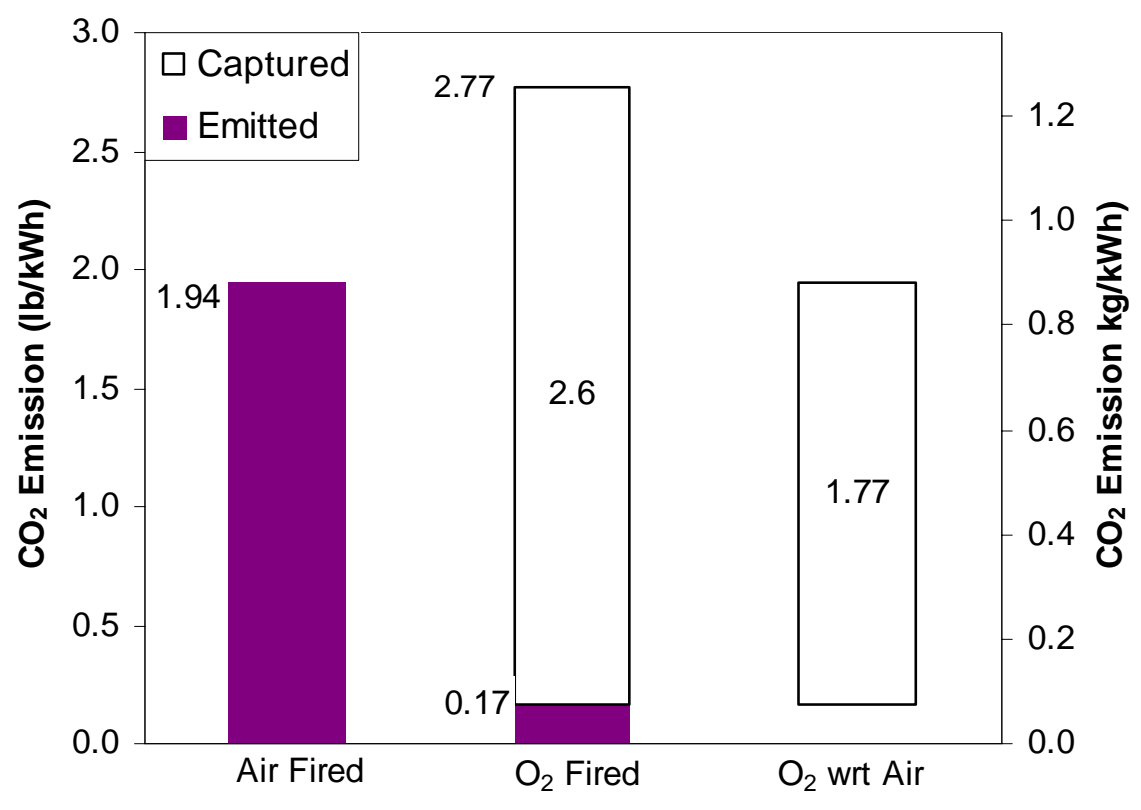

Figure 4.30: Plant $\mathrm{CO}_{2}$ Emissions per kWh

\subsection{Retrofit Cost Analysis}

The plant investment cost basis and operating and maintenance cost basis are defined in this section as well as the actual cost estimates for the case studies. The investment costs for the retrofit case (Case-2) are shown as incremental costs, which are required to accommodate this retrofit. The incremental investment cost estimate summary is shown in this section for the power plant retrofitted with $\mathrm{O}_{2}$ firing and $\mathrm{CO}_{2}$ capture (Case-2). Case-1 is an existing CFB based steam power plant without $\mathrm{CO}_{2}$ capture and since the economic analysis described later (see Section 4.6) is developed on an incremental cost of electricity (COE) basis, plant investment costs are not required or shown for Case-1. The retrofit investment cost estimate does not include owner's costs. Owner's costs are, however, included in the economic analysis in Section 4.6. Annual operating and maintenance cost estimates for the entire power plant are also presented in this section for both cases.

All costs shown are expressed in July 2005 dollars. The level of accuracy for the investment costs for this conceptual level design is expected to be about \pm 30 percent. The retrofit plant equipment is constructed on the existing plant site in the Gulf Coast region of southeastern Texas.

\subsubsection{Cost Estimation Basis:}

The plant investment cost basis and O\&M cost basis are defined in this section. The cost basis used in this study is similar to what was used in two previous studies (Marion, et al., 2003 and Nsakala, Liljedahl, and Turek, 2004) and is summarized below.

\section{Investment Cost Estimation Basis:}

The plant investment cost for retrofit includes engineering, procurement, and construction (i.e., EPC basis). The cost includes all new equipment and modifications to existing 
equipment. The plant scope includes all required equipment including the traditional Boiler Island equipment, and Balance of Plant equipment (steam turbine, generator, condensate and feedwater systems, draft system, particulate removal, desulfurization, material handling (coal, sorbent, and ash), cooling system, electrical, instrumentation and control, and misc.). Additionally, for the $\mathrm{CO}_{2}$ removal Case (Case-2) the non-traditional equipment is included. This encompasses new equipment for $\mathrm{CO}_{2}$ capture, compression and liquefaction system, the new Air Separation Unit equipment, and the modified boiler equipment.

The boundary limit for the plant includes the complete plant facility within the "fence line." It includes the coal receiving and water supply systems and terminates at the highvoltage side of the main power transformers. Also, for the case with $\mathrm{CO}_{2}$ capture, the boundary terminates at the outlet flange of the $\mathrm{CO}_{2}$ product pipe (It does not include the $\mathrm{CO}_{2}$ pipeline offsite or the $\mathrm{CO}_{2}$ injection well).

The costs include equipment, materials, labor, indirect construction costs, and engineering. The labor cost to install the equipment and materials was estimated on the basis of labor man-hours. The labor costing approach was a multiple contract labor basis with the labor cost including direct and indirect labor cost plus fringe benefits and allocations for contractor expenses and markup.

These costs include professional services and "other costs." Professional services consist of the cost for engineering, construction management, and startup assistance. The engineering services include all preliminary and detailed engineering and design for the total retrofit scope. It includes specifying equipment for purchase, procurement, performing project scheduling and cost control services for the project; providing engineering and design liaison during the construction period; and providing startup support. Construction management services cost includes a field management staff capable of performing all field contract administration; field inspection and quality assurance; project construction control; safety and medical services as required; field and construction insurance administration, field office clerical and administrative support. The "other costs" category includes a cost allowance for freight costs, heavy haul, insurance, taxes, and indirect startup spares.

The retrofit capital cost estimate for the plant was calculated based on a combination of vendor-furnished quotes, and cost estimating database values. The Boiler Island retrofit costs were estimated based on calculated material weights for all components. Conceptual equipment arrangement drawings and equipment lists were developed as a part of the conceptual design of the required retrofit equipment.

The following assumptions were made in developing the EPC cost estimate for the concept evaluated:

- Investment costs are expressed in July 2005 US dollars

- Construction labor rates are based on Gulf Coast non-union rates

- The plant retrofit is constructed on an existing site in southeastern Texas

- All costs are based on mature level ( $\mathrm{n}^{\text {th }}$ plant) commercial retrofit design

- Owners costs (including interest during construction, start-up fuel, land, land 
rights, plant licensing, permits, etc.) are not included in the investment costs but are included in the Cost of Electricity analysis (see Section 4.6)

- Ash is to be shipped off site with provisions for short-term storage only

- Outdoor installation for Gas Processing System (GPS) and Air Separation Unit (ASU)

- Investment in new utility systems is outside the scope

- No special limitations for transportation of large equipment

- No protection against unusual airborne contaminants (dust, salt, etc.)

- No unusual wind storms

- No earthquakes

- No piling required

- All releases can go to atmosphere - no flare provided

- $\mathrm{CO}_{2}$ Pump designed to API standards, all other pumps conform to ANSI

- All GPS heat exchangers designed to TEMA “ $C$ "

- All GPS vessels are designed to ASME Section VIII, Div 1.

- The retrofit investment cost estimate was developed as a factored estimate based on a combination of vendor quotes and in-house data for the major equipment. Such an estimate can be expected to have accuracy of \pm 30 percent.

- No purchases of utilities or charges for shutdown time have been charged against the project.

Other exclusions from the EPC retrofit investment cost estimate are as follows:

- $\mathrm{CO}_{2}$ pipeline offsite

- $\mathrm{CO}_{2}$ injection well

- Fuels required for startup

- Relocation or removal of buildings, utilities, and highways

- Permits

- Land and land rights

- Soil investigation

- Environmental Permits

- Disposal of hazardous or toxic waste

- Disposal of existing materials

- Custom's and Import duties

- Sales/Use tax. 
- Forward Escalation

- Capital spare parts

- Chemical loading facilities

- GPS Buildings except for Compressor building and electrical substation.

- Financing cost

- Owners costs

- Guards during construction

- Site Medical and Ambulance service

- Cost \& Fees of Authorities

- Overhead High voltage feed lines

- Cost to run a natural gas pipeline to the plant

\section{Operating and Maintenance Cost Estimation Basis:}

Operating and maintenance (O\&M) costs were calculated for all systems for both cases (Case-1 and Case-2). O\&M costs calculated are listed as either fixed or variable. The fixed operating and maintenance (FOM) are those costs, which are incurred irrespective of the number of hours of plant operation whereas the variable operating and maintenance (VOM) costs are directly proportional to the operating hours. These costs are calculated separately for the traditional power plant equipment, the oxygen supply system (ASU), and the Gas Processing System (GPS) where applicable. The FOM costs for the new equipment includes operating labor only. The VOM costs for the new equipment (used in Case-2) included such categories as chemicals and desiccants, waste handling, maintenance material and labor, supplemental fuel usage, and contracted services.

The O\&M costs for the ASU were calculated by ALSTOM with consultation from Praxair by prorating values from those shown in a previous study (Nsakala, Liljedahl, and Turek, 2004). ABB Lummus Global Inc. (Lummus) calculated the O\&M costs for the GPS.

The O\&M costs for the traditional power plant equipment was developed quantitatively by ALSTOM using procedures similar to those used in a previous study (Nsakala, Liljedahl, and Turek, 2004). Operating labor cost for all equipment was calculated based on the number of operator jobs (O.J.) required. The average labor rate used to determine the annual cost was $32.80 \$ / \mathrm{hr}$, with a labor burden of 30 percent. The labor administration and overhead cost was assessed at a rate of 25 percent of the O\&M labor. Maintenance cost was evaluated as a percentage of the initial capital cost.

Consumable costs including fuel, limestone, water, and chemicals were determined on the basis of individual flow rates as listed in the material and energy balances, individual unit costs and the plant annual operating hours. Waste disposal cost was also based on flow rates from the material and energy balances, unit costs, and operating hours. 
- Annual operating time is $7008 \mathrm{hr}$ - an $80 \%$ capacity factor.

- Coal cost: $1.19 \$ / G J(1.25 \$ / M M B t u)$

- Natural Gas cost: 3.79 \$/GJ (4.00 \$/MMBtu)

- Limestone cost: $11.02 \$ /$ tonne (10.00 \$/ton)

- Lime cost: 55.12 \$/tonne (50.00 \$/ton)

- Water cost: $0.26 \$ / 1,000$ liters (1.00 \$/1,000 gallons)

- Water Treatment Chemicals cost: $0.35 \$ / \mathrm{kg}(0.16 \$ / \mathrm{lbm})$

- Ash Disposal cost: $8.82 \$ /$ tonne (8.00 \$/ton)

The $\mathrm{CO}_{2}$ captured in Case-2 is cleaned and used for enhanced oil recovery. A by-product credit of $\$ 16.53 /$ tonne $\left(\$ 15 /\right.$ ton) was taken for the $\mathrm{CO}_{2}$.

\subsubsection{Plant Investment Cost and Operating and Maintenance Cost Summary:}

A summary of plant costs (Capital and O\&M) for the retrofit case is shown in Table 4.23. Capital costs are not shown for Case-1 (existing plant) because this is a retrofit study and any capital costs assigned to the existing plant would also need to be assigned to the retrofit plant. The capital costs shown for Case- 2 therefore are the incremental investment costs that are required to retrofit the Case- 1 existing plant to $\mathrm{O}_{2}$ firing and $\mathrm{CO}_{2}$ capture. A breakdown of the costs for each case is shown later in this section.

Table 4.23: Plant Investment Costs (EPC basis) and O\&M Costs Summary

\begin{tabular}{|c|c|c|c|c|c|c|c|}
\hline \multirow{3}{*}{ Study Case } & \multirow{2}{*}{\multicolumn{2}{|c|}{ EPC Capital Cost }} & \multicolumn{5}{|c|}{ Operating \& Maintenance Costs } \\
\hline & & & \multicolumn{2}{|c|}{ Fixed } & \multicolumn{2}{|c|}{ Variable @ 80\% CF } & Total \\
\hline & $\mathrm{k} \$$ & $\$ / \mathrm{kW}$ & $\$$ & $\$ / \mathrm{kW}$ & $\$$ & $\$ / \mathrm{kWh}$ & $\$$ \\
\hline Case-1: Base Case - Air Fired CFB w/o $\mathrm{CO}_{2}$ Capture & --- & --- & $3,529,377$ & 39.03 & $2,763,317$ & 0.00436 & 6,292,695 \\
\hline Case-2: Case-1 1 CFB Retrofit with $\mathrm{O}_{2}$ Firing and $\mathrm{CO}_{2}$ Capture & $96,024,000$ & 1,545 & $5,330,083$ & 85.77 & $6,114,714$ & 0.01404 & $11,444,797$ \\
\hline
\end{tabular}

Overall plant retrofit costs and the associated specific plant retrofit costs $(\$ / \mathrm{kW})$ can vary quite significantly for any given plant retrofit technology depending on several factors. Some of the more important factors are listed below.

- Plant Size

- Plant Location and Site Conditions

- Construction Labor Basis

- Coal Analysis

- Ambient Conditions

For the retrofit case in this study, the design coal analysis, design ambient conditions, plant location and site conditions are described in Section 4.2. The construction labor 
basis used is Gulf Coast non-union. The sensitivity of plant specific retrofit cost to construction labor basis is indicated by observing that changing from Gulf Coast nonunion to Ohio River Valley union basis, for example, would increase the EPC plant retrofit costs by about 20 percent (Bozzuto et. al., 2001).

\subsubsection{Case-1: Plant Costs}

This section discusses plant investment costs and operating and maintenance costs for the existing Case-1 plant.

\section{Case-1 Investment Costs:}

Case- 1 is an existing CFB based steam power plant without $\mathrm{CO}_{2}$ capture and since the economic analysis (see Section 4.6) is developed on an incremental cost of electricity (COE) basis, plant investment costs are not required or shown for Case-1.

\section{Case-1 Operating and Maintenance Costs:}

The operating and maintenance costs and expenses for Case-1 were developed on a firstyear basis with a July 2005 plant in-service date. The costs consist of plant operating labor, maintenance (material and labor), allowances for administrative and support labor, consumables, and solid waste disposal. The costs were determined on a first-year basis that includes evaluation at an equivalent plant operating capacity factor of 80 percent (7,008 hrs/yr). The results are summarized in Table 4.24. 
COMMERCIALIZATION DEVELOPMENT OF OXYGEN FIRED CFB

FOR GREENHOUSE GAS CONTROL

\section{Table 4.24: Case-1: Total Plant Operating and Maintenance Costs}

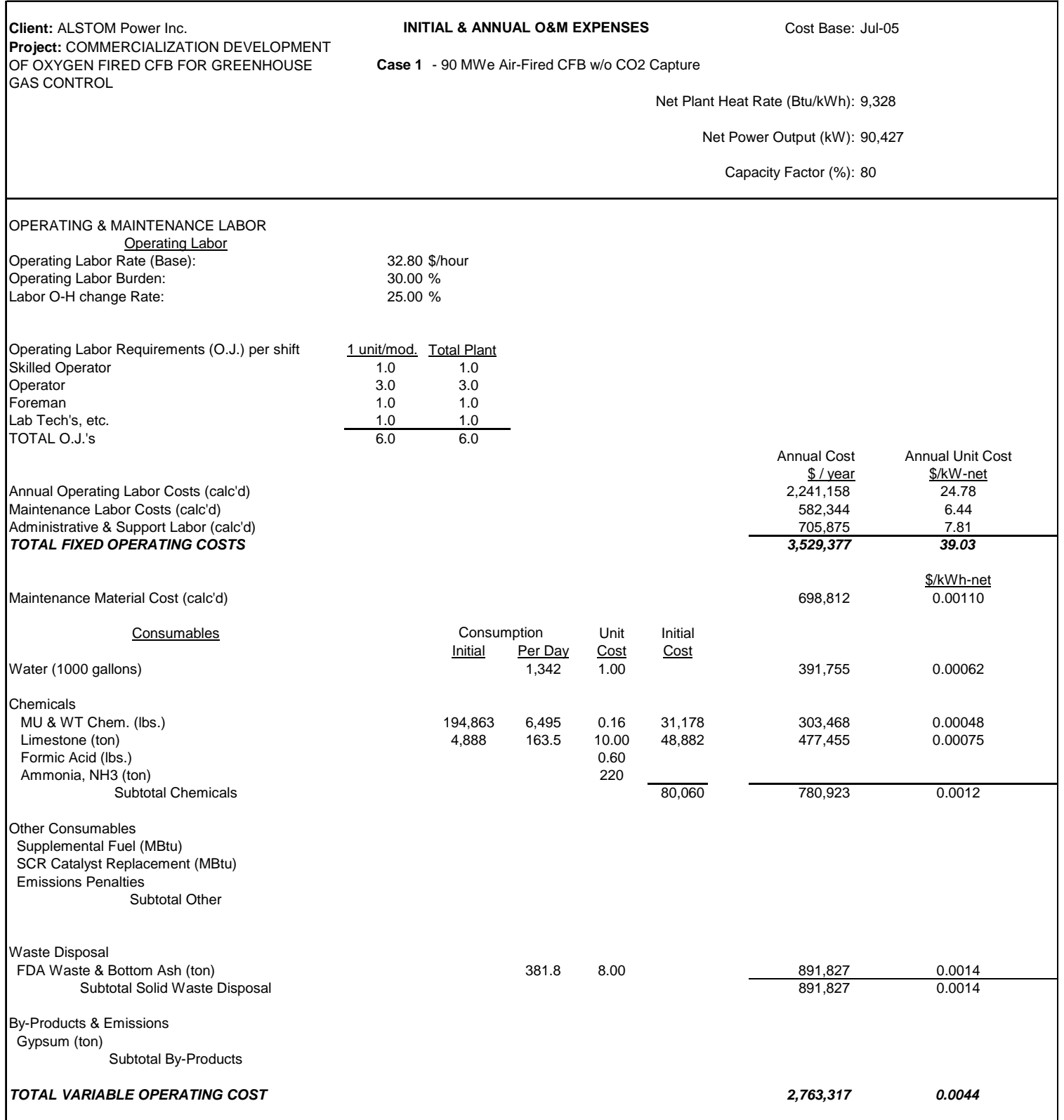




\subsubsection{Case-2: Plant Costs}

This section discusses plant retrofit investment costs and operating and maintenance costs for the Case- 2 plant. The Case- 2 plant is a retrofit of the existing Base Case plant (Case1) to include $\mathrm{O}_{2}$ firing and $\mathrm{CO}_{2}$ capture.

\section{Case-2 Investment Cost Summary:}

The retrofit of the plant to $\mathrm{O}_{2}$ firing and $\mathrm{CO}_{2}$ capture was developed consistent with the approach and basis identified in the design basis (Section 4.2). The capital cost estimate is expressed in July 2005 dollars. The plant retrofit investment cost summary is shown in Table 4.25 as total dollars, dollars per new $\mathrm{kW}$-net, and dollars per original $\mathrm{kW}$-net. The new output is reduced to about 69 percent of the original net output due primarily to the additional power consumption required for the ASU and GPS.

Table 4.25: Case-2 Plant Retrofit Investment Cost Summary

\begin{tabular}{|l|c|c|c|}
\hline \multirow{2}{*}{ Category } & \multicolumn{3}{|c|}{ Retrofit Investment Costs } \\
\cline { 2 - 4 } & $\$$ & $\$ / \mathrm{kW}$-new & $\$ / \mathrm{kW}$-original \\
\hline Boiler Modifications (Seal leaks, GR system, ID fan, Controls) & $4,500,000$ & 72 & 50 \\
\hline FDA System \& Baghouse Modifications & $5,850,000$ & 94 & 65 \\
\hline Gas Processing System & $48,174,000$ & 775 & 533 \\
\hline Air Separation Unit & $37,500,000$ & 603 & 415 \\
\hline Total & $\mathbf{9 6 , 0 2 4 , 0 0 0}$ & $\mathbf{1 , 5 4 5}$ & $\mathbf{1 , 0 6 2}$ \\
\hline
\end{tabular}

\section{Case-2 Operating and Maintenance Cost Summary:}

The operating and maintenance costs and expenses were developed on a first-year basis with a July 2005 plant in-service date. The operating and maintenance costs are expressed in July 2005 dollars. The operating and maintenance costs consist of plant operating labor, maintenance (material and labor), allowances for administrative and support labor, consumables, and solid waste disposal. The costs were determined on a first-year basis that includes evaluation at an equivalent plant operating capacity factor of 80 percent $(7,008 \mathrm{hrs} / \mathrm{yr})$. The total plant operating and maintenance costs results for Case-2 are summarized in Table 4.26. 
Table 4.26: Case-2: Total Plant Operating and Maintenance Cost Summary

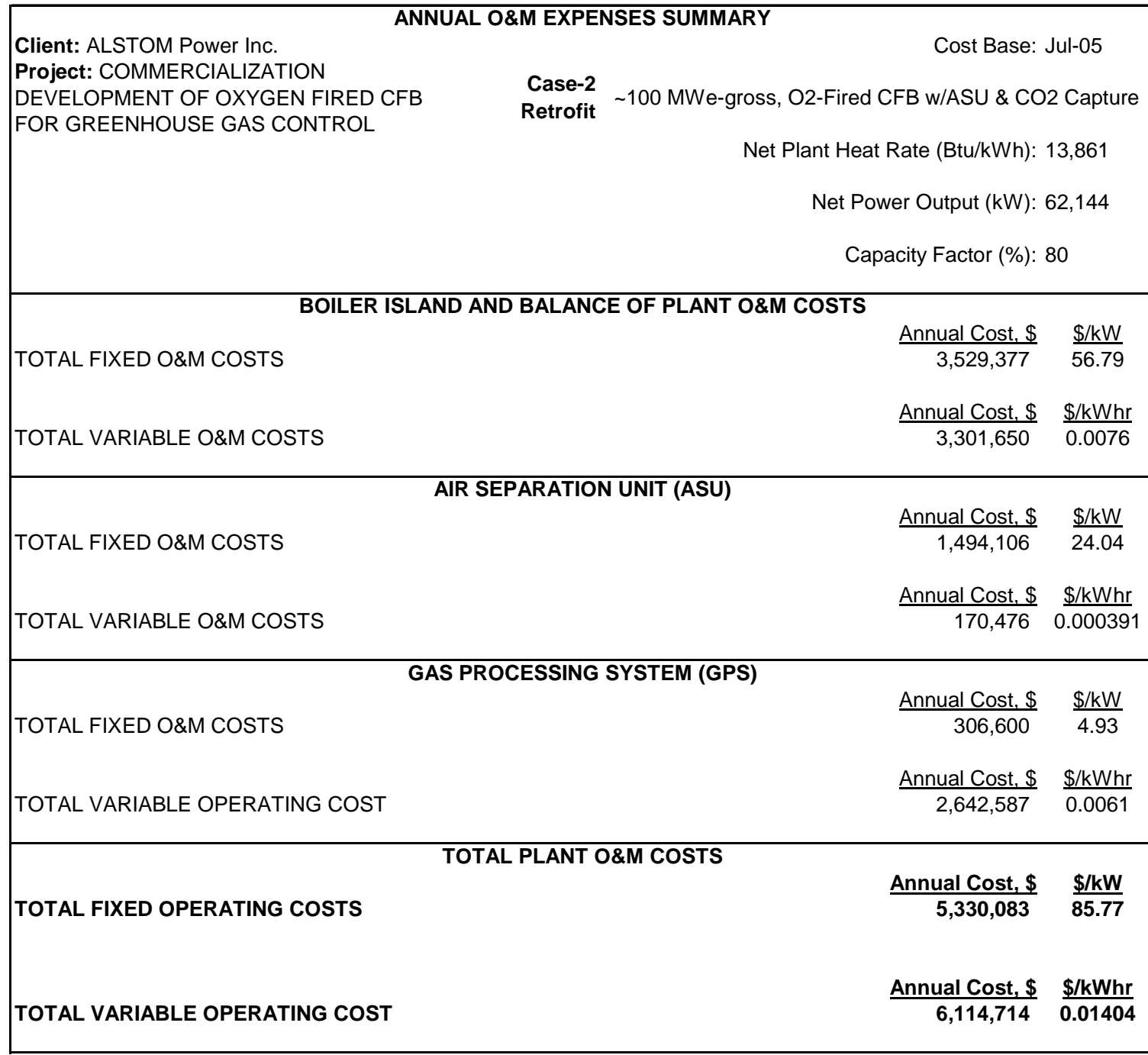

\section{Discussion of Cost Categories:}

As described above, the cost estimate for the Case-2 retrofit is further broken down into three primary categories as listed below:

- Boiler Modifications

- Gas Processing System

- Air Separation Unit

The following three sections provide investment cost and O\&M cost breakdowns and discussion for the three individual categories.

\section{Case-2 Boiler Modification Costs:}

The boiler modification cost required for Case-2 is relatively minor as compared to the other new equipment required for the retrofit (i.e., ASU and GPS). For this project the 
boiler scope is defined as everything on the gas side upstream of the Stack (excluding the new Gas Cooler which is part of the Gas Processing System). Therefore the boiler scope includes all boiler equipment such as fans, ductwork, baghouse, air heater, steam generator, coal feed system, and ash removal system, etc. Boiler Island scope modifications for Case-2 include such items as sealing the boiler for air leaks, new ductwork and dampers for the flue gas recirculation system, modification to the baghouse to accommodate the new Flash Dryer Absorber (FDA) $\mathrm{SO}_{2}$ removal system, a new ID fan and motor to accommodate the higher draft loss associated with the new FDA system, and modified controls and instrumentation.

The total EPC cost required for the Boiler Island scope modifications of Case- 2 is about $\mathbf{\$ 1 0 , 3 5 0 , 0 0 0}$ or on a normalized basis $(\$ 114 / \mathrm{kWe}$ original or $\$ 167 / \mathrm{kWe}$ new $)$. The cost to modify just the boiler is estimated to be about $\$ 4,500,000$ or on a normalized basis $\left(\$ 50 / \mathrm{kWe}\right.$ original or $\left.\$ 72 / \mathrm{kWe}_{\text {new }}\right)$. The cost for the new FDA system, which is included in the above Boiler Island cost, is $\$ 5,850,000$ or on a normalized basis $\left(\$ 65 / \mathrm{kWe}_{\text {original }}\right.$ or $\$ 94 / \mathrm{kWe}_{\text {new }}$ ). This cost (EPC basis) includes all the new FDA equipment and the required modifications to the existing baghouse and ductwork.

These cost estimates include all material, engineering and construction. The expected level of accuracy for this budget level cost estimate is $+/-30$ percent.

The total annual operating and maintenance costs for the modified Case-2 Boiler and Balance of Plant (BOP) equipment are shown below in Table 4.27. 
Table 4.27: Case-2: Modified Boiler \& BOP Annual Operating and Maintenance Costs

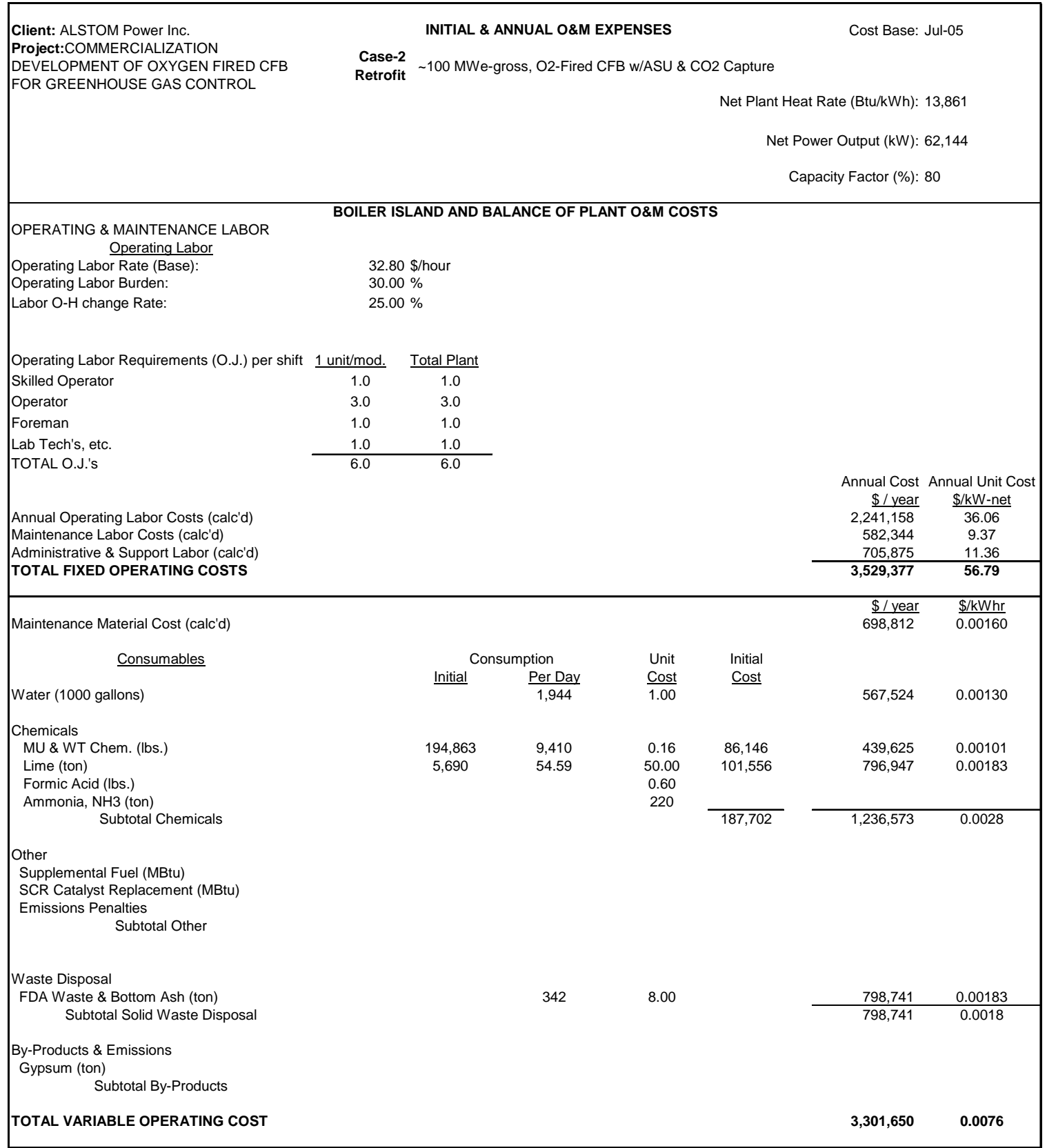

\section{Case-2 Gas Processing System Costs:}

Table 4.28 shows investment costs for the Case-2 Gas Processing System (GPS). This system provides $\mathrm{CO}_{2}$ compression, purification, and liquefaction to meet the $\mathrm{CO}_{2}$ specification shown previously in Section 4.2.2. The $\mathrm{CO}_{2}$ is provided at the plant fence line at 138 barg $(2,000$ psig). These costs were estimated by ABB Lummus Global Inc. and are on an EPC basis. The expected level of accuracy for this budget level cost estimate is $+/-30$ percent. 
Table 4.28: Case-2 Gas Processing System Investment Costs

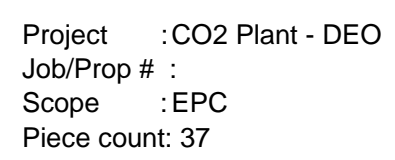

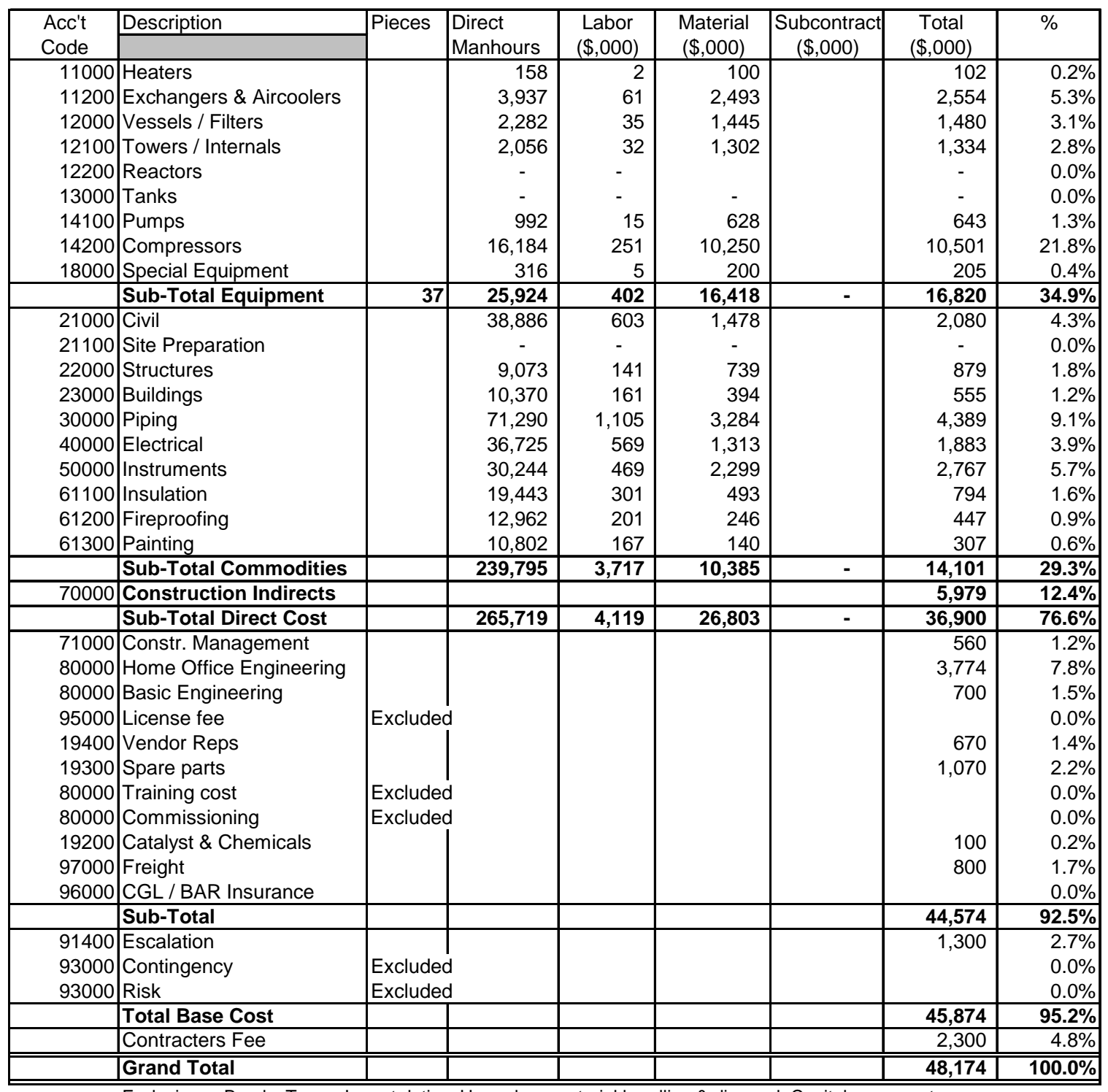

Exclusions : Bonds, Taxes, Import duties, Hazardous material handling \& disposal, Capital spare parts,

Reactor Catalyst, Chemicals, Commissioning and Initial operations, Buildings other than Control room \& MCC.

The annual operating and maintenance costs, also estimated by ABB Lummus Global Inc., for the GPS are shown below in Table 4.29. 
Table 4.29: Case-2 Gas Processing System Annual Operating and Maintenance Costs

\begin{tabular}{|l|r|r|}
\hline Operating Costs (\$/yr) & Variable Costs & Fixed Costs \\
\hline Chemical and Dessicant & 7,437 & \\
Waste Handling & - & \\
Natural Gas * & 98,210 & \\
Electricity* & - & \\
Operating Labor & - & 306,600 \\
Maintenance (Material \& Labor) & $1,706,940$ & \\
Contracted services & 830,000 & \\
\hline Column Total & $2,642,587$ & 306,600 \\
\hline Grand Total (Fixed \& Variable) & \multicolumn{2}{|c|}{$\mathbf{2 , 9 4 9 , 1 8 7}$} \\
\hline * & & \\
\hline Based on $\$ 4 /$ MMBU and 7008 hours/ yr. \\
** Included in overall facility operating cost
\end{tabular}

\section{Case-2 Air Separation Unit Costs:}

The Air Separation Unit (ASU) that is required for this $\mathrm{O}_{2}$ fired retrofit is a commercially available cryogenic type system. The unit has the capacity to provide nominally 1,635 tonne/day ( 1,800 ton/day) of oxygen to the Boiler Island at a purity of 99 percent and a pressure of 0.28 barg ( $4.0 \mathrm{psig}$ ). The EPC cost for this unit is estimated to be $\mathbf{\$ 3 7 , 5 0 0 , 0 0 0}$ as provided by Praxair Inc. The expected level of accuracy for this budget level cost estimate is $+/-30$ percent.

The annual operating costs for the ASU are shown below in Table 4.30. These O\&M costs were developed based on the O\&M costs from a previous study (Nsakala, Liljedahl, and Turek, 2004). 
Table 4.30: Case-2 ASU Annual Operating Costs

\begin{tabular}{|c|c|c|}
\hline Operating Cost (\$/yr) & Variable Costs & Fixed Costs \\
\hline Minor Consumables & 9,038 & \\
\hline Cooling Water* & 0 & \\
\hline Natural Gas ${ }^{\star * *}$ & 161,439 & \\
\hline Prepurified Adsorbent** & 0 & \\
\hline Operating Labor & & $1,494,106$ \\
\hline Column Total & 170,476 & $1,494,106$ \\
\hline Grand Total (Fixed + Variable) & \multicolumn{2}{|c|}{$1,664,582$} \\
\hline \multirow{2}{*}{\multicolumn{3}{|c|}{$\begin{array}{l}\text { * Cooling water is supplied by others; thus, major treatment } \\
\text { chemicals are part of this supply } \\
\text { ** Prepurified adsorbent is included in the plant and is typically } \\
\text { not replaced }\end{array}$}} \\
\hline & & \\
\hline \multicolumn{3}{|c|}{$\star \star \star$ Based on $\$ 4.0 / 10^{6}$ Btu and 7008 hours/year } \\
\hline
\end{tabular}

\subsubsection{Economy of Scale Effects}

It should be emphasized that because of the small size of this unit ( $\sim 62 \mathrm{MWe}$-net after retrofit) some of the cost impacts listed above are strongly influenced by economy of scale effects. The retrofit costs shown above and the resulting economic impacts shown in Section 4.6 are significantly greater than would be expected with more typically sized CFB or PC power plants. The selection of a small CFB for this study was however done purposely. This was done in order to investigate a unit size that would be relatively close to the size that will be chosen for ALSTOM's large-scale $\mathrm{O}_{2}$ fired technology demonstration.

To illustrate the economy of scale, we can focus on the gas processing system (GPS) costs. Table 4.31 shows cost results for five gas processing systems of similar design but with a wide range of capacities. Capacities for these plants range from a low of about 1,750 tonne $\mathrm{CO}_{2}$ / day (1,900 tons $\mathrm{CO}_{2}$ / day) (used in this study) up to a high of almost 11,000 tonne $\mathrm{CO}_{2} /$ day $\left(12,000\right.$ tons $\mathrm{CO}_{2} /$ day) - over a 6:1 capacity range. The EPC costs were all escalated to July 2005 US\$ and plotted as a function of capacity in Figure 4.31 . 
Table 4.31: Comparison of Gas Processing System Costs

\begin{tabular}{|c|c|c|c|c|c|c|}
\hline Study Description & & Present Study & GHG Phase-I & OCDO & Transalta & IEA \\
\hline \multicolumn{2}{|l|}{ Reference } & This Study & \begin{tabular}{|c|} 
Marion, et al., \\
2003 \\
\end{tabular} & $\begin{array}{l}\text { Bozzuto, et } \\
\text { al., } 2001^{(1)}\end{array}$ & $\begin{array}{c}\text { Palkes, et } \\
\text { al., } 1999\end{array}$ & $\begin{array}{c}\text { IEA, Report } \\
2005 / 9\end{array}$ \\
\hline \multicolumn{2}{|l|}{ Cost Date } & Jul-05 & Jul-02 & Jun-01 & Jun-99 & Jul-05 \\
\hline & Units & & & & & \\
\hline Plant Net Output & $\mathrm{MWe}$ & 62.4 & 134.5 & 273.3 & 197.5 & 532 \\
\hline \multirow[t]{2}{*}{$\mathrm{CO}_{2}$ Production } & Tons/day & 1938 & 4229 & 9555 & 6876 & 11690 \\
\hline & Tonne/day & 1758 & 3837 & 8668 & 6238 & 10605 \\
\hline EPC Cost & MM-\$ & 48.2 & 57.1 & 97.58 & 51.6 & 102 \\
\hline Escalation & Years & 0.0 & 3.0 & 4.1 & 6.1 & 0.0 \\
\hline EPC Cost (7/05 USD) & MM-\$ & 48.2 & 69.3 & 125.3 & 73.0 & 102.0 \\
\hline \multirow[t]{3}{*}{ Specific Cost } & $\$ / \mathrm{kWe}$ & 772 & 515 & 458 & 370 & 192 \\
\hline & \$/Ton/Day & 24,858 & 16,379 & 13,110 & 10,624 & 8,725 \\
\hline & \$/Tonne/day & 27,401 & 18,054 & 14,451 & 11,711 & 9,618 \\
\hline
\end{tabular}

(1) Note: Specific Costs reduced for this case to account for GPS location 1/4th mile from boiler and other extra items

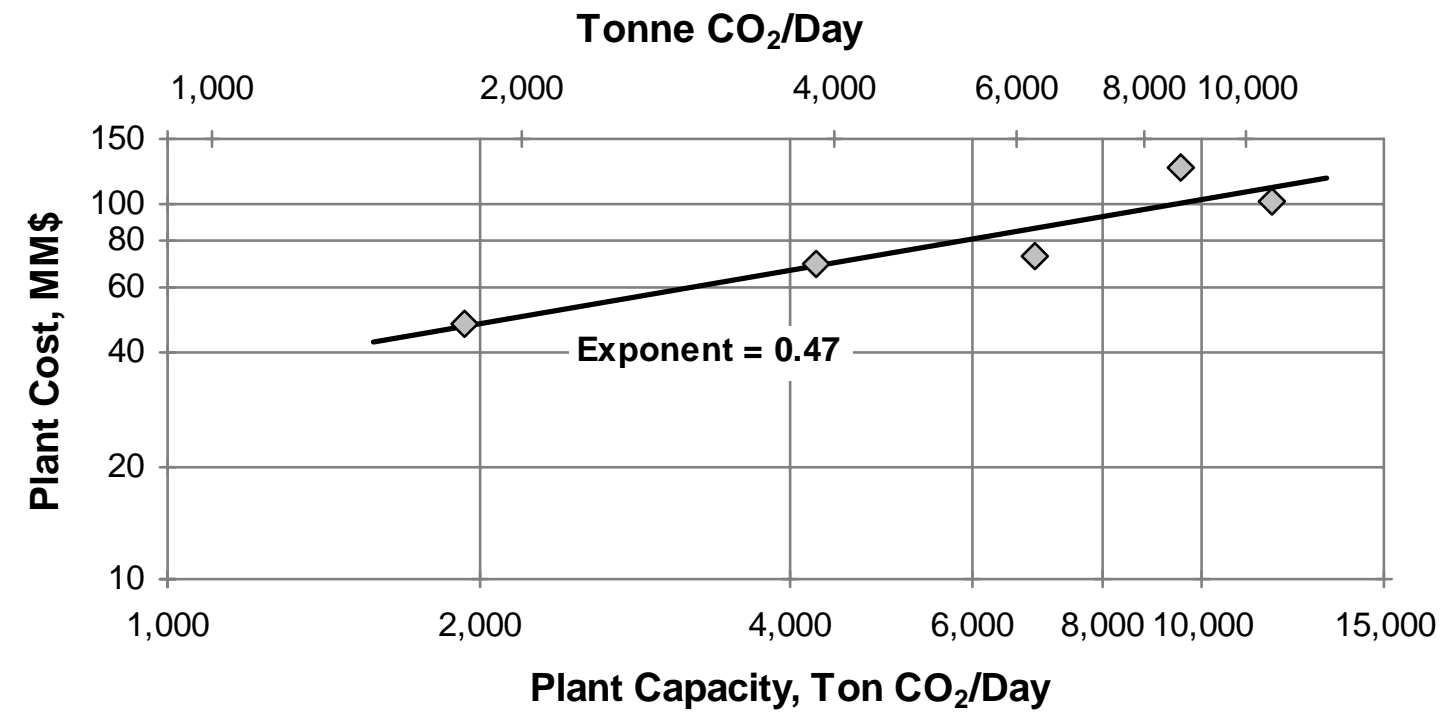

Figure 4.31: Gas Processing System Specific Cost Comparison

As shown above, the specific costs show a fairly wide range from about 10,000 to 27,000 $\$ /\left(\right.$ tonne/day) of $\mathrm{CO}_{2}\left(9,000\right.$ to $25,000 \$ /\left(\right.$ ton/day) of $\left.\mathrm{CO}_{2}\right)$. Although this is a wide range, when the total costs are plotted as a function of plant capacity a fairly good curve fit is obtained using a scaling exponent of 0.47. This exponent value indicates a strong economy of scale impact for capacity changes.

For perspective with other boiler island costs, Table 4.31 also shows the GPS costs as $\$ / \mathrm{kWe}$. These range from $775 \$ / \mathrm{kWe}$ for the small plant in the present study down to $192 \$ / \mathrm{kWe}$ for a large supercritical unit in the IEA study. 
This economy of scale effect is also quite evident with operating and maintenance costs where staffing levels and other O\&M cost items are typically not linearly related to plant capacity. Other plant retrofit costs (i.e., ASU and boiler modifications) also exhibit this same type of an effect.

\subsection{Economic Analysis}

This section shows the results of an economic evaluation that compares the retrofit $\mathrm{CO}_{2}$ capture concept (Case-2) with the Base Case study unit without $\mathrm{CO}_{2}$ capture (Case-1). The basic purpose of the economic evaluation is to quantify the economic impacts of retrofitting an existing CFB based power plant to $\mathrm{O}_{2}$ firing and $\mathrm{CO}_{2}$ capture. The economic evaluation results are presented as incremental Cost of Electricity (levelized basis). The incremental cost of electricity is incremental relative to the existing Base Case plant (air fired Case-1). $\mathrm{CO}_{2}$ mitigation cost ( $\$$ tonne of $\mathrm{CO}_{2}$ avoided) was also determined in this analysis for the $\mathrm{CO}_{2}$ capture case (Case-2) relative to Case-1. The comparisons shown in this section quantify the economic impact of retrofitting an existing $\mathrm{CFB}$ based power plant to $\mathrm{O}_{2}$ firing and $\mathrm{CO}_{2}$ capture.

The model used to perform the economic evaluations was the proprietary ALSTOM Power Plant Laboratories' Project Economic Evaluation Pro-Forma. This cash flow model, developed by the Company's Project \& Trade Finance group, has the capability to analyze the economic effects of different technologies based on differing efficiencies, investment costs, operating and maintenance costs, fuel costs, and cost of capital assumptions. Various categories of results are available from the model. In addition to cost of electricity, net present value, project internal rate of return, payback period, and other evaluation parameters are available.

\subsubsection{Economic Analysis Assumptions:}

Numerous financial assumptions were used in performing the economic evaluations. The primary assumptions are listed in Table 4.32. The assumptions used for the economic evaluations in this study are similar to what was used in two previous studies (Marion, et al., 2003 and Nsakala, Liljedahl, and Turek, 2004) and are summarized below. The shaded items in Table 4.32 represent parameters that were varied in the economic sensitivity study.

\section{Incremental Cost of Electricity Calculation:}

Levelized incremental cost of electricity (COE) was used as a criterion to compare the systems in this study. The levelized incremental cost of electricity result comprises five components: financial, fixed O\&M, variable $\mathrm{O} \& \mathrm{M}, \mathrm{CO}_{2}$ product credit, and fuel. The cash flow model used is structured to calculate the corresponding annual cash flows for each of these items over the evaluation life of the project. The annual expenses are distributed over the corresponding net annual electricity generated (kWh/year) in order to determine a unit cost (cents/kWh). These costs are subsequently levelized to get a corresponding value of each component over the plant life. In other words, each of the cash flow streams is converted to annuity payments corresponding to a constant value over the life of the study. 
Table 4.32: Economic Evaluation Study Assumptions

\begin{tabular}{|c|c|}
\hline \multirow{2}{*}{\multicolumn{2}{|c|}{ POWER GENERATION }} \\
\hline & \\
\hline Net output (MW) & Case Sensitive \\
\hline Capacity factor (\%) & $80 \%$ \\
\hline Availability factor (\%) & $100 \%$ \\
\hline Net plant heat rate, HHV basis & Case Sensitive \\
\hline Degradation factor (\%) & $0.00 \%$ \\
\hline \multicolumn{2}{|l|}{ TIME FRAME } \\
\hline Construction period (months) & 24 \\
\hline Depreciation Term (years) & 30 \\
\hline Analysis Horizon (years) & 30 \\
\hline \multicolumn{2}{|l|}{ PROJECT COSTS } \\
\hline EPC Price $(\$ 1000$ s) & Case Sensitive \\
\hline Fixed O\&M costs (\$ per kW) & Case Sensitive \\
\hline Variable O\&M costs (cents per kWh) & Case Sensitive \\
\hline Owner's EPC Contingency & $0.00 \%$ \\
\hline Initial spares and consumables & $1.00 \%$ \\
\hline Insurance & \\
\hline Insurance during Construction & $1.00 \%$ \\
\hline Insurance during first year of operation & $0.50 \%$ \\
\hline Development Costs & \\
\hline Development Costs \& Fees & $4.00 \%$ \\
\hline Reimburseable Dev't Costs & $3.00 \%$ \\
\hline Advisory Fees & $3.00 \%$ \\
\hline Financial and Legal Fees & $3.00 \%$ \\
\hline Start-up Fuel & $0.00 \%$ \\
\hline Fuel Stock Pile & $0.00 \%$ \\
\hline Other Costs & $0.50 \%$ \\
\hline Total Initial Project Costs (\% of EPC) & $16.00 \%$ \\
\hline \multicolumn{2}{|l|}{ FUEL COST } \\
\hline Coal Price (\$ per MMBtu) & 1.25 \\
\hline (\$ per GJ) & 1.19 \\
\hline Natural Gas Price (\$ per MMBtu) & 4.00 \\
\hline (\$ per GJ) & 3.79 \\
\hline \multicolumn{2}{|l|}{ PROJECT CREDITS } \\
\hline $\mathrm{CO}_{2}$ Sell Price (\$/ton) & 15.00 \\
\hline (\$ per Tonne) & 14.22 \\
\hline $\mathrm{N}_{2}$ Sell Price (\$/ton) & 0.00 \\
\hline (\$ per Tonne) & 0.00 \\
\hline \multicolumn{2}{|l|}{ ESCALATION FACTORS } \\
\hline Coal Price & $0.00 \%$ \\
\hline Variable O\&M & $0.00 \%$ \\
\hline Fixed O\&M (including payroll) & $0.00 \%$ \\
\hline Consumer Price Index & $0.00 \%$ \\
\hline
\end{tabular}

\begin{tabular}{|c|c|}
\hline FINANCING ASSUMPTIONS & \multirow[b]{2}{*}{$50.00 \%$} \\
\hline Equity & \\
\hline Debt & $50.00 \%$ \\
\hline \multicolumn{2}{|l|}{ DEBT PORTFOLIO } \\
\hline \multicolumn{2}{|l|}{ Interest Rates (Financed) ${ }^{1}$} \\
\hline \multicolumn{2}{|l|}{ During Construction } \\
\hline Base Rate & $1.32 \%$ \\
\hline Swap/Reinvestment cushion & $1.28 \%$ \\
\hline Fixed Rate Margin & $3.00 \%$ \\
\hline All-In Fixed Rate & $5.60 \%$ \\
\hline \multicolumn{2}{|l|}{ During Operation } \\
\hline Base Rate & $1.32 \%$ \\
\hline Swap/Reinvestment cushion & $1.28 \%$ \\
\hline Fixed Rate Margin & $2.50 \%$ \\
\hline All-In Fixed Rate & $5.10 \%$ \\
\hline Up-front Fee (Financed) & $2.00 \%$ \\
\hline Commitment Fee & $1.00 \%$ \\
\hline Grace Period (months) & 0 \\
\hline Loan Tenor (years after construction) & 30 \\
\hline \multicolumn{2}{|l|}{ TAXES } \\
\hline Corporate Tax & $20.00 \%$ \\
\hline Tax holiday (years after commissioning) & $0.00 \%$ \\
\hline Customs Duty & $0.00 \%$ \\
\hline Customs Clearance Fee & $0.00 \%$ \\
\hline \multicolumn{2}{|l|}{ COST OF CAPITAL ASSUMPTIONS } \\
\hline Discount Factor & $10.00 \%$ \\
\hline \multicolumn{2}{|l|}{ PROGRESS PAYMENT SCHEDULES } \\
\hline Month & \\
\hline 1 & $10 \%$ \\
\hline 6 & $15 \%$ \\
\hline 12 & $25 \%$ \\
\hline 18 & $25 \%$ \\
\hline 24 & $25 \%$ \\
\hline Total & $100 \%$ \\
\hline
\end{tabular}

${ }^{1}$ Wall Street Journal, 4/23/03, London Interbank Offered Rate (LIBOR) Swap Curve

The financial component of the COE represents the costs which are associated with payment of the engineered, procured and constructed (EPC) retrofit price, all associated owner's costs, customs and financing fees, and interest accrued both during construction and during operation. The fixed O\&M component represents the operating and maintenance costs that occur regardless of whether the unit is in operation or not. The variable $\mathbf{O} \& \mathbf{M}$ component represents the incremental operating and maintenance costs that occur only when the unit is in operation. The $\mathbf{C O}_{2}$ product credit represents revenues obtained for the sale of the $\mathrm{CO}_{2}$ product for an EOR application as was assumed for this study. The fuel cost component represents the cost of the fuel, which is consumed during operation of the plant. 


\subsubsection{Economic Analysis Results Summary}

The case studies are compared using two evaluation criteria, (1) the levelized incremental cost of electricity compared to the reference plant without $\mathrm{CO}_{2}$ capture, and (2) the mitigated costs of avoided $\mathrm{CO}_{2}$, also with respect to Case-1.

The incremental COE is defined as:

$$
\text { Incremental } \mathrm{COE}=\left(\mathrm{COE}_{\mathrm{CP}}-\mathrm{COE}_{\mathrm{Ref}}\right)
$$

Where:

$$
\begin{aligned}
& \text { COE } \equiv \text { levelized Cost of Electricity (cents / kWh), } \\
& \text { CP } \equiv \text { Capture Plant, and } \\
& \text { Ref } \equiv \text { Reference Plant. }
\end{aligned}
$$

The mitigation cost is defined as:

$$
\begin{aligned}
& \text { Mitigation Cost }=\left(\mathrm{COE}_{\mathrm{CP}}-\mathrm{COE}_{\mathrm{Ref}}\right) /\left(\mathrm{CO}_{2-\mathrm{Ref}}-\mathrm{CO}_{2-\mathrm{CP}}\right) \\
& \text { Where: } \\
& \text { Mitigation Cost } \equiv \$ / \text { tonne or } \$ / \text { ton of } \mathrm{CO}_{2} \text { Avoided, } \\
& \mathbf{C O E} \equiv \text { levelized Cost of Electricity }(\$ / \mathbf{k W h}), \\
& \mathbf{C O} \equiv \text { Carbon dioxide emitted (tonne } / \mathbf{k W h} \text { or ton } / \mathbf{k W h}), \\
& \mathrm{CP} \equiv \text { Capture Plant, and } \\
& \text { Ref } \equiv \text { Reference Plant. }
\end{aligned}
$$

The levelized COE is summarized in Figure 4.32. The total cost of electricity for the airfired Case- 1 is 2.16 cents $/ \mathrm{kWh}$, excluding a capital investment charge for the existing plant. The incremental costs for the retrofitted system with $\mathrm{O}_{2}$ firing and $\mathrm{CO}_{2}$ capture (Case-2) are shown as the dark bars in Figure 4.32. The incremental cost of electricity for Case- 2 is about 3.12 cents $/ \mathrm{kWh}$. This incremental cost can be expressed as a $\mathrm{CO}_{2}$ mitigation cost of about $38.8 \$$ tonne $(35.3 \$ /$ ton $)$ of $\mathrm{CO}_{2}$ avoided, compared to Case-1. 


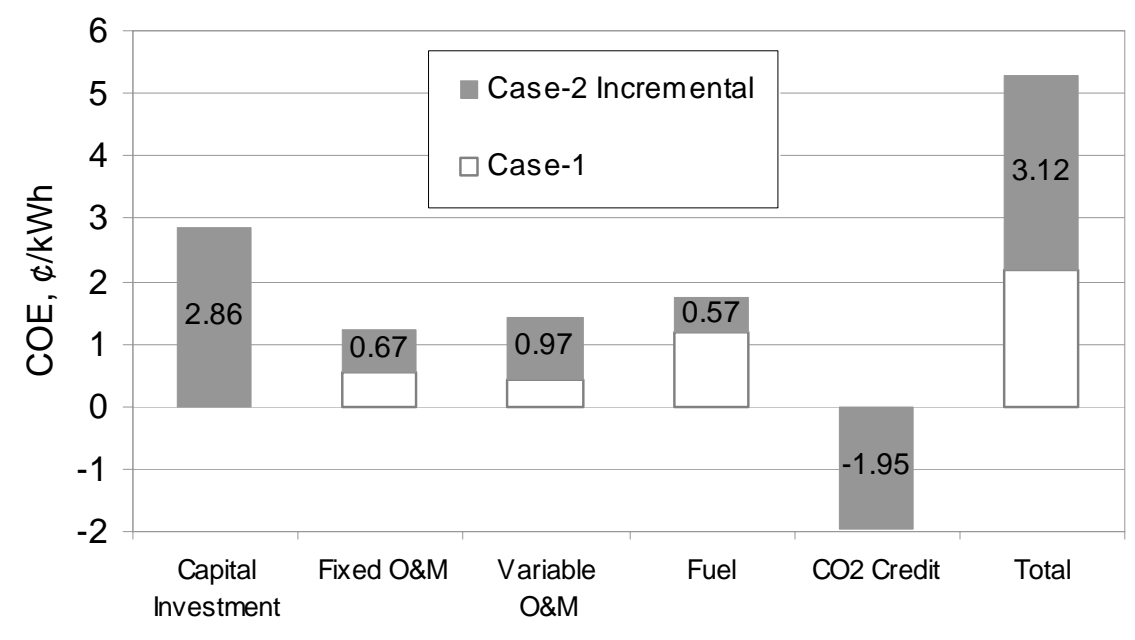

Figure 4.32: Incremental Cost of Electricity for Case-2

\subsubsection{Economic Analysis Sensitivity Study Results:}

An economic sensitivity analyses was also conducted for Case-2 to determine the effect on levelized COE of variations of selected base parameter values by \pm 25 percent and $\mathrm{CO}_{2}$ by-product selling price up to $\$ 27.6$ per tonne ( $\$ 25$ per ton). These parameters are listed in Table 4.33: EPC plant price, coal price, capacity factor, equity rate, corporate tax rate, the discount rate for cost of capital, and $\mathrm{CO}_{2}$ credit sell price.

\section{Table 4.33: Economic Sensitivity Study Parameters and Parameter Values}

\begin{tabular}{|l|c|c|c|c|}
\hline Parameter & Units & Base Value & Minimum & Maximum \\
\hline Investment Cost & $\$$ & as estimated & Base - 25\% & Base + 25\% \\
Coal Cost & $\$ /$ MM-Btu & 1.25 & 0.94 & 1.56 \\
& $\$ / G J$ & 1.19 & 0.89 & 1.49 \\
Capacity Factor & $\%$ & 80 & 60 & 100 \\
Equity & $\%$ & 50 & 37.50 & 62.50 \\
Corporate Tax & $\%$ & 20 & 15.00 & 25.00 \\
Discount Rate & $\%$ & 10 & 7.50 & 12.50 \\
$\mathrm{CO}_{2}$ Byproduct Sell Price & $\$ /$ Ton & 15 & 0 & 25 \\
& \$/Tonne & 16.5 & 0 & 27.6 \\
\hline
\end{tabular}

Results for the Case-2 COE sensitivity study are shown in Table 4.34. The largest change is from varying the credit for $\mathrm{CO}_{2}$ product: incremental $\mathrm{COE}$ ranges from 1.82 to 5.06 cents/kWh; $\mathrm{CO}_{2}$ mitigation cost ranges from 22.6 - 63.1 \$/tonne (20.6 - 57.4 \$/ton).

Capacity Factor and then EPC investment cost had the next largest impacts on the COE for the ranges studied.

The variations in the incremental cost of electricity are also shown as "spider plots" in Figure 4.33 . 
COMMERCIALIZATION DEVELOPMENT OF OXYGEN FIRED CFB

FOR GREENHOUSE GAS CONTROL
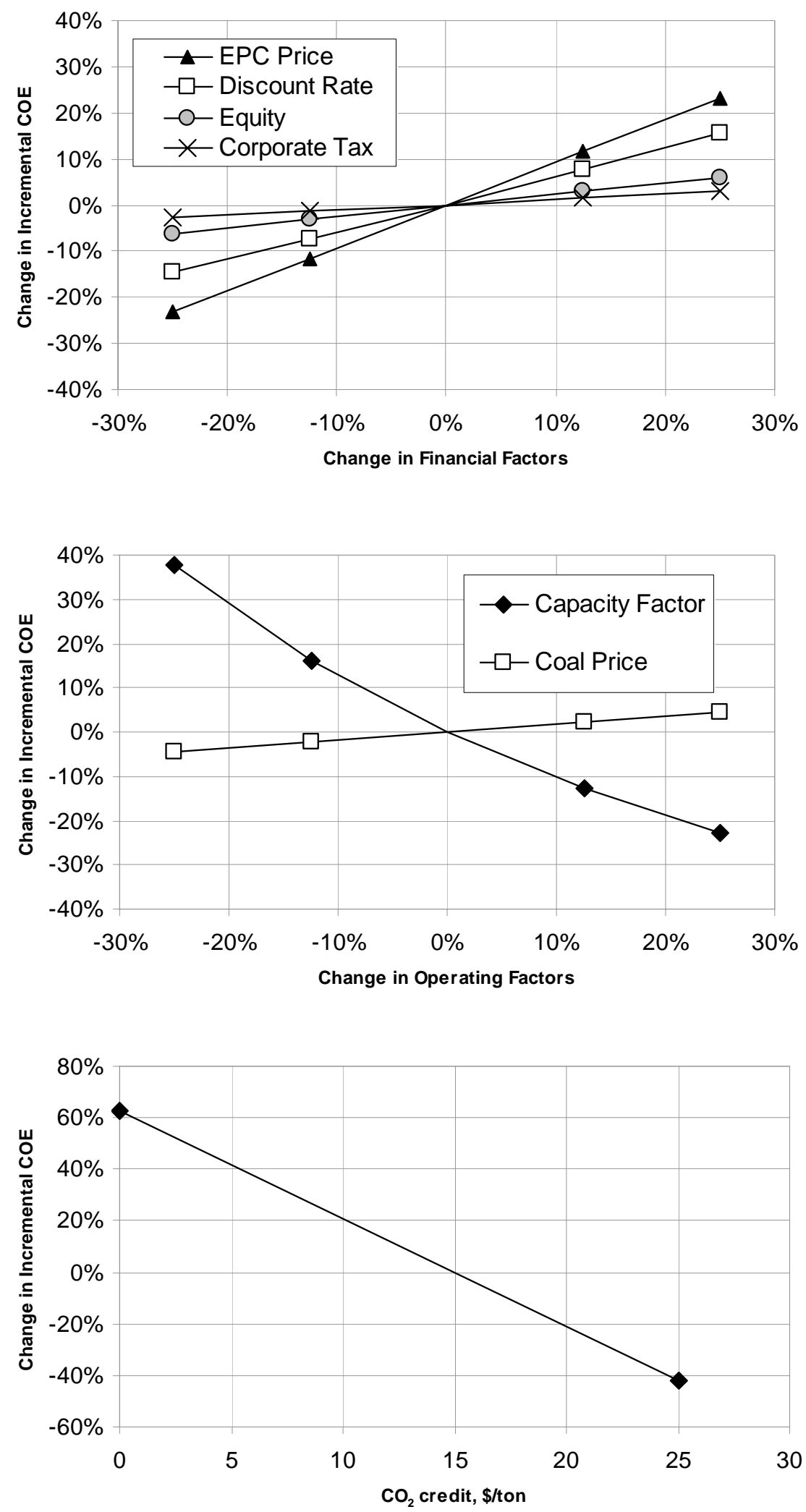

Figure 4.33: Economic Sensitivity Analysis Results for Case 2 


\section{Table 4.34: Economic Sensitivity Analysis Results for Case 2 - Oxygen-Fired CFB with ASU and $\mathrm{CO}_{2}$ Capture}

\begin{tabular}{|c|c|c|c|c|c|c|c|c|c|c|c|c|c|}
\hline \multirow[b]{2}{*}{$\begin{array}{l}\text { GENERATION } \\
\text { Reference Year }\end{array}$} & \multirow{2}{*}{$\begin{array}{r}\text { BASE } \\
2005\end{array}$} & \multicolumn{4}{|c|}{ vary capacity factor } & \multicolumn{4}{|c|}{ vary EPC price } & \multicolumn{4}{|c|}{ vary fuel price } \\
\hline & & 2005 & 2005 & 2005 & 2005 & 2005 & 2005 & 2005 & & 2005 & & & \\
\hline Net output (MW) & 62.1 & 62.1 & $\begin{array}{l}2005 \\
62.1\end{array}$ & 62.1 & 62.1 & $\begin{array}{l}2005 \\
62.1\end{array}$ & 62.1 & 2005 & 2005 & 2005 & 2005 & 2005 & 2005 \\
\hline Availability factor (\%) & 100 & 100 & 100 & 100 & 100 & 100 & 100 & 100 & 100 & 100 & 100 & 100 & 100 \\
\hline Capacity factor (\%) & 80 & 60 & 70 & 90 & 100 & 80 & 80 & 80 & 80 & 80 & 80 & 80 & 80 \\
\hline Actual operating hours per year & 7,008 & 5,256 & 6,132 & 7,884 & 8,760 & 7,008 & 7,008 & 7,008 & 7,008 & 7,008 & 7,008 & 7,008 & 7,008 \\
\hline Net efficiency, HHV (\%) & 24.6 & 24.6 & 24.6 & 24.6 & 24.6 & 24.6 & 24.6 & 24.6 & 24.6 & 24.6 & 24.6 & 24.6 & 24.6 \\
\hline Net plant heat rate, HHV (Btu/ kWh) & 13,861 & 13,861 & 13,861 & 13,861 & 13,861 & 13,861 & 13,861 & 13,861 & 13,861 & 13,861 & 13,861 & 13,861 & 13,861 \\
\hline (kJ/ kWh) & 14,620 & 14,620 & 14,620 & 14,620 & 14,620 & 14,620 & 14,620 & 14,620 & 14,620 & 14,620 & 14,620 & 14,620 & 14,620 \\
\hline Net generation $(\mathrm{MWh} / \mathrm{yr})$ & 435,508 & 326,631 & 381,070 & 489,947 & 544,385 & 435,508 & 435,508 & 435,508 & 435,508 & 435,508 & 435,508 & 435,508 & 435,508 \\
\hline \multicolumn{14}{|l|}{ cosTs * } \\
\hline EPC Price $(\$ / k W)$ & 1,545 & 1,545 & 1,545 & 1,545 & 1,545 & 1,159 & 1,352 & 1,738 & 1,931 & 1,545 & 1,545 & 1,545 & 1,545 \\
\hline EPC Price ( $\$ 1000 \mathrm{~s})$ & 96,024 & 96,024 & 96,024 & 96,024 & 96,024 & 72,018 & 84,021 & 108,027 & 120,030 & 96,024 & 96,024 & 96,024 & 96,024 \\
\hline Construction period (months) & 24 & 24 & 24 & 24 & 24 & 24 & 24 & 24 & 24 & 24 & 24 & 24 & 24 \\
\hline Insurance (\% EPC) & 1.0 & 1.0 & 1.0 & 1.0 & 1.0 & 1.0 & 1.0 & 1.0 & 1.0 & 1.0 & 1.0 & 1.0 & 1.0 \\
\hline Initial spares and consumables (\% EPC) & \multirow{2}{*}{\multicolumn{13}{|c|}{$\begin{array}{l}1.0 \\
\text { included in EPC }\end{array}$}} \\
\hline Infrastructure costs & & & & & & & & & & & & & \\
\hline Fixed O\&M costs $(\$ 1000 / y r)$ & 5,330 & 5,330 & 5,330 & 5,330 & 5,330 & 5,330 & 5,330 & 5,330 & 5,330 & 5,330 & 5,330 & 5,330 & 5,330 \\
\hline Fixed O\&M costs $(\$ / \mathrm{kW})$ & 85.77 & 85.77 & 85.77 & 85.77 & 85.77 & 85.77 & 85.77 & 85.77 & 85.77 & 85.77 & 85.77 & 85.77 & 85.77 \\
\hline Variable O\&M costs $(\$ 1000 / y r)$ & 2,374 & 1,781 & 2,078 & 2,671 & 2,968 & 2,374 & 2,374 & 2,374 & 2,374 & 2,374 & 2,374 & 2,374 & 2,374 \\
\hline Variable O\&M costs ( $\Phi / \mathrm{kWh})$ & 1.40 & 1.40 & 1.40 & 1.40 & 1.40 & 1.40 & 1.40 & 1.40 & 1.40 & 1.40 & 1.40 & 1.40 & 1.40 \\
\hline Total O\&M costs ( $\$ /$ kWh) & 2.63 & 3.04 & 2.80 & 2.49 & 2.38 & 2.63 & 2.63 & 2.63 & 2.63 & 2.63 & 2.63 & 2.63 & 2.63 \\
\hline $\mathrm{CO}_{2}$ Credit (\$/kWh) & 1.95 & 1.95 & 1.95 & 1.95 & 1.95 & 1.95 & 1.95 & 1.95 & 1.95 & 1.95 & 1.95 & 1.95 & 1.95 \\
\hline \multicolumn{14}{|l|}{ FUEL COST } \\
\hline Coal Price (\$/MMBtu) & 1.25 & 1.25 & 1.25 & 1.25 & 1.25 & 1.25 & 1.25 & 1.25 & 1.25 & 0.94 & 1.09 & 1.41 & 1.56 \\
\hline$(\$ / \mathrm{kJ})$ & 1.19 & 1.19 & 1.19 & 1.19 & 1.19 & 1.19 & 1.19 & 1.19 & 1.19 & 0.89 & 1.04 & 1.33 & 1.48 \\
\hline \multicolumn{14}{|l|}{ FINANCING ASSUMPTIONS } \\
\hline Equity (\%) & 50.0 & 50.0 & 50.0 & 50.0 & 50.0 & 50.0 & 50.0 & 50.0 & 50.0 & 50.0 & 50.0 & 50.0 & 50.0 \\
\hline Corporate Tax (\%) & 20.0 & 20.0 & 20.0 & 20.0 & 20.0 & 20.0 & 20.0 & 20.0 & 20.0 & 20.0 & 20.0 & 20.0 & 20.0 \\
\hline Discount Factor (\%) & 10.0 & 10.0 & 10.0 & 10.0 & 10.0 & 10.0 & 10.0 & 10.0 & 10.0 & 10.0 & 10.0 & 10.0 & 10.0 \\
\hline \multicolumn{14}{|l|}{ Incremental Levelized COE (\$/kWh) ** } \\
\hline Financial Component & 2.86 & 3.82 & 3.27 & 2.55 & 2.29 & 2.15 & 2.51 & 3.22 & 3.58 & 2.86 & 2.86 & 2.86 & 2.86 \\
\hline Fixed O\&M & 0.67 & 0.89 & 0.76 & 0.59 & 0.53 & 0.67 & 0.67 & 0.67 & 0.67 & 0.67 & 0.67 & 0.67 & 0.67 \\
\hline Variable O\&M & 0.97 & 0.97 & 0.97 & 0.97 & 0.97 & 0.97 & 0.97 & 0.97 & 0.97 & 0.97 & 0.97 & 0.97 & 0.97 \\
\hline CO2 Credit & -1.95 & -1.95 & -1.95 & -1.95 & -1.95 & -1.95 & -1.95 & -1.95 & -1.95 & -1.95 & -1.95 & -1.95 & -1.95 \\
\hline Fuel & $\underline{0.57}$ & $\underline{0.57}$ & 0.57 & $\underline{0.57}$ & 0.57 & 0.57 & 0.57 & 0.57 & 0.57 & 0.42 & $\underline{0.50}$ & 0.64 & 0.71 \\
\hline Total & $\overline{3.12}$ & $\overline{4.29}$ & $\overline{3.62}$ & $\overline{2.72}$ & $\overline{2.41}$ & $\overline{2.40}$ & 2.76 & 3.47 & $\overline{3.83}$ & $\overline{2.97}$ & $\overline{3.04}$ & $\overline{3.19}$ & 3.26 \\
\hline $\mathrm{CO}_{2}$ Mitigation Cost $(\$$ & 35.3 & 48.6 & 41.0 & 30.9 & 27.3 & 27.2 & 31.2 & 39.4 & 43.4 & 33.7 & 34.5 & 36.1 & 36.9 \\
\hline (\$/tonne) & 38.8 & 53.5 & 45.1 & 33.9 & 30.0 & 29.9 & 34.4 & 43.3 & 47.8 & 37.1 & 38.0 & 39.7 & 40.6 \\
\hline
\end{tabular}


Table 4.34: Economic Sensitivity Analysis Results for Case 2 - Oxygen-Fired CFB with ASU and CO2 Capture (Continued)

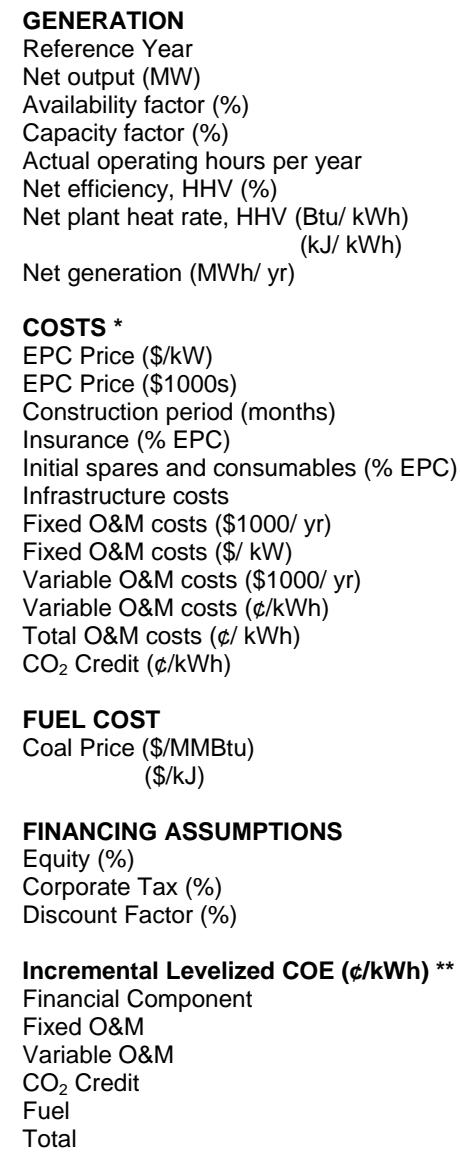

* Total costs for Case-2

** Incremental costs above Case-1 values

${ }^{* * *}$ Base case $=\$ 15 /$ ton $\mathrm{CO}_{2}$; variations to 0 and $25 \$ /$ ton 


\section{SUMMARY AND RECOMMENDATIONS}

\section{Summary of Pilot Testing Results}

Pilot-scale testing of the oxygen-fired CFB concept was performed at ALSTOM's 3.0 $\mathrm{MW}_{\text {th }}(9.9 \mathrm{MMBtu} / \mathrm{hr}$ ) Multi-use Test Facility (MTF), located in Windsor, Connecticut. Key results from the testing are summarized below.

- The furnace was successfully operated on bituminous coal and petcoke in a $30 \%$ $\mathrm{O}_{2}$ combustion medium (balance $\mathrm{CO}_{2}$ ). There was no evidence of particle agglomeration or defluidization in the furnace.

- Because of the high $\mathrm{CO}_{2}$ content of the flue gas, the furnace operated above 890 ${ }^{\circ} \mathrm{C}\left(1,650^{\circ} \mathrm{F}\right)$ to ensure calcination of the limestone for sulfur capture. In regions where the temperature was much cooler, there was evidence of recarbonation.

- The sulfur capture with lime only to the back-end baghouse/FDA system was slightly lower with oxygen firing compared to air firing. There is evidence of some $\mathrm{CO}_{2}$ being captured in the FDA, along with the $\mathrm{SO}_{2}$.

- Because of the high temperature, the sulfur emissions from the combustor were higher than normal for bituminous coal. For pet coke, the optimum temperature for sulfur capture is higher, so the oxygen-fired emissions were very low.

- Carbon monoxide emissions were higher with oxygen firing. This is likely due to the high $\mathrm{CO}_{2}$ content of the flue gas, which hinders oxidation of the $\mathrm{CO}$.

- As expected, the $\mathrm{NO}_{\mathrm{x}}$ emissions were low with oxygen firing. Ammonia addition further reduced the $\mathrm{NO}_{\mathrm{x}}$ emissions.

- The $\mathrm{N}_{2} \mathrm{O}$ and VOC emissions were low under all circumstances.

- Carbon heat loss in the fly ash was comparable to, or lower than, the levels with air firing. The carbon loss was lower for pet coke than for bituminous coal.

- There was no significant difference in heat transfer to the furnace waterwall test sections between air and oxygen firing. This heat transfer is dominated by solids effects, which do not depend on the gas composition.

- The emissions of mercury and other trace metals when oxy-firing were at least as low as with air firing.

- The Moving Bed Heat Exchanger performed as expected in terms of heat transfer. The performance did not deteriorate or change due to changes in firing conditions of the test campaign; load, fuel, limestone, or air vs. $\mathrm{O}_{2}$.

- The MBHE performance did not change with time due to fouling of the heat transfer surface, or experience loss of solids flow due to agglomeration

These results are largely as expected based upon earlier test results, and did not identify any major technical barriers to the oxygen-fired CFB concept. 


\section{Summary of Retrofit Design Study Results}

This section summarizes the technical and economic evaluation results for the two case studies provided in this report. The two cases studied include Case-1: an existing air fired CFB steam plant base case and Case-2: a retrofit of the existing air fired CFB steam plant with oxygen firing and $\mathrm{CO}_{2}$ capture. Further descriptions of the two study cases are presented below followed by a brief discussion of the major impacts of $\mathrm{O}_{2}$ firing and $\mathrm{CO}_{2}$ capture on the overall plant performance and economics.

Case-1: Existing CFB steam power plant without $\mathrm{CO}_{2}$ Capture (Base Case).

Conventional existing air-fired CFB based steam power plant ( $\sim 90 \mathrm{MWe}-n$ et) without $\mathrm{CO}_{2}$ capture using a steam cycle with the following conditions: $138 \mathrm{bara} / 538{ }^{\circ} \mathrm{C} / 538{ }^{\circ} \mathrm{C}$, $7.6 \mathrm{cmHg}\left(2,000 \mathrm{psia} / 1,000^{\circ} \mathrm{F} / 1,000^{\circ} \mathrm{F}, 3.0 \mathrm{in}\right.$. Hga $)$.

Implication: Provides reference point for comparison of performance \& economic analyses. Provides the existing plant to which the retrofit technology for $\mathrm{O}_{2}$ firing and $\mathrm{CO}_{2}$ capture are applied in Case-2.

Case-2: Retrofit of the Case- 1 existing power plant to an oxygen firing with $\mathrm{CO}_{2}$ capture, purification, compression and liquefaction.

Oxygen is provided from a cryogenic Air Separation Unit (ASU). The CFB Boiler Island provides a concentrated $\mathrm{CO}_{2}$ flue gas product stream to the Gas Processing System (GPS) where it is further purified, compressed and liquefied to meet a specification for an Enhanced Oil Recovery (EOR) application.

Implication: Near term $\mathrm{CO}_{2}$ capture concept. Cost savings for the Gas Processing System equipment as compared to commercially available amine scrubbing systems. Improved plant thermal efficiency and lower net plant output reduction as compared to amine based $\mathrm{CO}_{2}$ capture systems (reduced energy penalty).

\section{Impacts of $\mathrm{O}_{2}$ Firing and $\mathrm{CO}_{2}$ Capture:}

The retrofit of an existing $\mathrm{CFB}$ boiler steam plant to oxygen firing and $\mathrm{CO}_{2}$ capture has several significant impacts on the overall plant performance and economics for producing electricity.

With respect to plant performance, the net plant output is reduced by about 31 percent while the net plant thermal efficiency is reduced by about 12.0 percentage points. $\mathrm{CO}_{2}$ emissions are reduced from 0.88 to $0.08 \mathrm{~kg} / \mathrm{kWh}(1.94$ to $0.17 \mathrm{lbm} / \mathrm{kWh})$.

Retrofitting the existing CFB boiler to oxygen firing capability is relatively simple from a technical standpoint. The boiler requires a small amount of new equipment such as a new gas recirculation system, oxygen supply piping, $\mathrm{FDA} \mathrm{SO} 2$ removal system, $\mathrm{CO}_{2}$ product ductwork (to the gas processing system), and new controls and instrumentation for the oxygen supply and the gas recirculation, and gas processing systems.

These new systems require significant acreage for locating new equipment. The new cryogenic air separation unit requires about $3,600 \mathrm{~m}^{2}(0.9$ acres $)$ and the new gas processing system requires about $6,500 \mathrm{~m}^{2}$ (1.6 acres). By comparison, the area required for the existing $90 \mathrm{MWe}$ Boiler Island including the CFB boiler, fans, ducts, fuel and limestone silos, and baghouse is about 0.9 acres. Location of this new equipment on some existing sites can be difficult and may require long duct and piping runs between 
the new and existing equipment.

The cost of the boiler modification scope is about $167 \$ / \mathrm{kW}$, based on the new power output. Most of this is for the new FDA system for $\mathrm{SO}_{2}$ removal. The addition of commercially available cryogenic air separation and gas processing systems is technically straightforward, but costly. The complete plant retrofit is estimated to cost $1,545 \$ / \mathrm{kW}$. Ultimately, the cost of electricity (COE) is estimated to increase by 3.1 cents/kWh and $\mathrm{CO}_{2}$ mitigation cost is calculated to be about $38.8 \$ /$ tonne( $35.3 \$ /$ ton $)$ of $\mathrm{CO}_{2}$ avoided for this existing $90 \mathrm{MWe}$ study unit.

\section{$\underline{\text { Recommendations }}$}

Work on the evaluation of the oxygen fired CFB concept has resulted in a successful accomplishment of the following milestones:

- Concept screening in a bench-scale FBC facility

- Approximately 300 hours of concept validation in a $3.0 \mathrm{MW}_{\text {th }}(9.9 \mathrm{MMBtu} / \mathrm{hr})$ pilot-scale CFB

- Techno-economic analysis

Based on these results, ALSTOM feels that the appropriate next step is to begin the development of a commercial-scale demonstration project of the $\mathrm{O}_{2}$ fired CFB technology, targeting the EOR application. To prepare for a large-scale demonstration of the oxygen-fired CFB concept, ALSTOM is actively seeking partners for this next step. 


\section{BIBLIOGRAPHY}

Allen, G., "Coal Combustion in Advanced Burners for Minimal Emissions and Carbon Dioxide Reduction Technologies," European Commission Joule II Clean Coal Technology Program1992-1995, Volume II, Powder Coal Combustion Projects Final Reports, ISBN 92-9-828-006-7, 1997

Andersson, K. and Maksinen, P., "Process Evaluation of $\mathrm{O}_{2} / \mathrm{CO}_{2}$ Free Combustion in an $\mathrm{O}_{2} / \mathrm{CO}_{2}$ Power Plant," MSc Thesis, Chalmers University of Technology, Sweden, 2002

Bose, A. C., "Performance Simulation and Cost Assessment of Oxy-Combustion process for $\mathrm{CO}_{2}$ Capture from Coal-Fired Power Plants," Presented at the Fourth Annual Conference on Carbon Capture and Sequestration, Alexandria, VA, May 2-5, 2005

Bozzuto, C., Nsakala, N., Liljedahl, G., Palkes, M., Marion, J., Vogel, D., Gupta, J.C., Fugate, M., and Guha, M., "Engineering Feasibility of $\mathrm{CO}_{2}$ Capture on an Existing CoalFired Power Plant," Final Report for OCDO / DOE-NETL, under OCDO Contract No. CDO/D-98-8 and DOE Contract No. DE-FC26-99FT40576, Prepared by ALSTOM Power Inc., June 29, 2001

Chatel-Pelage, F., Marin, O., Perrin, N., Carty, R., Philo, G.R., Farzan, H., and Vecci, S.J., "A Pilot-Scale Demonstration of Oxy-Combustion with Flue Gas Recirculation in a Pulverized Coal-Fired Boiler," 28th International Technical Conference on Coal Utilization \& Fuel Systems, Clearwater FL, USA, 2003

Chatel-Pelage, F., Varagani, R., Pranda, P., Perrin, N., Farzan, H., Vecci, S.J., Lu, Y., Chen, S., Rostam-Abadi, M., and Bose, A.C., "NO ${ }_{x}$ Control or CO2 Capture in CoalFired Power Plants: Why Using Oxygen?," 2004 AFRC-JFRC Joint International Combustion Symposium, Maui, USA, 2004

Charon, O., "Recent Developments and Future Trends in Oxy-Combustion Applications," 17th IFRF Topic Oriented Technical Meetings, Les Vaux de Cernay, France, 2000

Croiset, E. and Thambimuthu, K.V., "Coal Combustion with Flue Gas Recirculation for $\mathrm{CO}_{2}$ Recovery," Proceedings of the $4^{\text {th }}$ Greenhouse Gas Control Technologies,"

Eliasson, B., Riemer, P. and Wokaun, A., (ed.), pp. 581-586, 1999

Croiset, E., Thambimuthu, K.V., and Palmer, A., "Coal Combustion in $\mathrm{O}_{2} / \mathrm{CO}_{2}$ Mixture Compared with Air," The Canadian Journal of Chemical Engineering, Vol. 78, pp. 402 407, 2000

Dillon, D.J., White, V., Allam, R.J., Wall, R.A., and Gibbins, J., “Oxy Combustion Process for $\mathrm{CO}_{2}$ Capture from Power Plant," IEA GHG R\&D Programme Report № . 2005/9, June 2005

Dakota Gasification Company, "Carbon Dioxide Specifications," April 2005, http://www.dakotagas.com/specs/co2spec.pdf

Field, M.A., Gill, D.W., Morgan, B.B., and Hawksley, P.G.W., "Combustion of Pulverised Coal," BCURA, Leatherhead, England, 1967

Hottel, H. C. and Sarofim, A. F., "Radiative Transfer," McGraw Hill Book Company, New York, 1967 
International Energy Agency, "Improvement in Power Generation with Post-Combustion Capture of $\mathrm{CO}_{2}$," Report Number PH4/33, November 2004

International Energy Agency, "Oxy Combustion Processes for $\mathrm{CO}_{2}$ Capture from Power Plants," Report Number 2005/9, July 2005

Jukkola, G., Turek, D., Levasseur, A., Teigen, B., and Thibeault, P., "Development of ALSTOM's Circulating Moving Bed Combustor," $17^{\text {th }}$ International Conference on Fluidized Bed Combustion, Jacksonville, Florida, May 2003

Kakaras, E., Doukelis, A., Giannakopoulos, D., and Koumanakos, A., " $\mathrm{CO}_{2}$ Sequestration Options for Coal-Fired Power Plants," 14th IFRF Members Conference, Noordwijkerhout, The Netherlands, 2004

Kiga, T., Takano, S., Kimura, N. Omata, K., Okawa, M., Mori, T., and Kato, M., "Characteristics of Pulverized-Coal Combustion in the System of Oxygen/Recycled Flue Gas Combustion," Energy Conversion and Management, Vol. 38, pp. S129-S134, 1997

Kimura, N., Omata, K., Kiga, T., Takano, S., and Shikisima, S., "The Characteristics of Pulverized Coal Combustion in $\mathrm{O}_{2} / \mathrm{CO}_{2}$ Recovery," Energy Conversion and Management, Vol. 36, pp. 805-808, 1995

Marin, O., Bugeat, B., Macadam, S., and Charon, O., "Oxygen Enrichment in Boilers," 2001 AFRC-JFRC-IEA Joint International Combustion Symposium, Kauai, USA, 2001

Marion, J., Bozzuto, C., Nsakala, N., and Liljedahl, G., "Evaluation Of Advanced Coal Combustion \& Gasification Power Plants With Greenhouse Gas Emission Control," Topical Phase-I DOE-NETL Report, under Co-operative Agreement No. DE-FC2601NT41146 Prepared by ALSTOM Power Inc., May 15, 2003

McPhail, J. et al., "Pulverized Coal Combustion System for $\mathrm{CO}_{2}$ Capture," European Commission Joule II Clean Coal Technology Program 1992-1995, Volume II: Powder Coal Combustion Projects Final Reports, ISBN 92-9-828-006-7, 1977

Nsakala, N., Liljedahl, G., and Turek, D., "Greenhouse Gas Emission Control by Oxygen Firing in Circulating Fluidized Bed Boilers: Phase II - Pilot Scale Testing and Updated Performance and Economics for Oxygen Fired CFB with $\mathrm{CO}_{2}$ Capture," Final DOE-NETL Report, under Co-operative Agreement No. DE-FC26-01NT41146 Prepared by ALSTOM Power Inc., October 27, 2004

Nsakala, N.Y., Marion, J., Bozzuto, C., Liljedahl, G., Palkes, M., Vogel, D., Gupta, J.C., Guha, M., Johnson, H., and Plasynski, S., "Engineering Feasibility of $\mathrm{CO}_{2}$ Capture on an Existing US Coal-Fired Power Plant," First National Conference on Carbon Sequestration, Washington, DC, 2001

Okawa, M., Kimura, N., Kiga, T., Takano, S., Arai, K., and Kato, M., "Trial Design for a $\mathrm{CO}_{2}$ Recovery Power Plant by Burning Pulverized Coal in $\mathrm{O}_{2} / \mathrm{CO}_{2}$," Energy Conversion and Management, Vol. 38, pp. S123-S127, 1997

Palkes, M., Liljedahl, G., Nsakala, N., McDonald, M., and Gupta, J.C., "Preliminary Design of a $\mathrm{CO}_{2} / \mathrm{O}_{2}$ Combustion Retrofit To an Existing Coal-Fired Boiler for $\mathrm{CO}_{2}$ Extraction," Presented at Electric Power Gen '99 Conference, Baltimore, MD, April 2022, 1999 
Payne, R., Chen, S.L., Wolsky, A.M., and Richter, W.F., " $\mathrm{CO}_{2}$ Recovery via Coal Combustion in Mixtures of Oxygen and Recycled Flue Gas," Vol. 67, pp. 1-16, 1989

Roberts, P.A., “Atmospheric Pulverized Coal Combustion Final Report,” European Commission Joule II Clean Coal Technology Program 1992-1995, Volume II: Powder Coal Combustion Projects Final Reports, ISBN: 92-9-828-006-7, 1997

Simbeck, D.R., " $\mathrm{CO}_{2}$ Mitigation Economics for Existing Coal-Fired Power Plants," First National Conference on Carbon Sequestration, Washington DC, 2001

Singh, D., Croiset, E., Douglas, P.L., and Douglas, M.A., "Techno-Economic study of $\mathrm{CO}_{2}$ Capture from an Existing Coal-Fired Power Plant: MEA Scrubbing vs. $\mathrm{O}_{2} / \mathrm{CO}_{2}$ Recycle Combustion,” Energy Conversion \& Management, Vol. 44, pp. 3073-3091, 2003

Tan, R., Corraglo, G., Santos, S., and Spliethoff, H., "Oxy-Coal Combustion with Flue Gas Recycle for Power Generation Industry: A Literature Review," Study Report, IFRF Doc. No. G23/y/1, Velsen Noord, September 2005

Tan, Y. and Thambimuthu, K., “Oxy-Fuel Combustion for Near Zero Emission Fossil Fuel Power Plants," 14th IFRF Members Conference, Noordwijkerhout, The Netherlands, 2004

Thambimuthu, K. and Freund, P., " $\mathrm{CO}_{2}$ Capture and Sequestration from Power Generation; Studies by the IEA Greenhouse Gas R\&D Program". IEA Report, 1998

Varagani, AR., Chatel-Pelage F., Pranda, P., Lu, Y., Chen, S., Rostam-Abadi, M H., Vecci, S.J., and Bose, A.C., "Oxy-Combustion in Pulverized Coal-Fired Boiler: A Promising Technology for the Future," 3rd Annual Conference on Carbon Sequestration, Alexandria , USA, 2004

Wall, T., Sheng, C., and Gupta, R., "Oxy-Fuel Combustion for Sequestration Ready CO2 - Technology Status, Assessment and Research Needs," 14th IFRF Members Conference, Noordwijkerhout, The Netherlands, 2004

Wang, C.S., Berry, G.F., Chang, K.C., and Wolsky, A.M., "Combustion of Pulverized Coal Using Waste Carbon Dioxide and Oxygen," Combustion and Flame, Vol. 72, pp. 301-310, 1988

Wolsky, A.M., Daniels, E.J., and Jody, B.J., "Recovering $\mathrm{CO}_{2}$ from Large and Medium Size Stationary Combustors," Journal of Air and Waste Management, Vol. 41, pp. 449454, 1991

Woycenko, D.M., Ikeda, I., and van de Kamp, W.L., "Combustion of Pulverized Coal in a Mixture of Oxygen and Recycled Flue Gas," IFRF Document No. F98/y/1, 1994

Woycenko, D.M., van de Kamp, A.W.L., and Roberts, P.A., "Combustion of Pulverized Coal in a Mixture of Oxygen and Recycled Flue Gas," European Commission Joule II Clean Coal Technology Program 1992-1995, Volume II: Powder Coal Combustion Projects Final Reports, ISBN 92-9-828-006-7, 1997, [Also cited as Woycenko, et al., IFRF Document No. F98/y/4, 1995] 
COMMERCIALIZATION DEVELOPMENT OF OXYGEN FIRED CFB

FOR GREENHOUSE GAS CONTROL

\section{APPENDICES}

Two appendices are provided which include the following information:

- Appendix I: Plant Drawings

- Appendix II: Plant Equipment Lists 


\subsection{Appendix I: Plant Drawings}

This appendix shows selected equipment drawings for both Case-1 (the existing power plant before retrofit) and Case-2 (the existing power plant retrofitted with $\mathrm{O}_{2}$ firing and $\mathrm{CO}_{2}$ capture). The following list indicates the drawings included in this appendix.

\section{Case 1 - Existing Plant Drawings:}

1. Existing Site Drawing

- Figure 7.1: Case 1 - Existing Site Plot Plan Drawing Identifying Selected Major Equipment Locations

2. Existing Boiler Drawings:

- Figure 7.2: Case-1 - General Arrangement Boiler Side Elevation Drawing (existing CFB boiler)

- Figure 7.3: Case-1 - General Arrangement Boiler Plot Plan Drawing (existing CFB boiler)

- Figure 7.4: Side Elevation Drawing of Existing Baghouse and ID Fan

- Figure 7.5: Plan View of Existing Baghouse and ID Fan

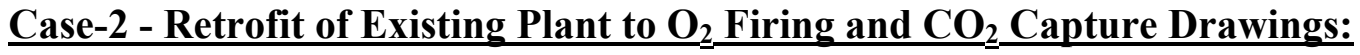

1. Modified Site Drawing:

- Figure 7.10: Case 2 - Modified Site Plot Plan Drawing

2. Modified Boiler Drawings (showing new gas recirculation system, $\mathrm{CO}_{2}$ product duct, and oxygen supply piping):

- Figure 7.6: Case-2 - General Arrangement of New Ductwork for Gas Recirculation and Oxygen Supply

- Figure 7.7: Case-2 - Section Views of New Ductwork for Gas Recirculation and Oxygen Supply

3. Gas Processing System Layout Drawing:

- Figure 7.8: Case-2 - New Gas Cooler and Gas Processing System Layout Drawing

4. Air Separation Unit Layout Drawing:

- Figure 7.9: Case 2-New Air Separation Unit Layout Drawing 


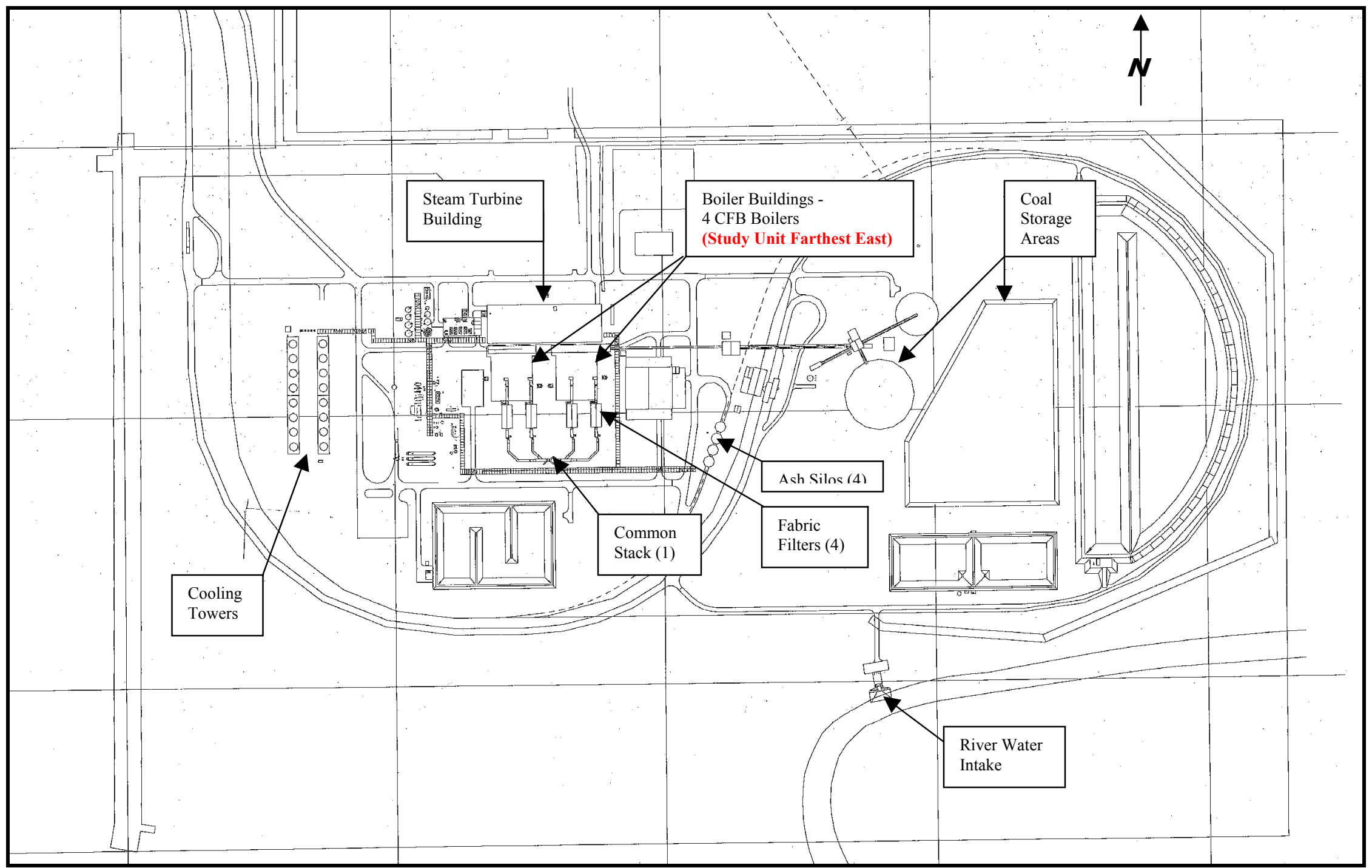

Figure 7.1: Case 1 - Existing Site Plot Plan Drawing Identifying Selected Major Equipment Locations 


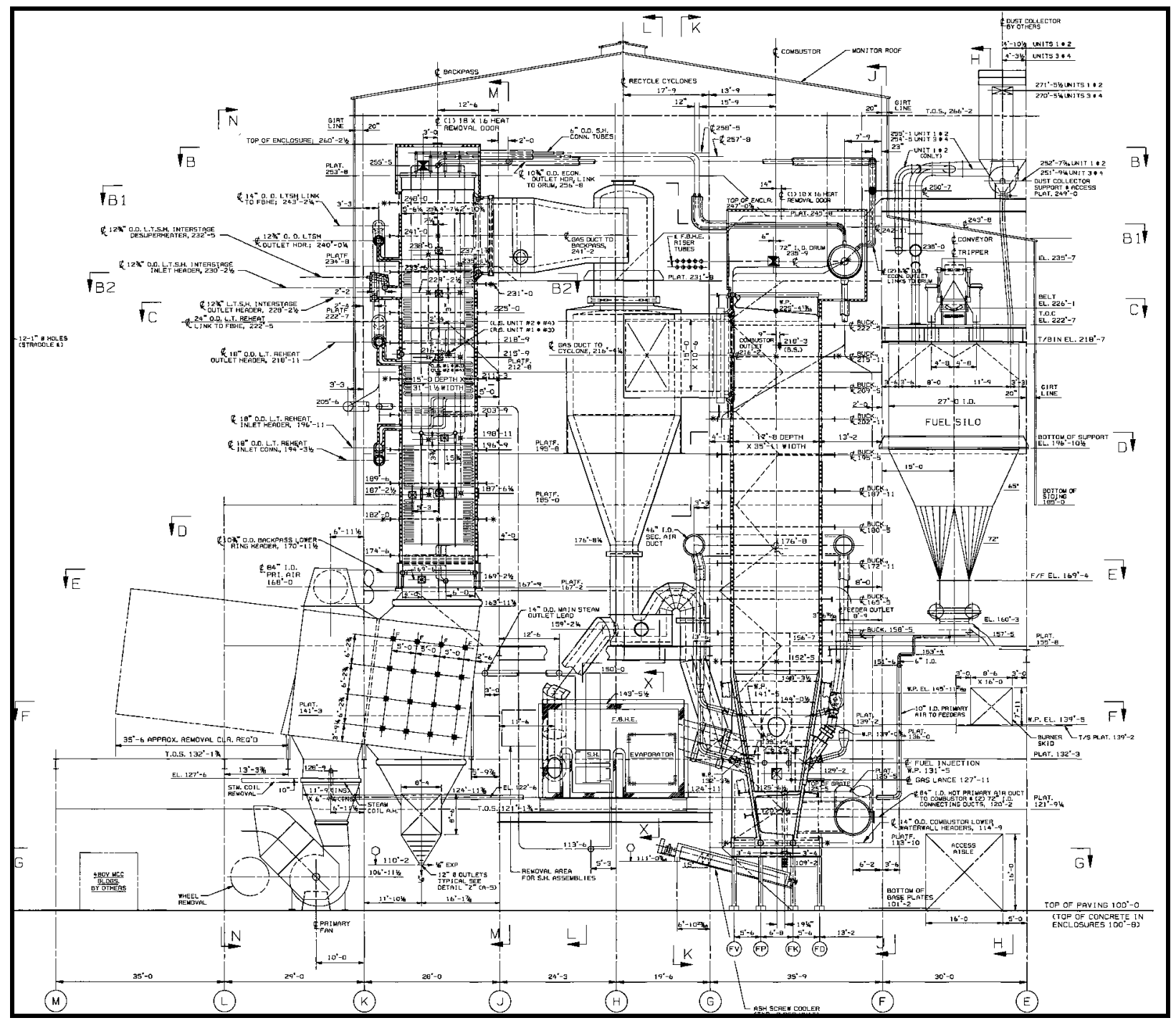

Figure 7.2: Case-1 - General Arrangement Boiler Side Elevation Drawing (existing CFB boiler) 


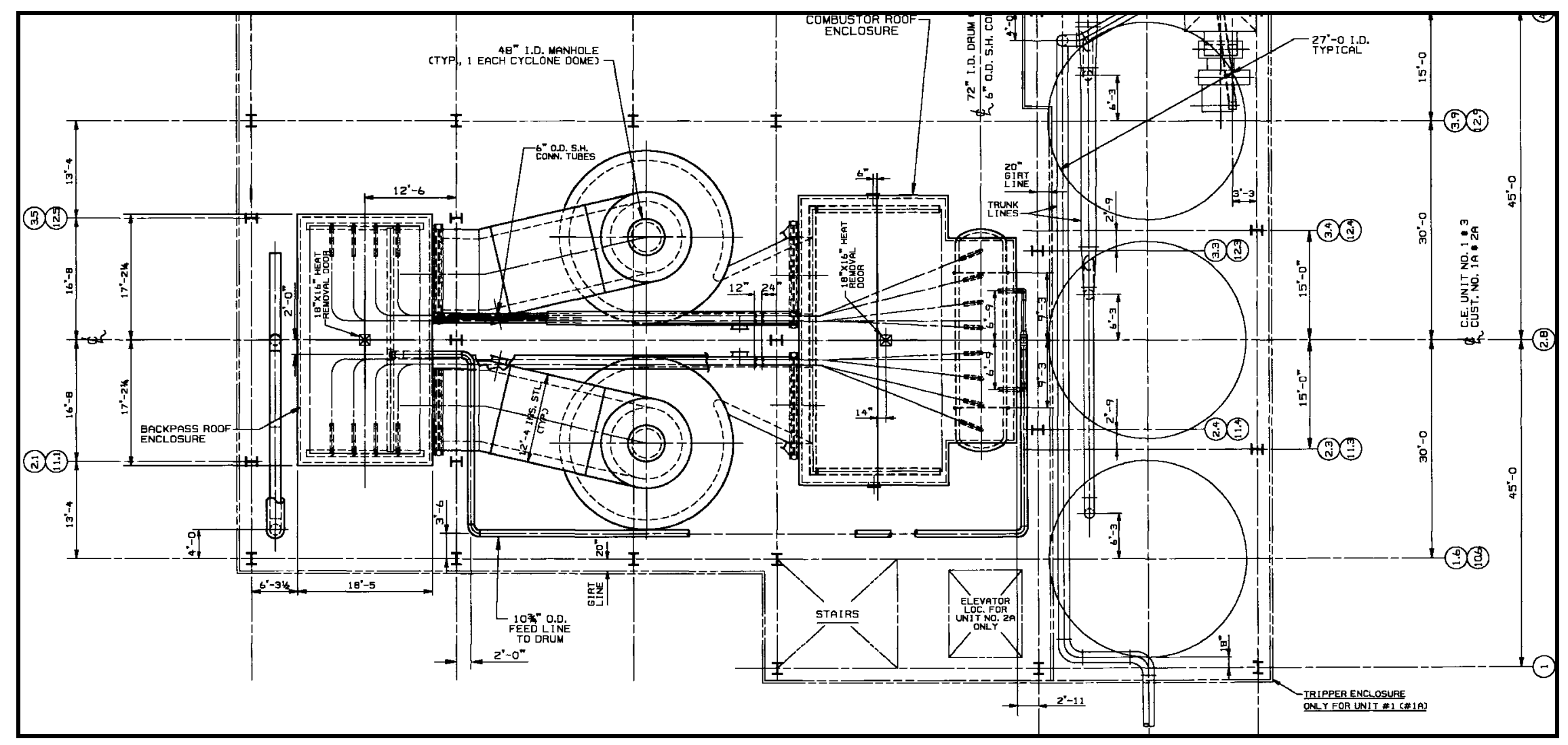

Figure 7.3: Case-1 - General Arrangement Boiler Plot Plan Drawing (existing CFB boiler) 


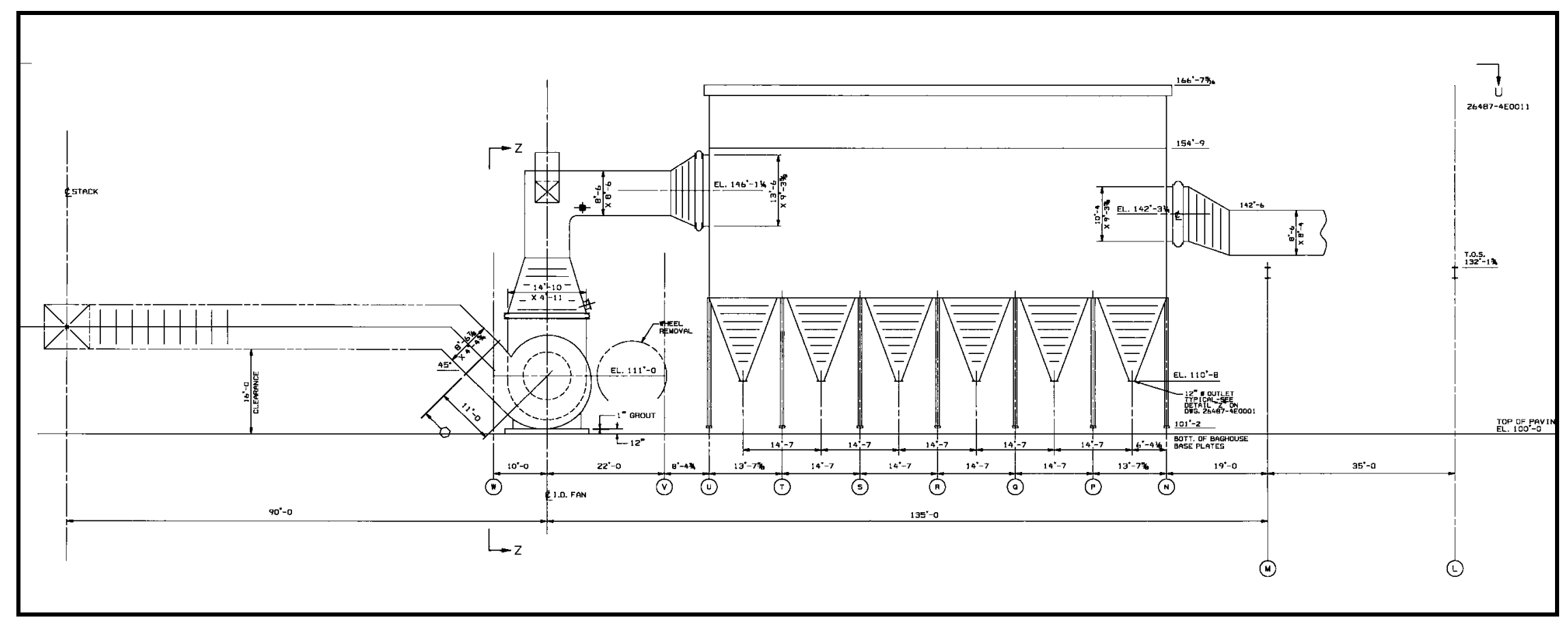

Figure 7.4: Side Elevation Drawing of Existing Baghouse and ID Fan 


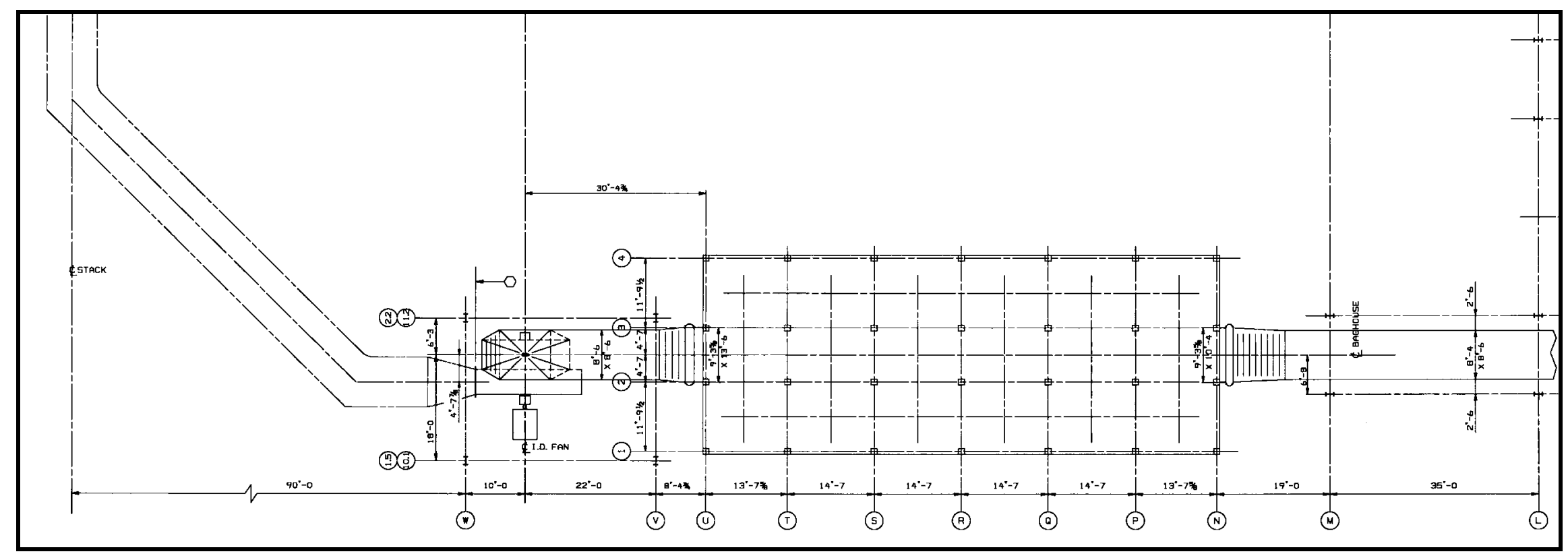

Figure 7.5: Plan View of Existing Baghouse and ID Fan 


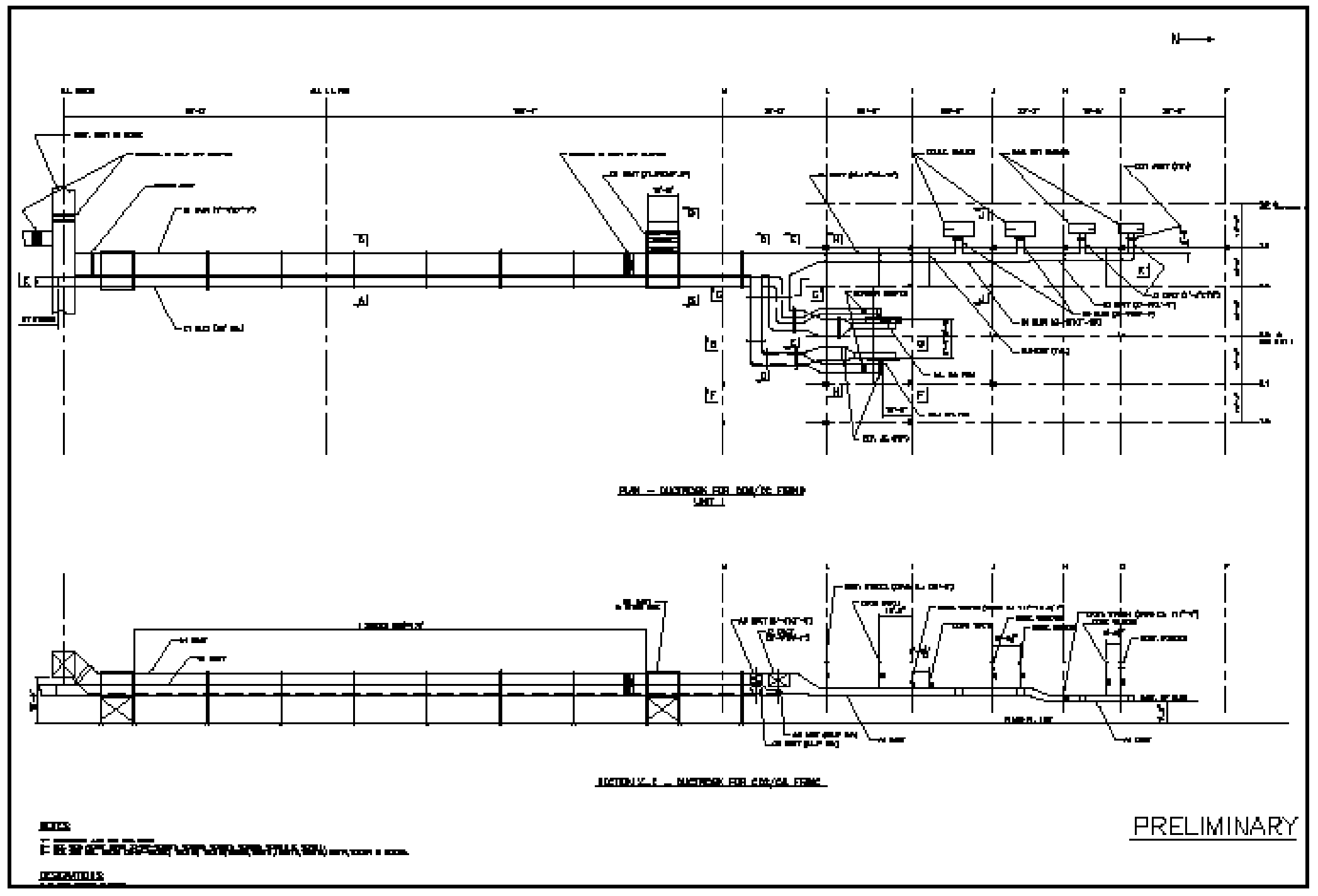

Figure 7.6: Case-2 - General Arrangement of New Ductwork for Gas Recirculation and Oxygen Supply 


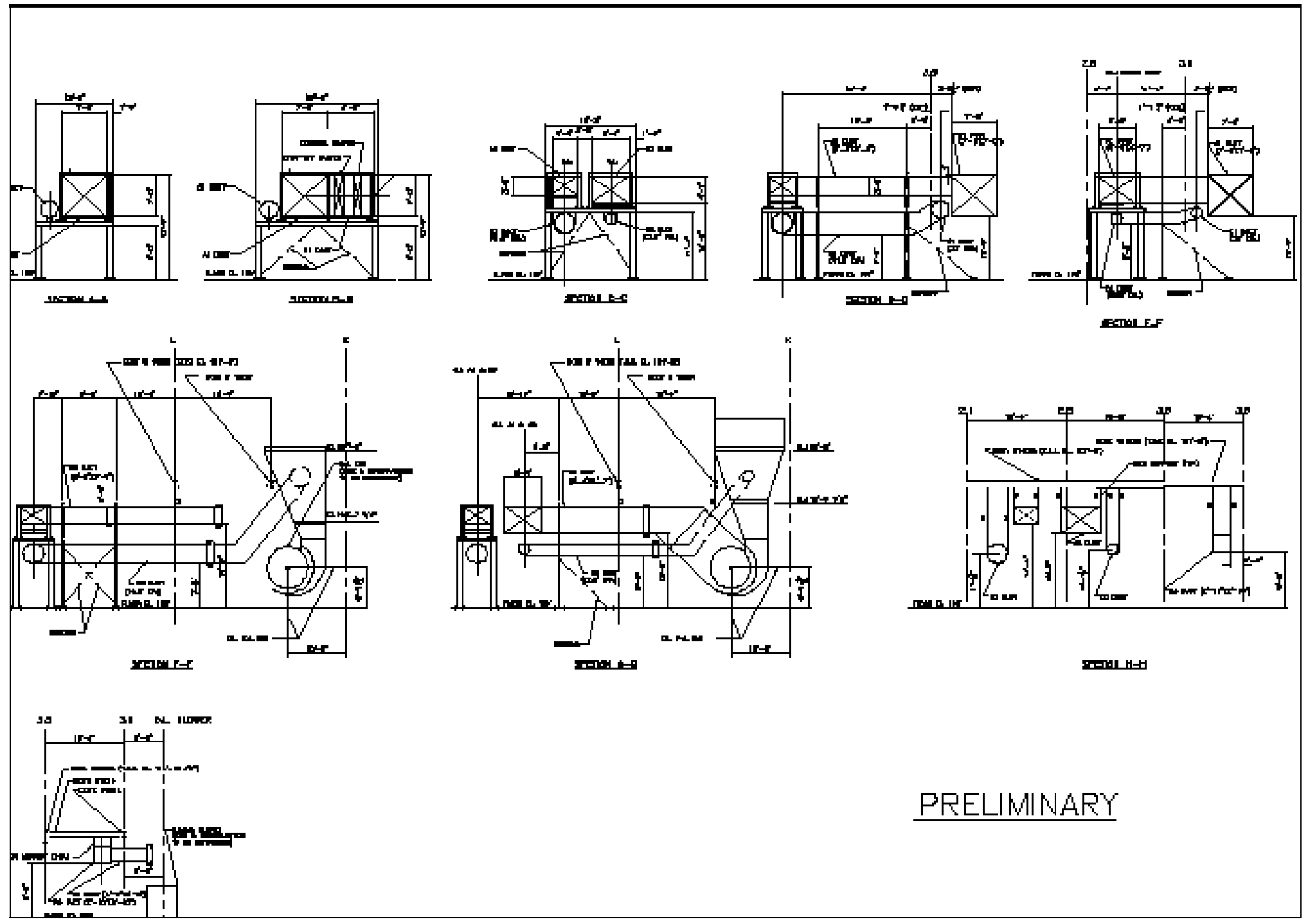

Figure 7.7: Case-2 - Section Views of New Ductwork for Gas Recirculation and Oxygen Supply 


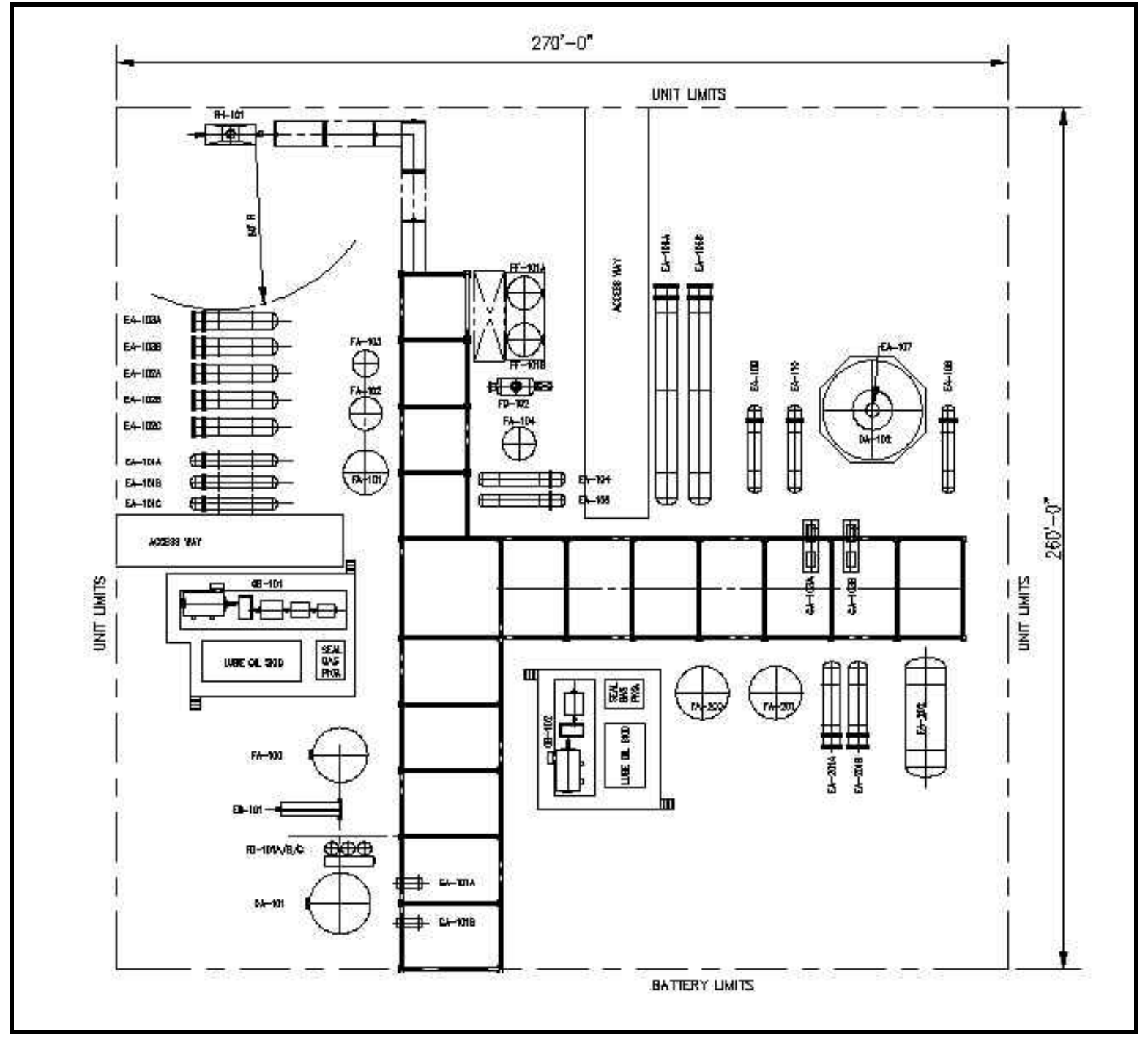

Figure 7.8: Case-2 - New Gas Cooler and Gas Processing System Layout Drawing 


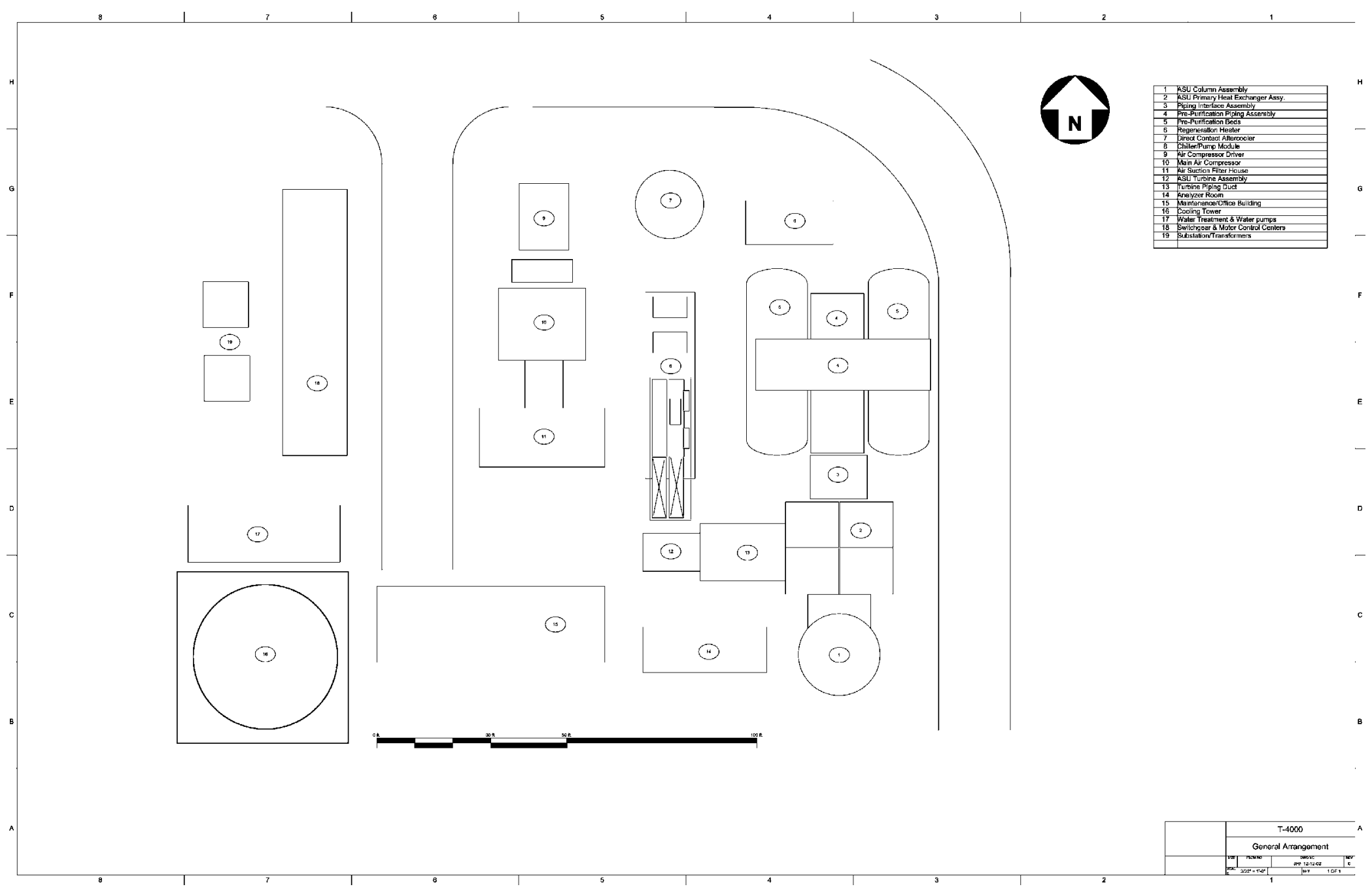

Figure 7.9: Case 2 - New Air Separation Unit Layout Drawing 


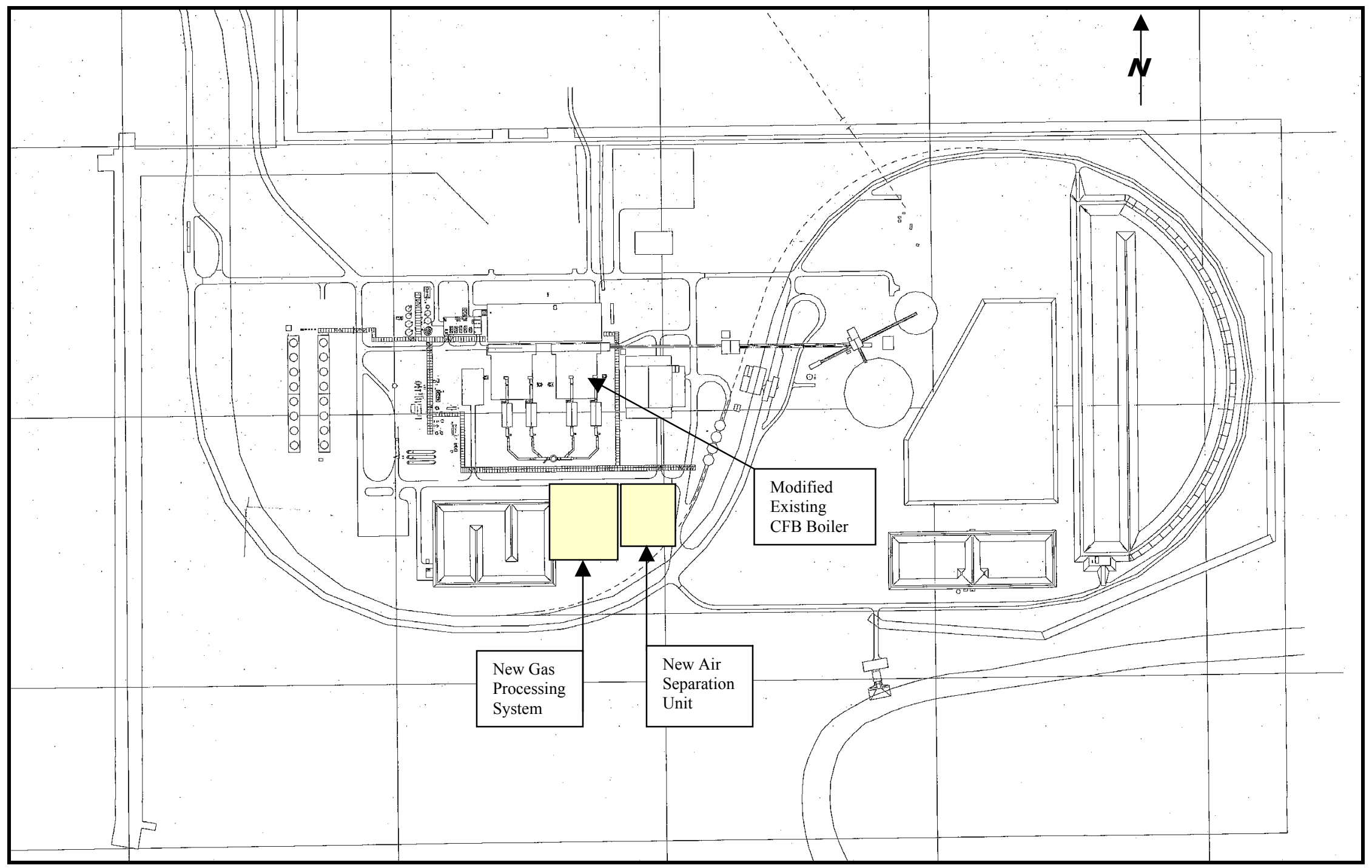

Figure 7.10: Case 2 - Modified Site Plot Plan Drawing Showing Locations of Existing Boiler and Major New Equipment 
COMMERCIALIZATION DEVELOPMENT OF OXYGEN FIRED CFB

FOR GREENHOUSE GAS CONTROL

\subsection{Appendix II: Plant Equipment Lists}

This appendix shows equipment lists. The existing plant equipment for Case- 1 is not listed. Only major new equipment that is added to the existing plant for retrofit Case- 2 is shown in these lists:

- The Case-2 Modified CFB Boiler (new equipment added for $\mathrm{O}_{2}$ fired retrofit)

- The Case-2 Gas Processing System

- The Case-2 Air Separation Unit 


\subsubsection{Case-2: Modified CFB Boiler Equipment}

The equipment listed below defines the new equipment that was added to the existing CFB boiler to support $\mathrm{O}_{2}$ firing and $\mathrm{CO}_{2}$ capture. Two groupings, boiler equipment and FDA system equipment, are shown.

\section{Boiler Retrofit Equipment:}

- $\mathrm{CO}_{2}$ Header Main Control Damper - V-1

- $\mathrm{CO}_{2}$ Header Control Damper - V-2

- External Heat Exchanger Isolation Damper and Actuator - V-3 (existing)

- External Heat Exchanger Isolation Damper and Actuator- V-4 (existing)

- Atmospheric Air Duct Vent Control Damper and Actuator - V-5

- Atmospheric Air Duct Vent Isolation Damper and Actuator - V-6

- Air Separation Unit Inlet Control Damper and Actuator to PA Fan - V-7

- Air Separation Unit Inlet Control Damper and Actuator to SA Fan - V-8

- Stack Zero Leakage Isolation Gate and Actuator - V-9

- Stack Flow Control Damper and Actuator - V-10

- Gas Processing System Control Damper and Actuator - V-11

- Gas Processing System Isolation Damper and Actuator - V-12

- A-1 Main $\mathrm{CO}_{2}$ header duct and expansion joints

- A-2 $\mathrm{CO}_{2}$ header duct to PA fan and expansion joints

- A-3 $\mathrm{CO}_{2}$ header duct to SA fan and expansion joints

- A-4 $\mathrm{CO}_{2}$ duct to FBHE and Seal Pot Fans with expansion joints

- A-5 $\mathrm{CO}_{2}$ duct to Seal Pot Fans with expansion joints

- A-6 $\mathrm{CO}_{2}$ takeoff duct to FBHE Fans with expansion joints

- A-7 $\mathrm{CO}_{2}$ takeoff duct to Seal Pot Fans with expansion joints

- A-8 $\mathrm{CO}_{2}$ duct to Seal Pot Fan and expansion joints

- A-9 $\mathrm{CO}_{2}$ duct to Gas Processing System and expansion joints

- B-1 Air inlet duct and expansion joints

- $\mathrm{C}-1 \mathrm{O}_{2}$ header duct with expansion joints

- $\mathrm{C}-2 \mathrm{O}_{2}$ duct to PA fan with expansion joints

- C-3 $\mathrm{O}_{2}$ duct to SA fan with expansion joints

- $\mathrm{CO}_{2}$ meters 
- $\mathrm{O}_{2}$ meters

- Associated pressure and flow transmitters

- New ID Fan and Motor

- Necessary design and engineered drawings, including mechanical and control, to complete the system retrofit.

Major equipment for the new FDA system:

- FDA Reactor Chamber

- FDA Mixer

- Fabric Filter Air Slides

- FDA Settling Chamber

- FDA Fluid Trough

- Fluidizing Air Blowers

- Compressed Air System

- FDA Controls 
COMMERCIALIZATION DEVELOPMENT OF OXYGEN FIRED CFB

FOR GREENHOUSE GAS CONTROL

\subsubsection{Case-2: New Gas Processing System Equipment}

This equipment list is for a Gas Processing System, which provides nominally 1,900 tonne/day (2,100 ton/day) of $\mathrm{CO}_{2}$ liquid product at $138 \mathrm{barg}(2,000 \mathrm{psig})$ and 99.8 percent purity for an EOR application.

\begin{tabular}{|c|c|c|c|c|c|c|}
\hline Tag No. & Service & Sizing Parameters & MOC & & & \\
\hline DA & Columns and Towers & & & & & \\
\hline DA-101 & Direct Contact Flue Gas Cooler & $20^{\prime} 0^{\prime \prime}$ ID $\times 40^{\prime} \mathrm{S} / \mathrm{S}, \mathrm{DP} 14 \mathrm{psig}, 3 \mathrm{psi}$ vacuum & CS w/SS liner & $10^{\prime}$ of $\mathrm{M} 250$ & X Sulzer structured packi & \\
\hline DA-102 & CO2 Column & $47^{\prime} 10^{\prime} \mathrm{ID} \times 57^{\prime} / 16^{\prime} \mathrm{S} / \mathrm{S}, \mathrm{DP} 475 \mathrm{psig}$ & LTCS & Twenty fou & 48 dia SS trays & \\
\hline EA & Shell \& Tube Exchangers & & & & & $t^{\wedge} 2 /$ shell \\
\hline EA-101 & Flue Gas Compressor 1 Stage Aftercooler & $10.9 \mathrm{MMBTU} / \mathrm{h}, \mathrm{DP} S \mathrm{~T}, 150 \mathrm{psig} / 85 \mathrm{psig}$ & CS/SS & 1 shell & $60^{\prime \prime}$ dia $\times 20^{\prime}$ long & 10900 \\
\hline EA-102 & Flue Gas Compressor 2 Stage Aftercooler & 9.3 MMBTU/HR, DP ST, $150 \mathrm{psig} / 125 \mathrm{psig}$ & cs/ss & 1 shell & $38^{\prime \prime}$ dia $\times 20^{\prime}$ long & 1210 \\
\hline EA-103 & Flue Gas Compressor 3 Stage Afterooler & 9.775 MMBTU/HR, DP ST, 150 psig / 225 psig & CS/SS & 1 shell & 32 "dia $\times 20^{\prime}$ long & 785 \\
\hline EA-104 & Flue Gas Compressor 4 Stage Aftercooler & 3.86 MMBTU/HR, DP ST, $150 \mathrm{psig} / 485 \mathrm{psig}$ & CSISS & 1 shell & $23^{\prime \prime}$ dia $\times 20^{\prime}$ long & 410 \\
\hline EA-105 & CO2 Feed Condenser & 26.3 MMBTU/HR DP S/T $300 \mathrm{psig} / 475 \mathrm{psig}$ & LTCS/LTCS & 2 shells & $60^{\prime \prime}$ dia $\times 40^{\prime}$ long (kettle) & $7800 \mathrm{ft} 2 /$ shell \\
\hline EA-106 & CO2 Column Reboiler & $4.75 \mathrm{MMBTU} / \mathrm{HR}, \mathrm{DP} S / \mathrm{T}, 485 \mathrm{psig} / 475 \mathrm{psig}$ & SSICS & 1 shell & $17^{\prime \prime} \times 20^{\prime}$ long & $750 \mathrm{ft} 2$ \\
\hline EA-107 & $\mathrm{CO} 2$ Column Condenser & 2.8 MMBTU/HR, DP ST, $475 \mathrm{psig} / 475 \mathrm{psig}$ & SS/SS & 1 shell & $48^{\prime \prime} \times 11^{\prime}$ long & $4100 \mathrm{tt2}$ \\
\hline EA-108 & $\mathrm{CO} 2$ Column Owhd Interchanger & 0.5 MMBTU/HR, DP S/T, $475 \mathrm{psig} / 475 \mathrm{psig}$ & SS/SS & 1 shell & $25^{\prime \prime} \times 20^{\prime}$ long & $1900 \mathrm{ft} 2$ \\
\hline EA - 109 & Recycle CO2 Superheater & 0.25 MMBTU/HR, DP S/T, $475 \mathrm{psig} / 475 \mathrm{psig}$ & SS/SS & 1 shell & $16^{\prime \prime} \times 20^{\prime}$ long & $700 \mathrm{tt}^{\wedge} 2$ \\
\hline EA-110 & Feed/ $\mathrm{CO} 2$ product interchanger & 2.0 MMBTU/HR, DP ST, $475 \mathrm{psig} / 2200 \mathrm{psig}$ & $\operatorname{csics}$ & 1 shell & $30^{\prime \prime} \times 20^{\prime}$ long & $2775 \mathrm{ft} 2$ \\
\hline EA-201 & Refrig condenser & 40.4 MMBTU/HR, DP S/T, $300 \mathrm{psig} / 125 \mathrm{psig}$ & $\operatorname{cs} / \mathrm{CS}$ & 2 shells & $56^{\prime \prime} \times 20^{\prime}$ long & $9880 \mathrm{ft} 2 /$ shell \\
\hline FB & & & & & & \\
\hline EB & Plate Exchangers & 67 MMBBTU/HR DP P/U $100 \mathrm{nsig} / 125 \mathrm{nsig}$ & ISS & 1 Exch & $3^{3 \prime 1} 10^{\prime \prime} \times 18^{\prime}$ & $22700+\pi / 2$ \\
\hline$[D-101$ & & 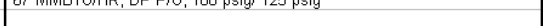 & Do & 1 Exch & 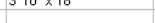 & $22,00 \pi \pi^{2} 2$ \\
\hline $\mathrm{FH}$ & Heaters & & & & & \\
\hline FH-101 & Drier Regeneration Gas Heater & Gas fired, 4.6 MMBTU/HR fired duty & & & & \\
\hline & & & & & & \\
\hline FA & Drums and Vessels & & & & & \\
\hline FA-100 & Flue Gas Compressor 1st Stage Suction Drum & $10^{\prime}-10^{\prime \prime} I D \times 18^{\prime} \mathrm{S} / \mathrm{S}, \mathrm{DP} 50 \mathrm{psig}$ & CS w/SS liner & & & \\
\hline FA-101 & Flue Gas Compressor 2nd Stage Suction Drum & $9^{\prime}-0^{\prime \prime}$ ID $\times 18^{\prime} S / S, D P 85$ psig & CS w/SS liner & & & \\
\hline FA-102 & Flue Gas Compressor 3rd Stage Suction Drum & $7^{\prime}$ - 8" ID $\times 14^{\prime}$ S/S DP $125 \mathrm{psig}$ & CS w/SS liner & & & \\
\hline FA-103 & Flue Gas Compressor 4th Stage Suction Drum & $6^{\prime}-2^{\prime \prime}$ ID $\times 14^{\prime}$ S/S, DP $225 \mathrm{psig}$ & CS w/SS liner & & & \\
\hline FA-104 & Flue Gas Compressor 4th Stage Discharge KJO Drum & $4^{\prime \prime}-4^{\prime \prime} \mathrm{ID} \times 12^{\prime \prime} \mathrm{S} / \mathrm{S} \mathrm{DP} 485 \mathrm{psig}$ & CS w/SS liner & & & \\
\hline FA-200 & Refrig Compr 1st Stage Suct Scrubber & $10^{\prime}-4^{\prime \prime}$ ID $\times 16^{\prime}$ S/S DP 300 psig & CS & & & \\
\hline FA-201 & Refrig System Economizer & $5^{\prime}-0^{\prime \prime}$ ID $\times 18^{\prime}$ S/S, DP 300 psig & LTCS & & & \\
\hline FA-202 & Refrig Surge Drum & $8^{\prime}-0^{\prime \prime}$ ID $\times 40^{\prime}$ S/S DP 300 psig & cs & & & \\
\hline FD & Filters & & & & & \\
\hline FD-101 & Water Filter & 3 units, $700 \mathrm{gpm}$ each, DP $100 \mathrm{psig}$ & Ss & 3 vertical fitt & ters 30 " dia & \\
\hline FD-102 & Flue Gas Filter & Total 1130 ACFM, DP $475 \mathrm{psig}$ & CS & Horizontal 3 & $4^{4}$ dia $\times 10^{\prime} \mathrm{SIS}$ & \\
\hline FF & Dryers (Dessicant Tyne) & & & & & \\
\hline FF-101AVB & Flue Gas Drier & Two Vessels 6' -7 " ID x 10' S/S DP 485 psig DT $550 \mathrm{~F}$ & CS & & & \\
\hline & & & & & & \\
\hline GA & Pumps Centrifugal & & & & & \\
\hline GA-101 A/B & Water Pump & $3,857 \mathrm{gpm}, \mathrm{DP} 40 \mathrm{psi}$ & Cl w/SS impeller & & & \\
\hline GA-103 A/B & CO2 Pipeline pump & $340 \mathrm{gpm}, 10 \%$ design margin, DP $1610 \mathrm{psi}$ & cs & & & \\
\hline GB & Compressors \& Blowers & & & & & \\
\hline & Flue Gas Compressor & Motor Drive 4 stages Includes Lube/Seal Oil Systems, 8,800 kW NOTE 1 & CS w/SS wheels & $45^{\prime} \times 11^{\prime}$ & & \\
\hline \multirow[t]{4}{*}{ GB-102 } & Propane Refrig Compressor & Motor Drive, 2 stage Includes lube oil/ seal oil system, 4,100 kW NOTE 1 & $\operatorname{cs}$ & $35^{\circ} \times 10^{\circ}$ & & \\
\hline & & & & & & \\
\hline & & NOTES & & & & \\
\hline & & for gear losses & 1.1 design marg & for API & & \\
\hline
\end{tabular}




\subsubsection{Case-2: New Air Separation Unit Equipment}

This equipment list is for an air separation unit, which provides nominally 1,640 tonne/day (1,800 ton/day) of oxygen to the CFB boiler at $0.3 \mathrm{barg}$ ( $4 \mathrm{psig})$ and 99 percent purity. The flows, capacities, adsorbent weights, and vessel sizes shown in this equipment list have been prorated from a similar equipment list provided by Praxair for a larger ASU used in a previous study (Marion, et al., 2003).

\section{Rotating Equipment}

Main Air Compressor (Qty 1)

One centrifugal compressor meets the entire range of plant air. The compressor is a 3stage high efficiency integral gear centrifugal compressor. Included with the compressor are adjustable inlet guide vanes, coupling with guard, lube oil system and three aftercoolers. The aftercoolers (shell and tube heat exchangers) are part of a low-level heat recovery system, which is integrated with the plant steam cycle to improve overall plant efficiency. Additionally, a Direct Contact Aftercooler is used after the third stage shell and tube aftercooler. The compressor is driven by a synchronous electric motor which is field mounted on its own foundation.

Delivered Air Flow: $224,000 \mathrm{Nm}^{3} / \mathrm{h}(8,500,000 \mathrm{cfh}-\mathrm{ntp})$

Suction Temperature: $27^{\circ} \mathrm{C}\left(80^{\circ} \mathrm{F}\right)$

Discharge Pressure: 6 bar(a) (87 psia)

\section{Upper Column Turbine Skid (UCT) (Qty 1)}

A Cryogenic expansion turbine provides refrigeration for producing liquid products and heat leak for the distillation process. The Turbine is sized for plant specific requirements. Lube oil is provided by an integral lube oil skid.

$\begin{array}{lr}\text { Delivered Flow: } & 9,900 \mathrm{Nm}^{3} / \mathrm{h}(376,400 \mathrm{cfh}-\mathrm{ntp}) \\ \text { Isothermal Efficiency: } & 90 \\ \text { Inlet Temperature: } & -88^{\circ} \mathrm{C}\left(-127^{\circ} \mathrm{F}\right) \\ \text { Exhaust Pressure: } & 1.4 \mathrm{bar}(\mathrm{a})(21 \mathrm{psia})\end{array}$

\section{Process Equipment}

Air Suction Filter House (ASFH) (Qty 1)

A pulse jet type filter house will be implemented for this case. The filter will be built in 3 modules.

Overall Efficiency:

Design Flow

100 retention of 3 micron particles $224,000 \mathrm{Nm}^{3} / \mathrm{h} \quad(8,500,000$ cfh-ntp $)$

\section{Aftercooler (shell \& tube) (Qty 3); Direct Contact Aftercooler (DCA) (Qty 1)}

The heat of compression from the MAC is removed with three aftercoolers (shell and tube heat exchangers) integrated with the plant steam cycle and a two-stage Direct Contact Aftercooler (DCA). The DCA is a packed column where water is put in direct contact with compressed air leaving the third stage shell and tube aftercooler. The $1^{\text {st }}$ stage of the DCA is cooled by water from the plant cooling water system. The air exiting this first stage is cooled to within $1^{\circ} \mathrm{C}\left(1.8^{\circ} \mathrm{F}\right)$ of the cooling water inlet temperature. The $2^{\text {nd }}$ stage of the DCA is fed by a closed chilled water loop. A Mechanical Chiller provides the refrigeration to chill this stage's water loop. The air exiting the $2^{\text {nd }}$ stage is 
designed to be at $15^{\circ} \mathrm{C}\left(59^{\circ} \mathrm{F}\right)$ or less to feed the Prepurifier system. An integral Moisture Separator is provided to remove 99.9 of free water droplet 3 microns and larger.

DCA - Design Discharge Air Temp.:

$10.0^{\circ} \mathrm{C}\left(50^{\circ} \mathrm{F}\right)$ Process Air to TSA PP

$1^{\text {st }}$ Stage Packing Height:

$2.4 \mathrm{~m}(9.5 \mathrm{ft})$

$1^{\text {st }}$ Stage Water Flow:

(2,200 gpm)

$2^{\text {nd }}$ Stage Packing Height:

$3.2 \mathrm{~m}(9.5 \mathrm{ft})$

$2^{\text {nd }}$ Stage Water Flow:

$3,8201 / \min (1,010 \mathrm{gpm})$

\section{Mechanical Chiller (Qty 4)}

An R-134A mechanical chiller provides refrigerant to cool the $2^{\text {nd }}$ stage DCA chilled water. The mechanical chiller cools down the water to within the desired process temperature. The chiller consists of one full sized, centrifugal refrigerant compressor, and shell and tube heat exchangers for the evaporator and condenser services.

Tons@100Load

200 (800 Total)

Water Design Temperature:

$8.9^{\circ} \mathrm{C}\left(48^{\circ} \mathrm{F}\right)$

Evaporator Water Flow:

$3,8201 / \min (1,010 \mathrm{gpm})$

DCA Chilled Water Pumps (Qty 2)

\begin{tabular}{|c|c|c|}
\hline & Chilled Water Pump & $1^{\text {st }}$ Stage DCA Pump \\
\hline Pump Flow Range: & $3,820 \mathrm{l} / \mathrm{min}(1,010 \mathrm{gpm})$ & $\begin{array}{r}18,9301 / \min (5,000 \\
\text { gnm })\end{array}$ \\
\hline Design TDH: & $20 \mathrm{~m}(65 \mathrm{ft})$ & $39 \mathrm{~m}(127 \mathrm{ft})$ \\
\hline
\end{tabular}

\section{TSA Prepurifier Vessels (Qty 2)}

The air purification system is designed to remove water and $\mathrm{CO}_{2}$ from the feed air stream going to the column or other warm end piping in order to prevent fouling heat exchangers from $\mathrm{CO}_{2}$ buildup in the main condenser. The system is designed as a horizontal two-bed system with each vessel containing a bed of molecular sieve. While one vessel is removing water and $\mathrm{CO}_{2}$ from the feed air stream, the other bed is being regenerated at low pressure by hot $\mathrm{N}_{2}$ from a Regeneration Heater. Water, $\mathrm{CO}_{2}$, and other hydrocarbons are desorbed from the sieve and vented to atmosphere.

Design Inlet Air

Temperature:

Adsorbents:

Est. Vessel Size: $10.0^{\circ} \mathrm{C}\left(50^{\circ} \mathrm{F}\right)\{$ Process Air from DCA $\}$

Sieve:

4x8 13X APG II Molecular Sieve $37,800 \mathrm{~kg}(83,400 \mathrm{lbs})$ Each

D-201 Alumina $12,900 \mathrm{~kg}(28,500 \mathrm{lbs})$ Each

3.4 m Diam. x $13.1 \mathrm{~m} \mathrm{~L}$ (11 ft. Diam. x $43 \mathrm{ft} . \mathrm{L})$

(Seam to Seam)

\section{TSA Prepurifier Dust Filter (Qty 2)}

Following adsorption, the air passes through one full-size Dust Filter to remove any particles of molecular sieve. The filter design provides positive gasket sealing to prevent by-pass of unfiltered fluids.

Filter Efficiency:

99 retention of 1 micron particles 100 retention of 3 micron particles 


\section{TSA Prepurifier Natural Gas Regeneration Heater}

One 100 Natural Gas Regeneration/Thaw heater is used to heat the Regeneration $\mathrm{N}_{2}$ and Thaw Air. The unit is packaged and mounted on a single skid. The burners are fully modulating, with combustion air blower and motor. A packaged control system is included for control and safety monitoring.
Design Regeneration Flow:
$33,000 \mathrm{Nm}^{3} / \mathrm{h}(1,253,000 \mathrm{cfh}-\mathrm{ntp})$
Design Heat Duty:
$3,123 \mathrm{~kW}(10,700,000 \mathrm{Btu} / \mathrm{hr})$
Inlet Temp
$29^{\circ} \mathrm{C}\left(85^{\circ} \mathrm{F}\right)$
Outlet Temp
$232{ }^{\circ} \mathrm{C}\left(450{ }^{\circ} \mathrm{F}\right)$
Peak Fuel Consumption
$424 \mathrm{Nm}^{3} / \mathrm{h}(15,000 \mathrm{scfh})$

\section{Silencers}

All silencers provide a $35-\mathrm{dBA}$-insertion loss. 50-dBA attenuation is also available.

Inlet:

Outlet:

Length:

Inlet:

Outlet:

Length:

\section{MAC Vent (Qty 1)} $303 \mathrm{~mm}$ (16 in) dia $1,817 \mathrm{~mm}$ (64 in) diam 3,046 mm (120 in)

Prepurifier Vent (Qty 1) $168 \mathrm{~mm}$ (7 in.) Diam $437 \mathrm{~mm}$ (17 in.) Diam $1,803 \mathrm{~mm}(71 \mathrm{in}$.
Waste Nitrogen Vent (Qty 1) $337 \mathrm{~mm}$ (13 in.) Diam 1,817 mm (64 in.) Diam $3,046 \mathrm{~mm}$ (120 in.)

Product Oxygen Vent (Qty 1) $454 \mathrm{~mm}$ (18 in.) Diam (Reduced) 663 mm (40 in.) Diam 4,242 mm (167 in.)

Cold Box Equipment

Primary Heat Exchanger (PHX) (Qty 1)

\section{$\underline{\text { Oxygen Boiler }}$}

\section{$\underline{\text { Main Condenser }}$}

\section{Lower Column}

\section{Upper Column}




\section{Additional Equipment and Services}

- Local Instruments \& Controls

- Switchgear \& MCC

- Process Analyzers

- Cooling System

- Project Management \& Engineering

- Construction Management

- Construction

- Commissioning \& Startup

- Land/Site

- Control Room/Administration Offices/Warehouse/Maintenance Shop, etc.

- Start-Up Utilities
Praxair

Praxair

Praxair

Client

Praxair

Praxair

Local Contractors

Praxair with Client support

Client

Client

Client 


\title{
COMMERCIALIZATION DEVELOPMENT OF OXYGEN FIRED CFB FOR GREENHOUSE GAS CONTROL
}

\section{VOLUME II}

\section{DESIGN STUDY OF A CAPTURE READY CFB STEAM PLANT RETROFIT TO OXYGEN FIRING AND $\mathrm{CO}_{2}$ CAPTURE}

FINAL REPORT

SUBMITTED BY

ALSTOM POWER INC. POWER PLANT LABORATORIES

2000 DAY HILL ROAD

WINDSOR, CT 06095

(860) 688-1911

\author{
Principal Authors: \\ Gregory N. Liljedahl \\ Nsakala ya Nsakala
}

PREPARED FOR

NETL AAD DOCUMENT CONTROL BLDG. 921

US DEPARTMENT OF ENERGY

NATIONAL ENERGY TECHNOLOGY LABORATORY

P.O. BOX 10940

PITTSBURGH, PENNSYLVANIA 15236-0940

(COOPERATIVE AGREEMENT NO. DE-FC26-04NT42205)

FINAL REPORT SUBMITTAL DATE: AUGUST 24, 2007

PERFORMANCE PERIOD: OCTOBER 1, 2004 - JUNE 30, 2007 


\section{DISCLAIMER}

This report was prepared as an account of work sponsored by an agency of the United Sates Government. Neither the United States Government nor any agency thereof, nor any of their employees makes any warranty, express or implied, or assumes any legal liability or responsibility for the accuracy, completeness, or usefulness of any information, apparatus, product, or process disclosed, or represents that its use would not infringe privately owned rights. Reference herein to any specific commercial product, process, or service by trade name, trademark, manufacturer, or otherwise does not necessarily constitute or imply its endorsement, recommendation, or favoring by the United States Government or any agency thereof. The views and opinions of authors expressed herein do not necessarily state or reflect those of the United States Government or any agency thereof. 


\section{ACKNOWLEDGMENTS}

The authors gratefully acknowledge the following people for their contributions to the successful performance of the work presented herein:

Richard Waryasz, Pierre Gauville, Roland Tetreault, Diane Calkin, Carl Bozzuto, Rolf Hesterman, Neil Canvin, Ray Chamberland, and Glen Jukkola of ALSTOM Power Inc., and Vlad Vaysman of WorleyParsons Group Inc. for their contributions.

The financial support of this project by DOE National Energy Technology Laboratory (Contract No DE-FC26-04NT42205) and ALSTOM Power Inc. is also acknowledged. 


\section{PUBLIC ABSTRACT}

Coal-fired power plants of the future will likely need systems that enable the cost effective capture and sequestration of their $\mathrm{CO}_{2}$ emissions, since fossil fuels will remain the primary energy source for the foreseeable future. ALSTOM is evaluating several options in the mitigation of greenhouse gases from fossil fuel combustion. One of the potential technologies to accomplish this is oxy-combustion.

The basic concept in using oxygen firing with today's coal combustion technologies is to replace combustion air with a mixture of oxygen and recycled flue gas, thereby creating a high $\mathrm{CO}_{2}$ content flue gas stream as shown in the figure below. The flue gas stream leaving the boiler can be simply dried and compressed for sequestration, or further processed into a high purity $\mathrm{CO}_{2}$ product for various uses such as enhanced oil recovery or enhanced gas recovery.

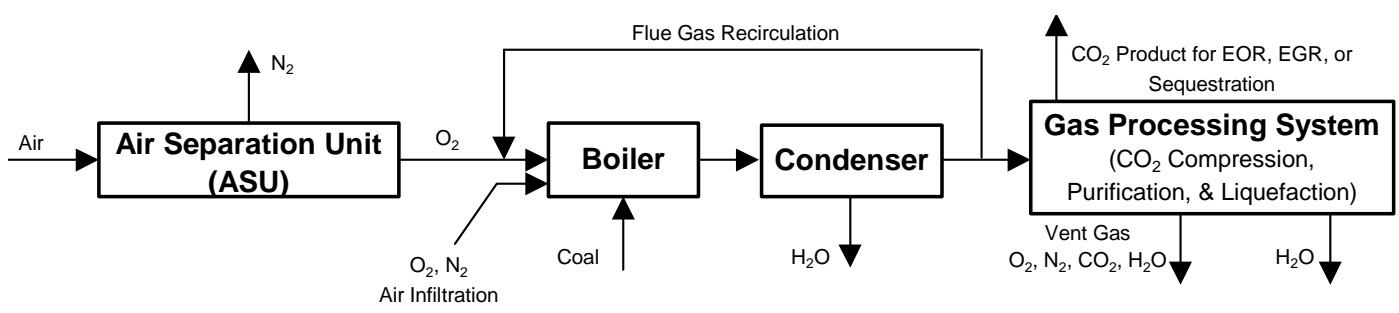

The objective of this study is to determine the attributes and quantify the economics of 600 MW-class supercritical (SC) circulating fluidized bed (CFB) power plants that are $\mathrm{CO}_{2}$ capture-ready via future oxygen firing. This study investigates the feasibility of designing capture-ready CFB based power plants with additional provisions (other than just adding the ASU and GPS) such that additional modifications can be made at the time the plant is converted to $\mathrm{O}_{2}$ firing and $\mathrm{CO}_{2}$ capture to allow the net power output from the plant to be conserved.

The retrofit of traditionally designed steam power plants for $\mathrm{CO}_{2}$ capture has been shown to reduce plant output significantly, be very energy intensive, costly, and quite often not enough site space is available for optimally installing the $\mathrm{CO}_{2}$ capture equipment. This work identifies the impacts on overall plant performance, costs, and economics of converting a capture-ready CFB plant to $\mathrm{O}_{2}$ firing and $\mathrm{CO}_{2}$ capture as compared to converting a non-capture-ready plant to $\mathrm{O}_{2}$ firing and $\mathrm{CO}_{2}$ capture. As such, this work quantifies the potential financial benefits of preinvesting some money into a capture-ready plant in order to facilitate its future conversion to $\mathrm{O}_{2}$ firing and $\mathrm{CO}_{2}$ capture.

As mentioned above, in general, when a power plant is converted to $\mathrm{O}_{2}$ firing and $\mathrm{CO}_{2}$ capture, although the gross electrical output does not change, there is a significant loss in the net electrical output from the plant. This output loss is primarily due to the power consumption requirements of the air separation unit (ASU) and the gas processing system (GPS). These systems typically consume a total of about 25-30 percent of the generator electrical output.

The retrofit of CFB boiler steam plants (both capture-ready and non capture-ready) to oxygen firing and $\mathrm{CO}_{2}$ capture causes several significant impacts on the overall plant performance, $\mathrm{CO}_{2}$ emissions, and cost of electricity as compared to the air fired Base Case. The net plant output for the non capture-ready plant is reduced from 637 to $476 \mathrm{MWe}$, a 25 percent reduction. Conversely, the net plant output for the capture-ready plant is maintained. The plant thermal efficiency (HHV basis) is reduced by about 10 percentage points (from about 38 
$\%$ to 28\%) for both capture-ready and non capture-ready retrofits. Specific $\mathrm{CO}_{2}$ emissions are reduced more than 92 percent from 0.82 to $0.07 \mathrm{~kg} / \mathrm{kWh}(1.82$ to $0.15 \mathrm{lbm} / \mathrm{kWh})$ for both capture-ready and non capture-ready retrofits.

Retrofitting the capture-ready and non capture-ready CFB plants to oxygen firing capability and $\mathrm{CO}_{2}$ capture is technically straightforward.

The non capture-ready CFB plant requires relatively minor modifications. Boiler island modifications include a new flue gas recirculation system, new oxygen supply piping, a new oxygen heater, new $\mathrm{CO}_{2}$ product ductwork to the new gas processing system, the addition of a new $\mathrm{SO}_{2}$ removal system (Flash Dryer Absorber), and associated new controls and instrumentation for these systems. Pressure part changes to the existing boiler are not required.

Relatively minor changes to the balance of plant are required such as modifications to the feedwater system to include low-level heat recovery from the ASU and GPS, and additional accessory electrical equipment to support the added ASU and GPS.

The capture-ready CFB plant, which is designed to maintain the original net plant electrical output after the conversion, requires significantly more modifications than the non captureready plant. Boiler island modifications, in addition to those mentioned above for the noncapture ready retrofit, include several pressure part changes to accommodate the increase in steam generation rate. Wingwalls are added to the combustor, economizer surface is added in the rear pass, and superheat and reheat surface is added in the external heat exchangers.

The modifications to the balance of plant include steam turbine/generator modifications to accommodate the increased steam flow, as well as modifications to various other BOP systems such as the feedwater system, the cooling water system, the ash handling system, and the accessory electrical system.

The major new systems required for retrofit of both capture-ready and non capture-ready plants are a cryogenic air separation unit (ASU), a gas processing system (GPS), and the addition of an FDA system for sulfur removal. The ASU and GPS have significant land area requirements for the location of new equipment.

The non capture-ready plant retrofit cost (EPC basis - May 2007 \$US) is estimated to be about $969 \$ / \mathrm{kW}$-new, based on the new power output (i.e. the total retrofit cost divided by the new net output). There is also a specific cost impact ( $\$ / \mathrm{kW}$-new) associated with the value of the existing plant equipment. Because the retrofitted plant produces less net output, the specific cost of the existing plant equipment is increased. If this is included, the total non capture-ready plant retrofit cost is estimated to be about $1,425 \$ / \mathrm{kW}$-new.

Modifications to the existing boiler are relatively minor as mentioned above and cost only about $6 \$ / \mathrm{kW}$-new. The new Flash Dryer Absorber $\mathrm{SO}_{2}$ removal system costs 118 \$/kW-new. The remaining costs - nearly $78 \%$ of the total retrofit cost - are for the cryogenic air separation and gas processing systems. Though costly, these systems are commercially proven and technically straightforward.

The capture-ready plant retrofit cost is estimated to be about $961 \$ / \mathrm{kW}$-new, based on the new power output (i.e. the total retrofit cost divided by the new net output). In this case, there is no retrofit cost associated with the value of the existing plant equipment (as there was for the non capture ready retrofit) because the plant still produces the same net output as it did before the retrofit.

Modifications to the existing boiler are more extensive, as mentioned above, and cost about 27 $\$ / \mathrm{kW}$-new or about 3\% of the total plant retrofit cost. The new Flash Dryer Absorber $\mathrm{SO}_{2}$ 
removal system costs $90 \$ / \mathrm{kW}$-new or about $9 \%$ of the total. BOP modifications, including the steam turbine/generator modifications, amount to about $16 \%$ of the total. The remaining costs about $72 \%$ of the total - are for the cryogenic air separation unit and gas processing system.

A comparison of the total power plant costs for Cases 1a and 2a shows that the capture ready design requires a relatively small pre-investment of about 4.5 percent. This pre-investment cost is provided for the future conversion of the plant to oxygen firing and $\mathrm{CO}_{2}$ capture, and to also allow an increase in the gross electrical output from the plant of about 32 percent when the plant is retrofitted with oxygen firing and $\mathrm{CO}_{2}$ capture (i.e., from Case $2 \mathrm{a}$ to Case $2 \mathrm{~b}$ ) such that the net electrical output is not decreased.

Hence, the purpose of the economic analysis was to determine whether or not this preinvestment cost is justified economically, by comparing the results from Case $2 \mathrm{~b}$ with those from Case $1 \mathrm{~b}$ (Capture unready converted to $\mathrm{O}_{2}$ firing and $\mathrm{CO}_{2}$ capture). These Results are summarized below:

- The levelized cost of electricity (LCOE) of the capture unready plant (Case 1b) is always higher than that of the capture ready plant (Case 2b), irrespective of the time of conversion to $\mathrm{O}_{2}$ firing and $\mathrm{CO}_{2}$ capture, up to 20 years.

- The differences between the LCOE's of these two plants get narrower with time of conversion, ultimately crossing at 20-year mark

- In the absence of conversion to $\mathrm{O}_{2}$ firing and $\mathrm{CO}_{2}$ capture, the LCOE of the capture ready plant (2a) is higher than that of capture unready (1a), due its additional preinvestment cost

- The relative net present value (NPV) between the Capture Ready and Capture Unready plants decreases with time of conversion to $\mathrm{O}_{2}$ firing and $\mathrm{CO}_{2}$ capture, consistent with the LCOE differences

- In the absence of conversion to $\mathrm{O}_{2}$ firing and $\mathrm{CO}_{2}$ capture, the NPV of the capture ready plant (2a) is $-\$ 42 \mathrm{M}$ relative to Capture Unready plant (1a), due its additional preinvestment cost

- Hence, the pre-investment cost is justified, provided that the plant conversion to $\mathrm{O}_{2}$ firing and $\mathrm{CO}_{2}$ capture is implemented within 20 years from initial operation. The earlier the conversion, the better based on both LCOE and NPV results

- The value of pre-investment cost disappears if the conversion to $\mathrm{O}_{2}$ firing and $\mathrm{CO}_{2}$ capture is implemented after 20 years from initial operation. 


\section{TABLE OF CONTENTS}

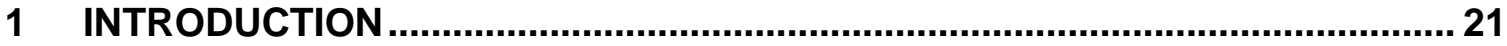

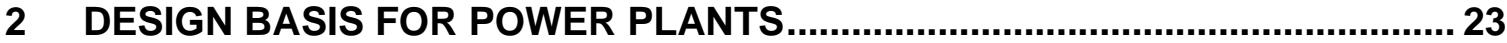

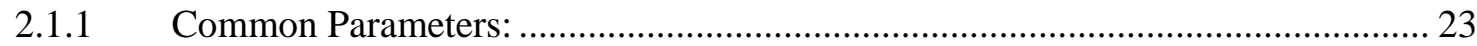

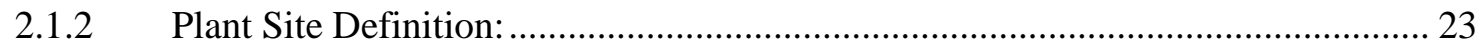

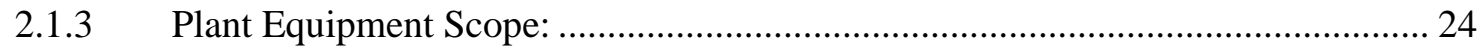

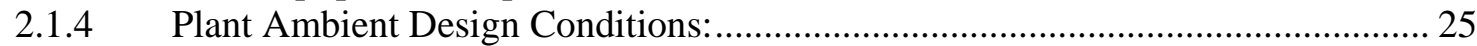

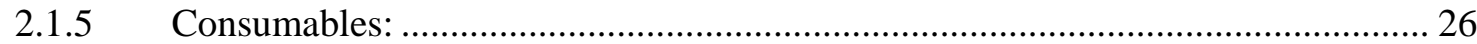

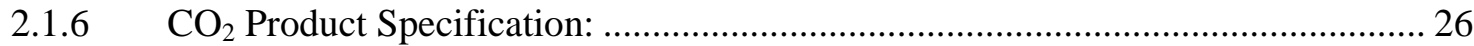

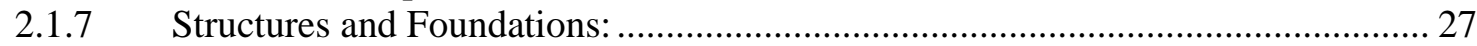

\section{DESCRIPTION OF POWER PLANT CASE STUDIES AND PLANT}

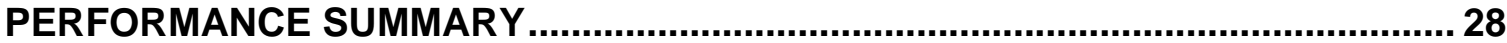

3.1 Power Plant Case Studies ...................................................................................................... 28

3.1.1 Case 1a - Air Fired $\mathrm{CO}_{2}$ Capture Unready Power Plant - Base Case .................... 28

3.1.2 Case $1 \mathrm{~b}$ - The Base Case Power Plant Retrofit with $\mathrm{O}_{2}$ Firing and $\mathrm{CO}_{2}$ Capture 28

3.1.3 Case 2a - Air Fired $\mathrm{CO}_{2}$ Capture-Ready Power Plant.......................................... 28

3.1.4 Case 2b - The Case 2a Capture-Ready Power Plant Retrofit with $\mathrm{O}_{2}$ Firing and

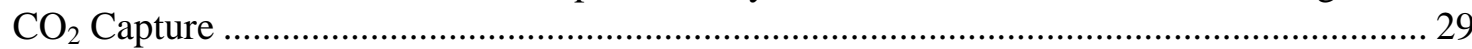

3.2 Power Plant Performance Summary and Comparison .............................................. 29

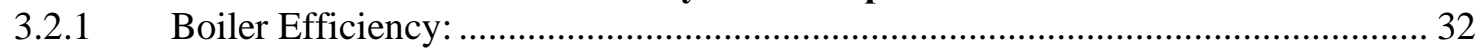

3.2.2 Coal Heat Input and Boiler Heat Output:....................................................... 32

Steam Cycle Efficiency:................................................................................ 33

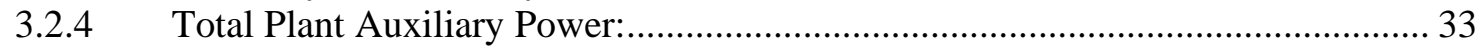

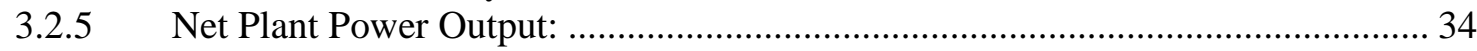

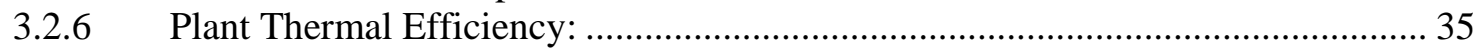

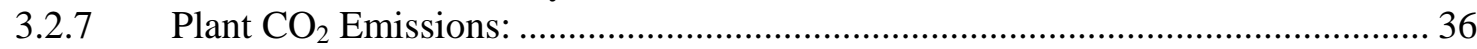

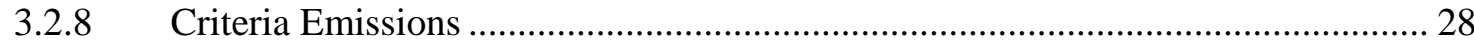

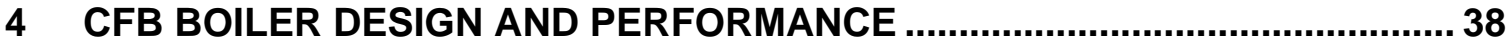

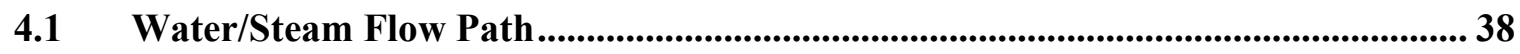

4.2 Case 1a - Air Fired CFB Boiler Island (Base Case) ............................................... 38

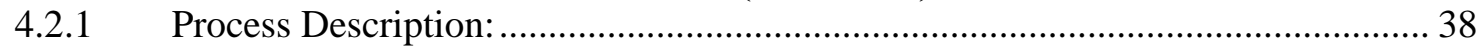

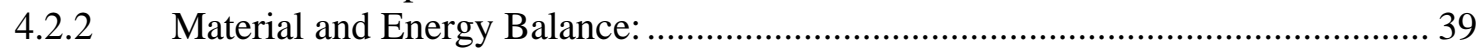

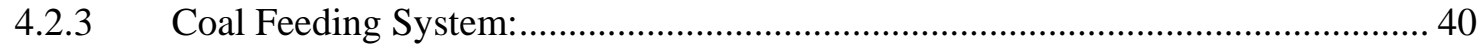

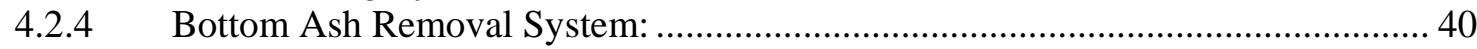

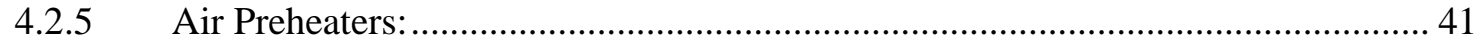

4.3 Case $1 \mathrm{~b}$ - The Case 1a CFB Boiler Island Retrofit with $\mathrm{O}_{2}$ Firing and $\mathrm{CO}_{2}$ Capture 41

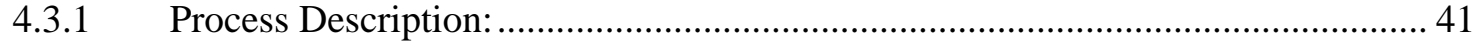

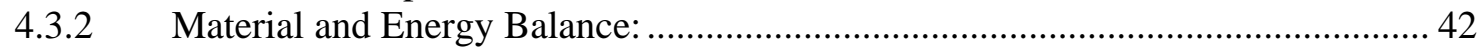

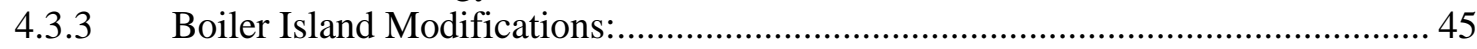




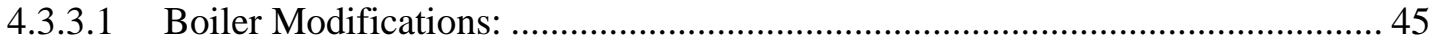

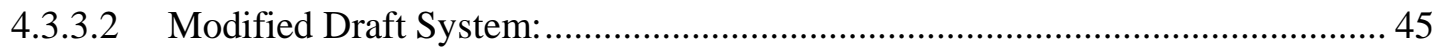

4.3.3.3 Modified Controls and Instrumentation for the Boiler Island:............................ 46

4.3.3.4 Modified Desulfurization System: ................................................................. 46

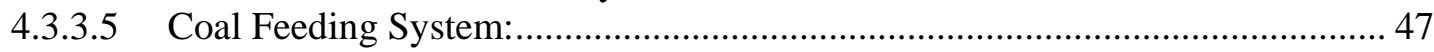

4.3.3.6 Bottom Ash Removal System: .................................................................... 47

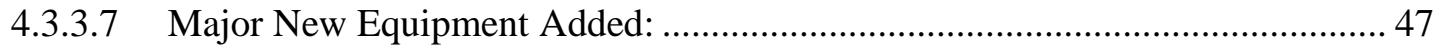

4.4 Case 2a - Air Fired Capture Ready CFB Boiler Island ......................................... 48

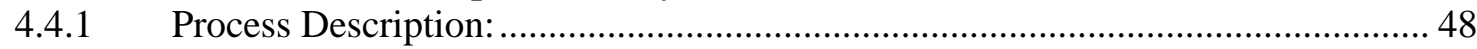

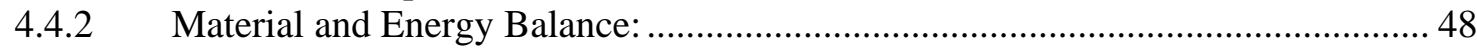

4.4.3 Capture Ready Features for the Case 2a Boiler Island......................................... 49

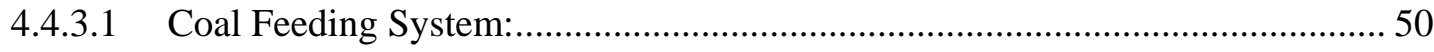

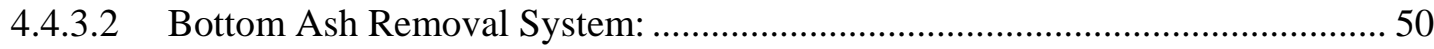

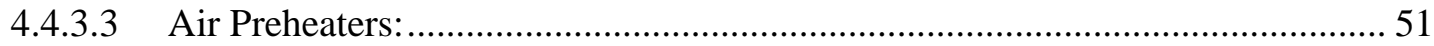

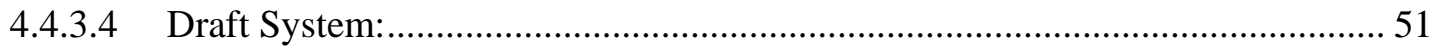

4.5 Case 2b - The Case 2a Capture Ready CFB Boiler Island Retrofit with $\mathrm{O}_{2}$ firing

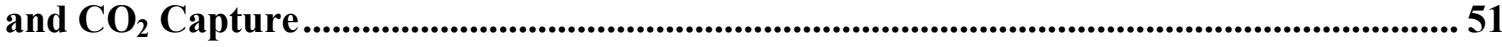

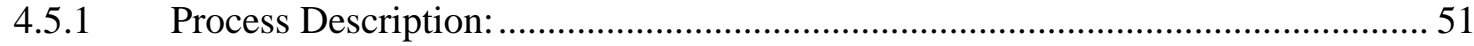

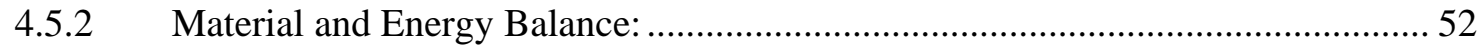

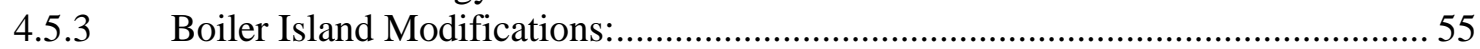

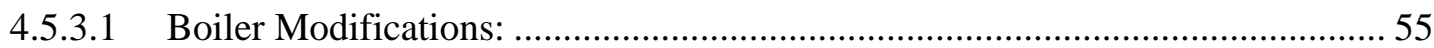

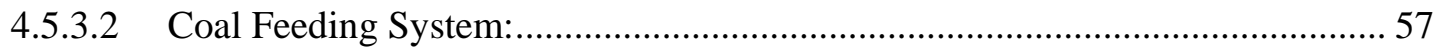

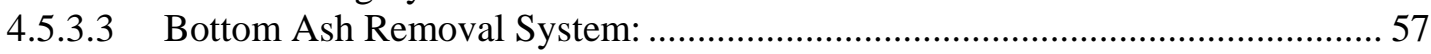

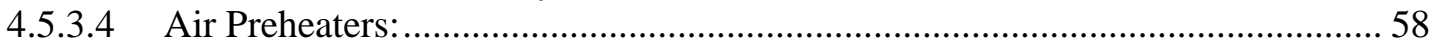

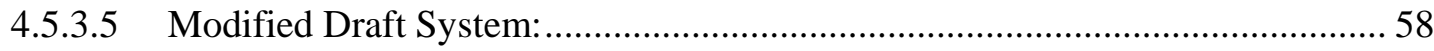

4.5.3.6 Modified Controls and Instrumentation for the Boiler Island:.......................... 59

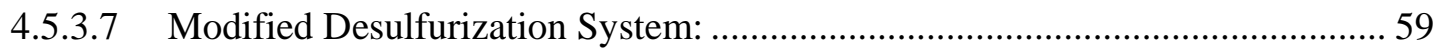

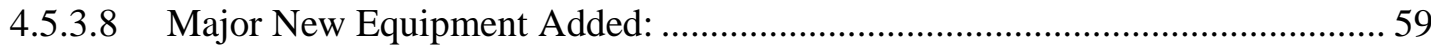

5 STEAM TURBINE DESIGN AND PERFORMANCE......................................60

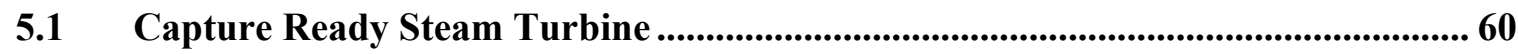

5.2 Capture Ready Converted Steam Turbine ............................................................60 60

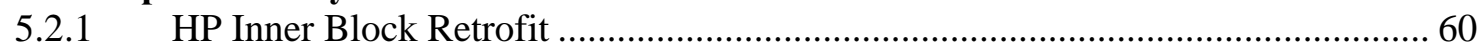

$5.3 \quad$ Steam Turbine/Generator Layout Drawings........................................................62

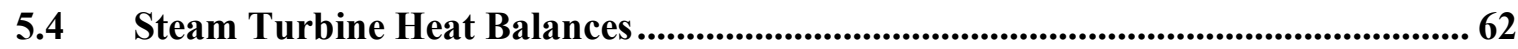

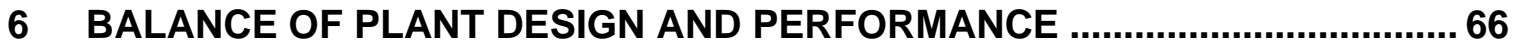

6.1 Air Separation Unit ............................................................................................................ 66

6.2 Gas Processing System ..................................................................................................... 67

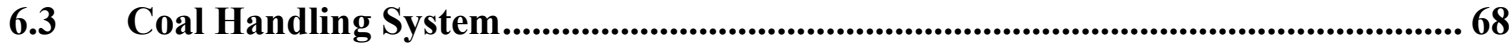




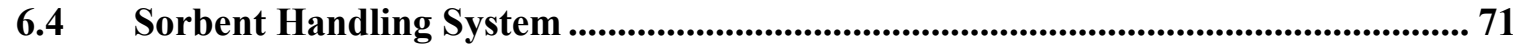

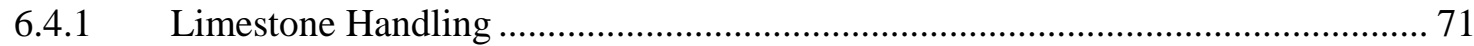

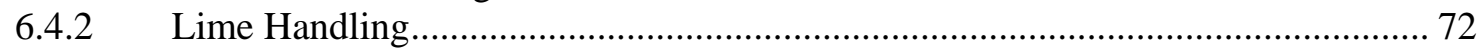

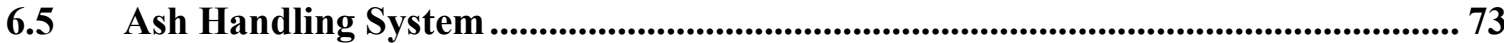

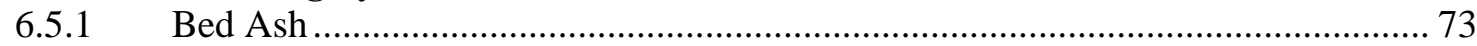

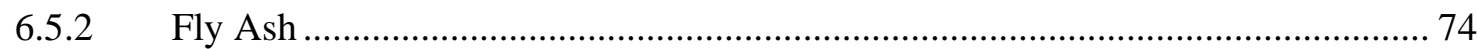

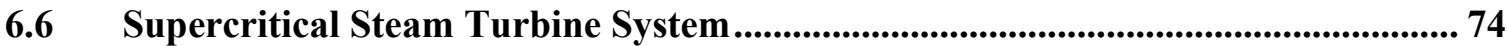

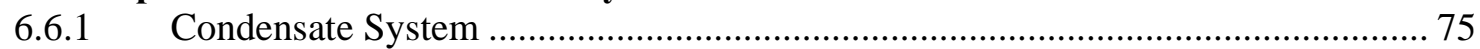

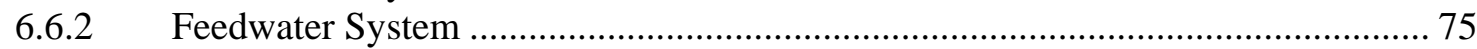

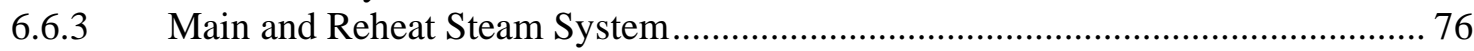

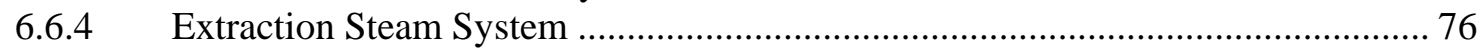

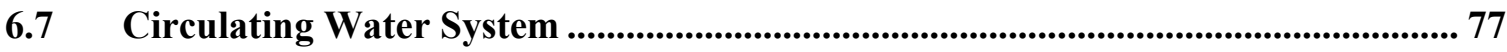

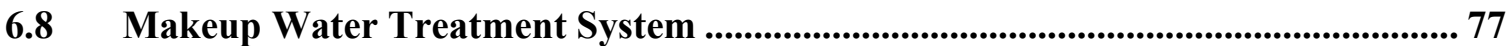

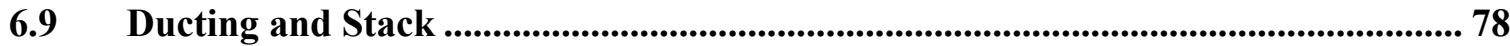

6.10 Wastewater Treatment System ...................................................................................... 78

6.11 Miscellaneous Systems ................................................................................................. 78

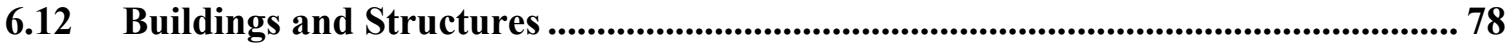

6.13 Accessory Electric Plant ................................................................................................ 79

6.14 Instrumentation and Control ........................................................................................ 79

6.15 Balance of Plant Auxiliary Loads ...................................................................... 79

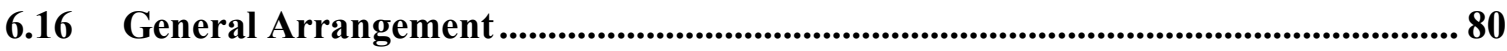

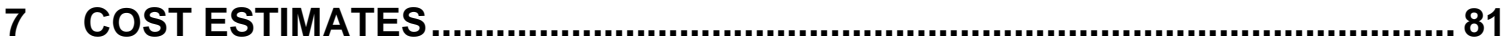

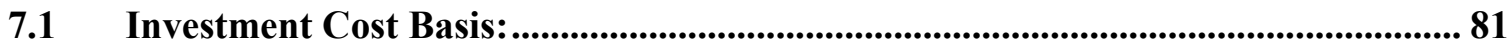

7.2 Operating and Maintenance Costs Basis: ................................................................... 83

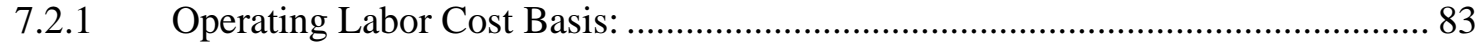

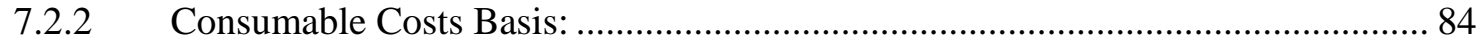

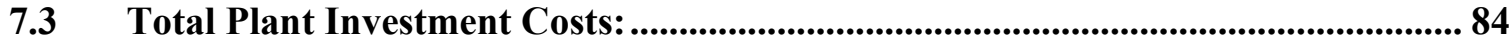

7.3.1 BOP Cost and Scope Differences Between the Cases ......................................... 87

7.3.2 Incremental Specific Investment Cost (\$/kWe-net) for Case 2b: ......................... 91

7.4 Operating and Maintenance Costs .............................................................................. 91

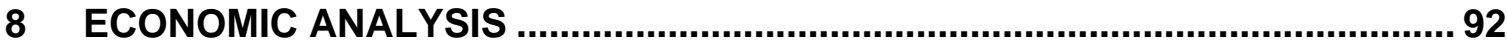

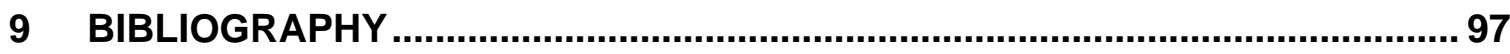




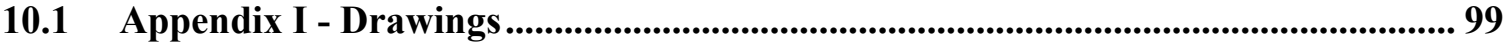

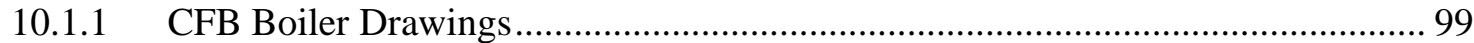

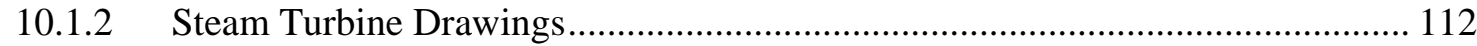

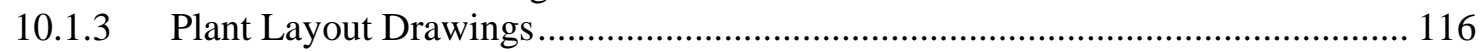

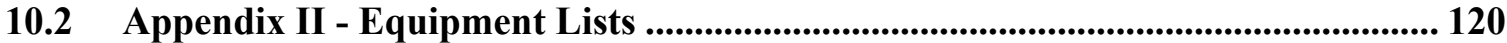

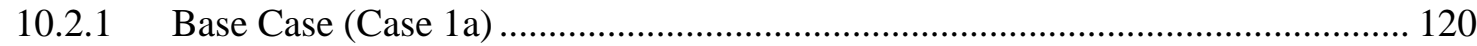

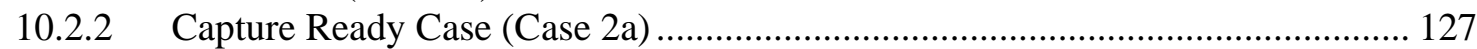

10.2.3 Capture Ready Converted to Oxygen Firing (Case 2b) .................................... 134

10.3 Appendix III - Detailed Balance of Plant Cost Breakdowns ................................. 137 


\section{LIST OF FIGURES}

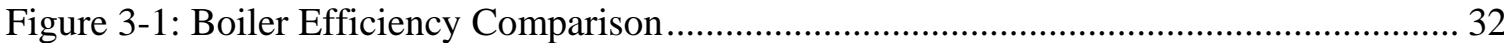

Figure 3-2: Coal Heat Input and Boiler Heat Output Comparison ......................................... 33

Figure 3-3: Steam Cycle Efficiency Comparison .................................................................. 33

Figure 3-4: Auxiliary Power Comparison between Air-Fired and Oxy-fuel Fired CFB Plants 34

Figure 3-5: Net Plant Electrical Output Comparison .......................................................... 35

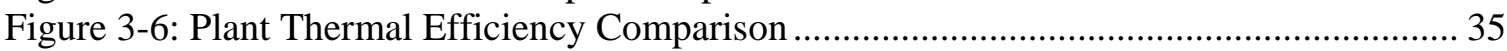

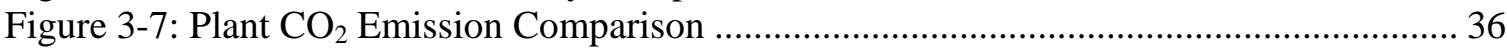

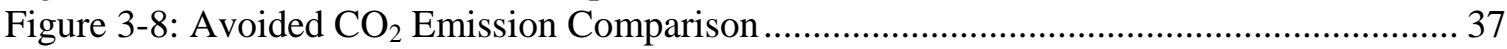

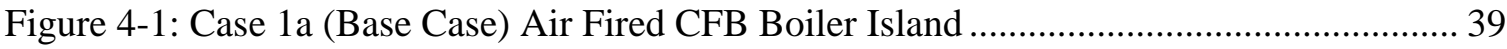

Figure 4-2: Case $1 \mathrm{~b}$ - CFB Boiler Retrofit with $\mathrm{O}_{2}$ Firing and $\mathrm{CO}_{2}$ Capture .......................... 42

Figure 4-3: Flash Dryer Absorber (FDA) System Schematic Diagram (simplified) ................. 47

Figure 4-4: Case 2a Capture Ready Air Fired CFB Boiler Island ............................................ 48

Figure 4-5: Case 2b -Capture Ready CFB Boiler (Case 2a) Retrofit with $\mathrm{O}_{2}$ Firing and $\mathrm{CO}_{2}$

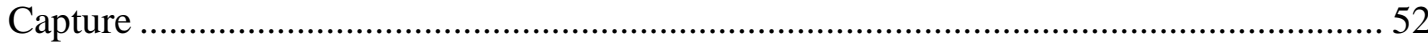

Figure 4-6: Case 2b - Sectional Side Elevation of the Capture Ready Converted CFB Boiler Showing the Wing Wall Surface Added in the Furnace and the Economizer Surface Added in the Backpass

Figure 4-7: Case 2b - Plan View Showing Modified External Fluidized Bed Heat Exchangers

Figure 4-8: Case 2b - Section View Showing the Added Tubular Oxygen Heater and its

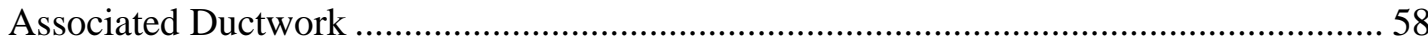

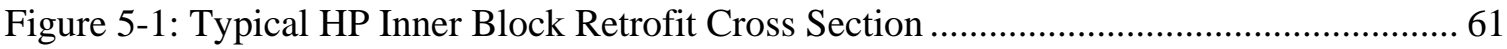

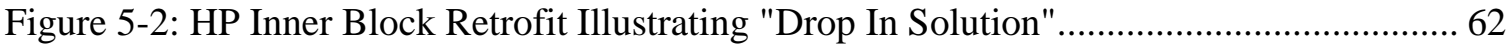

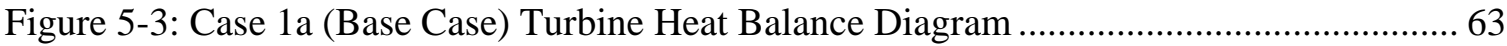

Figure 5-4: Case 2a Capture Ready Turbine Heat Balance Diagram ....................................... 64

Figure 5-5: Case 2b Capture Ready Converted Turbine Heat Balance Diagram........................ 65

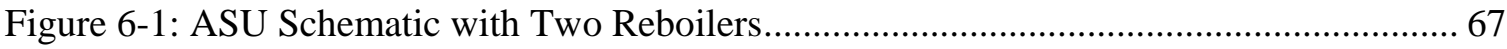

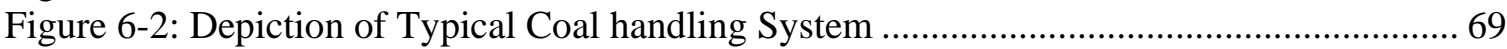

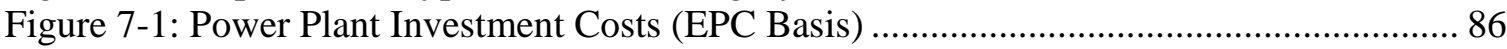

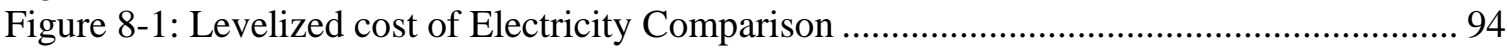

Figure 8-2: Relative Net Present Value Comparisons ............................................................ 95

Figure 10-1: Cases 1a, 1b, 2a Steam Turbine/Generator Layout Plan Drawing (operating floor el 1188')

Figure 10-2: Cases 1a, 1b, 2a Steam Turbine/Generator Layout Plan Drawings (floor el. 1,146' / 1,124')

Figure 10-3: Case 2b Capture Ready Converted Generator General Arrangement Drawing .. 115

Figure 10-4: Case 1a (Base Case) Air Blown CFB Steam Plant (Not Capture Ready) Layout117

Figure 10-5: Case 2a Air Blown Capture Ready CFB Steam Plant Layout ............................ 119

Figure 10-6:Case 2b Oxygen Blown CFB Steam Plant Layout with $\mathrm{CO}_{2}$ Capture .................. 119 


\section{LIST OF TABLES}

Table 2-1: Makeup Water Characteristics............................................................................... 24

Table 2-2: Site Characteristics for all Material and Energy Balances ...................................... 25

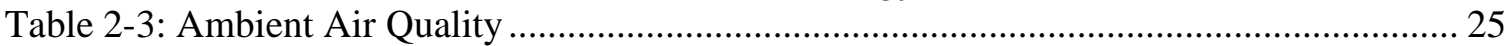

Table 2-4: Design Coal Analysis (Medium Volatile Bituminous)......................................... 26

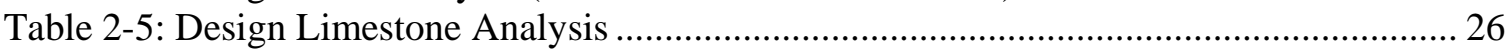

Table 2-6: Dakota Gasification Project's $\mathrm{CO}_{2}$ Product Specification for EOR ......................... 27

Table 3-1: Plant Performance and $\mathrm{CO}_{2}$ Emissions Summary and Comparison.......................... 30

Table 3-2: Comparison of Plant Auxiliary Power Requirements ........................................... 31

Table 4-1: Case 1a Boiler Island Material and Energy Balance (Base Case) ............................. 40

Table 4-2: Case 1b Boiler Island Material and Energy Balance (Base Case Retrofit with

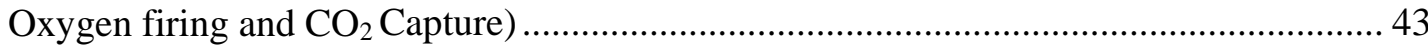

Table 4-3: Case 2a Boiler Island Material and Energy Balance $\left(\mathrm{CO}_{2}\right.$ Capture Ready) ............. 49

Table 4-4: Case 2b Boiler Island Material and Energy Balance (Capture Ready CFB Retrofit

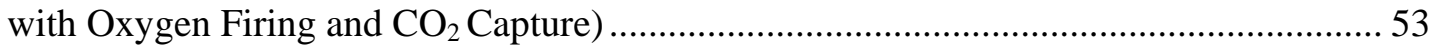

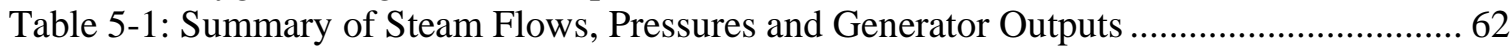

Table 6-1: ASU Oxygen Production and Purity..................................................................... 67

Table 6-2: Dakota Gasification Project's $\mathrm{CO}_{2}$ Specification for EOR and the Calculated

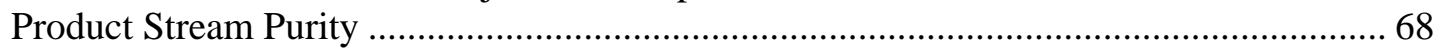

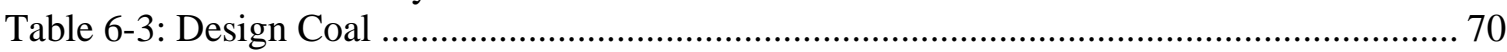

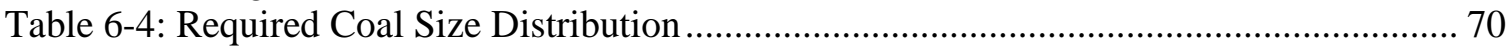

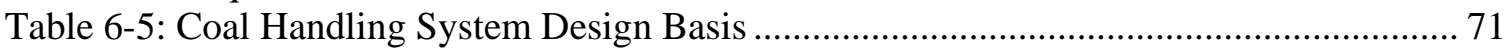

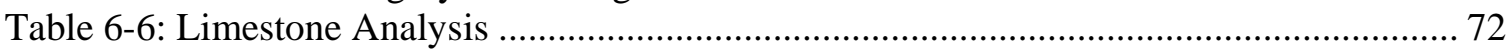

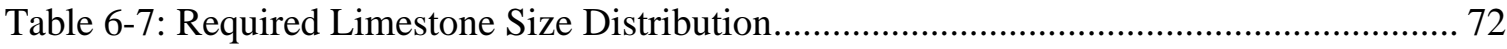

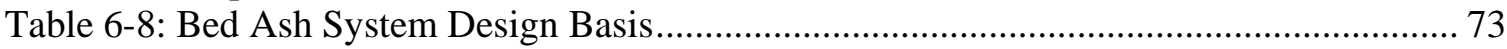

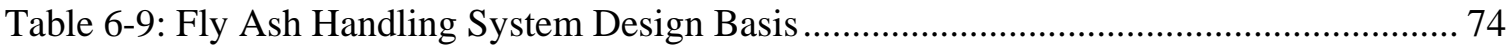

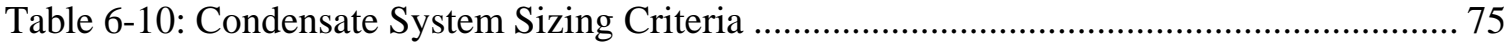

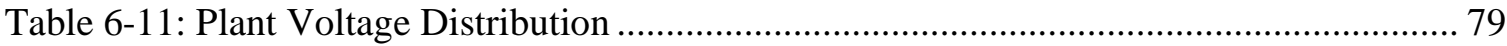

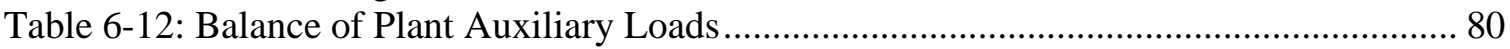

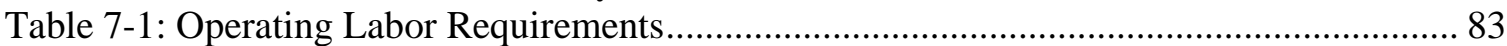

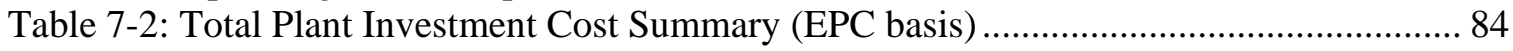

Table 7-3: BOP Cost and Scope Differences Between the Cases........................................... 88

Table 7-4: Operating and Maintenance Cost Summary …...................................................... 91

Table 8-1: Common Economic Parameters ............................................................................ 92

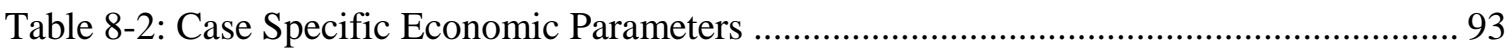

Table 8-3: Economic Comparison of Capture Ready and Capture Unready Plants .................. 93

Table 10-1: Detailed BOP Costs for Case 1a (Base Case)..................................................... 137

Table 10-2: BOP Costs for Case $1 \mathrm{~b}$ (Base Case Power Plant Retrofit to $\mathrm{O}_{2}$ Firing and $\mathrm{CO}_{2}$

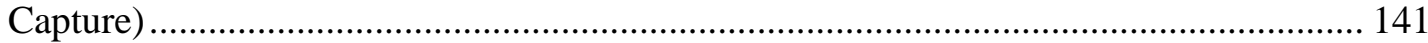

Table 10-3: Detailed BOP Costs for Case 2a (Capture Ready Power Plant) ........................... 142

Table 10-4: Detailed BOP Costs for Case 2b (Capture Ready Power Plant Retrofit to $\mathrm{O}_{2}$ Firing

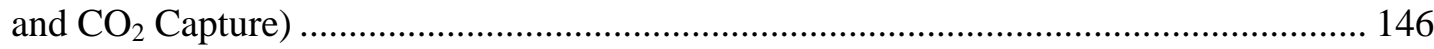




\section{LIST OF ACRONYMS AND ABBREVIATIONS}

\begin{tabular}{|c|c|c|c|}
\hline ABMA & American Boiler Manufacturers Association & $\mathrm{kV}$ & Kilovolt \\
\hline ANSI & American National Standards Institute & $\mathrm{lbm}$ & Pound mass \\
\hline ASU & Air Separation Unit & LMTD & Log Mean Temperature Difference \\
\hline Bara & Bar, absolute & LP & Low Pressure \\
\hline Barg & Bar, gauge & Ipm & Liters per minute \\
\hline BOP & Balance of Plant & MDEA & Methyl Diethanolamine \\
\hline Btu & British Thermal Unit & MEA & Monoethanolamine \\
\hline CFB & Circulating Fluidized Bed & $\mathrm{mm} \mathrm{H} \mathrm{H}_{2} \mathrm{O}$ & Millimeters of Water \\
\hline CFM & Cubic Feet per Minute & $\mathrm{mm} \mathrm{Hga}$ & Millimeters of Mercury, Absolute \\
\hline $\mathrm{CHL}$ & Carbon Heat Loss & MTF & Multi-use Test Facility \\
\hline CS & Carbon Steel & $\mathrm{N}_{2}$ & Nitrogen Gas \\
\hline $\mathrm{dB}$ & Decibel & NPHR & Net Plant Heat Rate \\
\hline DCA & Direct Contact Aftercooler & $\mathrm{O}_{2}$ & Oxygen Gas \\
\hline DCS & Distributed Control System & O\&M & Operation \& Maintenance \\
\hline DGC & Dakota Gasification Company & P\&ID & Process \& Instrumentation Diagram \\
\hline DOE/NETL & Department of Energy/National Energy Technology Laboratory & PA & Primary Air \\
\hline EHE & External Heat Exchanger & PC & Pulverized Coal \\
\hline EOR & Enhanced Oil Recovery & PFD & Process Flow Diagram \\
\hline EPC & Engineered, Procured and Constructed (cost basis) & PFWH & Parallel Feedwater Heater \\
\hline FBC & Fluidized Bed Combustion & $\mathrm{PHX}$ & Primary Heat Exchanger \\
\hline FBHE & Fluidized Bed Heat Exchanger & ppm & Parts per million \\
\hline GPS & Gas Processing System & TPD & Ton Per Day \\
\hline $\mathrm{HHV}$ & Higher Heating Value & TPH & Ton Per Hour \\
\hline HP & High Pressure & UBC & Unburned Carbon \\
\hline hp & Horse Power & UCT & Upper Column Turbine \\
\hline $\mathrm{hr}$ & Hour & V & Volt \\
\hline ID & Induced Draft & VOC & Volatile Organic Compounds \\
\hline IP & Intermediate Pressure & VOM & Variable Operation \& Maintenance \\
\hline in. $\mathrm{H}_{2} \mathrm{O}$ & Inches of Water & & \\
\hline in. $\mathrm{Hga}$ & Inches of Mercury, Absolute & & \\
\hline $\mathrm{kg}$ & Kilogram & & \\
\hline $\mathrm{kJ}$ & Kilojoule & & \\
\hline
\end{tabular}




\section{EXECUTIVE SUMMARY}

Coal-fired power plants of the future will likely need systems that enable the cost effective capture and sequestration of their $\mathrm{CO}_{2}$ emissions, since fossil fuels will remain the primary energy source for the foreseeable future. ALSTOM is evaluating several options in the mitigation of greenhouse gases from fossil fuel combustion. One of the potential technologies to accomplish this is oxy-combustion. This study investigated the concept of building a conventional CFB steam plant with provisions for facilitating future conversion to oxygen firing and $\mathrm{CO}_{2}$ capture.

Burning fossil fuels in mixtures of oxygen and recirculated flue gas (principally $\mathrm{CO}_{2}$ ) essentially eliminates the presence of atmospheric nitrogen in the flue gas. The resulting flue gas is comprised primarily of $\mathrm{CO}_{2}$, along with some moisture, nitrogen, oxygen, and trace gases like $\mathrm{SO}_{2}$ and $\mathrm{NO}_{\mathrm{X}}$. Oxygen firing in Circulating Fluid Bed Boilers (CFB's) can be done with boilers that are smaller and less costly than their air fired counterparts (Marion, et al. 2003).

\section{Background:}

In 2001, ALSTOM Power Inc. (ALSTOM) began a two-phase program to investigate the feasibility of various carbon capture technologies. This program was sponsored under a Cooperative Agreement from the US Department of Energy's National Energy Technology Laboratory (DOE).

The first phase entailed a comprehensive study evaluating the technical feasibility and economics of alternate $\mathrm{CO}_{2}$ capture technologies applied to Greenfield US coal-fired electric generation power plants. Thirteen cases, representing various levels of technology development, were evaluated. Seven cases represented coal combustion in CFB type equipment. Four cases represented Integrated Gasification Combined Cycle (IGCC) systems. Two cases represented advanced Chemical Looping Combined Cycle systems. Marion, et al. reported the details of this work in 2003.

One of the thirteen cases studied utilized an oxygen-fired circulating fluidized bed (CFB) boiler. In this concept, the fuel is fired with a mixture of oxygen and recirculated flue gas (mainly $\mathrm{CO}_{2}$ ) - see schematic below. This combustion process yields a flue gas containing over 80 percent (by volume) $\mathrm{CO}_{2}$. This flue gas can be processed relatively easily to enrich the $\mathrm{CO}_{2}$ content to over 96 percent for use in enhanced oil or gas recovery (EOR or EGR) or simply dried for sequestration.

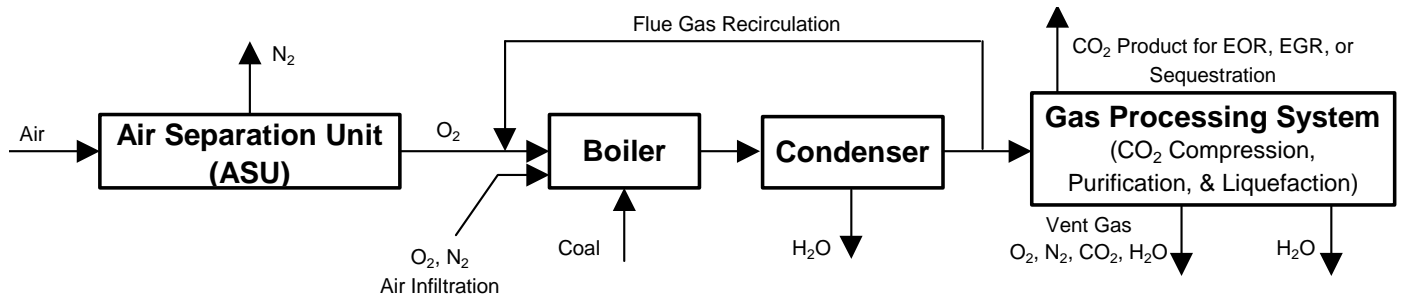

The Phase I study identified the $\mathrm{O}_{2}$-fired CFB as having a near term development potential, because it uses conventional commercial CFB technology and commercially available $\mathrm{CO}_{2}$ capture enabling technologies such as cryogenic air separation and simple rectification or distillation gas processing systems. In the long term, air separation technology advancements offer significant reductions in power requirements, which would improve plant efficiency and economics for the oxygen-fired technology.

The second phase consisted of pilot-scale testing followed by a refined performance and 
economic evaluation of the $\mathrm{O}_{2}$ fired CFB concept. As a part of this workscope, ALSTOM modified its $3 \mathrm{MW}_{\text {th }}(9.9 \mathrm{MM}-\mathrm{Btu} / \mathrm{hr}$ ) Multiuse Test Facility (MTF) pilot plant to operate with $\mathrm{O}_{2} / \mathrm{CO}_{2}$ mixtures of up to 70 percent $\mathrm{O}_{2}$ by volume. Tests were conducted with coal and petroleum coke. The test objectives were to determine the impacts of oxygen firing on heat transfer, bed dynamics, potential agglomeration, and gaseous and particulate emissions. The test data results were used to refine the design, performance, costs, and economic models developed in Phase-I for the $\mathrm{O}_{2}$-fired CFB with $\mathrm{CO}_{2}$ capture. Nsakala, Liljedahl, and Turek reported results from this study in 2004.

At that time ALSTOM identified several items needing further investigation in preparation for large-scale demonstration of the oxygen-fired CFB concept, namely:

- Operation and performance of the moving bed heat exchanger (MBHE) to avoid recarbonation and also for cost savings compared to the standard bubbling fluid bed heat exchanger (FBHE).

- Performance of the back-end flash dryer absorber (FDA) for sulfur capture under high $\mathrm{CO}_{2}$ / high moisture flue gas environment using calcined limestone in the fly ash and using fresh commercial lime directly in the FDA.

- Determination of the effect of recarbonation on fouling in the convective pass.

- Assessment of the impact of oxygen firing on the mercury, other trace elements, and volatile organic compound (VOC) emissions.

- Develop a proposal-level oxygen-fired retrofit design for a relatively small existing CFB steam power plant in preparation for a large-scale demonstration of the $\mathrm{O}_{2}$ fired CFB concept.

Hence, ALSTOM responded to a DOE Solicitation to address all these issues with further $\mathrm{O}_{2}$ fired MTF pilot testing and a subsequent retrofit design study of oxygen firing and $\mathrm{CO}_{2}$ capture on an existing air-fired CFB plant. ALSTOM received a contract award from the DOE to conduct a project entitled "Commercialization Development of Oxygen Fired CFB for Greenhouse Gas Control,” under Cooperative Agreement DE-FC26-04NT42205. The results from this effort are reported in Volume-I of this report.

During Phases I-III, ALSTOM also identified a need to investigate the design of the $\mathrm{CO}_{2}$ capture ready oxygen-fired CFB power plant concept, which is the subject of this report as discussed herein.

\section{$\mathrm{CO}_{\mathbf{2}}$ Capture Ready Study Results Summary:}

The purpose of this study is to quantitatively determine the attributes of designing supercritical (SC) circulating fluidized bed (CFB) power plants (600 MW class) that are $\mathrm{CO}_{2}$ capture-ready via future oxygen firing. The retrofit of traditionally designed steam power plants for $\mathrm{CO}_{2}$ capture has been shown to reduce plant output significantly, be very energy intensive, costly, and quite often not enough site space is available for optimally installing the $\mathrm{CO}_{2}$ capture equipment. This work identifies the impacts on overall plant performance, costs, and economics of converting a capture-ready $\mathrm{CFB}$ plant to $\mathrm{O}_{2}$ firing and $\mathrm{CO}_{2}$ capture as compared to converting a non-capture-ready CFB plant to $\mathrm{O}_{2}$ firing and $\mathrm{CO}_{2}$ capture. As such, this work quantifies the potential financial benefits of pre-investing some money into a capture-ready plant in order to facilitate its future conversion to $\mathrm{O}_{2}$ firing and $\mathrm{CO}_{2}$ capture.

As mentioned above, in general, when a power plant is converted to $\mathrm{O}_{2}$ firing and $\mathrm{CO}_{2}$ capture, although the gross electrical output does not change, there is a significant loss in the net electrical output from the plant. This output loss is primarily due to the power consumption 
requirements of the air separation unit (ASU) and the gas processing system (GPS). These systems typically consume a total of about 25-30 percent of the generator electrical output.

This study investigates the feasibility of designing capture-ready CFB based power plants with additional provisions (other than just adding the ASU and GPS for $\mathrm{CO}_{2}$ capture) such that additional modifications can be made at the time the plant is converted to $\mathrm{O}_{2}$ firing and $\mathrm{CO}_{2}$ capture to allow the net power output from the plant to be conserved.

\section{Plant Performance:}

The retrofit of CFB boiler steam plants (both capture-ready and non capture-ready) to oxygen firing and $\mathrm{CO}_{2}$ capture causes several significant impacts on the overall plant performance, $\mathrm{CO}_{2}$ emissions, and cost of electricity as compared to the air fired Base Case. The net plant output for the non capture-ready plant is reduced from 637 to 476 MWe, a 25 percent reduction whereas the net plant output for the capture-ready plant is maintained. The plant thermal efficiency (HHV basis) is reduced by about 10 percentage points (from about $38 \%$ to $28 \%$ ) for both capture-ready and non capture-ready retrofits. Specific $\mathrm{CO}_{2}$ emissions are reduced more than 92 percent from 0.82 to $0.07 \mathrm{~kg} / \mathrm{kWh}(1.82$ to $0.15 \mathrm{lbm} / \mathrm{kWh})$ for both capture-ready and non capture-ready retrofits.

\section{Plant Modifications:}

Retrofitting the capture-ready and non capture-ready CFB plants to oxygen firing capability and $\mathrm{CO}_{2}$ capture is technically straightforward.

The non capture-ready CFB plant requires relatively minor modifications to the existing equipment. Boiler island modifications include a new flue gas recirculation system, new oxygen supply piping, a new oxygen heater, new $\mathrm{CO}_{2}$ product ductwork feeding the new gas processing system, the addition of a new $\mathrm{SO}_{2}$ removal system (Flash Dryer Absorber), and associated new controls and instrumentation for these systems. Pressure part changes to the existing boiler are not required.

Relatively minor changes to the balance of plant are required such as modifications to the feedwater system to include low-level heat recovery from the ASU and GPS, and additional accessory electrical equipment to support the added ASU and GPS.

The capture-ready CFB plant, which is designed to maintain the original net plant electrical output after the conversion, requires significantly more modifications than the non captureready plant. Boiler island modifications, in addition to those mentioned above for the noncapture ready retrofit, include several pressure part changes to accommodate the increase in steam generation rate. Wingwalls are added to the combustor, economizer surface is added in the rear pass, and superheat and reheat surface is added in the external heat exchangers.

The modifications to the balance of plant include steam turbine/generator modifications to accommodate the increased steam flow, as well as modifications to various other BOP systems such as the feedwater system, the cooling water system, the ash handling system, and the accessory electrical system.

The major new systems required for retrofit of both capture-ready and non capture-ready plants are a cryogenic air separation unit (ASU), a gas processing system (GPS), and the addition of an FDA system for sulfur removal. The ASU and GPS have significant land area requirements for the location of new equipment.

The following tables and lists further summarize the capture ready design provisions and the actual retrofit modifications required for the plants.

Table ES-1 identifies with respect to the Boiler Island: 
o The design provisions made for the Capture-Ready plant (Case 2a) in anticipation of increased steam flow after conversion of this plant to $\mathrm{O}_{2}$ firing and $\mathrm{CO}_{2}$ capture

o The design specifications implemented on the Capture-Ready Converted Plant (Case 2b) to accommodate increased steam flow

o Provisions made for future installations of the Air Separation Unit and Gas Processing System in conjunction with Case $2 \mathrm{~b}$ implementation

ES- 1: Boiler Island Comparison

\begin{tabular}{|c|c|c|c|c|}
\hline & $\begin{array}{l}\text { Base } \\
\text { Case } \\
\text { (Case 1a) }\end{array}$ & $\begin{array}{l}\text { Capture- } \\
\text { Unready } \\
\text { Converted } \\
\text { Ready } \\
\text { (Case 1b) }\end{array}$ & $\begin{array}{l}\text { Capture-Ready } \\
\text { (Case 2a) }\end{array}$ & $\begin{array}{l}\text { Capture-Ready } \\
\text { Converted } \\
\text { (Case } 2 b)\end{array}$ \\
\hline Steam Flow: & Per Design & $\begin{array}{l}\text { Per Design of } \\
\text { Base Case (Case } \\
\text { 1a) }\end{array}$ & $\begin{array}{l}\text { 1) Steam flow same as } \\
\text { Base Case } \\
\text { 2) Increase boiler } \\
\text { height by } 5 \mathrm{ft} \text { and } \\
\text { provision for future } \\
\text { addition of wing walls } \\
\text { 3) Leave sufficient } \\
\text { space for future } \\
\text { increases in } \\
\text { economizer, FBHE, } \\
\text { SH, \& RH surfaces }\end{array}$ & $\begin{array}{l}\text { Increase steam flow by } \\
\text { 38\% with following } \\
\text { modifications: } \\
\text { 1) Install } 32 \text { wing walls } \\
\text { 2) Add } 43 \% \text { more } \\
\text { economizer surface } \\
\text { 3) Add 30\% more SH \& } \\
\text { RH surfaces to the FBHE's }\end{array}$ \\
\hline $\begin{array}{l}\text { Other: ASU, GPS, } \\
\mathrm{O}_{2} \text { heater, Lime feed } \\
\text { system for FDA, \& } \\
\text { Flue gas } \\
\text { recirculation system }\end{array}$ & $\begin{array}{l}\text { Not } \\
\text { Applicable }\end{array}$ & $\begin{array}{l}\text { Add ASU, GPS, } \\
\text { O2 heater, FDA } \\
\text { System, Lime feed } \\
\text { system for FDA, } \\
\text { \& Flue gas } \\
\text { recirculation } \\
\text { system }\end{array}$ & $\begin{array}{l}\text { Leave space for future } \\
\text { additions of all the } \\
\text { items in column \#1 }\end{array}$ & $\begin{array}{l}\text { Add ASU, GPS, O2 heater, } \\
\text { FDA System, Lime feed } \\
\text { system for FDA, \& Flue } \\
\text { gas recirculation system }\end{array}$ \\
\hline
\end{tabular}

Table ES-2 identifies with respect to the Steam Turbine/Generator:

o The design provisions made for the HP, IP \& LP turbines of the Capture-Ready plant (Case 2a) in anticipation of increased steam flow after conversion of this plant to $\mathrm{O}_{2}$ firing and $\mathrm{CO}_{2}$ capture

o The design specifications implemented on generator of the Capture-Ready Converted Plant (Case 2b) for operation with increased steam flow after conversion to $\mathrm{O}_{2}$ firing and $\mathrm{CO}_{2}$ capture 
ES- 2: Steam Turbine/Generator Comparison

\begin{tabular}{|l|l|l|l|l||}
\hline \hline & $\begin{array}{l}\text { Base Case } \\
\text { (Case 1a) }\end{array}$ & $\begin{array}{l}\text { Capture- } \\
\text { Unready } \\
\text { Converted } \\
\text { Ready } \\
\text { (Case 1b) }\end{array}$ & $\begin{array}{l}\text { Capture-Ready } \\
\text { (Case 2a) }\end{array}$ & $\begin{array}{l}\text { Capture-Ready } \\
\text { Converted } \\
\text { (Case 2b) }\end{array}$ \\
\hline $\begin{array}{l}\text { HP, IP \& LP } \\
\text { Turbines }\end{array}$ & Per Design & $\begin{array}{l}\text { Per Design of Base } \\
\text { Case (Case 1a) }\end{array}$ & $\begin{array}{l}\text { 1) IP \& LP turbines } \\
\text { capable of } \\
\text { swallowing added } \\
\text { 38\% steam flow } \\
\text { 2) HP designed for } \\
100 \% \text { flow }\end{array}$ & $\begin{array}{l}\text { HP Inner Block Retrofit: } \\
\text { New Rotor with Blades \& } \\
\text { Coupling } \\
\text { New Inner Casing \& } \\
\text { Blades }\end{array}$ \\
\hline Generator & Per Design & $\begin{array}{l}\text { Per Design of Base } \\
\text { Case (Case 1a) }\end{array}$ & Per Design & $\begin{array}{l}32 \% \text { more output - Install } \\
\text { larger generator }\end{array}$ \\
\hline \hline
\end{tabular}

Table ES-3 identifies with respect to the Balance of Plant (BOP):

o The design provisions made/design specifications implemented on the Capture-Ready Plant (Case 2a) and Capture-Ready Converted Plant (2b) in anticipation of higher solids handling capacities, more feedwater and cooling water capacities after conversion to $\mathrm{O}_{2}$ firing and $\mathrm{CO}_{2}$ capture

o The design provisions made/design specifications implemented on the Capture-Ready Plant (Case 2a) and Capture-Ready Converted Plant (2b) in anticipation of higher demand of electrical accessories after conversion to $\mathrm{O}_{2}$ firing and $\mathrm{CO}_{2}$ capture. 
ES- 3: BOP Comparison

\begin{tabular}{|l|l|l|l|l||}
\hline & $\begin{array}{l}\text { Base Case } \\
\text { (Case 1a) }\end{array}$ & Papture-Ready & $\begin{array}{l}\text { Capture-Ready } \\
\text { Converted } \\
\text { (Case 2b) }\end{array}$ \\
\hline Solids Handling & Per Design & $\begin{array}{l}\text { Per Design of } \\
\text { Base Case } \\
\text { (Case 1a) }\end{array}$ & $\begin{array}{l}\text { All, except lime } \\
\text { handling system for } \\
\text { FDA, same as Base } \\
\text { Case }\end{array}$ & $\begin{array}{l}\text { 1) Coal (increase operation } \\
\text { 33\%, i.e., from 10- to 15-8 hour } \\
\text { shifts per week) } \\
\text { 2) Limestone not in use in } \\
\text { converted plant } \\
\text { 3) Lime system added for FDA } \\
\text { 4) Ash (increase operation by } \\
\text { 40\%) }\end{array}$ \\
\hline $\begin{array}{l}\text { Feedwater } \\
\text { System }\end{array}$ & Per Design & $\begin{array}{l}\text { Add low level } \\
\text { heat } \\
\text { integration } \\
\text { between ASU, } \\
\text { GPS, and LP } \\
\text { feed water }\end{array}$ & $\begin{array}{l}\text { De-aerator, BFP, } \\
\text { HP-FWH's } \\
\text { capacities 38\% } \\
\text { larger }\end{array}$ & $\begin{array}{l}\text { Add low level heat integration } \\
\text { between ASU, GPS, and LP } \\
\text { feed water }\end{array}$ \\
\hline $\begin{array}{l}\text { Cooling Water } \\
\text { System \& } \\
\text { Condenser }\end{array}$ & Per Design & $\begin{array}{l}\text { Per Design of } \\
\text { Base Case } \\
\text { (Case 1a) }\end{array}$ & $\begin{array}{l}\text { 1) Leave space for } \\
\text { future circulating } \\
\text { water pump, and } \\
\text { cooling tower. } \\
\text { 2) Larger condenser } \\
\text { (+50\% capacity) }\end{array}$ & $\begin{array}{l}\text { Add circulating water pump, } \\
\text { and cooling tower ( 50\% } \\
\text { increase in capacity) }\end{array}$ \\
\hline $\begin{array}{l}\text { Accessory } \\
\text { Electric Plant }\end{array}$ & Per Design & $\begin{array}{l}\text { Add } \\
\text { transformers } \\
\text { \& switchgear } \\
\text { for ASU, \& } \\
\text { GPS }\end{array}$ & $\begin{array}{l}\text { Leave space for } \\
\text { future additions of } \\
\text { transformers \& } \\
\text { switchgear for } \\
\text { ASU, \& GPS }\end{array}$ & $\begin{array}{l}\text { Add transformers \& switchgear } \\
\text { for ASU, \& GPS }\end{array}$ \\
\hline
\end{tabular}

\section{Plant Costs:}

The non capture-ready plant retrofit cost (EPC basis - May 2007 \$US) is estimated to be about $969 \$ / \mathrm{kW}$-new, based on the new power output (i.e. the total retrofit cost divided by the new net output). There is also a specific cost impact ( $\$ / \mathrm{kW}$-new) associated with the value of the existing plant equipment. Because the retrofitted plant produces less net output, the specific cost of the existing plant equipment is increased. If this is included, the total non capture-ready plant retrofit cost is estimated to be about $1,425 \$ / \mathrm{kW}$-new.

Modifications to the existing boiler are relatively minor as mentioned above and cost only about $6 \$ / \mathrm{kW}$-new. The new Flash Dryer Absorber $\mathrm{SO}_{2}$ removal system costs 118 \$/kW-new. The remaining costs - nearly $78 \%$ of the total retrofit cost - are for the cryogenic air separation and gas processing systems. Though costly, these systems are commercially proven and technically straightforward.

The capture-ready plant retrofit cost is estimated to be about $961 \$ / \mathrm{kW}$-new, based on the new power output (i.e. the total retrofit cost divided by the new net output). In this case, there is no retrofit cost associated with the value of the existing plant equipment (as there was for the 
non capture ready retrofit) because the plant still produces the same net output as it did before the retrofit.

Modifications to the existing boiler are more extensive, as mentioned above, and cost about 27 $\$ / \mathrm{kW}$-new or about 3\% of the total plant retrofit cost. The new Flash Dryer Absorber $\mathrm{SO}_{2}$ removal system costs $90 \$ / \mathrm{kW}$-new or about $9 \%$ of the total. BOP modifications, including the steam turbine/generator modifications, amount to about $16 \%$ of the total. The remaining costs about $72 \%$ of the total - are for the cryogenic air separation unit and gas processing system.

ES- 4: Investment Cost Comparison (EPC Basis)

\begin{tabular}{|c|c|c|c|c|c|c|c|c|c|}
\hline \multirow{2}{*}{$\begin{array}{l}\text { Acct } \\
\text { No. }\end{array}$} & \multirow{2}{*}{$\begin{array}{l}\text { Total Plant Cost Summary } \\
\text { Item/Description }\end{array}$} & \multicolumn{2}{|c|}{ Case 1a } & \multicolumn{2}{|c|}{ Case 1b } & \multicolumn{2}{|c|}{ Case 2a } & \multicolumn{2}{|c|}{ Case 2b } \\
\hline & & $\$ \times 1000$ & $\$ / \mathbf{k W}$ & $\$ \times 1000$ & $\$ / \mathbf{k W}$ & $\$ \times 1000$ & $\$ / k W$ & $\$ \times 1000$ & $\$ / k W$ \\
\hline 1 & COAL \& SORBENT HANDLING & 41,010 & 65 & 44,451 & 94 & 41,010 & 64 & 44,451 & 72 \\
\hline 2 & COAL \& SORBENT PREP \& FEED & 16,807 & 26 & 16,807 & 35 & 16,807 & 26 & 16,807 & 27 \\
\hline 3 & FEEDWATER \& MISC. BOP SYSTEMS & 74,155 & 117 & 80,267 & 169 & 86,626 & 136 & 92,738 & 149 \\
\hline 4 & CFB BOILER \& ACCESSORIES & 350,175 & 551 & 353,236 & 743 & 356,036 & 560 & 372,825 & 601 \\
\hline $4 a$ & Air Separation Unit & $\mathrm{n} / \mathrm{a}$ & $\mathrm{n} / \mathrm{a}$ & 226,005 & 476 & $\mathrm{n} / \mathrm{a}$ & $\mathrm{n} / \mathrm{a}$ & 278,730 & 449 \\
\hline 5 & FLUE GAS CLEANUP & 53,068 & 83 & 109,068 & 230 & 53,068 & 83 & 109,068 & 176 \\
\hline $5 a$ & CO2 Processing System (Purif, Compr, Liquef) & $\mathrm{n} / \mathrm{a}$ & $\mathrm{n} / \mathrm{a}$ & 130,916 & 276 & $n / a$ & $\mathrm{n} / \mathrm{a}$ & 148,004 & 239 \\
\hline 6 & COMBUSTION TURBINE/ACCESSORIES & $\mathrm{n} / \mathrm{a}$ & $\mathrm{n} / \mathrm{a}$ & n/a & $\mathrm{n} / \mathrm{a}$ & $\mathrm{n} / \mathrm{a}$ & $\mathrm{n} / \mathrm{a}$ & $\mathrm{n} / \mathrm{a}$ & $\mathrm{n} / \mathrm{a}$ \\
\hline 7 & HRSG, DUCTING \& STACK & 34,983 & 55 & 34,983 & 74 & 34,983 & 55 & 38,866 & 63 \\
\hline 8 & STEAM TURBINE GENERATOR / PIPING & 107,981 & 170 & 108,273 & 228 & 119,104 & 187 & 151,895 & 245 \\
\hline 9 & COOLING WATER SYSTEM & 28,767 & 45 & 30,540 & 64 & 30,732 & 48 & 38,422 & 62 \\
\hline 10 & ASH/SPENT SORBENT HANDLING SYS & 18,723 & 29 & 18,723 & 39 & 18,723 & 29 & 22,033 & 36 \\
\hline 11 & ACCESSORY ELECTRIC PLANT & 33,588 & 53 & 55,655 & 117 & 33,588 & 53 & 62,240 & 100 \\
\hline 12 & INSTRUMENTATION \& CONTROL & 24,399 & 38 & 29,423 & 62 & 24,399 & 38 & 29,423 & 47 \\
\hline 13 & IMPROVEMENTS TO SITE & 12,785 & 20 & 15,268 & 32 & 12,785 & 20 & 15,268 & 25 \\
\hline 14 & BUILDINGS \& STRUCTURES & 61,691 & 97 & 64,939 & 137 & 69,221 & 109 & 72,469 & 117 \\
\hline & TOTAL COST & 858,132 & 1,350 & $1,318,554$ & 2,775 & 897,081 & 1,410 & $1,493,238$ & 2,406 \\
\hline
\end{tabular}

\section{Economics:}

A comparison of the total power plant costs (EPC basis) for Cases 1a and 2a shows that the capture ready design requires a relatively small pre-investment of about 4.5 percent $(\sim 60 \$ / \mathrm{kW})$. This pre-investment cost is provided for the future conversion of the plant to oxygen firing and $\mathrm{CO}_{2}$ capture, and to also allow an increase in the gross electrical output from the plant of about 32 percent when the plant is retrofitted with oxygen firing and $\mathrm{CO}_{2}$ capture (i.e., from Case $2 \mathrm{a}$ to Case 2b) such that the net electrical output is not decreased.

Hence, the purpose of the economic analysis was to determine whether or not this preinvestment cost is justified economically, by comparing the results from Case $2 \mathrm{~b}$ with those from Case $1 \mathrm{~b}$ (Capture unready converted to $\mathrm{O}_{2}$ firing and $\mathrm{CO}_{2}$ capture). These results are summarized below:

o The levelized cost of electricity (LCOE) of the capture unready plant (Case 1b) is always higher than that of the capture ready plant (Case $2 \mathrm{~b}$ ), irrespective of the time of conversion to $\mathrm{O}_{2}$ firing and $\mathrm{CO}_{2}$ capture, up to 20 years.

o The differences between the LCOE's of these two plants get narrower with time of conversion, ultimately crossing at 20-year mark

0 In the absence of conversion to $\mathrm{O}_{2}$ firing and $\mathrm{CO}_{2}$ capture, the LCOE of the capture ready plant (2a) is higher than that of capture unready (1a), due its additional preinvestment cost

o The relative net present value (NPV) between the Capture Ready and Capture Unready plants decreases with time of conversion to $\mathrm{O}_{2}$ firing and $\mathrm{CO}_{2}$ capture, consistent with the LCOE differences as shown in Figure ES-1.

0 In the absence of conversion to $\mathrm{O}_{2}$ firing and $\mathrm{CO}_{2}$ capture, the NPV of the capture ready plant (2a) is $-\$ 42 \mathrm{M}$ relative to Capture Unready plant (1a), due its additional preinvestment cost 
o Hence, the pre-investment cost is justified, provided that the plant conversion to $\mathrm{O}_{2}$ firing and $\mathrm{CO}_{2}$ capture is implemented within 20 years from initial operation. The earlier the conversion, the better based on both LCOE and NPV results

o The value of pre-investment cost disappears if the conversion to $\mathrm{O}_{2}$ firing and $\mathrm{CO}_{2}$ capture is implemented after 20 years from initial operation.

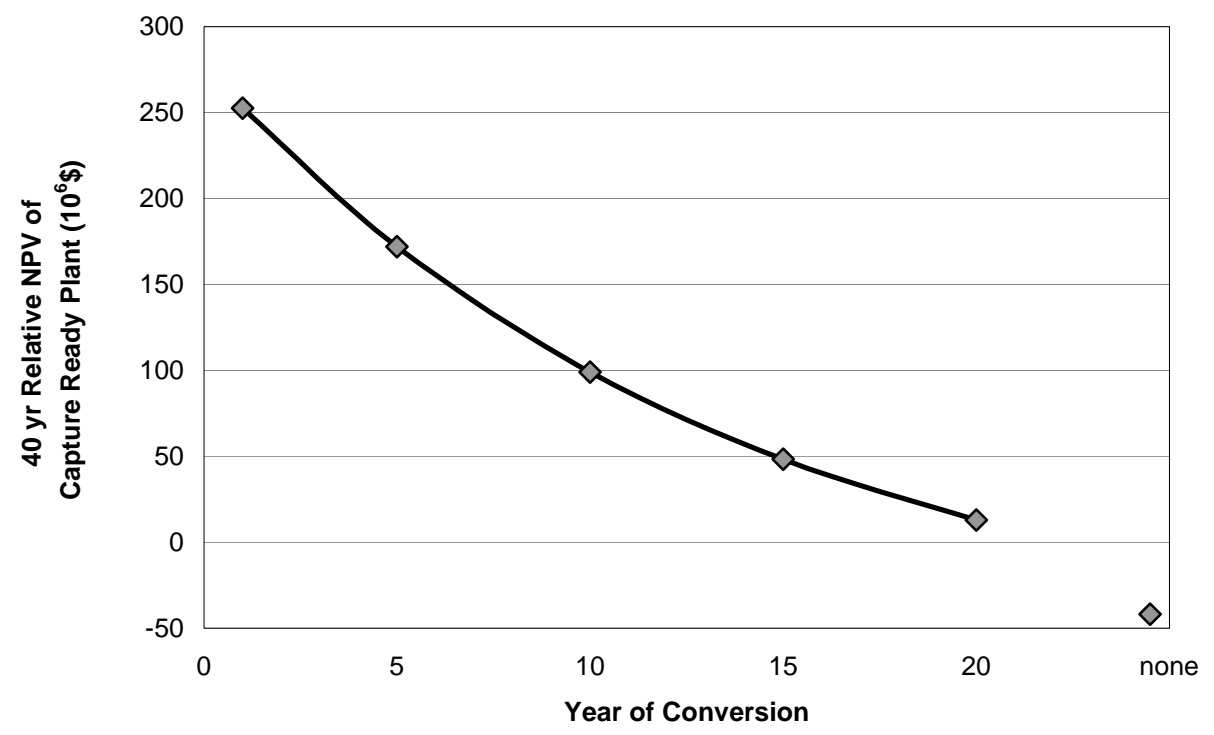

Figure ES-1: Relative Net Present Value Comparisons 


\section{INTRODUCTION}

Electric utility companies planning today to add coal-fired power generation capacity may be hesitant to add steam power plants (PC or CFB), because such assets may be perceived to become disadvantaged economically if $\mathrm{CO}_{2}$ emissions control legislation should be implemented in the future. This is true particularly if these assets were designed in the traditional manner. Hence, the term “Capture-ready plant” has become a popular vocabulary in the industry, as it offers the opportunity to modify traditional steam plant designs to enable future retrofits to $\mathrm{CO}_{2}$ capture with significantly reduced cost, reduced energy penalty, improved economics, and with sufficient areas left available on site for optimum location of the $\mathrm{CO}_{2}$ capture equipment.

This work facet is designed to quantitatively determine the attributes of designing supercritical (SC) circulating fluidized bed (CFB) power plants that are $\mathrm{CO}_{2}$ capture-ready via future oxygen firing. The retrofit of traditionally designed steam power plants for $\mathrm{CO}_{2}$ capture has been shown to reduce plant output significantly, be very energy intensive, costly, and quite often not enough site space is available for optimally installing the $\mathrm{CO}_{2}$ capture equipment. This work compares the impacts on overall plant performance, costs, and economics of converting a capture-ready CFB plant to $\mathrm{O}_{2}$ firing and $\mathrm{CO}_{2}$ capture vs. converting a noncapture-ready plant to $\mathrm{O}_{2}$ firing and $\mathrm{CO}_{2}$ capture. As such, this work quantifies the potential financial benefits of pre-investing some money into a capture-ready plant in order to facilitate its future conversion to $\mathrm{O}_{2}$ firing and $\mathrm{CO}_{2}$ capture.

An added advantage of the CFB technology, compared to the PC technology, is that it is relatively easy to enhance the capture-ready retrofit of CFB plants with $\mathrm{O}_{2}$ firing and $\mathrm{CO}_{2}$ capture such that the original net electrical output of the plant is maintained after conversion. This allows the utility to not be concerned with purchasing replacement power for the lost net electrical output, which would typically occur.

\section{Background}

A recent study by IEA (Dillon et. al., 2005) has shown that removal of $91 \%$ of the $\mathrm{CO}_{2}$ from a new, state-of-the-art supercritical PC power plant via $\mathrm{O}_{2}$ firing would raise the price of electricity by 2.4 cents per $\mathrm{kWh}$ and reduce the output by $21 \%$. The study by ALSTOM (Marion, et. al., 2003) showed that removal of $94 \%$ of the $\mathrm{CO}_{2}$ from a new sub-critical CFB power plant via $\mathrm{O}_{2}$ firing would raise the price of electricity by 3.4 cents per $\mathrm{kWh}$ and reduce the output by $28 \%$.

The work conducted prior to this particular work facet entailed pilot-scale testing at $~ 3 \mathrm{MWth}$ and a retrofit design study of oxygen firing and $\mathrm{CO}_{2}$ capture on an existing 90-MWe CFB. Results from these studies are presented in Volume I of this report.

\section{Concept}

The $\mathrm{CO}_{2}$ capture-ready concept entailed designing a steam power plant without $\mathrm{CO}_{2}$ capture equipment but with design provisions for a future $\mathrm{CO}_{2}$ capture retrofit. The $\mathrm{CO}_{2}$ capture ready concept investigated was an oxygen-fired supercritical CFB power plant.

\section{Objectives}

The objectives were four-fold as follows, i.e., determine the plant performance, $\mathrm{CO}_{2}$ emissions, costs and economics of: (1) Base Case- non-capture-ready traditional steam power plant; (2) Base Case plant (non-capture-ready) retrofitted to $\mathrm{O}_{2}$ firing and $\mathrm{CO}_{2}$ capture; (3) $\mathrm{CO}_{2}$ captureready steam plant; and (4) Capture-ready steam plant retrofitted to $\mathrm{O}_{2}$ firing and $\mathrm{CO}_{2}$ capture. 


\section{Targets for Capture-Ready Plant}

(1) Before retrofit, good economics and minimum extra cost (for capture-ready capability) with maximum future flexibility.

(2) After retrofit, maintain original net power output, near zero gaseous emissions, reduced energy penalty, and reduced incremental cost of electricity (as compared to non-capture ready retrofit).

\section{Goals}

The goals for the four power plants are described in the following list:

(1) High efficiency and low emissions

(2) Minimum efficiency loss (after conversion)

(3) Zero electric revenue loss (net output maintained)

(4) Minimum added investment cost

(5) Minimum outage time for conversion to $\mathrm{CO}_{2}$ capture

(6) Equivalent plant availability (before and after conversion)

(7) Equivalent dispatch time (before and after conversion)

(8) Low O\&M costs

(9) Good Return on Investment (ROI)

\section{Discussion of Maintaining the Original Net Electrical Output}

As mentioned above, in general, when a power plant is converted to $\mathrm{O}_{2}$ firing and $\mathrm{CO}_{2}$ capture, although the gross electrical output does not change, there is a significant loss in the net electrical output from the plant. This output loss is primarily due to the power consumption requirements of the air separation unit (ASU) and the gas processing system (GPS). These systems typically consume a total of about 25-30 percent of the generator electrical output.

This study investigates the feasibility of designing capture-ready CFB based power plants with additional provisions (other than just adding the ASU and GPS) such that additional modifications can be made at the time the plant is converted to $\mathrm{O}_{2}$ firing and $\mathrm{CO}_{2}$ capture to allow the net power output from the plant to be conserved. This is possible with CFB plants by providing the necessary plant modifications to support an increase in the fuel input rate to the unit. The additional fuel input is used for the generation of additional steam flow, which is responsible for an increase in the gross electrical output to offset the power consumption of the ASU and GPS. The increase in the fuel input rate is made possible by increasing the $\mathrm{O}_{2}$ content of the oxidant stream (recycled flue gas + oxygen) feeding the combustor. In this manner, the superficial gas velocity in the $\mathrm{O}_{2}$ fired CFB combustor is maintained to be the same value as it was with the original air fired combustor. Additional steam generating surfaces are added to the CFB (at the time of the conversion) to absorb the increased fuel heat input and to generate the additional steam. Other modifications to the steam turbine/generator and other balance of plant equipment are also provided to fully support these modifications. 


\section{DESIGN BASIS FOR POWER PLANTS}

This section describes the basis for plant equipment design and performance calculations for each of the power plants analyzed in this study. All of the plants designed for this conceptual level study, are assumed to be located on a common Greenfield site and are assumed to be operated under common conditions of fuel, sorbent, utility, and environmental standards. This section is intended to define the common parameters, the site conditions, the equipment scope for the cost estimate, and various other items, which will be used as a common design basis for all of these plants.

\subsubsection{Common Parameters:}

All of the plants were designed for the identical coal and sorbent analyses, ambient conditions, site conditions, etc. such that each case study provides results which are directly comparable, on a common basis, to all other cases analyzed within this work. The ambient conditions used for all material and energy balances were based on the standard American Boiler Manufacturers Association (ABMA) atmospheric conditions (i.e. $80^{\circ} \mathrm{F}, 14.7 \mathrm{psia}$, and 60 percent relative humidity). Many other items were common between cases such as the plant site, equipment scope, plant services, etc. as described below.

\subsubsection{Plant Site Definition:}

The generic plant site, which is common to all study cases, is assumed to be located in the Gulf Coast region of southeastern Texas. The site consists of approximately 300 usable acres within 15 miles of a medium-sized metropolitan area, with a well-established infrastructure capable of supporting the required construction work force. The area immediately surrounding the site has a mixture of agricultural and light industrial uses. The site is served by a river of adequate quantity for use as makeup cooling water with minimal pretreatment and for the receipt of cooling system blowdown discharges.

A railroad line suitable for unit coal trains passes within 2-1/2 miles of the site boundary. A well-developed road network serves the site, capable of carrying AASHTO H-20 S-16 loads and with overhead restriction of not less than 16 feet (Interstate Standard).

The site is on relatively flat land with a maximum difference in elevation within the site of about 30 feet. The topography of the area surrounding the site is rolling hills, with elevations within 2,000 yards not more than 300 feet above the site elevation. The site is within Seismic Zone 1, as defined by the Uniform Building Code. The following list further describes the assumed site characteristics.

- The site is Greenfield with no existing improvements or facilities.

- The site is relatively clear and level with no characteristics that would cause any unusual construction problems.

- The structural strength of the soil is adequate for spread footings (no piling is required) at this site.

- No rock excavation is required on this site.

- An abundant sub-surface water supply is assumed available on this site. 
- The characteristics of cooling tower makeup water assumed in the study are presented in Table 2-1. This makeup water quality will allow cooling tower operation with 5 cycles of concentration of dissolved solids in the circulating water.

Table 2-1: Makeup Water Characteristics

\begin{tabular}{|l|l|c|c|}
\hline Constituent & Formula & Units & Design Value \\
\hline Calcium & $\mathrm{Ca}$ & $\mathrm{mg} / \mathrm{l}$ & 75 \\
Magnesium & $\mathrm{Mg}$ & $\mathrm{mg} / \mathrm{l}$ & 16 \\
Potassium & $\mathrm{K}$ & $\mathrm{mg} / \mathrm{l}$ & 3 \\
Sodium & $\mathrm{Na}$ & $\mathrm{mg} / \mathrm{l}$ & 20 \\
Bicarbonates & $\mathrm{HCO}_{3}$ & $\mathrm{mg} / \mathrm{l}$ & 240 \\
Chlorides & $\mathrm{Cl}$ & $\mathrm{mg} / \mathrm{l}$ & 25 \\
Silica & $\mathrm{SiO}_{2}$ & $\mathrm{mg} / \mathrm{l}$ & 4 \\
Sulfates & $\mathrm{SO}_{4}$ & $\mathrm{mg} / \mathrm{l}$ & 58 \\
Nitrate & $\mathrm{NO}_{3}$ & $\mathrm{mg} / \mathrm{l}$ & 7 \\
TDS-Dissolved & $\mathrm{TDS}$ & $\mathrm{mg} / \mathrm{l}$ & 460 \\
Total Organic Carbon & $\mathrm{TOC}$ & $\mathrm{mg} / \mathrm{l}$ & 3 \\
Temperature & & ${ }^{0} \mathrm{~F}$ & 60 \\
pH & $\mathrm{pH}$ & & 8.0 \\
\hline
\end{tabular}

\subsubsection{Plant Equipment Scope:}

The boundary limit for these plants includes the complete plant facility within the "fence line". It encompasses all equipment from the coal pile to the bus bar and includes the coal receiving and water supply systems and terminates at the high-voltage side of the main power transformers. For plants with $\mathrm{CO}_{2}$ capture systems (Case $1 \mathrm{~b}$ and $2 \mathrm{~b}$ ), the equipment scope does not include the $\mathrm{CO}_{2}$ pipeline or $\mathrm{CO}_{2}$ injection well. The scope of supply is further defined by the following list:

- Site preparation and site improvements

- Foundations, buildings, and structures required for all plant equipment and facilities

- General support facilities for administration, maintenance, and storage

- Coal, limestone, and lime receiving, storage, and handling systems

- Boiler Island from coal feed through gas cleanup system including associated solids handling systems

- Power block, including steam turbine, heat rejection, and makeup water systems

- Plant electrical distribution, lighting, and communication systems

- High-voltage electrical system through step-up transformer

- Instruments and controls

- Miscellaneous power plant equipment

The electrical facilities within the plant scope include all switchgear and control equipment, 
generator equipment, station service equipment, conduit and cable trays, all wire and cable. It also includes the main power transformer, foundations, and standby equipment.

Additionally, the following utilities are assumed to be available at the site boundary.

- Communication lines

- Electrical power for plant construction

- Potable water and sanitary sewer connections

- Electrical transmission facilities and lines

\subsubsection{Plant Ambient Design Conditions:}

Table 2-2 lists ambient and other relevant characteristic assumptions for this site. The ambient conditions used for all material and energy balances were based on the standard American Boiler Manufacturers Association (ABMA) atmospheric conditions (i.e. 80 $\mathrm{F}, 14.7$ psia, and 60 percent relative humidity).

Table 2-2: Site Characteristics for all Material and Energy Balances

\begin{tabular}{|l|c|}
\hline Design Parameter & Value \\
\hline Elevation (ft) & 500 \\
Design Atmospheric Pressure (psia) & 14.7 \\
Design Temperature, dry bulb $\left({ }^{\circ} \mathrm{F}\right)$ & 80 \\
Design Temperature, wet bulb $\left({ }^{\circ} \mathrm{F}\right)$ & 69.6 \\
Design Relative Humidity (percent) & 60 \\
Ash Disposal & Off Site \\
Water Source & River \\
\hline
\end{tabular}

The ambient air quality is assumed to be consistent with a dry clean air without contaminants as presented in Table 2-3 (Himmelblau, 1974).

Table 2-3: Ambient Air Quality

\begin{tabular}{|l|l|c|}
\hline \multicolumn{1}{|c|}{ Impurities } & $\begin{array}{c}\text { Chemical } \\
\text { Formula }\end{array}$ & Mole $\%$, dry \\
\hline Nitrogen & $\mathrm{N}_{2}$ & $78.08 \%$ \\
Oxygen & $\mathrm{O}_{2}$ & $20.95 \%$ \\
Argon & $\mathrm{Ar}$ & $0.93 \%$ \\
Carbon Dioxide & $\mathrm{CO}_{2}$ & $0.03 \%$ \\
\hline \hline & Total & $100.00 \%$ \\
\hline Methane & $\mathrm{CH}_{4}$ & $\sim 2 \mathrm{ppm}$ \\
Other & & Trace, (Note A) \\
Dust & & $<0.2 \mathrm{mg} / \mathrm{Nm} 3$ \\
\hline
\end{tabular}

Note A: It is assumed that total content of $\mathrm{C}_{\mathrm{X}} \mathrm{H}_{\mathrm{Y}}$ compounds in ambient air does not exceed 9 ppm.

For equipment sizing, the maximum dry bulb temperature is $95^{\circ} \mathrm{F}$, and the minimum dry bulb temperature for mechanical design is $20^{\circ} \mathrm{F}$. 


\subsubsection{Consumables:}

Table 2-4 shows the design coal analyses (Ultimate and Higher Heating Value) used for all cases. The coal is classified as a medium volatile bituminous coal. Table 2-5 shows the design limestone analysis used in Cases 1a and $2 \mathrm{a}$ for sulfur capture within the furnace.

Table 2-4: Design Coal Analysis (Medium Volatile Bitumin
\begin{tabular}{|c|c|c|}
\hline Constituent & Units & $\begin{array}{c}\text { Weight } \\
\text { Fraction }\end{array}$ \\
\hline $\mathbf{O}_{2}$ & & 0.0316 \\
$\mathbf{N}_{\mathbf{2}}$ & & 0.0146 \\
$\mathbf{H}_{\mathbf{2}} \mathbf{O}$ & & 0.0399 \\
$\mathbf{H}_{\mathbf{2}}$ & & 0.0357 \\
Carbon & & 0.6205 \\
Sulfur & & 0.0234 \\
Ash & & 0.2343 \\
\hline \hline Total & & 1.0000 \\
\hline HHV Coal & $(\mathrm{Btu} / \mathrm{lbm})$ & 11,070 \\
& $(\mathrm{~kJ} / \mathrm{kg})$ & 23,132 \\
\hline
\end{tabular}

Table 2-5: Design Limestone Analysis

\begin{tabular}{|c|c|}
\hline Constituent & $\begin{array}{c}\text { Weight } \\
\text { Fraction }\end{array}$ \\
\hline $\mathrm{CaCO}_{3}$ & 0.9830 \\
Moisture & 0.0000 \\
Ash & 0.0170 \\
\hline \hline Total & 1.0000 \\
\hline
\end{tabular}

Additionally, a small quantity of natural gas is used in Cases $1 \mathrm{~b}$ and $2 \mathrm{~b}$ for desiccant drying in both the Gas Processing System and Air Separation Unit. For the purpose of this study, the natural gas was assumed to be pure Methane $\left(\mathrm{CH}_{4}\right)$ with a higher Heating Value (HHV) of $55,578 \mathrm{~kJ} / \mathrm{kg}(23,896 \mathrm{Btu} / \mathrm{lbm})$. Also for Cases $1 \mathrm{~b}$ and $2 \mathrm{~b}$, lime is used as the sulfur-absorbing compound. In this analysis, the lime analysis is assumed to be pure $\mathrm{CaO}$.

\subsection{6 $\mathrm{CO}_{2}$ Product Specification:}

The $\mathrm{CO}_{2}$ capture systems used for Cases $1 \mathrm{~b}$ and $2 \mathrm{~b}$ were designed for a minimum of 94 percent $\mathrm{CO}_{2}$ capture from the boiler flue gas stream. Table 2-6 shows the Dakota Gasification Project's $\mathrm{CO}_{2}$ Product Specification achieved for EOR (Dakota, 2005). This purity specification was used as a guideline for the Gas Processing System (GPS) design in this study. It should be understood that product purity specifications for the $\mathrm{CO}_{2}$ are very dependent on the individual oil field being flooded. 
Table 2-6: Dakota Gasification Project's $\mathrm{CO}_{2}$ Product Specification for EOR

\begin{tabular}{|l|l|c|}
\hline Component & (units) & Value \\
\hline $\mathrm{CO}_{2}$ & $($ vol \%) & 96 \\
$\mathrm{H}_{2} \mathrm{~S}$ & $($ vol \%) & 1 \\
$\mathrm{CH}_{4}$ & $($ vol \%) & 0.3 \\
$\mathrm{C}_{2}+\mathrm{HC}^{\prime} \mathrm{S}$ & $($ vol \%) & 2 \\
$\mathrm{CO}$ & $($ vol \%) & -- \\
$\mathrm{N}_{2}$ & $($ ppm by vol. $)$ & 6000 \\
$\mathrm{H}_{2} \mathrm{O}$ & $($ ppm by vol.) & 2 \\
$\mathrm{O}_{2}$ & $($ ppm by vol.) & 100 \\
Mercaptans and other Sulfides & $($ vol \%) & 0.03 \\
\hline
\end{tabular}

The nitrogen concentration in Table 2-6 is 6,000 ppmv. It should be noted that according to Charles Fox of Kinder Morgan (Fox, 2002), a maximum nitrogen concentration of 4 percent (by volume) would be required to control the minimum miscibility pressure.

The $\mathrm{CO}_{2}$ product is provided in a liquid state at the plant boundary at 138 barg (2,000 psig).

\subsubsection{Structures and Foundations:}

Structures are provided to support and permit access to all plant components requiring support to conform to the site criteria. The structure(s) are enclosed if deemed necessary to conform to the environmental conditions.

Foundations are provided for the support structures, pumps, tanks, and other plant components. A soil-bearing load of $5,000 \mathrm{lbm} / \mathrm{ft}^{2}$ is used for foundation design. 


\section{DESCRIPTION OF POWER PLANT CASE STUDIES AND PLANT PERFORMANCE SUMMARY}

\subsection{Power Plant Case Studies}

A total of four (4) power plant case studies are included in this analysis. The four plants investigated are all steam power plants utilizing CFB combustors and supercritical pressure steam cycles. The equipment scope for each plant includes the entire power plant from the coal pile through the bus bar. The equipment scope for the plants capturing $\mathrm{CO}_{2}$ does not include the $\mathrm{CO}_{2}$ pipeline or the $\mathrm{CO}_{2}$ injection well. The primary purpose of the study is to investigate the concept of building $\mathrm{CO}_{2}$ capture ready steam power plants utilizing CFB combustors and to quantify the attributes of such plants as compared to $\mathrm{CO}_{2}$ capture unready steam plants. Therefore four power plant cases were defined for this study as listed below:

o Case 1a - Air Fired $\mathrm{CO}_{2}$ Capture Unready Power Plant - Base Case

o Case $1 \mathrm{~b}$ - The Base Case Power Plant Retrofit with $\mathrm{O}_{2}$ Firing and $\mathrm{CO}_{2}$ Capture

o Case 2a - Air Fired $\mathrm{CO}_{2}$ Capture-Ready Power Plant

o Case $2 \mathrm{~b}$ - The Case 2a Capture-Ready Power Plant Retrofit with $\mathrm{O}_{2}$ Firing and $\mathrm{CO}_{2}$ Capture

The following paragraphs further define these four study cases.

\subsubsection{Case 1a - Air Fired $\mathrm{CO}_{2}$ Capture Unready Power Plant - Base Case}

The Base Case (Case 1a) for this project is based on a power plant that utilizes two (2) parallel steam generators feeding a single steam turbine. Each steam generator is designed for a steam capacity of about 2,205,000 lbm/hr (1,000 tonne/h) utilizing an air fired circulating fluidized bed (CFB) process. The two boilers are operated with supercritical steam conditions of approximately $3,600 \mathrm{psi}(250 \mathrm{bar})$ and deliver $1,050^{\circ} \mathrm{F}\left(560^{\circ} \mathrm{C}\right)$ steam temperature to both the high pressure and intermediate pressure sections of a common steam turbine. The design for the Base Case power plant has been developed to comply with this basic technical specification. The Base Case power plant produces a net output of about 637 MWe. No provisions are included in the design of the Base Case power plant for future conversion to $\mathrm{CO}_{2}$ capture.

\subsubsection{Case $1 \mathrm{~b}$ - The Base Case Power Plant Retrofit with $\mathrm{O}_{2}$ Firing and $\mathrm{CO}_{2}$ Capture}

When the conversion of Case $1 \mathrm{a}$ (Base Case) to oxygen firing and $\mathrm{CO}_{2}$ capture is made (i.e. Case 1b), the power plant is retrofit with an air separation unit (ASU) to provide substantially pure oxygen to the furnace and a gas processing system (GPS) to further purify and compress the $\mathrm{CO}_{2}$ product. Modifications to the existing power plant are minimized for this case. After the conversion of Case $1 \mathrm{a}$ to oxygen firing and $\mathrm{CO}_{2}$ capture is made (i.e. Case $1 \mathrm{~b}$ ) the net electrical output from the plant will be reduced significantly due to the power consumption of the ASU and GPS. The Case 1b power plant produces a net output of about 476 MWe or about 75 percent of the Base Case electrical output.

\subsubsection{Case 2a - Air Fired $\mathrm{CO}_{2}$ Capture-Ready Power Plant}

The Case 2a power plant is very similar in design to the Case 1a (Base Case) power plant. Two air fired CFB boilers are provided which generate the same amount of steam at the same steam conditions as the Base Case. The plant produces the same net power output as the Base Case (about $637 \mathrm{MWe}$ ). The Case 2a power plant design is however slightly different than the Base Case plant in that there are several provisions made in the plant design to make the future 
conversion to oxygen firing and $\mathrm{CO}_{2}$ capture more easily achievable. Therefore, Case 2a is identified as the " $\mathrm{CO}_{2}$ capture ready" case. Additionally, this case includes design provisions to support an increase in steam generation rate and gross electrical output, which would be implemented at the time of conversion to oxygen firing and $\mathrm{CO}_{2}$ capture (i.e. Case $2 \mathrm{~b}$ ). These additional design provisions are provided such that the net electrical output after conversion is maintained at about the same value as before conversion. Comparison of Case $2 \mathrm{a}$ to the Base Case (Case 1a) identifies what $\mathrm{CO}_{2}$ capture ready features and gross electrical output enhancement features are included in the Case 2a plant design. Comparison of the plant costs for these two cases indicates the pre-investment costs included in Case 2a to provide the $\mathrm{CO}_{2}$ capture ready capability and the equivalent net electrical output feature.

\subsubsection{Case 2b - The Case 2a Capture-Ready Power Plant Retrofit with $\mathrm{O}_{2}$ Firing and $\mathrm{CO}_{2}$ Capture}

When the conversion of Case 2a (the $\mathrm{CO}_{2}$ capture ready power plant) to $\mathrm{CO}_{2}$ capture is made (i.e. Case $2 \mathrm{~b}$ ), the power plant is retrofit with an ASU and a GPS. Typically when this type of conversion is made the net plant output is reduced by about 25-30 percent (refer to Case $1 \mathrm{~b}$ above). For Case $2 \mathrm{~b}$, the steam capacity will be increased during the retrofit by about $38 \%$ through the modification of and the addition of various plant equipment. The equipment modifications and additions to provide this extra generating capacity are in the areas of the CFB boiler, the steam turbine/generator, and the balance of plant equipment. This steam flow increase is utilized to offset the additional auxiliary power used by the ASU and GPS, thus allowing the converted power plant to produce approximately the same net electrical output after conversion to $\mathrm{CO}_{2}$ capture as it produced before conversion (i.e. Case 2a). The Case 2b power plant produces a net output of about 621 MWe or about 98 percent of what capture ready Case 2a produces. The 621 MWe net electrical output for Case $2 b$ does not represent a specific limit but is simply the result of trying to match the Case 2a net output.

Hence, by comparing results between Case $2 \mathrm{~b}$ and Case $1 \mathrm{~b}$, the effectiveness of a $\mathrm{CO}_{2}$ capture ready power plant which includes the feature of providing additional steam flow to maintain net electrical output capacity can be evaluated and quantified.

\subsection{Power Plant Performance Summary and Comparison}

This section provides a summary and comparison of several important plant performance related outputs from this study. Comparisons of the four case study power plants described above in terms of plant performance and $\mathrm{CO}_{2}$ emissions are provided in Table 3-1. Table 3-2 shows a comparison of auxiliary power for the four cases.

Additionally, selected results from Table 3-1 are illustrated and compared in Figure 3-1 Figure 3-8. The comparisons shown in the figures are Boiler Efficiency, Coal Heat Input, Boiler Heat Output, Steam Cycle Efficiency, Total Plant Auxiliary Power, Net Plant Output, Plant Thermal Efficiency, and Plant $\mathrm{CO}_{2}$ Emissions. 
Table 3-1: Plant Performance and $\mathrm{CO}_{2}$ Emissions Summary and Comparison

\begin{tabular}{|c|c|c|c|c|c|c|c|c|c|}
\hline \multirow[b]{3}{*}{ Auxiliary Power Summary } & \multirow{3}{*}{ (Units) } & \multicolumn{2}{|c|}{$\begin{array}{c}\text { Case-1a: } \\
\text { Air Fired CFB } \\
\text { (Base-Case) } \\
\text { w/o } \mathrm{CO}_{2} \text { Capture }\end{array}$} & \multicolumn{2}{|c|}{$\begin{array}{c}\text { Case-1b: } \\
\text { Base Case CFB } \\
\text { Converted to } \mathrm{O}_{2} \text { Firing } \\
\text { and } \mathrm{CO}_{2} \text { Capture } \\
\text { (Lower Net Output) }\end{array}$} & \multicolumn{2}{|c|}{$\begin{array}{c}\text { Case-2a: } \\
\text { Air Fired CFB } \\
\text { (Capture Ready) } \\
\text { w/o } \mathrm{CO}_{2} \text { Capture } \\
\end{array}$} & \multicolumn{2}{|c|}{$\begin{array}{c}\text { Case-2b: } \\
\text { Capture Ready CFB } \\
\text { Converted to } \mathrm{O}_{2} \text { Firing } \\
\text { and } \mathrm{CO}_{2} \text { Capture } \\
\text { (Maintain Net Output) }\end{array}$} \\
\hline & & (English) & (SI) & (English) & (SI) & (English) & (SI) & (English) & (SI) \\
\hline & & & & & & & & & \\
\hline Power Plant Auxiliary Power & $(\mathrm{kW})$ & 41814 & 41814 & 39423 & 39423 & 41784 & 41784 & 44040 & 44040 \\
\hline Air Separation Unit - ASU & $(\mathrm{kW})$ & $\mathrm{n} / \mathrm{a}$ & $\mathrm{n} / \mathrm{a}$ & 91446 & 91446 & $\mathrm{n} / \mathrm{a}$ & $\mathrm{n} / \mathrm{a}$ & 118849 & 118849 \\
\hline Gas Processing System - GPS ( $\mathrm{CO}_{2}$ purification, compression, liquefaction) & $(\mathrm{kW})$ & $\mathrm{n} / \mathrm{a}$ & $\mathrm{n} / \mathrm{a}$ & 86239 & 86239 & $\mathrm{n} / \mathrm{a}$ & $\mathrm{n} / \mathrm{a}$ & 111960 & 111960 \\
\hline Total Plant Auxiliary Power & $(\mathrm{kW})$ & 41814 & 41814 & 217107 & 217107 & 41784 & 41784 & 274850 & 274850 \\
\hline & (frac. of Gen. Output) & 0.062 & 0.062 & 0.314 & 0.314 & 0.062 & 0.062 & 0.307 & 0.307 \\
\hline Steam Flows, Efficiencies and Electrical Outputs & & & & & & & & & \\
\hline Main Steam Flow & $(\mathrm{lbm} / \mathrm{hr} ; \mathrm{kg} / \mathrm{hr})$ & 4409345 & 2000035 & 4409345 & 2000035 & 4409238 & 1999986 & 6087844 & 2761385 \\
\hline Reheat Steam Flow & $(\mathrm{lbm} / \mathrm{hr} ; \mathrm{kg} / \mathrm{hr})$ & 3695553 & 1676266 & 3695553 & 1676266 & 3701082 & 1678774 & 5052557 & 2291789 \\
\hline Boiler Efficiency $(\mathrm{HHV})^{1}$ & (fraction) & 0.8975 & 0.8975 & 0.8869 & 0.8869 & 0.8975 & 0.8975 & 0.8883 & 0.8883 \\
\hline Steam Cycle Efficiency & (fraction) & 0.4520 & 0.4520 & 0.4237 & 0.4237 & 0.4528 & 0.4528 & 0.4198 & 0.4198 \\
\hline Steam Turbine Generator Output & $(\mathrm{kW})$ & 677489 & 677489 & 692293 & 692293 & 677999 & 677999 & 895377 & 895377 \\
\hline Net Plant Output & $(\mathrm{kW})$ & 635675 & 635675 & 475186 & 475186 & 636215 & 636215 & 620527 & 620527 \\
\hline${ }^{1}$ Boiler Heat Output / (Qcoal-HHV + Qcredits) & (frac. of Case-1 Net Output) & 1.00 & 1.00 & 0.75 & 0.75 & 1.00 & 1.00 & 0.98 & 0.98 \\
\hline Fuel Heat Inputs & & & & & & & & & \\
\hline Coal Heat Input (HHV) & $\left(10^{6} \mathrm{Btu} / \mathrm{hr} ; 10^{6} \mathrm{KJ} / \mathrm{hr}\right)$ & 5645 & 5955 & 5767 & 6083 & 5640 & 5949 & 7488 & 7899 \\
\hline Natural Gas Heat Input (HHV) ${ }^{2}$ & $\left(10^{6} \mathrm{Btu} / \mathrm{hr} ; 10^{6} \mathrm{KJ} / \mathrm{hr}\right)$ & $\mathrm{n} / \mathrm{a}$ & $\mathrm{n} / \mathrm{a}$ & 43.2 & 45.6 & $\mathrm{n} / \mathrm{a}$ & $\mathrm{n} / \mathrm{a}$ & 55.1 & 58.1 \\
\hline $\begin{array}{l}\text { Total Fuel Heat Input (HHV) } \\
{ }^{2} \text { Required for GPS \& ASU Desiccant Regeneration in Cases } 3 \text { and } 4\end{array}$ & $\left(10^{6} \mathrm{Btu} / \mathrm{hr} ; 10^{6} \mathrm{KJ} / \mathrm{hr}\right)$ & 5645 & 5955 & 5811 & 6129 & 5640 & 5949 & 7543 & 7957 \\
\hline Overall Plant Efficiency & & & & & & & & & \\
\hline Net Plant Heat Rate (HHV) & (Btu/kwhr; KJ/kwhr) & 8881 & 9368 & 12228 & 12898 & 8866 & 9351 & 12156 & 12822 \\
\hline Net Plant Thermal Efficiency (HHV) & (fraction) & 0.3843 & 0.3843 & 0.2791 & 0.2791 & 0.3850 & 0.3850 & 0.2808 & 0.2808 \\
\hline Normalized Thermal Efficiency (HHV; Relative to Base Case) & (fraction) & 1.00 & 1.00 & 0.73 & 0.73 & 1.00 & 1.00 & 0.73 & 0.73 \\
\hline Energy Penalty & (fraction) & 0.00 & 0.00 & 0.27 & 0.27 & 0.00 & 0.00 & 0.27 & 0.27 \\
\hline $\mathrm{CO}_{2}$ Emissions & & & & & & & & & \\
\hline $\mathrm{CO}_{2}$ Produced & $(\mathrm{lbm} / \mathrm{hr} ; \mathrm{kg} / \mathrm{hr})$ & 1155799 & 524259 & 1160653 & 526460 & 1154783 & 523798 & 1506831 & 683483 \\
\hline $\mathrm{CO}_{2}$ Captured & $(\mathrm{lbm} / \mathrm{hr} ; \mathrm{kg} / \mathrm{hr})$ & & 0 & 1087469 & 493265 & 0 & 0 & 1411820 & 640387 \\
\hline Fraction of $\mathrm{CO}_{2}$ Captured & (fraction) & 0.000 & 0.000 & 0.937 & 0.937 & 0.000 & 0.000 & 0.937 & 0.937 \\
\hline $\mathrm{CO}_{2}$ Emitted & $(\mathrm{lbm} / \mathrm{hr} ; \mathrm{kg} / \mathrm{hr})$ & 1155799 & 524259 & 73183 & 33195 & 1154783 & 523798 & 95011 & 43096 \\
\hline Specific $\mathrm{CO}_{2}$ Emissions & (lbm/kwhr; kg/kwhr) & 1.82 & 0.82 & 0.15 & 0.07 & 1.82 & 0.82 & 0.15 & 0.07 \\
\hline Normalized Specific $\mathrm{CO}_{2}$ Emissions (Relative to Base Case) & (fraction) & 1.00 & 1.00 & 0.08 & 0.08 & 1.00 & 1.00 & 0.08 & 0.08 \\
\hline Avoided $\mathrm{CO}_{2}$ Emissions (as compared to Base Case) & (lbm/kwhr; kg/kwhr) & 0.00 & 0.00 & 1.66 & 0.75 & 0.00 & 0.00 & 1.67 & 0.76 \\
\hline
\end{tabular}


COMMERCIALIZATION DEVELOPMENT OF OXYGEN FIRED

CFB FOR GREENHOUSE GAS CONTROL

Table 3-2: Comparison of Plant Auxiliary Power Requirements

\section{Power Plant Auxiliary Power}

Induced Draft Fan

Primary Air Fan

Secondary Air Fan

Fluidizing Air Blowers

Coal Handling, Preparation, and Feed

Limestone Handling and Feed (Lime for $1 \mathrm{~b}$ and $2 \mathrm{~b}$ )

Ash Handling

Particulate Removal System Auxiliary Power (baghouse)

Condensate Pump

Circulating Water Pumps

Cooling Tower Fans

Steam Turbine Auxiliaries

Misc. Auxiliary Power (Controls, Lighting, HVAC etc.)

Transformer Loss

\section{Auxiliary Power Summary}

Power Plant Auxiliary Power

Air Separation Unit - ASU

Gas Processing System - GPS ( $\mathrm{CO}_{2}$ purification, compression, liquefaction)

Total Plant Auxiliary Power

\begin{tabular}{|c|c|c|c|c|}
\hline & $\begin{array}{c}\text { Case-1a: } \\
\text { Air Fired } \\
\text { CFB } \\
\text { (Base-Case) } \\
\text { w/o } \mathrm{CO}_{2} \\
\text { Capture } \\
\end{array}$ & $\begin{array}{c}\text { Case-1b: } \\
\text { Base Case } \\
\text { CFB } \\
\text { Converted } \\
\text { to } \mathrm{O}_{2} \text { Firing } \\
\text { and } \mathrm{CO}_{2} \\
\text { Capture } \\
\text { (Lower Net } \\
\text { Output) } \\
\end{array}$ & $\begin{array}{c}\text { Case-2a: } \\
\text { Air Fired } \\
\text { CFB } \\
\text { (Capture } \\
\text { Ready) } \\
\text { w/o } \mathrm{CO}_{2} \\
\text { Capture } \\
\end{array}$ & $\begin{array}{c}\text { Case-2b: } \\
\text { Capture } \\
\text { Ready CFB } \\
\text { Converted to } \\
\mathrm{O}_{2} \text { Firing and } \\
\mathrm{CO}_{2} \text { Capture } \\
\text { (Maintain Net } \\
\text { Output) } \\
\end{array}$ \\
\hline (Units) & (English) & (English) & (English) & (English) \\
\hline$(\mathrm{kW})$ & 6289 & 4900 & 6284 & 4820 \\
\hline$(\mathrm{kW})$ & 9766 & 8174 & 9757 & 8177 \\
\hline$(\mathrm{kW})$ & 4125 & 5058 & 4121 & 4282 \\
\hline$(\mathrm{kW})$ & 2827 & 2348 & 2824 & 2349 \\
\hline$(\mathrm{kW})$ & 2479 & 2533 & 2474 & 2891 \\
\hline$(\mathrm{kW})$ & 843 & 231 & 842 & 300 \\
\hline$(\mathrm{kW})$ & 636 & 809 & 633 & 1050 \\
\hline$(\mathrm{kW})$ & 1217 & 1243 & 1216 & 1614 \\
\hline$(\mathrm{kW})$ & 1010 & 1010 & 1010 & 1300 \\
\hline$(\mathrm{kW})$ & 6400 & 6795 & 6400 & 9600 \\
\hline$(\mathrm{kW})$ & 1611 & 1710 & 1611 & 2327 \\
\hline$(\mathrm{kW})$ & 648 & 648 & 649 & 648 \\
\hline$(\mathrm{kW})$ & 2009 & 2009 & 2008 & 2683 \\
\hline$(\mathrm{kW})$ & 1954 & 1954 & 1955 & 1999 \\
\hline ubtotal & 41814 & 39423 & 41784 & 44040 \\
\hline (frac. of Gen. Output) & 0.062 & 0.057 & 0.062 & 0.049 \\
\hline$(\mathrm{kW})$ & 41814 & 39423 & 41784 & 44040 \\
\hline$(\mathrm{kW})$ & $\mathrm{n} / \mathrm{a}$ & 91446 & $\mathrm{n} / \mathrm{a}$ & 118849 \\
\hline$(\mathrm{kW})$ & $\mathrm{n} / \mathrm{a}$ & 86239 & $\mathrm{n} / \mathrm{a}$ & 111960 \\
\hline$(\mathrm{kW})$ & 41814 & 217107 & 41784 & 274850 \\
\hline (frac. of Gen. Output) & 0.062 & 0.314 & 0.062 & 0.307 \\
\hline
\end{tabular}




\subsubsection{Boiler Efficiency:}

Figure 3-1 compares CFB boiler efficiencies among the four cases. Cases $2 b$ and $1 b$, the oxygen-fired cases, are slightly lower than the air-fired cases ( $2 \mathrm{a}$ and 1a respectively) primarily due to a higher cooling medium temperature entering the air heaters. In the oxygen-fired cases the recirculated flue gas is the cooling medium and it is at about $110 \mathrm{~F}$ entering the PA and SA fans as compared to $80 \mathrm{~F}$ ambient air entering the air heaters for air-fired cases 1a and 2a. This causes about a one percentage point reduction in boiler efficiency for the oxygen-fired cases.

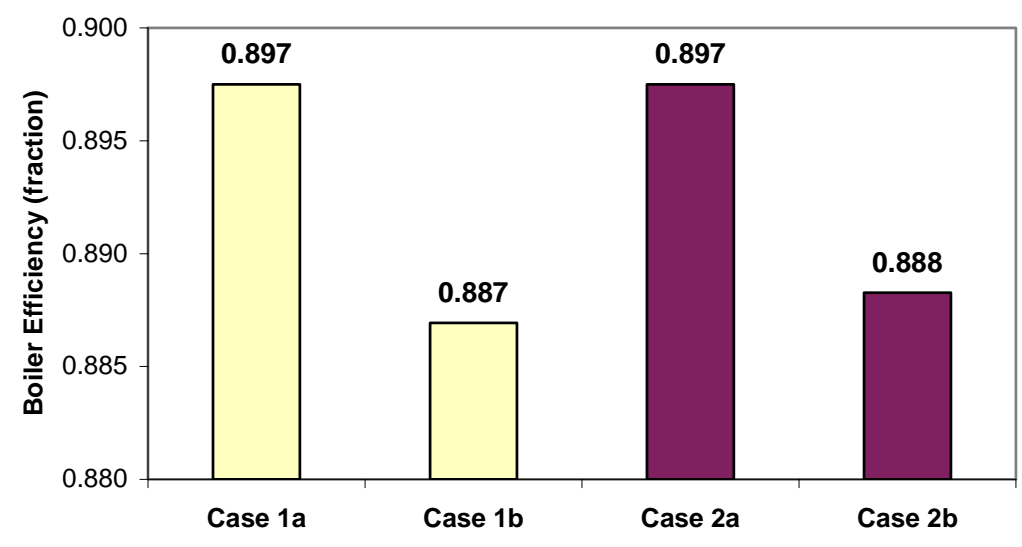

Figure 3-1: Boiler Efficiency Comparison

\subsubsection{Coal Heat Input and Boiler Heat Output:}

Figure 3-2 compares coal heat input to the CFB boilers and boiler heat output from the boilers for the four cases. The coal heat input and boiler heat output for Case $2 b$ is about $33 \%$ higher than for the other cases due to the increase in steam generation for this case. Case $2 b$ is the oxygen-fired case with increased steam generation to offset the added auxiliary power of the ASU and GPS.

The coal heat input and boiler heat output for Cases 1a, 1b, and 2a are nearly the same since each of these cases use a steam cycle that is nearly identical. The only differences in the steam cycles for these three cases is in the use of a low-level heat recovery system for Case 1b. 

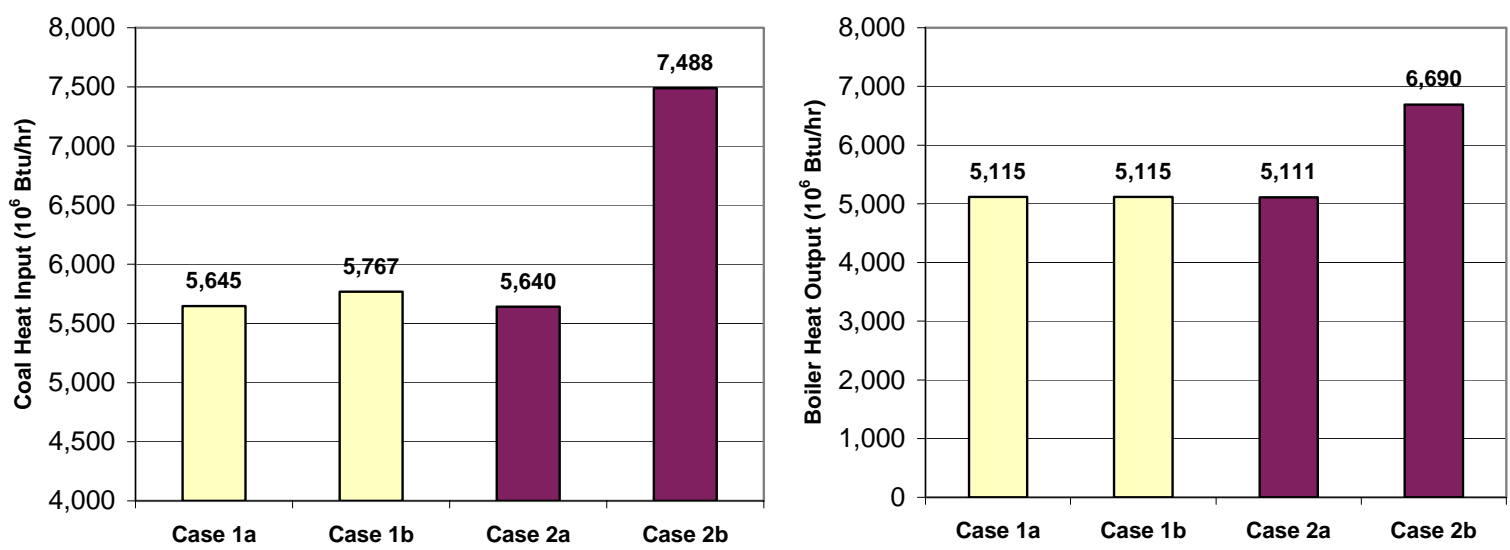

Figure 3-2: Coal Heat Input and Boiler Heat Output Comparison

\subsubsection{Steam Cycle Efficiency:}

Figure 3-3 compares steam cycle efficiency for the four cases. Cases 1a and 2a, the air-fired Base Case and air-fired capture ready case, have slightly higher steam cycle efficiency than the comparable oxygen-fired cases (Case $1 \mathrm{~b}$ and $2 \mathrm{~b}$, respectively). This is primarily due to the fact that in Cases 1a and 2a there is no low-level heat recovery system utilized. The low-level heat recovery system used in Cases $1 \mathrm{~b}$ and $2 \mathrm{~b}$ use feedwater heating (via heat recovery in the ASU and GPS) in parallel with the traditional low-pressure extraction feedwater heaters (Heaters \#1, 2, 3 and 4).

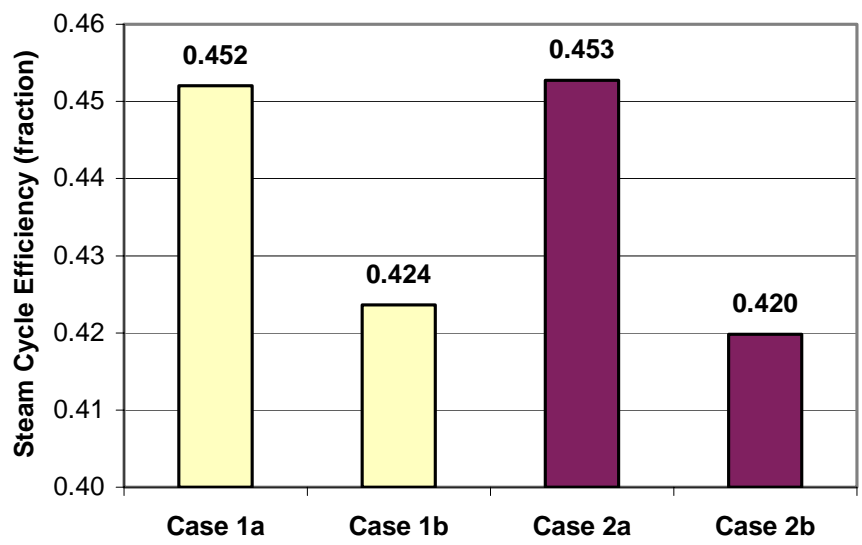

Figure 3-3: Steam Cycle Efficiency Comparison

\subsubsection{Total Plant Auxiliary Power:}

Figure 3-4 compares total plant auxiliary power among the cases. There are three main categories that comprise the total plant auxiliary power. These are:

1. The Gas Processing System (GPS)

2. The Air Separation Unit (ASU)

3. The traditional power plant auxiliaries associated with the draft system for the CFB boiler, 
the cooling water system, and the solids handling systems (coal, sorbent, ash), etc.
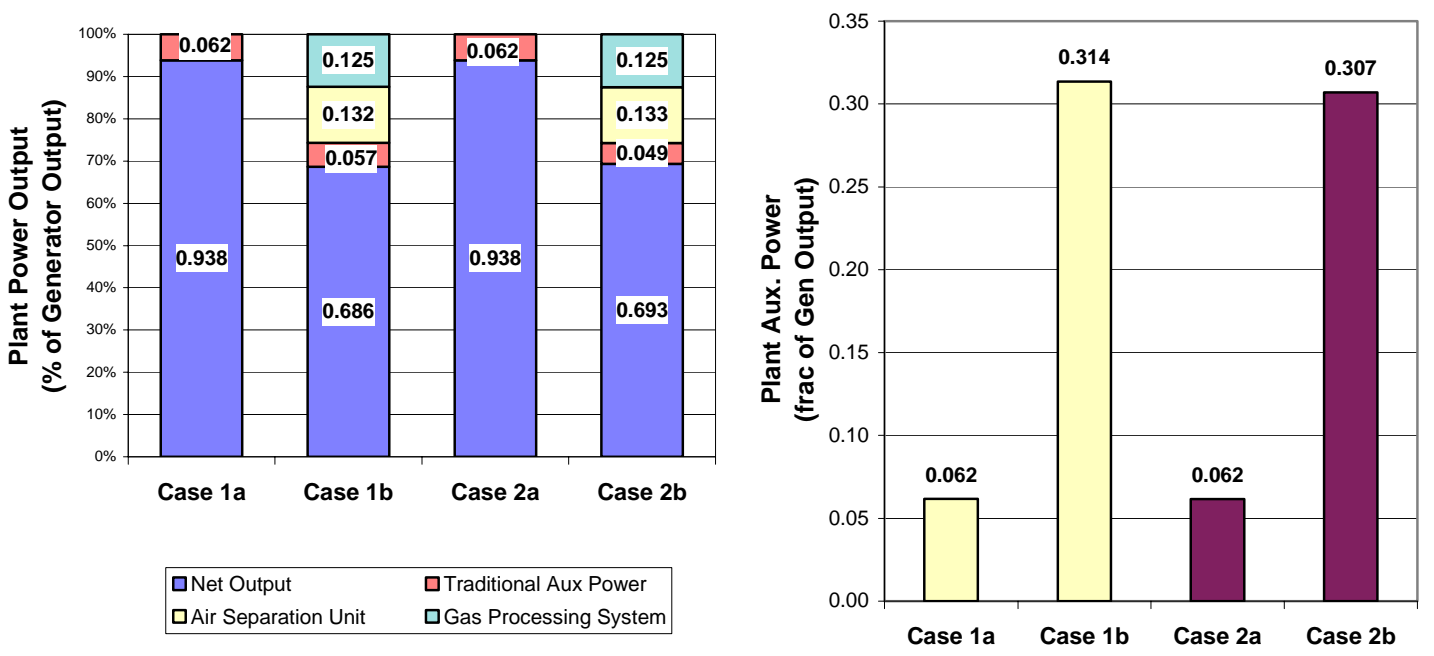

Figure 3-4: Auxiliary Power Comparison between Air-Fired and Oxy-fuel Fired CFB Plants

Cases 1a and 2a, the air-fired Base Case and air-fired capture ready case without $\mathrm{CO}_{2}$ recovery, require much less auxiliary power than the other cases, since they do not require an ASU or a Gas Processing System to purify and compress the $\mathrm{CO}_{2}$. The auxiliary power requirements for these cases are only that which is attributable to the traditional power plant equipment. This includes equipment for solids handling (coal, limestone, and ash), air and gas handling, water pumping for the steam cycle and cooling water systems, as well as other miscellaneous systems within the traditional power plant. These cases require slightly more than 6 percent of the generator output for auxiliary power. A detailed listing of plant auxiliary power was shown in Table 3-2.

Case $1 \mathrm{~b}$ and Case $2 \mathrm{~b}$ both include the ASU and GPS each of which consume about $13 \%$ of the gross output, while the traditional auxiliary power consumption is reduced to about $5 \%$ of the generator output for Case $2 \mathrm{~b}$ and about 6\% for Case 2a (see Table 3-2).

\subsubsection{Net Plant Power Output:}

Figure 3-5 compares the resulting net plant electrical output (MWe) among these four cases. Case $1 \mathrm{a}$ and 2a, the air-fired Base Case and air-fired capture ready case without $\mathrm{CO}_{2}$ recovery, each have essentially the same net plant electrical output. Case $1 \mathrm{~b}$ suffers about a 25 percent net electrical output reduction due to the power consumption of the ASU and GPS systems. Case $2 \mathrm{~b}$, the capture ready case (Case $2 \mathrm{a}$ ) retrofitted to oxygen firing and $\mathrm{CO}_{2}$ capture, was designed to be able to recover the net electrical output reduction due to the power consumption of the ASU and GPS systems with increased coal firing and steam generation. The actual net output for Case $2 \mathrm{~b}$ fell slightly short of the goal of 636 MWe due to a slight under estimation of the coal input needed for this case. No limitation was reached for this case and a small additional increase in the coal firing rate and associated steam generation rate would provide the original net plant electrical output. 


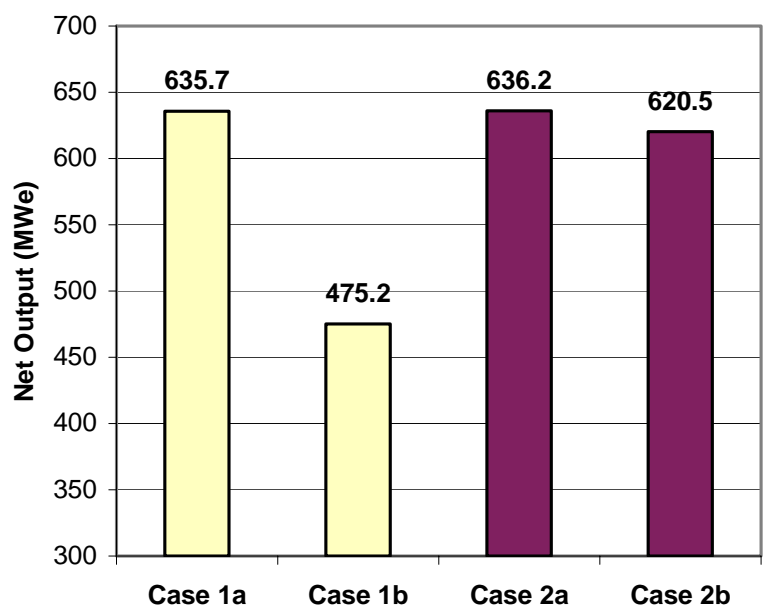

Figure 3-5: Net Plant Electrical Output Comparison

\subsubsection{Plant Thermal Efficiency:}

Figure 3-6 shows a comparison of Plant Thermal Efficiency between the four cases. These thermal efficiency results reflect the combined impact of boiler efficiency, steam cycle efficiency, and plant auxiliary power on net plant thermal efficiency. As shown previously, the differences in plant auxiliary power associated with the capture of $\mathrm{CO}_{2}$ represents the dominant factor for differences in overall plant thermal efficiency for the cases studied.

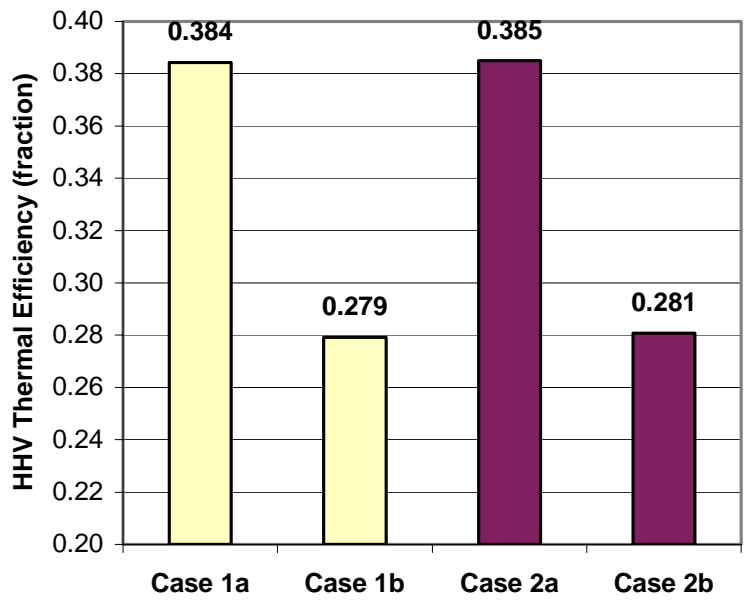

Figure 3-6: Plant Thermal Efficiency Comparison

The resulting energy penalties for Cases $1 \mathrm{~b}$ and $2 \mathrm{~b}$ are both about 27 percent as compared to Cases $1 \mathrm{a}$ and $2 \mathrm{a}$ respectively. There are two primary reasons for the energy penalty associated with Cases $1 \mathrm{~b}$ and $2 \mathrm{~b}$. First, the integration into the power plant of the Air Separation Unit (ASU) to provide combustion oxygen, and second, the Gas Processing System (GPS) to, compress, purify, and liquefy the $\mathrm{CO}_{2}$ product. The oxygen-fired cases utilize a cryogenic based ASU system, which adds a significant load to the plant auxiliary power requirement [about $180 \mathrm{kWh} /$ ton (200 kWh/tonne) of oxygen supplied or about 13 percent of the steam turbine generator output]. The distillation type GPS power requirements were calculated to be 
about $159 \mathrm{kWh} /$ ton ( $159 \mathrm{kWh} / \mathrm{ton})$ of $\mathrm{CO}_{2}$ captured or about 12 percent of the steam turbine generator output. Both these systems (ASU and GPS) consume large quantities of auxiliary power as shown in Table 3-2.

\subsubsection{Plant $\mathrm{CO}_{2}$ Emissions:}

Figure 3-7 compares overall plant $\mathrm{CO}_{2}$ emissions on a normalized basis ( $\mathrm{lbm} / \mathrm{kWh}-\mathrm{kg} / \mathrm{kWh}$ ) among these four cases. Also shown in this figure are the quantities of captured $\mathrm{CO}_{2}$ (normalized basis). The air-fired Base Case (Case1a) and air-fired capture ready case (Case 2a), both without $\mathrm{CO}_{2}$ recovery, emit about $1.82 \mathrm{lbm} / \mathrm{kWh}(0.82 \mathrm{~kg} / \mathrm{kWh})$ of $\mathrm{CO}_{2}$ as is typical for bituminous coal fired power plants with supercritical steam cycles. The oxygen-fired cases, which include $\mathrm{CO}_{2}$ capture systems, show normalized $\mathrm{CO}_{2}$ emissions of about $0.15 \mathrm{lbm} / \mathrm{kWh}$ $(0.07 \mathrm{~kg} / \mathrm{kWh})$ of $\mathrm{CO}_{2}$. Both of the oxygen-fired cases capture almost 94 percent of the $\mathrm{CO}_{2}$ produced.

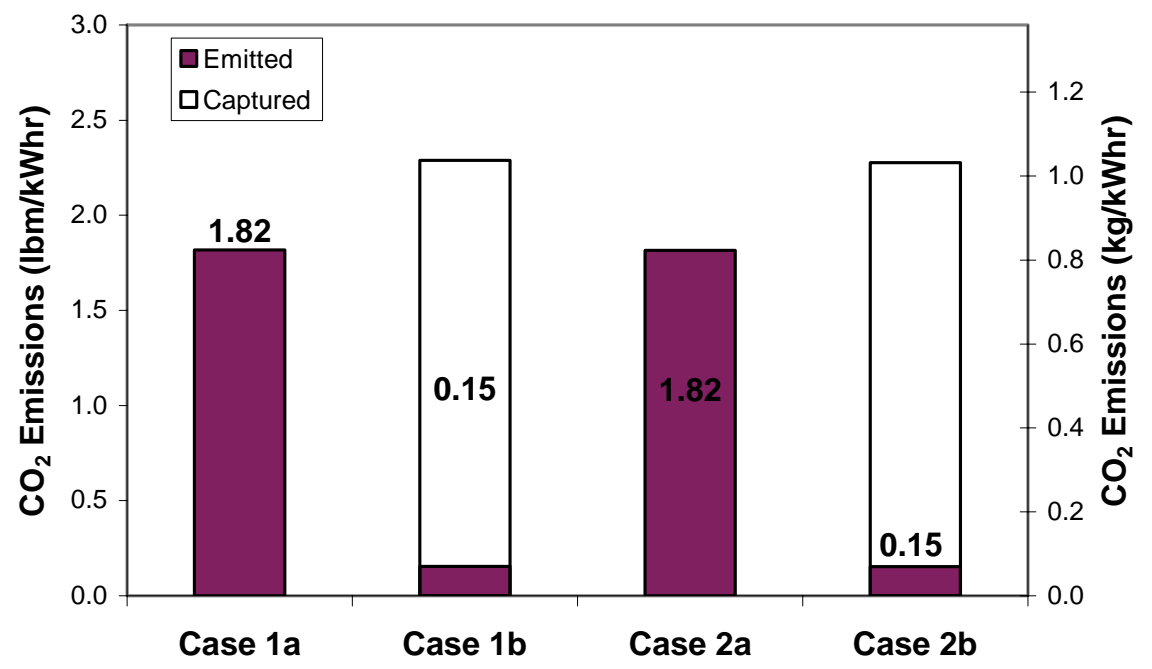

Figure 3-7: Plant $\mathrm{CO}_{2}$ Emission Comparison

The upper bars (lighter shade) shown on the figure indicate the normalized quantities of $\mathrm{CO}_{2}$ captured. The captured quantities of $\mathrm{CO}_{2}$ are about 2.28 and $2.29 \mathrm{lbm} / \mathrm{kWh}(1.03$ and 1.04 $\mathrm{kg} / \mathrm{kWh}$ ) for Case $2 \mathrm{~b}$ and Case $1 \mathrm{~b}$ respectively. The lower bars (darker shade) and the lower set of data labels show the normalized $\mathrm{CO}_{2}$ emitted. The emitted quantity of $\mathrm{CO}_{2}$ is about 0.15 $\mathrm{lbm} / \mathrm{kWh}(0.07 \mathrm{~kg} / \mathrm{kWh})$ for both the $\mathrm{CO}_{2}$ capture cases. The sum of these two quantities (captured + emitted) represents the quantity of $\mathrm{CO}_{2}$ produced [e.g., the Case $2 \mathrm{~b}$ power plant produces $2.28+0.15=2.43 \mathrm{lbm} / \mathrm{kWh}(1.10 \mathrm{~kg} / \mathrm{kWh})$ of $\mathrm{CO}_{2}$ on a normalized basis].

Figure 3-8 compares avoided $\mathrm{CO}_{2}$ emissions on a normalized basis $(\mathrm{lbm} / \mathrm{kWh})$ for the two capture cases (Cases $1 \mathrm{~b}$ and $2 \mathrm{~b}$ ). The avoided $\mathrm{CO}_{2}$ emissions are calculated relative to the appropriate non-capture case (i.e. Case $1 \mathrm{a}$ and 2a respectively). The avoided quantities of $\mathrm{CO}_{2}$ for Cases $1 \mathrm{~b}$ and $2 \mathrm{~b}$ are 1.66 and $1.67 \mathrm{lbm} / \mathrm{kWh}(0.75$ and $0.76 \mathrm{~kg} / \mathrm{kWh})$ respectively. 


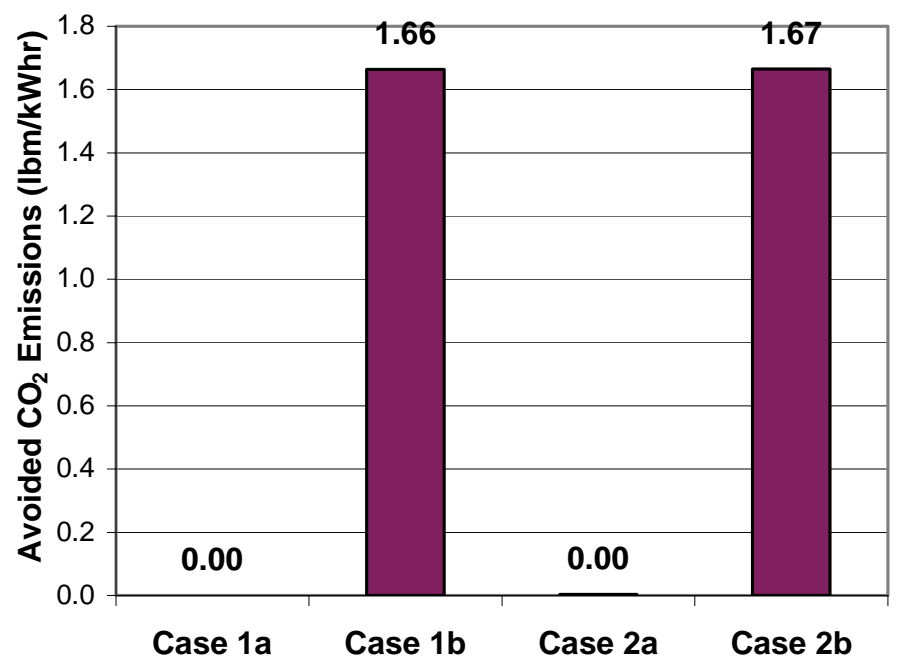

Figure 3-8: Avoided $\mathrm{CO}_{2}$ Emission Comparison

\subsubsection{Criteria Emissions}

Case 1a and 2a are designed to meet federal and local emission regulations. Case $2 \mathrm{~b}$ is modified to fire $38 \%$ more fuel and, therefore, will require a new emissions permit at the time of conversion to oxygen firing and $\mathrm{CO}_{2}$ capture. Case $1 \mathrm{~b}$, in which the firing rate is not increased at the time of conversion, but entails major modifications for oxygen firing and $\mathrm{CO}_{2}$ capture, will also require a new emissions permit. 


\section{CFB BOILER DESIGN AND PERFORMANCE}

This section describes the conceptual designs of the two CFB boilers (Case 1a and Case 2a). Additionally, the modifications to accommodate oxygen firing and $\mathrm{CO}_{2}$ capture are also described (Case $1 \mathrm{~b}$ and Case $2 \mathrm{~b}$ ) and the capture ready features are indicated. The performance of the boiler islands for the four case studies is presented in terms of boiler island material and energy balances.

\subsection{Water/Steam Flow Path}

Each of the four CFB steam generators (Case 1a, 1b, 2a, and 2b) in this study is designed as a once through forced circulation type boiler. The basic steam/water flow path for each of the boilers is briefly described below. Feedwater leaving the final extraction feedwater heater flows through the economizer section located in the backpass of the CFB boiler before entering into the waterwalls of the furnace and the evaporator section located in the external fluidized bed heat exchanger. One steam/water separator is located downstream of the evaporator sections for separating the water/steam mixture while the boiler is operated at low load (below 40\%). The separated water is returned to the economizer inlet and the separated steam flows to the superheater circuit at low load.

Above $40 \%$ MCR the dry steam produced in the evaporator sections does not need any water separation and flows directly through the separator before feeding the first stages of the superheat circuit. The superheater circuit starts with the inlet ducts of the cyclones, the cyclone enclosures, ducts from the cyclones to the backpass, and the backpass enclosure walls. Two intermediate superheaters located in the external beds located on each side of the furnace are fed in parallel by the steam leaving the backpass walls. The steam leaving the intermediate superheaters is sent to the finishing superheater located at the top of the backpass. Adjusting the ratio of feedwater flow to coal flow controls the steady state superheater outlet steam temperature. During transients, the steam temperature is controlled by two spray water stages; the first stage is upstream of the intermediate superheater and the second stage is located at the finishing superheater inlet.

The reheat system includes a low temperature reheater in the backpass and the finishing reheater in one external bed. Reheat temperature is controlled by adjusting the ash cone valve opening thus biasing the hot solids leaving the cyclones between an uncooled stream which flow directly back to the furnace and a cooled stream which flows through the external beds. In this manner, there isn't any spray water used under steady state operation.

The water/steam path is modified somewhat for Case $2 \mathrm{~b}$ with the added steam generation surface as described in Sections 4.4 and 4.5.

\subsection{Case 1a - Air Fired CFB Boiler Island (Base Case)}

This section describes the boiler island for the Base Case (Case 1a). The description includes a process description and a material and energy balance for this case.

\subsubsection{Process Description:}

This process description briefly describes the function of the major equipment and systems included within the boiler island. A simplified Gas/Solids process flow diagram for the Case 1a boiler island (air fired Base Case) is shown in Figure 4-1. Selected mass flow rates (lbm/hr) and temperatures $\left({ }^{\circ} \mathrm{F}\right)$ are shown on this figure. The flow rates shown are the combined flows for the two parallel CFB boilers. Complete data for all streams are shown in Table 4-1. 


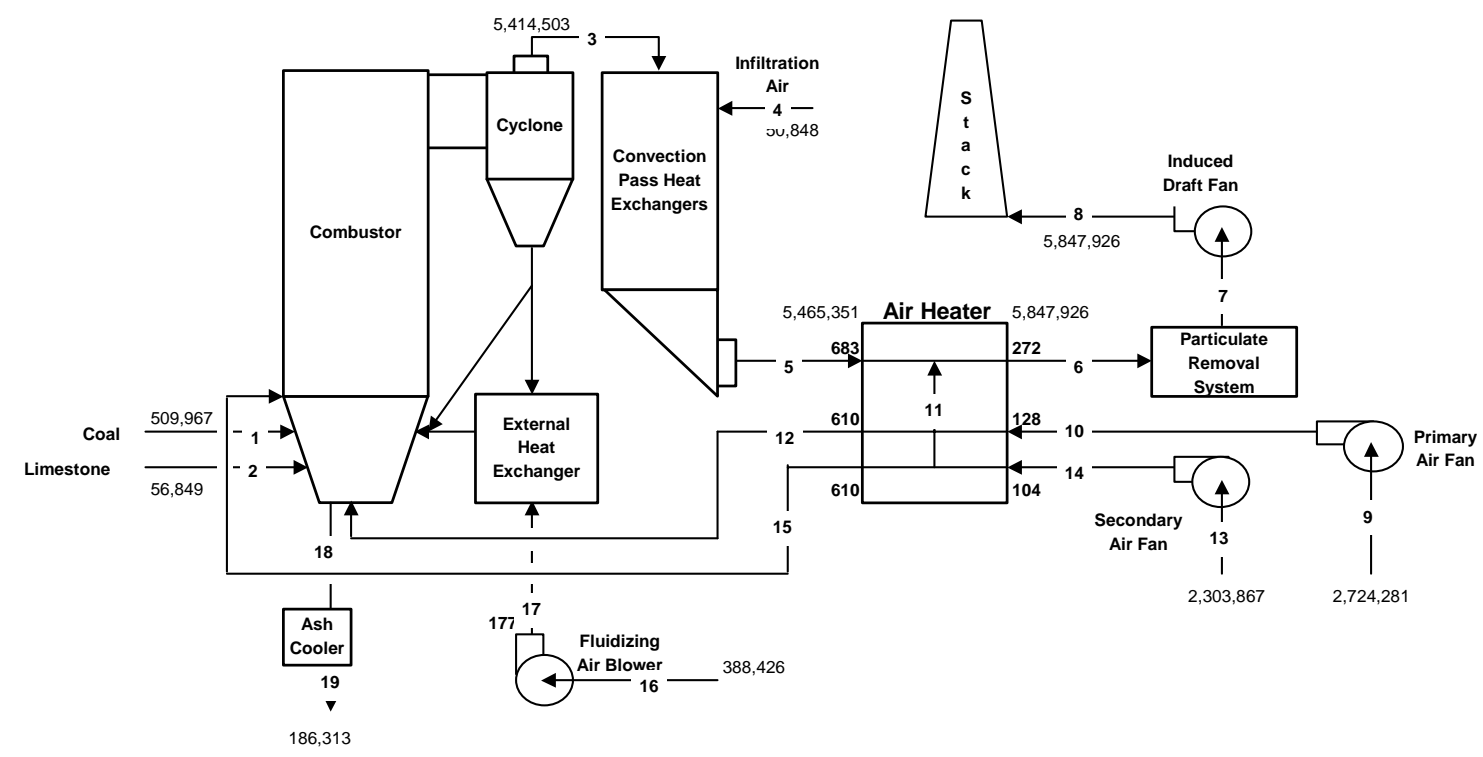

Figure 4-1: Case 1a (Base Case) Air Fired CFB Boiler Island

In this case, coal (Stream 1) is reacted with preheated air (Streams 12, 15) in the Combustor section of the Circulating Fluidized Bed (CFB) system. A traditional furnace limestone injection system is used to remove about 90 percent of the $\mathrm{SO}_{2}$ produced. The combustor is a water-cooled refractory lined vessel designed to evaporate high-pressure steam. The air (Streams 12, 15, 17) is supplied from primary, secondary and fluidizing air fans. The products of combustion leaving the Combustor flow through cyclones where most of the entrained hot solids are removed and recirculated to the Combustor. By properly splitting the flow of hot recirculated solids leaving the cyclone bottom, between an uncooled stream which flows directly back to the Combustor and the External Heat Exchanger where the solids are cooled before returning to the Combustor, the temperature in the combustor can be controlled to the desired level for a wide variety of operating conditions. Exchanging heat with the power cycle working fluid cools the solids in the External Heat Exchanger.

Draining hot solids from the combustor through water-cooled ash coolers (Stream 18) controls solids inventory in the system while recovering heat from the hot ash.

The flue gas leaving the Cyclones (Stream 3) is cooled in heat exchanger sections located in the convection pass of the system, also by exchanging heat with the power cycle working fluid (steam/water). The flue gas leaving the convection pass heat exchanger sections (Stream 5) is further cooled in the Air Heaters. The flue gas leaving the Air Heaters (Stream 6) is cleaned of fine particulate matter in a baghouse (fabric filter) and enters the Induced Draft (ID) Fan (Stream 7). The flue gas leaving the ID Fan (Stream 8) is then discharged to the atmosphere through a stack.

\subsubsection{Material and Energy Balance:}

Table 4-1 shows the Boiler Island material and energy balance for Case 1a. The stream numbers shown at the top of each column of the table refer to stream numbers shown in Figure 4-1. The performance shown was calculated with air firing at MCR conditions for this unit and at ambient conditions as defined in the design basis. 
Table 4-1: Case 1a Boiler Island Material and Energy Balance (Base Case)

\begin{tabular}{|c|c|c|c|c|c|c|c|c|c|c|c|}
\hline Constituent & (Units) & 1 & 2 & 3 & 4 & 5 & 6 & 7 & 8 & 9 & 10 \\
\hline $\mathrm{O}_{2}$ & (Lbm/hr) & 16115 & & 184113 & 11639 & 195752 & 283323 & 283323 & 283323 & 623588 & 623588 \\
\hline $\mathrm{N}_{2}$ & $"$ & 7446 & & 3824728 & 38558 & 3863286 & 4153392 & 4153392 & 4153392 & 2065822 & 2065822 \\
\hline $\mathrm{H}_{2} \mathrm{O}$ & $"$ & 20348 & & 247479 & 651 & 248130 & 253027 & 253027 & 253027 & 34871 & 34871 \\
\hline $\mathrm{CO}_{2}$ & $"$ & & & 1155799 & & 1155799 & 1155799 & 1155799 & 1155799 & & \\
\hline $\mathrm{SO}_{2}$ & $"$ & & & 2384 & & 2384 & 2384 & 2384 & 2384 & & \\
\hline $\mathrm{H}_{2}$ & $"$ & 18206 & & & & & & & & & \\
\hline Carbon & $"$ & 316434 & & & & & & & & & \\
\hline Sulfur & $"$ & 11933 & & & & & & & & & \\
\hline $\mathrm{CaO}$ & $"$ & & & & & & & & & & \\
\hline $\mathrm{CaSO}_{4}$ & $"$ & & & & & & & & & & \\
\hline $\mathrm{CaCO}_{3}$ & $"$ & & 55883 & & & & & & & & \\
\hline Ash & $"$ & 119485 & 966 & & & & & & & & \\
\hline \multirow{3}{*}{\begin{tabular}{|l} 
Total Gas \\
Total Solids \\
Total Flow \\
\end{tabular}} & \multirow{3}{*}{$\begin{array}{c}\text { (Lbm/hr) } \\
" \\
" \\
\end{array}$} & Coal & Limestone & $\begin{array}{c}\text { Flue Gas to BP || } \\
5414503\end{array}$ & $\begin{array}{r}\text { Infiltration Air } \\
50848\end{array}$ & $\begin{array}{l}\text { Flue Gas to AH } \\
5465351\end{array}$ & $\begin{array}{r}\text { Flue Gas to PR } \\
5847926\end{array}$ & $\begin{array}{l}\text { Flue Gas to ID } \\
5847926\end{array}$ & $\begin{array}{l}\text { FGas from ID } \\
5847926\end{array}$ & $\begin{array}{l}\text { Primary Air } \\
2724281\end{array}$ & $\begin{array}{r}\text { Primary Air } \\
2724281\end{array}$ \\
\hline & & 509967 & 56849 & & $\begin{array}{r}000+0 \\
0\end{array}$ & 0 & 0 & 0 & 0 & & \\
\hline & & 509967 & 56849 & 5414503 & 50848 & 5465351 & 5847926 & 5847926 & 5847926 & 2724281 & 2724281 \\
\hline \multirow{7}{*}{ 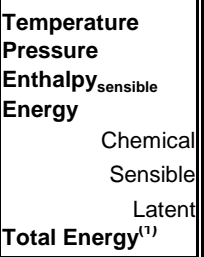 } & \multirow{7}{*}{$\begin{array}{c}\text { (Deg F) } \\
\text { (Psia) } \\
(\mathrm{Btu} / \mathrm{lbm}) \\
\\
\left(10^{6} \mathrm{Btu} / \mathrm{hr}\right) \\
\left(10^{6} \mathrm{Btu} / \mathrm{hr}\right) \\
\left(10^{6} \mathrm{Btu} / \mathrm{hr}\right) \\
\left(10^{\circ} \mathrm{Btu} / \mathrm{hr}\right)\end{array}$} & 80 & 80 & 1639 & 80 & 683 & 272 & 272 & 286 & 80 & 128 \\
\hline & & 14.7 & 14.7 & 14.7 & 14.7 & 14.6 & 14.4 & 14.0 & 14.7 & 14.7 & 18.31 \\
\hline & & 0.000 & 0.000 & 426.180 & 0.000 & 154.278 & 47.727 & 47.727 & 51.214 & 0.000 & 11.623 \\
\hline & & \multicolumn{2}{|l|}{5645.334} & & & & & & & & \\
\hline & & 0.000 & 0.000 & 2307.553 & 0.000 & 843.185 & 279.102 & 279.102 & 299.494 & 0.000 & 31.664 \\
\hline & & 0.000 & 0.000 & 259.853 & 0.683 & 260.537 & 265.679 & 265.679 & 265.679 & 36.614 & 36.614 \\
\hline & & 5645.334 & 0.000 & 2567.406 & 0.683 & 1103.722 & 544.780 & 544.780 & 565.173 & 36.614 & 68.278 \\
\hline Constituent & (Units) & 11 & 12 & 13 & 14 & 15 & 16 & 17 & 18 & 19 & \\
\hline $\mathrm{O}_{2}$ & $\overline{(\mathrm{Lbm} / \mathrm{hr})}$ & 87571 & 576141 & 527355 & 527355 & 487231 & 88911 & 88911 & & & \\
\hline $\mathrm{N}_{2}$ & " & 290106 & 1908641 & 1747023 & 1747023 & 1614098 & 294543 & 294543 & & & \\
\hline $\mathrm{H}_{2} \mathrm{O}$ & $"$ & 4897 & 32218 & 29490 & 29490 & 27246 & 4972 & 4972 & & & \\
\hline $\mathrm{CO}_{2}$ & $"$ & & & & & & & & & & \\
\hline $\mathrm{SO}_{2}$ & $"$ & & & & & & & & & & \\
\hline & $"$ & & & & & & & & & & \\
\hline Carbon & " & & & & & & & & 7731 & 7731 & \\
\hline Sulfur & " & & & & & & & & 0 & & \\
\hline $\mathrm{CaO}$ & $"$ & & & & & & & & 12524 & 12524 & \\
\hline $\mathrm{CaSO}_{4}$ & $"$ & & & & & & & & 45606 & 45606 & \\
\hline $\mathrm{CaCO}_{3}$ & $"$ & & & & & & & & 0 & & \\
\hline Ash & " & & & & & & & & 120452 & 120452 & \\
\hline \multirow{3}{*}{$\begin{array}{l}\text { Total Gas } \\
\text { Total Solids } \\
\text { Total Flow } \\
\end{array}$} & \multirow{3}{*}{$\begin{array}{c}\text { (Lbm/hr) } \\
" \\
" \\
\end{array}$} & $\begin{array}{r}\text { AH Lkg Air } \\
382575\end{array}$ & $\begin{array}{l}\text { Primary Air } \\
2517000\end{array}$ & $\begin{array}{l}\text { Secondary Air } \\
2303867\end{array}$ & $\begin{array}{l}\text { Secondary Air } \\
2303867\end{array}$ & $\begin{array}{l}\text { Secondary Air } \\
2128574\end{array}$ & $\begin{array}{l}\text { Fluidizing Air } \\
388426\end{array}$ & $\begin{array}{c}\text { Fluidizing Air } \\
388426\end{array}$ & Ash Drain & & \\
\hline & & & & & & & & & 186313 & 186313 & \\
\hline & & 382575 & 2517000 & 2303867 & 2303867 & 2128574 & 388426 & 388426 & 186313 & 186313 & \\
\hline \multirow{3}{*}{$\begin{array}{l}\text { Temperature } \\
\text { Pressure } \\
\text { Enthalpy } \\
\text { Enensible } \\
\text { Energy }\end{array}$} & \multirow{7}{*}{\begin{tabular}{|c} 
(Deg F) \\
(Psia) \\
$($ Btu/lbm $)$ \\
\\
$\left(10^{6} \mathrm{Btu} / \mathrm{hr}\right)$ \\
$\left(10^{6} \mathrm{Btu} / \mathrm{hr}\right)$ \\
$\left(10^{6} \mathrm{Btu} / \mathrm{hr}\right)$ \\
$\left(10^{\circ} \mathrm{Btu} / \mathrm{hr}\right)$
\end{tabular}} & 128 & 610 & 80 & 104 & 610 & 80 & 177 & 1616 & 302 & \\
\hline & & 18.3 & 18.1 & 14.7 & 16.4 & 16.2 & 14.7 & 22.642 & 14.7 & 14.7 & \\
\hline & & 11.623 & 131.118 & 0.000 & 5.805 & 131.118 & 0.000 & 23.597 & 413.015 & 44.700 & \\
\hline \multirow{4}{*}{$\begin{array}{l}\text { Latent } \\
\text { Total Energy }^{(1)}\end{array}$} & & & & & & & & & 108.955 & 108.955 & \\
\hline & & 4.447 & 330.025 & 0.000 & 13.373 & 279.095 & 0.000 & 9.166 & 76.950 & 8.328 & \\
\hline & & 5.142 & 33.828 & 30.964 & 30.964 & 28.608 & 5.220 & 5.220 & 0.000 & 0.000 & \\
\hline & & 9.588 & 363.854 & 30.964 & 44.337 & 307.703 & 5.220 & 14.386 & 185.905 & 117.283 & \\
\hline
\end{tabular}

Notes:

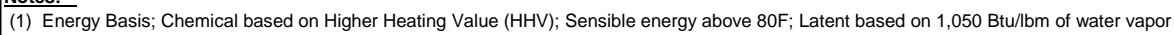

\subsubsection{Coal Feeding System:}

Coal is introduced into the furnace through the solids return ducts, which run from the seal pots to the furnace. There are eight (8) coal injection points, two (2) in each solids return duct. The arrangement and number of coal feeders and coal conveyors ensure an even distribution of coal into the furnace even though a coal conveyor may be out of service. Design capacity for the Base Case is based on a coal flow of about 130 ton/h (115 tonne/h).

\subsubsection{Bottom Ash Removal System:}

Capacity of the bottom ash removal system is defined by the operation before conversion (Case 
1a) while the $\mathrm{SO}_{2}$ capture is achieved by limestone injection into the furnace. Coal flow at MCR is equal to about 130 ton/h (115 tonne/h) before conversion with limestone flow around $17 \mathrm{ton} / \mathrm{h}$ (15 tonne/h). Hence, total ash flow is around $47 \mathrm{ton} / \mathrm{h}$ (43 tonne/h); 29 ton/h (26 tonne/h) produced by the coal and remaining ash created by the calcination/sulfation reactions.

The bottom ash removal system includes 6 screw coolers with about 9 ton/h (8 tonne/h) capacity per screw. The ash handling will be by a pneumatic transport system for feeding the bottom ash silo.

\subsubsection{Air Preheaters:}

Two identical regenerative air heaters have been selected for the Base Case and arranged in parallel flue gas streams. Primary air and secondary air pass through the air preheaters and cool the flue gas to around $272^{\circ} \mathrm{F}\left(140^{\circ} \mathrm{C}\right)$.

\subsection{Case $1 \mathrm{~b}$ - The Case 1a CFB Boiler Island Retrofit with $\mathrm{O}_{2}$ Firing and $\mathrm{CO}_{2}$ Capture}

This section describes the boiler island for Case 1b, which is the retrofit of Case 1a (the capture unready Base Case) with $\mathrm{O}_{2}$ Firing and $\mathrm{CO}_{2}$ Capture. The description includes a process description, a material and energy balance, and a description of the modifications required to the boiler island for this case.

\subsubsection{Process Description:}

This process description briefly describes the function of the major equipment and systems included within the Boiler Island. Figure 4-2 shows a simplified process flow diagram for the Boiler Island of the Case 1b oxygen-fired CFB retrofit. Selected mass flow rates (lbm/hr) and temperatures $\left({ }^{\circ} \mathrm{F}\right)$ are shown on this figure. Complete data for all streams are shown in the material and energy balance shown in Table 4-2.

In this concept coal (Stream 1 ) is reacted with a preheated mixture of substantially pure oxygen and recirculated flue gas (Streams 16 and 20) in the Combustor section of the Circulating Fluidized Bed (CFB) system. The oxygen supply (Streams 21, 22, 23a and 23b) is provided from a new cryogenic Air Separation Unit (ASU).

Flue gas (mainly $\mathrm{CO}_{2}$ and $\mathrm{H}_{2} \mathrm{O}$ ) and ash enter the two existing cyclones (Stream 3). Most of the solids are removed in the cyclones. The hot solids are recirculated to the combustor through two parallel paths: (1) an uncooled stream, which flows directly back to the combustor, and (2) a stream flowing through the existing two External Heat Exchangers where the solids are cooled before returning to the combustor. The External Heat Exchangers provide evaporator, superheat, and reheat duty.

Draining hot solids through the existing water-cooled ash coolers (Streams 26 and 27) controls solids inventory in the system while effectively recovering heat from the hot ash.

The flue gas leaving the cyclones (Stream 3) is cooled in existing heat exchanger sections (Superheater, Reheater, and Economizer) located in the convection pass (backpass) of the system, also by exchanging heat with the power cycle working fluid. The flue gas leaving the convection pass heat exchanger sections (Stream 5) is further cooled in an existing air heater. The oxygen stream leaving the new Air Separation Unit (Stream 21) is heated in a new tubular oxygen heater, split and mixed with primary and secondary streams of heated recirculated flue gas (Streams 15 and 19) and the mixtures supplied to the furnace. The quantity of recirculated flue gas used (Stream 12) is adjusted to provide proper fluidization for the bed and other equipment in the CFB system requiring a fluidizing medium. 


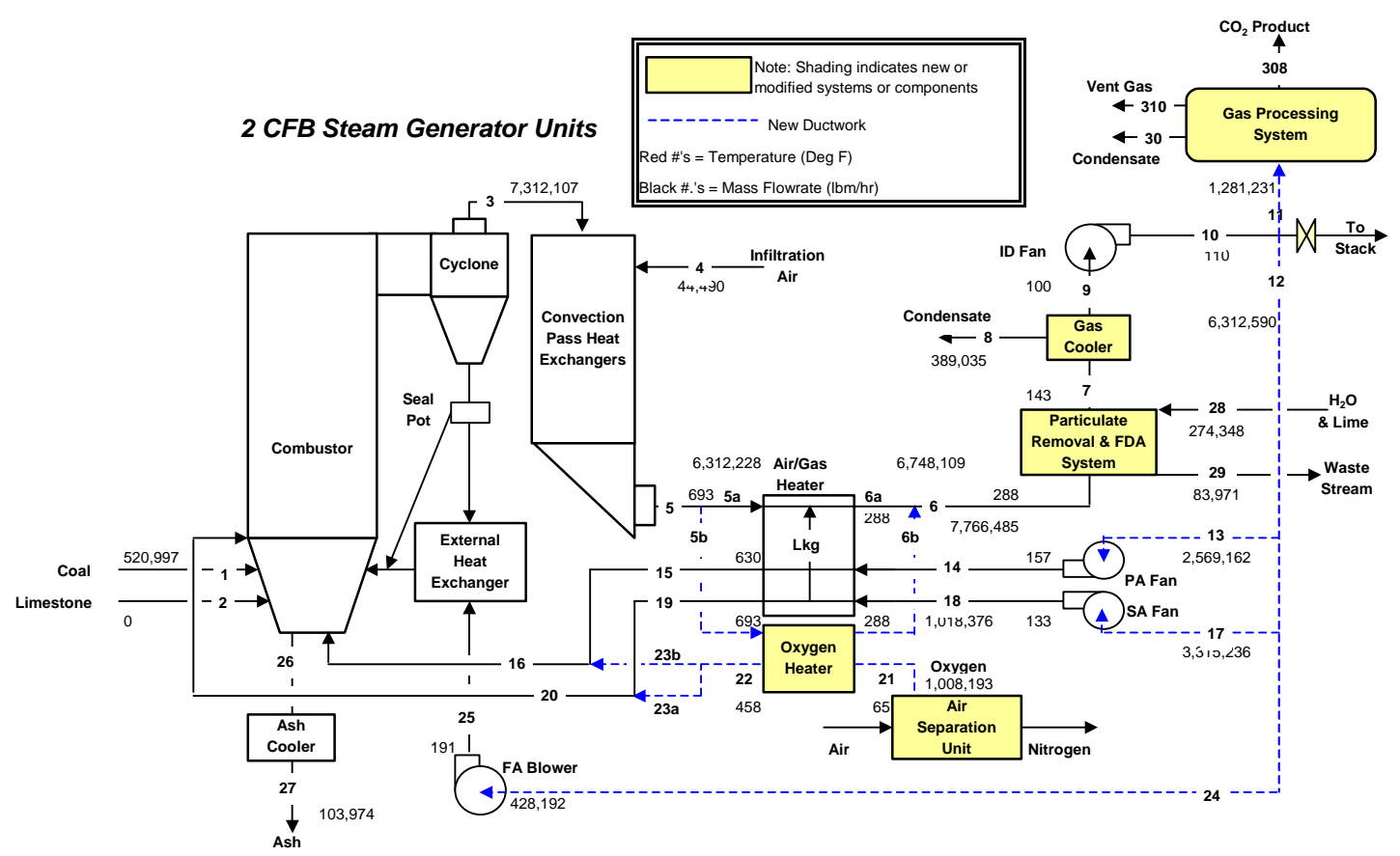

Figure 4-2: Case 1b - CFB Boiler Retrofit with $\mathrm{O}_{2}$ Firing and $\mathrm{CO}_{2}$ Capture

The flue gas leaving the existing air heater (Stream 6) is cleaned of fine particulate matter and $\mathrm{SO}_{2}$ in the modified Particulate Removal and Flash Dryer Absorber (FDA) system where $\mathrm{SO}_{2}$ is removed. Finally, a new Gas Cooler is used to cool the gas before the flue gas enters the Induced Draft (ID) Fan (Stream 9). The Gas Cooler is used to cool the flue gas to as low a temperature as is possible (using a direct contact water system) before recycling. This is done to minimize the power requirements for the draft system (induced draft fan, fluidizing air blowers, primary air and secondary air fans) and the product gas compression system, which is part of the Gas Processing System. Some $\mathrm{H}_{2} \mathrm{O}$ vapor is condensed out of the flue gas in the Gas Cooler. The flue gas leaving the ID Fan (Stream 10), comprised of mostly $\mathrm{CO}_{2}$, is split with about 17 percent of the flue gas going to the product stream (Stream 11) for further processing for an EOR application. The remainder of the flue gas (about 83 percent) is recirculated to the CFB system (Stream 12).

\subsubsection{Material and Energy Balance:}

Table 4-2 shows the Boiler Island material and energy balance for Case $1 \mathrm{~b}$. The stream numbers shown at the top of each column of the table refer to stream numbers shown in Figure 4-2. The performance shown was calculated with oxygen firing at the Base Case MCR conditions for this unit and at ambient conditions as defined in the design basis. 
COMMERCIALIZATION DEVELOPMENT OF OXYGEN FIRED

CFB FOR GREENHOUSE GAS CONTROL

Table 4-2: Case 1b Boiler Island Material and Energy Balance (Base Case Retrofit with Oxygen firing and $\mathrm{CO}_{2} \mathrm{Capture}$

\begin{tabular}{|c|c|c|c|c|c|c|c|c|c|c|c|c|c|c|c|c|c|c|c|c|}
\hline \multicolumn{21}{|l|}{ English Units } \\
\hline Constituent & (Units) & 1 & 2 & 3 & 4 & 5 & $5 a$ & $5 b$ & Lkg & $6 a$ & $6 \mathrm{~b}$ & 6 & 7 & 8 & 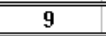 & 10 & 11 & 12 & 13 & 14 \\
\hline 02 & (Lbm/hr) & 16463 & & 183913 & 10184 & 194097 & 167133 & 26964 & 11819 & 178952 & 26964 & 205916 & 205916 & & 205916 & 205916 & 34742 & 171174 & 69666 & 69666 \\
\hline N2 & " & 7607 & & 254133 & 33737 & 287870 & 247879 & 39991 & 17530 & 265408 & 39991 & 305400 & 305400 & & 305400 & 305400 & 51527 & 253873 & 103324 & 103324 \\
\hline $\mathrm{H} 2 \mathrm{O}$ & $"$ & 20788 & & 363767 & 569 & 364336 & 313722 & 50614 & 13111 & 326833 & 50614 & 377447 & 617447 & 389035 & 228412 & 228412 & 38538 & 189874 & 77277 & 77277 \\
\hline $\mathrm{CO} 2$ & $"$ & & & 6456590 & & 6456590 & 5559632 & 896957 & 393173 & 5952805 & 896957 & 6849762 & 6849762 & & 6849762 & 6849762 & 1155693 & 5694069 & 2317430 & 2317430 \\
\hline SO2 & $"$ & & & 27712 & & 27712 & 23862 & 3850 & 249 & 24111 & 3850 & 27960 & 4331 & & 4331 & 4331 & 731 & 3601 & 1465 & 1465 \\
\hline H2 & " & 18600 & & & & & & & & & & & & & & & & & & \\
\hline Carbon & $"$ & 323278 & & 1580 & & 1580 & 1360 & 219 & & 1360 & 1360 & 1580 & & & & & & & & \\
\hline Sulfur & $"$ & 12191 & & & & & & & & & & & & & & & & & & \\
\hline $\mathrm{CaO}$ & $"$ & & & & & & & & & & & & & & & & & & & \\
\hline CaSO3 & " & & & & & & & & & & & & & & & & & & & \\
\hline $\mathrm{CaSO} 4$ & $"$ & & & & & & & & & & & & & & & & & & & \\
\hline $\mathrm{CaCO3}$ & " & & 0 & & & & & & & & & & & & & & & & & \\
\hline \multirow[t]{2}{*}{ Ash } & $"$ & 122070 & 0 & 24414 & & 24414 & 21022 & 3392 & & 21022 & 3392 & 24414 & & & & & & & & \\
\hline & & Coal & Limestone & Flue Gas & Infiltration Air & Flue Gas & Flue Gas & Flue Gas & AH Leakage & Flue Gas & Flue Gas & Flue Gas & Flue Gas & Condensate & Flue Gas & Flue Gas & $\begin{array}{l}\text { Flue Gas } \\
\end{array}$ & Recirc Gas & PA Fan in & PA Fan out \\
\hline Total Gas & (Lbm/hr) & & & 7286114 & 44490 & 7330604 & 6312228 & 1018376 & 435881 & 6748109 & 1018376 & 7766485 & 7982856 & & 7593821 & 7593821 & 1281231 & 6312590 & 2569162 & 2569162 \\
\hline Total Solids & , & 520997 & & 25994 & & 25994 & 22383 & 3611 & 0 & 22383 & 4752 & 25994 & & & & & & & & \\
\hline \multirow{2}{*}{$\begin{array}{l}\text { Total Flow } \\
\end{array}$} & $"$ & 520997 & 0 & 7312107 & 44490 & 7356597 & 6334610 & 1021987 & 435881 & 6770491 & 1023128 & 7792479 & 7982856 & 389035 & 7593821 & 7593821 & 1281231 & 6312590 & 2569162 & 2569162 \\
\hline & & & & & & & & & & & & & & & & & & & & \\
\hline \begin{tabular}{|l} 
Temperature \\
Pressure
\end{tabular} & (Deg F) & $\begin{array}{r}80 \\
147\end{array}$ & $\begin{array}{r}80 \\
\end{array}$ & 1639 & 80 & 693 & 693 & 693 & 143 & 288 & 288 & 288 & 143 & 100 & 100 & 110 & 110 & 110 & 110 & 157 \\
\hline Pressure & (Psia) & 14.7 & 14.7 & 14.7 & 14.7 & 14.6 & 14.6 & 14.6 & 0.0 & 0.0 & 0.0 & 14.4 & 14.0 & 14.7 & 13.9 & 14.7 & 14.7 & 14.7 & 14.7 & 19.0 \\
\hline $\begin{array}{l}\mathbf{h}_{\text {sensible-gas }} \\
\end{array}$ & $\begin{array}{l}\text { (Btu/lbm) } \\
\end{array}$ & & & 434.593 & & $\begin{array}{l}152.301 \\
\end{array}$ & $\begin{array}{ll}152.301 \\
\end{array}$ & 152.301 & 13.598 & \begin{tabular}{ll|}
47.414 \\
\end{tabular} & 年7.473 & (47.422 & 14.161 & (0.000 & 4.224 & 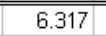 & \begin{tabular}{|c|}
6.317 \\
\end{tabular} & 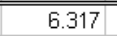 & \begin{tabular}{l|l|l}
6.317 \\
\end{tabular} & 16.633 \\
\hline $\mathbf{h}_{\text {sensible-solids }}$ & & & & 420.540 & & 138.993 & 138.993 & 138.993 & 0.000 & 41.740 & 41.740 & 41.740 & & & & & & & & \\
\hline Energy & & & & & & & & & & & & & & 19.960 & & & & & & \\
\hline Chemical & $\left(10^{6} \mathrm{Btu} / \mathrm{hr}\right)$ & 5767.433 & & 22.262 & & 22.262 & 19.170 & 3.093 & 0.000 & 19.170 & 19.170 & 22.262 & & & & & & & & \\
\hline Sensible & $\left(10^{6} \mathrm{Btu} / \mathrm{hr}\right)$ & 0.000 & 0.000 & 3177.425 & 0.000 & 1120.073 & 964.471 & 155.602 & 5.927 & 320.889 & 48.544 & 369.385 & 113.041 & 7.765 & 32.079 & 47.968 & 8.093 & 39.875 & 16.229 & 42.732 \\
\hline & $\left(10^{6} \mathrm{Btu} / \mathrm{hr}\right)$ & 0.000 & 0.000 & 381.955 & 0.598 & 382.553 & 329.408 & 53.145 & 13.766 & 343.174 & 53.145 & 396.319 & 648.319 & 0.000 & 239.833 & 239.833 & 40.465 & 199.368 & 81.141 & 81.141 \\
\hline \multirow[t]{2}{*}{ Total Energy ${ }^{(1)}$} & $\left(10^{6} \mathrm{Btu} / \mathrm{hr}\right)$ & 5767.433 & 0.000 & 3581.642 & 0.598 & 1524.888 & 1313.049 & 211.839 & 19.693 & 683.233 & 120.858 & 787.966 & 761.360 & 7.765 & 271.912 & 287.800 & 48.558 & 239.243 & 97.369 & 123.873 \\
\hline & & & & & & & & & & & & & & & & & & & & \\
\hline (1) Energy Basis; $\mathrm{C}$ & $m$ & ner $\mathrm{He}$ & de (H & & oove & & & vat & vapor & & & & & & & & & & & \\
\hline
\end{tabular}


COMMERCIALIZATION DEVELOPMENT OF OXYGEN FIRED

CFB FOR GREENHOUSE GAS CONTROL

\begin{tabular}{|c|c|c|c|c|c|c|c|c|c|c|c|c|c|c|c|c|c|c|c|c|}
\hline Constituent & (Units) & 15 & 16 & 17 & 18 & 19 & 20 & 21 & 22 & $23 \mathrm{~b}$ & $23 a$ & 24 & 25 & 26 & 27 & 28 & 29 & 30 & 310 & 308 \\
\hline 02 & (Lbm/hr) & 64506 & 504688 & 89897 & 89897 & 83238 & 651248 & 1008193 & 1008193 & 440183 & 568010 & 11611 & 11611 & & & & & & 34731 & 11 \\
\hline N2 & $"$ & 95670 & 100116 & 133328 & 133328 & 123452 & 129190 & 10184 & 10184 & 4446 & 5737 & 17221 & 17221 & & & & & & 51525 & 2 \\
\hline $\mathrm{H} 2 \mathrm{O}$ & $"$ & 71553 & 71553 & 99718 & 99718 & 92331 & 92331 & 0 & 0 & 0 & 0 & 12879 & 12879 & & & 243320 & 3320 & 5571 & 32967 & \\
\hline $\mathrm{CO} 2$ & $"$ & 2145768 & 2145768 & 2990402 & 2990402 & 2768891 & 2768891 & 0 & 0 & 0 & 0 & 386237 & 386237 & & & & & -265860 & 9734 & 1411820 \\
\hline SO2 & $"$ & 1357 & 1357 & 1891 & 1891 & 1751 & 1751 & 0 & 0 & 0 & 0 & 244 & 244 & & & & & & & 731 \\
\hline H2 & " & & & & & & & & & & & & & & & & & & & \\
\hline Carbon & $"$ & & & & & & & & & & & & & 6319 & & & 1580 & & & \\
\hline Sulfur & " & & & & & & & & & & & & & & & & & & & \\
\hline $\mathrm{CaO}$ & $"$ & & & & & & & & & & & & & & 31028 & 31028 & 10343 & & & \\
\hline $\mathrm{CaSO3}$ & $"$ & & & & & & & & & & & & & & & & 44315 & & & \\
\hline CaSO4 & $"$ & & & & & & & & & & & & & & & & & & & \\
\hline $\mathrm{CaCO3}$ & $"$ & & & & & & & & & & & & & & & & & & & \\
\hline Ash & $"$ & & & & & & & & & & & & & 97656 & 97656 & & 24414 & & & \\
\hline & & $O x y+P A$ & tot $O x y+P A$ & SA Fan in & SA. Fan out & $0 x y+S A$ & - & otal Oxygen! & Hot Oxygen & Primary $\mathrm{O} 2$ & $\mathrm{Sec} 02$ & Grease Gas. & Grease Gas. & Hot Ash Drair: & ool Ash Drailt & drated LimeN & aste Strear & Condensate & Vent Gas & CO2 Prod \\
\hline Total Gas & (Lbm/hr) & 2378854 & 2823483 & 3315236 & 3315236 & 3069663 & 3643410 & 1018376 & 1018376 & 444629 & 573747 & 428192 & 428192 & & & & & & 128957 & 1412564 \\
\hline Total Solids & & & & & & & & & & & & & & 103974 & 103974 & 31028 & 80651 & & & \\
\hline Total Flow & $"$ & 2378854 & 2823483 & 3315236 & 3315236 & 3069663 & 3643410 & 1018376 & 1018376 & 444629 & 573747 & 428192 & 428192 & 103974 & 103974 & 274348 & 83971 & -260289 & 128957 & 1412564 \\
\hline & & & & & & & & & & & & & & & & & & & & \\
\hline Temperature & (Deg F) & 630 & 606 & 110 & 133 & 630 & 606 & 65 & 458 & 458 & 458 & 110 & 191 & 1616 & 302 & 80 & 143 & 127 & 66 & 58 \\
\hline Pressure & (Psia) & 19.0 & 18.8 & 14.7 & 16.7 & 16.7 & 16.5 & 19.0 & 19.0 & 19.0 & 19.0 & 14.7 & 22.6 & 14.7 & 14.7 & 14.7 & 14.7 & 14.7 & 345.0 & 2015.0 \\
\hline $\mathbf{h}_{\text {sensible-gas }}$ & (Btu/lbm) & 132.817 & 125.441 & 6.317 & 11.264 & 132.817 & 125.441 & -3.361 & 85.978 & 85.978 & 85.978 & \begin{tabular}{ll|}
6.317 \\
\end{tabular} & 24.10 & & & & & & & \\
\hline $\mathbf{h}_{\text {sensible-solids }}$ & & & & & & & & & & & & & & 413.02 & 44.70 & & 15.71 & 0.00 & 0.00 & 0.00 \\
\hline Energy & & & & & & & & & & & & & & & & & & & & \\
\hline Chemical & $\left(10^{6} \mathrm{Btu} / \mathrm{hr}\right)$ & & & & & & & & & & & & & 89.049 & 89.049 & & 22.262 & 0.000 & 0.000 & 0.000 \\
\hline Sensible & $\left(10^{6}\right.$ Btu/hr) & 315.952 & 354.181 & 20.941 & 37.341 & 407.704 & 457.034 & -3.423 & 87.558 & 38.228 & 49.330 & 2.705 & 10.318 & 42.943 & 4.648 & 0.000 & 1.319 & -12.211 & -0.516 & -15.538 \\
\hline Latent & $\left(10^{6} \mathrm{Btu} / \mathrm{hr}\right)$ & 75.130 & 75.130 & 104.704 & 104.704 & 96.948 & 96.948 & 0.000 & 0.000 & 0.000 & 0.000 & 13.523 & 13.523 & 0.000 & 0.000 & 0.000 & 3.486 & 0.000 & 34.615 & 0.000 \\
\hline Total Energy $y^{(1)}$ & $\mid\left(10^{6} \mathrm{Btu} / \mathrm{hr}\right)$ & 391.083 & 429.311 & 125.645 & 142.045 & 504.652 & 553.981 & -3.423 & 87.558 & 38.228 & 49.330 & 16.228 & 23.842 & 131.992 & 93.697 & 0.000 & 27.067 & $\begin{array}{l}-12.211 \\
\end{array}$ & 34.099 & -15.538 \\
\hline
\end{tabular}

Hotes:

$\frac{\text { Notes: }}{\text { (1) Energy Basis; Chenical based on Higher Heating Value (HHV); Sensible energy above 80F; Latent based on } 1050 \text { BtuLbm of water vapor }}$ 


\subsubsection{Boiler Island Modifications:}

Boiler Island modifications to the existing Base Case CFB unit to accommodate $\mathrm{O}_{2}$ firing and $\mathrm{CO}_{2}$ capture involve relatively minor modifications to the CFB boiler, draft system, desulfurization system, and controls and instrumentation. The major new equipment added is the air separation unit (ASU) and the gas processing system (GPS). The basic modifications required in these areas are indicated in Figure 4-2 and discussed briefly below.

\subsubsection{Boiler Modifications:}

The Boiler Island should be inspected for potential air leaks into the system and should be sealed to minimize any air infiltration. Special attention should be given to all penetrations including seal boxes for convective surfaces, access doors, fuel piping, sootblowers, ductwork, dampers, expansion joints, and fans. Modifications to the existing boiler pressure parts are not required.

\subsubsection{Modified Draft System:}

The draft system comprises all the fans and blowers (primary air fan, secondary air fan, fluidizing air blowers, and induced draft fan), ductwork, dampers, expansion joints, etc., that supply air to and remove flue gas from the unit. This system must be modified such that the boiler can operate in the air-fired mode for start-up and in the new oxygen-fired mode with gas recirculation for $\mathrm{CO}_{2}$ capture. The system also must be flexible enough to allow the on line transition from air to oxygen firing.

Fans and Blowers: The forced draft system (PA \& SA fans, FA Blowers) will be handling recirculated flue gas rather than air during $\mathrm{O}_{2}$ fired operations. The recirculated flue gas has a higher molecular weight (more $\mathrm{CO}_{2}$ and less $\mathrm{N}_{2}$ ) and a higher inlet temperature to the fans and blowers than air. The recirculated flue gas even with the higher inlet temperature to the fans has an increased density. Taking all these differences into consideration, the existing primary air fan, secondary air fan, and fluidizing air blowers (FBHE and Seal Pot blowers) will easily accommodate the new operating conditions expected with $\mathrm{O}_{2}$ firing.

Although the ID fan will also be handling the increased density flue gas, it must now additionally accommodate a larger pressure rise across the fan. The increased system draft loss is due primarily to the addition of the flash dryer absorber (FDA) system for $\mathrm{SO}_{2}$ removal. Because of the increased draft losses, a new ID fan and motor are required.

An additional benefit of the higher molecular weight gas is that the draft system fans and blowers will consume less power as compared to the equivalent MCR operating condition with air firing. Some of this reduction results from introducing the oxygen from the ASU downstream of the PA and SA fans and some results from the reduction in inlet temperature for the ID fan. Even though the ID fan must handle more mass flow and produces a higher pressure rise with $\mathrm{O}_{2}$ firing, because the inlet temperature with $\mathrm{O}_{2}$ firing is so much lower than with air firing, the power requirement is significantly lower with $\mathrm{O}_{2}$ firing as compared to air firing. Partially offsetting these reductions is the slightly higher inlet temperatures to the PA, SA, and fluidizing air blowers.

New and Modified Ductwork: Significant modifications and additions were required to the existing plant ductwork system in order to accommodate the new gas recirculation system, FDA system, Oxygen heater, and the addition of $\mathrm{O}_{2}$ firing capability as described below. New ductwork is required in several areas of the Boiler Island. Oxygen supply control valves and piping from the new ASU to the existing primary and secondary air heater outlet ducts is required. New ductwork with control and isolation dampers is also required for the recycle flue gas streams that feed the primary and secondary air fans and the existing fluidizing air blowers. 
Ductwork is also modified to accommodate the new oxygen heater and FDA system.

Additionally, new ductwork and dampers are required to supply product gas (primarily $\mathrm{CO}_{2}$ ) to the new Gas Processing System. Various isolation dampers are also required. Provisions in the new ductwork system to accommodate startup with air firing (air inlet duct with associated isolation dampers) are also required.

\subsubsection{Modified Controls and Instrumentation for the Boiler Island:}

Additional controls and instrumentation will be required for the new components and systems. The transition between air firing and oxygen firing as well as additional safety precautions associated with oxygen use in this type of setting needs careful consideration.

\subsubsection{Modified Desulfurization System:}

In the Base Case (Case 1a), a traditional furnace limestone injection system is used to remove about 90 percent of the $\mathrm{SO}_{2}$ produced. For the oxygen fired Case $1 \mathrm{~b}$, limestone is not added to the furnace. Instead, sulfur capture is done in a backend Flash Dryer Absorber (FDA) system with lime injection.

The FDA system is a dry $\mathrm{SO}_{2}$ removal process, which operates in a humid flue gas condition. The heart of the FDA system is the patented mixer/humidifier. The equilibrium moisture content in the ash received from the fabric filter is increased a few percent by the addition of water. The mixer uniformly distributes the water into the entire collected ash stream prior to reinjection into the flue gas. The humidified solids in the mixer continue to behave as a freeflowing powder, without clumping, enabling even distribution of the moist powder into the flue gas for $\mathrm{SO}_{2}$ absorption. The blending of the fresh lime, water, and recycle product is done externally from the flue gas. This ensures a homogeneous mixture prior to injection back into the flue gas stream.

The typical end product is a dry powder consisting of a mixture of fly ash, calcium sulfite/sulfate, hydroxide, carbonate, chloride, etc.

Figure 4-3 shows a simplified schematic process diagram of the FDA system. In the current application the existing baghouse (fabric filter) from Case 1a is used with modifications as required for the addition of the FDA system.

Flue gas leaving the existing air heater, with a high $\mathrm{SO}_{2}$ content enters the reactor section prior to entering the fabric filter. Here, a mixture of recirculated ash, fresh lime and water are injected into the flue gas stream and most of the $\mathrm{SO}_{2}$ reacts with the lime to form $\mathrm{CaSO}_{3} \cdot 1 / 2$ $\mathrm{H}_{2} \mathrm{O}$. Some $\mathrm{CaSO}_{4} \cdot 2 \mathrm{H}_{2} \mathrm{O}$ is formed and a small amount of $\mathrm{CaCO}_{3}$ is also formed. The particulate matter is collected in the modified existing fabric filter. A portion of the collected particulate is removed as the waste product stream with the remainder of the particulate matter being recirculated as described previously. Water is added to control the humidity of the flue gas stream leaving the fabric filter to a proper level. Fresh lime is also added.

Because of the high $\mathrm{CO}_{2}$ content in the flue gas with oxygen firing, there is less confidence in the FDA performance predictions for Case $1 \mathrm{~b}$ than for air firing. Various performance assumptions were made based on test results that were developed in an earlier part of this project (refer to Volume I) and these assumptions were used to develop the FDA system performance used for Case $1 \mathrm{~b}$. 


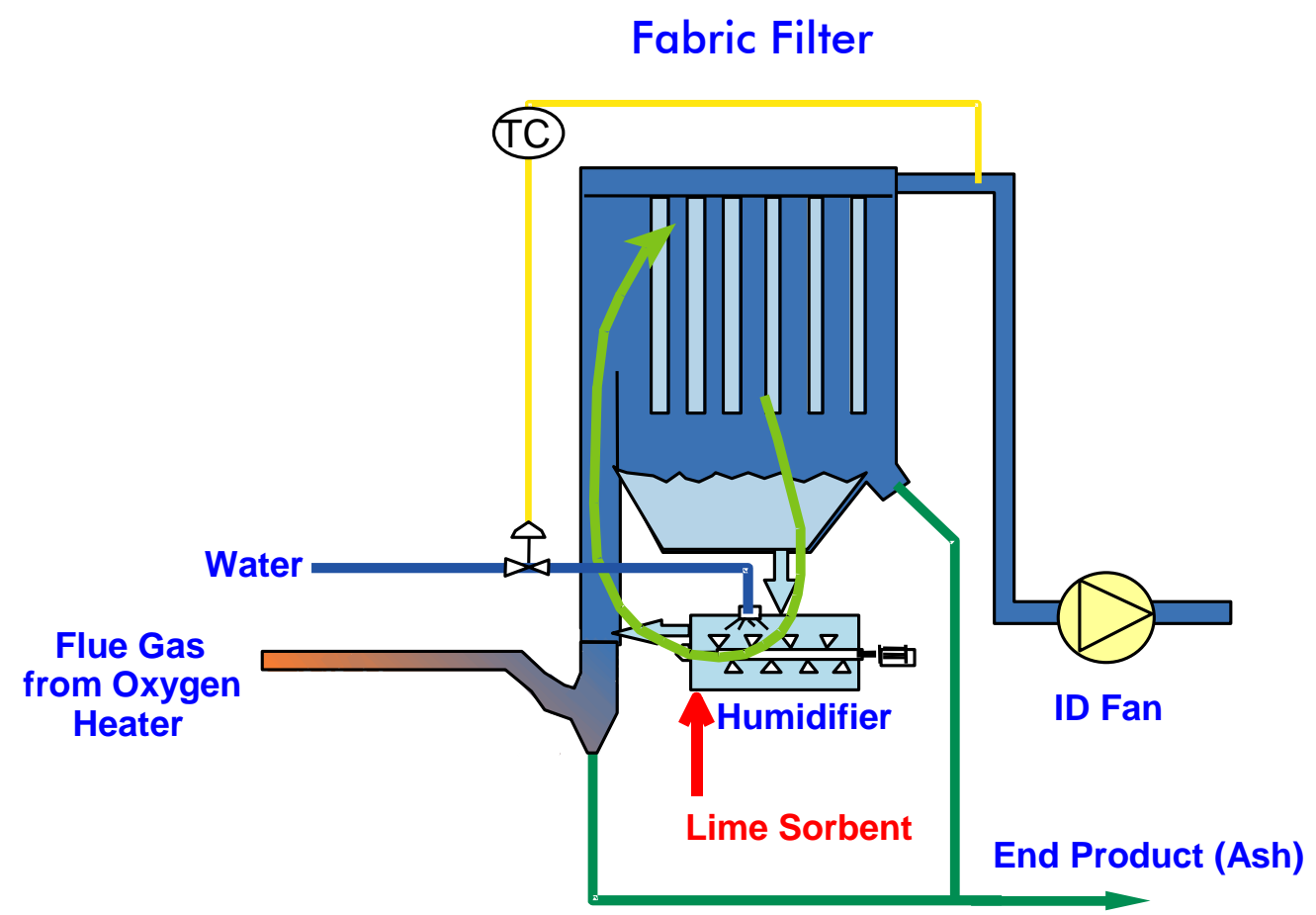

Figure 4-3: Flash Dryer Absorber (FDA) System Schematic Diagram (simplified)

Addition of the new FDA system will require the following basic modifications:

o Modifications to the existing Fabric Filter (FF) hoppers for air-slide attachments

o Elevation of the FF to accommodate the FDA system and its components

o Modification of the existing FF inlet duct for connection to the FDA outlet

o Modification of the existing duct leaving the air heater for connection to the FDA system

o Internal coating of the FF outlet duct and tube sheet to mitigate moisture corrosion

o Modification to the ash handling system

\subsubsection{Coal Feeding System:}

Modifications are not required for the coal feeding system for Case $1 \mathrm{~b}$.

\subsubsection{Bottom Ash Removal System:}

Capacity of the bottom ash removal system for Case 1a where $\mathrm{SO}_{2}$ capture is achieved by limestone injection into the furnace is greater than for Case $1 \mathrm{~b}$. In Case $1 \mathrm{~b} \mathrm{SO} \mathrm{S}_{2}$ removal is done in the FDA system with lime injection and no limestone is added in the furnace. This reduces the bottom ash discharge rate for Case $1 \mathrm{~b}$ as compared to Case $1 \mathrm{a}$. Therefore modifications are not required for the bottom ash removal system for Case $1 \mathrm{~b}$.

\subsubsection{Major New Equipment Added:}

The major new equipment added to the boiler island for Case $1 \mathrm{~b}$ is the air separation unit (ASU) to provide oxygen to the boiler and the gas processing system (GPS) to purify and compress the $\mathrm{CO}_{2}$ product gas. 


\subsection{Case 2a - Air Fired Capture Ready CFB Boiler Island}

This section describes the boiler island for Case 2a (the air fired capture ready case). The description includes a process description and a material and energy balance for this case as well as a description of the capture ready features included in the design of this boiler island.

\subsubsection{Process Description:}

The process description for Case $2 \mathrm{a}$ is identical to that of Case 1a and is not repeated here. A simplified Gas/Solids process flow diagram for Case 2a (air fired Capture Ready CFB) is shown in Figure 4-4. Selected mass flow rates (lbm/hr) and temperatures $\left({ }^{\circ} \mathrm{F}\right)$ are shown on this figure. The flow rates shown are the combined flows for the two parallel CFB boilers.

Complete data for all streams are shown in Table 4-3.

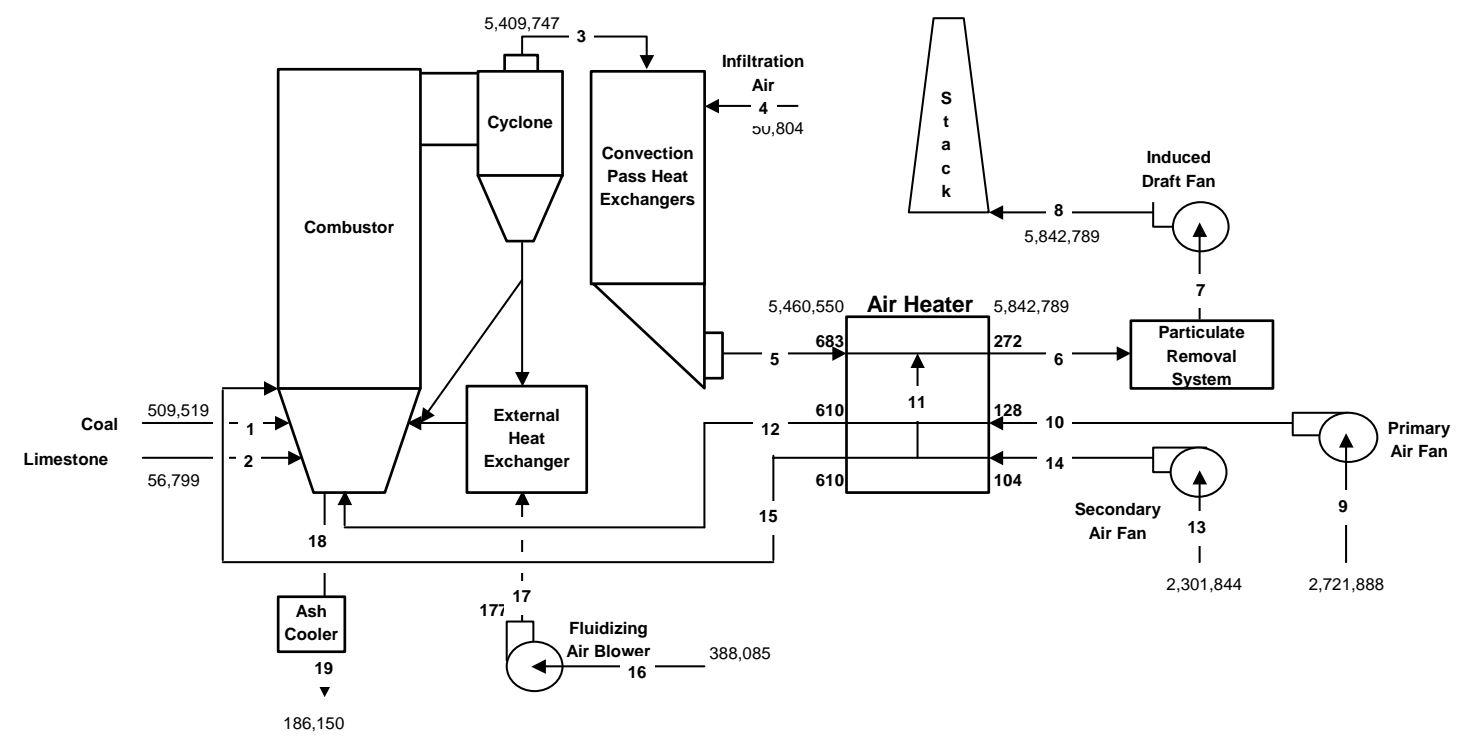

Figure 4-4: Case 2a Capture Ready Air Fired CFB Boiler Island

\subsubsection{Material and Energy Balance:}

Table 4-3 shows the Boiler Island material and energy balance for Case 2a. The stream numbers shown at the top of each column of the table refer to stream numbers shown in Figure 4-4. The performance shown was calculated with air firing at MCR conditions for this unit and at ambient conditions as defined in the design basis. 
Table 4-3: Case 2a Boiler Island Material and Energy Balance ( $\mathrm{CO}_{2}$ Capture Ready)

\begin{tabular}{|c|c|c|c|c|c|c|c|c|c|c|c|}
\hline Constituent & (Units) & 1 & 2 & 3 & 4 & 5 & 6 & 7 & 8 & 9 & 10 \\
\hline$\overline{\mathrm{O}_{2}}$ & (Lbm/hr) & "16101 & & 183951 & 11629 & 195580 & 283074 & 283074 & 283074 & 623040 & "623040 \\
\hline $\mathrm{N}_{2}$ & $"$ & 7439 & & 3821368 & 38525 & 3859893 & 4149744 & 4149744 & 4149744 & 2064008 & 2064008 \\
\hline $\mathrm{H}_{2} \mathrm{O}$ & $"$ & 20330 & & 247262 & 650 & 247912 & 252805 & 252805 & 252805 & 34840 & 34840 \\
\hline $\mathrm{CO}_{2}$ & $"$ & & & 1154783 & & 1154783 & 1154783 & 1154783 & 1154783 & & \\
\hline $\mathrm{SO}_{2}$ & $"$ & & & 2382 & & 2382 & 2382 & 2382 & 2382 & & \\
\hline $\mathrm{H}_{2}$ & $"$ & 18190 & & & & & & & & & \\
\hline Carbon & $"$ & 316157 & & & & & & & & & \\
\hline Sulfur & $"$ & 11923 & & & & & & & & & \\
\hline $\mathrm{CaO}$ & $"$ & & & & & & & & & & \\
\hline $\mathrm{CaSO}_{4}$ & $"$ & & & & & & & & & & \\
\hline $\mathrm{CaCO}_{3}$ & $"$ & & 55833 & & & & & & & & \\
\hline Ash & $"$ & 119380 & 966 & & & & & & & & \\
\hline \multirow{3}{*}{$\begin{array}{l}\text { Total Gas } \\
\text { Total Solids } \\
\text { Total Flow }\end{array}$} & \multirow{3}{*}{$\begin{array}{c}\text { (Lbm/hr) } \\
" \\
"\end{array}$} & Coal & Limestone & Flue Gas to BP & Infiltration Air & Flue Gas to $\mathrm{AH}$ & Flue Gas to PR & Flue Gas to ID & FGas from ID & Primary Air & Primary Air \\
\hline & & 509519 & 56799 & 5409747 & 50804 & 5460550 & 5842789 & 5842789 & 5842789 & 2721888 & \\
\hline & & 509519 & 56799 & 5409747 & 50804 & 5460550 & 5842789 & 5842789 & 5842789 & 2721888 & 2721888 \\
\hline \multirow{4}{*}{$\begin{array}{l}\text { Temperature } \\
\text { Pressure } \\
\text { Enthalpy } \\
\text { Enensible } \\
\text { Energy }\end{array}$} & \multirow{3}{*}{$\begin{array}{c}\text { (Deg F) } \\
\text { (Psia) } \\
\text { (Btu/lbm) }\end{array}$} & 80 & 80 & 1639 & 80 & 683 & 272 & 272 & 286 & 80 & 128 \\
\hline & & 14.7 & 14.7 & 14.7 & 14.7 & 14.6 & 14.4 & 14.0 & 14.7 & 14.7 & 18.3 \\
\hline & & 0.000 & 0.000 & 426.180 & 0.000 & 154.278 & 47.727 & 47.727 & 51.214 & 0.000 & 11.623 \\
\hline & \multirow{4}{*}{$\begin{array}{l}\left(10^{6} \text { Btu/hr }\right) \\
\left(10^{6} \text { Btu/hr }\right) \\
\left(10^{6} \text { Btu/hr }\right) \\
\left(10^{0} \text { Btu/hr }\right)\end{array}$} & & & & & & & & & & \\
\hline \multirow{3}{*}{$\begin{array}{r}\text { Chemical } \\
\text { Sensible } \\
\text { Latent } \\
\text { Total Energy }{ }^{(1)}\end{array}$} & & $\begin{array}{r}5640.375 \\
0.000\end{array}$ & חم0 0 & 2305526 & (2000 & 842444 & 278 & 278.857 & 299 & מחم ח & 31636 \\
\hline & & 0.000 & 0.000 & $\begin{array}{r}2305.520 \\
259.625\end{array}$ & 0.683 & $\begin{array}{l}042.444 \\
260.308\end{array}$ & 265.445 & 265.445 & $\begin{array}{l}299.231 \\
265.445\end{array}$ & 36.582 & $\begin{array}{l}31.030 \\
36.582\end{array}$ \\
\hline & & 5640.375 & 0.000 & 2565.151 & 0.683 & 1102.752 & 544.302 & 544.302 & 564.676 & 36.582 & 68.218 \\
\hline
\end{tabular}

\begin{tabular}{|c|c|c|c|c|c|c|c|c|c|c|}
\hline Constituent & (Units) & 11 & 12 & 13 & 14 & 15 & 16 & 17 & 18 & 19 \\
\hline $\mathrm{O}_{2}$ & (Lbm/hr) & 87494 & 575635 & 526892 & 526892 & 486803 & 88833 & 88833 & & \\
\hline $\mathrm{N}_{2}$ & $"$ & 289851 & 1906965 & 1745488 & 1745488 & 1612680 & 294285 & 294285 & & \\
\hline $\mathrm{H}_{2} \mathrm{O}$ & $"$ & 4893 & 32189 & 29464 & 29464 & 27222 & 4967 & 4967 & & \\
\hline $\mathrm{CO}_{2}$ & $"$ & & & & & & & & & \\
\hline $\mathrm{SO}_{2}$ & " & & & & & & & & & \\
\hline $\mathrm{H}_{2}$ & $"$ & & & & & & & & & \\
\hline Carbon & $"$ & & & & & & & & 7724 & 7724 \\
\hline Sulfur & $"$ & & & & & & & & 0 & 0 \\
\hline $\mathrm{CaO}$ & $"$ & & & & & & & & 12513 & 12513 \\
\hline $\mathrm{CaSO}_{4}$ & " & & & & & & & & 45566 & 45566 \\
\hline $\mathrm{CaCO}_{3}$ & $"$ & & & & & & & & 0 & 0 \\
\hline Ash & $"$ & & & & & & & & 120346 & 120346 \\
\hline \multirow{3}{*}{$\begin{array}{l}\text { Total Gas } \\
\text { Total Solids } \\
\text { Total Flow } \\
\end{array}$} & \multirow{3}{*}{$\begin{array}{c}\text { (Lbm/hr) } \\
" \\
" \\
\end{array}$} & AH Lkg Air & Primary Air & Secondary Air & Secondary Air & Secondary Air & Fluidizing Air & Fluidizing Air & Ash Drain & Ash Drain \\
\hline & & 382239 & 2514789 & 2301844 & 2301844 & 2126704 & 388085 & 388085 & 186150 & 186150 \\
\hline & & 382239 & 2514789 & 2301844 & 2301844 & 2126704 & 388085 & 388085 & 186150 & 186150 \\
\hline \multirow{3}{*}{$\begin{array}{l}\text { Temperature } \\
\text { Pressure } \\
\text { Enthalpy } \\
\text { Enensible } \\
\text { Energy }\end{array}$} & \multirow{3}{*}{$\begin{array}{c}\text { (Deg F) } \\
\text { (Psia) } \\
(\text { Btu/lbm) }\end{array}$} & 128 & 610 & 80 & 104 & 610 & 80 & 177 & 1616 & 302 \\
\hline & & 18.3 & 18.1 & 14.7 & 16.4 & 16.2 & 14.7 & 22.6 & 14.7 & 14.7 \\
\hline & & 11.623 & 131.118 & 0.000 & 5.805 & 131.118 & 0.000 & 23.597 & 413.015 & 44.700 \\
\hline Chemical & $\left(10^{6} \mathrm{Btu} / \mathrm{hr}\right)$ & & & & & & & & 108.859 & 108.859 \\
\hline Sensible & $\left(10^{6} \mathrm{Btu} / \mathrm{hr}\right)$ & 4.443 & 329.735 & 0.000 & 13.362 & 278.850 & 0.000 & 9.158 & 76.883 & 8.321 \\
\hline \multirow{2}{*}{$\begin{array}{l}\text { Latent } \\
\text { Total Energy }^{(1)}\end{array}$} & \multirow{2}{*}{$\begin{array}{l}\left(10^{6} \mathrm{Btu} / \mathrm{hr}\right) \\
\left(10^{\mathrm{b}} \mathrm{Btu} / \mathrm{hr}\right)\end{array}$} & 5.137 & 33.799 & 30.937 & 30.937 & 28.583 & 5.216 & 5.216 & 0.000 & 0.000 \\
\hline & & 9.580 & 363.534 & 30.937 & 44.298 & 307.433 & 5.216 & 14.374 & 185.742 & 117.180 \\
\hline
\end{tabular}

Notes:

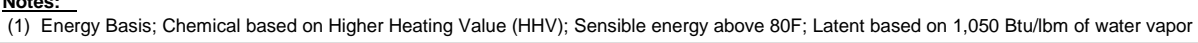

\subsubsection{Capture Ready Features for the Case 2a Boiler Island}

The $\mathrm{CO}_{2}$ capture ready features in the design of the Case 2a CFB boiler and the modifications of this boiler to implement oxygen firing and $\mathrm{CO}_{2}$ capture (Case $2 \mathrm{~b}$ ) are described briefly below. The $\mathrm{CO}_{2}$ capture ready features of the draft system, coal feeding system, the bottom ash removal system, and the air preheater system are also discussed. CFB Boiler System:

The Case 2a capture ready steam generator design has been modified, as compared to the Base Case (Case 1a), to enhance the implementation of future equipment when moving to oxygen firing and $\mathrm{CO}_{2}$ capture (Case $2 \mathrm{~b}$ ). When the conversion is made, additional heating surfaces 
will be installed throughout the unit (furnace, economizer, external beds) to accommodate the increase in the steam flow by $38 \%$.

Furnace: Provisions are made to add extended walls welded to the front and the rear walls of the furnace when the unit is converted to oxygen firing and $\mathrm{CO}_{2}$ capture (Case 2b). Figure 4-6 shows the extended walls (wing walls) in blue added to the furnace.

A slightly higher furnace is required for Case $2 a / 2 b$ as compared to the Base Case to accommodate the longer backpass which has additional space left for future economizer surface as explained below. The furnace for Case 2a (and Case 2b) is therefore 1.5 meters (4.9 $\mathrm{ft}$ ) higher than the Base Case (Case 1a).

External Fluidized Bed Heat Exchangers: Compared to the Base Case, the dimensions of the Case 2a external fluidized bed heat exchangers are increased to allow the future additional assemblies to be added. The box length of the external heat exchanger bed with the intermediate superheater will be increased by 0.7 meter $(2.3 \mathrm{ft})$, so that the length will increase from 5.71 meters $(18.7 \mathrm{ft})$ to 6.41 meters $(21.0 \mathrm{ft})$. The dimensions of the grate will be increased accordingly as well as the number of fluidizing nozzles. The length of inlet and outlet headers will also be increased by $20 \%$ including the nozzles needed for the future welding of assemblies. Seven (7) assemblies per FBHE will be installed when converting Case 2a to $\mathrm{CO}_{2}$ capture (Case 2b).

Also, the box length of the external heat exchanger bed where the finishing reheat is located will be increased from 7.03 meters $(23.1 \mathrm{ft})$ to 8.63 meters $(28.3 \mathrm{ft})$. The length of headers will be increased by $28 \%$. Thirteen (13) assemblies will be added when Case 2a is converted to $\mathrm{CO}_{2}$ capture (Case $2 \mathrm{~b}$ ). This arrangement maintains the ash flow through the external bed about the same as for the Base Case as well as the pressure drop along the reheat steam flow path.

The modifications of FBHE's dimensions bring about 11\% higher fluidizing airflow compared to the Base Case.

Economizer: The backpass for Case 2a will be designed to allow three (3) additional loops in the economizer circuit to be added when converted to $\mathrm{CO}_{2}$ capture (Case $2 \mathrm{~b}$ ). The economizer inlet header will be shifted to enhance the addition of the economizer surface in the future. With this modification the flue gas temperature entering the air preheaters will be kept close to the temperature before conversion.

Generally speaking, the pressure parts of the Case 2a (capture ready) boilers are sized to withstand a slight increase in pressure drop brought out by the future increased steam flow of Case 2b, the capture ready converted unit.

\subsubsection{Coal Feeding System:}

Coal is introduced into the furnace through the solids return ducts, which run from the seal pots to the furnace. There are eight (8) coal injection points, two (2) in each solids return duct. The arrangement and number of coal feeders and coal conveyors ensure an even distribution of coal into the furnace even though a coal conveyor may be out of service. Design capacity for the Base Case (Case 1a) is based on a coal flow of about 115 tonne/h whereas the coal flow will have to be increased by about $33 \%$ when operating in the $\mathrm{CO}_{2}$ capture mode (Case $2 \mathrm{~b}$ ). The coal feeding system is therefore sized with a $33 \%$ margin before conversion (i.e. Case $2 a$ ).

\subsubsection{Bottom Ash Removal System:}

Capacity of the bottom ash removal system is defined by the operation before conversion (Case $2 \mathrm{a}$ ) where the $\mathrm{SO}_{2}$ capture is achieved by limestone injection into the furnace. Coal flow at MCR is equal to about 115 tonne/h before conversion with limestone flow around 15 tonne/h. 
Hence, total ash flow is around 43 tonne/h; 26 tonne/h produced by the coal and remaining ash created by the calcination sulfation reactions. Although the coal input capacity is to be increased by $33 \%$ when converted (Case 2b), total ash will not exceed 33 tonne/h because the total sulfur capture will be done with lime through the back end equipment.

The bottom ash removal system includes 6 screws coolers with 8 tonne/h capacity per screw and the ash handling will be by a pneumatic transport system for feeding the bottom ash silo.

\subsubsection{Air Preheaters:}

Two identical regenerative air heaters have been selected for the Capture Ready case (Case 2a) and arranged in parallel flue gas streams. Primary air and secondary air pass through the air preheaters and cool the flue gas to around $272^{\circ} \mathrm{F}\left(140^{\circ} \mathrm{C}\right)$. Space has been left for the addition of a tubular oxygen heater and its associated ductwork (oxygen to and from; flue gas to and from), which will be added when the unit is retrofit with oxygen firing and $\mathrm{CO}_{2}$ capture. This heater will be used for heating the oxygen supplied by ASU. This gas stream will be in parallel with the two regenerative air heaters. After the retrofit, the regenerative air heaters will be used for heating the cool recirculated flue gas coming from the PA and SA fans. Heated oxygen, leaving the tubular oxygen heater, will be blended into the hot recirculated flue gas leaving the regenerative air preheaters before the mixture is introduced to the furnace. The oxygen from the ASU will be provided at the needed pressure for mixing with the flue gas leaving the regenerative air preheaters.

\subsubsection{Draft System:}

The draft system comprises all the fans and blowers (primary air fan, secondary air fan, fluidizing air blowers, and induced draft fan), ductwork, dampers, expansion joints, etc., that supply air to and remove flue gas from the unit. The primary capture ready feature in this system is to leave enough space in the layout of the boiler to allow the addition of the new gas recirculation ducts, oxygen ducts, and oxygen heater when the unit is converted to oxygen firing and $\mathrm{CO}_{2}$ capture (Case 2b).

\subsection{Case 2b - The Case 2a Capture Ready CFB Boiler Island Retrofit with $\mathrm{O}_{2}$ firing and $\mathrm{CO}_{2}$ Capture}

This section describes the boiler island for Case 2b, which is the retrofit of Case 2a (the capture ready case) with $\mathrm{O}_{2}$ firing and $\mathrm{CO}_{2}$ capture. The description includes a process description, a material and energy balance, and a description of the modifications required to the boiler island for this case.

\subsubsection{Process Description:}

This process description briefly describes the function of the major equipment and systems included within the Boiler Island for this case. Figure 4-5 shows a simplified process flow diagram for the Boiler Island of the Case $2 b$ oxygen-fired CFB retrofit. Selected mass flow rates $(\mathrm{lbm} / \mathrm{hr})$ and temperatures $\left({ }^{0} \mathrm{~F}\right)$ are shown on this figure. This process description is identical to that described for Case $1 \mathrm{~b}$ and is not repeated here. Please refer to Section 4.3.1 for this description. Complete data for all streams are shown in the material and energy balance shown in Table 4-4. 


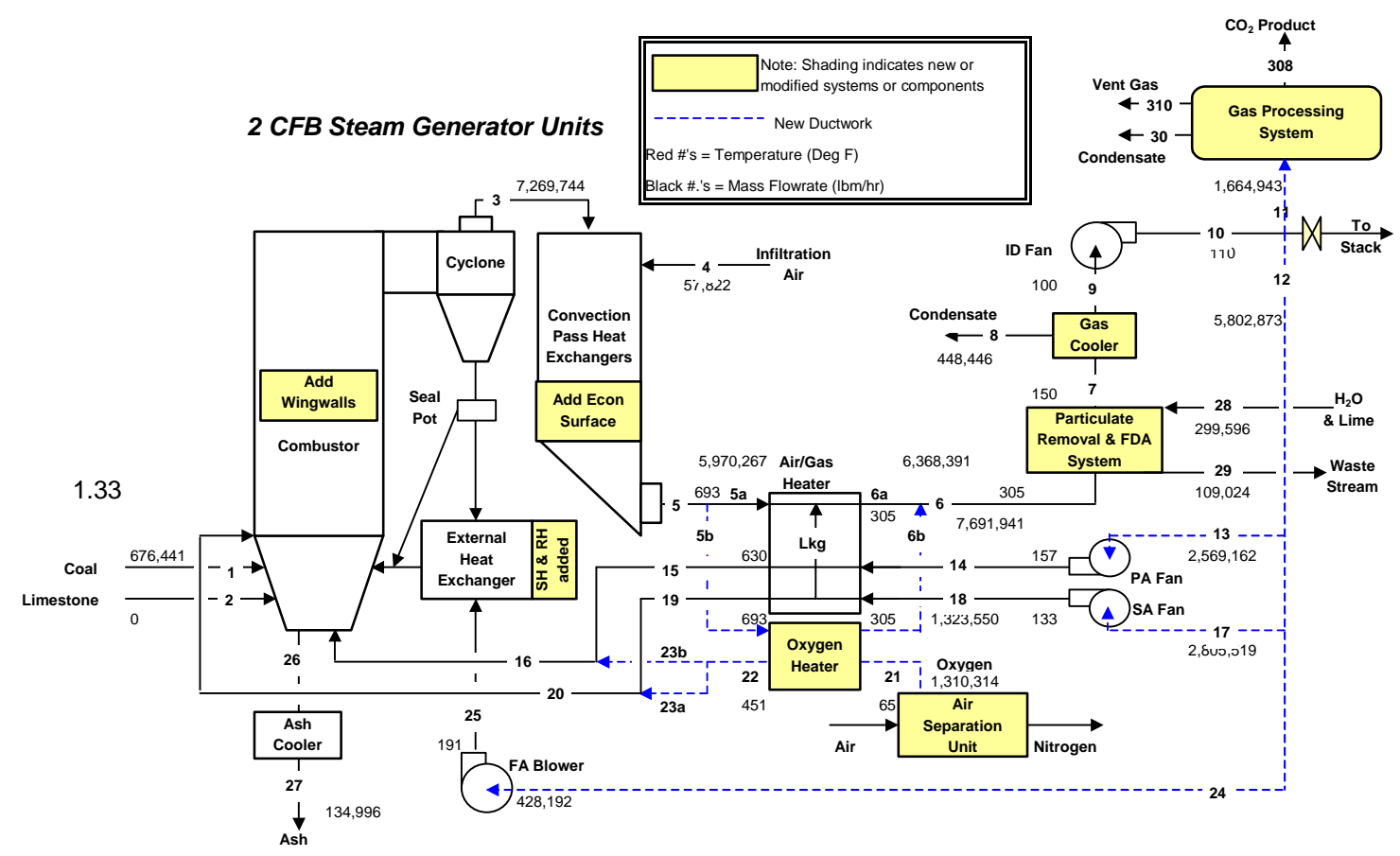

Figure 4-5: Case 2b-Capture Ready CFB Boiler (Case 2a) Retrofit with $\mathrm{O}_{2}$ Firing and $\mathrm{CO}_{2}$ Capture

\subsubsection{Material and Energy Balance:}

Table 4-4 shows the Boiler Island material and energy balance for Case $2 \mathrm{~b}$. The stream numbers shown at the top of each column of the table refer to stream numbers shown in Figure 4-5. The performance shown was calculated with oxygen firing and $138 \%$ of the original steam flow for this unit with ambient conditions as defined in the design basis. 
COMMERCIALIZATION DEVELOPMENT OF OXYGEN FIRED

CFB FOR GREENHOUSE GAS CONTROL

Table 4-4: Case 2b Boiler Island Material and Energy Balance (Capture Ready CFB Retrofit with Oxygen Firing and $\mathrm{CO}_{2} \mathrm{Capture}$

\begin{tabular}{|c|c|c|c|c|c|c|c|c|c|c|c|c|c|c|c|c|c|c|c|c|}
\hline \multicolumn{21}{|l|}{ English Units } \\
\hline Constituent & (Units) & 1 & 2 & 3 & $\overline{4}$ & 5 & $5 a$ & $5 \mathrm{~b}$ & Lkg & $6 \mathbf{a}$ & $6 \mathrm{~b}$ & 6 & 7 & $\overline{88}$ & 9 & 10 & 11 & 12 & 13 & 14 \\
\hline 02 & (Lbm/hr) & 21376 & & 183951 & 13235 & 197187 & 161405 & 35782 & 11104 & 172509 & 35782 & 208291 & 208291 & & 208291 & 208291 & 446438 & 161853 & 71659 & 71659 \\
\hline N2 & $"$ & 9876 & & 240471 & 43847 & 284318 & 232725 & 51593 & 16011 & 248736 & 51593 & 300329 & 300329 & & 300329 & 300329 & 66958 & 233371 & 103323 & 103323 \\
\hline $\mathrm{H} 2 \mathrm{O}$ & " & 26990 & & 405404 & 740 & 406144 & 332444 & 73700 & 11978 & 344422 & 73700 & 418122 & 673122 & 448446 & 224676 & 224676 & 50091 & 174585 & 77296 & 77296 \\
\hline $\mathrm{CO} 2$ & " & & & 6371460 & & 6371460 & 5215283 & 1156177 & 358804 & 5574087 & 1156177 & 6730264 & 6730264 & & 6730264 & 46730264 & 1500506 & 5229758 & 2315421 & 2315421 \\
\hline S02 & " & & & 34708 & & 34708 & 28410 & 6298 & 227 & 28637 & 6298 & 34935 & 4256 & & 4256 & 4256 & 949 & 3307 & 1464 & 1464 \\
\hline $\mathrm{H} 2$ & $"$ & 24149 & & & & & & & & & & & & & & & & & & \\
\hline Carbon & $"$ & 419732 & & 2051 & & 2051 & 1679 & 372 & & 1679 & 1679 & 2051 & & & & & & & & \\
\hline Sulfur & " & 15829 & & & & & & & & & & & & & & & & & & \\
\hline $\mathrm{CaO}$ & " & & & & & & & & & & & & & & & & & & & \\
\hline CaSO3 & " & & & & & & & & & & & & & & & & & & & \\
\hline CaSO4 & " & & & & & & & & & & & & & & & & & & & \\
\hline $\mathrm{CaCO3}$ & " & & 0 & & & & & & & & & & & & & & & & & \\
\hline \multirow[t]{2}{*}{ Ash } & $"$ & 158490 & 0 & 31698 & & 31698 & 25946 & 5752 & & 25946 & 5752 & 31698 & & & & & & & & \\
\hline & & Coal & Limestone & Flue Gas & Infilitration Air & Flue Gas & Flue Gas & Flue Gas & AH Leakage & Flue Gas & Flue Gas & Flue Gas & Flue Gas & Condensate & Flue Gas & Flue Gas & Flue Gas & Recirc Gas & PA Fan in & PA Fan out \\
\hline Total Gas & (Lbm/hr) & & & 7235995 & 57822 & 7293817 & 5970267 & 1323550 & 398125 & 6368391 & 1323550 & 7691941 & 7916262 & & 7467816 & 67467816 & 1664943 & 5802873 & 2569162 & 2569162 \\
\hline Total Solids & " & 676441 & & 33749 & & 33749 & 27625 & 6124 & 0 & 27625 & 7431 & 33749 & & & & & & & & \\
\hline Total Flow & $"$ & 676441 & 0 & 7269744 & 57822 & 7327566 & 5997892 & 1329674 & 398125 & 6396016 & 1330981 & 7725690 & 7916262 & 448446 & 7467816 & 87467816 & 1664943 & 5802873 & 2569162 & 2569162 \\
\hline Temperature & (Deg F) & 80 & 80 & 1639 & 80 & 693 & 693 & 693 & 145 & 305 & 305 & 305 & 150 & 100 & 100 & 110 & 110 & 110 & 110 & 157 \\
\hline $\begin{array}{l}\text { Pressure } \\
\end{array}$ & (Psia) & 14.7 & 14.7 & 14.7 & 14.7 & 14.6 & 14.6 & 14.6 & 0.0 & 0.0 & 0.0 & 14.4 & 14.0 & 14.7 & 13.9 & 14.7 & 14.7 & 14.7 & 14.7 & 19.0 \\
\hline 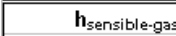 & (Btu/lbm) & & & 436.714 & & 153.091 & 153.091 & 153.091 & 13.823 & \begin{tabular}{|c|c|}
51.812 \\
\end{tabular} & 51.892 & 51.826 & 15.990 & 0.000 & 4.225 & \begin{tabular}{|c|}
6.318 \\
\end{tabular} & \begin{tabular}{|c|c|}
6.318 \\
\end{tabular} & 6.318 & 6.318 & 16.637 \\
\hline $\mathbf{h}_{\text {sensible-solids }}$ & & & & 420.540 & & 138.993 & 138.993 & 138.993 & 0.000 & 45.466 & 45.466 & 45.466 & & & & & & & & \\
\hline Energy & & & & & & & & & & & & & & 19.960 & & & & & & \\
\hline Chemica & $\mid\left(10^{6} \mathrm{Btu} / \mathrm{hr}\right)$ & 7488.207 & & 28.904 & & 28.904 & 23.659 & 5.245 & 0.000 & 23.659 & 23.659 & 28.904 & & & & & & & & \\
\hline Sensible & $\left(10^{6} \mathrm{Btu} / \mathrm{hr}\right)$ & 0.000 & 0.000 & 3174.256 & 0.000 & 1121.307 & 917.832 & 203.474 & 5.503 & 331.213 & 69.020 & 400.173 & 126.583 & 8.951 & 31.549 & 47.179 & 10.518 & 36.660 & 16.231 & 42.742 \\
\hline Latent & $\left(10^{6} \mathrm{Btu} / \mathrm{hr}\right)$ & 0.000 & 0.000 & 425.674 & 0.777 & 426.451 & 349.067 & 77.385 & 12.577 & 361.644 & 77.385 & 439.028 & 706.778 & 0.000 & 235.910 & 235.910 & 52.596 & 183.314 & 81.160 & 81.160 \\
\hline Total Energy ${ }^{(1)}$ & $\left(10^{6} \mathrm{Btu} / \mathrm{hr}\right)$ & 7488.207 & 0.000 & 3628.835 & 0.777 & 1576.663 & 1290.559 & 286.104 & 18.080 & 716.516 & 170.064 & 868.106 & 833.361 & 8.951 & 267.459 & 283.088 & 63.114 & 219.974 & 97.391 & 123.903 \\
\hline
\end{tabular}


COMMERCIALIZATION DEVELOPMENT OF OXYGEN FIRED

CFB FOR GREENHOUSE GAS CONTROL

\begin{tabular}{|c|c|c|c|c|c|c|c|c|c|c|c|c|c|c|c|c|c|c|c|c|}
\hline Constituent & (Units) & 15 & 16 & 17 & 18 & 19 & 20 & 21 & 22 & $23 \mathrm{~b}$ & $23 a$ & 24 & 25 & 26 & 27 & 28 & 29 & 30 & 310 & 308 \\
\hline 02 & (Lbm/hr) & 66351 & 692697 & 78251 & 78251 & 72455 & 756423 & 1310314 & 1310314 & 626346 & 683968 & 11943 & 11943 & & & & & & 46427 & 11 \\
\hline N2 & $"$ & 95669 & 101996 & 112828 & 112828 & 104470 & 111379 & 13235 & 13235 & 6327 & 6909 & 17220 & 17220 & & & & & & 66956 & 2 \\
\hline $\mathrm{H} 2 \mathrm{O}$ & $"$ & 71570 & 71570 & 84407 & 84407 & 78154 & 78154 & 0 & 0 & 0 & 0 & 12883 & 12883 & & & 259310 & 4310 & 48883 & 1208 & \\
\hline $\mathrm{CO} 2$ & $"$ & 2143908 & 2143908 & 2528434 & 2528434 & 2341143 & 2341143 & 0 & 0 & 0 & 0 & 385902 & 385902 & & & & & 631 & 88056 & 1411820 \\
\hline SO2 & $"$ & 1356 & 1356 & 1599 & 1599 & 1480 & 1480 & 0 & 0 & 0 & 0 & 244 & 244 & & & & & & & 949 \\
\hline H2 & $"$ & & & & & & & & & & & & & & & & & & & \\
\hline Carbon & $"$ & & & & & & & & & & & & & 8204 & 8204 & & 2051 & & & \\
\hline Sulfur & $"$ & & & & & & & & & & & & & & & & & & & \\
\hline $\mathrm{CaO}$ & $"$ & & & & & & & & & & & & & & & 40286 & 13429 & & & \\
\hline CaSO3 & $"$ & & & & & & & & & & & & & & & & 57536 & & & \\
\hline CaSO4 & $"$ & & & & & & & & & & & & & & & & & & & \\
\hline $\mathrm{CaCO3}$ & $"$ & & & & & & & & & & & & & & & & & & & \\
\hline \multirow[t]{2}{*}{ Ash } & $"$ & & & & & & & & & & & & & 126792 & 126792 & & 31698 & & & \\
\hline & & $O x y+P A$ & tot $O x y+P A$ & SA Fan in & SA Fan out & $O x y+S A$ & Hot $O x y+S, A]$ & Total Oxygen & Hot Oxygen & Primary 02 & $\mathrm{Sec} 02$ & Grease Gas & Grease Gas & Hot Ash Drair & col Ash Drailt & ydrated Limen & Vaste Strear & Condensate & Vent Gas & CO2 Prod \\
\hline Total Gas & (Lbm/hr) & 2378854 & 3011526 & 2805519 & 2805519 & 2597703 & 3288580 & 1323550 & 1323550 & 632673 & 690877 & 428192 & 428192 & & & & & & 202647 & 1412782 \\
\hline Total Solids & " & & & & & & & & & & & & & 134996 & 134996 & 40286 & 104714 & & & \\
\hline Total Flow & $"$ & 2378854 & 3011526 & 2805519 & 2805519 & 2597703 & 3288580 & 1323550 & 1323550 & 632673 & 690877 & 428192 & 428192 & 134996 & 134996 & 299596 & 109024 & 49514 & 202647 & 1412782 \\
\hline Temnerature & (Dea F) & 630 & 596 & 110 & 133 & 630 & 596 & 65 & 451 & 451 & 451 & 110 & 191 & 1616 & 302 & 80 & 150 & 127 & 66 & 58 \\
\hline \begin{tabular}{|l} 
Pressure \\
\end{tabular} & (Psia) & 19.0 & 18.8 & 14.7 & 16.7 & 16.7 & 16.5 & 19.0 & 19.0 & 19.0 & 19.0 & 14.7 & 22.6 & 14.7 & 14.7 & $\begin{array}{r}14.7 \\
\end{array}$ & 14.7 & 14.7 & 345.0 & $\begin{array}{r}50 \\
2015.0\end{array}$ \\
\hline $\mathbf{h}_{\text {sensible-gas }}$ & (Btu/lbm) & $\begin{array}{l}132.816 \\
\end{array}$ & \begin{tabular}{ll|}
122.626 \\
\end{tabular} & (2.318 & \begin{tabular}{ll|}
11.266 \\
\end{tabular} & $\begin{array}{l}132.816 \\
\end{array}$ & $\begin{array}{l}122.626 \\
\end{array}$ & |-3.361 & (84.312 & $\begin{array}{l}84.312 \\
\end{array}$ & 84.312 & 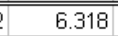 & 24.10 & & & & & & & \\
\hline $\mathbf{h}_{\text {sensible-solids }}$ & & & & & & & & & & & & & & 413.02 & 44.70 & & 17.56 & 0.00 & 0.00 & 0.00 \\
\hline Energy & & & & & & & & & & & & & & & & & & & & \\
\hline Chemical & $\|\left(10^{6} \mathrm{Btu} / \mathrm{hrr}\right)$ & & & & & & & & & & & & & 115.618 & 115.618 & & 28.904 & 0.000 & 0.000 & 0.000 \\
\hline Sensible & $\left(10^{6} \mathrm{Btu} / \mathrm{hr}\right)$ & 315.951 & 369.293 & 17.724 & 31.607 & 345.017 & 403.267 & -4.449 & 111.592 & 53.342 & 58.249 & 2.705 & 10.321 & 55.755 & 6.034 & 0.000 & 1.914 & 2.323 & -0.627 & -15.541 \\
\hline Latent & $\|\left(10^{6} \mathrm{Btu} / \mathrm{hr}\right)$ & 75.148 & 75.148 & 88.627 & 88.627 & 82.062 & 82.062 & 0.000 & 0.000 & 0.000 & 0.000 & 13.527 & 13.527 & 0.000 & 0.000 & 0.000 & 4.526 & 0.000 & 1.268 & 0.000 \\
\hline Total Energy $y^{11}$ & $\|\left(10^{6} \mathrm{Btu} / \mathrm{hr}\right)$ & 391.099 & 444.441 & 106.351 & 120.234 & 427.079 & 485.329 & -4.449 & 111.592 & 53.342 & 58.249 & 16.232 & 23.847 & 171.373 & 121.652 & 0.000 & 35.344 & 2.323 & 0.641 & -15.540 \\
\hline
\end{tabular}

(1) Energy Basis; Chemical based on Higher Heating Value (HHV); Sensible energy above 80F; Latent based on 1050 BtuLbm of water vapor 


\subsubsection{Boiler Island Modifications:}

Boiler Island modifications to the Case 2a capture ready CFB unit to accommodate $\mathrm{O}_{2}$ firing and $\mathrm{CO}_{2}$ capture involve modifications to the CFB boiler, draft system, desulfurization system, and controls and instrumentation. In order to increase the steam generation capacity to overcome the auxiliary power increase due to the addition of the ASU and GPS, pressure part modifications are done to the CFB boiler. Pressure part modifications include the addition of extended walls in the furnace, an additional economizer bank, and the addition of SH \& RH surface in the external fluidized bed heat exchangers. The major new equipment added during this retrofit is the air separation unit (ASU) and the gas processing system (GPS). The basic modifications required in these areas are indicated in Figure 4-5 and discussed briefly below.

\subsubsection{Boiler Modifications:}

As described in Section 4.3.3, the Boiler Island should be inspected for potential air leaks into the system and should be sealed to minimize any air infiltration. Special attention should be given to all penetrations including seal boxes for convective surfaces, access doors, fuel piping, sootblowers, ductwork, dampers, expansion joints, and fans.

Pressure Part Modifications for Increased Steam Generation:

The Case 2a capture ready steam generator was designed to enhance the implementation of future equipment when moving to oxygen firing and $\mathrm{CO}_{2}$ capture (Case 2b). When the conversion is made, additional heating surfaces will be installed throughout the unit (furnace, economizer, external fluidized bed heat exchangers) to accommodate the increase in steam flow by $38 \%$ as described below.

Furnace: Extended walls (wing walls) welded to the front and the rear walls of the furnace will be added when the unit is converted to oxygen firing and $\mathrm{CO}_{2}$ capture (Case 2b). The extended walls are very similar to the furnace water walls except that the tube diameter is slightly larger, $38 \mathrm{~mm}$ (1.5 inches) instead of $26.8 \mathrm{~mm}$ (1.06 inches) and the tube spacing is smaller, $51 \mathrm{~mm}$ (2.0 inches) compared to $58 \mathrm{~mm}$ (2.28 inches). These changes (as compared to the furnace water walls) are required in order to withstand the additional heat absorption, which occurs on both sides of the extended wall. The spacing between each extended wall is $870 \mathrm{~mm}(34.25$ inches) and each wall is $306 \mathrm{~mm}$ wide (12.05 inches). Each extended wall is comprised of six (6) tubes with an outside diameter of $38 \mathrm{~mm}$ (1.5 inches). This arrangement leads to a water mass flow rate inside the tubes which is very close to the mass flow rate before conversion to $\mathrm{CO}_{2}$ capture although the steam flow is increased by $38 \%$.

Figure 4-6 shows a sectional side elevation of the capture ready converted (Case 2b) CFB boiler furnace with the wing walls installed. The wing walls are shown in blue on this figure. A more complete set of drawings for the Case 2b CFB boiler is included in the Section 10.1.1. 


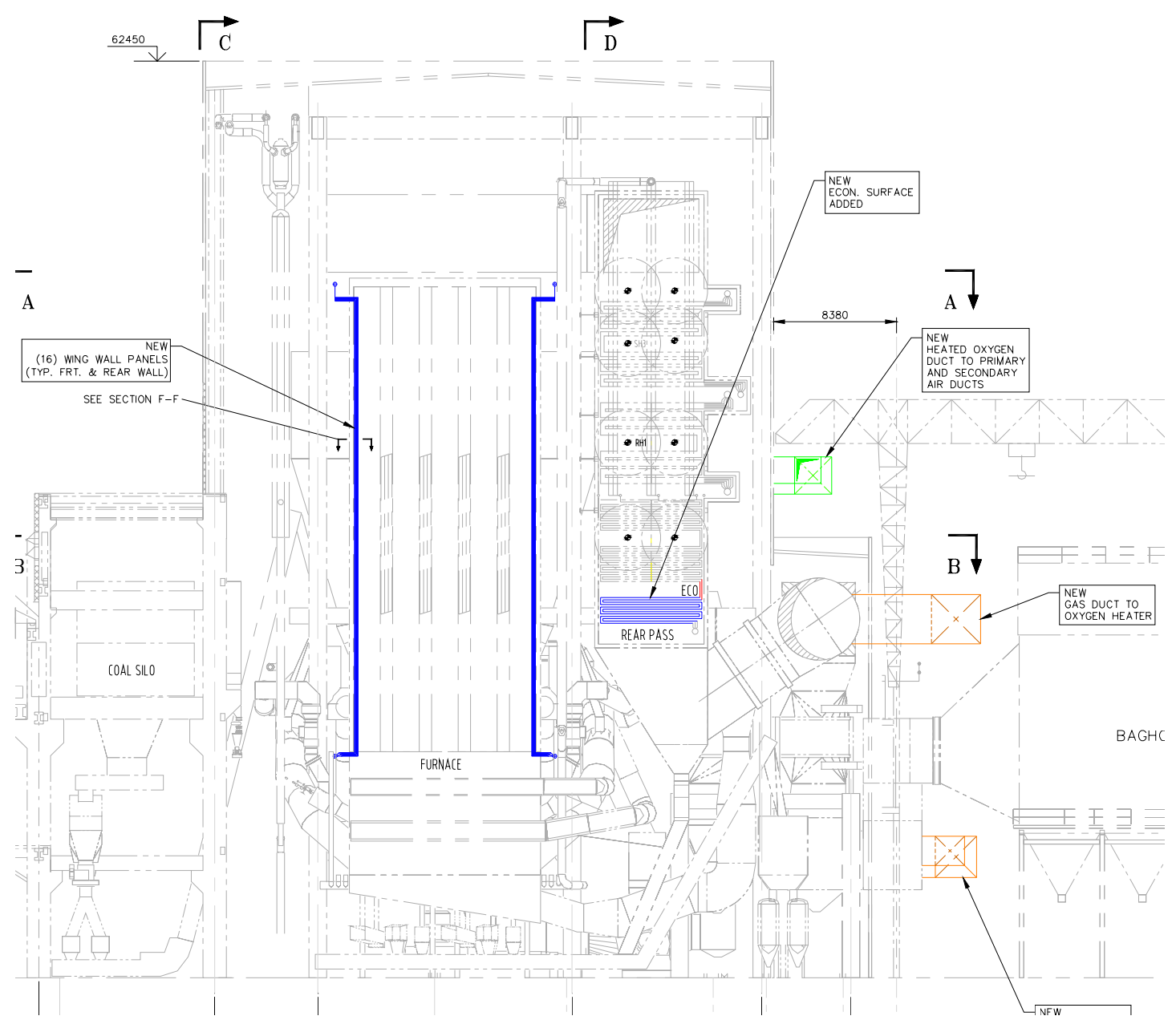

Figure 4-6: Case 2b - Sectional Side Elevation of the Capture Ready Converted CFB Boiler Showing the Wing Wall Surface Added in the Furnace and the Economizer Surface Added in the Backpass

As described in Section 4.3.3, a slightly taller furnace is required for Case 2a/2b as compared to the Base Case to accommodate the longer backpass which has additional space left for the added economizer surface as explained below. The furnace for Case 2a (and Case 2b) is therefore 1.5 meters $(4.9 \mathrm{ft}$ ) taller than the Base Case (Case 1a).

Economizer: As described in Section 4.3.3, the backpass for Case 2a was designed to allow three (3) additional loops in the economizer circuit to be added when converted to oxygen firing and $\mathrm{CO}_{2}$ capture (Case $2 \mathrm{~b}$ ). Figure 4-6 shows a sectional side elevation of the capture ready converted (Case 2b) CFB furnace and backpass with the additional economizer surface installed. The added economizer surface is shown in blue color on the right side of this figure at the bottom of the backpass. The economizer inlet header was also shifted to enhance the addition of the economizer surface. With this modification the flue gas temperature entering the air preheaters is kept close to the temperature before conversion.

External Fluidized Bed Heat Exchangers: As described in Section 4.3.3 The dimensions of the Case 2a external fluidized bed heat exchangers were increased (as compared to the Base Case) to allow for the addition of superheat and reheat circuit assemblies when the unit is retrofit with oxygen firing and $\mathrm{CO}_{2}$ capture. Seven (7) superheater assemblies per FBHE will be installed when converting Case $2 \mathrm{a}$ to oxygen firing and $\mathrm{CO}_{2}$ capture (Case $2 \mathrm{~b}$ ). 
Also, the external heat exchanger bed where the finishing reheat section is located will be modified with the addition of thirteen (13) reheater assemblies when Case 2a is converted to oxygen firing and $\mathrm{CO}_{2}$ capture (Case 2b). This arrangement maintains the ash flow through the external bed about the same as for the Base Case as well as the pressure drop along the reheat steam flow path.

Figure 4-7 shows the added surface for the external fluidized bed heat exchangers.

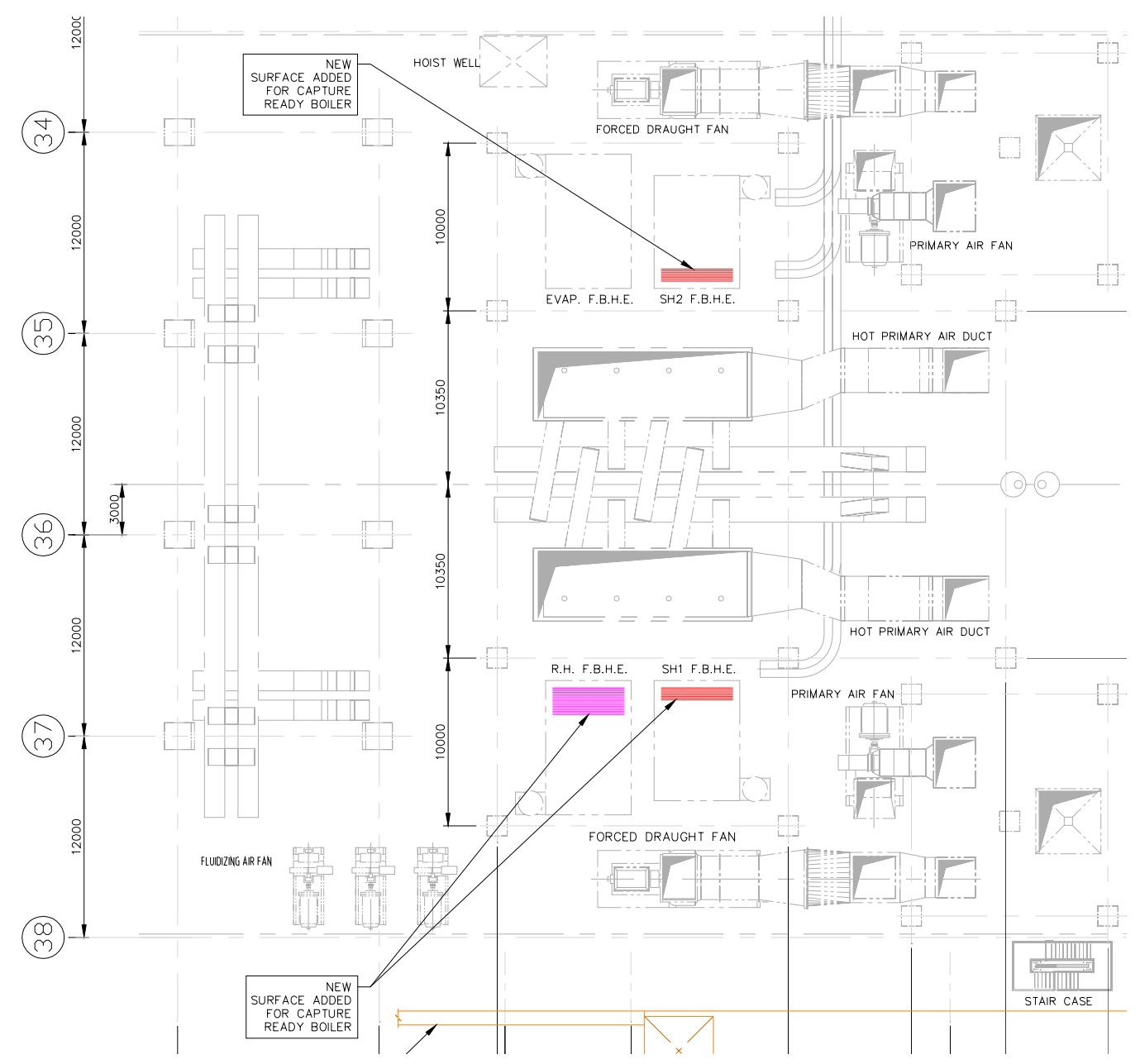

Figure 4-7: Case 2b - Plan View Showing Modified External Fluidized Bed Heat Exchangers

\subsubsection{Coal Feeding System:}

As described in Section 4.3.3, no modifications are required for the coal feeding system since the coal feeding system for Case 2a (Capture Ready) is sized with a 33\% margin before conversion to accommodate the increased coal flow when the unit is retrofit with $\mathrm{O}_{2}$ firing and $\mathrm{CO}_{2}$ capture.

\subsubsection{Bottom Ash Removal System:}

As described in Section 4.3.3, the capacity of the bottom ash removal system is defined by the operation before conversion (Case 2a) where the $\mathrm{SO}_{2}$ capture is achieved by limestone injection into the furnace. Therefore, no modifications are required for the bottom ash removal system when the unit is retrofit with $\mathrm{O}_{2}$ firing and $\mathrm{CO}_{2}$ capture (i.e. Case $2 \mathrm{~b}$ ). 


\subsubsection{Air Preheaters:}

As described in Section 4.3.3, two identical regenerative air heaters were selected for the Capture Ready case (Case 2a) and arranged in parallel flue gas streams. When the unit is retrofit with oxygen firing and $\mathrm{CO}_{2}$ capture (Case 2b), a tubular oxygen heater and its associated ductwork (oxygen to and from; flue gas to and from) is added in a third parallel flue gas stream. Figure 4-8 shows the added tubular oxygen heater and its associated ductwork.

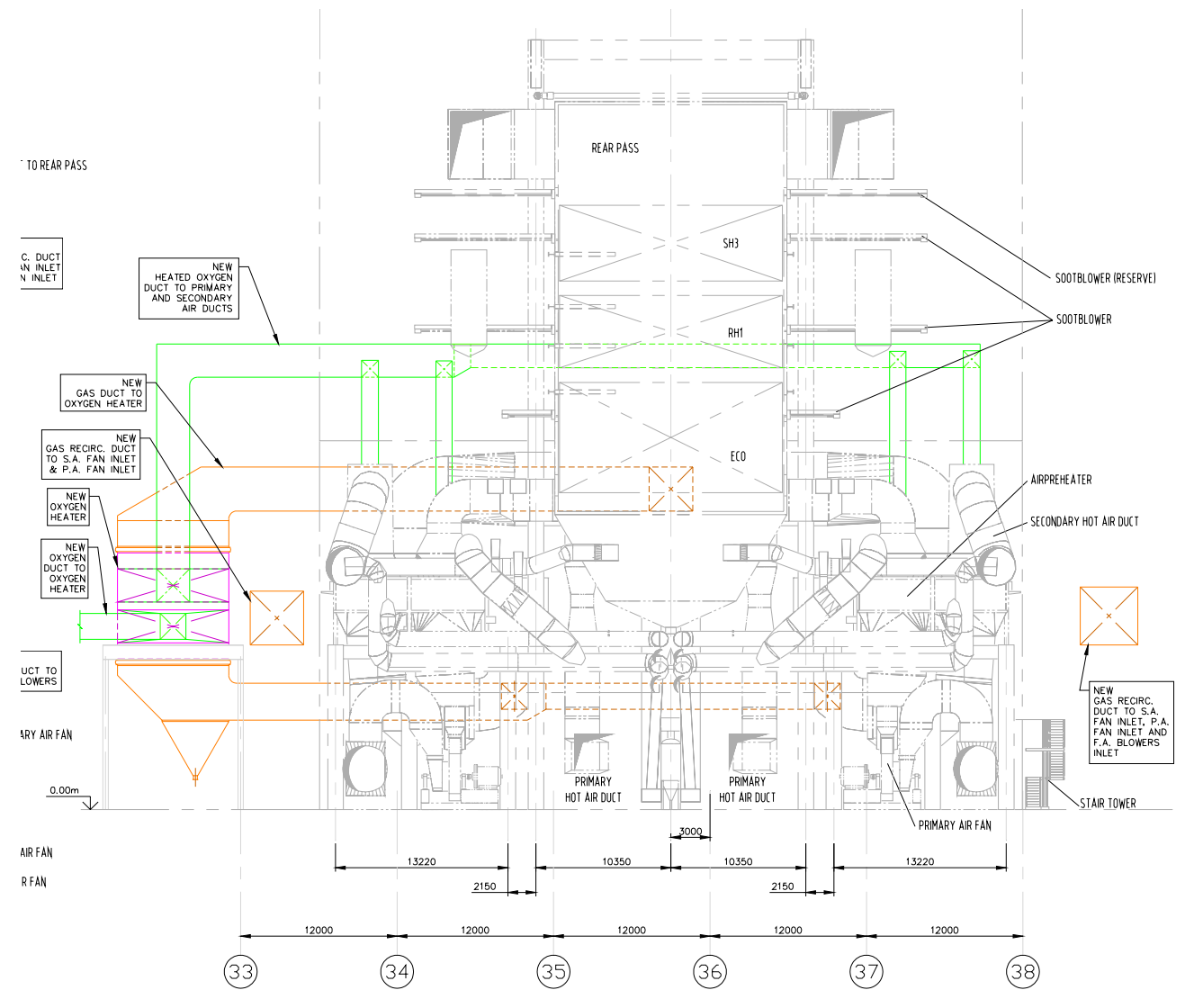

Figure 4-8: Case 2b - Section View Showing the Added Tubular Oxygen Heater and its Associated Ductwork

This heater will be used for heating the oxygen supplied by ASU. This third parallel flue gas stream is in parallel with the two regenerative air heaters.

After the retrofit, the regenerative air heaters will be used for heating the cool recirculated flue gas coming from the PA and SA fans. Heated oxygen, leaving the tubular oxygen heater, will be blended into the hot recirculated flue gas leaving the regenerative air preheaters before the mixture is introduced to the furnace. The oxygen from the ASU will be provided at the needed pressure for mixing with the flue gas leaving the regenerative air preheaters.

\subsubsection{Modified Draft System:}

As described in Section 4.3.3, the draft system comprises all the fans and blowers (primary air fan, secondary air fan, fluidizing air blowers, and induced draft fan), ductwork, dampers, expansion joints, etc., that supply air to and remove flue gas from the unit. This system must be modified such that the boiler can operate in the air-fired mode for start-up and in the new 
oxygen-fired mode with gas recirculation for $\mathrm{CO}_{2}$ capture. The system also must be flexible enough to allow the on line transition between air and oxygen firing.

Fans and Blowers: The forced draft system (PA \& SA fans, FA Blowers) will be handling recirculated flue gas rather than air during $\mathrm{O}_{2}$ fired operations. The recirculated flue gas has a higher molecular weight (more $\mathrm{CO}_{2}$ and less $\mathrm{N}_{2}$ ) and a higher inlet temperature to the fans and blowers than air. The recirculated flue gas, even with the higher inlet temperature to the fans, has an increased density. Taking all these differences into consideration, the existing primary air fan, secondary air fan, and fluidizing air blowers (FBHE and Seal Pot blowers) will easily accommodate the new operating conditions expected with $\mathrm{O}_{2}$ firing and therefore will not require any modifications

Although the ID fan will also be handling the increased density flue gas, it must now additionally accommodate a larger pressure rise across the fan. The increased system draft loss is due primarily to the addition of the flash dryer absorber (FDA) system for $\mathrm{SO}_{2}$ removal. Because of the increased draft losses, a new ID fan and motor are required for Case 2b.

New and Modified Ductwork: Significant modifications and additions are required to the Case 2a plant ductwork system in order to accommodate the new gas recirculation system, FDA system, Oxygen heater, and the addition of $\mathrm{O}_{2}$ firing capability as described below. New ductwork is required in several areas of the Boiler Island. Oxygen supply control valves and piping from the new ASU to the existing primary and secondary air heater outlet ducts is required. New ductwork with control and isolation dampers is also required for the recycle flue gas streams that feed the primary and secondary air fans and the existing fluidizing air blowers. Ductwork is also modified to accommodate the new oxygen heater and FDA system.

Additionally, new ductwork and dampers are required to supply product gas (primarily $\mathrm{CO}_{2}$ ) to the new Gas Processing System. Various isolation dampers are also required. Provisions in the new ductwork system to accommodate startup with air firing (air inlet duct with associated isolation dampers) are also required.

\subsubsection{Modified Controls and Instrumentation for the Boiler Island:}

As described in Section 4.3.3, additional controls and instrumentation will be required for the new components and systems. The transition between air firing and oxygen firing as well as additional safety precautions associated with oxygen use in this type of setting needs careful consideration.

\subsubsection{Modified Desulfurization System:}

In Case 2a (capture ready) a traditional furnace limestone injection system is used to remove about 90 percent of the $\mathrm{SO}_{2}$ produced. For the oxygen fired Case $2 \mathrm{~b}$, limestone is not added to the furnace. Instead, sulfur capture is done in a backend Flash Dryer Absorber (FDA) system with lime injection. This requires the same types of modifications as described for this system in Section 4.3.3.

\subsubsection{Major New Equipment Added:}

The major new equipment added to the boiler island is the air separation unit (ASU) to provide oxygen to the boiler and the gas processing system (GPS) to purify and compress the $\mathrm{CO}_{2}$ product gas. 


\section{STEAM TURBINE DESIGN AND PERFORMANCE}

This section briefly describes the designs and or modifications of the steam turbines. Also shown is the performance of the steam cycles in terms of material and energy balances (i.e. turbine heat balance diagrams).

With respect to the steam turbine, the basic study was focused on specifying the optimal steam turbine hardware scope including details, dimensions, weights and boundary conditions for the conceptual power plants. Three cases have been investigated as follows:

o Case 1a is the Base Case, which is a supercritical 680 MWe (nominal) unit.

o Case 2a is similar to the Base Case, except that provisions are made in the design to accommodate a future increase in steam flow of $38 \%$.

o Case $2 \mathrm{~b}$ represents the Case 2a steam turbine retrofit for the increased steam flow.

The steam turbines evaluated in this study are based on a standard ALSTOM supercritical unit typical of the types of steam turbines being offered to potential operators of coal-fired power stations in the US.

\subsection{Capture Ready Steam Turbine}

The Capture Ready steam turbine consists of components selected from the ALSTOM RTSeries of standard turbine modules. The primary design constraint for the Capture Ready steam turbine is that it must be capable of being upgraded to expand an additional 38\% steam flow when the plant is converted to oxygen firing and $\mathrm{CO}_{2}$ capture. The IP Turbine Module is designed from the outset to be capable of swallowing the additional steam flow required for future "capture ready converted " operation. The standard LP Turbine Module is also fully capable of swallowing the additional steam flow required for "capture ready converted" operation. The HP steam turbine however is designed for $100 \%$ flow.

\subsection{Capture Ready Converted Steam Turbine}

The Capture Ready Converted (converted to oxygen firing and $\mathrm{CO}_{2}$ capture) steam turbine operated in the future would comprise the Capture Ready steam turbine train described above incorporating a retrofitted HP steam turbine, which is designed for $138 \%$ flow. In order to achieve this, the HP Turbine Module would require upgrading by means of a HP Turbine Inner Block Retrofit. Additionally, the recovery and integration of low-level heat from the ASU and GPS must be accommodated. This modification will reduce the extraction flows to the LP feedwater heaters. Finally, the generator would be replaced with a unit of the required capacity as shown in the Appendix (Section 10.1.2), Figure 10-3.

An additional constraint, with respect to the capture ready converted steam turbine, is that the main steam pressure entering the HP turbine must not be increased as compared to the capture ready operating condition when this additional 38\% steam flow is expanded. This is a requirement in order not to exceed the design pressure for the existing boiler pressure parts, steam/feedwater piping, etc.

\subsubsection{HP Inner Block Retrofit}

The HP Inner Block Retrofit would make use of the existing outer casing and various other existing equipment (described below) supplied with the original turbine. A typical cross sectional view of the retrofit is shown in Figure 5-1. The colored sections (blue, red, gray, and yellow) comprise the equipment that would be replaced in the HP Inner Block Retrofit. 
Key:

Red - Shrink Rings

Gray - Inner Casing

Yellow - Fixed and Moving Blades

Blue - Rotor plus integral coupling

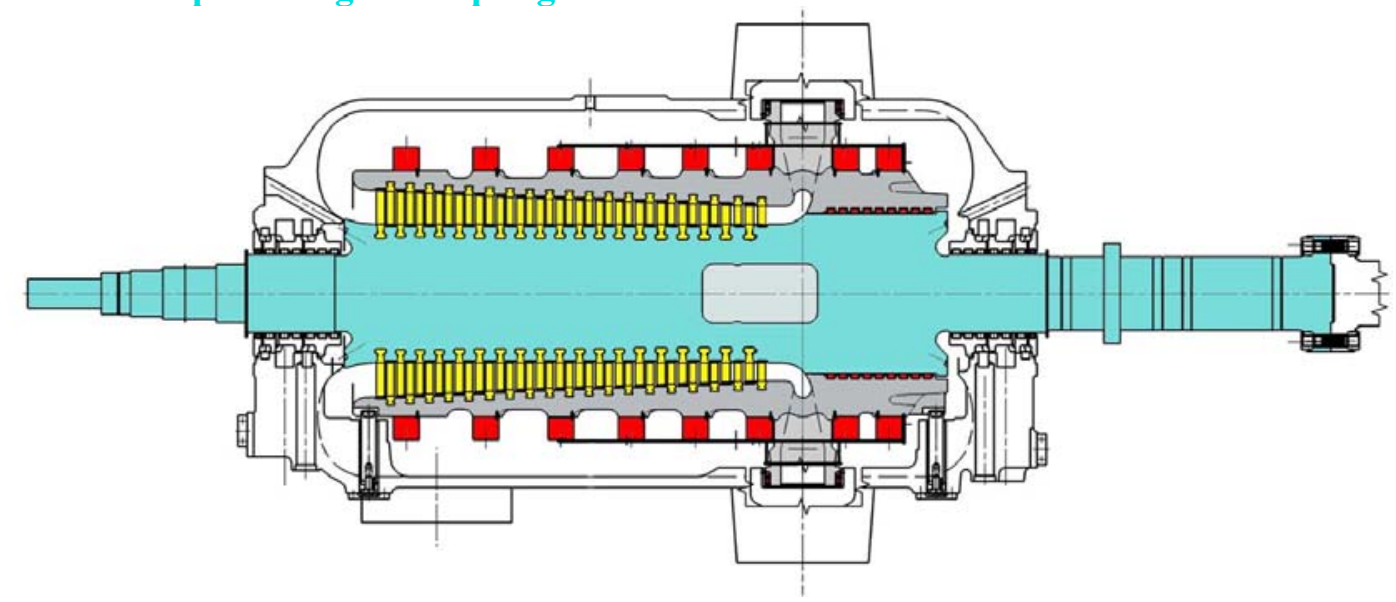

Figure 5-1: Typical HP Inner Block Retrofit Cross Section

A typical new equipment scope of supply for a HP Inner Block Retrofit would be as follows:

o One (1) drum type HP rotor with integral coupling, fully bladed, high-speed balanced and over-speed tested to $120 \%$ of nominal speed, including piston sealing.

o One (1) new HP inner casing of ALSTOM design, fully bladed, shrink rings, heat shields, pre-assembled.

o Four (4) sets of steam seals at the HP inlet interfaces.

o One (1) complete set of shims, keys and spacers necessary to fit and align new components to existing stationary components.

The following existing equipment delivered with the original steam turbine would be re-used after retrofitting the HP turbine:

o Existing outer casing

o Inlet pipes (welded to steam ducts)

o HP stop- and control valves

o HP shaft glands housing and gland steam system

o Bearing pedestals and bearings

o Turning gear, main oil pump

o Governing and control devices

o Instrumentation related to reused components

The HP Inner Block Retrofit is delivered to the site as an assembled module. The concept of the "drop in solution" for the HP inner Block Retrofit is illustrated in Figure 5-2. 

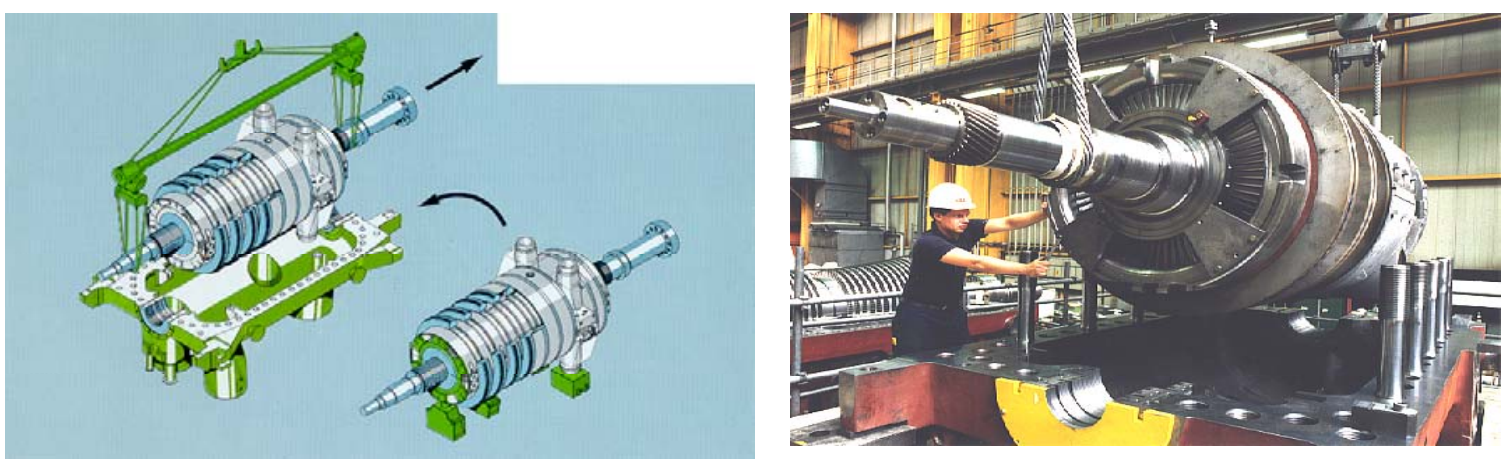

Figure 5-2: HP Inner Block Retrofit Illustrating "Drop In Solution"

\subsection{Steam Turbine/Generator Layout Drawings}

The layout plan drawings for the steam turbine/generators are shown in Section 10.1.2. The steam turbine external dimensions are identical for all Cases (1a, 1b, 2a, and 2b) as shown in dFigure 10-1 and Figure 10-2. The generator external dimensions are identical for Cases (1a, 1b, and 2a) as shown in Figure 10-1 and Figure 10-2. The generator external dimensions are larger for Case 2b as shown in Figure 10-3.

\subsection{Steam Turbine Heat Balances}

Turbine heat balance diagrams for the three cases described above (Case 1a, 2a, and 2b) are shown in Figure 5-3, Figure 5-4, and Figure 5-5 respectively. A turbine heat balance diagram was not developed for Case $1 \mathrm{~b}$ since it is very similar to Case 1a except for the recovery and integration of the low-level heat from the ASU and GPS. Table 5-1 shows a summary of main steam flows pressures and generator outputs for the four cases.

Table 5-1: Summary of Steam Flows, Pressures and Generator Outputs

\begin{tabular}{|l|l|l|l||}
\hline & $\begin{array}{l}\text { MAIN STEAM } \\
\text { FLOW } \\
\text { (K-LBM/HR) }\end{array}$ & $\begin{array}{l}\text { MAIN STEAM } \\
\text { PRESSURE } \\
\text { (PSIA) }\end{array}$ & $\begin{array}{l}\text { GENERATOR } \\
\text { OUTPUT } \\
\text { (KW) }\end{array}$ \\
\hline Case 1a - Base Case Turbine & 4,409 & 3,590 & 677,489 \\
\hline $\begin{array}{l}\text { Case 1b - Base Case Turbine with Low } \\
\text { Level Heat Recovery (LLHR) }\end{array}$ & 4,409 & 3,590 & 692,293 \\
\hline Case 2a - Capture Ready Turbine & 4,409 & 3,590 & 677,999 \\
\hline $\begin{array}{l}\text { Case 2b - Case 2a Turbine Converted } \\
\text { for 138\% steam flow and LLHR }\end{array}$ & 6,088 & 3,590 & 895,377 \\
\hline
\end{tabular}




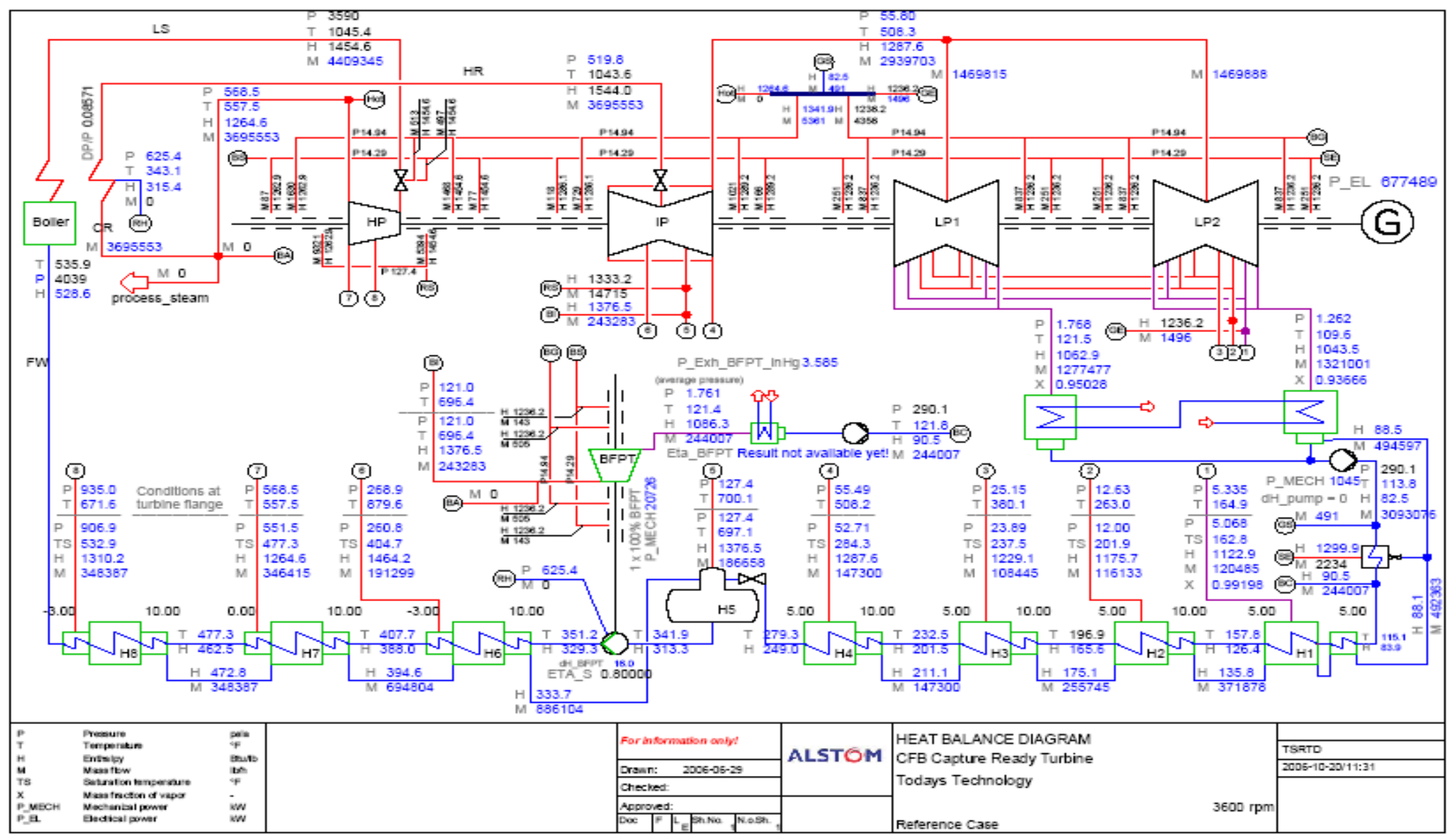

Figure 5-3: Case 1a (Base Case) Turbine Heat Balance Diagram 
COMMERCIALIZATION DEVELOPMENT OF OXYGEN FIRED

CFB FOR GREENHOUSE GAS CONTROL

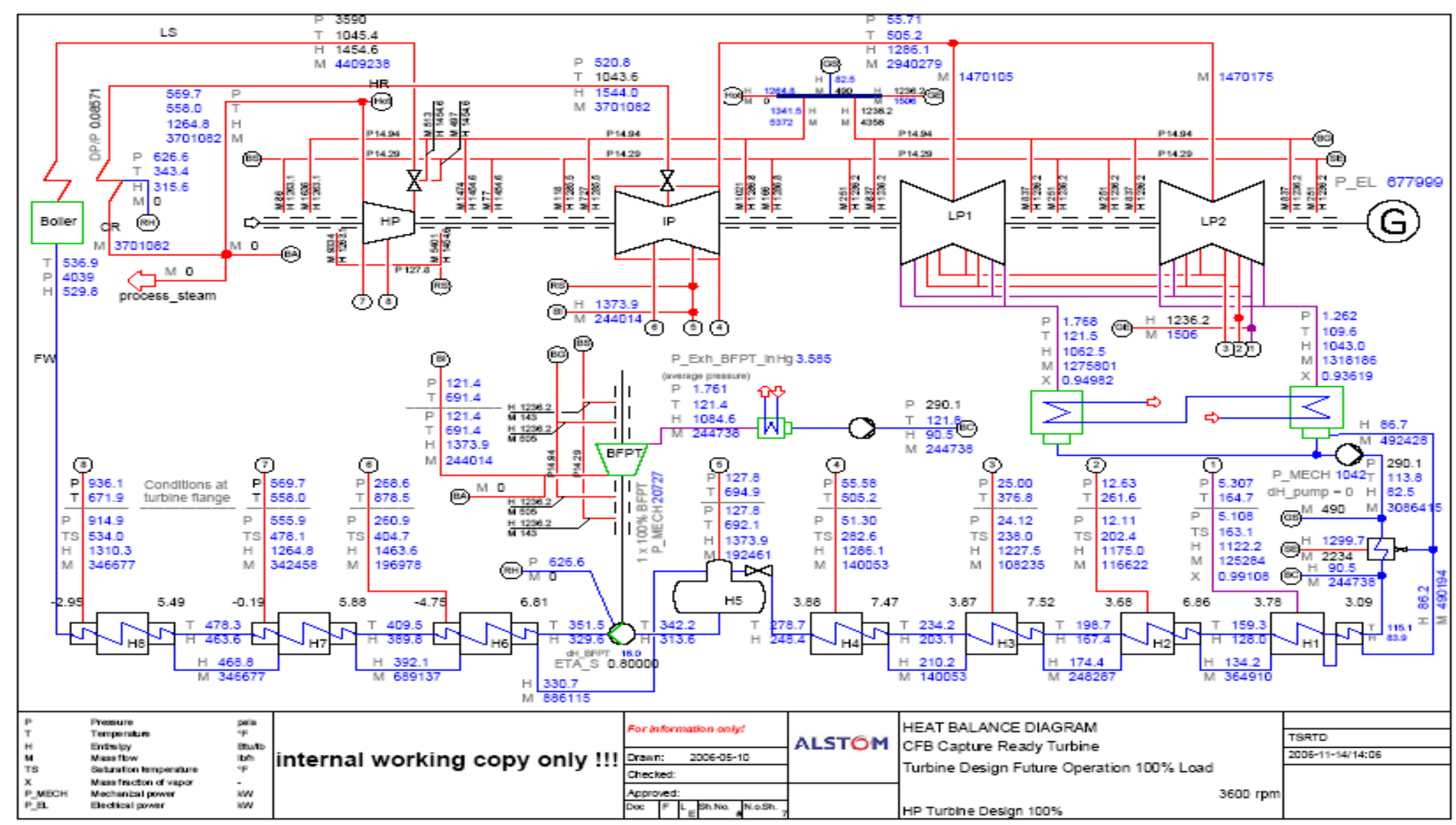

Figure 5-4: Case 2a Capture Ready Turbine Heat Balance Diagram 
COMMERCIALIZATION DEVELOPMENT OF OXYGEN FIRED

CFB FOR GREENHOUSE GAS CONTROL

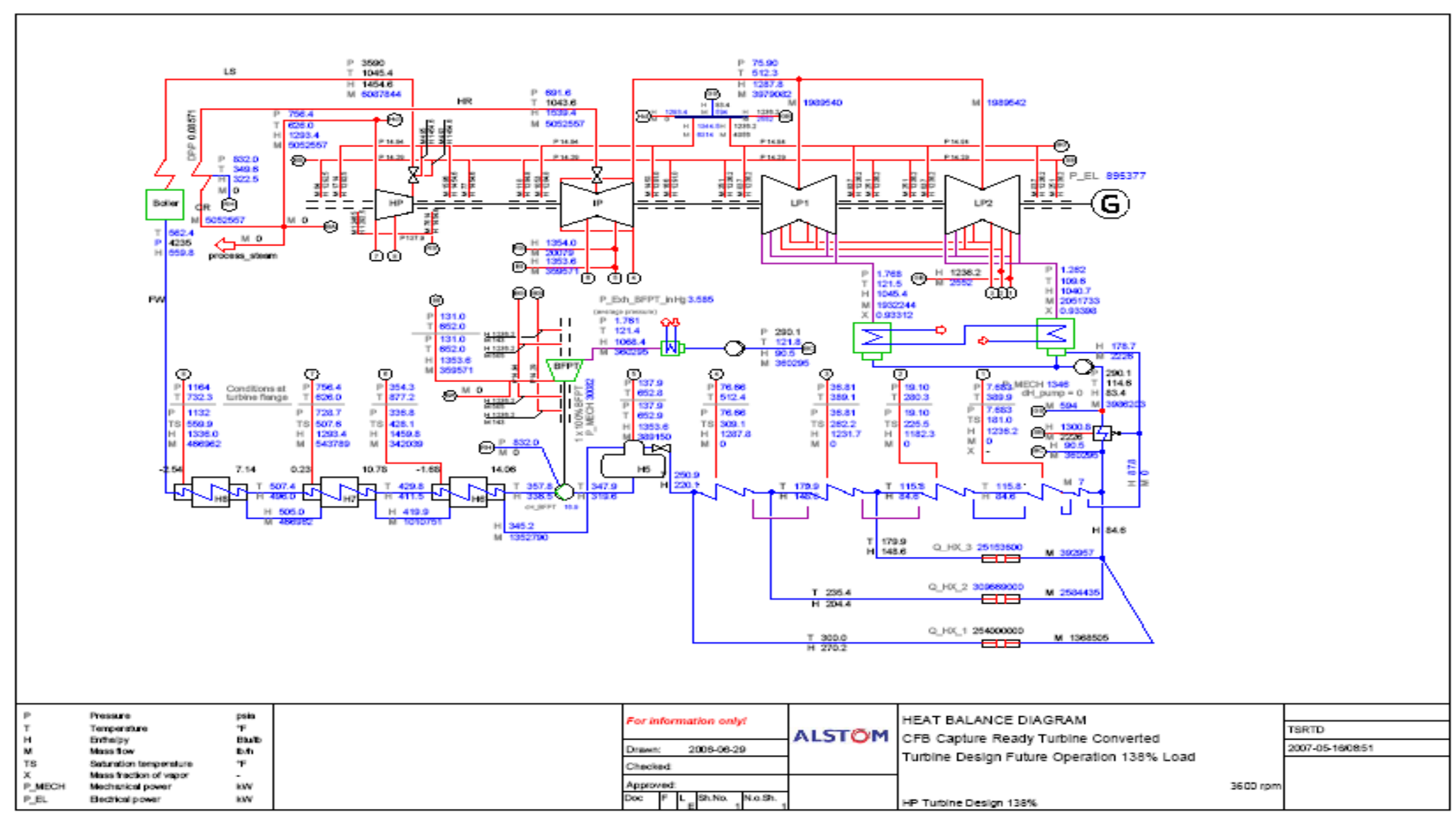

Figure 5-5: Case 2b Capture Ready Converted Turbine Heat Balance Diagram 


\section{BALANCE OF PLANT DESIGN AND PERFORMANCE}

This section describes the conceptual designs of the equipment included in the balance of plant (BOP) systems for the four power plants. The BOP systems for the four cases in this study include everything except the CFB boilers, the steam turbine generator, and the particulate and sulfur removal system. Other exceptions for the $\mathrm{CO}_{2}$ capture cases (Case $1 \mathrm{~b}$ and $2 \mathrm{~b}$ ) include the air separation unit and the gas processing system.

\subsection{Air Separation Unit}

Commercial cryogenic air separation units (ASU's) are highly energy-intensive, consuming, in auxiliary power, large amounts of the gross plant electric power output. For example, the cryogenic ASU used in conjunction with the work discussed in Volume I of this report (Section 4.4.7) required $233 \mathrm{kWh} /$ ton of oxygen supplied or about 17.2 percent of the steam turbine generator output is attributable to operating the ASU.

Hence, the information on the design, performance and cost analysis of a special cryogenic air separation unit (ASU) developed by Anheden and Morin (2004) was used in conjunction with the present study. Anheden and Morin state that the configuration of an air separation unit (ASU) is dependent upon the product requirement in terms of flow rates, state (i.e., liquid or vapor), and purity. As an example, if nitrogen is a desired product, then the process must guarantee a required purity. Otherwise, it (the nitrogen) can be vented off to atmosphere. ASU configurations are also application-specific. That is, in oxy-combustions plants, they are designed to supply the oxygen at almost atmospheric pressure; whereas, in IGCC, they are designed to supply the oxygen and nitrogen at elevated pressures (e.g., 50, and 20 bar, respectively).

The ASU configuration used by Anheden and Morin (2004) for oxy-CFB application is depicted in Figure 6-1. This configuration, which includes two reboilers in the low-pressure column, is explained as follows: "The lower of them condenses partially the air coming from the main compressor against the liquid at the bottom of the lower pressure column. A fraction of this air is distilled in the medium-pressure column. The upper reboiler vaporizes a lowpressure oxygen-rich mixture against hotter pure nitrogen from the medium-pressure column. In this way, required state-change temperature for the double distillation can be reached at a global lower pressure. Therefore, a significantly lower amount of compression energy should be required.” For details on the design of this special ASU, see Anheden and Morin (2004).

As shown in Table 6-1, this ASU is designed to supply to Case 2b Oxy-CFB plant (CaptureReady Converted) 14,295 tonnes/day $\mathrm{O}_{2}$ of $99.8 \%$ purity and is at $18{ }^{\circ} \mathrm{C}$ temperature and 1.3 bara pressure. This ASU required about $180 \mathrm{kWh} /$ ton $\mathrm{O}_{2}$, as shown previously in Section 3.2 (Power Plant Performance Summary and Comparison). This auxiliary power consumption represents an improvement of 23\% over the ASU described in Volume I (i.e., 180 vs. 233 $\mathrm{kWh} /$ ton $\mathrm{O}_{2}$ ). 


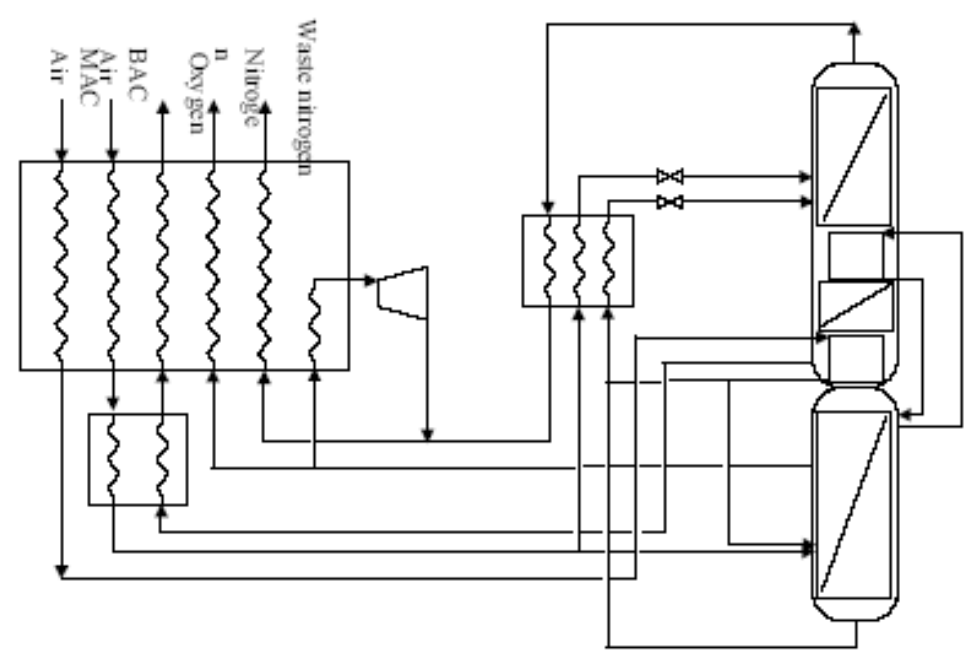

Figure 6-1: ASU Schematic with Two Reboilers

Table 6-1: ASU Oxygen Production and Purity

\begin{tabular}{|c|l|c|c|c|c|c|c|c|}
\hline \multirow{2}{*}{ Plant Site } & \multirow{2}{*}{ Case \# } & \multicolumn{2}{|c|}{$\mathbf{O}_{2}$ Supply Capacity } & \multicolumn{2}{|c|}{$\mathbf{O}_{2}$ Temperature } & \multicolumn{2}{|c|}{$\mathbf{O}_{2}$ Pressure } & $\mathbf{O}_{2}$ Purity \\
\cline { 3 - 8 } & Tonne/Day & Ton/Day & ${ }^{\circ} \mathrm{C}$ & ${ }^{\circ} \mathrm{F}$ & Bara & Psia & $(\%)$ \\
\hline $\begin{array}{c}\text { Southeast } \\
\text { USA }\end{array}$ & Case 1b & 10,998 & 12,098 & 18 & 65 & 1.3 & 19 & 99 \\
\cline { 2 - 8 } & Case 2b & 14,295 & 15,724 & 18 & 65 & 1.3 & 19 & 99 \\
\hline
\end{tabular}

\subsection{Gas Processing System}

The purpose of the Gas Processing System (GPS) for this project is to process the flue gas stream leaving the oxygen-fired Boiler Island to provide a liquid $\mathrm{CO}_{2}$ product stream of suitable conditions for enhance oil recovery (EOR) application. The GPS first cools and then compresses a $\mathrm{CO}_{2}$ rich flue gas stream from an oxygen-fired CFB boiler to a pressure high enough so $\mathrm{CO}_{2}$ can be liquefied. The resulting liquid $\mathrm{CO}_{2}$ is passed through a $\mathrm{CO}_{2}$ distillation column to reduce the $\mathrm{N}_{2}$ and $\mathrm{O}_{2}$ content to meet the stringent specification noted in Table 6-2. Then the liquid $\mathrm{CO}_{2}$ is pumped to a high pressure so it can be economically transported for usage or sequestration. The overhead gas from the $\mathrm{CO}_{2}$ distillation column condenser outlet is ultimately vented to atmosphere. This system has been described in detail in Section 4.4.4 of Volume I of this report

This $\mathrm{CO}_{2}$ capture system is designed for more than 94 percent $\mathrm{CO}_{2}$ capture from the GPS feed stream. Process design, equipment selection, performance calculations and cost estimates were developed for all the systems and equipment required for cooling, purifying, compressing and liquefying of the $\mathrm{CO}_{2}$ rich flue gas stream to a product quality acceptable for pipeline transport. The Dakota Gasification Company’s $\mathrm{CO}_{2}$ specification for EOR (Dakota Gasification Company, 2005), given in

Table 6-2, was used as the basis for the $\mathrm{CO}_{2}$ capture system design. The calculated volume percent values for the product stream using the gas processing system described in section 4.4.4 
of Volume I are shown for comparison in the far right column of

Table 6-2. As shown, the $\mathrm{CO}_{2}$ product meets or exceeds all of the specification values.

Table 6-2: Dakota Gasification Project's $\mathrm{CO}_{2}$ Specification for EOR and the Calculated Product Stream Purity

\begin{tabular}{|l|l|c|c|}
\multicolumn{2}{l|}{ Component } & Spec & Actual \\
Value & Value \\
\hline $\mathrm{CO}_{2}$ & (vol \%) & 96 & 99.8 \\
$\mathrm{H}_{2} \mathrm{~S}$ & $($ vol \%) & 1 & --- \\
$\mathrm{CH}_{4}$ & $($ vol \%) & 0.3 & --- \\
$\mathrm{C}_{2}+\mathrm{HC}$ 's & $($ vol \%) & 2 & --- \\
$\mathrm{CO}$ & $($ vol \%) & -- & --- \\
$\mathrm{N}_{2}$ & $($ ppm by vol.) & 6000 & 19.0 \\
$\mathrm{H}_{2} \mathrm{O}$ & $($ ppm by vol.) & 2 & 0.5 \\
$\mathrm{O}_{2}$ & $($ ppm by vol.) & 100 & 95.0 \\
Mercaptans and other Sulfides & (vol \%) & 0.03 & --- \\
\hline
\end{tabular}

\subsection{Coal Handling System}

The function of the coal handling system is the same in all cases. It is to provide equipment necessary for unloading, conveying, preparing, and storing the fuel delivered to the plant. The scope of the system is from the coal delivery point up to the boiler day bin inlet. A typical coal handling system is depicted in Figure 6-2. Although this figure shows a barge discharging the coal into a conveyor belt, this particular study used a railroad system for coal supply. 
COMMERCIALIZATION DEVELOPMENT OF OXYGEN FIRED

CFB FOR GREENHOUSE GAS CONTROL

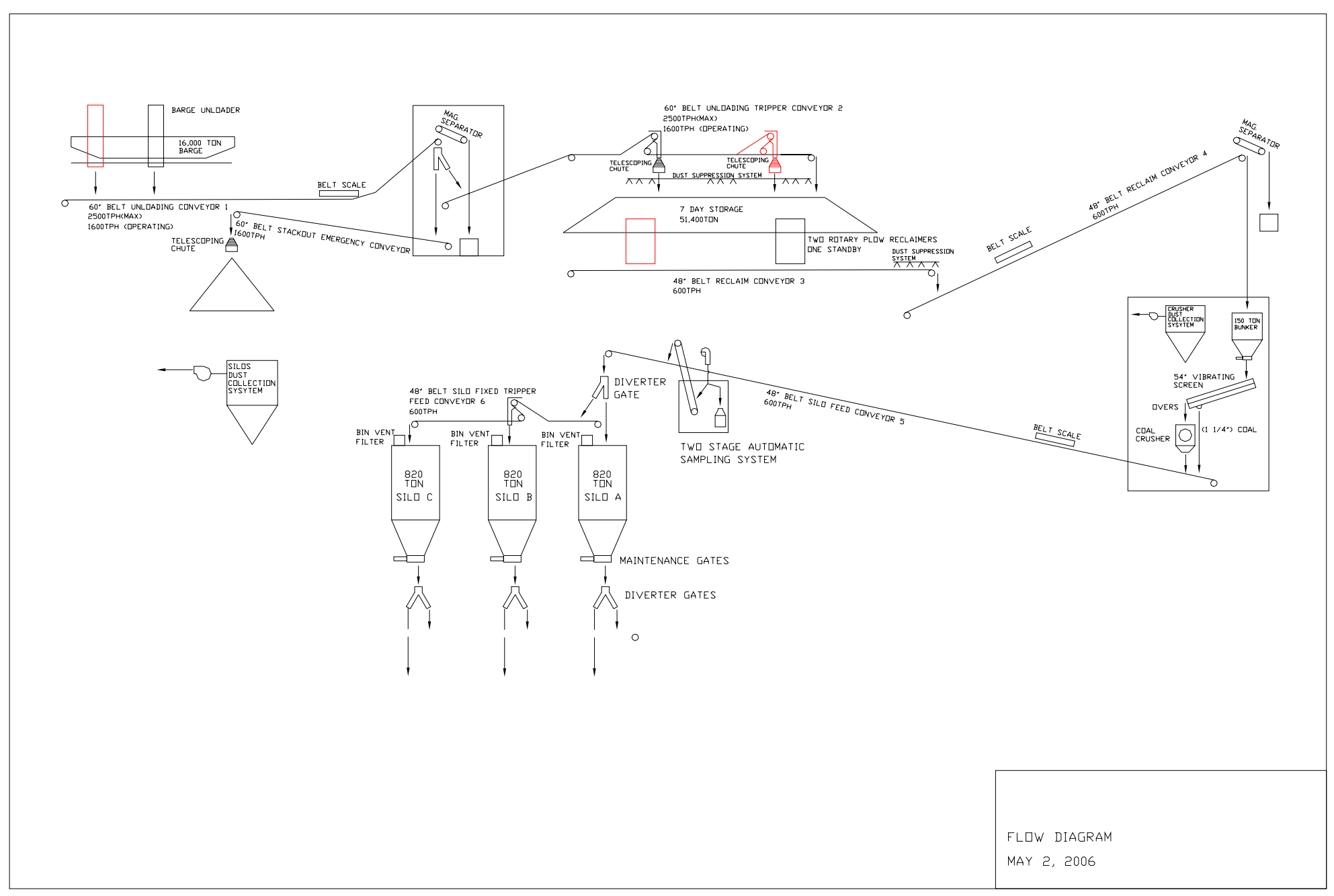

Figure 6-2: Depiction of Typical Coal handling System 
The coal handling system utilizes belt conveyors, variable speed belt feeders, magnetic separators, enclosed conveyor galleries, open pile storage, crusher house, unloading building, and dust collection at all transfer points. The materials of construction are industrial grade and include stainless steel liners at coal impact areas. The Coal Unloading Building and Crusher House have aluminum box-beam siding.

The coal handling system will be designed to handle coal with characteristics as presented in Table 6-3.

Table 6-3: Design Coal

\begin{tabular}{|c|c|c|}
\hline Constituent & Units & $\begin{array}{c}\text { Weight } \\
\text { Fraction }\end{array}$ \\
\hline O2 & & 0.0316 \\
N2 & & 0.0146 \\
H2O & & 0.0399 \\
H2 & & 0.0357 \\
Carbon & & 0.6205 \\
Sulfur & & 0.0234 \\
Ash & & 0.2343 \\
\hline \hline Total & & $\mathbf{1 . 0 0 0 0}$ \\
\hline HHV Coal & $(\mathrm{Btu} / \mathrm{lbm})$ & 11,070 \\
& $(\mathrm{~kJ} / \mathrm{kg})$ & 23,132 \\
\hline
\end{tabular}

The 2" x 0 medium volatile bituminous coal is delivered to the site by unit trains of 100-ton rail cars. Each unit train consists of one hundred 100-ton rail cars. The unloading is done by a trestle bottom dumper, which unloads the coal into two receiving hoppers. Coal from each hopper is fed directly onto a belt feeder. The 2 " $\mathrm{x} 0$ coal from the feeder is discharged onto a belt conveyor (Conveyor No. 1). The coal is then transferred to a second conveyor (Conveyor No. 2) that transfers the coal to the reclaim area. The conveyor passes under a magnetic plate separator to remove tramp iron, and then to the double wing traveling stacker that forms active storage and long-term storage coal piles. Coal is spread over the long-term pile storage area by mobile equipment.

Coal from the active storage pile is reclaimed by a rotary plow located under the pile onto a reclaim belt conveyor located in a tunnel. The reclaim conveyer discharges coal onto the belt conveyer (Conveyor No. 3), which transports the coal to the coal surge bins located in the crusher tower. The coal is reduced in size by two coal crushers (see Table 6-4) and transferred by conveyor (Conveyor No. 4) to the as-fired coal-sampling tower.

Table 6-4: Required Coal Size Distribution

\begin{tabular}{|c|c|}
\hline Cumulative Weight Passing & Particle Size \\
\hline $100 \%$ & $<12,000$ micron \\
\hline $90 \%$ & $<5,000$ micron \\
\hline $50 \%$ & $<1,350$ micron \\
\hline $10 \%$ & $<160$ micron \\
\hline
\end{tabular}


Another belt conveyor (Conveyor No. 5) transfers the crushed coal to the transfer tower. In the transfer tower, the coal is routed to the tripper that loads the coal into one of the parallel boiler bunkers for Circulating Fluidized Bed Boiler \# 1 (CFB \# 1) and Circulating Fluidized Bed Boiler \# 2 (CFB \# 2).

From the long-term storage pile, coal can be reclaimed via an emergency reclaim hopper, belt feeder, and emergency reclaim conveyor.

The coal handling system is based on the handling rates, capacities, and frequencies presented in Table 6-5.

Table 6-5: Coal Handling System Design Basis

\begin{tabular}{|l|c|c|c|c|}
\hline & Case 1a & Case 1b & Case 2a & Case 2b \\
\hline $\begin{array}{l}\text { Coal feed rate (two boilers at MCR), } \\
\text { tons/hour }\end{array}$ & 255 & 260 & 255 & 338 \\
\hline Coal delivery, days/week & 5 & 5 & 5 & 6 \\
\hline $\begin{array}{l}\text { Coal handling crew operation, } \\
\text { hours/day }\end{array}$ & 16 & 16 & 76 & 24 \\
\hline $\begin{array}{l}\text { Active storage pile capacity, } \\
\text { days of operation at MCR }\end{array}$ & 7 & 7 & 7 & 5 \\
\hline $\begin{array}{l}\text { Long term storage pile capacity, } \\
\text { days of operation at MCR }\end{array}$ & $\begin{array}{c}30 \\
(184,000 \text { tons })\end{array}$ & $\begin{array}{c}30 \\
(184,000 \\
\text { tons })\end{array}$ & $\begin{array}{c}30 \\
(184,000 \text { tons })\end{array}$ & $\begin{array}{c}30 \\
(244,000 \text { tons })\end{array}$ \\
\hline
\end{tabular}

The coal handling system equipment sizing is the same for all cases. However, for the Case $2 \mathrm{~b}$ system the operating hours will be increased to accommodate the approximately $34 \%$ higher coal feed rate.

\subsection{Sorbent Handling System}

Limestone will be utilized as the sulfur absorbing agent in the air-blown CFB designs (Cases $1 \mathrm{a}$ and $2 \mathrm{a}$ ), and lime in the oxygen-blown designs (Cases $1 \mathrm{~b}$ and $2 \mathrm{~b}$ ). As a part of the Oxyfuel conversion, the lime handling system is added and the limestone handling equipment is removed from operation and abandoned in place. During startup of the oxygen fired boilers, while in the air-fired mode, Cases $1 \mathrm{~b}$ and $2 \mathrm{~b}$ will use lime as the sulfur absorbing agent. Descriptions of the limestone and lime handling systems are provided in this section.

\subsubsection{Limestone Handling}

The limestone will be used as a sulfur-absorbing agent in the air-blown CFB boilers (Cases 1a and 2a). The function of the limestone handling and preparation system is to receive, store, convey, and grind the limestone delivered to the plant.

The limestone handling system is designed to handle limestone with analysis as presented in. System design is based on assumed limestone bulk density of $80 \mathrm{lb} / \mathrm{ft}^{3}$. 
Table 6-6: Limestone Analysis

\begin{tabular}{|l|c|}
\hline Constituent & Weight Fraction \\
\hline $\mathrm{CaCO}_{3}$ & 0.9830 \\
\hline Moisture & 0.0000 \\
\hline Ash & 0.0170 \\
\hline & 1.0000 \\
\hline
\end{tabular}

The limestone handling system will receive limestone delivered to the site by trucks, crush it to an appropriate size for injection in the CFB boilers, and transfer it to the prepared limestone silos (day bins) adjacent to each CFB boiler. The system also maintains a 7-day supply of uncrushed limestone in pile storage on site as a reserve against disruptions in delivery.

The Limestone Handling System is designed to receive 2”x 0 limestone. Limestone is received by trucks and discharged into an underground receiving hopper. Limestone is transported from the receiving hopper and discharged onto a stacking belt conveyor using a belt feeder. The stacking conveyor transports the limestone, and discharges it into an open pile with 7-day storage capacity ( 4,800 tons).

The reclaim conveyor transports the coarse limestone to a surge hopper with shutoff gates. Limestone is transported from the surge hopper outlet via belt feeder and discharged into a crusher, where the limestone is reduced from a feed size of 2" 0 to net output size as presented in Table 6-7.

Table 6-7: Required Limestone Size Distribution

\begin{tabular}{|c|c|}
\hline Cumulative Weight Passing & Particle Size \\
\hline $100 \%$ & $<2,400$ micron \\
\hline $90 \%$ & $<650$ micron \\
\hline $50 \%$ & $<275$ micron \\
\hline $10 \%$ & $<35$ micron \\
\hline
\end{tabular}

The sized limestone is then transported to two (2) limestone storage silos (one for each CFB), using an enclosed belt conveyer.

The system includes a dust suppression system for the receiving hopper, and a dust collection system for the crusher.

\subsubsection{Lime Handling}

The lime will be used as the sulfur-absorbing agent in the Flash Dryer Absorbers (FDA) of the oxygen-blown CFB boilers (Cases $1 \mathrm{~b}$ and $2 \mathrm{~b}$ ). The lime handling system receives lime delivered to the site by trucks and pneumatically transports it to the lime storage silos adjacent to each CFB. The lime storage silos are equipped with blanketing systems to prevent contact with moist air. The lime will be delivered already prepared. Its sizing will be $\sim 1 / 4 " \mathrm{x} 0$. The lime handling system boundaries are from the quick disconnect fitting at the truck receiving station up to, but not including, the lime day bins at each boiler. The lime handling system will require trucks with mounted blowers.

From the storage silo, lime will be pneumatically transported to the day bins at the CFB absorber areas. The system also maintains a 7-day supply ( 3,400 tons) of prepared lime in a storage silo on site as a reserve against disruptions in delivery. 


\subsection{Ash Handling System}

The ash handling system consists of two main sub-systems: (1) the bottom (bed) ash system and (2) the fly ash system. Bed and fly ash are handled separately and stored in a dry state in dedicated silos. The material is conveyed pneumatically by a positive pressure pneumatic system. Each type of ash is conveyed in a separate pneumatic system from its source collection point to an air separator located on the top of each collection silo, and from there it is loaded into a truck for offsite disposal. The ash handling system is sized to serve two CFB boilers simultaneously firing at their maximum continuous rate. To reduce fugitive dust, the area for ash loading into vehicles is sheltered. This area is equipped with a ventilation system connected to the baghouse. Ash is discharged from the silo to the surge hopper by a screw feeder that operates in a batch mode. From the surge hopper ash is discharged to a truck through a rotary dust-conditioning unloader.

\subsubsection{Bed Ash}

The Bed Ash Handling system is designed to sequentially remove dry free flowing ash from the CFB boiler interface points, transport it, and store it in an ash storage silo. The system will include provisions to condition (mix with water) the ash, and discharge the conditioned ash into dump trucks.

The system will be a dilute phase pressurized system. Bottom ash will be drained from each collection point and fill airlock vessels (lock hoppers), one for each collection point. Upon reaching a level in the airlock vessel hopper, the inlet valve will close stopping the filling process. The controls will sequence and cycle the airlock vessels, from which ash is pneumatically transported by compressed air to the bed ash storage silo. Ash is separated from the conveying air by a primary cyclone separator followed by a pulse jet type bag filter. The storage silo arrangement will be equipped with an elevated outlet, fully fluidized bottom, an internal platform to hold the batch ash conditioner, and a skirt with a large opening for a truck drive through.

The system includes a pressure blower, ash airlock assemblies, fluidizing silo bottom blower, material transport piping, clean air piping, 5,200-ton capacity concrete storage silo, bin-vent filter, batch ash (wet-out) system, mixer discharge chute, supports, etc.

The bed ash handling system design is based on the handling rates, capacities, and frequencies presented in Table 6-8.

Table 6-8: Bed Ash System Design Basis

\begin{tabular}{|l|c|c|c|c|}
\hline & Case 1a & Case 1b & Case 2a & Case 2b \\
\hline Total Ash generated $^{1}$, tons/hour & 93 & 94 & 93 & 122 \\
\hline Bed Ash Operating flowrate, tons/h & 28 & 28 & 28 & 68 \\
\hline Bed Ash Design Capacity, tons/h ${ }^{2}$ & 65 & 65 & $65 / 85$ & 85 \\
\hline Bed Ash removal, days/week & 5 & 5 & 5 & 6 \\
\hline Bed Ash removal, hours/day & 12 & 12 & 12 & 14 \\
\hline $\begin{array}{l}\text { Bed Ash silo storage capacity, } \\
\text { hours of operation at MCR }\end{array}$ & $\begin{array}{c}72 \\
(5,200 \text { tons })\end{array}$ & $\begin{array}{c}72 \\
(5,200 \text { tons })\end{array}$ & $\begin{array}{c}72 \\
(5,200 \text { tons })\end{array}$ & $\begin{array}{c}55 \\
(5,200 \text { tons })\end{array}$ \\
\hline
\end{tabular}

${ }^{1}$ Total bed and fly ash generated by two boilers at a Maximum Continuous rating (MCR)

${ }^{2}$ Designed to handle $70 \%$ of total ash production

For the capture ready design (Case 2a), the bed ash system piping is sized based on the increased bed ash design flowrate of the plant converted to oxygen firing operation (Case $2 \mathrm{~b}$ ). 
As a part of Oxyfuel conversion and to accommodate the increased design flowrate, a third bed ash air compressor will be added.

\subsubsection{Fly Ash}

The Fly Ash Handling system is designed to sequentially remove dry free flowing ash from the baghouse hoppers. The fly ash is collected in multiple collection points at the bottom hopper connections of the bag filters. The system will be a dilute phase pressurized system.

Ash is withdrawn from each hopper thorough a fly ash airlock vessel and pneumatically transported under positive pressure to the Fly Ash storage silo.

The cyclone separators and bagfilters separate the fly ash from the conveying air. The storage silo arrangement will be equipped with an elevated outlet, fully fluidized bottom, an internal platform to hold the batch ash conditioner, and a skirt with a large opening for a truck drive through. The system will include provisions to condition (mix with water) the ash, and discharge the conditioned ash into dump trucks.

The system includes a pressure blower, fluidizing silo bottom blower, material transport piping, clean air piping, filter/separator, 5,200-ton capacity concrete storage silo, bin-vent filter, batch ash (wet-out) system, mixer discharge chute, supports, etc.

The fly ash handling system design is based on the handling rates, capacities, and frequencies presented in Table 6-9.

Table 6-9: Fly Ash Handling System Design Basis

\begin{tabular}{|l|c|c|c|c|}
\hline & Case 1a & Case 1b & Case 2a & Case 2b \\
\hline Total Ash generated ${ }^{1}$, tons/hour & 93 & 93 & 93 & 122 \\
\hline Fly Ash Operating flowrate, tons/h & 65 & 65 & 65 & 55 \\
\hline Fly Ash Design Capacity, tons/h ${ }^{2}$ & 65 & 65 & $65 / 85$ & 85 \\
\hline Fly Ash removal, days/week & 5 & 5 & 5 & 6 \\
\hline Fly Ash removal, hours/day & 12 & 12 & 12 & 14 \\
\hline $\begin{array}{l}\text { Fly Ash silo storage capacity, } \\
\text { hours of operation at MCR }\end{array}$ & 72 & 72 & 72 & 55 \\
(5,200 tons) & $(5,200$ tons) & $(5,200$ tons) & $(5,200$ tons) \\
\hline
\end{tabular}
Total bed and fly ash generated by two boilers at a Maximum Continuous rating (MCR).
Designed to handle 70\% of total ash production.

For capture ready design (Case 2a) fly ash system piping is sized based on increased fly ash design flowrate of the plant converted to oxygen firing operation (Case 2b). As a part of the Oxyfuel conversion and to accommodate the increased design flowrate, a third fly ash air compressor will be added.

\subsection{Supercritical Steam Turbine System}

The steam turbine for all four of these supercritical cases is equipped with six non-automatic steam extractions, which along with the HP and IP sections exhausts provide steam for four low pressure (LP) feedwater heaters, deaerator and three high pressure (HP) feedwater heaters. All feedwater heaters (except the deaerator) are closed type. The condensate drains from the low-pressure heaters (\#1 through \#4) are cascaded to the condenser. The condensate drains from the high pressure heaters (\#6 through \#8) are cascaded to the deaerator. The deaerator storage tank provides suction to the boiler feedwater pumps. Heater \#7 is on the cold reheat extraction and heater \#8 is a heater above the reheat point (HARP). 


\subsubsection{Condensate System}

The function of the condensate system is to pump condensate from the condenser hot well to the deaerator, through the gland steam condenser and the low-pressure (LP) feedwater heaters. The condensate system is sized to service the total plant, and consists of one main dualpressure condenser; two 100 percent capacity, variable speed electric motor-driven vertical condensate pumps; one gland steam condenser; four LP heaters; and one deaerator with storage tank.

The condensate pump discharge lines are each equipped with a check valve and a gate valve. A common minimum flow recirculation line discharging to the condenser is provided downstream of the gland steam condenser to maintain minimum flow requirements for the gland steam condenser and the condensate pumps.

LP feedwater heaters 1 through 4 are 100 percent capacity shell and U-tube heat exchangers. Each LP feedwater heater is provided with inlet/outlet isolation valves and a full capacity bypass. LP feedwater heater drains cascade down to the next lowest extraction pressure heater and finally discharge into the condenser. Pneumatic level control valves control normal drain levels in the heaters. High heater level dump lines discharging to the condenser are provided for each heater for turbine water induction protection.

The deaerator is a horizontal, spray tray type with internal direct contact stainless steel vent condenser and storage tank. The deaerator is placed at high elevation to assure sufficient Net Positive Suction Head (NPSH) for the feedwater pumps.

For Case 2a (capture ready plant) condensate pumps have been sized to meet increased condensate flowrate of the plant converted to oxygen firing operation. Condensate pumps will be equipped with variable frequency drives (VFD) to provide for their efficient operation at a lower flowrate in a capture ready configuration.

Upon conversion to oxygen firing (Cases $1 b$ and $2 b$ ), the LP feedwater heaters will not be operating, and LP feedwater heating will be performed by recovering heat produced by the Air Separation Unit (ASU) and Gas Processing System (GPS). Hence, LP feedwater heaters for case 2a have been sized based on a lower condensate flowrate.

Sizing criteria for condensate system components is presented in Table 6-10.

Table 6-10: Condensate System Sizing Criteria

\begin{tabular}{|l|c|c|c|c|}
\hline \multirow{2}{*}{\multicolumn{1}{|c|}{ System Component }} & \multicolumn{4}{c|}{ Flowrate Basis, lb/h } \\
\cline { 2 - 5 } & Case 1a & Case 1b & Case 2a & Case 2b \\
\hline Condensate pumps & $3,093,075$ & $3,093,075$ & $3,986,203$ & $3,986,203$ \\
\hline LP feedwater heaters & $3,093,075$ & $3,093,075$ & $3,086,415$ & $3,086,415$ \\
\hline $\begin{array}{l}\text { Condenser (LPT1 + LPT2 } \\
\text { exhaust) }\end{array}$ & $2,598,478$ & $2,598,478$ & $3,983,977$ & $3,983,977$ \\
\hline Deaerator & $4,409,353$ & $4,409,353$ & $6,089,032$ & $6,089,032$ \\
\hline \hline Condenser hot well inventory & $5 \mathrm{~min}$ & $5 \mathrm{~min}$ & $6.5 \mathrm{~min}$ & $5 \mathrm{~min}$ \\
\hline Deaerator storage tank inventory & $5 \mathrm{~min}$ & $5 \mathrm{~min}$ & $7 \mathrm{~min}$ & $5 \mathrm{~min}$ \\
\hline
\end{tabular}

\subsubsection{Feedwater System}

The function of the feedwater system is to pump the feedwater from the deaerator storage tank through the HP feedwater heaters to the boiler economizer. Two identical feedwater trains (one per boiler) are provided. Each train is equipped with one 100 percent capacity turbine-driven 
boiler feedwater pump, three High Pressure (HP) feedwater heaters and one 30 percent capacity motor-driven startup boiler feed pump. All feedwater system equipment is sized based on a total feedwater flowrate per one boiler. CFB \#1 and CFB \#2 feedwater trains are interconnected via normally closed crossover ties enabling each feedwater train to operate with either boiler. One (per plant) spare main feedwater pump and one (per plant) spare startup feedwater pump are provided, capable of serving either boiler feedwater train.

All pumps are provided with inlet and outlet isolation valves, and individual minimum flow recirculation lines discharging back to the deaerator storage tank. The recirculation flow is controlled by automatic recirculation valves, which are a combination check valve in the main line and in the bypass, bypass control valve, and flow sensing element. The suction of the boiler feed pump is equipped with startup strainers, which are utilized during initial startup and following major outages or system maintenance.

Each of the HP feedwater heaters is provided with inlet/outlet isolation valves and a full capacity bypass. Feedwater heater drains cascade down to the next lowest extraction pressure heater and finally discharge into the deaerator. Pneumatic level control valves control normal drain level in the heaters. High heater level dump lines discharging to the condenser are provided for each heater for turbine water induction protection. Dump line flow is controlled by pneumatic level control valves.

For Case 2a (capture ready plant) all components of the feedwater system have been sized to meet the increased feedwater flowrate of the plant converted to oxygen firing operation (Case 2b).

\subsubsection{Main and Reheat Steam System}

The function of the main steam system is to convey main steam from the boiler superheater outlet to the HP turbine stop valves. The function of the reheat system is to convey steam from the HP turbine exhaust to the boiler reheater and from the boiler reheater outlet to the IP turbine stop valves.

Main steam exits the boiler superheater through a motor-operated stop/check valve and a motor-operated gate valve, and is routed in a single line feeding the HP turbine. A branch line off the IP turbine exhaust feeds the boiler feedwater pump turbine during unit operation starting at approximately 60 percent load.

Cold reheat steam exits the HP turbine, flows through a motor-operated isolation gate valve and a flow control valve, and enters the boiler reheater. Hot reheat steam exits the boiler reheater through a motor-operated gate valve and is routed to the IP turbine.

\subsubsection{Extraction Steam System}

The function of the extraction steam system is to convey steam from the turbine extraction points to the feedwater heaters.

The turbine is protected from over speed on turbine trip and from flash steam reverse flow from the heaters through the extraction piping to the turbine. This protection is provided by positive closing, balanced disc non-return valves located in all extraction lines except the lines to the LP feedwater heaters in the condenser neck. The extraction non-return valves are located only in horizontal runs of piping and as close to the turbine as possible.

The turbine trip signal automatically trips the non-return valves through relay dumps. The remote manual control for each heater level control system is used to release the non-return valves to normal check valve service when required to restart the system. 


\subsection{Circulating Water System}

The circulating water system provides cooling water to the condenser and the auxiliary cooling water system. Water quality assumed in this study (Table 2-1) is consistent with the water quality of a public water facility or groundwater and can be used as a makeup cooling water with minimal pretreatment. All filtration and treatment of the circulating water are conducted on site. A mechanical draft, fiberglass, multi-cell, counter-flow cooling tower is provided for the circulating water heat sink (GEA, 2007).

The auxiliary cooling water system is a closed-loop system. Plate and frame heat exchangers with circulating water as the cooling medium are provided. This system provides cooling water to the lube oil coolers, turbine generator, boiler feed pumps, etc. All pumps, vacuum breakers, air release valves, instruments, controls, etc. are included for a complete operable system.

Two 50 percent capacity circulating water pumps are provided for the base case (Case 1a) and capture ready case (Case 2a). For capture ready design (Case 2a) the circulating water system piping is sized based on the increased circulating water flowrate of the plant converted to oxygen firing operation (Case 2b). The cooling tower for Case 2a is sized based on the capture ready plant design heat duty with space provisions for future expansion. As a part of Oxyfuel conversion and to accommodate increased heat duty, a third circulating water pump will be added, the cooling tower basin area will be increased, and the cooling tower will be expanded by four additional cells.

\subsection{Makeup Water Treatment System}

The makeup water treatment system provides high quality demineralized water for makeup to the condensate system. The principal function of the system is to purify the supply water for delivery to the condensate receiver tank. The demineralized water storage tank is provided in the system to receive or supply water to the system to accommodate volume changes due to transient operating conditions. Filtered water from municipal or ground water sources will supply the cycle makeup water treatment system. The system makeup water treatment system is comprised of ion exchange (IX) softeners and demineralization trains. One train normally operates, with one train on standby. Each train consists of a reverse osmosis (RO) membrane assembly and an electrodeionization (EDI) membrane assembly. Associated chemical feed equipment and a clean-in-place (CIP) system are common to the trains.

Filtered water is directed to the softeners for removal of scale-forming calcium and magnesium that would otherwise concentrate in and plug the RO membranes. Additionally, chemicals are injected into the softened water prior to the RO system to further protect the RO membranes from scaling or degradation.

A replaceable cartridge filter at each train assembly provides the fine filtration necessary to prevent suspended solids from plugging the RO membranes.

An RO booster pump is provided for each RO train to increase the pressure of the water supply entering the $\mathrm{RO}$ membranes. The reject water from the operating RO trains is discharged to the cooling tower basin to make up for evaporation and blowdown losses. The water exiting the $\mathrm{RO}$ trains is passed through the operating EDI units for final demineralization. The concentrate and reject water from the EDI units is discharged to the cooling tower basin along with the RO reject. A portion of concentrate may be recycled back to the inlet of the RO trains pending final design considerations. The EDI product water is transferred to the demineralized water storage tank. 


\subsection{Ducting and Stack}

One stack is provided with two fiberglass-reinforced plastic (FRP) liners (one per boiler). The

stack is constructed of reinforced concrete, with an outside diameter at the base of 70 feet. The stack is 500 feet high for adequate particulate dispersion. The stack has two FRP liners, each 17 feet in diameter.

\subsection{Wastewater Treatment System}

The wastewater treatment and discharge system collects various wastewater streams from the power plant, treats those wastewater streams requiring $\mathrm{pH}$ adjustment or oil removal, and discharges the combined wastewater to the municipal sewer system. The combined wastewater discharge will be continuously monitored for flow, temperature, and $\mathrm{pH}$. The combined discharge will be periodically sampled and analyzed as required by the municipal sewer authority.

Wastewater streams, which may at times be below a pH of 6 (acidic) or above a $\mathrm{pH}$ of 9 (alkaline), will be directed to a wastewater neutralization system. Such streams include coal dumper sump pump discharge, sulfuric acid storage tank dike and tank truck unloading areas rainfall, and reverse osmosis clean-in-place spent solutions. Sulfuric acid or caustic will be metered into the wastewater to automatically adjust the wastewater $\mathrm{pH}$ within the 6 to 9 range for discharge to the municipal sewer system.

Wastewater streams that potentially could contain oil and grease will be directed to an oil/water separator. Such streams include turbine building and boiler area floor drains, transformer dike rainfall, and oil storage tank dike and unloading area rainfall. Oil that floats to the top of the separator will be periodically pumped to a tank truck for offsite disposal. Treated water (separator underflow) will be discharged to the municipal sewer system.

Neutral, oil-free wastewater streams will be discharged to the municipal sewer system without pre-treatment. These streams generally will contain higher concentrations of dissolved solids and include boiler and cooling tower blowdown, softener and condensate polisher regeneration wastes, and water treatment building floor drains.

All wastewater streams will be directed to a wastewater monitoring manhole. Flow, temperature, and $\mathrm{pH}$ will be monitored. As required by the municipal sewer authority, wastewater samples will be periodically taken and analyzed.

\subsection{Miscellaneous Systems}

Miscellaneous systems consisting of startup natural gas, service air, instrument air, and service water are provided. A natural gas system is used for startup and for a small auxiliary boiler.

\subsection{Buildings and Structures}

The development of the plant site to incorporate the new structures required for this technology is based on the assumption of a flat site. Foundations are provided for the support structures, pumps, tanks, and other plant components. The following buildings are included in the design: 


$\begin{array}{lll}\text { Steam turbine building } & >\text { Makeup water building } & >\text { Guard house } \\ \text { Boiler building } & >\text { Machine shop building } & >\text { Coal crusher building } \\ \text { Warehouse } & >\text { Waste treatment building }>\text { Circulating water pump house } \\ \text { Continuous emissions } & >\text { Administration and } \\ \text { monitoring building } & \text { service building }\end{array}$

\subsection{Accessory Electric Plant}

The accessory electric plant for all cases consists of switchgear and control equipment, generator equipment, station service equipment, conduit and cable trays, and wire and cable. It also includes the main power transformer, required foundations, and standby equipment.

The plant voltage distribution system assumed in this study is presented in Table 6-11.

Table 6-11: Plant Voltage Distribution

\begin{tabular}{|l|l|}
\hline Motors below $1 \mathrm{hp}$ & $110 / 220$ volt \\
\hline Motors $250 \mathrm{hp}$ and below & 480 volt \\
\hline Motors above $250 \mathrm{hp}$ & 4,160 volt \\
\hline Motors above $5,000 \mathrm{hp}$ & 13,800 volt \\
\hline Steam Turbine generators & 24,000 volt \\
\hline Grid Interconnection voltage & $345 \mathrm{kV}$ \\
\hline
\end{tabular}

\subsection{Instrumentation and Control}

An integrated plant-wide control and monitoring distributed control system (DCS) is provided for all cases. The DCS is a redundant microprocessor-based, functionally distributed system. The control room houses an array of multiple video monitor and keyboard units. The monitor/keyboard units are the primary interface between the generating process and operations personnel. The DCS incorporates plant monitoring and control functions for all the major plant equipment. The DCS is designed to provide 99.5 percent availability. The plant equipment and the DCS are designed for automatic response to load changes from minimum load to 100 percent. Startup and shutdown routines are implemented as supervised manual, with operator selection of modular automation routines available.

\subsection{Balance of Plant Auxiliary Loads}

A summary of auxiliary loads associated with the balance of plant equipment is presented in Table 6-12. 
Table 6-12: Balance of Plant Auxiliary Loads

\begin{tabular}{|c|c|c|c|c|}
\hline BOP AUXILIARY LOAD SUMMARY, kWe & Case 1a & Case 1b & Case 2a & Case 2b \\
\hline Estimated Subtotal Miscellaneous BOP loads @ 480 V & 2,009 & 2,009 & 2,008 & 2,683 \\
\hline \multicolumn{5}{|l|}{ 4.16 kV Auxiliary Loads } \\
\hline Coal handling & 2,479 & 2,533 & 2,474 & 2,891 \\
\hline \multirow[b]{2}{*}{ 2b) } & & & & \\
\hline & 843 & 231 & 842 & 300 \\
\hline Circulating Water Pump & 6,400 & 6,795 & 6,400 & 9,600 \\
\hline Cooling Tower Fans & 1,611 & 1,710 & 1,611 & 2,327 \\
\hline Condensate pump & 1,010 & 1,010 & 1,010 & 1,300 \\
\hline Air Compressor & 417 & 417 & 417 & 417 \\
\hline FW Pump (Steam turbine driven) & 0 & 0 & 0 & 0 \\
\hline Ash Handling & $\underline{636}$ & 809 & 633 & $\underline{1,050}$ \\
\hline Subtotal Electrically-Driven BOP Auxiliaries@ @ 4.16 kV & 13,394 & 13,505 & 13,386 & 17,884 \\
\hline Auxiliary Step-down Transformer 24 kV/4160 V & 77 & 77 & 77 & 103 \\
\hline Subtotal BOP Auxiliary Loads @ 24 kV & 18,727 & 18,727 & 18,723 & 25,436 \\
\hline Estimated Main Step-Up Transformer 24 kV/345 V & 1,877 & 1,877 & 1,878 & 1,896 \\
\hline
\end{tabular}

\subsection{General Arrangement}

The site is designed to be accessible by automobile and railroads. The CFB plant components are arranged in several technological islands separated by access roads and with adequate space for construction, operations, and maintenance. Major technological islands include:

Coal Handling Island: $\quad$ Coal receiving, storage and reclaim systems

Sorbent Handling: $\quad$ Sorbent receiving, storage and reclaim

Power Island: $\quad$ CFB boilers and steam turbine systems

Balance of Plant Island: Cooling tower, water storage and treatment systems

Switch Yard: High and medium voltage electrical equipment

Waste Water Treatment: Waste treatment and coal pile runoff ponds, waste treatment building

Oxidant Island: $\quad$ Air Separation unit and air compressors

Gas Processing Island: $\quad \mathrm{CO}_{2}$ compression and conditioning systems

In the Capture Ready layout (Case 2a), space allowances are provided for the future conversion to oxygen firing and $\mathrm{CO}_{2}$ capture and compression. Those space allowances include:

o Space allowance for ASU Island

o Space allowance for Gas Processing Island

o Space allowance for cooling tower extension

o Larger Boiler and Steam turbine buildings

o Larger Coal storage area

Estimated space requirement for the new air-fired CFB facility (Case 1a) is approximately 155 acres, excluding railroad loop and buffer zone. The capture ready (Case 2a) and converted oxygen-fired plants (Cases 1b and 2b) designs would require an estimated 168 acres each.

Site general arrangement drawings are presented in Section 10.1.3 


\section{COST ESTIMATES}

The plant investment cost estimate summaries, including engineering, procurement, and construction (EPC basis), are shown in this section for the four (4) power plants included in this study. The EPC basis does not include owner's costs. Owner's costs are, however, included in the economic analysis (Section 8). Operating and Maintenance costs are also shown in this section. All costs are expressed in May 2007 dollars. The level of accuracy of the cost estimates for these conceptual level designs is expected to be about +/- 30 percent.

\subsection{Investment Cost Basis:}

The power plants in this study are assumed to be constructed on a common Greenfield site in the Gulf Coast region of southeastern Texas. The boundary limit for these plants includes the complete plant facility within the "fence line". It includes the coal receiving and water supply systems and terminates at the high-voltage side of the main power transformers.

The EPC costs for these cases include all required equipment, including the traditional Boiler Island equipment (including the draft system and gas clean-up system), and Balance of Plant equipment (steam turbine/generator, condensate and feedwater system, material handling, cooling, electrical, instrumentation and control, and miscellaneous). The cases with oxygen firing and $\mathrm{CO}_{2}$ capture include the air separation unit (ASU) and gas processing system (GPS) but do not include the $\mathrm{CO}_{2}$ pipeline and $\mathrm{CO}_{2}$ injection well.

The cost estimates include equipment, materials, labor, indirect construction costs, and engineering. The labor cost to install the equipment and materials was estimated on the basis of labor man-hours. The labor costing approach was a multiple contract labor basis with the labor cost including direct and indirect labor cost plus fringe benefits and allocations for contractor expenses and markup.

The costs included in the Engineering, Construction Management (CM), Home Office (H.O.) \& Fee category consists of professional services and "other costs". Professional services include the cost for engineering, construction management, and startup assistance. The engineering services include all preliminary and detailed engineering and design for the total plant scope. It includes specifying equipment for purchase, procurement, performing project scheduling and cost control services for the project; providing engineering and design liaison during the construction period; and providing startup support. Construction management (CM) services cost includes a field management staff capable of performing all field contract administration; field inspection and quality assurance; project construction control; safety and medical services as required; field and construction insurance administration, field office clerical and administrative support. The "other costs” category includes a cost allowance for freight costs, heavy haul, insurance, taxes, and indirect startup spares.

The investment cost estimates for these plants were calculated based on a combination of vendorfurnished quotes and cost estimating database values. The CFB Boiler costs were estimated based on calculated material weights for all components, conceptual equipment arrangement drawings, and equipment lists which were developed as a part of the conceptual design of the required equipment.

The following assumptions were made in developing the EPC cost estimates for each concept evaluated: 
o Investment costs are expressed in May 2007 US dollars

o Construction labor rates are based on Gulf Coast non-union rates

o The plant is constructed on a Greenfield site in southeastern Texas

0 All costs are based on mature level ( $\mathrm{n}^{\text {th }}$ plant) commercial design

o Owners costs (including interest during construction, start-up fuel, land, land rights, plant licensing, permits, etc.) are not included in the investment costs but are included in the Cost of Electricity analysis

o Ash is to be shipped off site with provisions for short-term storage only

o Investment in new utility systems is outside the scope

o No special limitations for transportation of large equipment

o No protection against unusual airborne contaminants (dust, salt, etc.)

o No unusual wind storms

o No earthquakes

o No piling required

o Annual operating time is $7008 \mathrm{~h} / \mathrm{yr}$ (80 percent capacity factor).

o The investment cost estimate was developed as a factored estimate based on a combination of vendor quotes and in-house data for the major equipment. Such an estimate can be expected to have an accuracy of $+/-30$ percent.

o No purchases of utilities or charges for shutdown time have been charged against the project.

Other exclusions from the EPC investment cost estimate are as follows:

o Fuels required for startup

o Relocation or removal of buildings, utilities, and highways

o Permits

o Land and land rights

o Soil investigation

o Environmental Permits

o Disposal of hazardous or toxic waste

o Disposal of existing materials

o Custom's and Import duties

o Sales/Use tax.

o Forward Escalation

o Capital spare parts

o Chemical loading facilities

o Financing cost

o Owners costs

o Guards during construction

- Site Medical and Ambulance service

o Cost \& Fees of Authorities

o Overhead High voltage feed lines

o Cost to run a natural gas pipeline to the plant

o Excessive piling

o $\mathrm{CO}_{2}$ pipeline and injection well 
Overall plant investment costs and the associated specific plant investment costs $(\$ / \mathrm{kW})$ can vary quite significantly for any given plant design depending on several factors. Some of the more important factors are listed below.

o Plant Location and Site Conditions

o Construction Labor Basis

o Coal Analysis

o Ambient Conditions

For the cases in this study, the design coal analysis, design ambient conditions, plant location and site conditions are described in Section 2.1 under Plant Design Basis. The construction labor basis used is Gulf Coast non-union.

\subsection{Operating and Maintenance Costs Basis:}

Operating and Maintenance (O\&M) costs are calculated for each plant and are listed as either fixed or variable. The fixed costs are those costs that are incurred irrespective of the number of hours of plant operation, whereas the variable costs are directly proportional to the operating hours. The variable operating and maintenance (VOM) costs for the new equipment included such categories as chemicals, waste handling, maintenance material and labor, supplemental fuel usage, and contracted services. The fixed operating and maintenance (FOM) costs for the new equipment includes operating labor only.

The O\&M costs for the power plant equipment were developed quantitatively by WorleyParsons and ALSTOM.

\subsubsection{Operating Labor Cost Basis:}

Operating labor cost was calculated based on the number of operator jobs (O.J.) required. Table 7-1 shows the operating labor requirements for these Greenfield power plants. There are four (4) equivalent shits per day. Hence, this particular plant employs sixty-five (65) full-time personnel.

Table 7-1: Operating Labor Requirements

\begin{tabular}{|l|r|r|}
\hline Operating Labor Requirements (O.J.) per equivalent shift & 1 unit/mod & Total Plant \\
\hline Skilled Operator & 2 & 2 \\
\hline Operator & 11.3 & 11.3 \\
\hline Foreman & 1 & 1 \\
\hline Lab Tech's & 2 & 2 \\
\hline TOTAL Operator Jobs (O.J.’s) & 16.3 & 16.3 \\
\hline
\end{tabular}

The average labor rate used to determine the annual cost was $33.00 \$ / \mathrm{hr}$, with a labor burden of 30 percent. The labor administration and overhead cost was assessed at a rate of 25 percent of the O\&M labor. Maintenance cost was evaluated as a percentage of the initial capital cost. 


\subsubsection{Consumable Costs Basis:}

Consumable costs including fuel, limestone, lime, water, and chemicals were determined on the basis of individual flow rates as listed in the material and energy balances, individual unit costs (listed below), and the plant annual operating hours. Waste disposal cost was also based on flow rates from the material and energy balances, unit costs, and operating hours. By-product credits were not considered for these cases.
o Coal cost:
1.52 \$/MM-Btu
o Limestone cost:
15.00 \$/Ton
o Lime cost:
85.00 \$/Ton
o Water cost:
$1.03 \$ / 1,000$ gallons
o Water treatment chemicals cost:
$0.16 \$ / \mathrm{lbm}$
o Ash Disposal cost:
15.45 \$/Ton
0 By-product credits were not considered for these cases

\subsection{Total Plant Investment Costs:}

The total plant investment cost summaries for the four (4) Greenfield plants are shown in Table 7-2 and these results are illustrated in Figure 7-1. The costs shown for the retrofit cases (Cases $1 \mathrm{~b}$ and 2b) include both the original costs for the unmodified plant plus the additional costs to convert the plant to oxygen firing and $\mathrm{CO}_{2}$ capture. The costs are broken down into fourteen (14) separate accounts. Further breakdowns of these costs are provided in an appendix (Section 10.3). These costs were developed consistent with the approach and basis identified in the design basis and investment cost basis. The investment cost estimates (EPC basis) are expressed in May 2007 dollars.

Table 7-2: Total Plant Investment Cost Summary (EPC basis)

\begin{tabular}{|c|c|c|c|c|c|c|c|c|c|}
\hline \multirow{2}{*}{$\begin{array}{l}\text { Acct } \\
\text { No. }\end{array}$} & \multirow{2}{*}{$\begin{array}{c}\text { Total Plant Cost Summary } \\
\text { Item/Description }\end{array}$} & \multicolumn{2}{|c|}{ Case 1a } & \multicolumn{2}{|c|}{ Case 1b } & \multicolumn{2}{|c|}{ Case 2a } & \multicolumn{2}{|c|}{ Case 2b } \\
\hline & & $\$ \times 1000$ & $\$ / \mathrm{kW}$ & $\$ \times 1000$ & $\$ / k W$ & $\$ \times 1000$ & $\$ / \mathrm{kW}$ & $\$ \times 1000$ & $\$ / \mathrm{kW}$ \\
\hline 1 & COAL \& SORBENT HANDLING & 41,010 & 65 & 44,451 & 94 & 41,010 & 64 & 44,451 & 72 \\
\hline 2 & COAL \& SORBENT PREP \& FEED & 16,807 & 26 & 16,807 & 35 & 16,807 & 26 & 16,807 & 27 \\
\hline 3 & FEEDWATER \& MISC. BOP SYSTEMS & 74,155 & 117 & 80,267 & 169 & 86,626 & 136 & 92,738 & 149 \\
\hline 4 & CFB BOILER \& ACCESSORIES & 350,175 & 551 & 353,236 & 743 & 356,036 & 560 & 372,825 & 601 \\
\hline $4 a$ & Air Separation Unit & $\mathrm{n} / \mathrm{a}$ & $\mathrm{n} / \mathrm{a}$ & 226,005 & 476 & $\mathrm{n} / \mathrm{a}$ & $\mathrm{n} / \mathrm{a}$ & 278,730 & 449 \\
\hline 5 & FLUE GAS CLEANUP & 53,068 & 83 & 109,068 & 230 & 53,068 & 83 & 109,068 & 176 \\
\hline $5 a$ & CO2 Processing System (Purif, Compr, Liquef) & $\mathrm{n} / \mathrm{a}$ & $\mathrm{n} / \mathrm{a}$ & 130,916 & 276 & $\mathrm{n} / \mathrm{a}$ & $\mathrm{n} / \mathrm{a}$ & 148,004 & 239 \\
\hline 6 & COMBUSTION TURBINE/ACCESSORIES & $\mathrm{n} / \mathrm{a}$ & $\mathrm{n} / \mathrm{a}$ & $\mathrm{n} / \mathrm{a}$ & $\mathrm{n} / \mathrm{a}$ & $\mathrm{n} / \mathrm{a}$ & $\mathrm{n} / \mathrm{a}$ & $\mathrm{n} / \mathrm{a}$ & $\mathrm{n} / \mathrm{a}$ \\
\hline 7 & HRSG, DUCTING \& STACK & 34,983 & 55 & 34,983 & 74 & 34,983 & 55 & 38,866 & 63 \\
\hline 8 & STEAM TURBINE GENERATOR / PIPING & 107,981 & 170 & 108,273 & 228 & 119,104 & 187 & 151,895 & 245 \\
\hline 9 & COOLING WATER SYSTEM & 28,767 & 45 & 30,540 & 64 & 30,732 & 48 & 38,422 & 62 \\
\hline 10 & ASH/SPENT SORBENT HANDLING SYS & 18,723 & 29 & 18,723 & 39 & 18,723 & 29 & 22,033 & 36 \\
\hline 11 & ACCESSORY ELECTRIC PLANT & 33,588 & 53 & 55,655 & 117 & 33,588 & 53 & 62,240 & 100 \\
\hline 12 & INSTRUMENTATION \& CONTROL & 24,399 & 38 & 29,423 & 62 & 24,399 & 38 & 29,423 & 47 \\
\hline 13 & IMPROVEMENTS TO SITE & 12,785 & 20 & 15,268 & 32 & 12,785 & 20 & 15,268 & 25 \\
\hline 14 & BUILDINGS \& STRUCTURES & 61,691 & 97 & 64,939 & 137 & 69,221 & 109 & 72,469 & 117 \\
\hline & TOTAL COST & 858,132 & 1,350 & $1,318,554$ & 2,775 & 897,081 & 1,410 & $1,493,238$ & 2,406 \\
\hline
\end{tabular}

As shown in Table 7-2, the EPC specific investment cost of Case 1a (Base-Case CFB plant burning an Eastern medium volatile bituminous coal) is $1350 \$ / \mathrm{kW}$ net. Comparatively, Booras and Holt (2006) report an EPC investment cost of 1395 \$/kWe net for a 500-MW ultra supercritical (USC) pulverized coal (PC) plant burning the Illinois \#6 high volatile bituminous coal. It must be emphasized here that:

o The two plants cited above are reference, air-fired, and non- $\mathrm{CO}_{2}$ capture plants

o The two EPC investment costs, also known as total plant costs (TPC), reported above do 
not include the owner's costs (e.g., Pre-production cots, working capital, land, license fees, interest during construction). Booras and Holt (2006) estimate that the total capital requirement (TCR) costs, i.e., EPC costs + owner's cost, are 16-19\% higher than the EPC costs.

o TPC is strongly dependent on, among other things, the site on which the plant is built. For example, the basis of the $1350 \$ / \mathrm{kW}$ value obtained in this study is U.S. Gulf-Coast, with non-union labor used for its construction. If this site were shifted to, say, Ohio Valley, using unionized labor for its construction, the cost could be $\sim 25 \%$ higher or $\sim 1690 \$ / \mathrm{kW}$.

Figure 7-1 shows six graphs, which provide cost breakdowns for the four cases. The upper left graph shows the total plant investment cost (\$/kWe-net), which includes all the accounts shown in Table 7-2. The upper right graph shows the boiler island cost (\$/kWe-net), which includes accounts 4, 4a, 5, 5a, and 7 shown in Table 7-2. The middle left graph shows the steam cycle system cost (\$/kWe-net), which includes accounts 3, 8, and 9 shown in Table 7-2. The middle right graph shows the solids handling systems cost (\$/kWe-net), which includes accounts 1 , 2, and 10 shown in Table 7-2. The lower left graph shows the electrical equipment cost (\$/kWe-net), which includes accounts 11 and 12 shown in Table 7-2. The lower right graph shows the miscellaneous costs (\$/kWe-net), which include accounts 13 and 14 shown in Table 7-2. 

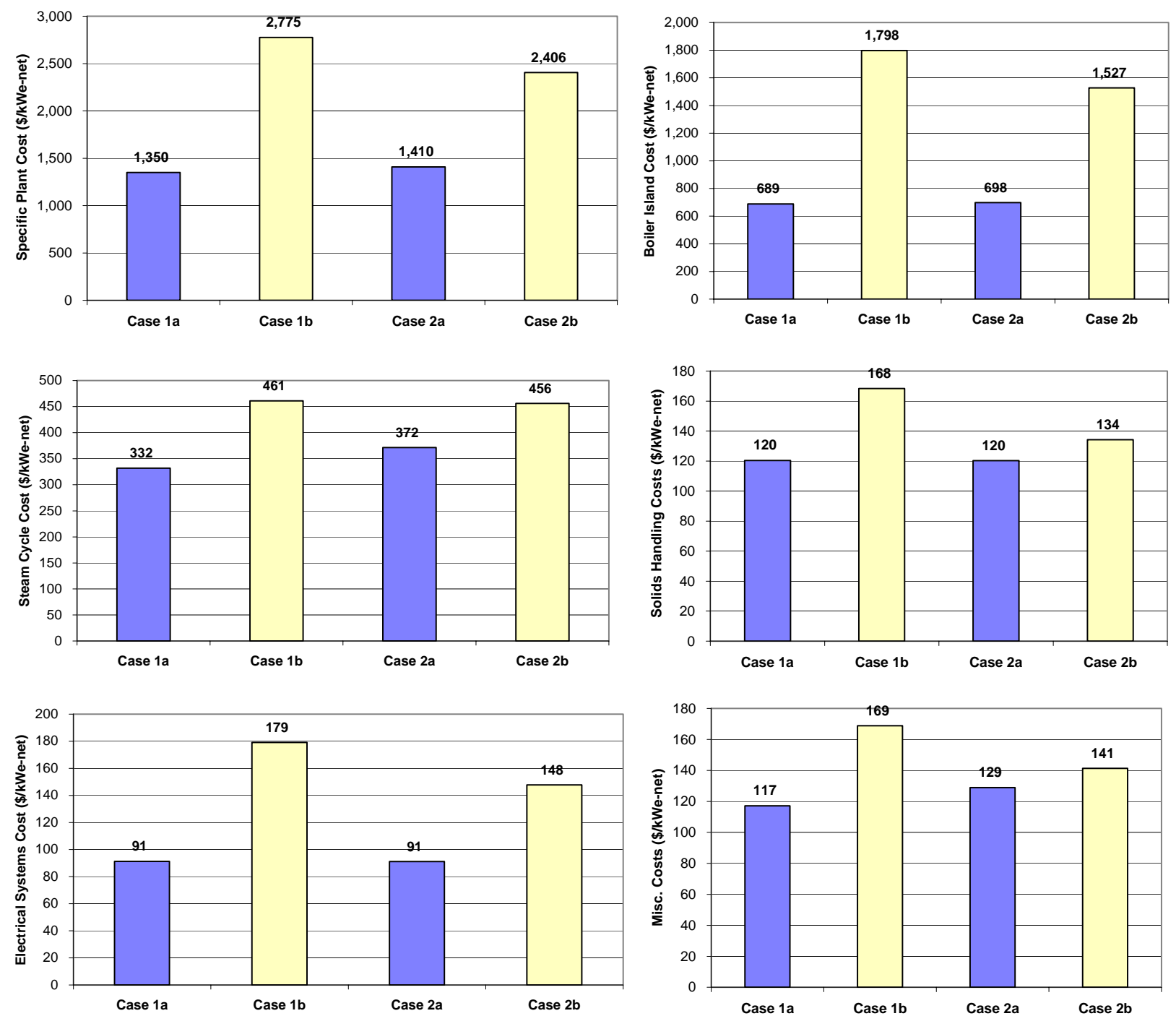

Figure 7-1: Power Plant Investment Costs (EPC Basis)

The upper left graph of Figure 7-1 shows the advantage of the capture ready design, which includes the impact of the additional steam generation used to maintain the net output. Comparison of the total power plant costs for Cases $1 \mathrm{a}$ and 2a shows that the capture ready design requires a relatively small pre-investment of about 4.5 percent. Some of this pre-investment cost is provided for the future conversion of the plant to oxygen firing and $\mathrm{CO}_{2}$ capture. Additionally, part of the pre-investment for Case 2a is to also allow an increase in the gross electrical output from the plant of about 32 percent when the plant is retrofitted with oxygen firing and $\mathrm{CO}_{2}$ capture. The increase in gross output is provided to offset the additional auxiliary power consumption of the ASU and GPS systems. In this manner, the plant net electrical output is maintained after the conversion is completed. Comparison of Cases $1 \mathrm{~b}$ and $2 \mathrm{~b}$ shows the effectiveness of the Case $2 \mathrm{~b}$ capture ready design (after conversion to oxygen firing and $\mathrm{CO}_{2}$ capture) as compared to the Case $1 \mathrm{~b}$ capture unready design. The specific plant cost $(\$ / \mathrm{kWe})$ is reduced by about 14 percent for Case $2 \mathrm{~b}$ as compared to Case $1 \mathrm{~b}$. 
The non capture-ready plant retrofit cost (EPC basis - May 2007 \$US) is estimated to be about $969 \$ / \mathrm{kW}$-new, based on the new power output (i.e. the total retrofit cost divided by the new net output). There is also an additional specific cost (\$/kW-new) impact associated with the value of the existing plant equipment. Because the retrofitted plant produces less net output, the specific cost $(\$ / \mathrm{kW}$-new) of the existing plant equipment is increased. If this cost for the existing plant equipment is included, the total non capture-ready plant retrofit cost is estimated to be about 1,425 $\$ / \mathrm{kW}$-new.

Modifications to the existing boiler are relatively minor as mentioned above and cost only about 6 $\$ / \mathrm{kW}$-new. The new Flash Dryer Absorber $\mathrm{SO}_{2}$ removal system costs 118 \$ $/ \mathrm{kW}$-new. The remaining costs - nearly $78 \%$ of the total retrofit cost - are for the cryogenic air separation and gas processing systems. Though costly, these systems are commercially proven and technically straightforward.

The capture-ready plant retrofit cost is estimated to be about $961 \$ / \mathrm{kW}$-new, based on the new power output (i.e. the total retrofit cost divided by the new net output). In this case, there is no additional specific cost ( $\$ / \mathrm{kW}$-new) associated with the value of the existing plant equipment (as there was for the non capture ready retrofit) because the plant still produces the same net output as it did before the retrofit.

\subsubsection{BOP Cost and Scope Differences Between the Cases}

Table 7-3 is provided below to help define the cost and scope differences between the cases for the balance of plant (BOP) equipment. 
COMMERCIALIZATION DEVELOPMENT OF OXYGEN FIRED

Table 7-3: BOP Cost and Scope Differences Between the Cases

\begin{tabular}{|c|c|c|c|c|c|c|c|c|}
\hline \multirow[t]{2}{*}{ Acct } & \multirow[t]{2}{*}{ Item/Description } & \multirow[t]{2}{*}{ Case 1a } & \multirow[t]{2}{*}{ Case 2a } & \multicolumn{2}{|c|}{$\begin{array}{c}\text { Differences Between } \\
\text { Cases } 1 \text { and 2a } \\
\end{array}$} & \multirow[t]{2}{*}{ Case 2b } & \multicolumn{2}{|c|}{$\begin{array}{l}\text { Differences Between } \\
\text { Cases 2a and 2b } \\
\end{array}$} \\
\hline & & & & $\Delta(\mathbf{2 a}-1 \mathbf{a})$ & Scope & & $\Delta(2 b-2 a)$ & Scope \\
\hline 1 & $\begin{array}{l}\text { COAL \& SORBENT } \\
\text { HANDLING }\end{array}$ & $\$ 41,010$ & $\$ 41,010$ & $\$ 0$ & & $\$ 44,451$ & $\$ 3,441$ & $\begin{array}{l}\text { New lime handling system is } \\
\text { added }\end{array}$ \\
\hline 2 & $\begin{array}{l}\text { COAL \& SORBENT PREP } \\
\& \text { FEED }\end{array}$ & $\$ 16,807$ & $\$ 16,807$ & $\$ 0$ & & $\$ 16,807$ & $\$ 0$ & \\
\hline 3 & $\begin{array}{l}\text { FEEDWATER \& MISC. } \\
\text { BOP SYSTEMS }\end{array}$ & $\$ 74,155$ & $\$ 86,626$ & $\$ 12,471$ & $\begin{array}{l}\text { Condensate pumps, } \\
\text { deaerator, HP FW } \\
\text { heaters with associated } \\
\text { piping systems have been } \\
\text { sized to meet future } \\
\text { higher flow rate of the } \\
\text { plant converted to oxygen } \\
\text { firing operation. }\end{array}$ & $\$ 92,738$ & $\$ 6,112$ & $\begin{array}{l}\text { Accounts for additional service } \\
\text { water, natural gas, waste } \\
\text { water treatment, boiler plant } \\
\text { auxiliaries and other } \\
\text { miscellaneous equipment }\end{array}$ \\
\hline $\begin{array}{c}4 \\
4.1 \\
4.2 \\
4.3 \\
4.4-4.9\end{array}$ & $\begin{array}{l}\text { FLUIDIZED BED BOILER } \\
\text { Fluidized Bed Boiler, w/o } \\
\text { Bag House \& Accessories } \\
\text { Air Separation Unit } \\
\text { Open } \\
\text { Boiler BOP } \\
\quad \text { SUBTOTAL } 4\end{array}$ & $\begin{array}{r}\$ 0 \\
\$ 0 \\
\$ 0 \\
\$ 0 \\
\$\end{array}$ & $\begin{array}{l}\$ 0 \\
\$ 0 \\
\$ 0 \\
\$ 0 \\
\$ 0\end{array}$ & $\begin{array}{l}\$ 0 \\
\$ 0 \\
\$ 0 \\
\$ 0 \\
\$ 0\end{array}$ & & $\begin{array}{l}\$ 0 \\
\$ 0 \\
\$ 0 \\
\$ 0 \\
\$ 0\end{array}$ & $\begin{array}{l}\$ 0 \\
\$ 0 \\
\$ 0 \\
\$ 0 \\
\$ 0\end{array}$ & \\
\hline 5 & FLUE GAS CLEANUP & $\$ 3,068$ & $\$ 3,068$ & $\$ 0$ & & $\$ 3,068$ & $\$ 0$ & \\
\hline $5 B$ & $\begin{array}{l}\text { CO2 REMOVAL \& } \\
\text { COMPRESSION }\end{array}$ & $\$ 0$ & $\$ 0$ & $\$ 0$ & & $\$ 0$ & $\$ 0$ & $\begin{array}{l}\mathrm{CO}_{2} \text { removal foundation } \\
\text { included in Account } 14 .\end{array}$ \\
\hline $\begin{array}{c}6 \\
6.1 \\
6.2-6.9\end{array}$ & $\begin{array}{l}\text { COMBUSTION } \\
\text { TURBINE/ACCESSORIES } \\
\text { Combustion Turbine } \\
\text { Generator } \\
\text { Combustion Turbine } \\
\text { Accessories } \\
\quad \text { SUBTOTAL } 6\end{array}$ & $\begin{array}{l}\$ 0 \\
\$ 0\end{array}$ & $\begin{array}{l}\$ 0 \\
\$ 0\end{array}$ & $\begin{array}{l}\$ \\
\$ 0 \\
\$ 0\end{array}$ & & $\begin{array}{l}\$ 0 \\
\$ 0\end{array}$ & $\begin{array}{l}\$ 0 \\
\$ 0 \\
\$ 0\end{array}$ & \\
\hline
\end{tabular}


COMMERCIALIZATION DEVELOPMENT OF OXYGEN FIRED CFB FOR GREENHOUSE GAS CONTROL

\begin{tabular}{|c|c|c|c|c|c|c|c|c|}
\hline \multirow[t]{2}{*}{ Acct } & \multirow[t]{2}{*}{ Item/Description } & \multirow[t]{2}{*}{ Case 1a } & \multirow[t]{2}{*}{ Case 2a } & \multicolumn{2}{|c|}{$\begin{array}{l}\text { Differences Between } \\
\text { Cases } 1 \text { and 2a }\end{array}$} & \multirow[t]{2}{*}{ Case 2b } & \multicolumn{2}{|c|}{$\begin{array}{l}\text { Differences Between } \\
\text { Cases 2a and 2b }\end{array}$} \\
\hline & & & & $\Delta(\mathbf{2 a}-1 \mathbf{a})$ & Scope & & $\Delta(2 b-2 a)$ & Scope \\
\hline $\begin{array}{c}7 \\
7.1 \\
7.2-7.9\end{array}$ & $\begin{array}{l}\text { HRSG, DUCTING \& } \\
\text { STACK } \\
\text { Heat Recovery Steam } \\
\text { Generator } \\
\text { HRSG Accessories, } \\
\text { Ductwork and Stack } \\
\text { SUBTOTAL } 7\end{array}$ & $\begin{array}{r}\$ 0 \\
\$ 34,983 \\
\$ 34,983\end{array}$ & $\begin{array}{r}\$ 0 \\
\$ 34,983 \\
\$ 34,983\end{array}$ & $\begin{array}{l}\$ 0 \\
\$ 0 \\
\$ 0\end{array}$ & & $\begin{array}{r}\$ 0 \\
\$ 38,866 \\
\$ 38,866\end{array}$ & $\begin{array}{r}\$ 0 \\
\$ 3,883 \\
\$ 3,883\end{array}$ & $\begin{array}{l}\text { Oxygen and } \mathrm{CO}_{2} \text { ductwork, } \\
\text { foundation for Alstom } \\
\text { recirculation ductwork. }\end{array}$ \\
\hline $\begin{array}{c}8 \\
8.1 \\
8.2-8.9\end{array}$ & $\begin{array}{l}\text { STEAM TURBINE } \\
\text { GENERATOR } \\
\text { Steam TG \& Accessories } \\
\text { Turbine Plant Auxiliaries and } \\
\text { Steam Piping } \\
\text { SUBTOTAL } 8\end{array}$ & $\begin{array}{r}\$ 0 \\
\$ 48,181 \\
\$ 48,181\end{array}$ & $\begin{array}{r}\$ 0 \\
\$ 59,304 \\
\$ 59,304\end{array}$ & $\begin{array}{r}\$ 0 \\
\$ 11,123 \\
\\
\$ 11,123\end{array}$ & $\begin{array}{l}\text { Condenser system has } \\
\text { been sized to meet future } \\
\text { higher flow rate of the } \\
\text { plant converted to Oxyfuel } \\
\text { operation }\end{array}$ & $\begin{array}{r}\$ 0 \\
\$ 59,595 \\
\$ 59,595\end{array}$ & $\begin{array}{r}\$ 0 \\
\$ 292 \\
\\
\$ 292\end{array}$ & $\begin{array}{l}\text { Increase in capacity of } \\
\text { miscellaneous auxiliary } \\
\text { systems due to increase in } \\
\text { STG generating capacity }\end{array}$ \\
\hline 9 & $\begin{array}{l}\text { COOLING WATER } \\
\text { SYSTEM }\end{array}$ & $\$ 28,767$ & $\$ 30,732$ & $\$ 1,965$ & $\begin{array}{l}\text { Piping has been sized to } \\
\text { meet future higher flow } \\
\text { rate of the plant converted } \\
\text { to Oxyfuel operation }\end{array}$ & $\$ 38,422$ & $\$ 7,690$ & $\begin{array}{l}\text { CW pump and has been } \\
\text { added and four-cell cooling } \\
\text { tower extension }\end{array}$ \\
\hline 10 & $\begin{array}{l}\text { ASH/SPENT SORBENT } \\
\text { HANDLING SYS }\end{array}$ & $\$ 18,723$ & $\$ 18,723$ & $\$ 0$ & & $\$ 22,033$ & $\$ 3,309$ & $\begin{array}{l}\text { Bed ash and fly ash } \\
\text { compressors have been } \\
\text { added. Also includes piping, } \\
\text { and instrumentation needed to } \\
\text { connect additional } \\
\text { compressors. }\end{array}$ \\
\hline 11 & $\begin{array}{l}\text { ACCESSORY ELECTRIC } \\
\text { PLANT }\end{array}$ & $\$ 33,588$ & $\$ 33,588$ & $\$ 0$ & & $\$ 62,240$ & $\$ 28,652$ & $\begin{array}{l}\text { Additional equipment } \\
\text { associated with ASU and GPS }\end{array}$ \\
\hline
\end{tabular}


COMMERCIALIZATION DEVELOPMENT OF OXYGEN FIRED CFB FOR GREENHOUSE GAS CONTROL

\begin{tabular}{|c|c|c|c|c|c|c|c|c|}
\hline \multirow[t]{2}{*}{ Acct } & \multirow[t]{2}{*}{ Item/Description } & \multirow[t]{2}{*}{ Case 1a } & \multirow[t]{2}{*}{ Case 2a } & \multicolumn{2}{|c|}{$\begin{array}{l}\text { Differences Between } \\
\text { Cases } 1 \text { and } 2 \text { a }\end{array}$} & \multirow[t]{2}{*}{ Case 2b } & \multicolumn{2}{|c|}{$\begin{array}{l}\text { Differences Between } \\
\text { Cases 2a and 2b }\end{array}$} \\
\hline & & & & $\Delta(\mathbf{2 a}-1 \mathrm{a})$ & Scope & & $\Delta(2 \mathrm{~b}-2 \mathrm{a})$ & Scope \\
\hline 12 & $\begin{array}{l}\text { INSTRUMENTATION \& } \\
\text { CONTROL }\end{array}$ & $\$ 24,399$ & $\$ 24,399$ & $\$ 0$ & & $\$ 29,423$ & $\$ 5,024$ & $\begin{array}{l}\text { Additional equipment } \\
\text { associated with new systems } \\
\text { being added upon oxygen } \\
\text { conversion }\end{array}$ \\
\hline 13 & IMPROVEMENTS TO SITE & $\$ 12,785$ & $\$ 12,785$ & $\$ 0$ & & $\$ 15,268$ & $\$ 2,483$ & $\begin{array}{l}\text { Additional clearing, grubbing, } \\
\text { roads, sidewalks, lighting, and } \\
\text { landscaping. }\end{array}$ \\
\hline 14 & $\begin{array}{l}\text { BUILDINGS \& } \\
\text { STRUCTURES }\end{array}$ & $\$ 61,691$ & $\$ 69,221$ & $\$ 7,530$ & $\begin{array}{l}\text { Reflects increase in } \\
\text { building and foundation } \\
\text { sizes to house } \\
\text { larger/more equipment }\end{array}$ & $\$ 72,469$ & $\$ 3,248$ & $\begin{array}{l}\text { Additional buildings and } \\
\text { foundations to house } \\
\text { larger/more equipment, and } \\
\text { operators. Also includes ASU, } \\
\text { and GPS foundations. }\end{array}$ \\
\hline & TOTAL COST & $\$ 398,156$ & $\$ 431,245$ & $\$ 33,089$ & & $\$ 495,379$ & $\$ 64,134$ & \\
\hline
\end{tabular}




\subsubsection{Incremental Specific Investment Cost (\$/kWe-net) for Case $2 \mathrm{~b}$ :}

Additional comparisons can be made between Cases $1 \mathrm{~b}$ and $2 \mathrm{~b}$ to determine the incremental specific investment cost for the additional power generated for Case $2 \mathrm{~b}$ as detailed below:

o 174,684 Incremental EPC costs $(\$ \times 1,000)$ added to Case $2 \mathrm{~b}$ as compared to Case $1 \mathrm{~b}$

o 145,341 Incremental electrical output (kWe-net) for Case $2 \mathrm{~b}$ as compared to Case $1 \mathrm{~b}$

o 1,202 Incremental specific plant investment cost (\$/kWe-net) for the added net plant electrical output (Note: The added output includes oxygen firing and $\mathrm{CO}_{2}$ capture).

It should be emphasized that this value (\$1,202/kWe-net) for incremental specific plant investment cost (for power that includes almost 94 percent $\mathrm{CO}_{2}$ capture) is quite favorable as compared to any feasible replacement power option (especially with $\mathrm{CO}_{2}$ capture) such as would need to be used for Case 1b. This is demonstrated as follows: The net electrical outputs for Cases $1 \mathrm{a}$ and $1 \mathrm{~b}$ are 635,675 and 475,186 $\mathrm{kW}$, respectively (Table 3-1). Hence, the make up power requirement for Case $1 \mathrm{~b}$ is $160,429 \mathrm{~kW}$. The total EPC investment cost of Case $1 \mathrm{~b}$ is $\$ 1,318,554,000$ (Table $7-2$ ). If the make up power for this plant were provided via the same Case $1 \mathrm{~b}$ plant (with $94 \% \mathrm{CO}_{2}$ capture), then the specific EPC investment cost would be equivalent to 2,775 \$/kW $1,318,554,000 / 475,186)$, which is more than $130 \%$ higher than 1,202 \$/kW.

\subsection{Operating and Maintenance Costs}

The operating and maintenance costs consist of plant operating labor, maintenance (material and labor), an allowance for administrative and support labor, consumables, and solid waste disposal. The operating and maintenance costs and expenses were developed on a first-year basis with a May 2007 plant in-service date. The costs were determined assuming an equivalent plant operating capacity factor of 80 percent.

The operating and maintenance (O\&M) results for the four (4) Greenfield plants are summarized in Table 7-4.

Table 7-4: Operating and Maintenance Cost Summary

\begin{tabular}{|c|c|c|c|c|c|c|c|}
\hline \multirow{3}{*}{ Case Number } & \multicolumn{5}{|c|}{ Operating \& Maintenance (O\&M) Costs } & \multirow{3}{*}{$\begin{array}{c}\text { Annual } \\
\text { Generation } \\
\left(10^{6} \mathrm{kWh}\right)\end{array}$} & \multirow{3}{*}{$\begin{array}{c}\text { Total O\&M } \\
\text { (Cents/kWh) }\end{array}$} \\
\hline & \multicolumn{2}{|c|}{ Fixed } & \multicolumn{2}{|c|}{ Variable @ 80\% CF } & \multirow{2}{*}{$\begin{array}{c}\text { Total } \\
\text { (\$/year) }\end{array}$} & & \\
\hline & (\$/year) & $(\$ / k W)$ & (\$/year) & $(\$ / k W h)$ & & & \\
\hline Case 1a & $11,947,666$ & 18.8 & $21,214,829$ & 0.0048 & $33,162,495$ & 4,455 & 0.744 \\
\hline Case 1 b - Base Case C & $14,236,229$ & 30.0 & $30,566,239$ & 0.0092 & $44,802,468$ & 3,330 & 45 \\
\hline Case 2a - Capture Ready & $12,142,411$ & 19.1 & $21,323,444$ & 0.0048 & $33,465,855$ & 4,459 & 0.751 \\
\hline Case 2b - Capture Ready Converted & $14,430,974$ & 23.3 & $41,001,830$ & 0.0094 & $55,432,804$ & 4,349 & 1.275 \\
\hline
\end{tabular}

The range of total O\&M costs for these four plants are from 0.744 to $1.345 \mathrm{\Phi} / \mathrm{kWh}$. Adding oxygen firing and $\mathrm{CO}_{2}$ capture to these plants adds about $0.5-0.6 \mathbb{\$} / \mathrm{kWh}$. A more detailed breakdown of the O\&M costs for each case including O\&M for the ASU and GPS systems is shown in the appendix (Section 10.3 


\section{ECONOMIC ANALYSIS}

Using an in-house economic model, an analysis was developed comparing the Capture Ready and Capture Unready plant designs for various times of conversion to carbon capture. The model can be operated to calculate either a levelized COE or the net present value (NPV) given the electricity price. The model has been modified to allow modeling of deferred capital investments, such as the addition of a $\mathrm{CO}_{2}$ capture system at some time after the plant went into initial operation.

Technical assumptions include parameters such as the EPC price of the plant, O\&M costs, time horizon, and net plant heat rate. Financial assumptions include items such as the cost of capital (interest rate), terms of the loan, and the required return on investment.

The results are calculated as levelized cost of electricity (COE) and also as a relative net present value (NVP) for the differences between two cases.

Four designs were included:

Case 1a - Capture Unready plant prior to conversion to carbon capture

Case 1b - Capture Unready plant after conversion to carbon capture

Case 2a - Capture Ready plant prior to conversion to carbon capture

Case 2b - Capture Ready plant after conversion to carbon capture

The analysis considered the first 40 years of plant life with conversion to carbon capture occurring from 1 to 20 years after initial startup. Additionally, the cases of never converting to carbon capture were also analyzed.

The common economic assumptions for each case are given in Error! Reference source not found.. Case specific parameters for each case are given in Table 8-2.

Table 8-1: Common Economic Parameters

\begin{tabular}{|l|c|c|}
\hline & Units & All Cases \\
\hline Fuel Price & & \\
\hline Gas Price & $\$ /$ MMBtu & 7.42 \\
\hline Coal Price & $\$ /$ MMBtu & 1.52 \\
\hline SCHEDULES AND GENERATION & & \\
\hline Depreciation Term & yr & 20 \\
\hline Capacity factor & - & $80 \%$ \\
\hline Availability factor & - & $100 \%$ \\
\hline Eq. operating hours at MCR & hrs/yr & 7,008 \\
\hline EQUITY, DEBT AND TAXES & & \\
\hline Discount factor/Minimum required IRR & - & $7.5 \%$ \\
\hline ROE & - & $8.5 \%$ \\
\hline Share of Equity & - & $44 \%$ \\
\hline Share of Debt & - & $56 \%$ \\
\hline Loan Interest Rate During Construction & - & $8.6 \%$ \\
\hline Loan Interest Rate During Operation & - & $6.6 \%$ \\
\hline Loan Up-front Fee & - & $0.0 \%$ \\
\hline Loan Commitment Fee & per year & $0.0 \%$ \\
\hline Loan Tenor (years after construction) & years & 20 \\
\hline Corporate Tax & & $20 \%$ \\
\hline
\end{tabular}


Table 8-2: Case Specific Economic Parameters

\begin{tabular}{|l|c|c|c|c|c|}
\hline \multicolumn{1}{|c|}{ Case } & & 1a & 1b & 2a & 2b \\
\hline & Units & Unready & $\begin{array}{c}\text { Capture } \\
\text { Unready - } \\
\text { Converted }\end{array}$ & $\begin{array}{c}\text { Capture } \\
\text { Ready }\end{array}$ & $\begin{array}{c}\text { Capture } \\
\text { Ready - } \\
\text { Converted }\end{array}$ \\
\hline CO2 TAX \& SALES & & & & & \\
\hline CO2 Production & Lb/kWh & 1.82 & 2.44 & 1.82 & 2.43 \\
\hline CO2 Capture & $\%$ & 0 & 93.7 & 0 & 93.7 \\
\hline CO2 Production & Ton/yr & $4,049,920$ & $4,066,928$ & $4,046,360$ & $5,279,936$ \\
\hline CO2 Emission & Ton/yr & $4,049,920$ & 256,216 & $4,046,360$ & 332,636 \\
\hline CO2 emission permit, initial & Ton/yr & $4,049,920$ & $4,049,920$ & $4,046,360$ & $4,046,360$ \\
\hline CO2 emission permit, final & Ton/yr & 255,145 & 255,145 & 404,636 & 404,636 \\
\hline SCHEDULES AND GENERATION & & & & & \\
\hline Construction period & Months & 48 & 36 & 48 & 36 \\
\hline In operation while in construction & Months & -- & 33 & -- & 33 \\
\hline Net degraded output & $\mathrm{MWe}$ & 635.675 & 475.186 & 636.215 & 620.527 \\
\hline Net plant heat rate, HHV & $\mathrm{Btu} / \mathrm{kWh}$ & 8,881 & 12,228 & 8,866 & 12,156 \\
\hline Total fuel heat input at MCR & $\mathrm{MMBtu} / \mathrm{hr}$ & $5,645.4$ & $5,767.4$ & $5,640.7$ & $7,488.0$ \\
\hline Gas HHV input & $\mathrm{MMBtu} / \mathrm{hr}$ & 0.0 & 43.2 & 0.0 & 55.1 \\
\hline Coal HHV input & $\mathrm{MMBtu} / \mathrm{hr}$ & $5,645.4$ & $5,810.6$ & $5,640.7$ & $7,543.1$ \\
\hline Net generation & $\mathrm{MWh/yr}$ & $4,454,810$ & $3,330,103$ & $4,458,595$ & $4,348,653$ \\
\hline COSTS & & & & & \\
\hline EPC Price & $1000 \$$ & 858,132 & 460,422 & 897,081 & 596,157 \\
\hline Owner's Cost & - & $11.2 \%$ & $10.0 \%$ & $11.2 \%$ & $10.0 \%$ \\
\hline Owner's EPC Cost & $1000 \$$ & 96,111 & 46,042 & 100,473 & 59,616 \\
\hline Total Initial Project Cost & $1000 \$$ & 954,243 & 506,464 & 997,554 & 655,773 \\
\hline Fixed O\&M costs & $\$ / \mathrm{kW}$ & 18.795 & 29.960 & 19.085 & 23.255 \\
\hline Variable O\&M costs & $\$ / \mathrm{kWh}$ & 0.476 & 0.918 & 0.478 & 0.943 \\
\hline Total O\&M costs & $\$ / \mathrm{kWh}$ & 0.744 & 1.345 & 0.751 & 1.275 \\
\hline & & & & & \\
\hline
\end{tabular}

The cost of electricity goes up after conversion of either plant (1a or 2a) to $\mathrm{CO}_{2}$ capture. This is expected due to additional capital cost, increased operating and maintenance cost, and decreased efficiency. To compare different cases, we have calculated the cost of electricity levelized over the first 40 years of plant operation.

Table 8-3 and Figure 8-1 show the levelized COE for the Capture Unready and Capture Ready cases.

Table 8-3: Economic Comparison of Capture Ready and Capture Unready Plants

\begin{tabular}{||c|c|c|c||}
\hline $\begin{array}{c}\text { Year of } \\
\text { Conversion }\end{array}$ & $\begin{array}{c}\text { Case 1b } \\
\text { (Capture } \\
\text { Unready } \\
\text { Converted) }\end{array}$ & $\begin{array}{c}\text { Case 2b } \\
\text { (Capture } \\
\text { Ready } \\
\text { Converted) }\end{array}$ & $\begin{array}{c}\text { Relative } \\
\text { NPV } \\
(2 b \text { Vs. 1b) }\end{array}$ \\
\hline & (Levelized COE, $\$ / k W h)$ & $\left(10^{6} \$\right)$ \\
\hline 1 & 7.08 & 6.51 & 252.6 \\
\hline 5 & 6.25 & 5.89 & 172.0 \\
\hline 10 & 5.51 & 5.33 & 99.1 \\
\hline 15 & 5.01 & 4.94 & 48.3 \\
\hline 20 & 4.66 & 4.67 & 12.9 \\
\hline Not Converted & 4.04 & 4.14 & -42.0 \\
\hline
\end{tabular}




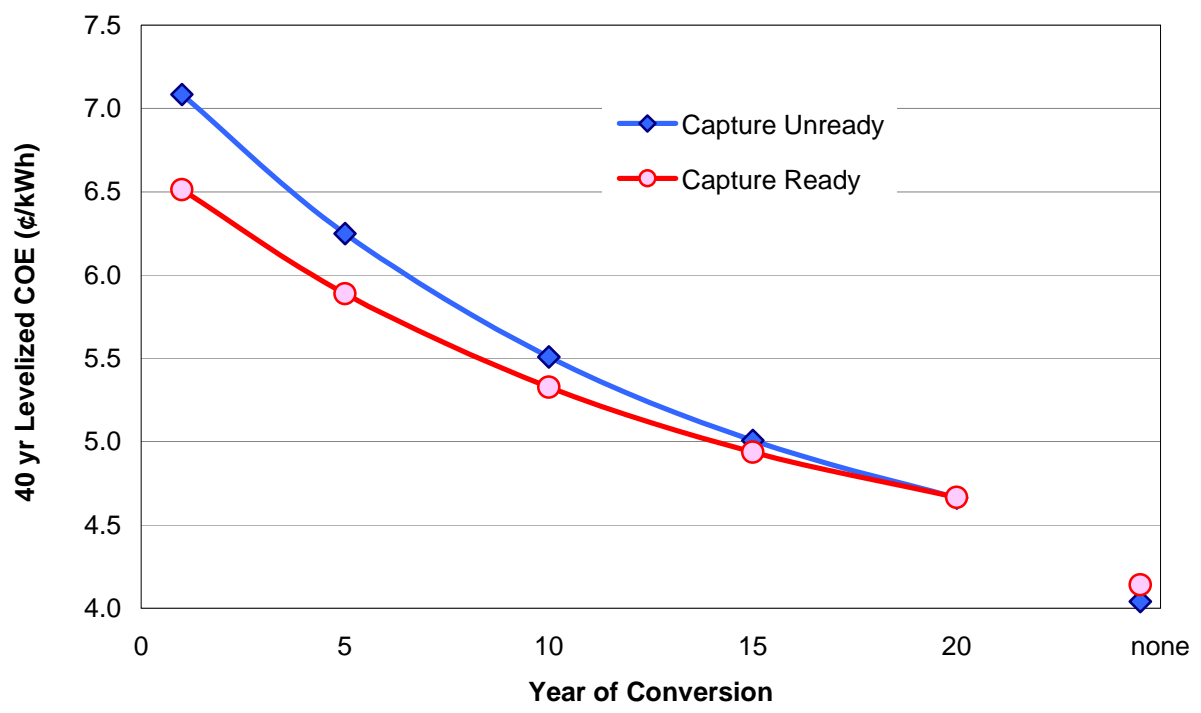

Figure 8-1: Levelized cost of Electricity Comparison

If the plants are never converted to $\mathrm{CO}_{2}$ capture, the Capture Ready plant has a slightly higher COE. This is expected, as no benefit is ever received from the additional investment up front for the capture-ready capability, so the cost of electricity is higher.

The sooner the plant is converted to $\mathrm{CO}_{2}$ capture, the more years (of the 40) are at a higher $\mathrm{COE}$, so the levelized COE is higher. The sooner the plant is converted to $\mathrm{CO}_{2}$ capture, the more years of benefit are received from the upfront capture-ready investment. This benefit in levelized COE decreases as the conversion is delayed; if the conversion does not occur until 20 years, there is no remaining benefit of the upfront capture-ready investment. This is because there are fewer years of benefit and because the value of the benefits is also reduced by the time value of money.

Looking at a relative net present value can also show the benefit of the upfront capture-ready investment. Assume that throughout its lifetime, the Capture Ready plant will sell electricity at the same dispatch COE as the Capture Unready plant. Before conversion, the Capture Ready plant will have a higher cost and therefore lower net revenue. After conversion, the situation is reversed.

Table 8-3 and Figure 8-2 show the Net Present Value of incremental cash flows over 40 years. (Each point on this curve represents the NPV of the Case 2b plants' entire life cycle cost relative to the Case $1 \mathrm{~b}$ plant - only the year of $\mathrm{CO}_{2}$ conversion varies for each point).

If the Capture Ready plant is never converted, the added capital pre-investment is never recovered over the 40-year plant life, resulting in a negative \$42 million dollars in NPV relative to the Capture Unready plant. The sooner the plant is converted to $\mathrm{CO}_{2}$ capture, the more years of benefit are received from the upfront capture-ready investment. This benefit in NPV decreases as the conversion is delayed; if the conversion does not occur until 20 years, there is little remaining benefit of the upfront capture-ready investment. 


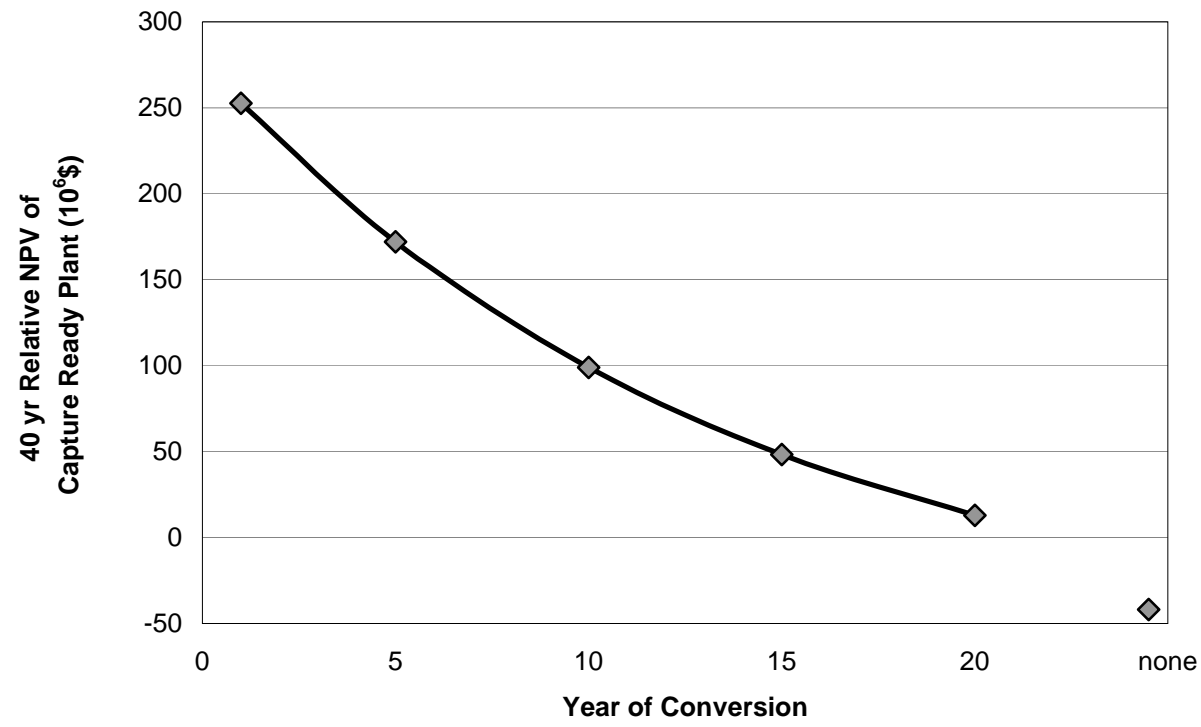

Figure 8-2: Relative Net Present Value Comparisons

\section{$\underline{\text { Remarks }}$}

It was discussed earlier (Section 7.3) that a comparison of the total power plant costs for Cases $1 \mathrm{a}$ and 2a shows that the capture ready design requires a relatively small pre-investment of about 4.5 percent. This pre-investment cost is provided for the future conversion of the plant to oxygen firing and $\mathrm{CO}_{2}$ capture, and to also allow an increase in the gross electrical output from the plant of about 32 percent when the plant is retrofitted with oxygen firing and $\mathrm{CO}_{2}$ capture (i.e., from Case 2a to Case 2b) such that the net electrical output is not decreased.

Hence, the purpose of the analysis presented above was to determine whether or not this preinvestment cost is justified economically, by comparing the results from Case $2 \mathrm{~b}$ with those from Case $1 \mathrm{~b}$ (Capture unready converted to $\mathrm{O}_{2}$ firing and $\mathrm{CO}_{2}$ capture). Results summary:

- The levelized cost of electricity (LCOE) of the capture unready plant (1b) is always higher than that of the capture ready plant (2b), irrespective of the time of conversion to $\mathrm{O}_{2}$ firing and $\mathrm{CO}_{2}$ capture, up to 20 years.

- The differences between the LCOE's of these two plants get narrower with time of conversion, ultimately crossing at 20-year mark

- In the absence of conversion to $\mathrm{O}_{2}$ firing and $\mathrm{CO}_{2}$ capture, the LCOE of the capture ready plant (2a) is higher than that of capture unready (1a), due its additional preinvestment cost

- The relative net present value (NPV) between the Capture Ready and Capture Unready plants decreases with time of conversion to $\mathrm{O}_{2}$ firing and $\mathrm{CO}_{2}$ capture, consistent with the LCOE differences

- In the absence of conversion to $\mathrm{O}_{2}$ firing and $\mathrm{CO}_{2}$ capture, the NPV of the capture ready plant (2a) is $-\$ 42 \mathrm{M}$ relative to Capture Unready plant (1a), due its additional preinvestment cost

- Hence, the pre-investment cost is justified, provided that the plant conversion to $\mathrm{O}_{2}$ 
firing and $\mathrm{CO}_{2}$ capture is implemented within 20 years from initial operation. The earlier the conversion, the better based on both LCOE and NPV results

- The value of pre-investment cost disappears if the conversion to $\mathrm{O}_{2}$ firing and $\mathrm{CO}_{2}$ capture is implemented after 20 years from initial operation.

For Case 1b, the net power output was reduced by $25 \%$ compared to Case 1a. Replacement power would be required to make up this shortfall. Several options are available for replacement power. One of the options is to use a supercritical CFB with oxygen firing and $\mathrm{CO}_{2}$ capture (i.e., Case $1 \mathrm{~b}$ ). In this case, there would essentially be no impact on the economics shown above for Case $1 \mathrm{~b}$. Choosing another replacement power technology would impact the economics consistent with the selection. 


\section{BIBLIOGRAPHY}

Anheden, M., and Morin, J. -X., “Oxy-CFB Process Analysis Report,” Private Communication, March, 2004

Booras, G., and Holt, N., "IGCC and Co-production Economics Update,“CoalFleet General Technical Meeting, Bismarck, ND, August 9, 2006

Dillon, D. J., Panesar, R. S., Wall, R. A., Allam, R. J., White, V., Gibbins, J., “Oxy-

Combustion Processes for $\mathrm{CO}_{2}$ Capture from Power Plants”, Report Number 2005/9, July 2005

Fox, C., Kinder Morgan $\mathrm{CO}_{2}$ Company L.P.; IBC Carbon Sequestration Conference, Houston; 2002.

Himmelblau, David M., “Basic Principles and Calculations in Chemical Engineering”, Prentice-Hall, Inc., Englewood Cliffs, NJ, 1974.

GEA Power Cooling Inc., Mechanical Draft Cooling Tower, Budgetary Information, Ref. No. 1490R1, May 18, 2007

Marion, J., Bozzuto, C., Nsakala, N., Liljedahl, G., "Evaluation Of Advanced Coal Combustion \& Gasification Power Plants With Greenhouse Gas Emission Control,” Topical Phase-I DOENETL Report, Prepared by ALSTOM Power Inc., May 15, 2003.

Nsakala, N., Liljedahl, G, Turek, D., “Greenhouse Gas Emission Control by Oxygen Firing in Circulating Fluidized Bed Boilers: Phase II - Pilot Scale Testing and Updated Performance and Economics for Oxygen Fired CFB with $\mathrm{CO}_{2}$ Capture,” Final DOE-NETL Report, Prepared by ALSTOM Power Inc., October 27, 2004. 
COMMERCIALIZATION DEVELOPMENT OF OXYGEN FIRED

CFB FOR GREENHOUSE GAS CONTROL

\section{APPENDICIES}

Three appendices are included in this section as listed below:

1. Plant Drawings

o CFB Boiler Drawings

o Steam Turbine Drawings

o Plant Layout Drawings

2. Plant Equipment Lists

3. Detailed Plant Costs 
COMMERCIALIZATION DEVELOPMENT OF OXYGEN FIRED

CFB FOR GREENHOUSE GAS CONTROL

\subsection{Appendix I - Drawings}

\subsubsection{CFB Boiler Drawings}

This section shows drawings of the CFB boilers for three of the cases in this study as listed below:

o Case 1a - Air Fired CFB Boiler (Base Case)

o Case 2a - Air Fired Capture Ready CFB Boiler

o Case $2 \mathrm{~b}$ - Capture Ready CFB Boiler (Case 2a) Retrofit with $\mathrm{O}_{2}$ firing and $\mathrm{CO}_{2}$ Capture

Note: Drawings for Case $1 \mathrm{~b}$ (Base Case retrofit with $\mathrm{O}_{2}$ firing and $\mathrm{CO}_{2}$ capture) were not developed. 
COMMERCIALIZATION DEVELOPMENT OF OXYGEN FIRED CFB FOR GREENHOUSE GAS CONTROL

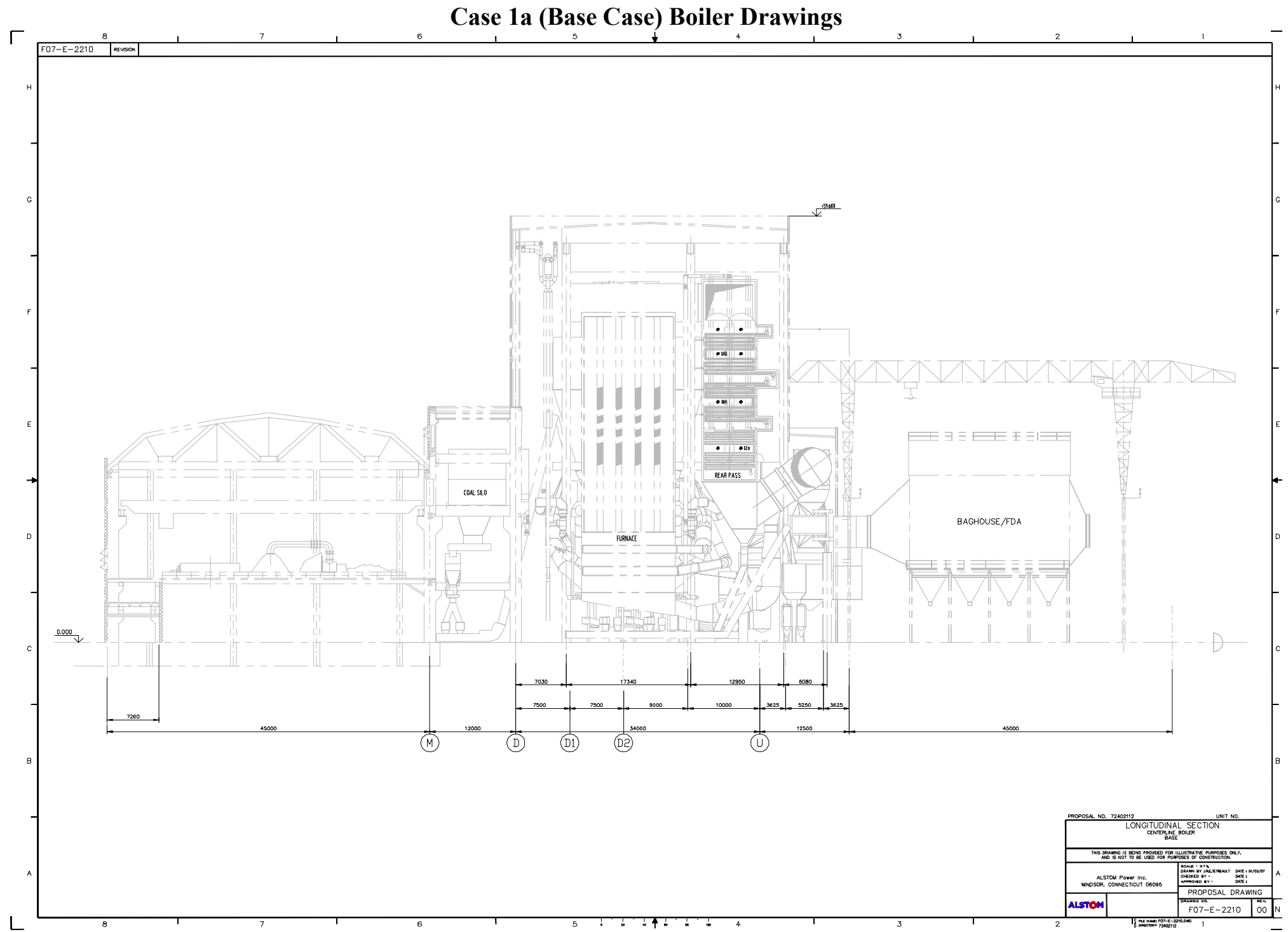


COMMERCIALIZATION DEVELOPMENT OF OXYGEN FIRED

CFB FOR GREENHOUSE GAS CONTROL

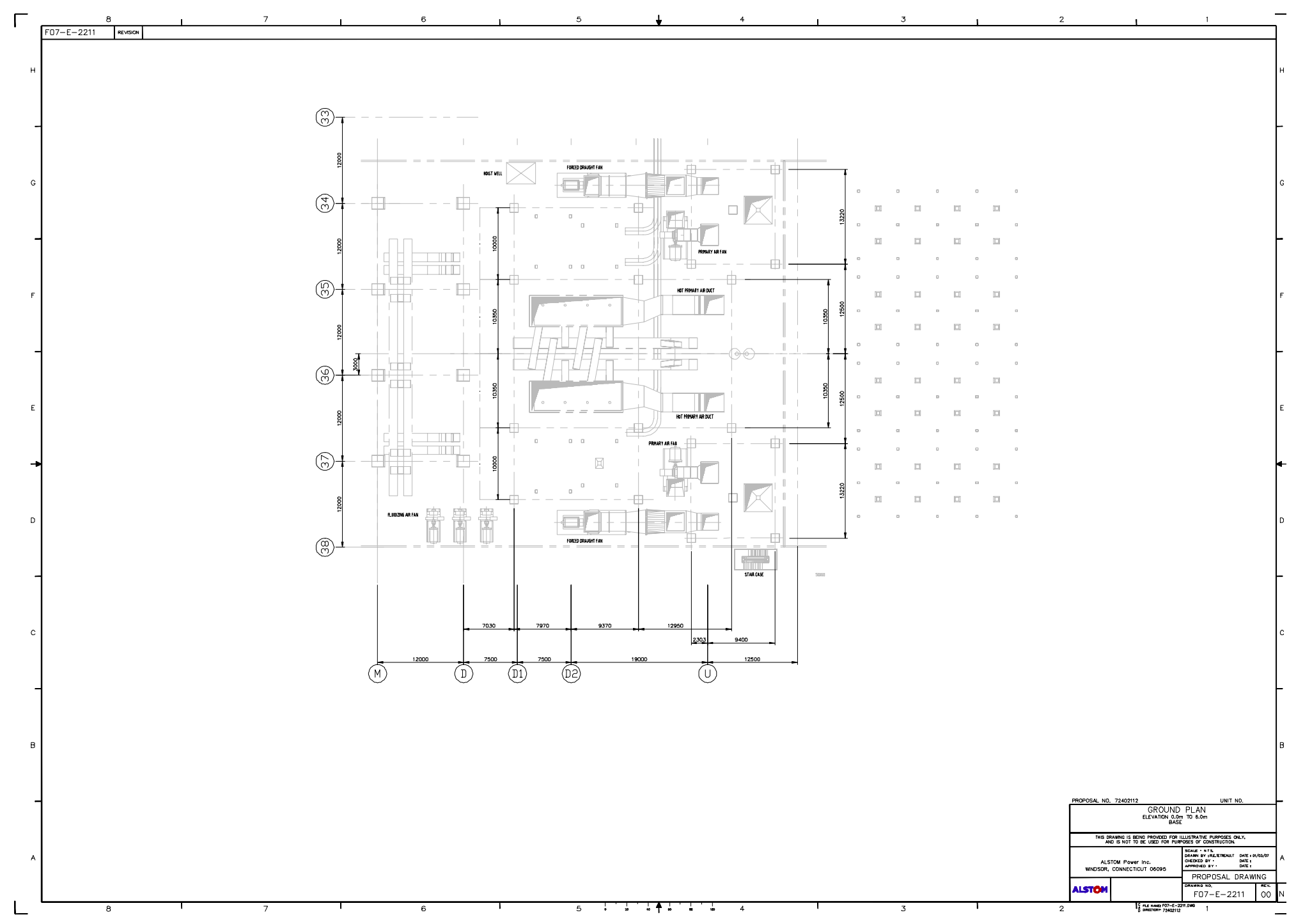


COMMERCIALIZATION DEVELOPMENT OF OXYGEN FIRED

CFB FOR GREENHOUSE GAS CONTROL

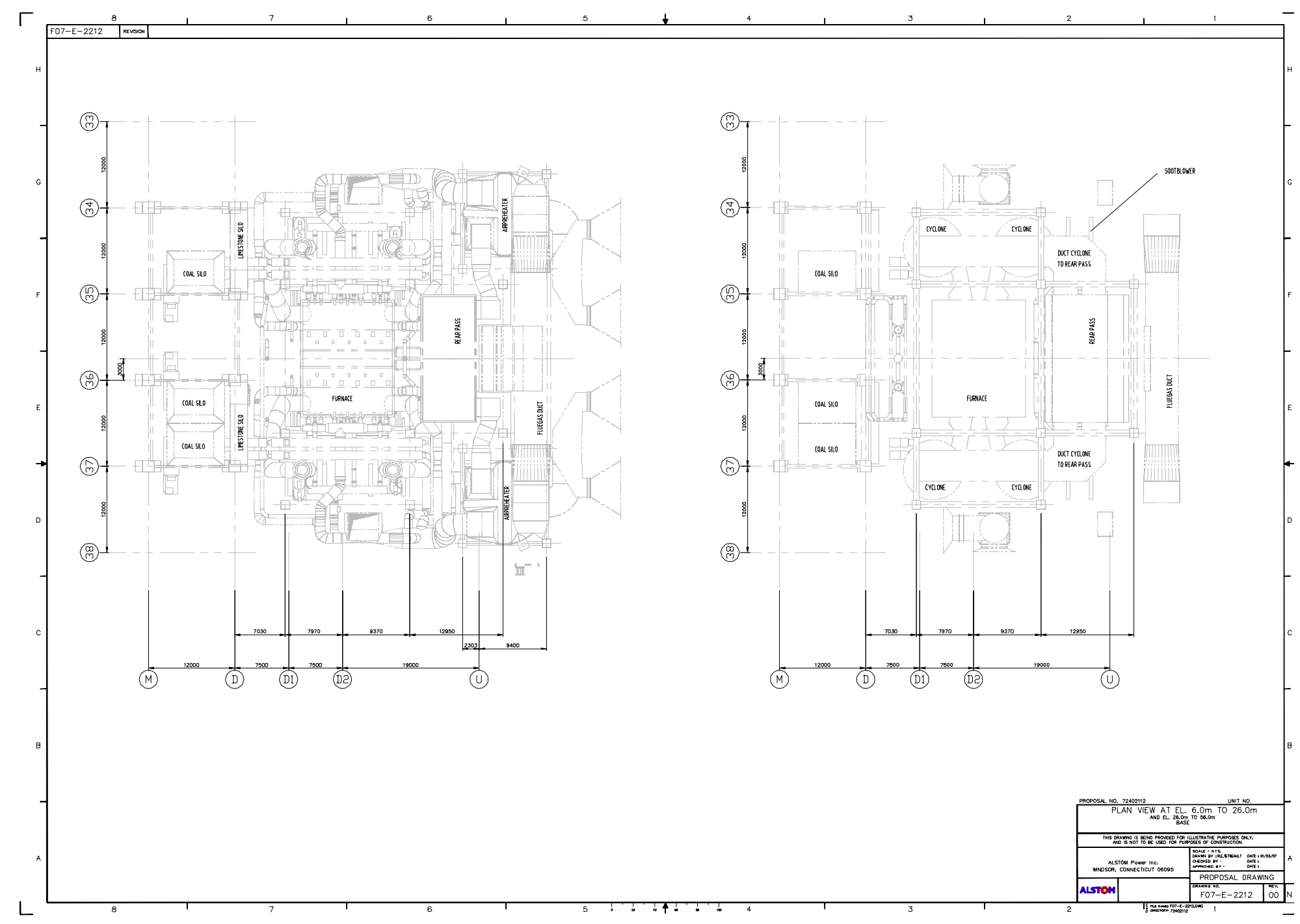


COMMERCIALIZATION DEVELOPMENT OF OXYGEN FIRED

CFB FOR GREENHOUSE GAS CONTROL

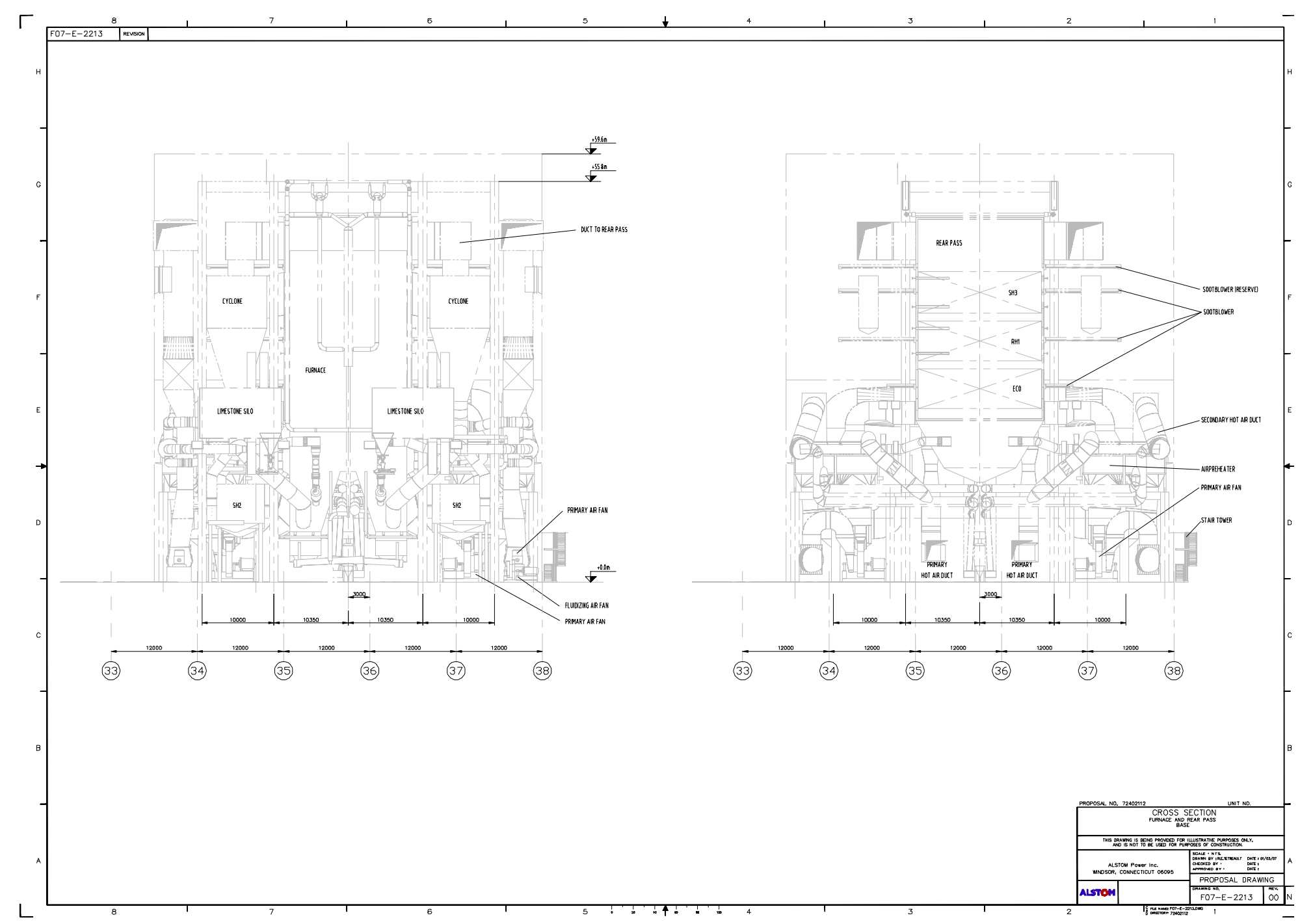


COMMERCIALIZATION DEVELOPMENT OF OXYGEN FIRED CFB FOR GREENHOUSE GAS CONTROL

\section{Case 2a Capture Ready Boiler Drawings}

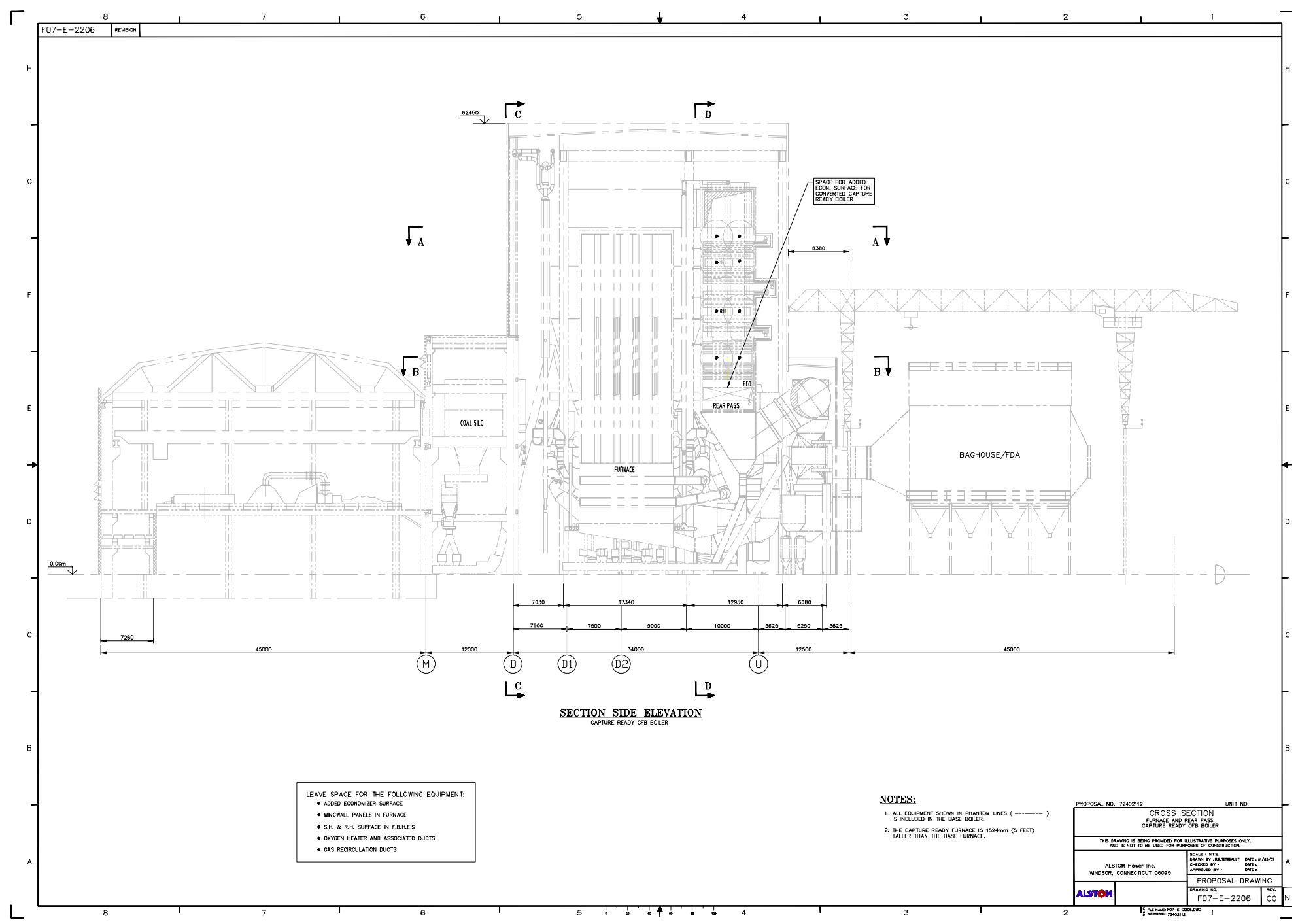


COMMERCIALIZATION DEVELOPMENT OF OXYGEN FIRED

CFB FOR GREENHOUSE GAS CONTROL

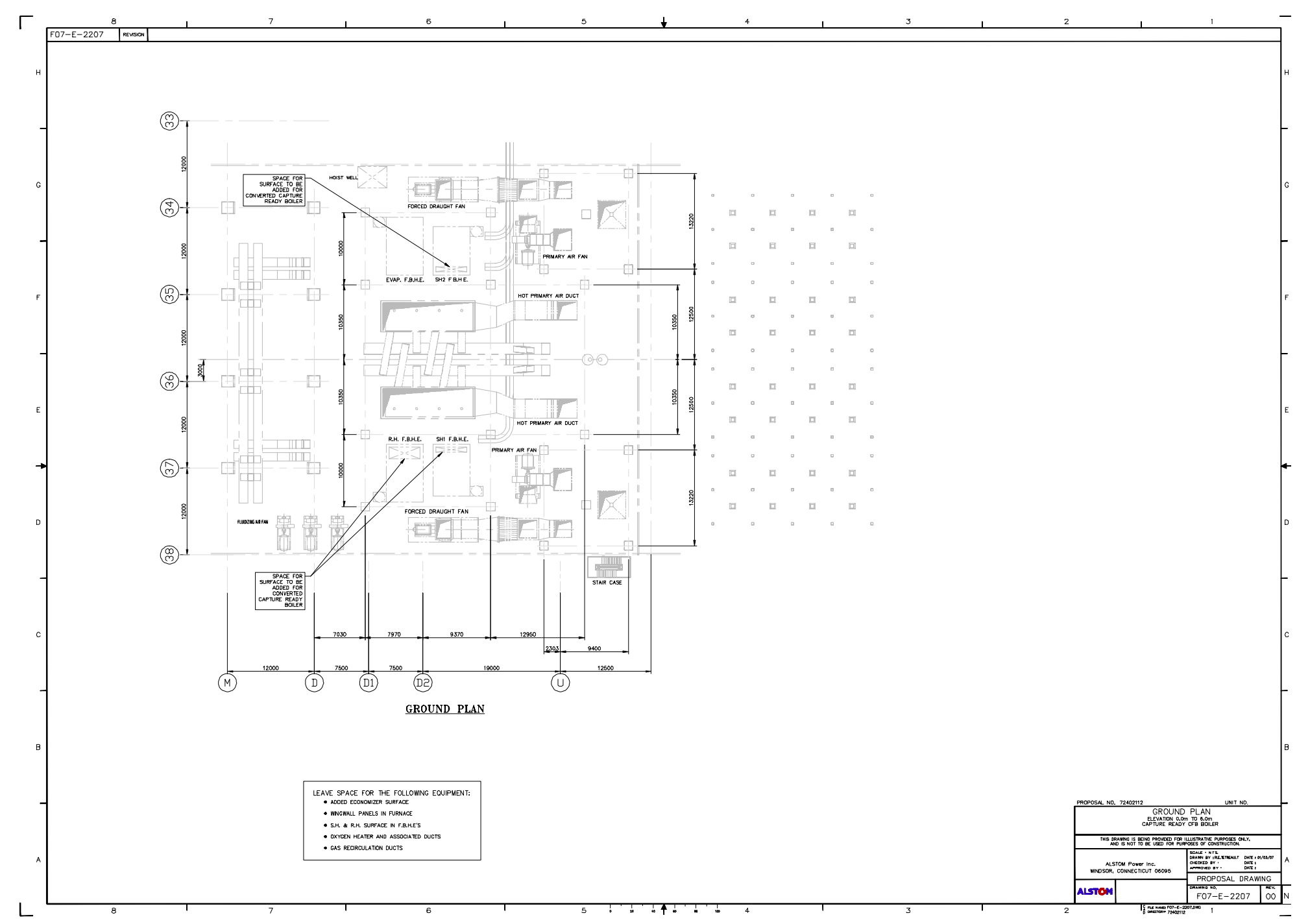


COMMERCIALIZATION DEVELOPMENT OF OXYGEN FIRED

CFB FOR GREENHOUSE GAS CONTROL

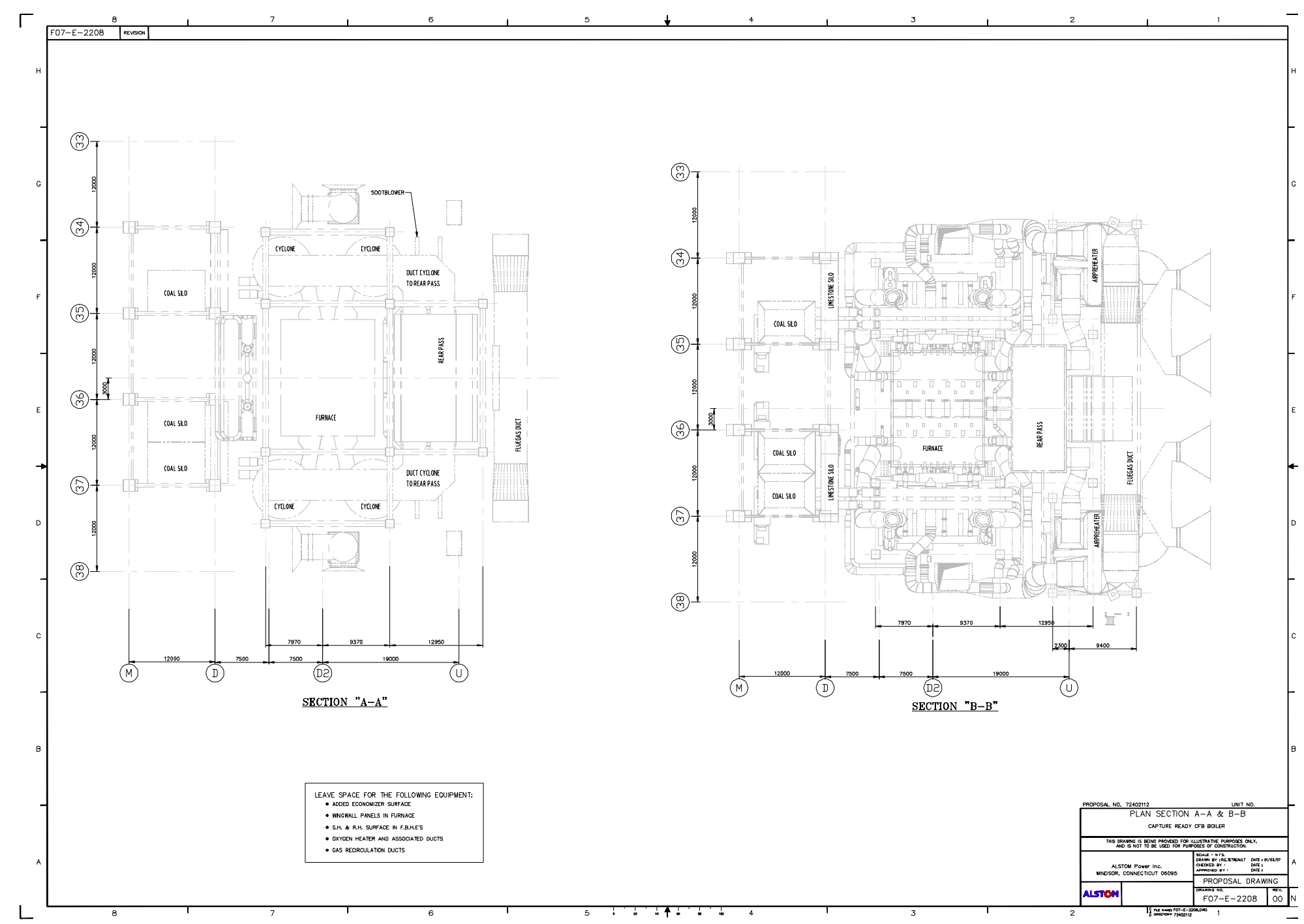


COMMERCIALIZATION DEVELOPMENT OF OXYGEN FIRED

CFB FOR GREENHOUSE GAS CONTROL

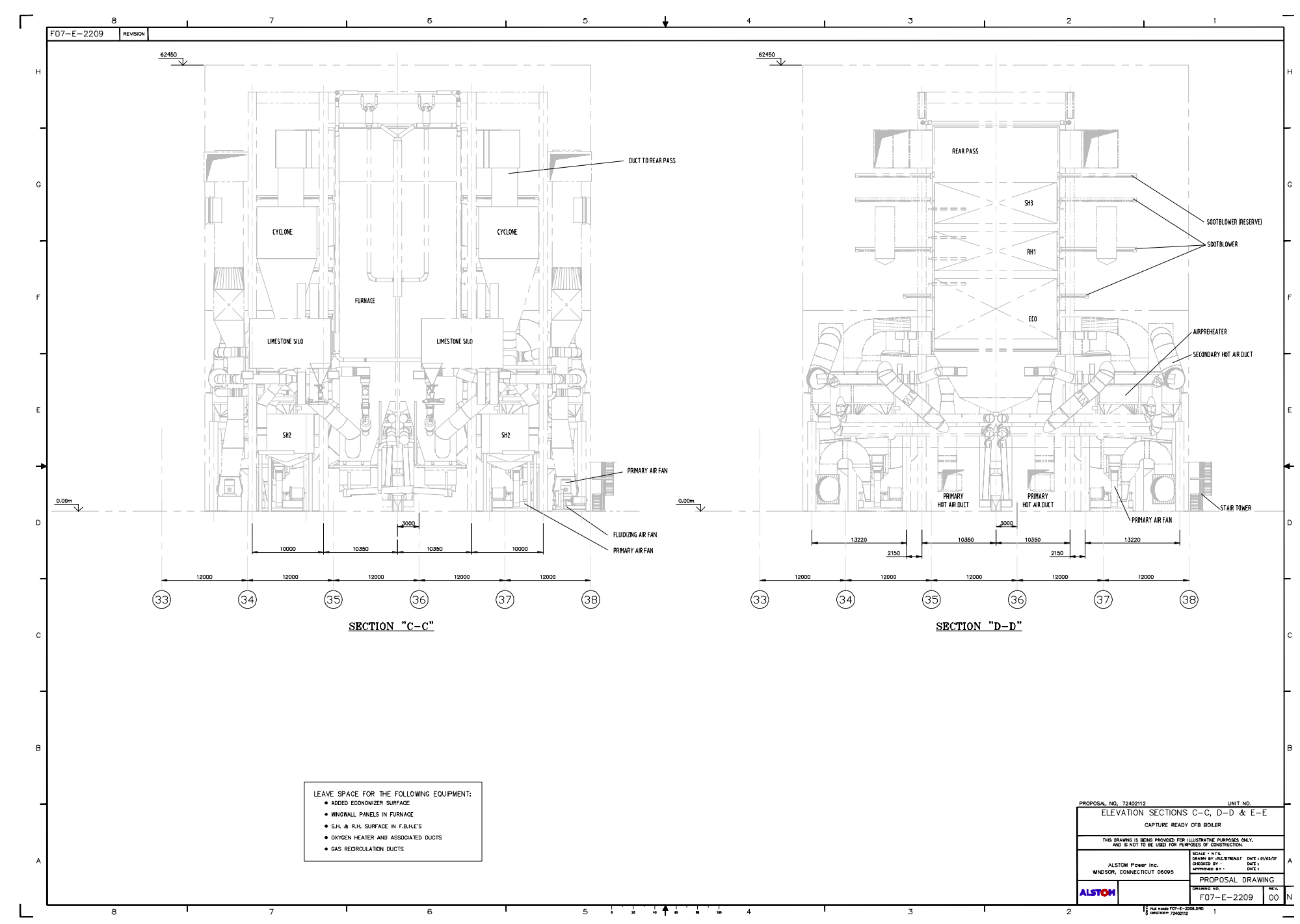


COMMERCIALIZATION DEVELOPMENT OF OXYGEN FIRED CFB FOR GREENHOUSE GAS CONTROL

\section{Case 2b Capture Ready Converted CFB Boiler Drawings}

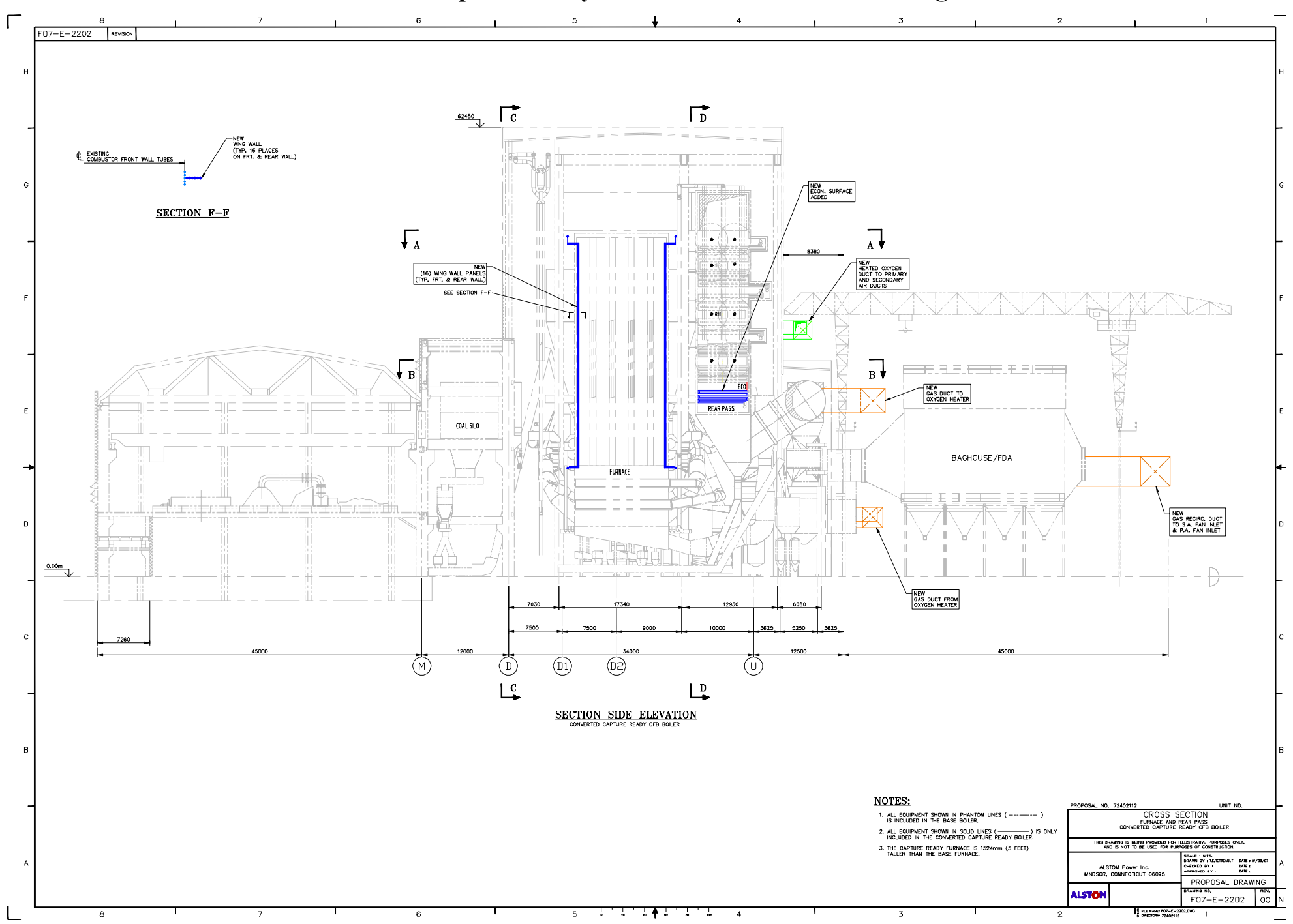


COMMERCIALIZATION DEVELOPMENT OF OXYGEN FIRED

CFB FOR GREENHOUSE GAS CONTROL

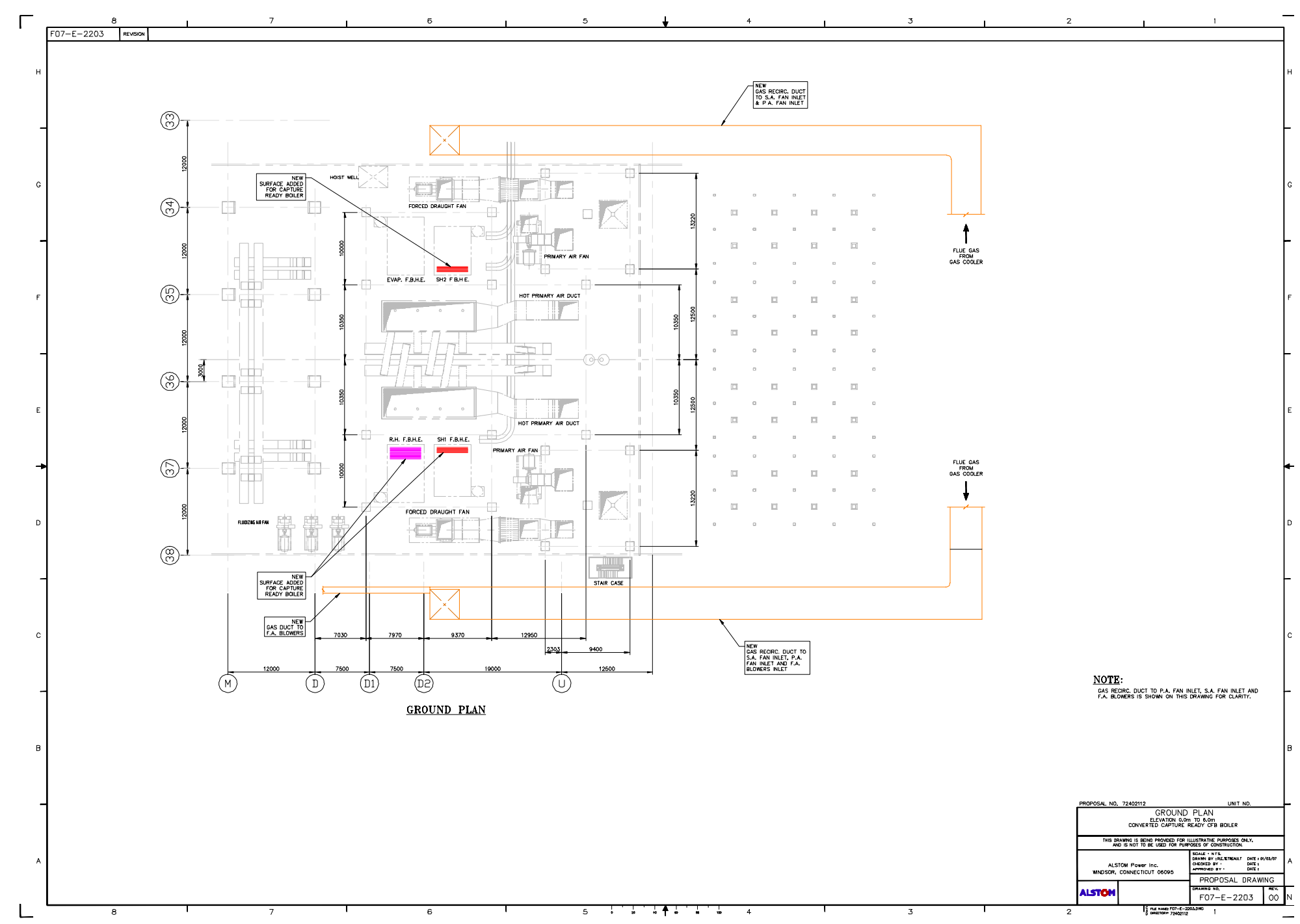


COMMERCIALIZATION DEVELOPMENT OF OXYGEN FIRED

CFB FOR GREENHOUSE GAS CONTROL

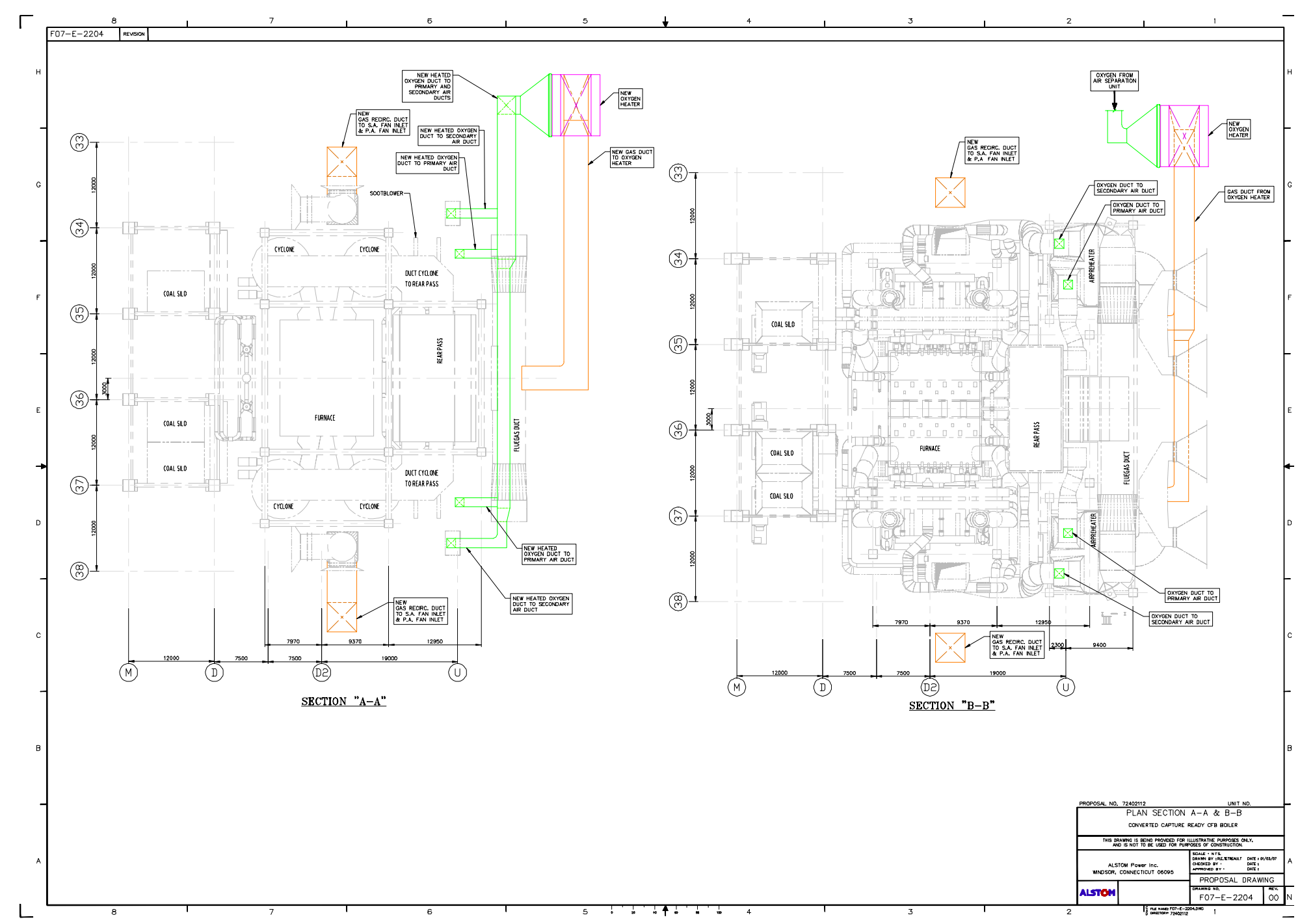


COMMERCIALIZATION DEVELOPMENT OF OXYGEN FIRED

CFB FOR GREENHOUSE GAS CONTROL

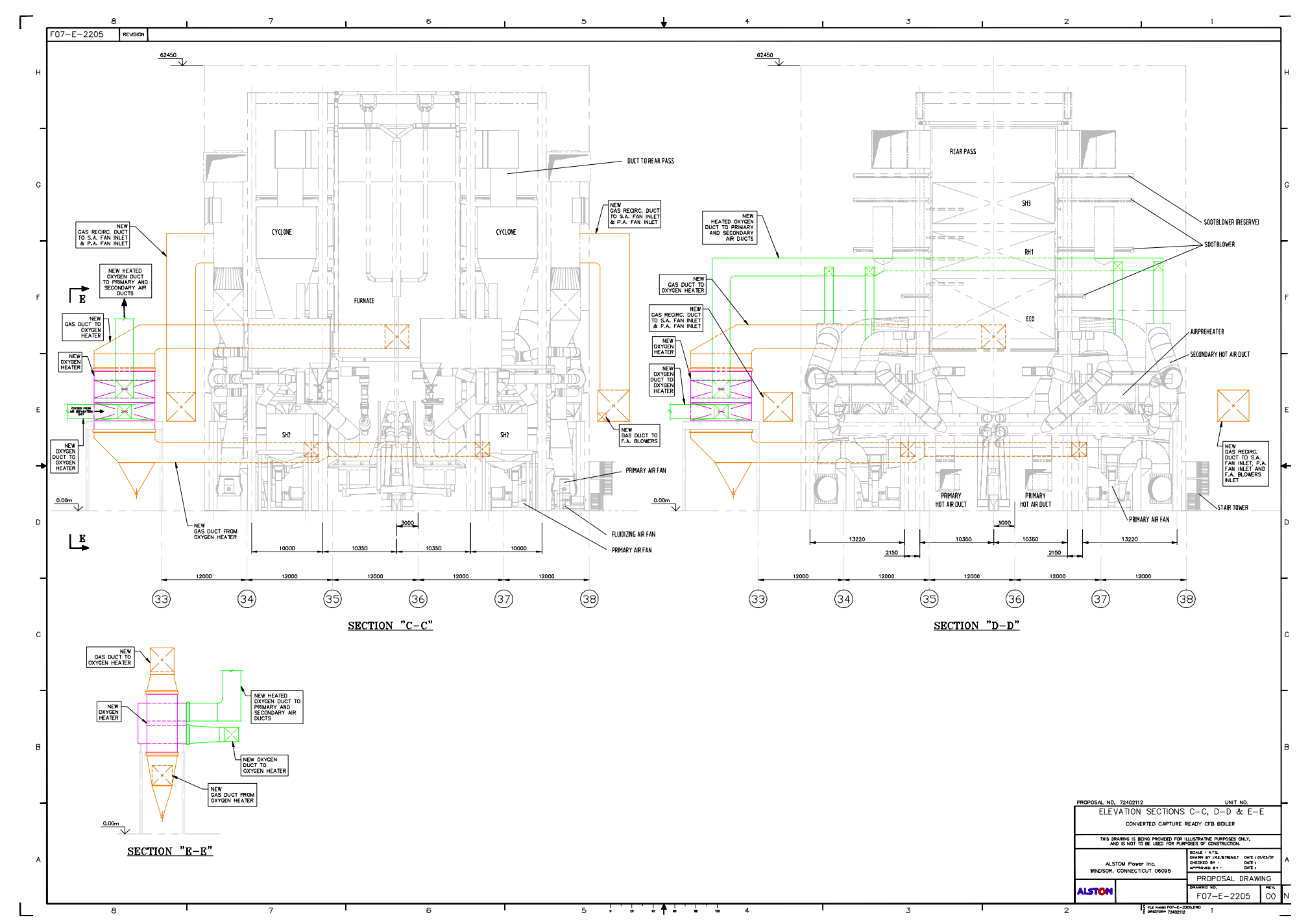


COMMERCIALIZATION DEVELOPMENT OF OXYGEN FIRED

CFB FOR GREENHOUSE GAS CONTROL

\subsubsection{Steam Turbine Drawings}

This section shows the layout plan drawings for the steam turbine/generators. The steam turbine external dimensions are identical for all Cases (1a, 1b, 2a, and 2b) as shown in Figure 10-1 and Figure 10-2. The generator external dimensions are identical for Cases (1a, $1 \mathrm{~b}$, and 2a) as shown in Figure 10-1 and Figure 10-2. The generator external dimensions are larger for Case $2 \mathrm{~b}$ as shown in Figure 10-3 
COMMERCIALIZATION DEVELOPMENT OF OXYGEN FIRED

CFB FOR GREENHOUSE GAS CONTROL

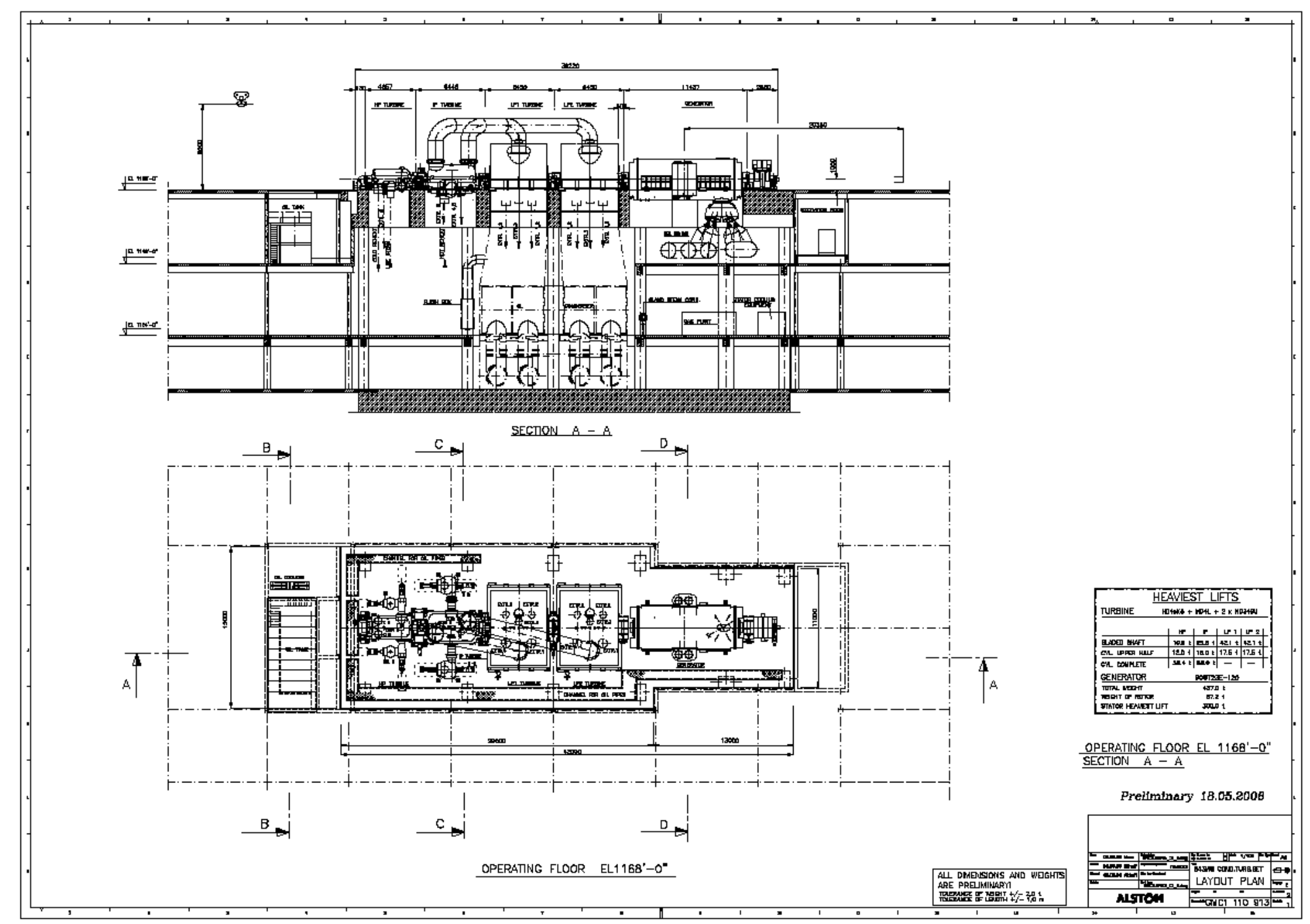

Figure 10-1: Cases 1a, 1b, 2a Steam Turbine/Generator Layout Plan Drawing (operating floor - el 1188') 
COMMERCIALIZATION DEVELOPMENT OF OXYGEN FIRED

CFB FOR GREENHOUSE GAS CONTROL

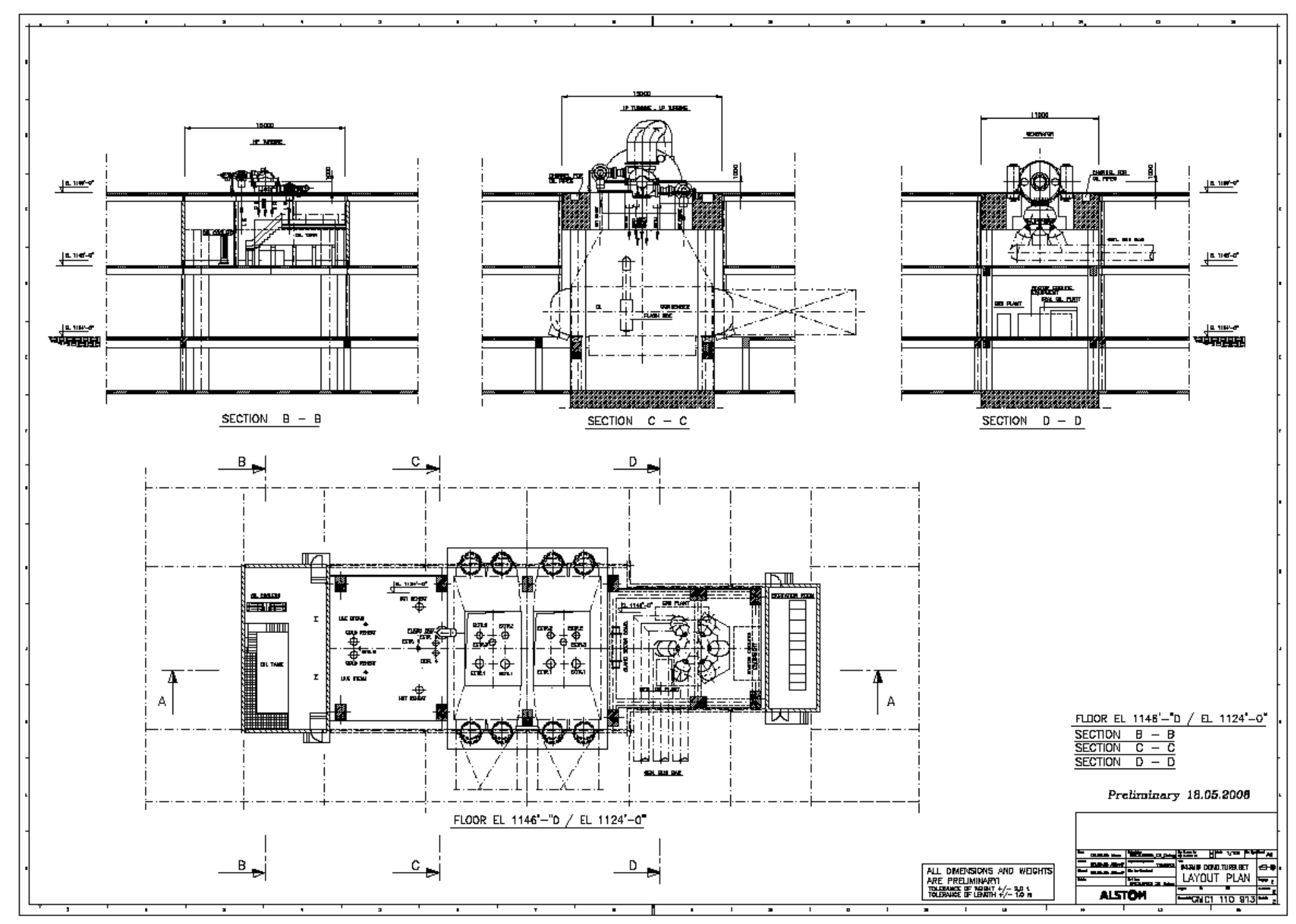

Figure 10-2: Cases 1a, 1b, 2a Steam Turbine/Generator Layout Plan Drawings (floor el. 1,146' / 1,124') 
COMMERCIALIZATION DEVELOPMENT OF OXYGEN FIRED

CFB FOR GREENHOUSE GAS CONTROL
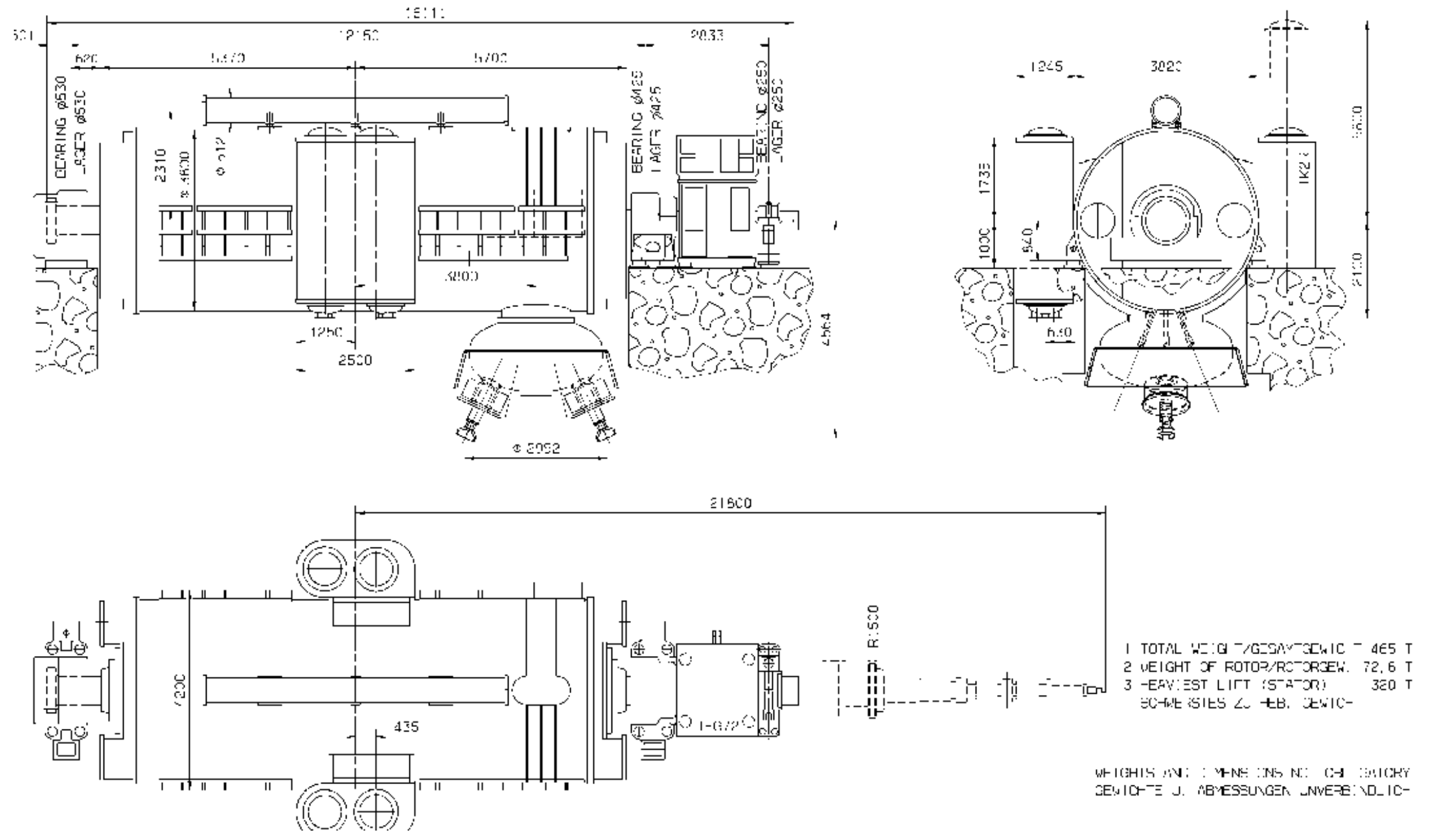

Figure 10-3: Case 2b Capture Ready Converted Generator General Arrangement Drawing 
COMMERCIALIZATION DEVELOPMENT OF OXYGEN FIRED

CFB FOR GREENHOUSE GAS CONTROL

\subsubsection{Plant Layout Drawings}

This section shows drawings of the power plant layouts for three of the cases in this study as listed below:

o Case 1a - Air Fired $\mathrm{CO}_{2}$ Capture Unready Power Plant - Base Case

o Case $1 \mathrm{~b}$ - The Base Case Power Plant Retrofit with $\mathrm{O}_{2}$ Firing and $\mathrm{CO}_{2}$ Capture

o Case 2a - Air Fired $\mathrm{CO}_{2}$ Capture-Ready Power Plant

o Case $2 \mathrm{~b}$ - The Case 2a Capture-Ready Power Plant Retrofit with $\mathrm{O}_{2}$ Firing and $\mathrm{CO}_{2}$ Capture 
COMMERCIALIZATION DEVELOPMENT OF OXYGEN FIRED CFB FOR GREENHOUSE GAS CONTROL

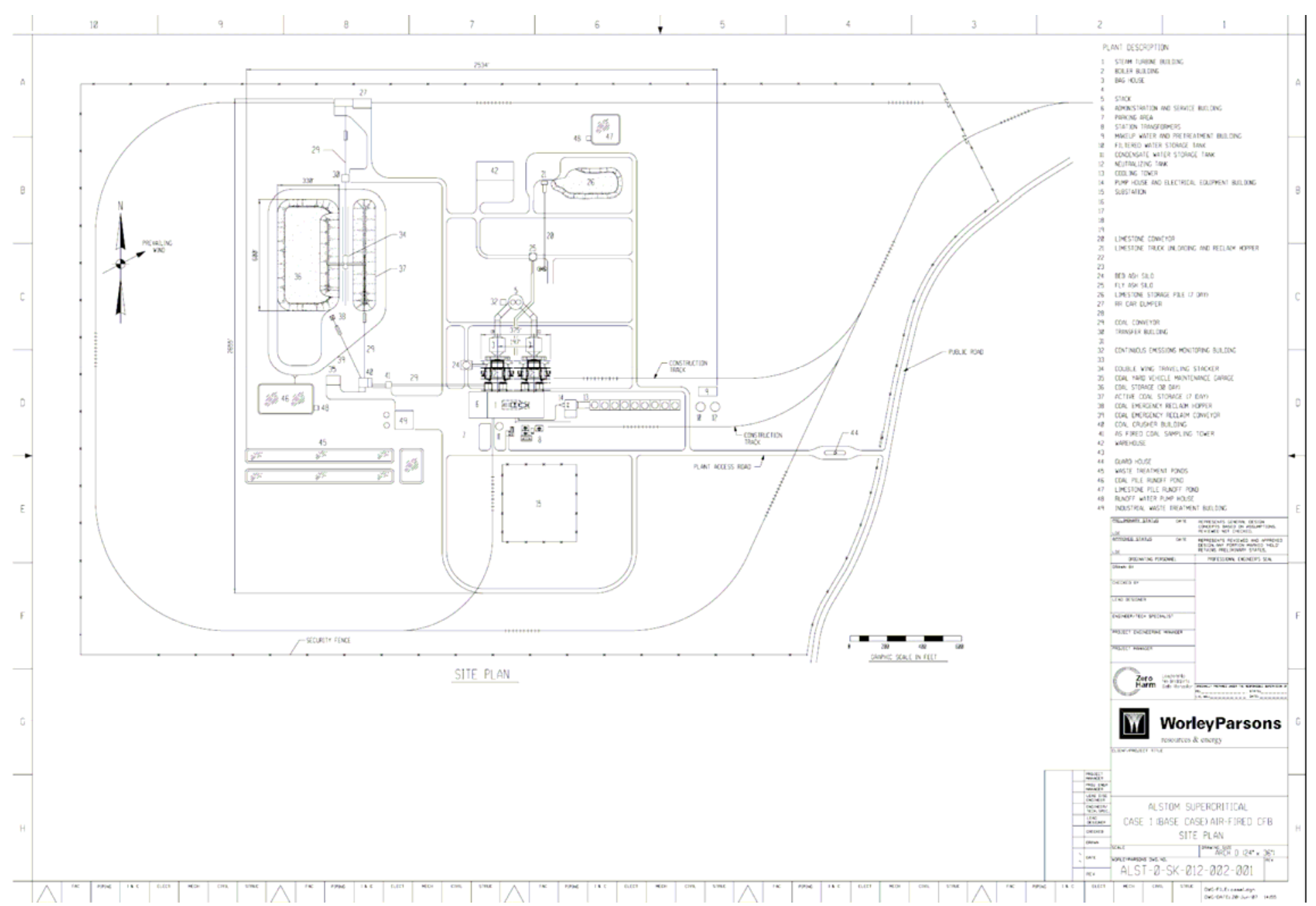

Figure 10-4: Case 1a (Base Case) Air Blown CFB Steam Plant (Not Capture Ready) Layout 
COMMERCIALIZATION DEVELOPMENT OF OXYGEN FIRED

CFB FOR GREENHOUSE GAS CONTROL

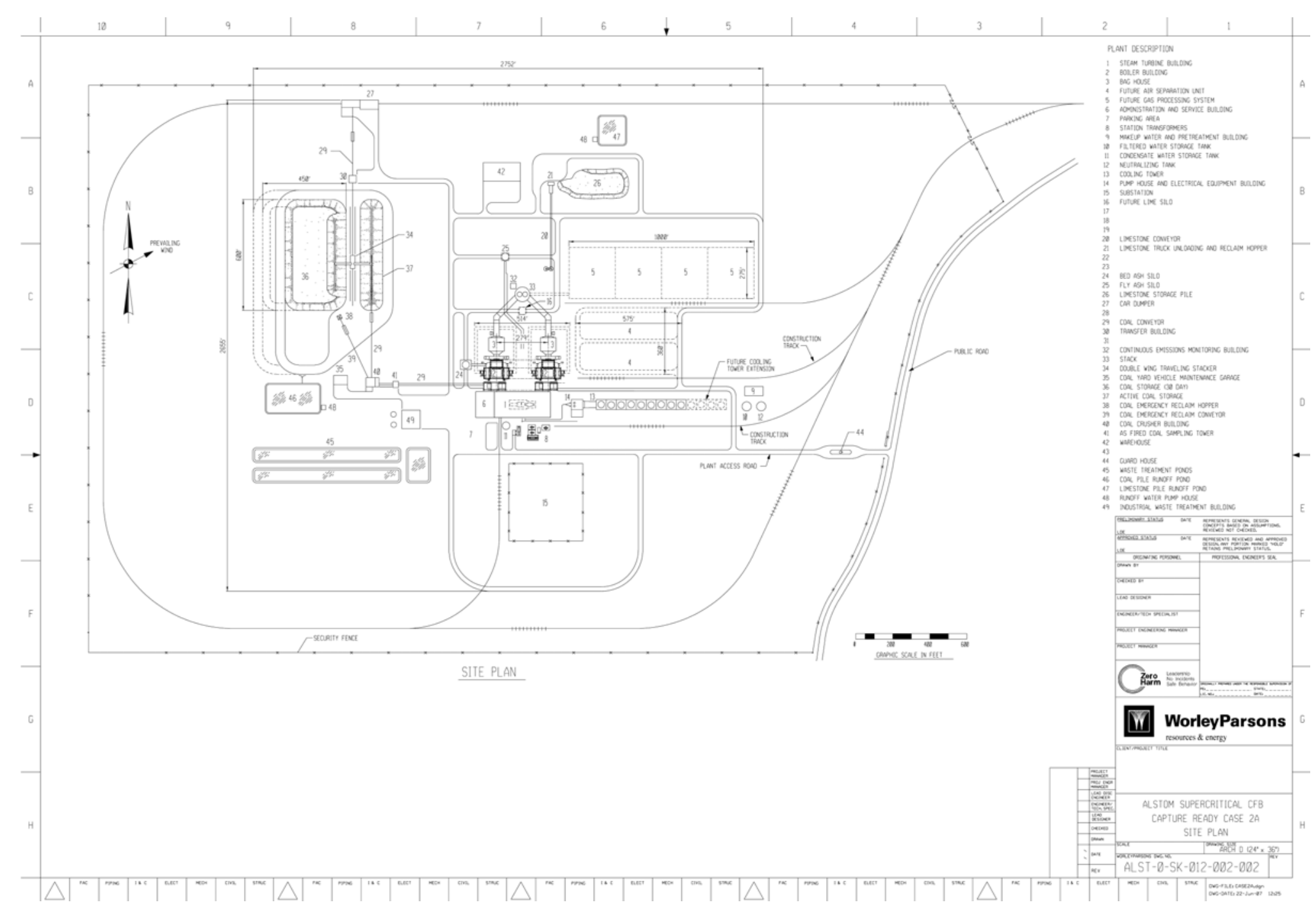


COMMERCIALIZATION DEVELOPMENT OF OXYGEN FIRED CFB FOR GREENHOUSE GAS CONTROL

Figure 10-5: Case 2a Air Blown Capture Ready CFB Steam Plant Layout

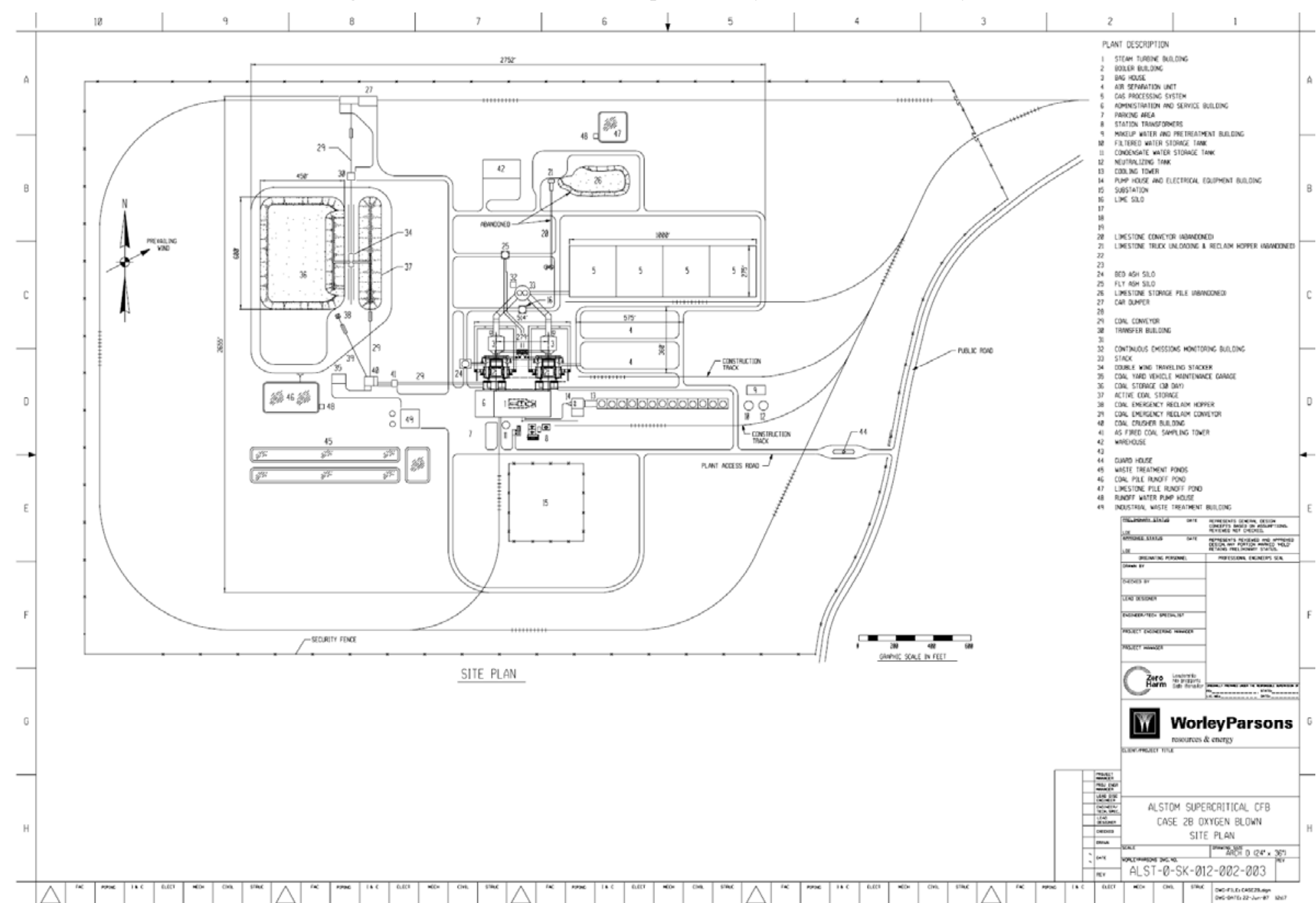

Figure 10-6:Case 2b Oxygen Blown CFB Steam Plant Layout with $\mathrm{CO}_{2}$ Capture 


\subsection{Appendix II - Equipment Lists}

This section contains the major balance of plant equipment lists corresponding to the power plant configurations described in Section 6. These lists, along with the heat and material balances and general arrangement drawings, were used to generate balance of plant costs.

\subsubsection{Base Case (Case 1a)}

The following tables describe the BOP equipment for Case 1a (Base Case)

Account 1 Fuel and Sorbent Handling

\begin{tabular}{|c|c|c|c|c|c|}
\hline $\begin{array}{c}\text { Equipment } \\
\text { No. }\end{array}$ & Description & Type & Design Condition & $\begin{array}{c}\text { Operating } \\
\text { Qty. }\end{array}$ & Spares \\
\hline 1 & $\begin{array}{l}\text { Bottom Trestle } \\
\text { Dumper and } \\
\text { Receiving Hoppers }\end{array}$ & N/A & 181 tonne (200 ton) & 2 & 0 \\
\hline 2 & Feeder & Belt & 572 tonne/h (630 tph) & 2 & 0 \\
\hline 3 & Conveyor No. 1 & Belt & $\begin{array}{c}1,134 \text { tonne/h }(1,250 \\
\text { tph) }\end{array}$ & 1 & 1 \\
\hline 4 & Transfer Tower No. 1 & $\begin{array}{l}\text { Enclosed, w/dust } \\
\text { collection }\end{array}$ & N/A & 1 & 0 \\
\hline 5 & Conveyor No. 2 & $\begin{array}{l}\text { Belt w/magnetic } \\
\text { separator }\end{array}$ & $\begin{array}{c}\text { 1,134 tonne/h }(1,250 \\
\text { tph) }\end{array}$ & 1 & 1 \\
\hline 6 & $\begin{array}{l}\text { As-Received Coal } \\
\text { Sampling System }\end{array}$ & Two-stage & N/A & 1 & 0 \\
\hline 7 & Stacker & $\begin{array}{l}\text { Traveling, linear, } \\
\text { double wing }\end{array}$ & $\begin{array}{c}\text { 1,134 tonne/h }(1,250 \\
\text { tph) }\end{array}$ & 1 & 0 \\
\hline 8 & Reclaim Rotary Plow & $\begin{array}{l}\text { Low profile, single } \\
\text { tunnel }\end{array}$ & 381 tonne (420 ton) & 1 & 1 \\
\hline 9 & Reclaim Conveyor & Belt w/ scale & 381 tonne/h (420 tph) & 1 & 0 \\
\hline 10 & Conveyor No. 3 & Belt w/ tripper & 381 tonne/h (420 tph) & 1 & 0 \\
\hline 11 & Crusher Tower & $\begin{array}{l}\text { Enclosed w/dust } \\
\text { collection }\end{array}$ & N/A & 1 & 0 \\
\hline 12 & $\begin{array}{l}\text { Coal Surge Bin w/ } \\
\text { Vent Filter }\end{array}$ & Dual outlet & 191 tonne (210 ton) & 2 & 0 \\
\hline 13 & Crusher & Granulator & 191 tonne/h (210 tph) & 2 & 1 \\
\hline 14 & $\begin{array}{l}\text { As-Fired Coal } \\
\text { Sampling System }\end{array}$ & N/A & N/A & 1 & 0 \\
\hline 15 & Conveyor No. 4 & Belt w/tripper & 381 tonne/h (420 tph) & 1 & 0 \\
\hline 16 & Transfer Tower No. 2 & Enclosed & N/A & 1 & 0 \\
\hline
\end{tabular}


COMMERCIALIZATION DEVELOPMENT OF OXYGEN FIRED

CFB FOR GREENHOUSE GAS CONTROL

\begin{tabular}{|c|c|c|c|c|c|}
\hline $\begin{array}{c}\text { Equipment } \\
\text { No. }\end{array}$ & Description & Type & Design Condition & $\begin{array}{c}\text { Operating } \\
\text { Qty. }\end{array}$ & Spares \\
\hline 17 & Conveyor No. 5 & Belt w/ tripper & 381 tonne/h (420 tph) & 1 & 0 \\
\hline 18 & $\begin{array}{l}\text { Reclaim Hopper } \\
\text { (Emergency) }\end{array}$ & N/A & 91 tonne (100 ton) & 0 & 1 \\
\hline 19 & $\begin{array}{l}\text { Reclaim Conveyor } \\
\text { (Emergency) }\end{array}$ & Belt w/scale & 381 tonne (420 ton) & 0 & 1 \\
\hline 20 & $\begin{array}{l}\text { Limestone Truck } \\
\text { Unloading Hopper }\end{array}$ & N/A & 36 tonne (40 ton) & 1 & 0 \\
\hline 21 & Limestone Feeder & Belt & 109 tonne/h (120 tph) & 1 & 0 \\
\hline 22 & $\begin{array}{l}\text { Limestone Conveyor } \\
\text { No. L1 }\end{array}$ & Belt & 109 tonne/h (120 tph) & 1 & 0 \\
\hline 23 & $\begin{array}{l}\text { Limestone Reclaim } \\
\text { Hopper }\end{array}$ & N/A & 18 tonne (20 ton) & 1 & 0 \\
\hline 24 & $\begin{array}{l}\text { Limestone Reclaim } \\
\text { Feeder }\end{array}$ & Belt & 91 tonne/h (100 tph) & 1 & 0 \\
\hline 25 & $\begin{array}{l}\text { Limestone Conveyor } \\
\text { No. L2 }\end{array}$ & Belt & 91 tonne/h (100 tph) & 1 & 0 \\
\hline 26 & Limestone Surge Bin & Dual outlet & 18 tonne (20 ton) & 1 & 0 \\
\hline 27 & Limestone Crusher & Impactor reduction & 91 tonne/h (100 ton) & 1 & 0 \\
\hline 28 & $\begin{array}{l}\text { Limestone Conveyor } \\
\text { No. L3 }\end{array}$ & Belt & 91 tonne/h (100 tph) & 1 & 0 \\
\hline
\end{tabular}

\section{Account 2 Coal and Sorbent Feed System}

Included with boiler scope supplied by ALSTOM

\section{Account 3 Feedwater and Miscellaneous Systems and Equipment}

\begin{tabular}{|c|l|l|l|c|c|}
\hline $\begin{array}{c}\text { Equipment } \\
\text { No. }\end{array}$ & \multicolumn{1}{|c|}{ Description } & \multicolumn{1}{|c|}{ Type } & Design Condition & $\begin{array}{c}\text { Operating } \\
\text { Qty. }\end{array}$ & Spares \\
\hline 1 & $\begin{array}{l}\text { Demineralized Water } \\
\text { Storage Tank }\end{array}$ & $\begin{array}{l}\text { Vertical, } \\
\text { cylindrical, } \\
\text { outdoor }\end{array}$ & $\begin{array}{c}2,642,238 \text { liters } \\
(698,000 \text { gal) }\end{array}$ & 2 & 0 \\
\hline 2 & Condensate Pumps & $\begin{array}{l}\text { Vertical canned, } \\
\text { with VFD }\end{array}$ & $\begin{array}{l}\text { 25,741 lpm @ 244 m H2O } \\
(6,800 \text { gpm @ 800 ft H2O) }\end{array}$ & 1 & 1 \\
\cline { 2 - 5 } & & &
\end{tabular}


COMMERCIALIZATION DEVELOPMENT OF OXYGEN FIRED

CFB FOR GREENHOUSE GAS CONTROL

\begin{tabular}{|c|c|c|c|c|c|}
\hline $\begin{array}{c}\text { Equipment } \\
\text { No. }\end{array}$ & Description & Type & Design Condition & $\begin{array}{c}\text { Operating } \\
\text { Qty. }\end{array}$ & Spares \\
\hline 3 & $\begin{array}{l}\text { Deaerator and Storage } \\
\text { Tank }\end{array}$ & $\begin{array}{l}\text { Horizontal } \\
\text { spray type }\end{array}$ & $\begin{array}{c}2,199,926 \mathrm{~kg} / \mathrm{h} \\
(4,850,000 \mathrm{lb} / \mathrm{h}), \\
10 \mathrm{~min} . \operatorname{tank} \\
\end{array}$ & 1 & 0 \\
\hline 4 & $\begin{array}{l}\text { Boiler Feed } \\
\text { Pump/Turbine }\end{array}$ & $\begin{array}{l}\text { Barrel type, } \\
\text { multi-stage, } \\
\text { centrifugal }\end{array}$ & $\begin{array}{c}\text { 18,549 lpm @ 3,841 m } \\
\text { H2O (4,900 gpm @ } \\
12,600 \text { ft H2O) }\end{array}$ & 2 & 1 \\
\hline 5 & $\begin{array}{l}\text { Startup Boiler Feed } \\
\text { Pump, Electric Motor } \\
\text { Driven }\end{array}$ & $\begin{array}{l}\text { Barrel type, } \\
\text { multi-stage, } \\
\text { centrifugal }\end{array}$ & $\begin{array}{c}\text { 5,678 lpm @ 3,841 m H2O } \\
\text { (1,500 gpm @ } \\
12,600 \text { ft H2O) }\end{array}$ & 2 & 0 \\
\hline 6 & LP Feedwater Heater 1 & $\begin{array}{l}\text { Horizontal U- } \\
\text { tube }\end{array}$ & $\begin{array}{l}1,542,216 \mathrm{~kg} / \mathrm{h}( \\
3,400,000 \mathrm{lb} / \mathrm{h})\end{array}$ & 1 & 0 \\
\hline 7 & LP Feedwater Heater 2 & $\begin{array}{l}\text { Horizontal U- } \\
\text { tube }\end{array}$ & $\begin{array}{c}1,542,216 \mathrm{~kg} / \mathrm{h} \\
(3,400,000 \mathrm{lb} / \mathrm{h})\end{array}$ & 1 & 0 \\
\hline 8 & LP Feedwater Heater 3 & $\begin{array}{l}\text { Horizontal U- } \\
\text { tube }\end{array}$ & $\begin{array}{c}1,542,216 \mathrm{~kg} / \mathrm{h} \\
(3,400,000 \mathrm{lb} / \mathrm{h})\end{array}$ & 1 & 0 \\
\hline 9 & LP Feedwater Heater 4 & $\begin{array}{l}\text { Horizontal U- } \\
\text { tube }\end{array}$ & $\begin{array}{c}1,542,216 \mathrm{~kg} / \mathrm{h}(3,400,000 \\
\mathrm{lb} / \mathrm{h})\end{array}$ & 1 & 0 \\
\hline 10 & $\begin{array}{l}\text { HP Feedwater Heater } \\
6 \mathrm{~A} / 6 \mathrm{~B}\end{array}$ & $\begin{array}{l}\text { Horizontal U- } \\
\text { tube }\end{array}$ & $\begin{array}{c}1,102,231 \mathrm{~kg} / \mathrm{h}(2,430,000 \\
\mathrm{lb} / \mathrm{h})\end{array}$ & 2 & 0 \\
\hline 11 & $\begin{array}{l}\text { HP Feedwater Heater } \\
\text { 7A/7B }\end{array}$ & $\begin{array}{l}\text { Horizontal U- } \\
\text { tube }\end{array}$ & $\begin{array}{c}1,102,231 \mathrm{~kg} / \mathrm{h}(2,430,000 \\
\mathrm{lb} / \mathrm{h})\end{array}$ & 2 & 0 \\
\hline 12 & $\begin{array}{l}\text { HP Feedwater heater } \\
\text { 8A/8B }\end{array}$ & $\begin{array}{l}\text { Horizontal U- } \\
\text { tube }\end{array}$ & $\begin{array}{c}1,102,231 \mathrm{~kg} / \mathrm{h}(2,430,000 \\
\mathrm{lb} / \mathrm{h})\end{array}$ & 2 & 0 \\
\hline 13 & Auxiliary Boiler & $\begin{array}{l}\text { Shop fabricated, } \\
\text { water tube }\end{array}$ & $\begin{array}{c}18,144 \mathrm{~kg} / \mathrm{h}, 2.8 \mathrm{MPa}, \\
343^{\circ} \mathrm{C} \\
(40,000 \mathrm{lb} / \mathrm{h}, 400 \mathrm{psig}, \\
\left.650^{\circ} \mathrm{F}\right)\end{array}$ & 1 & 0 \\
\hline 14 & Natural Gas System & $\begin{array}{l}\text { Pressure } \\
\text { reducing \& } \\
\text { metering station }\end{array}$ & $\begin{array}{l}46,609 \mathrm{Nm} 3 / \mathrm{h} \\
(29,000 \mathrm{scfm})\end{array}$ & 1 & 0 \\
\hline 15 & $\begin{array}{l}\text { Service Air } \\
\text { Compressors }\end{array}$ & Flooded Screw & $\begin{array}{c}28 \text { m3/min @ 0.7 MPa } \\
\text { (1,000 scfm @100 psig) }\end{array}$ & 2 & 1 \\
\hline 16 & Instrument Air Dryers & $\begin{array}{l}\text { Duplex, } \\
\text { regenerative }\end{array}$ & $28 \mathrm{~m} 3 / \mathrm{min}(1,000 \mathrm{scfm})$ & 2 & 1 \\
\hline 17 & $\begin{array}{l}\text { Closed Cycle Cooling } \\
\text { Heat Exchangers }\end{array}$ & Shell and tube & $\begin{array}{c}53 \mathrm{MMkJ} / \mathrm{h} \\
\text { (50 MMBtu/h) each }\end{array}$ & 2 & 0 \\
\hline 18 & $\begin{array}{l}\text { Closed Cycle Cooling } \\
\text { Water Pumps }\end{array}$ & $\begin{array}{l}\text { Horizontal } \\
\text { centrifugal }\end{array}$ & $\begin{array}{c}\text { 20,820 lpm @ } 30 \text { m H2O } \\
\text { (5,500 gpm @ } 100 \text { ft H2O) }\end{array}$ & 2 & 1 \\
\hline 19 & $\begin{array}{l}\text { Engine-Driven Fire } \\
\text { Pump }\end{array}$ & $\begin{array}{l}\text { Vertical turbine, } \\
\text { diesel engine }\end{array}$ & $\begin{array}{c}\text { 3,785 lpm @ } 88 \text { m H2O } \\
\text { (1,000 gpm @ } 290 \text { ft H2O) }\end{array}$ & 1 & 1 \\
\hline
\end{tabular}




\begin{tabular}{|c|c|c|c|c|c|}
\hline $\begin{array}{c}\text { Equipment } \\
\text { No. }\end{array}$ & Description & Type & Design Condition & $\begin{array}{l}\text { Operating } \\
\text { Qty. }\end{array}$ & Spares \\
\hline 20 & $\begin{array}{l}\text { Fire Service Booster } \\
\text { Pump }\end{array}$ & $\begin{array}{l}\text { Two-stage } \\
\text { horizontal } \\
\text { centrifugal }\end{array}$ & $\begin{array}{l}\text { 2,650lpm @ } 64 \text { m H2O } \\
\text { (700 gpm @ } 210 \text { ft H2O) }\end{array}$ & 1 & 1 \\
\hline 21 & Raw Water Pumps & $\begin{array}{l}\text { Stainless steel, } \\
\text { single suction }\end{array}$ & $\begin{array}{c}\text { 11,470 lpm @ } 43 \text { m H2O } \\
\text { (3,030 gpm @ } 140 \text { ft H2O) }\end{array}$ & 2 & 1 \\
\hline 22 & Filtered Water Pumps & $\begin{array}{l}\text { Stainless steel, } \\
\text { single suction }\end{array}$ & $\begin{array}{c}492 \text { lpm @ } 49 \text { m H2O } \\
\text { (130 gpm @ } 160 \text { ft H2O) }\end{array}$ & 2 & 1 \\
\hline 23 & Filtered Water Tank & $\begin{array}{l}\text { Vertical, } \\
\text { cylindrical }\end{array}$ & 458,038 liter (121,000 gal) & 1 & 0 \\
\hline 24 & $\begin{array}{l}\text { Makeup Water } \\
\text { Demineralizer }\end{array}$ & $\begin{array}{l}\text { Multi-media } \\
\text { filter, cartridge } \\
\text { filter, } \\
\text { RO membrane } \\
\text { assembly, } \\
\text { electro- } \\
\text { deionization } \\
\text { unit } \\
\end{array}$ & 719 lpm (190 gpm) & 1 & 1 \\
\hline 25 & $\begin{array}{l}\text { Liquid Waste } \\
\text { Treatment System }\end{array}$ & -- & 10 years, 24-hour storm & 1 & 0 \\
\hline
\end{tabular}

\section{Account 4 Boiler and Accessories}

Included with boiler scope supplied by ALSTOM

\section{Account 5 Flue Gas Cleanup}

Included with boiler scope supplied by ALSTOM

\section{Account 5B Carbon Dioxide Processing System}

Included with scope supplied by ALSTOM

\section{Account 6 Combustion Turbine and Accessories}

NA

\section{Account 7 HRSG Ducting And Stack}

\begin{tabular}{|c|l|l|c|c|c|}
\hline $\begin{array}{c}\text { Equipment } \\
\text { No. }\end{array}$ & Description & Type & Design Condition & $\begin{array}{c}\text { Operating } \\
\text { Qty. }\end{array}$ & Spares \\
\hline & & Reinforced & & & \\
1 & Stack & concrete, dual & $152 \mathrm{~m}(500 \mathrm{ft})$ high $\mathrm{x}$ & 1 & 0 \\
\hline
\end{tabular}

\section{Account 8 Steam Turbine Generator and Auxiliaries}

\begin{tabular}{|c|c|c|c|c|c|}
\hline $\begin{array}{c}\text { Equipment } \\
\text { No. }\end{array}$ & Description & Type & Design Condition & $\begin{array}{c}\text { Operating } \\
\text { Qty. }\end{array}$ & Spares \\
\hline
\end{tabular}




\begin{tabular}{|c|c|c|c|c|c|}
\hline $\begin{array}{c}\text { Equipment } \\
\text { No. }\end{array}$ & Description & Type & Design Condition & $\begin{array}{c}\text { Operating } \\
\text { Qty. }\end{array}$ & Spares \\
\hline 1 & Steam Turbine & $\begin{array}{l}\text { Included with } \\
\text { scope supplied by } \\
\text { ALSTOM }\end{array}$ & & & \\
\hline 2 & $\begin{array}{l}\text { Steam Turbine } \\
\text { Generator }\end{array}$ & $\begin{array}{l}\text { Included with } \\
\text { scope supplied by } \\
\text { ALSTOM }\end{array}$ & & & \\
\hline 3 & Surface Condenser & $\begin{array}{l}\text { Single pass, } \\
\text { separate shells, } \\
\text { multi-pressure } \\
\text { including vacuum } \\
\text { pumps. } \\
5 \text { min hot well } \\
\text { inventory }\end{array}$ & $\begin{array}{c}\text { 2,920 MMkJ/h } \\
(2,770 \mathrm{MMBtu} / \mathrm{h}), \\
\text { Inlet water temperature } \\
33^{\circ} \mathrm{C}\left(92^{\circ} \mathrm{F}\right), \\
\text { Water temperature rise } \\
13^{\circ} \mathrm{C}\left(24^{\circ} \mathrm{F}\right)\end{array}$ & 1 & 0 \\
\hline
\end{tabular}

\section{Account 9 Cooling Water System}

\begin{tabular}{|c|c|c|c|c|c|}
\hline $\begin{array}{c}\text { Equipment } \\
\text { No. }\end{array}$ & Description & Type & Design Condition & $\begin{array}{l}\text { Operating } \\
\text { Qty. }\end{array}$ & Spares \\
\hline 1 & $\begin{array}{l}\text { Circulating } \\
\text { Water Pumps }\end{array}$ & Vertical, wet pit & $\begin{array}{l}\text { 458,038 lpm @ } 45.7 \text { m } \\
\text { 121,000 gpm @ } 150 \text { ft) }\end{array}$ & 2 & 0 \\
\hline 2 & Cooling Tower & $\begin{array}{l}\text { Evaporative, } \\
\text { mechanical draft, } \\
\text { multi-cell }\end{array}$ & $\begin{array}{c}21^{\circ} \mathrm{C}\left(70^{\circ} \mathrm{F}\right) \text { wet bulb / } \\
33^{\circ} \mathrm{C}\left(92^{\circ} \mathrm{F}\right) \mathrm{CWT} / \\
46^{\circ} \mathrm{C}\left(116^{\circ} \mathrm{F}\right) \mathrm{HWT} \\
3,036 \mathrm{MMkJ} / \mathrm{h}(2,880 \\
\mathrm{MMBtu} / \mathrm{h}) \text { heat load }\end{array}$ & 1 & 0 \\
\hline
\end{tabular}

\section{Account 10 Ash Handling}

\begin{tabular}{|c|l|c|c|c|c|}
\hline $\begin{array}{c}\text { Equipment } \\
\text { No. }\end{array}$ & Description & Type & Design Condition & $\begin{array}{c}\text { Operating } \\
\text { Qty. }\end{array}$ & Spares \\
\hline 1 & $\begin{array}{l}\text { Bed Ash Air } \\
\text { Compressor }\end{array}$ & -- & $\begin{array}{c}2,539 \text { Nm3/h @ 0.25 } \\
\text { MPa (1580 scfm @ 36 } \\
\text { psi) }\end{array}$ & 4 & 0 \\
\hline 2 & Lock hoppers & -- & -- & 12 & 4 \\
\hline 3 & Bed Ash Silo & Reinforced concrete & 4,717 tonnes (5,200 tons) & 1 & 0 \\
\hline 4 & Mixer unloader & -- & 179 tonnes/h (200 tph) & 1 \\
\hline
\end{tabular}


COMMERCIALIZATION DEVELOPMENT OF OXYGEN FIRED

CFB FOR GREENHOUSE GAS CONTROL

\begin{tabular}{|c|c|c|c|c|c|}
\hline $\begin{array}{c}\text { Equipment } \\
\text { No. }\end{array}$ & Description & Type & Design Condition & $\begin{array}{c}\text { Operating } \\
\text { Qty. }\end{array}$ & Spares \\
\hline 5 & $\begin{array}{l}\text { Bed ash silo } \\
\text { vent fan }\end{array}$ & Centrifugal & $\begin{array}{c}\text { 10,125 Nm3/h@ } 0.03 \\
\text { MPa (6300 scfm @ } 5 \\
\text { psi) }\end{array}$ & 1 & 1 \\
\hline 6 & $\begin{array}{l}\text { Slide Gate } \\
\text { Valves }\end{array}$ & -- & -- & 2 & 0 \\
\hline 7 & $\begin{array}{l}\text { Fly Ash Air } \\
\text { Compressor }\end{array}$ & -- & $\begin{array}{l}\text { 1,270 Nm3/h@ } 0.2 \mathrm{MPa} \\
\text { (790 scfm @ 24 psi) }\end{array}$ & 4 & 0 \\
\hline 9 & Lock hoppers & -- & -- & 16 & 0 \\
\hline 10 & Fly Ash Silo & Reinforced concrete & 4,717 tonne $(5,200$ ton $)$ & 1 & 0 \\
\hline 11 & $\begin{array}{l}\text { Slide Gate } \\
\text { Valves }\end{array}$ & -- & -- & 2 & 0 \\
\hline 12 & $\begin{array}{l}\text { Fly ash Mixer } \\
\text { Unloader }\end{array}$ & -- & 179 tonnes/h (200 tph) & 1 & 0 \\
\hline 13 & $\begin{array}{l}\text { Fly ash silo vent } \\
\text { fan }\end{array}$ & Centrifugal & $\begin{array}{c}\text { 5,143 Nm3/h@ } 0.03 \\
\text { MPa(3200 scfm @ } 5 \\
\text { psi) }\end{array}$ & 1 & 1 \\
\hline
\end{tabular}

Account 11 Accessory Electric Plant

\begin{tabular}{|c|c|c|c|c|c|}
\hline $\begin{array}{c}\text { Equipment } \\
\text { No. }\end{array}$ & Description & Type & Design Condition & $\begin{array}{l}\text { Operating } \\
\text { Qty. }\end{array}$ & Spares \\
\hline 1 & $\begin{array}{l}\text { STG } \\
\text { Transformer }\end{array}$ & Oil-filled & $\begin{array}{c}24 \text { kV/345 kV, } 730 \text { MVA, } \\
\text { 3-ph, } 60 \mathrm{~Hz}\end{array}$ & 1 & 0 \\
\hline 2 & $\begin{array}{l}\text { Auxiliary } \\
\text { Transformer }\end{array}$ & Oil-filled & $\begin{array}{c}24 \mathrm{kV} / 4.16 \mathrm{kV}, 58 \mathrm{MVA} \text {, } \\
\text { 3-ph, } 60 \mathrm{~Hz}\end{array}$ & 1 & 1 \\
\hline 3 & $\begin{array}{l}\text { Low } \\
\text { Voltage } \\
\text { Transformer }\end{array}$ & Dry ventilated & $\begin{array}{c}4.16 \mathrm{kV} / 480 \mathrm{~V}, 9 \mathrm{MVA} \text {, } \\
\text { 3-ph, } 60 \mathrm{~Hz}\end{array}$ & 1 & 1 \\
\hline 4 & $\begin{array}{l}\text { STG } \\
\text { Isolated } \\
\text { Phase Bus } \\
\text { Duct and } \\
\text { Tap Bus }\end{array}$ & $\begin{array}{l}\text { Aluminum, self- } \\
\text { cooled }\end{array}$ & 24 kV, 3-ph, $60 \mathrm{~Hz}$ & 1 & 0 \\
\hline 5 & $\begin{array}{l}\text { Medium } \\
\text { Voltage } \\
\text { Switchgear }\end{array}$ & Metal clad & $4.16 \mathrm{kV}, 3-\mathrm{ph}, 60 \mathrm{~Hz}$ & 1 & 1 \\
\hline 6 & $\begin{array}{l}\text { Low } \\
\text { Voltage } \\
\text { Switchgear }\end{array}$ & Metal enclosed & 480 V, 3-ph, $60 \mathrm{~Hz}$ & 1 & 1 \\
\hline
\end{tabular}


COMMERCIALIZATION DEVELOPMENT OF OXYGEN FIRED

CFB FOR GREENHOUSE GAS CONTROL

\begin{tabular}{|c|l|l|c|c|c|}
\hline $\begin{array}{c}\text { Equipment } \\
\text { No. }\end{array}$ & Description & Type & Design Condition & $\begin{array}{c}\text { Operating } \\
\text { Qty. }\end{array}$ & Spares \\
\hline 7 & $\begin{array}{l}\text { Emergency } \\
\text { Diesel } \\
\text { Generator }\end{array}$ & $\begin{array}{l}\text { Sized for emergency } \\
\text { shutdown }\end{array}$ & $750 \mathrm{~kW}, 480 \mathrm{~V}, 3-\mathrm{ph}, 60 \mathrm{~Hz}$ & 1 & 0 \\
\hline
\end{tabular}

Account 12 Instrumentation and Control

\begin{tabular}{|c|l|l|c|c|c|}
\hline $\begin{array}{c}\text { Equipment } \\
\text { No. }\end{array}$ & \multicolumn{1}{|c|}{ Description } & \multicolumn{1}{|c|}{ Type } & Design Condition & $\begin{array}{c}\text { Operating } \\
\text { Qty. }\end{array}$ & Spares \\
\hline 1 & $\begin{array}{l}\text { DCS - Main } \\
\text { Control }\end{array}$ & $\begin{array}{l}\text { Monitor/keyboard; } \\
\text { Operator printer (laser } \\
\text { color); Engineering } \\
\text { printer (laser B\&W) }\end{array}$ & $\begin{array}{c}\text { Operator stations/printers } \\
\text { and engineering } \\
\text { stations/printers }\end{array}$ & 1 & 0 \\
\hline 2 & $\begin{array}{l}\text { DCS - } \\
\text { Processor }\end{array}$ & $\begin{array}{l}\text { Microprocessor with } \\
\text { redundant input/output }\end{array}$ & N/A & 1 & 0 \\
\hline 3 & $\begin{array}{l}\text { DCS - Data } \\
\text { Highway }\end{array}$ & Fiber optic & Fully redundant, 25\% \\
spare & 1 & 0 \\
\hline
\end{tabular}


COMMERCIALIZATION DEVELOPMENT OF OXYGEN FIRED

CFB FOR GREENHOUSE GAS CONTROL

\subsubsection{Capture Ready Case (Case 2a)}

The following tables describe the BOP equipment for Case 2a (Capture Ready)

Account 1 Fuel and Sorbent Handling

\begin{tabular}{|c|c|c|c|c|c|}
\hline $\begin{array}{c}\text { Equipment } \\
\text { No. }\end{array}$ & Description & Type & Design Condition & $\begin{array}{l}\text { Operating } \\
\text { Qty. }\end{array}$ & Spares \\
\hline 1 & $\begin{array}{l}\text { Bottom Trestle Dumper } \\
\text { and Receiving Hoppers }\end{array}$ & N/A & 181 tonne (200 ton) & 2 & 0 \\
\hline 2 & Feeder & Belt & 572 tonne/h (630 tph) & 2 & 0 \\
\hline 3 & Conveyor No. 1 & Belt & $\begin{array}{c}1,134 \text { tonne/h }(1,250 \\
\text { tph })\end{array}$ & 1 & 1 \\
\hline 4 & Transfer Tower No. 1 & $\begin{array}{l}\text { Enclosed, w/dust } \\
\text { collection }\end{array}$ & N/A & 1 & 0 \\
\hline 5 & Conveyor No. 2 & $\begin{array}{l}\text { Belt w/magnetic } \\
\text { separator }\end{array}$ & $\begin{array}{c}1,134 \text { tonne/h }(1,250 \\
\text { tph })\end{array}$ & 1 & 1 \\
\hline 6 & $\begin{array}{l}\text { As-Received Coal } \\
\text { Sampling System }\end{array}$ & Two-stage & N/A & 1 & 0 \\
\hline 7 & Stacker & $\begin{array}{l}\text { Traveling, linear, } \\
\text { double wing }\end{array}$ & $\begin{array}{c}1,134 \text { tonne/h }(1,250 \\
\text { tph })\end{array}$ & 1 & 0 \\
\hline 8 & Reclaim Rotary Plow & $\begin{array}{l}\text { Low profile, } \\
\text { single tunnel }\end{array}$ & 381 tonne (420 ton) & 1 & 1 \\
\hline 9 & Reclaim Conveyor & Belt w/ scale & 381 tonne/h (420 tph) & 1 & 0 \\
\hline 10 & Conveyor No. 3 & Belt w/ tripper & 381 tonne/h (420 tph) & 1 & 0 \\
\hline 11 & Crusher Tower & $\begin{array}{l}\text { Enclosed w/dust } \\
\text { collection }\end{array}$ & N/A & 1 & 0 \\
\hline 12 & $\begin{array}{l}\text { Coal Surge Bin w/ Vent } \\
\text { Filter }\end{array}$ & Dual outlet & 191 tonne (210 ton) & 2 & 0 \\
\hline 13 & Crusher & Granulator & 191 tonne/h (210 tph) & 2 & 1 \\
\hline 14 & $\begin{array}{l}\text { As-Fired Coal Sampling } \\
\text { System }\end{array}$ & N/A & N/A & 1 & 0 \\
\hline 15 & Conveyor No. 4 & Belt w/tripper & 381 tonne/h (420 tph) & 1 & 0 \\
\hline 16 & Transfer Tower No. 2 & Enclosed & N/A & 1 & 0 \\
\hline 17 & Conveyor No. 5 & Belt w/ tripper & 381 tonne/h (420 tph) & 1 & 0 \\
\hline 18 & $\begin{array}{l}\text { Reclaim Hopper } \\
\text { (Emergency) }\end{array}$ & N/A & 91 tonne (100 ton) & 0 & 1 \\
\hline
\end{tabular}


COMMERCIALIZATION DEVELOPMENT OF OXYGEN FIRED

CFB FOR GREENHOUSE GAS CONTROL

\begin{tabular}{|c|c|c|c|c|c|}
\hline $\begin{array}{c}\text { Equipment } \\
\text { No. }\end{array}$ & Description & Type & Design Condition & $\begin{array}{l}\text { Operating } \\
\text { Qty. }\end{array}$ & Spares \\
\hline 19 & $\begin{array}{l}\text { Reclaim Conveyor } \\
\text { (Emergency) }\end{array}$ & Belt w/scale & 381 tonne (420 ton) & 0 & 1 \\
\hline 20 & $\begin{array}{l}\text { Limestone Truck } \\
\text { Unloading Hopper }\end{array}$ & N/A & 36 tonne (40 ton) & 1 & 0 \\
\hline 21 & Limestone Feeder & Belt & 109 tonne/h (120 tph) & 1 & 0 \\
\hline 22 & $\begin{array}{l}\text { Limestone Conveyor } \\
\text { No. L1 }\end{array}$ & Belt & 109 tonne/h (120 tph) & 1 & 0 \\
\hline 23 & $\begin{array}{l}\text { Limestone Reclaim } \\
\text { Hopper }\end{array}$ & N/A & 18 tonne (20 ton) & 1 & 0 \\
\hline 24 & $\begin{array}{l}\text { Limestone Reclaim } \\
\text { Feeder }\end{array}$ & Belt & 91 tonne/h (100 tph) & 1 & 0 \\
\hline 25 & $\begin{array}{l}\text { Limestone Conveyor } \\
\text { No. L2 }\end{array}$ & Belt & 91 tonne/h (100 tph) & 1 & 0 \\
\hline 26 & Limestone Surge Bin & Dual outlet & 18 tonne (20 ton) & 1 & 0 \\
\hline 27 & Limestone Crusher & $\begin{array}{l}\text { Impactor } \\
\text { reduction }\end{array}$ & 91 tonne/h (100 ton) & 1 & 0 \\
\hline 28 & $\begin{array}{l}\text { Limestone Conveyor } \\
\text { No. L3 }\end{array}$ & Belt & 91 tonne/h (100 tph) & 1 & 0 \\
\hline
\end{tabular}

\section{Account 2 Coal and Sorbent Feed System}

Included with boiler scope supplied by ALSTOM

\section{Account 3 Feedwater and Miscellaneous Systems and Equipment}

\begin{tabular}{|c|l|c|c|c|c|}
\hline $\begin{array}{c}\text { Equipment } \\
\text { No. }\end{array}$ & \multicolumn{1}{|c|}{ Description } & Type & Design Condition & $\begin{array}{c}\text { Operating } \\
\text { Qty. }\end{array}$ & Spares \\
\hline 1 & $\begin{array}{l}\text { Demineralized } \\
\text { Water Storage Tank }\end{array}$ & $\begin{array}{c}\text { Vertical, cylindrical, } \\
\text { outdoor }\end{array}$ & $\begin{array}{c}2,642,238 \text { liters } \\
(700,000 \text { gal })\end{array}$ & 2 & 0 \\
\hline 2 & Condensate Pumps & $\begin{array}{c}\text { Vertical canned, with } \\
\text { VFD }\end{array}$ & $\begin{array}{c}\text { H2O,312 lpm @ } 244 \mathrm{~m} \\
(8,800 \mathrm{gpm} @ \\
800 \mathrm{ft} \mathrm{H} 2 \mathrm{O})\end{array}$ & 1 & 1 \\
\hline 3 & Deaerator and & Horizontal spray type & $\begin{array}{c}3,138,165 \mathrm{~kg} / \mathrm{h} \\
(7,700,000 \mathrm{lb} / \mathrm{h}), \\
10 \mathrm{~min} . \mathrm{tank}\end{array}$ & 1 & 0 \\
\hline
\end{tabular}


COMMERCIALIZATION DEVELOPMENT OF OXYGEN FIRED

CFB FOR GREENHOUSE GAS CONTROL

\begin{tabular}{|c|c|c|c|c|c|}
\hline $\begin{array}{c}\text { Equipment } \\
\text { No. }\end{array}$ & Description & Type & Design Condition & $\begin{array}{l}\text { Operating } \\
\text { Qty. }\end{array}$ & Spares \\
\hline 4 & $\begin{array}{l}\text { Boiler Feed } \\
\text { Pump/Turbine }\end{array}$ & $\begin{array}{l}\text { Barrel type, multi-stage, } \\
\text { centrifugal }\end{array}$ & $\begin{array}{c}\text { 25,362 lpm } \\
\text { @ } 3,841 \mathrm{~m} \mathrm{H} 2 \mathrm{O} \\
(6,700 \mathrm{gpm} \\
\text { @ } 12,600 \mathrm{ft} \mathrm{H2O})\end{array}$ & 2 & 1 \\
\hline 5 & $\begin{array}{l}\text { Startup Boiler Feed } \\
\text { Pump, Electric } \\
\text { Motor Driven }\end{array}$ & $\begin{array}{l}\text { Barrel type, multi-stage, } \\
\text { centrifugal }\end{array}$ & $\begin{array}{c}\text { 7,571 lpm } \\
\text { @ } 3,841 \mathrm{~m} \mathrm{H} 2 \mathrm{O} \\
(2,000 \mathrm{gpm} \\
\text { @ } 12,600 \mathrm{ft} \mathrm{H} 2 \mathrm{O})\end{array}$ & 2 & 1 \\
\hline 6 & $\begin{array}{l}\text { LP Feedwater } \\
\text { Heater } 1\end{array}$ & Horizontal U-tube & $\begin{array}{c}1,542,216 \mathrm{~kg} / \mathrm{h} \\
(3,400,000 \mathrm{lb} / \mathrm{h})\end{array}$ & 1 & 0 \\
\hline 7 & $\begin{array}{l}\text { LP Feedwater } \\
\text { Heater } 2\end{array}$ & Horizontal U-tube & $\begin{array}{c}1,542,216 \mathrm{~kg} / \mathrm{h} \\
(3,400,000 \mathrm{lb} / \mathrm{h})\end{array}$ & 1 & 0 \\
\hline 8 & $\begin{array}{l}\text { LP Feedwater } \\
\text { Heater } 3\end{array}$ & Horizontal U-tube & $\begin{array}{c}1,542,216 \mathrm{~kg} / \mathrm{h} \\
(3,400,000 \mathrm{lb} / \mathrm{h})\end{array}$ & 1 & 0 \\
\hline 9 & $\begin{array}{l}\text { LP Feedwater } \\
\text { Heater } 4\end{array}$ & Horizontal U-tube & $\begin{array}{c}1,542,216 \mathrm{~kg} / \mathrm{h} \\
(3,400,000 \mathrm{lb} / \mathrm{h})\end{array}$ & 1 & 0 \\
\hline 10 & $\begin{array}{l}\text { HP Feedwater } \\
\text { Heater } 6 \mathrm{~A} / 6 \mathrm{~B}\end{array}$ & Horizontal U-tube & $\begin{array}{c}1,519,536 \mathrm{~kg} / \mathrm{h} \\
(3,350,000 \mathrm{lb} / \mathrm{h})\end{array}$ & 2 & 0 \\
\hline 11 & $\begin{array}{l}\text { HP Feedwater } \\
\text { Heater 7A/7B }\end{array}$ & Horizontal U-tube & $\begin{array}{c}1,519,536 \mathrm{~kg} / \mathrm{h} \\
(3,350,000 \mathrm{lb} / \mathrm{h})\end{array}$ & 2 & 0 \\
\hline 12 & $\begin{array}{l}\text { HP Feedwater heater } \\
\text { 8A/8B }\end{array}$ & Horizontal U-tube & $\begin{array}{c}1,519,536 \mathrm{~kg} / \mathrm{h} \\
(3,350,000 \mathrm{lb} / \mathrm{h})\end{array}$ & 2 & 0 \\
\hline 13 & Auxiliary Boiler & $\begin{array}{l}\text { Shop fabricated, water } \\
\text { tube }\end{array}$ & $\begin{array}{c}18,144 \mathrm{~kg} / \mathrm{h}, 2.8 \\
\mathrm{MPa}, 343^{\circ} \mathrm{C} \\
(40,000 \mathrm{lb} / \mathrm{h}, 400 \\
\left.\text { psig, } 650^{\circ} \mathrm{F}\right)\end{array}$ & 1 & 0 \\
\hline 14 & Natural Gas System & $\begin{array}{l}\text { Pressure reducing \& } \\
\text { metering station }\end{array}$ & $\begin{array}{l}46,609 \mathrm{Nm} 3 / \mathrm{h} \\
(29,000 \mathrm{scfm})\end{array}$ & 1 & 0 \\
\hline 15 & $\begin{array}{l}\text { Service Air } \\
\text { Compressors }\end{array}$ & Flooded Screw & $\begin{array}{c}28 \text { m3/min @ } 0.7 \\
\text { MPa } 1,000 \text { scfm @ } \\
100 \text { psig) }\end{array}$ & 2 & 1 \\
\hline 16 & $\begin{array}{l}\text { Instrument Air } \\
\text { Dryers }\end{array}$ & Duplex, regenerative & $\begin{array}{c}28 \mathrm{~m} 3 / \min (1,000 \\
\text { scfm })\end{array}$ & 2 & 1 \\
\hline 17 & $\begin{array}{l}\text { Closed Cycle } \\
\text { Cooling Heat } \\
\text { Exchangers } \\
\end{array}$ & Shell and tube & $\begin{array}{c}53 \mathrm{MMkJ} / \mathrm{h} \\
\text { (50 MMBtu/h) each }\end{array}$ & 2 & 0 \\
\hline 18 & $\begin{array}{l}\text { Closed Cycle } \\
\text { Cooling Water } \\
\text { Pumps }\end{array}$ & Horizontal centrifugal & $\begin{array}{c}\text { 20,820 lpm @ } 30 \text { m } \\
\text { H2O (5,500 gpm @ } \\
100 \text { ft H2O) }\end{array}$ & 2 & 1 \\
\hline 19 & $\begin{array}{l}\text { Engine-Driven Fire } \\
\text { Pump }\end{array}$ & $\begin{array}{l}\text { Vertical turbine, diesel } \\
\text { engine }\end{array}$ & $\begin{array}{c}\text { 3,785 lpm @ } 88 \text { m } \\
\text { H2O (1,000 gpm @ } \\
290 \text { ft H2O) }\end{array}$ & 1 & 1 \\
\hline 20 & $\begin{array}{l}\text { Fire Service Booster } \\
\text { Pump }\end{array}$ & $\begin{array}{l}\text { Two-stage horizontal } \\
\text { centrifugal }\end{array}$ & $\begin{array}{l}\text { 2,650lpm @ } 64 \text { m } \\
\text { H2O (700 gpm } \\
\text { @ 210 ft H2O) }\end{array}$ & 1 & 1 \\
\hline
\end{tabular}




\begin{tabular}{|c|c|c|c|c|c|}
\hline $\begin{array}{c}\text { Equipment } \\
\text { No. }\end{array}$ & Description & Type & Design Condition & $\begin{array}{l}\text { Operating } \\
\text { Qty. }\end{array}$ & Spares \\
\hline 21 & Raw Water Pumps & $\begin{array}{l}\text { Stainless steel, single } \\
\text { suction }\end{array}$ & $\begin{array}{l}\text { 16,050 lpm @ } 43 \text { m } \\
\text { H2O (4,240 gpm } \\
\text { @140 ft H2O) }\end{array}$ & 2 & 1 \\
\hline 22 & $\begin{array}{l}\text { Filtered Water } \\
\text { Pumps }\end{array}$ & $\begin{array}{l}\text { Stainless steel, single } \\
\text { suction }\end{array}$ & $\begin{array}{l}681 \text { lpm @ } 49 \text { m } \\
\text { H2O (180 gpm } \\
\text { @ } 160 \mathrm{ft} \mathrm{H2O})\end{array}$ & 2 & 1 \\
\hline 23 & Filtered Water Tank & Vertical, cylindrical & $\begin{array}{l}\text { 458,038 liter } \\
(121,000 \text { gal })\end{array}$ & 1 & 0 \\
\hline 24 & $\begin{array}{l}\text { Makeup Water } \\
\text { Demineralizer }\end{array}$ & $\begin{array}{l}\text { Multi-media filter, } \\
\text { cartridge filter, RO } \\
\text { membrane assembly, } \\
\text { electro-deionization unit }\end{array}$ & 1,022 lpm (270 gpm) & 1 & 1 \\
\hline 25 & $\begin{array}{l}\text { Liquid Waste } \\
\text { Treatment System }\end{array}$ & -- & $\begin{array}{l}10 \text { years, } 24 \text {-hour } \\
\text { storm }\end{array}$ & 1 & 0 \\
\hline
\end{tabular}

\section{Account 4 Boiler and Accessories}

Included with boiler scope supplied by ALSTOM

\section{Account 5 Flue Gas Cleanup}

Included with boiler scope supplied by ALSTOM

\section{Account 5B Carbon Dioxide Processing System}

Included with scope supplied by ALSTOM

\section{Account 6 Combustion Turbine and Accessories}

NA

Account 7 HRSG Ducting and Stack

\begin{tabular}{|c|c|c|c|c|c|}
\hline $\begin{array}{l}\text { Equipment } \\
\text { No. }\end{array}$ & Description & Type & Design Condition & $\begin{array}{l}\text { Operating } \\
\text { Qty. }\end{array}$ & Spares \\
\hline 1 & Stack & $\begin{array}{l}\text { Reinforced concrete, } \\
\text { dual flues with FRP } \\
\text { liner }\end{array}$ & $\begin{array}{c}152 \mathrm{~m} \text { (500 ft) high x } 5.2 \mathrm{~m} \\
\text { (17ft) flue ID }\end{array}$ & 1 & 0 \\
\hline
\end{tabular}

\section{Account 8 Steam Turbine Generator and Auxiliaries}

\begin{tabular}{|c|c|c|c|c|c|}
\hline $\begin{array}{c}\text { Equipment } \\
\text { No. }\end{array}$ & Description & Type & Design Condition & $\begin{array}{c}\text { Operating } \\
\text { Qty. }\end{array}$ & Spares \\
\hline
\end{tabular}




\begin{tabular}{|c|c|c|c|c|c|}
\hline $\begin{array}{c}\text { Equipment } \\
\text { No. }\end{array}$ & Description & Type & Design Condition & $\begin{array}{l}\text { Operating } \\
\text { Qty. }\end{array}$ & Spares \\
\hline 1 & Steam Turbine & $\begin{array}{l}\text { Included with scope } \\
\text { supplied by } \\
\text { ALSTOM }\end{array}$ & & & \\
\hline 2 & $\begin{array}{l}\text { Steam Turbine } \\
\text { Generator }\end{array}$ & $\begin{array}{l}\text { Included with scope } \\
\text { supplied by } \\
\text { ALSTOM }\end{array}$ & & & \\
\hline 1 & Surface Condenser & $\begin{array}{l}\text { Single pass, } \\
\text { separate shells, } \\
\text { multi-pressure } \\
\text { including vacuum } \\
\text { pumps. } 5 \text { min hot } \\
\text { well inventory }\end{array}$ & $\begin{array}{c}\text { 4,406 MMkJ/h } \\
(4,180 \mathrm{MMBtu} / \mathrm{h}) \text {, } \\
\text { Inlet water temperature } \\
33^{\circ} \mathrm{C}\left(92^{\circ} \mathrm{F}\right) \text {, } \\
\text { Water temperature rise } \\
13^{\circ} \mathrm{C}\left(24^{\circ} \mathrm{F}\right)\end{array}$ & 1 & 0 \\
\hline
\end{tabular}

\section{Account 9 Cooling Water System}

\begin{tabular}{|c|c|c|c|c|c|}
\hline $\begin{array}{l}\text { Equipment } \\
\text { No. }\end{array}$ & Description & Type & Design Condition & $\begin{array}{l}\text { Operating } \\
\text { Qty. }\end{array}$ & Spares \\
\hline 1 & $\begin{array}{l}\text { Circulating } \\
\text { Water Pumps }\end{array}$ & Vertical, wet pit & $\begin{array}{c}\text { 458,038 lpm @ } 45.7 \text { m } \\
(121,000 \text { gpm @ } 150 \mathrm{ft})\end{array}$ & 2 & 0 \\
\hline 2 & Cooling Tower & $\begin{array}{l}\text { Evaporative, } \\
\text { mechanical draft, } \\
\text { nine cells }\end{array}$ & $\begin{array}{c}21^{\circ} \mathrm{C}\left(70^{\circ} \mathrm{F}\right) \text { wet bulb / } \\
33^{\circ} \mathrm{C}\left(92^{\circ} \mathrm{F}\right) \mathrm{CWT} / \\
46^{\circ} \mathrm{C}\left(116^{\circ} \mathrm{F}\right) \mathrm{HWT} \\
3,036 \mathrm{MMkJ} / \mathrm{h} \\
(2,880 \mathrm{MMBtu} / \mathrm{h}) \text { heat load }\end{array}$ & 1 & 0 \\
\hline
\end{tabular}

\section{Account 10 Ash Handling}

\begin{tabular}{|c|l|c|c|c|c|}
\hline $\begin{array}{c}\text { Equipment } \\
\text { No. }\end{array}$ & Description & Type & Design Condition & $\begin{array}{c}\text { Operating } \\
\text { Qty. }\end{array}$ & Spares \\
\hline 1 & $\begin{array}{l}\text { Bed Ash Air } \\
\text { Compressor }\end{array}$ & -- & $\begin{array}{c}2,539 \text { Nm3/h @ 0.25 MPa } \\
(1580 \text { scfm @ 36 psi) }\end{array}$ & 4 & 0 \\
\hline 2 & Lock hoppers & -- & -- & 12 & 4 \\
\hline
\end{tabular}


COMMERCIALIZATION DEVELOPMENT OF OXYGEN FIRED

CFB FOR GREENHOUSE GAS CONTROL

\begin{tabular}{|c|c|c|c|c|c|}
\hline $\begin{array}{c}\text { Equipment } \\
\text { No. }\end{array}$ & Description & Type & Design Condition & $\begin{array}{c}\text { Operating } \\
\text { Qty. }\end{array}$ & Spares \\
\hline 3 & Bed Ash Silo & Reinforced concrete & 4,717 tonnes $(5,200$ tons $)$ & 1 & 0 \\
\hline 4 & $\begin{array}{l}\text { Mixer } \\
\text { Unloader }\end{array}$ & -- & 179 tonnes/h (200 tph) & 1 & 0 \\
\hline 5 & $\begin{array}{l}\text { Bed ash silo } \\
\text { vent fan }\end{array}$ & Centrifugal & $\begin{array}{c}\text { 10,125 Nm3/h@ } 0.03 \text { MPa } \\
\text { (6300 scfm @ } 5 \text { psi) }\end{array}$ & 1 & 1 \\
\hline 6 & $\begin{array}{l}\text { Slide Gate } \\
\text { Valves }\end{array}$ & -- & -- & 2 & 0 \\
\hline 7 & $\begin{array}{l}\text { Fly Ash Air } \\
\text { Compressor }\end{array}$ & -- & $\begin{array}{l}\text { 1,270 Nm3/h@ } 0.2 \mathrm{MPa} \\
\text { (790 scfm @ } 24 \text { psi) }\end{array}$ & 4 & 0 \\
\hline 9 & Lock hoppers & -- & -- & 16 & 0 \\
\hline 10 & Fly Ash Silo & Reinforced concrete & 4,717 tonne $(5,200$ ton $)$ & 1 & 0 \\
\hline 11 & $\begin{array}{l}\text { Slide Gate } \\
\text { Valves }\end{array}$ & -- & -- & 2 & 0 \\
\hline 12 & $\begin{array}{l}\text { Fly ash Mixer } \\
\text { Unloader }\end{array}$ & -- & 179 tonnes/h (200 tph) & 1 & 0 \\
\hline 13 & $\begin{array}{l}\text { Fly ash silo } \\
\text { vent fan }\end{array}$ & Centrifugal & $\begin{array}{l}\text { 5,143 Nm3/h@ } 0.03 \text { MPa } \\
\text { (3200 scfm @ } 5 \text { psi) }\end{array}$ & 1 & 1 \\
\hline
\end{tabular}

Account 11 Accessory Electric Plant

\begin{tabular}{|c|l|l|c|c|c|}
\hline $\begin{array}{c}\text { Equipment } \\
\text { No. }\end{array}$ & Description & \multicolumn{1}{|c|}{ Type } & Design Condition & $\begin{array}{c}\text { Operating } \\
\text { Qty. }\end{array}$ & Spares \\
\hline 1 & $\begin{array}{l}\text { STG } \\
\text { Transformer }\end{array}$ & Oil-filled & $\begin{array}{r}24 \mathrm{kV} / 345 \mathrm{kV}, 730 \mathrm{MVA}, \\
3-\mathrm{ph}, 60 \mathrm{~Hz}\end{array}$ & 1 & 0 \\
\hline 2 & $\begin{array}{l}\text { Auxiliary } \\
\text { Transformer }\end{array}$ & Oil-filled & $\begin{array}{c}24 \mathrm{kV} / 4.16 \mathrm{kV}, 58 \mathrm{MVA}, \\
3-\mathrm{ph}, 60 \mathrm{~Hz}\end{array}$ & 1 & 1 \\
\hline 3 & $\begin{array}{l}\text { Low } \\
\text { Voltage } \\
\text { Transformer }\end{array}$ & Dry ventilated & $\begin{array}{r}4.16 \mathrm{kV} / 480 \mathrm{~V}, 9 \mathrm{MVA}, \\
3-\mathrm{ph}, 60 \mathrm{~Hz}\end{array}$ & 1 & 1 \\
\hline 4 & $\begin{array}{l}\text { STG } \\
\text { Isolated } \\
\text { Phase Bus } \\
\text { Duct and } \\
\text { Tap Bus }\end{array}$ & Aluminum, self-cooled & $24 \mathrm{kV}, 3-\mathrm{ph}, 60 \mathrm{~Hz}$ & 1 & 0 \\
\hline
\end{tabular}


COMMERCIALIZATION DEVELOPMENT OF OXYGEN FIRED

CFB FOR GREENHOUSE GAS CONTROL

\begin{tabular}{|c|l|l|c|c|c|}
\hline $\begin{array}{c}\text { Equipment } \\
\text { No. }\end{array}$ & Description & Type & Design Condition & $\begin{array}{c}\text { Operating } \\
\text { Qty. }\end{array}$ & Spares \\
\hline 5 & $\begin{array}{l}\text { Medium } \\
\text { Voltage } \\
\text { Switchgear }\end{array}$ & Metal clad & $4.16 \mathrm{kV}, 3-\mathrm{ph}, 60 \mathrm{~Hz}$ & 1 & 1 \\
\hline 6 & $\begin{array}{l}\text { Low } \\
\text { Voltage } \\
\text { Switchgear }\end{array}$ & Metal enclosed & $480 \mathrm{~V}, 3-\mathrm{ph}, 60 \mathrm{~Hz}$ & 1 & 1 \\
\hline 7 & $\begin{array}{l}\text { Emergency } \\
\text { Diesel } \\
\text { Generator }\end{array}$ & $\begin{array}{l}\text { Sized for emergency } \\
\text { shutdown }\end{array}$ & $750 \mathrm{~kW}, 480 \mathrm{~V}, 3-\mathrm{ph}, 60 \mathrm{~Hz}$ & 1 & 0 \\
\hline
\end{tabular}

Account 12 Instrumentation and Control

\begin{tabular}{|c|l|l|l|c|c|}
\hline $\begin{array}{c}\text { Equipment } \\
\text { No. }\end{array}$ & \multicolumn{1}{|c|}{ Description } & \multicolumn{1}{|c|}{ Type } & Design Condition & $\begin{array}{c}\text { Operating } \\
\text { Qty. }\end{array}$ & Spares \\
\hline 1 & $\begin{array}{l}\text { DCS - Main } \\
\text { Control }\end{array}$ & $\begin{array}{l}\text { Monitor/keyboard; } \\
\text { Operator printer (laser } \\
\text { color); Engineering } \\
\text { printer (laser B\&W) }\end{array}$ & $\begin{array}{l}\text { Operator } \\
\text { stations/printers and } \\
\text { engineering } \\
\text { stations/printers }\end{array}$ & 1 & 0 \\
\hline 2 & $\begin{array}{l}\text { DCS - } \\
\text { Processor }\end{array}$ & $\begin{array}{l}\text { Microprocessor with } \\
\text { redundant input/output }\end{array}$ & N/A & 1 & 0 \\
\hline 3 & $\begin{array}{l}\text { DCS - Data } \\
\text { Highway }\end{array}$ & Fiber optic & $\begin{array}{l}\text { Fully redundant, 25\% } \\
\text { spare }\end{array}$ & 1 & 0 \\
\hline
\end{tabular}




\subsubsection{Capture Ready Converted to Oxygen Firing (Case 2b)}

The following tables describe the BOP equipment for Case 2b (Capture Ready converted to oxygen firing and $\mathrm{CO}_{2}$ capture)

\section{Account 1 Fuel and Sorbent Handling}

The existing Capture ready plant (Case 2a) coal handling system will operate 6 days/week and three 8-hour shifts per day (vs. 5 days/week and two 8-hour shift per day for Case 2a) to handle increased coal feed rate.

Coal inventory in the existing active storage coal pile will be reduced from 7 days to 5 days of operation. Coal inventory in the long-term storage pile will be increased and maintained at 30 days of operation.

The existing Capture ready plant limestone handling equipment will be removed from operation and abandoned in place.

The following new lime handling system is added as a part of Oxyfuel conversion.

\begin{tabular}{|c|c|c|c|c|c|}
\hline $\begin{array}{c}\text { Equipment } \\
\text { No. }\end{array}$ & Description & Type & Design Condition & $\begin{array}{l}\text { Operating } \\
\text { Qty. }\end{array}$ & Spares \\
\hline 1 & $\begin{array}{l}\text { Lime Truck } \\
\text { Unloading }\end{array}$ & $\begin{array}{l}\text { Pipeline with Quick } \\
\text { disconnect fitting }\end{array}$ & 45 tonne/h (50 tph) & 1 & 1 \\
\hline 2 & Lime Silo & $\begin{array}{l}\text { Reinforced } \\
\text { concrete }\end{array}$ & 3,084 tonne $(3,400$ ton $)$ & 1 & 0 \\
\hline 3 & Lime Feeder & Rotary & 20 tonne/h (22 tph) & 1 & 1 \\
\hline 4 & $\begin{array}{l}\text { Lime Transfer } \\
\text { Compressor }\end{array}$ & -- & $\begin{array}{c}\text { 1,607 Nm3/h@ } 0.17 \\
\text { MPa(1000 scfm @ } 25 \\
\text { psi) }\end{array}$ & 1 & 1 \\
\hline 5 & Lime Day Bin & Carbon steel & 245 tonne (270 tons) & 2 & 0 \\
\hline 6 & Lime Feeder & Rotary & 10 tonne/h (11 tph) & 2 & 0 \\
\hline 7 & $\begin{array}{l}\text { Lime Feed } \\
\text { Compressor }\end{array}$ & -- & $\begin{array}{c}804 \text { Nm3/h @ } 0.17 \text { MPa } \\
\text { (500 scfm @ } 25 \text { psi) }\end{array}$ & 2 & 1 \\
\hline
\end{tabular}

\section{Account 2 Coal and Sorbent Feed System}

Included with boiler scope supplied by ALSTOM

\section{Account 3 Feedwater and Miscellaneous Systems and Equipment}

The existing capture ready plant (Case 2a) feedwater and miscellaneous systems have been sized to meet increased requirements of the plant converted to Oxyfuel operation. 


\section{Account 4 Boiler and Accessories}

Included with boiler scope supplied by ALSTOM

\section{Account 5 Flue Gas Cleanup}

Included with boiler scope supplied by ALSTOM

\section{Account 5B Carbon Dioxide Processing System}

Included with scope supplied by ALSTOM

\section{Account 6 Combustion Turbine and Accessories}

NA

\section{Account 7 HRSG Ducting and Stack}

The existing capture ready plant (Case 2a) stack and ducting is sufficient for part load air-fired operation during startup. A relatively small amount of flue gas ( $3 \%$ of Case 2 a flow) will be vented through the stack during the oxygen fired operation.

\section{Account 8 Steam Turbine Generator and Auxiliaries}

The existing capture ready plant (Case 2a) condenser system has been sized to meet increased requirements of the plant converted to Oxyfuel operation. Steam turbine-generator modifications are included in ALSTOM's scope.

\section{Account 9 Cooling Water System}

The following additional equipment will be added as a part of Oxyfuel conversion.

\begin{tabular}{|c|c|c|c|c|c|}
\hline $\begin{array}{c}\text { Equipment } \\
\text { No. }\end{array}$ & Description & Type & Design Condition & $\begin{array}{l}\text { Operating } \\
\text { Qty. }\end{array}$ & Spares \\
\hline 1 & $\begin{array}{l}\text { Circulating } \\
\text { Water Pump }\end{array}$ & Vertical, wet pit & $\begin{array}{l}\text { 458,038 lpm @ } 45.7 \text { m } \\
(121,000 \text { gpm @ } 150 \text { ft) }\end{array}$ & 1 & 0 \\
\hline 2 & Cooling Tower & $\begin{array}{l}\text { Evaporative, } \\
\text { mechanical draft, } \\
\text { four-cell extension }\end{array}$ & $\begin{array}{c}21^{\circ} \mathrm{C}\left(70^{\circ} \mathrm{F}\right) \text { wet bulb / } \\
33^{\circ} \mathrm{C}\left(92^{\circ} \mathrm{F}\right) \mathrm{CWT} / \\
46^{\circ} \mathrm{C}\left(116^{\circ} \mathrm{F}\right) \mathrm{HWT} \\
\text { 1,486 MMkJ/h } \\
(1,410 \mathrm{MMBtu} / \mathrm{h}) \\
\text { additional heat load }\end{array}$ & 1 & 0 \\
\hline
\end{tabular}

\section{Account 10 Ash Handling}

The existing Capture ready plant (Case 2a) ash handling system will operate 6 days/week and 14 hours per day (vs. 5 days/week and two 12 hours shift per day for Case 2a) to handle increased ash flow rate.

Retention time of the existing ash silos will be reduced from 72 hours to 55 hours.

The following additional equipment will be added as a part of Oxyfuel conversion. 


\begin{tabular}{|c|l|c|c|c|c|}
\hline $\begin{array}{c}\text { Equipment } \\
\text { No. }\end{array}$ & Description & Type & Design Condition & $\begin{array}{c}\text { Operating } \\
\text { Qty. }\end{array}$ & Spares \\
\hline 1 & $\begin{array}{l}\text { Bed Ash Air } \\
\text { Compressor }\end{array}$ & -- & $\begin{array}{c}2,539 \mathrm{Nm} 3 / \mathrm{h} @ 0.25 \mathrm{MPa} \\
(1580 \mathrm{scfm} @ 36 \mathrm{psi})\end{array}$ & 1 & 0 \\
\hline 2 & $\begin{array}{l}\text { Fly Ash Air } \\
\text { Compressor }\end{array}$ & -- & $\begin{array}{c}1,270 \mathrm{Nm} 3 / \mathrm{h} @ 0.2 \mathrm{MPa} \\
(790 \mathrm{scfm} @ 24 \mathrm{psi})\end{array}$ & 1 \\
\hline
\end{tabular}

\section{Account 11 Accessory Electric Plant}

The following additional equipment will be added as a part of Oxyfuel conversion.

\begin{tabular}{|c|c|c|c|c|c|}
\hline $\begin{array}{c}\text { Equipment } \\
\text { No. }\end{array}$ & Description & Type & Design Condition & $\begin{array}{l}\text { Operating } \\
\text { Qty. }\end{array}$ & Spares \\
\hline 1 & $\begin{array}{l}\text { ASU \& Gas } \\
\text { Processing } \\
\text { Auxiliary } \\
\text { Transformer }\end{array}$ & Oil-filled & $\begin{array}{l}24 \mathrm{kV} / 13.8 \mathrm{kV}, 220 \mathrm{MVA} \text {, } \\
\text { 3-ph, } 60 \mathrm{~Hz}\end{array}$ & 1 & 1 \\
\hline 2 & $\begin{array}{l}\text { ASU \& Gas } \\
\text { Processing } \\
\text { Medium } \\
\text { voltage } \\
\text { Transformer }\end{array}$ & Oil-filled & $\begin{array}{l}24 \mathrm{kV} / 4.16 \mathrm{kV}, 90 \mathrm{MVA} \text {, } \\
\text { 3-ph, } 60 \mathrm{~Hz}\end{array}$ & 1 & 1 \\
\hline 3 & $\begin{array}{l}\text { ASU \& Gas } \\
\text { Processing } \\
\text { Low Voltage } \\
\text { Transformer }\end{array}$ & Dry ventilated & $\begin{array}{l}4.16 \mathrm{kV} / 480 \mathrm{~V}, 10 \mathrm{MVA} \text {, } \\
\text { 3-ph, } 60 \mathrm{~Hz}\end{array}$ & 1 & 1 \\
\hline 4 & $\begin{array}{l}\text { ASU \& Gas } \\
\text { Processing } \\
\text { Isolated } \\
\text { Phase Bus } \\
\text { Duct and Tap } \\
\text { Bus }\end{array}$ & $\begin{array}{l}\text { Aluminum, } \\
\text { self-cooled }\end{array}$ & $13.8 \mathrm{kV}, 3-\mathrm{ph}, 60 \mathrm{~Hz}$ & 1 & 0 \\
\hline 5 & $\begin{array}{l}\text { ASU \& Gas } \\
\text { Processing } \\
\text { Voltage } \\
\text { Switchgear }\end{array}$ & Metal clad & $13.8 \mathrm{kV}, 3-\mathrm{ph}, 60 \mathrm{~Hz}$ & 1 & 0 \\
\hline 6 & $\begin{array}{l}\text { ASU \& Gas } \\
\text { Processing } \\
\text { Medium } \\
\text { Voltage } \\
\text { Switchgear } \\
\end{array}$ & Metal clad & $4.16 \mathrm{kV}, 3-\mathrm{ph}, 60 \mathrm{~Hz}$ & 1 & 0 \\
\hline 7 & $\begin{array}{l}\text { ASU Low } \\
\text { Voltage } \\
\text { Switchgear }\end{array}$ & Metal enclosed & 480 V, 3-ph, $60 \mathrm{~Hz}$ & 1 & 0 \\
\hline
\end{tabular}

\section{Account 12 Instrumentation and Control}

The existing capture ready plant (Case 2a) DCS system has been selected to meet increased requirements of the plant converted to Oxyfuel operation. 


\subsection{Appendix III - Detailed Balance of Plant Cost Breakdowns}

This section shows detailed BOP cost breakdowns (two levels) for the cases in this study as listed below:

o Case 1a - Air Fired CFB Boiler (Base Case)

o Case $1 \mathrm{~b}$ - Base Case Retrofit With $\mathrm{O}_{2}$ Firing And $\mathrm{CO}_{2}$ Capture

o Case 2a - Air Fired Capture Ready CFB Boiler

o Case 2b - Capture Ready CFB Boiler (Case 2a) Retrofit with $\mathrm{O}_{2}$ firing and $\mathrm{CO}_{2}$ Capture Note: Detailed second level BOP costs for Case $1 \mathrm{~b}$ (Base Case retrofit with $\mathrm{O}_{2}$ firing and $\mathrm{CO}_{2}$ capture) were not developed.

Table 10-1: Detailed BOP Costs for Case 1a (Base Case)

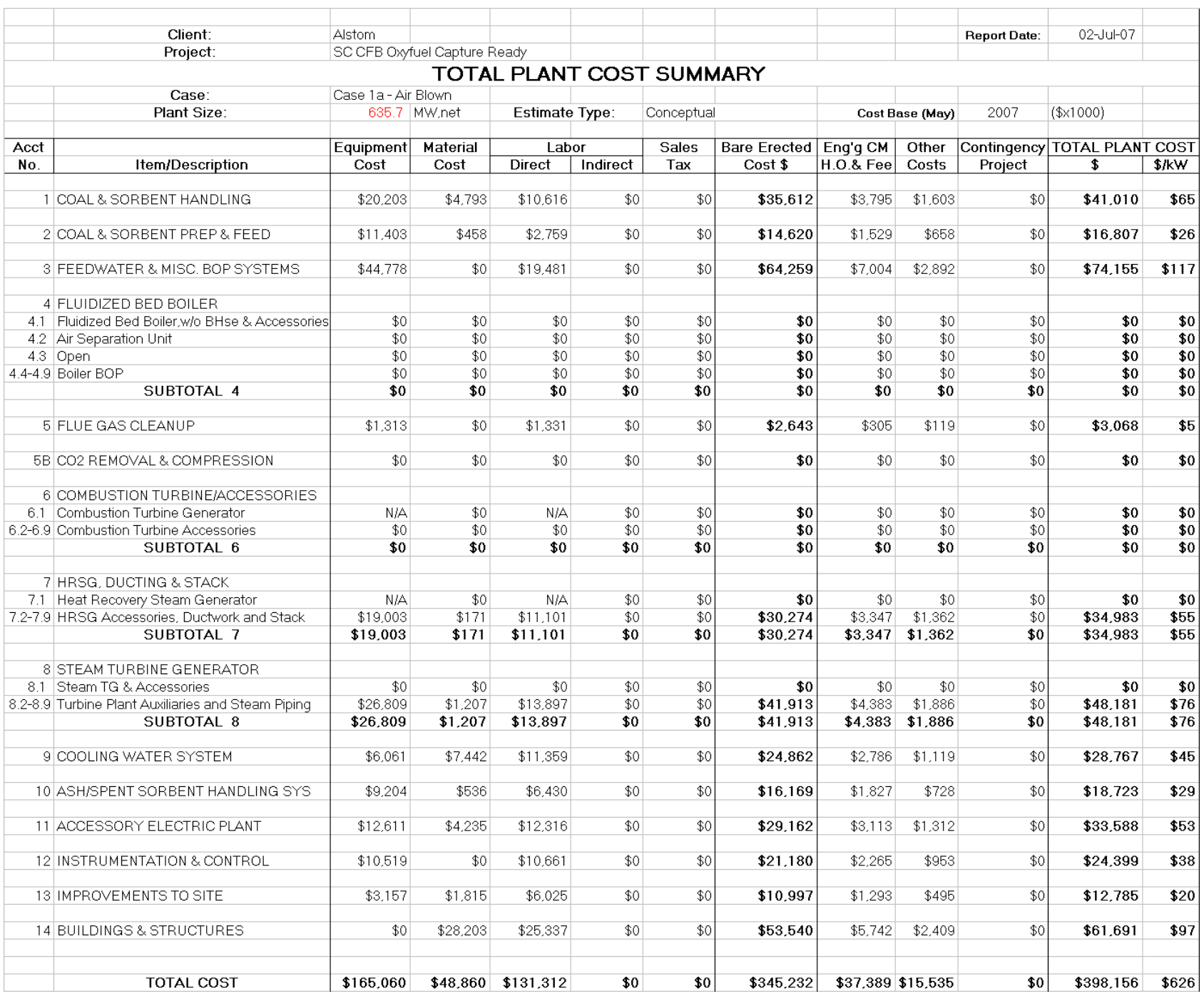


COMMERCIALIZATION DEVELOPMENT OF OXYGEN FIRED CFB FOR GREENHOUSE GAS CONTROL

\begin{tabular}{|c|c|c|c|c|c|c|c|c|c|c|c|c|}
\hline & Client: & Alstom & & & & & & & & Report Date: & 02-Jul-07 & \\
\hline & Project: & \multicolumn{3}{|c|}{ SC CFB Oxyfuel Capture Ready } & & & & & & & & \\
\hline \multicolumn{13}{|c|}{ TOTAL PLANT COST SUMMARY } \\
\hline & Case: & \multicolumn{2}{|c|}{ Case 1a-Air Blown } & \multirow{2}{*}{\multicolumn{2}{|c|}{ Estimate Type: }} & \multirow{2}{*}{\multicolumn{2}{|c|}{ Conceptual }} & \multirow{2}{*}{\multicolumn{2}{|c|}{ Cost Base (May) }} & & & \\
\hline & Plant Size: & 635.7 & MW net & & & & & & & 2007 & $(\$ \times 1000)$ & \\
\hline Acct & & Equipment & Material & \multicolumn{2}{|c|}{ Labor } & Sales & Bare Erected & Eng'g CM & Other & Contingency & \multicolumn{2}{|c|}{ TOTAL PLANT COST } \\
\hline \multirow[t]{2}{*}{ No. } & Item/Description & Cost & Cost & Direct & Indirect & Tax & $\operatorname{Cost} \$$ & H.O.\& Fee & Costs & Project & $\$$ & $\$ / \mathrm{kW}$ \\
\hline & \multicolumn{12}{|l|}{1 COAL \& SORBENT HANDLING } \\
\hline 1.1 & Coal Receive \& Unload & $\$ 3,817$ & $\$ 0$ & $\$ 1.651$ & $\$ 0$ & $\$ 0$ & $\$ 5.468$ & $\$ 582$ & $\$ 246$ & $\$ 0$ & $\$ 6.296$ & $\$ 10$ \\
\hline 1.2 & Coal Stackout \& Reclaim & $\$ 4.933$ & $\$ 0$ & $\$ 1,164$ & $\$ 0$ & $\$ 0$ & $\$ 6.097$ & $\$ 637$ & $\$ 274$ & $\$ 0$ & $\$ 7.009$ & $\$ 11$ \\
\hline 1.3 & Coal Conveyors & $\$ 4,586$ & $\$ 0$ & $\$ 1,047$ & $\$ 0$ & $\$ 0$ & $\$ 5.633$ & $\$ 588$ & $\$ 254$ & $\$ 0$ & $\$ 6.475$ & $\$ 10$ \\
\hline 1.4 & Other Coal Handling & $\$ 1,200$ & $\$ 0$ & $\$ 242$ & $\$ 0$ & $\$ 0$ & $\$ 1.442$ & $\$ 150$ & $\$ 65$ & $\$ 0$ & $\$ 1.657$ & $\$ 3$ \\
\hline 1.5 & Sorbent Receive \& Unload & $\$ 215$ & $\$ 0$ & $\$ 61$ & $\$ 0$ & $\$ 0$ & $\$ 276$ & $\$ 29$ & $\$ 12$ & $\$ 0$ & $\$ 317$ & $\$ 0$ \\
\hline 1.6 & Sorbent Stackout \& Reclaim & $\$ 3,468$ & $\$ 0$ & $\$ 602$ & $\$ 0$ & $\$ 0$ & $\$ 4,070$ & $\$ 422$ & $\$ 183$ & $\$ 0$ & $\$ 4,675$ & $\$ 7$ \\
\hline 1.7 & Sorbent Conveyors & $\$ 1,237$ & $\$ 268$ & $\$ 287$ & $\$ 0$ & $\$ 0$ & $\$ 1.793$ & $\$ 185$ & $\$ 81$ & $\$ 0$ & $\$ 2,058$ & $\$ 3$ \\
\hline 1.8 & Other Sorbent Handling & $\$ 747$ & $\$ 175$ & $\$ 371$ & $\$ 0$ & $\$ 0$ & $\$ 1.294$ & $\$ 136$ & $\$ 58$ & $\$ 0$ & $\$ 1.488$ & $\$ 2$ \\
\hline \multirow[t]{2}{*}{1.9} & Coal \& Sorbent Hnd. Foundations & $\$ 0$ & $\$ 4,350$ & $\$ 5.189$ & $\$ 0$ & $\$ 0$ & $\$ 9.540$ & $\$ 1.065$ & $\$ 429$ & $\$ 0$ & $\$ 11.034$ & $\$ 17$ \\
\hline & SUBTOTAL 1. & $\$ 20.203$ & $\$ 4.793$ & $\$ 10.616$ & $\$ 0$ & $\$ 0$ & $\$ 35.612$ & $\$ 3.795$ & $\$ 1.603$ & $\$ 0$ & $\$ 41.010$ & $\$ 65$ \\
\hline \multicolumn{13}{|c|}{2 COAL \& SORBENT PREP \& FEED } \\
\hline 2.1 & Coal Crushing \& Drying & $\$ 2,206$ & $\$ 0$ & $\$ 407$ & $\$ 0$ & $\$ 0$ & $\$ 2.613$ & $\$ 272$ & $\$ 118$ & $\$ 0$ & $\$ 3,002$ & $\$ 5$ \\
\hline 2.2 & Coal Conveyor to Storage & $\$ 7.059$ & $\$ 0$ & $\$ 1.459$ & $\$ 0$ & $\$ 0$ & $\$ 8,518$ & $\$ 887$ & $\$ 383$ & $\$ 0$ & $\$ 9.789$ & $\$ 15$ \\
\hline 2.3 & Coal Injection System & $\$ 0$ & $\$ 0$ & $\$ 0$ & $\$ 0$ & $\$ 0$ & $\$ 0$ & $\$ 0$ & $\$ 0$ & $\$ 0$ & $\$ 0$ & $\$ 0$ \\
\hline 2.4 & Misc Coal Prep \& Feed & $\$ 0$ & $\$ 0$ & $\$ 0$ & $\$ 0$ & $\$ 0$ & $\$ 0$ & $\$ 0$ & $\$ 0$ & $\$ 0$ & $\$ 0$ & $\$ 0$ \\
\hline 2.5 & Sorbent Prep Equipment & $\$ 1.427$ & $\$ 0$ & $\$ 281$ & $\$ 0$ & $\$ 0$ & $\$ 1.707$ & $\$ 178$ & $\$ 77$ & $\$ 0$ & $\$ 1.962$ & $\$ 3$ \\
\hline 2.6 & Sorbent Storage \&. Feed & $\$ 712$ & $\$ 0$ & $\$ 257$ & $\$ 0$ & $\$ 0$ & $\$ 969$ & $\$ 102$ & $\$ 44$ & $\$ 0$ & $\$ 1.115$ & $\$ 2$ \\
\hline 2.7 & Sorbent Injection System & $\$ 0$ & $\$ 0$ & $\$ 0$ & $\$ 0$ & $\$ 0$ & $\$ 0$ & $\$ 0$ & $\$ 0$ & $\$ 0$ & $\$ 0$ & $\$ 0$ \\
\hline 2.8 & Booster Air Supply System & $\$ 0$ & $\$ 0$ & $\$ 0$ & $\$ 0$ & $\$ 0$ & $\$ 0$ & $\$ 0$ & $\$ 0$ & $\$ 0$ & $\$ 0$ & $\$ 0$ \\
\hline \multirow[t]{2}{*}{2.9} & Coal \& Sorbent Feed Foundation & $\$ 0$ & $\$ 458$ & $\$ 355$ & $\$ 0$ & $\$ 0$ & $\$ 813$ & $\$ 90$ & $\$ 37$ & $\$ 0$ & $\$ 939$ & $\$ 1$ \\
\hline & SUBTOTAL 2 & $\$ 11.403$ & $\$ 458$ & $\$ 2.759$ & $\$ 0$ & $\$ 0$ & $\$ 14.620$ & $\$ 1,529$ & $\$ 658$ & $\$ 0$ & $\$ 16.807$ & $\$ 26$ \\
\hline 3 & FEEDWATER \& MISC. BOP SYSTEMS & & & & & & & & & & & \\
\hline 3.1 & FeedwaterSystem & $\$ 16,904$ & $\$ 0$ & $\$ 5,702$ & $\$ 0$ & $\$ 0$ & $\$ 22,606$ & $\$ 2,362$ & $\$ 1.017$ & $\$ 0$ & $\$ 25,985$ & $\$ 41$ \\
\hline 3.2 & Water Makeup \& Pretreating & $\$ 5,882$ & $\$ 0$ & $\$ 1,793$ & $\$ 0$ & $\$ 0$ & $\$ 7.675$ & $\$ 865$ & $\$ 345$ & $\$ 0$ & $\$ 8,886$ & $\$ 14$ \\
\hline 3.3 & Other Feedwater Subsystems & $\$ 9,451$ & $\$ 0$ & $\$ 3,784$ & $\$ 0$ & $\$ 0$ & $\$ 13.234$ & $\$ 1,412$ & $\$ 596$ & $\$ 0$ & $\$ 15,242$ & $\$ 24$ \\
\hline 3.4 & Service Water Systems & $\$ 853$ & $\$ 0$ & $\$ 439$ & $\$ 0$ & $\$ 0$ & $\$ 1.292$ & $\$ 145$ & $\$ 58$ & $\$ 0$ & $\$ 1.495$ & $\$ 2$ \\
\hline 3.5 & Other Boiler Plant Systems & $\$ 5,173$ & $\$ 0$ & $\$ 4,512$ & $\$ 0$ & $\$ 0$ & $\$ 9.685$ & $\$ 1,094$ & $\$ 436$ & $\$ 0$ & $\$ 11.215$ & $\$ 18$ \\
\hline 3.6 & FO Supply Sys \& Nat Gas & $\$ 276$ & $\$ 0$ & $\$ 327$ & $\$ 0$ & $\$ 0$ & $\$ 603$ & $\$ 68$ & $\$ 27$ & $\$ 0$ & $\$ 698$ & $\$ 1$ \\
\hline 3.7 & Waste Treatment Equipment & $\$ 2.949$ & $\$ 0$ & $\$ 1.592$ & $\$ 0$ & $\$ 0$ & $\$ 4.541$ & $\$ 527$ & $\$ 204$ & $\$ 0$ & $\$ 5.272$ & $\$ 8$ \\
\hline \multirow[t]{2}{*}{3.8} & Misc. Equip (cranes.AirComp.Comm.) & $\$ 3.291$ & $\$ 0$ & $\$ 1,331$ & $\$ 0$ & $\$ 0$ & $\$ 4,622$ & $\$ 532$ & $\$ 208$ & $\$ 0$ & $\$ 5.362$ & $\$ 8$ \\
\hline & SUBTOTAL 3 . & $\$ 44.778$ & $\$ 0$ & $\$ 19.481$ & $\$ 0$ & $\$ 0$ & $\$ 64.259$ & $\$ 7.004$ & $\$ 2.892$ & $\$ 0$ & $\$ 74.155$ & $\$ 117$ \\
\hline 4 & FLUIDIZED BED BOILER & & & & & & & & & & & \\
\hline 4.1 & Fluidized Bed Boiler,wjo BHse \& Accessories & $\$ 0$ & $\$ 0$ & $\$ 0$ & $\$ 0$ & $\$ 0$ & $\$ 0$ & $\$ 0$ & $\$ 0$ & $\$ 0$ & $\$ 0$ & $\$ 0$ \\
\hline 4.2 & Air Separation Unit & $\$ 0$ & $\$ 0$ & $\$ 0$ & $\$ 0$ & $\$ 0$ & $\$ 0$ & $\$ 0$ & $\$ 0$ & $\$ 0$ & $\$ 0$ & $\$ 0$ \\
\hline 4.3 & Open & $\$ 0$ & $\$ 0$ & $\$ 0$ & $\$ 0$ & $\$ 0$ & $\$ 0$ & $\$ 0$ & $\$ 0$ & $\$ 0$ & $\$ 0$ & $\$ 0$ \\
\hline 4.4 & Boiler BoP (Fluidizing Air Fans) & $\$ 0$ & $\$ 0$ & $\$ 0$ & $\$ 0$ & $\$ 0$ & $\$ 0$ & $\$ 0$ & $\$ 0$ & $\$ 0$ & $\$ 0$ & $\$ 0$ \\
\hline 4.5 & Primary Air System (Fans) & $w / 4.1$ & $\$ 0$ & $w / 4.1$ & $\$ 0$ & $\$ 0$ & $\$ 0$ & $\$ 0$ & $\$ 0$ & $\$ 0$ & $\$ 0$ & $\$ 0$ \\
\hline 4.6 & Secondary Air System (Fans) & $w / 4.1$ & $\$ 0$ & $w / 4.1$ & $\$ 0$ & $\$ 0$ & $\$ 0$ & $\$ 0$ & $\$ 0$ & $\$ 0$ & $\$ 0$ & $\$ 0$ \\
\hline 4.8 & Major Component Rigging & $\$ 0$ & $w / 4.1$ & $w / 4.1$ & $\$ 0$ & $\$ 0$ & $\$ 0$ & $\$ 0$ & $\$ 0$ & $\$ 0$ & $\$ 0$ & $\$ 0$ \\
\hline \multirow[t]{2}{*}{4.9} & Boiler Foundations & $\$ 0$ & $w / 14.1$ & $w / 14.1$ & $\$ 0$ & $\$ 0$ & $\$ 0$ & $\$ 0$ & $\$ 0$ & $\$ 0$ & $\$ 0$ & $\$ 0$ \\
\hline & SUBTOTAL 4 & $\$ 0$ & $\$ 0$ & $\$ 0$ & $\$ 0$ & $\$ 0$ & $\$ 0$ & $\$ 0$ & $\$ 0$ & $\$ 0$ & $\$ 0$ & $\$ 0$ \\
\hline
\end{tabular}


COMMERCIALIZATION DEVELOPMENT OF OXYGEN FIRED

CFB FOR GREENHOUSE GAS CONTROL

\begin{tabular}{|c|c|c|c|c|c|c|c|c|c|c|c|c|}
\hline & Client: & Alstom & & & & & & & & Report Date: & 02-Jul-07 & \\
\hline & Project: & \multicolumn{3}{|c|}{ SC CFB Oxyfuel Capture Ready } & & & & & & & & \\
\hline \multicolumn{13}{|c|}{ TOTAL PLANT COST SUMMARY } \\
\hline & Case: & \multicolumn{2}{|c|}{ Case 1a-Air Blown } & \multirow{2}{*}{\multicolumn{2}{|c|}{ Estimate Type: }} & \multirow{2}{*}{\multicolumn{2}{|c|}{ Conceptual }} & & & & & \\
\hline & Plant Size: & 635.7 & MW.net & & & & & \multicolumn{2}{|c|}{ Cost Base (May) } & 2007 & $(\$ \times 1000)$ & \\
\hline Acct & & Equipment & Material & \multicolumn{2}{|c|}{ Labor } & Sales & Bare Erected & Eng'g CM & Other & Contingency & \multicolumn{2}{|c|}{ TOTAL PLANT COST } \\
\hline No. & Item/Description & Cost & Cost & Direct & Indirect & $\operatorname{Tax}$ & Cost $\$$ & H.O.\& Fee & Costs & Project & $\$$ & $\$ / \mathrm{kW}$ \\
\hline & & & & & & & & & & & & \\
\hline 5 & FLUE GAS CLEANUP & & & & & & & & & & & \\
\hline 5.1 & Absorber Vessels \& Accessories & $\$ 0$ & $\$ 0$ & $\$ 0$ & $\$ 0$ & $\$ 0$ & $\$ 0$ & $\$ 0$ & $\$ 0$ & $\$ 0$ & $\$ 0$ & $\$ 0$ \\
\hline 5.2 & Other FGD & $\$ 0$ & $\$ 0$ & $\$ 0$ & $\$ 0$ & $\$ 0$ & $\$ 0$ & $\$ 0$ & $\$ 0$ & $\$ 0$ & $\$ 0$ & $\$ 0$ \\
\hline 5.3 & Bag House \& Accessories & $\$ 0$ & $\$ 0$ & $\$ 0$ & $\$ 0$ & $\$ 0$ & $\$ 0$ & $\$ 0$ & $\$ 0$ & $\$ 0$ & $\$ 0$ & $\$ 0$ \\
\hline 5.4 & Other Particulate Removal Materials & $\$ 1.313$ & $\$ 0$ & $\$ 1.331$ & $\$ 0$ & $\$ 0$ & $\$ 2.643$ & $\$ 305$ & $\$ 119$ & $\$ 0$ & $\$ 3.068$ & $\$ 5$ \\
\hline 5.5 & PFWH \& Gas Cooler & $\$ 0$ & $\$ 0$ & $\$ 0$ & $\$ 0$ & $\$ 0$ & $\$ 0$ & $\$ 0$ & $\$ 0$ & $\$ 0$ & $\$ 0$ & $\$ 0$ \\
\hline 5.6 & Gas Processing System & $\$ 0$ & $\$ 0$ & $\$ 0$ & $\$ 0$ & $\$ 0$ & $\$ 0$ & $\$ 0$ & $\$ 0$ & $\$ 0$ & $\$ 0$ & $\$ 0$ \\
\hline \multirow[t]{2}{*}{5.9} & Open & $\$ 0$ & $\$ 0$ & $\$ 0$ & $\$ 0$ & $\$ 0$ & $\$ 0$ & $\$ 0$ & $\$ 0$ & $\$ 0$ & $\$ 0$ & $\$ 0$ \\
\hline & SUBTOTAL 5. & $\$ 1.313$ & $\$ 0$ & $\$ 1,331$ & $\$ 0$ & $\$ 0$ & $\$ 2.643$ & $\$ 305$ & $\$ 119$ & $\$ 0$ & $\$ 3.068$ & $\$ 5$ \\
\hline $5 \mathrm{~B}$ & CO2 REMOVAL \& COMPRESSION & & & & & & & & & & & \\
\hline 5B.1 & CO2 Removal System & $\$ 0$ & $\$ 0$ & $\$ 0$ & $\$ 0$ & $\$ 0$ & $\$ 0$ & $\$ 0$ & $\$ 0$ & $\$ 0$ & $\$ 0$ & $\$ 0$ \\
\hline \multirow{2}{*}{$5 \mathrm{~B} .2$} & CO2 Compression \& Drying & $\$ 0$ & $\$ 0$ & $\$ 0$ & $\$ 0$ & $\$ 0$ & $\$ 0$ & $\$ 0$ & $\$ 0$ & $\$ 0$ & $\$ 0$ & $\$ 0$ \\
\hline & SUBTOTAL 5B. & $\$ 0$ & $\$ 0$ & $\$ 0$ & $\$ 0$ & $\$ 0$ & $\$ 0$ & $\$ 0$ & $\$ 0$ & $\$ 0$ & $\$ 0$ & $\$ 0$ \\
\hline 6 & COMBUSTION TURBINE/ACCESSORIES & & & & & & & & & & & \\
\hline 6.1 & Combustion Turbine Generator & N/A & $\$ 0$ & NKA & $\$ 0$ & $\$ 0$ & $\$ 0$ & $\$ 0$ & $\$ 0$ & $\$ 0$ & $\$ 0$ & $\$ 0$ \\
\hline 6.2 & Combustion Turbine Accessories & $\$ 0$ & $\$ 0$ & $\$ 0$ & $\$ 0$ & $\$ 0$ & $\$ 0$ & $\$ 0$ & $\$ 0$ & $\$ 0$ & $\$ 0$ & $\$ 0$ \\
\hline 6.3 & Compressed Air Piping & $\$ 0$ & $\$ 0$ & $\$ 0$ & $\$ 0$ & $\$ 0$ & $\$ 0$ & $\$ 0$ & $\$ 0$ & $\$ 0$ & $\$ 0$ & $\$ 0$ \\
\hline \multirow[t]{2}{*}{6.9} & Combustion Turbine Foundations & $\$ 0$ & $\$ 0$ & $\$ 0$ & $\$ 0$ & $\$ 0$ & $\$ 0$ & $\$ 0$ & $\$ 0$ & $\$ 0$ & $\$ 0$ & $\$ 0$ \\
\hline & SUBTOTAL 6 . & $\$ 0$ & $\$ 0$ & $\$ 0$ & $\$ 0$ & $\$ 0$ & $\$ 0$ & $\$ 0$ & $\$ 0$ & $\$ 0$ & $\$ 0$ & $\$ 0$ \\
\hline 7 & HRSG, DUCTING \& STACK & & & & & & & & & & & \\
\hline 7.1 & Heat Recovery Steam Generator & N/A & $\$ 0$ & N/A & $\$ 0$ & $\$ 0$ & $\$ 0$ & $\$ 0$ & $\$ 0$ & $\$ 0$ & $\$ 0$ & $\$ 0$ \\
\hline 7.2 & ID Fans & $\$ 0$ & $\$ 0$ & $\$ 0$ & $\$ 0$ & $\$ 0$ & $\$ 0$ & $\$ 0$ & $\$ 0$ & $\$ 0$ & $\$ 0$ & $\$ 0$ \\
\hline 7.3 & Ductwork & $\$ 7.103$ & $\$ 0$ & $\$ 4,322$ & $\$ 0$ & $\$ 0$ & $\$ 11.425$ & $\$ 1,185$ & $\$ 514$ & $\$ 0$ & $\$ 13,123$ & $\$ 21$ \\
\hline 7.4 & Stack & $\$ 11.900$ & $\$ 0$ & $\$ 6.595$ & $\$ 0$ & $\$ 0$ & $\$ 18.495$ & $\$ 2,123$ & $\$ 832$ & $\$ 0$ & $\$ 21.450$ & $\$ 34$ \\
\hline \multirow[t]{2}{*}{7.9} & Duct \& Stack Foundations & $\$ 0$ & $\$ 171$ & $\$ 184$ & $\$ 0$ & $\$ 0$ & $\$ 355$ & $\$ 39$ & $\$ 16$ & $\$ 0$ & $\$ 410$ & $\$ 1$ \\
\hline & SUBTOTAL 7. & $\$ 19.003$ & $\$ 171$ & $\$ 11.101$ & $\$ 0$ & $\$ 0$ & $\$ 30.274$ & $\$ 3.347$ & $\$ 1.362$ & $\$ 0$ & $\$ 34.983$ & $\$ 55$ \\
\hline 8 & STEAM TURBINE GENERATOR & & & & & & & & & & & \\
\hline 8.1 & Steam TG \& Accessories & $\$ 0$ & $\$ 0$ & $\$ 0$ & $\$ 0$ & $\$ 0$ & $\$ 0$ & $\$ 0$ & $\$ 0$ & $\$ 0$ & $\$ 0$ & $\$ 0$ \\
\hline 8.2 & Turbine Plant Auxiliaries & $\$ 384$ & $\$ 0$ & $\$ 779$ & $\$ 0$ & $\$ 0$ & $\$ 1,163$ & $\$ 135$ & $\$ 52$ & $\$ 0$ & $\$ 1,351$ & $\$ 2$ \\
\hline 8.3 & Condenser \& Auxiliaries & $\$ 7.328$ & $\$ 0$ & $\$ 2,397$ & $\$ 0$ & $\$ 0$ & $\$ 9,725$ & $\$ 1,110$ & $\$ 438$ & $\$ 0$ & $\$ 11,273$ & $\$ 18$ \\
\hline 8.4 & Steam Piping & $\$ 19,097$ & $\$ 0$ & $\$ 8.918$ & $\$ 0$ & $\$ 0$ & $\$ 28.015$ & $\$ 2,798$ & $\$ 1.261$ & $\$ 0$ & $\$ 32,074$ & $\$ 50$ \\
\hline \multirow[t]{2}{*}{8.9} & TG Foundations & $\$ 0$ & $\$ 1.207$ & $\$ 1.803$ & $\$ 0$ & $\$ 0$ & $\$ 3.010$ & $\$ 339$ & $\$ 135$ & $\$ 0$ & $\$ 3.484$ & $\$ 5$ \\
\hline & SUBTOTAL 8. & $\$ 26.809$ & $\$ 1.207$ & $\$ 13.897$ & $\$ 0$ & $\$ 0$ & $\$ 41.913$ & $\$ 4.383$ & $\$ 1.886$ & $\$ 0$ & $\$ 48.181$ & $\$ 76$ \\
\hline 9 & COOLING WATER SYSTEM & & & & & & & & & & & \\
\hline 9.1 & Cooling Towers & $\$ 3,216$ & $\$ 0$ & $\$ 1.636$ & $\$ 0$ & $\$ 0$ & $\$ 4,852$ & $\$ 556$ & $\$ 218$ & $\$ 0$ & $\$ 5.627$ & $\$ 9$ \\
\hline 9.2 & Circulating Water Pumps & $\$ 1.263$ & $\$ 0$ & $\$ 185$ & $\$ 0$ & $\$ 0$ & $\$ 1.448$ & $\$ 148$ & $\$ 65$ & $\$ 0$ & $\$ 1,661$ & $\$ 3$ \\
\hline 9.3 & Circ.Water System Auxiliaries & $\$ 589$ & $\$ 0$ & $\$ 74$ & $\$ 0$ & $\$ 0$ & $\$ 663$ & $\$ 75$ & $\$ 30$ & $\$ 0$ & $\$ 769$ & $\$ 1$ \\
\hline 9.4 & Circ.Water Piping & $\$ 0$ & $\$ 4,670$ & $\$ 4,287$ & $\$ 0$ & $\$ 0$ & $\$ 8.957$ & $\$ 998$ & $\$ 403$ & $\$ 0$ & $\$ 10.358$ & $\$ 16$ \\
\hline 9.5 & Make-up Water System & $\$ 518$ & $\$ 0$ & $\$ 655$ & $\$ 0$ & $\$ 0$ & $\$ 1.173$ & $\$ 134$ & $\$ 53$ & $\$ 0$ & $\$ 1,360$ & $\$ 2$ \\
\hline 9.6 & Component Cooling Water Sys & $\$ 475$ & $\$ 0$ & $\$ 358$ & $\$ 0$ & $\$ 0$ & $\$ 833$ & $\$ 94$ & $\$ 37$ & $\$ 0$ & $\$ 965$ & $\$ 2$ \\
\hline 9.9 & Circ.Water System Foundations\& Structures & $\$ 0$ & $\$ 2,771$ & $\$ 4.164$ & $\$ 0$ & $\$ 0$ & $\$ 6.935$ & $\$ 780$ & $\$ 312$ & $\$ 0$ & $\$ 8,027$ & $\$ 13$ \\
\hline & SUBTOTAL 9. & $\$ 6.061$ & $\$ 7.442$ & $\$ 11.359$ & $\$ 0$ & $\$ 0$ & $\$ 24,862$ & $\$ 2.786$ & $\$ 1.119$ & $\$ 0$ & $\$ 28.767$ & $\$ 45$ \\
\hline
\end{tabular}


COMMERCIALIZATION DEVELOPMENT OF OXYGEN FIRED

CFB FOR GREENHOUSE GAS CONTROL

\begin{tabular}{|c|c|c|c|c|c|c|c|c|c|c|c|c|}
\hline & Cliont. & Alstom & & & & & & & & & & \\
\hline & Cilent: & \multicolumn{3}{|c|}{ SC CFB Oxyfuel Capture Ready } & & & & & & Report Date: & 02-Jul-07 & \\
\hline \multirow{2}{*}{\multicolumn{13}{|c|}{ TOTAL PLANT COST SUMMARY }} \\
\hline & & & & & & & & & & & & \\
\hline & Case: & \multicolumn{2}{|c|}{ Case 1a-Air Blown } & \multirow{2}{*}{\multicolumn{2}{|c|}{ Estimate Type: }} & \multirow{2}{*}{\multicolumn{2}{|c|}{ Conceptual }} & \multirow{2}{*}{\multicolumn{2}{|c|}{ Cost Base (May) }} & & & \\
\hline & Plant Size: & 635.7 & MW.net & & & & & & & 2007 & $(\$ \times 1000)$ & \\
\hline Acct & & \multirow{2}{*}{$\begin{array}{c}\text { Equipment } \\
\text { Cost }\end{array}$} & \multirow{2}{*}{\begin{tabular}{c|} 
Material \\
Cost
\end{tabular}} & \multicolumn{2}{|c|}{ Labor } & & Bare Erected & Eng'g CM & Other & Contingency & \multicolumn{2}{|c|}{ TOTAL PLANT COST } \\
\hline No. & Item/Description & & & \multicolumn{2}{|c|}{\begin{tabular}{|c|c|}
\multicolumn{2}{|c|}{ Labor } \\
Direct & Indirect \\
\end{tabular}} & Tax & Cost $\$$ & H.O.\& Fee & Costs & Project & $\$$ & $\$ / \mathrm{kW}$ \\
\hline & & & & & & & & & & & & \\
\hline & ASHISPENT SORBENT HANDLING SYS & & & & & & & & & & & \\
\hline 10.1 & $\begin{array}{l}\text { ASHISPENI SURBEIVI HAINULING STS } \\
\text { Ash Coolers }\end{array}$ & N/A & $\$ 0$ & N/A & $\$ 0$ & $\$ 0$ & $\$ 0$ & $\$ 0$ & $\$ 0$ & $\$ 0$ & $\$ 0$ & $\$ 0$ \\
\hline 10.2 & Cyclone Ash Letdown & N/A & $\$ 0$ & N/A & $\$ 0$ & $\$ 0$ & $\$ 0$ & $\$ 0$ & $\$ 0$ & $\$ 0$ & $\$ 0$ & $\$ 0$ \\
\hline 10.3 & HGCU Ash Letdown & N/A & $\$ 0$ & N/A & $\$ 0$ & $\$ 0$ & $\$ 0$ & $\$ 0$ & $\$ 0$ & $\$ 0$ & $\$ 0$ & $\$ 0$ \\
\hline 10.4 & High Temperature Ash Piping & N/A & $\$ 0$ & N/A & $\$ 0$ & $\$ 0$ & $\$ 0$ & $\$ 0$ & $\$ 0$ & $\$ 0$ & $\$ 0$ & $\$ 0$ \\
\hline 10.5 & Other Ash Recovery Equipment & N/A & $\$ 0$ & N/A & $\$ 0$ & $\$ 0$ & $\$ 0$ & $\$ 0$ & $\$ 0$ & $\$ 0$ & $\$ 0$ & $\$ 0$ \\
\hline 10.6 & Ash Storage Silos & $\$ 563$ & $\$ 0$ & $\$ 1,642$ & $\$ 0$ & $\$ 0$ & $\$ 2.204$ & $\$ 258$ & $\$ 99$ & $\$ 0$ & $\$ 2,561$ & $\$ 4$ \\
\hline 10.7 & Ash Transport \& Feed Equipment & $\$ 8.641$ & $\$ 0$ & $\$ 4,192$ & $\$ 0$ & $\$ 0$ & $\$ 12.833$ & $\$ 1,443$ & $\$ 577$ & $\$ 0$ & $\$ 14.853$ & $\$ 23$ \\
\hline 10.8 & Misc. Ash Handling Equipment & $\$ 0$ & $\$ 0$ & $\$ 0$ & $\$ 0$ & $\$ 0$ & $\$ 0$ & $\$ 0$ & $\$ 0$ & $\$ 0$ & $\$ 0$ & $\$ 0$ \\
\hline 10.9 & Ash/Spent Sorbent Foundation & $\$ 0$ & $\$ 536$ & $\$ 596$ & $\$ 0$ & $\$ 0$ & $\$ 1.132$ & $\$ 126$ & $\$ 51$ & $\$ 0$ & $\$ 1.309$ & $\$ 2$ \\
\hline & SUBTOTAL 10. & $\$ 9.204$ & $\$ 536$ & $\$ 6.430$ & $\$ 0$ & $\$ 0$ & $\$ 16.169$ & $\$ 1.827$ & $\$ 728$ & $\$ 0$ & $\$ 18.723$ & $\$ 29$ \\
\hline 11 & ACCESSORY ELECTRIC PLANT & & & & & & & & & & & \\
\hline 11.1 & Generator Equipment & $\$ 1.731$ & $\$ 0$ & $\$ 266$ & $\$ 0$ & $\$ 0$ & $\$ 1.997$ & $\$ 221$ & $\$ 90$ & $\$ 0$ & $\$ 2,307$ & $\$ 4$ \\
\hline 11.2 & Station Service Equipment & $\$ 2,767$ & $\$ 0$ & $\$ 861$ & $\$ 0$ & $\$ 0$ & $\$ 3.628$ & $\$ 404$ & $\$ 163$ & $\$ 0$ & $\$ 4,196$ & $\$ 7$ \\
\hline 11.3 & Switchgear \& Motor Control & $\$ 3,095$ & $\$ 0$ & $\$ 498$ & $\$ 0$ & $\$ 0$ & $\$ 3,593$ & $\$ 397$ & $\$ 162$ & $\$ 0$ & $\$ 4,151$ & $\$ 7$ \\
\hline 11.4 & Conduit \& Cable Tray & $\$ 0$ & $\$ 1,365$ & $\$ 4,470$ & $\$ 0$ & $\$ 0$ & $\$ 5,834$ & $\$ 672$ & $\$ 263$ & $\$ 0$ & $\$ 6.769$ & $\$ 11$ \\
\hline 11.5 & Wire \& Cable & $\$ 0$ & $\$ 2,527$ & $\$ 4,628$ & $\$ 0$ & $\$ 0$ & $\$ 7.155$ & $\$ 714$ & $\$ 322$ & $\$ 0$ & $\$ 8.191$ & $\$ 13$ \\
\hline 11.6 & Protective Equipment & $\$ 199$ & $\$ 0$ & $\$ 641$ & $\$ 0$ & $\$ 0$ & $\$ 841$ & $\$ 98$ & $\$ 38$ & $\$ 0$ & $\$ 976$ & $\$ 2$ \\
\hline 11.7 & Standby Equipment & $\$ 1,358$ & $\$ 0$ & $\$ 29$ & $\$ 0$ & $\$ 0$ & $\$ 1,387$ & $\$ 152$ & $\$ 62$ & $\$ 0$ & $\$ 1.601$ & $\$ 3$ \\
\hline 11.8 & Main Power Transformers & $\$ 3,461$ & $\$ 0$ & $\$ 128$ & $\$ 0$ & $\$ 0$ & $\$ 3.589$ & $\$ 326$ & $\$ 161$ & $\$ 0$ & $\$ 4.077$ & $\$ 6$ \\
\hline 11.9 & Electrical Foundations & $\$ 0$ & $\$ 343$ & $\$ 796$ & $\$ 0$ & $\$ 0$ & $\$ 1.139$ & $\$ 129$ & $\$ 51$ & $\$ 0$ & $\$ 1.319$ & $\$ 2$ \\
\hline & SUBTOTAL 11. & $\$ 12.611$ & $\$ 4.235$ & $\$ 12.316$ & $\$ 0$ & $\$ 0$ & $\$ 29.162$ & $\$ 3.113$ & $\$ 1.312$ & $\$ 0$ & $\$ 33.588$ & $\$ 53$ \\
\hline 12 & INSTRUMENTATION \& CONTROL & & & & & & & & & & & \\
\hline 12.1 & PC Control Equipment & $w / 12.7$ & $\$ 0$ & $w / 12.7$ & $\$ 0$ & $\$ 0$ & $\$ 0$ & $\$ 0$ & $\$ 0$ & $\$ 0$ & $\$ 0$ & $\$ 0$ \\
\hline 12.2 & Combustion Turbine Control & N/A & $\$ 0$ & N/A & $\$ 0$ & $\$ 0$ & $\$ 0$ & $\$ 0$ & $\$ 0$ & $\$ 0$ & $\$ 0$ & $\$ 0$ \\
\hline 12.3 & Steam Turbine Control & $w / 8.1$ & $\$ 0$ & w/8.1 & $\$ 0$ & $\$ 0$ & $\$ 0$ & $\$ 0$ & $\$ 0$ & $\$ 0$ & $\$ 0$ & $\$ 0$ \\
\hline 12.4 & Other Major Component Control & $\$ 0$ & $\$ 0$ & $\$ 0$ & $\$ 0$ & $\$ 0$ & $\$ 0$ & $\$ 0$ & $\$ 0$ & $\$ 0$ & $\$ 0$ & $\$ 0$ \\
\hline 12.5 & Signal Processing Equipment & W/12.7 & $\$ 0$ & $w / 12.7$ & $\$ 0$ & $\$ 0$ & $\$ 0$ & $\$ 0$ & $\$ 0$ & $\$ 0$ & $\$ 0$ & $\$ 0$ \\
\hline 12.6 & Control Boards. Panels \& Racks & $\$ 466$ & $\$ 0$ & $\$ 264$ & $\$ 0$ & $\$ 0$ & $\$ 730$ & $\$ 82$ & $\$ 33$ & $\$ 0$ & $\$ 845$ & $\$ 1$ \\
\hline 12.7 & Distributed Control System Equipment & $\$ 5,171$ & $\$ 0$ & $\$ 856$ & $\$ 0$ & $\$ 0$ & $\$ 6.027$ & $\$ 666$ & $\$ 271$ & $\$ 0$ & $\$ 6.964$ & $\$ 11$ \\
\hline 12.8 & Instrument Wiring \& Tubing & $\$ 3.555$ & $\$ 0$ & $\$ 6.686$ & $\$ 0$ & $\$ 0$ & $\$ 10,241$ & $\$ 1.034$ & $\$ 461$ & $\$ 0$ & $\$ 11.736$ & $\$ 18$ \\
\hline 12.9 & Other I \& C Equipment & $\$ 1,328$ & $\$ 0$ & $\$ 2,855$ & $\$ 0$ & $\$ 0$ & $\$ 4,183$ & $\$ 483$ & $\$ 188$ & $\$ 0$ & $\$ 4,854$ & $\$ 8$ \\
\hline & SUBTOTAL 12. & $\$ 10.519$ & $\$ 0$ & $\$ 10.661$ & $\$ 0$ & $\$ 0$ & $\$ 21.180$ & $\$ 2.265$ & $\$ 953$ & $\$ 0$ & $\$ 24.399$ & $\$ 38$ \\
\hline 13 & IMPROVEMENTS TO SITE & & & & & & & & & & & \\
\hline 13.1 & Site Preparation & $\$ 0$ & $\$ 53$ & $\$ 1.005$ & $\$ 0$ & $\$ 0$ & $\$ 1.058$ & $\$ 125$ & $\$ 48$ & $\$ 0$ & $\$ 1.231$ & $\$ 2$ \\
\hline 13.2 & Site Improvements & $\$ 0$ & $\$ 1.762$ & $\$ 2.072$ & $\$ 0$ & $\$ 0$ & $\$ 3.834$ & $\$ 451$ & $\$ 173$ & $\$ 0$ & $\$ 4,457$ & $\$ 7$ \\
\hline 13.3 & Site Facilities & $\$ 3,157$ & $\$ 0$ & $\$ 2,948$ & $\$ 0$ & $\$ 0$ & $\$ 6.105$ & $\$ 717$ & $\$ 275$ & $\$ 0$ & $\$ 7.097$ & $\$ 11$ \\
\hline & SUBTOTAL 13. & $\$ 3,157$ & $\$ 1.815$ & $\$ 6.025$ & $\$ 0$ & $\$ 0$ & $\$ 10.997$ & $\$ 1.293$ & $\$ 495$ & $\$ 0$ & $\$ 12,785$ & $\$ 20$ \\
\hline 14 & BUILDINGS \& STRUCTURES & & & & & & & & & & & \\
\hline 14.1 & FB Boiler Building Foundation & $\$ 0$ & $\$ 14.329$ & $\$ 11.929$ & $\$ 0$ & $\$ 0$ & $\$ 26.258$ & $\$ 2,806$ & $\$ 1,182$ & $\$ 0$ & $\$ 30.245$ & $\$ 48$ \\
\hline 14.2 & Turbine Building & $\$ 0$ & $\$ 9.596$ & $\$ 8.467$ & $\$ 0$ & $\$ 0$ & $\$ 18,063$ & $\$ 1.936$ & $\$ 813$ & $\$ 0$ & $\$ 20.811$ & $\$ 33$ \\
\hline 14.3 & Administration Building & $\$ 0$ & $\$ 954$ & $\$ 954$ & $\$ 0$ & $\$ 0$ & $\$ 1.908$ & $\$ 206$ & $\$ 86$ & $\$ 0$ & $\$ 2,200$ & $\$ 3$ \\
\hline 14.4 & Circulation Water Pumphouse & $\$ 0$ & $\$ 205$ & $\$ 154$ & $\$ 0$ & $\$ 0$ & $\$ 359$ & $\$ 38$ & $\$ 16$ & $\$ 0$ & $\$ 413$ & $\$ 1$ \\
\hline 14.5 & Water Treatment Buildings & $\$ 0$ & $\$ 664$ & $\$ 517$ & $\$ 0$ & $\$ 0$ & $\$ 1,181$ & $\$ 126$ & $\$ 53$ & $\$ 0$ & $\$ 1,360$ & $\$ 2$ \\
\hline 14.6 & Machine Shop & $\$ 0$ & $\$ 850$ & $\$ 541$ & $\$ 0$ & $\$ 0$ & $\$ 1.391$ & $\$ 147$ & $\$ 63$ & $\$ 0$ & $\$ 1,600$ & $\$ 3$ \\
\hline 14.7 & Warehouse & $\$ 0$ & $\$ 576$ & $\$ 547$ & $\$ 0$ & $\$ 0$ & $\$ 1.123$ & $\$ 121$ & $\$ 51$ & $\$ 0$ & $\$ 1.295$ & $\$ 2$ \\
\hline 14.8 & Other Buildings \& Structures & $\$ 0$ & $\$ 353$ & $\$ 285$ & $\$ 0$ & $\$ 0$ & $\$ 638$ & $\$ 68$ & $\$ 29$ & $\$ 0$ & $\$ 734$ & $\$ 1$ \\
\hline 14.9 & Waste Treating Building \& Str. & $\$ 0$ & $\$ 676$ & $\$ 1,942$ & $\$ 0$ & $\$ 0$ & $\$ 2.619$ & $\$ 296$ & $\$ 118$ & $\$ 0$ & $\$ 3,032$ & $\$ 5$ \\
\hline & SUBTOTAL 14. & $\$ 0$ & $\$ 28.203$ & $\$ 25,337$ & $\$ 0$ & $\$ 0$ & $\$ 53.540$ & $\$ 5.742$ & $\$ 2.409$ & $\$ 0$ & $\$ 61.691$ & $\$ 97$ \\
\hline & TOTAL COST & $\$ 165.060$ & $\$ 48.860$ & $\$ 131.312$ & $\$ 0$ & $\$ 0$ & $\$ 345.232$ & $\$ 37.389$ & $\$ 15.535$ & $\$ 0$ & $\$ 398.156$ & $\$ 626$ \\
\hline
\end{tabular}


COMMERCIALIZATION DEVELOPMENT OF OXYGEN FIRED

CFB FOR GREENHOUSE GAS CONTROL

Table 10-2: BOP Costs for Case $1 \mathrm{~b}$ (Base Case Power Plant Retrofit to $\mathrm{O}_{2}$ Firing and $\mathrm{CO}_{2}$ Capture)

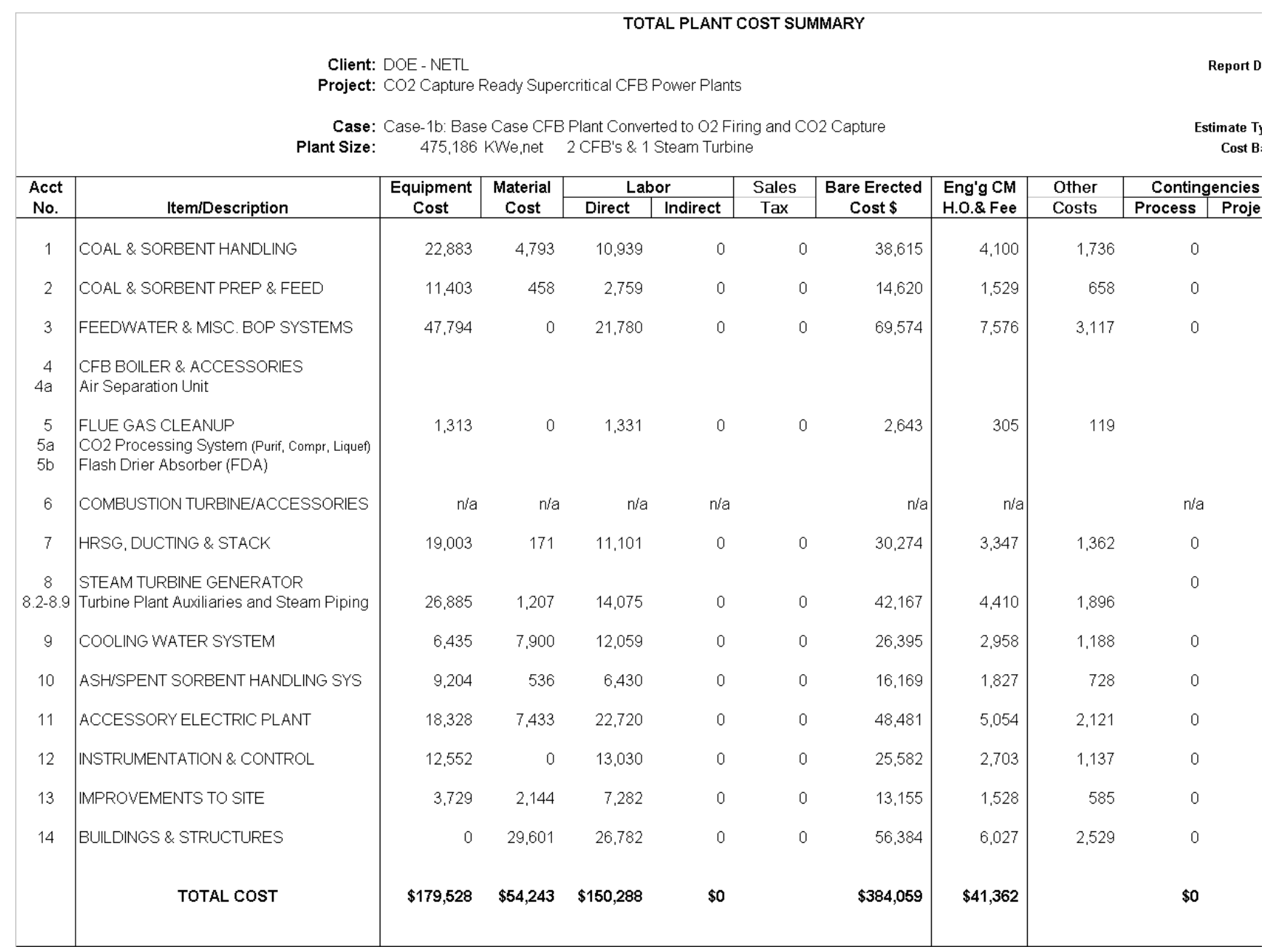


COMMERCIALIZATION DEVELOPMENT OF OXYGEN FIRED

CFB FOR GREENHOUSE GAS CONTROL

Table 10-3: Detailed BOP Costs for Case 2a (Capture Ready Power Plant)

\begin{tabular}{|c|c|c|c|c|c|c|c|c|c|c|c|c|}
\hline & & & & & & & & & & & & \\
\hline & Client: & Alstom & & & & & & & & Report Date: & 02-Jul-07 & \\
\hline & Project: & \multicolumn{3}{|c|}{ SC CFB Oxyfuel Capture Ready } & & & & & & & & \\
\hline \multicolumn{13}{|c|}{ TOTAL PLANT COST SUMMARY } \\
\hline & Case: & \multicolumn{3}{|c|}{ Case 2a - Air Blown Capture Ready } & & \multirow{2}{*}{\multicolumn{2}{|c|}{ Conceptual }} & \multirow{2}{*}{\multicolumn{2}{|c|}{ Cost Base (May) }} & & & \\
\hline & Plant Size: & 636.2 & MW net & Estimate & Type: & & & & & 2007 & $(\$ \times 1000)$ & \\
\hline Acct & & Equipment & Material & \multicolumn{2}{|c|}{ Labor } & Sales & Bare Erected & Eng'g CM & Other & Contingency & \multicolumn{2}{|c|}{ TOTAL PLANT COST } \\
\hline No. & Item/Description & Cost & Cost & Direct & Indirect & $\operatorname{Tax}$ & Cost $\$$ & H.O.\& Fee & Costs & Project & $\$$ & $\$ / \mathrm{kW}$ \\
\hline 1 & COAL \& SORBENT HANDLING & $\$ 20.203$ & $\$ 4.793$ & $\$ 10.616$ & $\$ 0$ & $\$ 0$ & $\$ 35.612$ & $\$ 3.795$ & $\$ 1.603$ & $\$ 0$ & $\$ 41.010$ & $\$ 64$ \\
\hline & & & & & & & & & & & & \\
\hline 2 & COAL \& SORBENT PREP \& FEED & $\$ 11.403$ & $\$ 458$ & $\$ 2.759$ & $\$ 0$ & $\$ 0$ & $\$ 14.620$ & $\$ 1.529$ & $\$ 658$ & $\$ 0$ & $\$ 16.807$ & $\$ 26$ \\
\hline 3 & B FEEDWATER \& MISC. BOP SYSTEMS & $\$ 52.792$ & $\$ 0$ & $\$ 22.293$ & $\$ 0$ & $\$ 0$ & $\$ 75.085$ & $\$ 8.162$ & $\$ 3.379$ & $\$ 0$ & $\$ 86.626$ & $\$ 136$ \\
\hline & & & & & & & & & & & & \\
\hline $4.1^{4}$ & $\begin{array}{l}4 \text { FLUIDIZED BED BOILER } \\
\text { Fluidized Bed Boiler w/o BHse \&.Accessories }\end{array}$ & $\$ 0$ & $\$ 0$ & $\$ 0$ & $\$ 0$ & $\$ 0$ & $\$ 0$ & $\$ 0$ & $\$ 0$ & $\$ 0$ & $\$ 0$ & $\$ 0$ \\
\hline 4.2 & Air Separation Unit & $\$ 0$ & $\$ 0$ & $\$ 0$ & $\$ 0$ & $\$ 0$ & $\$ 0$ & $\$ 0$ & $\$ 0$ & $\$ 0$ & $\$ 0$ & $\$ 0$ \\
\hline 4.3 & Open & $\$ 0$ & $\$ 0$ & $\$ 0$ & $\$ 0$ & $\$ 0$ & $\$ 0$ & $\$ 0$ & $\$ 0$ & $\$ 0$ & $\$ 0$ & $\$ 0$ \\
\hline $4.4-4.9$ & Boiler BOP & $\$ 0$ & $\$ 0$ & $\$ 0$ & $\$ 0$ & $\$ 0$ & $\$ 0$ & $\$ 0$ & $\$ 0$ & $\$ 0$ & $\$ 0$ & $\$ 0$ \\
\hline & SUBTOTAL 4 & $\$ 0$ & $\$ 0$ & $\$ 0$ & $\$ 0$ & $\$ 0$ & $\$ 0$ & $\$ 0$ & $\$ 0$ & $\$ 0$ & $\$ 0$ & $\$ 0$ \\
\hline 5 & FLUE GAS CLEANUP & $\$ 1.313$ & $\$ 0$ & $\$ 1,331$ & $\$ 0$ & $\$ 0$ & $\$ 2.643$ & $\$ 305$ & $\$ 119$ & $\$ 0$ & $\$ 3.068$ & $\$ 5$ \\
\hline & & & & & & & & & & & & \\
\hline $5 \mathrm{~B}$ & 3 CO2 REMOVAL \& COMPRESSION & $\$ 0$ & $\$ 0$ & $\$ 0$ & $\$ 0$ & $\$ 0$ & $\$ 0$ & $\$ 0$ & $\$ 0$ & $\$ 0$ & $\$ 0$ & $\$ 0$ \\
\hline & & & & & & & & & & & & \\
\hline & COMBUSTION TURBINE/ACCESSORIES & & & & & & & & & & & \\
\hline 6.1 & Combustion Turbine Generator & N/A & $\$ 0$ & N/A & $\$ 0$ & $\$ 0$ & $\$ 0$ & $\$ 0$ & $\$ 0$ & $\$ 0$ & $\$ 0$ & $\$ 0$ \\
\hline $6.2-6.9$ & Combustion Turbine Accessories & $\$ 0$ & $\$ 0$ & $\$ 0$ & $\$ 0$ & $\$ 0$ & $\$ 0$ & $\$ 0$ & $\$ 0$ & $\$ 0$ & $\$ 0$ & $\$ 0$ \\
\hline & SUBTOTAL 6 & $\$ 0$ & $\$ 0$ & $\$ 0$ & $\$ 0$ & $\$ 0$ & $\$ 0$ & $\$ 0$ & $\$ 0$ & $\$ 0$ & $\$ 0$ & $\$ 0$ \\
\hline 7 & HRSG, DUCTING \& STACK & & & & & & & & & & & \\
\hline 7.1 & Heat Recovery Steam Generator & N/A & $\$ 0$ & N/A & $\$ 0$ & $\$ 0$ & $\$ 0$ & $\$ 0$ & $\$ 0$ & $\$ 0$ & $\$ 0$ & $\$ 0$ \\
\hline $7.2-7.9$ & HRSG Accessories, Ductwork and Stack & $\$ 19,003$ & $\$ 171$ & $\$ 11,101$ & $\$ 0$ & $\$ 0$ & $\$ 30.274$ & $\$ 3,347$ & $\$ 1,362$ & $\$ 0$ & $\$ 34.983$ & $\$ 55$ \\
\hline & SUBTOTAL 7 & $\$ 19.003$ & $\$ 171$ & $\$ 11.101$ & $\$ 0$ & $\$ 0$ & $\$ 30.274$ & $\$ 3.347$ & $\$ 1.362$ & $\$ 0$ & $\$ 34.983$ & $\$ 55$ \\
\hline 8 & STEAM TURBINE GENERATOR & & & & & & & & & & & \\
\hline 8.1 & Steam TG \& Accessories & $\$ 0$ & $\$ 0$ & $\$ 0$ & $\$ 0$ & $\$ 0$ & $\$ 0$ & $\$ 0$ & $\$ 0$ & $\$ 0$ & $\$ 0$ & $\$ 0$ \\
\hline $8.2-8.9$ & Turbine Plant Auxiliaries and Steam Piping & $\$ 33,449$ & $\$ 1.447$ & $\$ 16,690$ & $\$ 0$ & $\$ 0$ & $\$ 51.586$ & $\$ 5,397$ & $\$ 2,321$ & $\$ 0$ & $\$ 59.304$ & $\$ 93$ \\
\hline & SUBTOTAL 8 & $\$ 33,449$ & $\$ 1,447$ & $\$ 16.690$ & $\$ 0$ & $\$ 0$ & $\$ 51.586$ & $\$ 5.397$ & $\$ 2.321$ & $\$ 0$ & $\$ 59.304$ & $\$ 93$ \\
\hline 9 & COOLING WATER SYSTEM & $\$ 6,061$ & $\$ 8,328$ & $\$ 12,173$ & $\$ 0$ & $\$ 0$ & $\$ 26.561$ & $\$ 2,975$ & $\$ 1,195$ & $\$ 0$ & $\$ 30.732$ & $\$ 48$ \\
\hline & & & & & & & & & & & & \\
\hline 10 & ASHISPENT SORBENT HANDLING SYS & $\$ 9,204$ & $\$ 536$ & $\$ 6.430$ & $\$ 0$ & $\$ 0$ & $\$ 16.169$ & $\$ 1.827$ & $\$ 728$ & $\$ 0$ & $\$ 18.723$ & $\$ 29$ \\
\hline 11 & ACCESSORY ELECTRIC PLANT & $\$ 12.611$ & $\$ 4,235$ & $\$ 12,316$ & $\$ 0$ & $\$ 0$ & $\$ 29.162$ & $\$ 3,113$ & $\$ 1,312$ & $\$ 0$ & $\$ 33.588$ & $\$ 53$ \\
\hline & & & & & & & & & & & & \\
\hline 12 & INSTRUMENTATION \& CONTROL & $\$ 10.519$ & $\$ 0$ & $\$ 10.661$ & $\$ 0$ & $\$ 0$ & $\$ 21.180$ & $\$ 2,265$ & $\$ 953$ & $\$ 0$ & $\$ 24.399$ & $\$ 38$ \\
\hline & & & & & & & & & & & & \\
\hline 13 & 3 IMPROVEMENTS TO SITE & $\$ 3.157$ & $\$ 1.815$ & $\$ 6.025$ & $\$ 0$ & $\$ 0$ & $\$ 10.997$ & $\$ 1.293$ & $\$ 495$ & $\$ 0$ & $\$ 12.785$ & $\$ 20$ \\
\hline 14 & 4 BUILDINGS \& STRUCTURES & $\$ 0$ & $\$ 31.730$ & $\$ 28,346$ & $\$ 0$ & $\$ 0$ & $\$ 60.076$ & $\$ 6,441$ & $\$ 2.703$ & $\$ 0$ & $\$ 69.221$ & $\$ 109$ \\
\hline & & & & & & & & & & & & \\
\hline & TOTAL COST & $\$ 179,714$ & $\$ 53.513$ & $\$ 140.740$ & $\$ 0$ & $\$ 0$ & $\$ 373.967$ & \begin{tabular}{l|l|}
40.449
\end{tabular} & $\$ 16.829$ & $\$ 0$ & $\$ 431.245$ & $\$ 678$ \\
\hline & & & & & & & & & & & & \\
\hline
\end{tabular}


COMMERCIALIZATION DEVELOPMENT OF OXYGEN FIRED

CFB FOR GREENHOUSE GAS CONTROL

\begin{tabular}{|c|c|c|c|c|c|c|c|c|c|c|c|c|}
\hline & Client: & Alstom & & & & & & & & Report Date: & 02-Jul-07 & \\
\hline & Project: & \multicolumn{3}{|c|}{ SC CFB Oxyfuel Capture Ready } & & & & & & & & \\
\hline \multicolumn{13}{|c|}{ TOTAL PLANT COST SUMMARY } \\
\hline & Case: & \multicolumn{3}{|c|}{ Case 2a - Air Blown Capture Ready } & & & & & & & & \\
\hline & Plant Size: & 636.2 & MW, net & \multicolumn{2}{|c|}{ Estimate Type: } & \multicolumn{2}{|l|}{ Conceptual } & \multicolumn{2}{|c|}{ Cost Base (May) } & 2007 & $(\$ \times 1000)$ & \\
\hline Acct & & Equipment & Material & \multicolumn{2}{|c|}{ Labor } & Sales & Bare Erected & Eng'g CM & Other & Contingency & \multicolumn{2}{|c|}{ TOTAL PLANT COST } \\
\hline No. & Item/Description & Cost & Cost & Direct & Indirect & Tax & $\operatorname{Cost} \$$ & H.O.\& Fee & Costs & Project & $\$$ & $\$ / \mathrm{kW}$ \\
\hline & COAL \& SORBENT HANDLING & & & & & & & & & & & \\
\hline 1.1 & Coal Receive \& Unload & $\$ 3.817$ & $\$ 0$ & $\$ 1.651$ & $\$ 0$ & $\$ 0$ & $\$ 5,468$ & $\$ 582$ & $\$ 246$ & $\$ 0$ & $\$ 6,296$ & $\$ 10$ \\
\hline 1.2 & Coal Stackout \& Reclaim & $\$ 4,933$ & $\$ 0$ & $\$ 1.164$ & $\$ 0$ & $\$ 0$ & $\$ 6,097$ & $\$ 637$ & $\$ 274$ & $\$ 0$ & $\$ 7.009$ & $\$ 11$ \\
\hline 1.3 & Coal Conveyors & $\$ 4,586$ & $\$ 0$ & $\$ 1.047$ & $\$ 0$ & $\$ 0$ & $\$ 5,633$ & $\$ 588$ & $\$ 254$ & $\$ 0$ & $\$ 6.475$ & $\$ 10$ \\
\hline 1.4 & Other Coal Handling & $\$ 1,200$ & $\$ 0$ & $\$ 242$ & $\$ 0$ & $\$ 0$ & $\$ 1,442$ & $\$ 150$ & $\$ 65$ & $\$ 0$ & $\$ 1.657$ & $\$ 3$ \\
\hline 1.5 & Sorbent Receive \& Unload & $\$ 215$ & $\$ 0$ & $\$ 61$ & $\$ 0$ & $\$ 0$ & $\$ 276$ & $\$ 29$ & $\$ 12$ & $\$ 0$ & $\$ 317$ & $\$ 0$ \\
\hline 1.6 & Sorbent Stackout \& Reclaim & $\$ 3,468$ & $\$ 0$ & $\$ 602$ & $\$ 0$ & $\$ 0$ & $\$ 4,070$ & $\$ 422$ & $\$ 183$ & $\$ 0$ & $\$ 4,675$ & $\$ 7$ \\
\hline 1.7 & Sorbent Conveyors & $\$ 1,237$ & $\$ 268$ & $\$ 287$ & $\$ 0$ & $\$ 0$ & $\$ 1.793$ & $\$ 185$ & $\$ 81$ & $\$ 0$ & $\$ 2,058$ & $\$ 3$ \\
\hline 1.8 & Other Sorbent Handling & $\$ 747$ & $\$ 175$ & $\$ 371$ & $\$ 0$ & $\$ 0$ & $\$ 1,294$ & $\$ 136$ & $\$ 58$ & $\$ 0$ & $\$ 1,488$ & $\$ 2$ \\
\hline \multirow[t]{2}{*}{1.9} & Coal \& Sorbent Hnd. Foundations & $\$ 0$ & $\$ 4,350$ & $\$ 5.189$ & $\$ 0$ & $\$ 0$ & $\$ 9.540$ & $\$ 1.065$ & $\$ 429$ & $\$ 0$ & $\$ 11.034$ & $\$ 17$ \\
\hline & SUBTOTAL 1. & $\$ 20.203$ & $\$ 4.793$ & $\$ 10.616$ & $\$ 0$ & $\$ 0$ & $\$ 35.612$ & $\$ 3.795$ & $\$ 1.603$ & $\$ 0$ & $\$ 41.010$ & $\$ 64$ \\
\hline \multicolumn{13}{|c|}{2 COAL \& SORBENT PREP \& FEED } \\
\hline 2.1 & Coal Crushing \& Drying & $\$ 2.206$ & $\$ 0$ & $\$ 407$ & $\$ 0$ & $\$ 0$ & $\$ 2.613$ & $\$ 272$ & $\$ 118$ & $\$ 0$ & $\$ 3,002$ & $\$ 5$ \\
\hline 2.2 & Coal Conveyor to Storage & $\$ 7.059$ & $\$ 0$ & $\$ 1.459$ & $\$ 0$ & $\$ 0$ & $\$ 8,518$ & $\$ 887$ & $\$ 383$ & $\$ 0$ & $\$ 9.789$ & $\$ 15$ \\
\hline 2.3 & Coal Injection System & $\$ 0$ & $\$ 0$ & $\$ 0$ & $\$ 0$ & $\$ 0$ & $\$ 0$ & $\$ 0$ & $\$ 0$ & $\$ 0$ & $\$ 0$ & $\$ 0$ \\
\hline 2.4 & Misc Coal Prep \& Feed & $\$ 0$ & $\$ 0$ & $\$ 0$ & $\$ 0$ & $\$ 0$ & $\$ 0$ & $\$ 0$ & $\$ 0$ & $\$ 0$ & $\$ 0$ & $\$ 0$ \\
\hline 2.5 & Sorbent Prep Equipment & $\$ 1,427$ & $\$ 0$ & $\$ 281$ & $\$ 0$ & $\$ 0$ & $\$ 1,707$ & $\$ 178$ & $\$ 77$ & $\$ 0$ & $\$ 1.962$ & $\$ 3$ \\
\hline 2.6 & Sorbent Storage \& Feed & $\$ 712$ & $\$ 0$ & $\$ 257$ & $\$ 0$ & $\$ 0$ & $\$ 969$ & $\$ 102$ & $\$ 44$ & $\$ 0$ & $\$ 1.115$ & $\$ 2$ \\
\hline 2.7 & Sorbent Injection System & $\$ 0$ & $\$ 0$ & $\$ 0$ & $\$ 0$ & $\$ 0$ & $\$ 0$ & $\$ 0$ & $\$ 0$ & $\$ 0$ & $\$ 0$ & $\$ 0$ \\
\hline 2.8 & Booster Air Supply System & $\$ 0$ & $\$ 0$ & $\$ 0$ & $\$ 0$ & $\$ 0$ & $\$ 0$ & $\$ 0$ & $\$ 0$ & $\$ 0$ & $\$ 0$ & $\$ 0$ \\
\hline \multirow[t]{2}{*}{2.9} & Coal \& Sorbent Feed Foundation & $\$ 0$ & $\$ 458$ & $\$ 355$ & $\$ 0$ & $\$ 0$ & $\$ 813$ & $\$ 90$ & $\$ 37$ & $\$ 0$ & $\$ 939$ & $\$ 1$ \\
\hline & SUBTOTAL 2 & $\$ 11.403$ & $\$ 458$ & $\$ 2.759$ & $\$ 0$ & $\$ 0$ & $\$ 14,620$ & $\$ 1,529$ & $\$ 658$ & $\$ 0$ & $\$ 16.807$ & $\$ 26$ \\
\hline 3 & FEEDWATER \& MISC. BOP SYSTEMS & & & & & & & & & & & \\
\hline 3.1 & FeedwaterSystem & $\$ 20,934$ & $\$ 0$ & $\$ 7.061$ & $\$ 0$ & $\$ 0$ & $\$ 27.995$ & $\$ 2,925$ & $\$ 1.260$ & $\$ 0$ & $\$ 32,180$ & $\$ 51$ \\
\hline 3.2 & Water Makeup \& Pretreating & $\$ 7,512$ & $\$ 0$ & $\$ 2,290$ & $\$ 0$ & $\$ 0$ & $\$ 9,802$ & $\$ 1,105$ & $\$ 441$ & $\$ 0$ & $\$ 11.349$ & $\$ 18$ \\
\hline 3.3 & Other Feedwater Subsystems & $\$ 11,704$ & $\$ 0$ & $\$ 4,686$ & $\$ 0$ & $\$ 0$ & $\$ 16,389$ & $\$ 1.749$ & $\$ 738$ & $\$ 0$ & $\$ 18.876$ & $\$ 30$ \\
\hline 3.4 & Service Water Systems & $\$ 875$ & $\$ 0$ & $\$ 451$ & $\$ 0$ & $\$ 0$ & $\$ 1.326$ & $\$ 149$ & $\$ 60$ & $\$ 0$ & $\$ 1.535$ & $\$ 2$ \\
\hline 3.5 & Other Boiler Plant Systems & $\$ 5,173$ & $\$ 0$ & $\$ 4,512$ & $\$ 0$ & $\$ 0$ & $\$ 9.684$ & $\$ 1.094$ & $\$ 436$ & $\$ 0$ & $\$ 11.214$ & $\$ 18$ \\
\hline 3.6 & FO Supply Sys \& Nat Gas & $\$ 276$ & $\$ 0$ & $\$ 327$ & $\$ 0$ & $\$ 0$ & $\$ 603$ & $\$ 68$ & $\$ 27$ & $\$ 0$ & $\$ 698$ & $\$ 1$ \\
\hline 3.7 & Waste Treatment Equipment & $\$ 3,027$ & $\$ 0$ & $\$ 1.634$ & $\$ 0$ & $\$ 0$ & $\$ 4.662$ & $\$ 541$ & $\$ 210$ & $\$ 0$ & $\$ 5,413$ & $\$ 9$ \\
\hline \multirow[t]{2}{*}{3.8} & Misc. Equip (cranes.AirComp. Comm.) & $\$ 3.291$ & $\$ 0$ & $\$ 1.331$ & $\$ 0$ & $\$ 0$ & $\$ 4.622$ & $\$ 532$ & $\$ 208$ & $\$ 0$ & $\$ 5,362$ & $\$ 8$ \\
\hline & SUBTOTAL 3 & $\$ 52.792$ & $\$ 0$ & $\$ 22.293$ & $\$ 0$ & $\$ 0$ & $\$ 75.085$ & $\$ 8.162$ & $\$ 3.379$ & $\$ 0$ & $\$ 86.626$ & $\$ 136$ \\
\hline \multirow{2}{*}{$\begin{array}{r}4 \\
4.1\end{array}$} & FLUIDIZED BED BOILER & & & & & & & & & & & \\
\hline & Fluidized Bed Boiler,wo BHse \&.Accessories & $\$ 0$ & $\$ 0$ & $\$ 0$ & $\$ 0$ & $\$ 0$ & $\$ 0$ & $\$ 0$ & $\$ 0$ & $\$ 0$ & $\$ 0$ & $\$ 0$ \\
\hline 4.2 & Air Separation Unit & $\$ 0$ & $\$ 0$ & $\$ 0$ & $\$ 0$ & $\$ 0$ & $\$ 0$ & $\$ 0$ & $\$ 0$ & $\$ 0$ & $\$ 0$ & $\$ 0$ \\
\hline 4.3 & Open & $\$ 0$ & $\$ 0$ & $\$ 0$ & $\$ 0$ & $\$ 0$ & $\$ 0$ & $\$ 0$ & $\$ 0$ & $\$ 0$ & $\$ 0$ & $\$ 0$ \\
\hline 4.4 & Boiler BoP (Fluidizing Air Fans) & $\$ 0$ & $\$ 0$ & $\$ 0$ & $\$ 0$ & $\$ 0$ & $\$ 0$ & $\$ 0$ & $\$ 0$ & $\$ 0$ & $\$ 0$ & $\$ 0$ \\
\hline 4.5 & Primary Air System (Fans) & $w / 4.1$ & $\$ 0$ & $w / 4.1$ & $\$ 0$ & $\$ 0$ & $\$ 0$ & $\$ 0$ & $\$ 0$ & $\$ 0$ & $\$ 0$ & $\$ 0$ \\
\hline 4.6 & Secondary Air System (Fans) & $w / 4.1$ & $\$ 0$ & $w / 4.1$ & $\$ 0$ & $\$ 0$ & $\$ 0$ & $\$ 0$ & $\$ 0$ & $\$ 0$ & $\$ 0$ & $\$ 0$ \\
\hline 4.8 & Major Component Rigging & $\$ 0$ & $w / 4.1$ & $w / 4.1$ & $\$ 0$ & $\$ 0$ & $\$ 0$ & $\$ 0$ & $\$ 0$ & $\$ 0$ & $\$ 0$ & $\$ 0$ \\
\hline \multirow[t]{2}{*}{4.9} & Boiler Foundations & $\$ 0$ & $w / 14.1$ & w/14.1 & $\$ 0$ & $\$ 0$ & $\$ 0$ & $\$ 0$ & $\$ 0$ & $\$ 0$ & $\$ 0$ & $\$ 0$ \\
\hline & SUBTOTAL 4 & $\$ 0$ & $\$ 0$ & $\$ 0$ & $\$ 0$ & $\$ 0$ & $\$ 0$ & $\$ 0$ & $\$ 0$ & $\$ 0$ & $\$ 0$ & $\$ 0$ \\
\hline
\end{tabular}


COMMERCIALIZATION DEVELOPMENT OF OXYGEN FIRED

CFB FOR GREENHOUSE GAS CONTROL

\begin{tabular}{|c|c|c|c|c|c|c|c|c|c|c|c|c|}
\hline & Client: & Alstom & & & & & & & & Report Date: & 02-Jul-07 & \\
\hline & Project: & \multicolumn{3}{|c|}{ SC CFB Oxyfuel Capture Ready } & & & & & & & & \\
\hline \multicolumn{13}{|c|}{ TOTAL PLANT COST SUMMARY } \\
\hline & Case: & \multicolumn{3}{|c|}{ Case 2a - Air Blown Capture Ready } & & & & & & & & \\
\hline & Plant Size: & 636.2 & MW, net & \multicolumn{2}{|c|}{ Estimate Type: } & \multicolumn{2}{|l|}{ Conceptual } & \multicolumn{2}{|c|}{ Cost Base (May) } & 2007 & $(\$ \times 1000)$ & \\
\hline Acct & & Equipment & Material & \multicolumn{2}{|c|}{ Labor } & Sales & Bare Erected & Eng'g CM & Other & Contingency & \multicolumn{2}{|c|}{ TOTAL PLANT COST } \\
\hline \multirow[t]{3}{*}{ No. } & Item/Description & Cost & Cost & Direct & Indirect & Tax & Cost $\$$ & H.O.\& Fee & Costs & Project & $\$$ & $\$ / \mathrm{kW}$ \\
\hline & & & & & & & & & & & & \\
\hline & FIUESASCLEANUP & & & & & & & & & & & \\
\hline \multirow{8}{*}{$\begin{array}{r}5 \\
5.1 \\
5.2 \\
53\end{array}$} & Absorber Vessels \& Accessories & $\$ 0$ & $\$ 0$ & $\$ 0$ & $\$ 0$ & $\$ 0$ & $\$ 0$ & $\$ 0$ & $\$ 0$ & $\$ 0$ & $\$ 0$ & $\$ 0$ \\
\hline & Other FGD & $\$ 0$ & $\$ 0$ & $\$ 0$ & $\$ 0$ & $\$ 0$ & $\$ 0$ & $\$ 0$ & $\$ 0$ & $\$ 0$ & $\$ 0$ & $\$ 0$ \\
\hline & Bag House \& Accessories & $\$ 0$ & $\$ 0$ & $\$ 0$ & $\$ 0$ & $\$ 0$ & $\$ 0$ & $\$ 0$ & $\$ 0$ & $\$ 0$ & $\$ 0$ & $\$ 0$ \\
\hline & Other Particulate Removal Materials & $\$ 1,313$ & $\$ 0$ & $\$ 1,331$ & $\$ 0$ & $\$ 0$ & $\$ 2,643$ & $\$ 305$ & $\$ 119$ & $\$ 0$ & $\$ 3,068$ & $\$ 5$ \\
\hline & PFWH \& Gas Cooler & $\$ 0$ & $\$ 0$ & $\$ 0$ & $\$ 0$ & $\$ 0$ & $\$ 0$ & $\$ 0$ & $\$ 0$ & $\$ 0$ & $\$ 0$ & $\$ 0$ \\
\hline & Gas Processing System & $\$ 0$ & $\$ 0$ & $\$ 0$ & $\$ 0$ & $\$ 0$ & $\$ 0$ & $\$ 0$ & $\$ 0$ & $\$ 0$ & $\$ 0$ & $\$ 0$ \\
\hline & Open & $\$ 0$ & $\$ 0$ & $\$ 0$ & $\$ 0$ & $\$ 0$ & $\$ 0$ & $\$ 0$ & $\$ 0$ & $\$ 0$ & $\$ 0$ & $\$ 0$ \\
\hline & SUBTOTAL 5. & $\$ 1.313$ & $\$ 0$ & $\$ 1.331$ & $\$ 0$ & $\$ 0$ & $\$ 2.643$ & $\$ 305$ & $\$ 119$ & $\$ 0$ & $\$ 3.068$ & $\$ 5$ \\
\hline \multirow{2}{*}{$\begin{array}{r}5 \mathrm{~B} \\
5 \mathrm{~B} .1\end{array}$} & CO2 REMOVAL \& COMPRESSION & & & & & & & & & & & \\
\hline & CO2 Removal System & $\$ 0$ & $\$ 0$ & $\$ 0$ & $\$ 0$ & $\$ 0$ & $\$ 0$ & $\$ 0$ & $\$ 0$ & $\$ 0$ & $\$ 0$ & $\$ 0$ \\
\hline \multirow[t]{2}{*}{ 5B.2 } & CO2 Compression \& Drying & $\$ 0$ & $\$ 0$ & $\$ 0$ & $\$ 0$ & $\$ 0$ & $\$ 0$ & $\$ 0$ & $\$ 0$ & $\$ 0$ & $\$ 0$ & $\$ 0$ \\
\hline & SUBTOTAL 5B. & $\$ 0$ & $\$ 0$ & $\$ 0$ & $\$ 0$ & $\$ 0$ & $\$ 0$ & $\$ 0$ & $\$ 0$ & $\$ 0$ & $\$ 0$ & $\$ 0$ \\
\hline 6 & COMBUSTION TURBINE/ACCESSORIES & & & & & & & & & & & \\
\hline 6.1 & Combustion Turbine Generator & N/A & $\$ 0$ & N/A & $\$ 0$ & $\$ 0$ & $\$ 0$ & $\$ 0$ & $\$ 0$ & $\$ 0$ & $\$ 0$ & $\$ 0$ \\
\hline 6.2 & Combustion Turbine Accessories & $\$ 0$ & $\$ 0$ & $\$ 0$ & $\$ 0$ & $\$ 0$ & $\$ 0$ & $\$ 0$ & $\$ 0$ & $\$ 0$ & $\$ 0$ & $\$ 0$ \\
\hline 6.3 & Compressed Air Piping & $\$ 0$ & $\$ 0$ & $\$ 0$ & $\$ 0$ & $\$ 0$ & $\$ 0$ & $\$ 0$ & $\$ 0$ & $\$ 0$ & $\$ 0$ & $\$ 0$ \\
\hline \multirow[t]{2}{*}{6.9} & Combustion Turbine Foundations & $\$ 0$ & $\$ 0$ & $\$ 0$ & $\$ 0$ & $\$ 0$ & $\$ 0$ & $\$ 0$ & $\$ 0$ & $\$ 0$ & $\$ 0$ & $\$ 0$ \\
\hline & SUBTOTAL 6 . & $\$ 0$ & $\$ 0$ & $\$ 0$ & $\$ 0$ & $\$ 0$ & $\$ 0$ & $\$ 0$ & $\$ 0$ & $\$ 0$ & $\$ 0$ & $\$ 0$ \\
\hline 7 & HRSG. DUCTING \& STACK & & & & & & & & & & & \\
\hline 7.1 & Heat Recovery Steam Generator & N/A & $\$ 0$ & N/A & $\$ 0$ & $\$ 0$ & $\$ 0$ & $\$ 0$ & $\$ 0$ & $\$ 0$ & $\$ 0$ & $\$ 0$ \\
\hline 7.2 & ID Fans & $\$ 0$ & $\$ 0$ & $\$ 0$ & $\$ 0$ & $\$ 0$ & $\$ 0$ & $\$ 0$ & $\$ 0$ & $\$ 0$ & $\$ 0$ & $\$ 0$ \\
\hline 7.3 & Ductwork & $\$ 7.103$ & $\$ 0$ & $\$ 4,322$ & $\$ 0$ & $\$ 0$ & $\$ 11.425$ & $\$ 1,185$ & $\$ 514$ & $\$ 0$ & $\$ 13,123$ & $\$ 21$ \\
\hline 7.4 & Stack & $\$ 11.900$ & $\$ 0$ & $\$ 6.595$ & $\$ 0$ & $\$ 0$ & $\$ 18,495$ & $\$ 2.123$ & $\$ 832$ & $\$ 0$ & $\$ 21.450$ & $\$ 34$ \\
\hline \multirow[t]{2}{*}{7.9} & Duct \& Stack Foundations & $\$ 0$ & $\$ 171$ & $\$ 184$ & $\$ 0$ & $\$ 0$ & $\$ 355$ & $\$ 39$ & $\$ 16$ & $\$ 0$ & $\$ 410$ & $\$ 1$ \\
\hline & SUBTOTAL 7. & $\$ 19.003$ & $\$ 171$ & $\$ 11.101$ & $\$ 0$ & $\$ 0$ & $\$ 30.274$ & $\$ 3.347$ & $\$ 1.362$ & $\$ 0$ & $\$ 34,983$ & $\$ 55$ \\
\hline 8 & STEAM TURBINE GENERATOR & & & & & & & & & & & \\
\hline 8.1 & Steam TG \& Accessories & $\$ 0$ & $\$ 0$ & $\$ 0$ & $\$ 0$ & $\$ 0$ & $\$ 0$ & $\$ 0$ & $\$ 0$ & $\$ 0$ & $\$ 0$ & $\$ 0$ \\
\hline 8.2 & Turbine Plant Auxiliaries & $\$ 384$ & $\$ 0$ & $\$ 779$ & $\$ 0$ & $\$ 0$ & $\$ 1,163$ & $\$ 135$ & $\$ 52$ & $\$ 0$ & $\$ 1,351$ & $\$ 2$ \\
\hline 8.3 & Condenser \& Auxiliaries & $\$ 9,774$ & $\$ 0$ & $\$ 2,873$ & $\$ 0$ & $\$ 0$ & $\$ 12.647$ & $\$ 1,442$ & $\$ 569$ & $\$ 0$ & $\$ 14,659$ & $\$ 23$ \\
\hline 8.4 & Steam Piping & $\$ 23,291$ & $\$ 0$ & $\$ 10.877$ & $\$ 0$ & $\$ 0$ & $\$ 34,168$ & $\$ 3,413$ & $\$ 1,538$ & $\$ 0$ & $\$ 39,119$ & $\$ 61$ \\
\hline \multirow[t]{2}{*}{8.9} & TG Foundations & $\$ 0$ & $\$ 1.447$ & $\$ 2,161$ & $\$ 0$ & $\$ 0$ & $\$ 3,608$ & $\$ 406$ & $\$ 162$ & $\$ 0$ & $\$ 4,176$ & $\$ 7$ \\
\hline & SUBTOTAL 8. & $\$ 33,449$ & $\$ 1.447$ & $\$ 16.690$ & $\$ 0$ & $\$ 0$ & $\$ 51.586$ & $\$ 5,397$ & $\$ 2,321$ & $\$ 0$ & $\$ 59,304$ & $\$ 93$ \\
\hline 9 & COOLING WATER SYSTEM & & & & & & & & & & & \\
\hline 9.1 & Cooling Towers & $\$ 3.216$ & $\$ 0$ & $\$ 1.636$ & $\$ 0$ & $\$ 0$ & $\$ 4,852$ & $\$ 556$ & $\$ 218$ & $\$ 0$ & $\$ 5,627$ & $\$ 9$ \\
\hline 9.2 & Circulating Water Pumps & $\$ 1,263$ & $\$ 0$ & $\$ 185$ & $\$ 0$ & $\$ 0$ & $\$ 1.448$ & $\$ 148$ & $\$ 65$ & $\$ 0$ & $\$ 1,661$ & $\$ 3$ \\
\hline 9.3 & Circ. Water System Auxiliaries & $\$ 589$ & $\$ 0$ & $\$ 74$ & $\$ 0$ & $\$ 0$ & $\$ 663$ & $\$ 75$ & $\$ 30$ & $\$ 0$ & $\$ 769$ & $\$ 1$ \\
\hline 9.4 & Circ.Water Piping & $\$ 0$ & $\$ 5.556$ & $\$ 5.100$ & $\$ 0$ & $\$ 0$ & $\$ 10,656$ & $\$ 1,187$ & $\$ 480$ & $\$ 0$ & $\$ 12,324$ & $\$ 19$ \\
\hline 9.5 & Make-up Water System & $\$ 518$ & $\$ 0$ & $\$ 655$ & $\$ 0$ & $\$ 0$ & $\$ 1,173$ & $\$ 134$ & $\$ 53$ & $\$ 0$ & $\$ 1,360$ & $\$ 2$ \\
\hline 9.6 & Component Cooling Water Sys & $\$ 475$ & $\$ 0$ & $\$ 358$ & $\$ 0$ & $\$ 0$ & $\$ 833$ & $\$ 94$ & $\$ 37$ & $\$ 0$ & $\$ 965$ & $\$ 2$ \\
\hline 9.9 & Circ. Water System Foundations\& Structures & $\$ 0$ & $\$ 2,771$ & $\$ 4,164$ & $\$ 0$ & $\$ 0$ & $\$ 6.935$ & $\$ 780$ & $\$ 312$ & $\$ 0$ & $\$ 8,027$ & $\$ 13$ \\
\hline & SUBTOTAL 9. & $\$ 6.061$ & $\$ 8,328$ & $\$ 12,173$ & $\$ 0$ & $\$ 0$ & $\$ 26.561$ & $\$ 2.975$ & $\$ 1.195$ & $\$ 0$ & $\$ 30.732$ & $\$ 48$ \\
\hline
\end{tabular}


COMMERCIALIZATION DEVELOPMENT OF OXYGEN FIRED

CFB FOR GREENHOUSE GAS CONTROL

\begin{tabular}{|c|c|c|c|c|c|c|c|c|c|c|c|c|}
\hline & Client: & Alstom & & & & & & & & Report Date: & $02-1407$ & \\
\hline & Project: & \multicolumn{3}{|c|}{ SC CFB Oxyfuel Capture Ready } & & & & & & & & \\
\hline \multicolumn{13}{|c|}{ TOTAL PLANT COST SUMMARY } \\
\hline & Case: & \multicolumn{3}{|c|}{ Case 2a - Air Blown Capture Ready } & & \multirow{2}{*}{\multicolumn{2}{|c|}{ Conceptual }} & \multirow{2}{*}{\multicolumn{2}{|c|}{ Cost Base (May) }} & & & \\
\hline & Plant Size: & 636.2 & MW, net & Estimate & Type: & & & & & 2007 & $(\$ \times 1000)$ & \\
\hline Acct & & Equipment & Material & \multicolumn{2}{|c|}{ Labor } & Sales & Bare Erected & Eng'g CM & Other & Contingency & \multicolumn{2}{|c|}{ TOTAL PLANT COST } \\
\hline No. & Item/Description & Cost & Cost & Direct & Indirect & Tax & Cost $\$$ & H.O.\& Fee & Costs & Project & 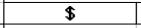 & $\$ / \mathrm{kW}$ \\
\hline 10 & ASH/SPENT SORBENT HANDLING SYS & & & & & & & & & & & \\
\hline 10.1 & Ash Coolers & N/A & $\$ 0$ & N/A & $\$ 0$ & $\$ 0$ & $\$ 0$ & $\$ 0$ & $\$ 0$ & $\$ 0$ & $\$ 0$ & $\$ 0$ \\
\hline 10.2 & Cyclone Ash Letdown & N/A & $\$ 0$ & N/A & $\$ 0$ & $\$ 0$ & $\$ 0$ & $\$ 0$ & $\$ 0$ & $\$ 0$ & $\$ 0$ & $\$ 0$ \\
\hline 10.3 & HGCU Ash Letdown & N/A & $\$ 0$ & N/A & $\$ 0$ & $\$ 0$ & $\$ 0$ & $\$ 0$ & $\$ 0$ & $\$ 0$ & $\$ 0$ & $\$ 0$ \\
\hline 10.4 & High Temperature Ash Piping & N/A & $\$ 0$ & N/A & $\$ 0$ & $\$ 0$ & $\$ 0$ & $\$ 0$ & $\$ 0$ & $\$ 0$ & $\$ 0$ & $\$ 0$ \\
\hline 10.5 & Other Ash Recovery Equipment & N/A & $\$ 0$ & N/A & $\$ 0$ & $\$ 0$ & $\$ 0$ & $\$ 0$ & $\$ 0$ & $\$ 0$ & $\$ 0$ & $\$ 0$ \\
\hline 10.6 & Ash Storage Silos & $\$ 563$ & $\$ 0$ & $\$ 1.642$ & $\$ 0$ & $\$ 0$ & $\$ 2,204$ & $\$ 258$ & $\$ 99$ & $\$ 0$ & $\$ 2,561$ & $\$ 4$ \\
\hline 10.7 & Ash Transport \& Feed Equipment & $\$ 8.641$ & $\$ 0$ & $\$ 4,192$ & $\$ 0$ & $\$ 0$ & $\$ 12,833$ & $\$ 1.443$ & $\$ 577$ & $\$ 0$ & $\$ 14.853$ & $\$ 23$ \\
\hline 10.8 & Misc. Ash Handling Equipment & $\$ 0$ & $\$ 0$ & $\$ 0$ & $\$ 0$ & $\$ 0$ & $\$ 0$ & $\$ 0$ & $\$ 0$ & $\$ 0$ & $\$ 0$ & $\$ 0$ \\
\hline \multirow[t]{2}{*}{10.9} & Ash/Spent Sorbent Foundation & $\$ 0$ & $\$ 536$ & $\$ 596$ & $\$ 0$ & $\$ 0$ & $\$ 1,132$ & $\$ 126$ & $\$ 51$ & $\$ 0$ & $\$ 1.309$ & $\$ 2$ \\
\hline & SUBTOTAL 10. & $\$ 9.204$ & $\$ 536$ & $\$ 6.430$ & $\$ 0$ & $\$ 0$ & $\$ 16.169$ & $\$ 1.827$ & $\$ 728$ & $\$ 0$ & $\$ 18.723$ & $\$ 29$ \\
\hline 11 & ACCESSORY ELECTRIC PLANT & & & & & & & & & & & \\
\hline 11.1 & Generator Equipment & $\$ 1.731$ & $\$ 0$ & $\$ 266$ & $\$ 0$ & $\$ 0$ & $\$ 1.997$ & $\$ 221$ & $\$ 90$ & $\$ 0$ & $\$ 2,307$ & $\$ 4$ \\
\hline 11.2 & Station Service Equipment & $\$ 2.767$ & $\$ 0$ & $\$ 861$ & $\$ 0$ & $\$ 0$ & $\$ 3.628$ & $\$ 404$ & $\$ 163$ & $\$ 0$ & $\$ 4,196$ & $\$ 7$ \\
\hline 11.3 & Switchgear \& Motor Control & $\$ 3.095$ & $\$ 0$ & $\$ 498$ & $\$ 0$ & $\$ 0$ & $\$ 3.593$ & $\$ 397$ & $\$ 162$ & $\$ 0$ & $\$ 4.151$ & $\$ 7$ \\
\hline 11.4 & Conduit \& Cable Tray & $\$ 0$ & $\$ 1.365$ & $\$ 4,470$ & $\$ 0$ & $\$ 0$ & $\$ 5.834$ & $\$ 672$ & $\$ 263$ & $\$ 0$ & $\$ 6.769$ & $\$ 11$ \\
\hline 11.5 & Wire \& Cable & $\$ 0$ & $\$ 2,527$ & $\$ 4,628$ & $\$ 0$ & $\$ 0$ & $\$ 7,155$ & $\$ 714$ & $\$ 322$ & $\$ 0$ & $\$ 8,191$ & $\$ 13$ \\
\hline 11.6 & Protective Equipment & $\$ 199$ & $\$ 0$ & $\$ 641$ & $\$ 0$ & $\$ 0$ & $\$ 841$ & $\$ 98$ & $\$ 38$ & $\$ 0$ & $\$ 976$ & $\$ 2$ \\
\hline 11.7 & Standby Equipment & $\$ 1.358$ & $\$ 0$ & $\$ 29$ & $\$ 0$ & $\$ 0$ & $\$ 1.387$ & $\$ 152$ & $\$ 62$ & $\$ 0$ & $\$ 1.601$ & $\$ 3$ \\
\hline 11.8 & Main Power Transformers & $\$ 3.461$ & $\$ 0$ & $\$ 128$ & $\$ 0$ & $\$ 0$ & $\$ 3.589$ & $\$ 326$ & $\$ 161$ & $\$ 0$ & $\$ 4.077$ & $\$ 6$ \\
\hline \multirow[t]{2}{*}{11.9} & Electrical Foundations & $\$ 0$ & $\$ 343$ & $\$ 796$ & $\$ 0$ & $\$ 0$ & $\$ 1,139$ & $\$ 129$ & $\$ 51$ & $\$ 0$ & $\$ 1,319$ & $\$ 2$ \\
\hline & SUBTOTAL 11. & $\$ 12.611$ & $\$ 4.235$ & $\$ 12.316$ & $\$ 0$ & $\$ 0$ & $\$ 29.162$ & $\$ 3.113$ & $\$ 1.312$ & $\$ 0$ & $\$ 33.588$ & $\$ 53$ \\
\hline 12 & INSTRUMENTATION \& CONTROL & & & & & & & & & & & \\
\hline 12.1 & PC Control Equipment & $w / 12.7$ & $\$ 0$ & $w / 12.7$ & $\$ 0$ & $\$ 0$ & $\$ 0$ & $\$ 0$ & $\$ 0$ & $\$ 0$ & $\$ 0$ & $\$ 0$ \\
\hline 12.2 & Combustion Turbine Control & N/A & $\$ 0$ & $\mathrm{~N} / \mathrm{A}$ & $\$ 0$ & $\$ 0$ & $\$ 0$ & $\$ 0$ & $\$ 0$ & $\$ 0$ & $\$ 0$ & $\$ 0$ \\
\hline 12.3 & Steam Turbine Control & w/8.1 & $\$ 0$ & $w / 8.1$ & $\$ 0$ & $\$ 0$ & $\$ 0$ & $\$ 0$ & $\$ 0$ & $\$ 0$ & $\$ 0$ & $\$ 0$ \\
\hline 12.4 & Other Major Component Control & $\$ 0$ & $\$ 0$ & $\$ 0$ & $\$ 0$ & $\$ 0$ & $\$ 0$ & $\$ 0$ & $\$ 0$ & $\$ 0$ & $\$ 0$ & $\$ 0$ \\
\hline 12.5 & Signal Processing Equipment & W/12.7 & $\$ 0$ & $w / 12.7$ & $\$ 0$ & $\$ 0$ & $\$ 0$ & $\$ 0$ & $\$ 0$ & $\$ 0$ & $\$ 0$ & $\$ 0$ \\
\hline 12.6 & Control Boards. Panels \& Racks & $\$ 466$ & $\$ 0$ & $\$ 264$ & $\$ 0$ & $\$ 0$ & $\$ 730$ & $\$ 82$ & $\$ 33$ & $\$ 0$ & $\$ 845$ & $\$ 1$ \\
\hline 12.7 & Distributed Control System Equipment & $\$ 5.171$ & $\$ 0$ & $\$ 856$ & $\$ 0$ & $\$ 0$ & $\$ 6.027$ & $\$ 666$ & $\$ 271$ & $\$ 0$ & $\$ 6.964$ & $\$ 11$ \\
\hline 12.8 & Instrument Wiring \& Tubing & $\$ 3,555$ & $\$ 0$ & $\$ 6.686$ & $\$ 0$ & $\$ 0$ & $\$ 10.241$ & $\$ 1.034$ & $\$ 461$ & $\$ 0$ & $\$ 11.736$ & $\$ 18$ \\
\hline \multirow[t]{2}{*}{12.9} & Other I \& C Equipment & $\$ 1.328$ & $\$ 0$ & $\$ 2,855$ & $\$ 0$ & $\$ 0$ & $\$ 4.183$ & $\$ 483$ & $\$ 188$ & $\$ 0$ & $\$ 4.854$ & $\$ 8$ \\
\hline & SUBTOTAL 12. & $\$ 10.519$ & $\$ 0$ & $\$ 10.661$ & $\$ 0$ & $\$ 0$ & $\$ 21.180$ & $\$ 2.265$ & $\$ 953$ & $\$ 0$ & $\$ 24.399$ & $\$ 38$ \\
\hline 13 & IMPROVEMENTS TO SITE & & & & & & & & & & & \\
\hline 13.1 & Site Preparation & $\$ 0$ & $\$ 53$ & $\$ 1.005$ & $\$ 0$ & $\$ 0$ & $\$ 1.058$ & $\$ 125$ & $\$ 48$ & $\$ 0$ & $\$ 1.231$ & $\$ 2$ \\
\hline 13.2 & Site Improvements & $\$ 0$ & $\$ 1.762$ & $\$ 2.072$ & $\$ 0$ & $\$ 0$ & $\$ 3,834$ & $\$ 451$ & $\$ 173$ & $\$ 0$ & $\$ 4,457$ & $\$ 7$ \\
\hline \multirow[t]{2}{*}{13.3} & Site Facilities & $\$ 3,157$ & $\$ 0$ & $\$ 2.948$ & $\$ 0$ & $\$ 0$ & $\$ 6,105$ & $\$ 717$ & $\$ 275$ & $\$ 0$ & $\$ 7.097$ & $\$ 11$ \\
\hline & SUBTOTAL 13 & $\$ 3.157$ & $\$ 1.815$ & $\$ 6.025$ & $\$ 0$ & $\$ 0$ & $\$ 10.997$ & $\$ 1.293$ & $\$ 495$ & $\$ 0$ & $\$ 12.785$ & $\$ 20$ \\
\hline 14 & BUILDINGS \& STRUCTURES & & & & & & & & & & & \\
\hline 14.1 & FB Boiler Building Foundation & $\$ 0$ & $\$ 16.241$ & $\$ 13.521$ & $\$ 0$ & $\$ 0$ & $\$ 29.762$ & $\$ 3,180$ & $\$ 1,339$ & $\$ 0$ & $\$ 34,282$ & $\$ 54$ \\
\hline 14.2 & Turbine Building & $\$ 0$ & $\$ 11.137$ & $\$ 9.826$ & $\$ 0$ & $\$ 0$ & $\$ 20.963$ & $\$ 2,246$ & $\$ 943$ & $\$ 0$ & $\$ 24,153$ & $\$ 38$ \\
\hline 14.3 & Administration Building & $\$ 0$ & $\$ 954$ & $\$ 954$ & $\$ 0$ & $\$ 0$ & $\$ 1.908$ & $\$ 206$ & $\$ 86$ & $\$ 0$ & $\$ 2,200$ & $\$ 3$ \\
\hline 14.4 & Circulation Water Pumphouse & $\$ 0$ & $\$ 222$ & $\$ 167$ & $\$ 0$ & $\$ 0$ & $\$ 390$ & $\$ 41$ & $\$ 18$ & $\$ 0$ & $\$ 449$ & $\$ 1$ \\
\hline 14.5 & Water Treatment Buildings & $\$ 0$ & $\$ 720$ & $\$ 562$ & $\$ 0$ & $\$ 0$ & $\$ 1,282$ & $\$ 137$ & $\$ 58$ & $\$ 0$ & $\$ 1.476$ & $\$ 2$ \\
\hline 14.6 & Machine Shop & $\$ 0$ & $\$ 850$ & $\$ 541$ & $\$ 0$ & $\$ 0$ & $\$ 1,391$ & $\$ 147$ & $\$ 63$ & $\$ 0$ & $\$ 1,600$ & $\$ 3$ \\
\hline 14.7 & Warehouse & $\$ 0$ & $\$ 576$ & $\$ 547$ & $\$ 0$ & $\$ 0$ & $\$ 1,123$ & $\$ 121$ & $\$ 51$ & $\$ 0$ & $\$ 1.295$ & $\$ 2$ \\
\hline & Other Buildings \& Structures & $\$ 0$ & $\$ 353$ & $\$ 285$ & $\$ 0$ & $\$ 0$ & $\$ 638$ & $\$ 68$ & $\$ 29$ & $\$ 0$ & $\$ 734$ & $\$ 1$ \\
\hline \multirow[t]{3}{*}{14.9} & Waste Treating Building \& Str. & $\$ 0$ & $\$ 676$ & $\$ 1.942$ & $\$ 0$ & $\$ 0$ & $\$ 2.619$ & $\$ 296$ & $\$ 118$ & $\$ 0$ & $\$ 3.032$ & $\$ 5$ \\
\hline & SUBTOTAL 14 & $\$ 0$ & $\$ 31.730$ & $\$ 28.346$ & $\$ 0$ & $\$ 0$ & $\$ 60.076$ & $\$ 6.441$ & $\$ 2.703$ & $\$ 0$ & $\$ 69.221$ & $\$ 109$ \\
\hline & TOTAL COST & $\$ 179.714$ & $\$ 53.513$ & $\$ 140.740$ & $\$ 0$ & $\$ 0$ & $\$ 373.967$ & $\$ 40.449$ & $\$ 16.829$ & $\$ 0$ & $\$ 431.245$ & $\$ 678$ \\
\hline
\end{tabular}


COMMERCIALIZATION DEVELOPMENT OF OXYGEN FIRED

CFB FOR GREENHOUSE GAS CONTROL

Table 10-4: Detailed BOP Costs for Case 2b (Capture Ready Power Plant Retrofit to $\mathrm{O}_{2}$ Firing and $\mathrm{CO}_{2}$ Capture)

\begin{tabular}{|c|c|c|c|c|c|c|c|c|c|c|c|c|}
\hline & & & & & & & & & & & & \\
\hline & Client: & Alstom & & & & & & & & Report Date: & 02-Jul-07 & \\
\hline & Project: & SC CFB Oxy & fuel Capture & Ready & & & & & & & & \\
\hline & & & TOTA & L PLAN & $\Gamma \mathrm{COST}$ & Г SUMM & AARY & & & & & \\
\hline & Case: & Case $2 b-O x$ & ygen Blown & w/CO2 Captc & & & & & & & & \\
\hline & Plant Size: & 620.5 & MW net & Estimate & Type: & Conceptual & & Cost B & ase (May) & 2007 & $(\$ \times 1000)$ & \\
\hline Acct & & Equipment & Material & Lab & & Sales & Bare Erected & Eng'g CM & Other & Contingency & TOTAL PLANT & $\mathrm{c} \operatorname{cosT}$ \\
\hline No. & Item/Description & Cost & Cost & Direct & Indirect & Tax & Cost $\$$ & H.O.\& Fee & Costs & Project & $\$$ & $\$ / \mathrm{kW}$ \\
\hline 1 & COAL \& SORBENT HANDLING & $\$ 22883$ & $\$ 4793$ & $\$ 10939$ & $\$ 0$ & $\$ 0$ & $\$ 38615$ & $\$ 4.100$ & $\$ 1736$ & $\$ 0$ & $\$ 44451$ & $\$ 72$ \\
\hline 2 & COAL \& SORBENT PREP \& FEED & $\$ 11.403$ & $\$ 458$ & $\$ 2,759$ & $\$ 0$ & $\$ 0$ & $\$ 14,620$ & $\$ 1,529$ & $\$ 658$ & $\$ 0$ & $\$ 16.807$ & $\$ 27$ \\
\hline 3 & FEEDWATER \&. MISC. BOP SYSTEMS & $\$ 55,808$ & $\$ 0$ & $\$ 24,592$ & $\$ 0$ & $\$ 0$ & $\$ 80.400$ & $\$ 8.734$ & $\$ 3,604$ & $\$ 0$ & $\$ 92.738$ & $\$ 149$ \\
\hline & & & & & & & & & & & & \\
\hline 4 & FLUIDIZED BED BOILER & & & & & & & & & & & \\
\hline 4.1 & Fluidized Bed Boiler,wo BHse \& Accessories & $\$ 0$ & $\$ 0$ & $\$ 0$ & $\$ 0$ & $\$ 0$ & $\$ 0$ & $\$ 0$ & $\$ 0$ & $\$ 0$ & $\$ 0$ & $\$ 0$ \\
\hline 4.2 & Air Separation Unit & $\$ 0$ & $\$ 0$ & $\$ 0$ & $\$ 0$ & $\$ 0$ & $\$ 0$ & $\$ 0$ & $\$ 0$ & $\$ 0$ & $\$ 0$ & $\$ 0$ \\
\hline 4.3 & Open & $\$ 0$ & $\$ 0$ & $\$ 0$ & $\$ 0$ & $\$ 0$ & $\$ 0$ & $\$ 0$ & $\$ 0$ & $\$ 0$ & $\$ 0$ & $\$ 0$ \\
\hline $4.4-4.9$ & Boiler BOP & $\$ 0$ & $\$ 0$ & $\$ 0$ & $\$ 0$ & $\$ 0$ & $\$ 0$ & $\$ 0$ & $\$ 0$ & $\$ 0$ & $\$ 0$ & $\$ 0$ \\
\hline & SUBTOTAL 4 & $\$ 0$ & $\$ 0$ & $\$ 0$ & $\$ 0$ & $\$ 0$ & $\$ 0$ & $\$ 0$ & $\$ 0$ & $\$ 0$ & $\$ 0$ & $\$ 0$ \\
\hline & & & & & & & & & & & & \\
\hline $5 B$ & CO2 REMOVAL \& COMPRESSION & $\$ 0$ & $\$ 0$ & $\$ 0$ & $\$ 0$ & $\$ 0$ & $\$ 0$ & $\$ 0$ & $\$ 0$ & $\$ 0$ & $\$ 0$ & $\$ 0$ \\
\hline & & & & & & & & & & & & \\
\hline 6 & COMBUSTION TURBINE/ACCESSORIES & & & & & & & & & & & \\
\hline 6.1 & Combustion Turbine Generator & N/A & $\$ 0$ & N/A & $\$ 0$ & $\$ 0$ & $\$ 0$ & $\$ 0$ & $\$ 0$ & $\$ 0$ & $\$ 0$ & $\$ 0$ \\
\hline $6.2-6.9$ & Combustion Turbine Accessories & $\$ 0$ & $\$ 0$ & $\$ 0$ & $\$ 0$ & $\$ 0$ & $\$ 0$ & $\$ 0$ & $\$ 0$ & $\$ 0$ & $\$ 0$ & $\$ 0$ \\
\hline & SUBTOTAL 6 & $\$ 0$ & $\$ 0$ & $\$ 0$ & $\$ 0$ & $\$ 0$ & $\$ 0$ & $\$ 0$ & $\$ 0$ & $\$ 0$ & $\$ 0$ & $\$ 0$ \\
\hline & & & & & & & & & & & & \\
\hline 7 & HRSG, DUCTING \& STACK & & & & & & & & & & & \\
\hline 7.1 & Heat Recovery Steam Generator & N/A & $\$ 0$ & N/A & $\$ 0$ & $\$ 0$ & $\$ 0$ & $\$ 0$ & $\$ 0$ & $\$ 0$ & $\$ 0$ & $\$ 0$ \\
\hline $7.2-7.9$ & HRSG Accessories, Ductwork and Stack & $\$ 20.944$ & $\$ 218$ & $\$ 12,517$ & $\$ 0$ & $\$ 0$ & $\$ 33.678$ & $\$ 3,681$ & $\$ 1,507$ & $\$ 0$ & $\$ 38.866$ & $\$ 63$ \\
\hline & SUBTOTAL 7 & $\$ 20.944$ & $\$ 218$ & $\$ 12.517$ & $\$ 0$ & $\$ 0$ & $\$ 33.678$ & $\$ 3.681$ & $\$ 1.507$ & $\$ 0$ & $\$ 38.866$ & $\$ 63$ \\
\hline 8 & & & & & & & & & & & & \\
\hline $81^{\circ}$ & Steam TG \& Accessories & $\$ 0$ & $\$ 0$ & $\$ 0$ & $\$ 0$ & $\$ 0$ & $\$ 0$ & $\$ 0$ & $\$ 0$ & $\$ 01$ & & \\
\hline $8.2-8.9$ & Turbine Plant Auxiliaries and Steam Piping & $\$ 33.525$ & $\$ 1.447$ & $\$ 16.868$ & $\$ 0$ & $\$ 0$ & $\$ 51.840$ & $\$ 5,424$ & $\$ 2,332$ & $\$ 0$ & $\begin{array}{r}\$ 0 \\
\$ 59595\end{array}$ & $\begin{array}{r}\$ 0 \\
\$ 96\end{array}$ \\
\hline & SUBTOTAL 8 & $\$ 33.525$ & $\$ 1,447$ & $\$ 16.868$ & $\$ 0$ & $\$ 0$ & $\$ 51.840$ & $\$ 5,424$ & $\$ 2.332$ & $\$ 0$ & $\$ 59.595$ & $\$ 96$ \\
\hline 9 & COOLING WATER SYSTEM & $\$ 8.787$ & $\$ 9,409$ & $\$ 15,063$ & $\$ 0$ & $\$ 0$ & $\$ 33.259$ & $\$ 3,684$ & $\$ 1,480$ & $\$ 0$ & $\$ 38.422$ & $\$ 62$ \\
\hline & & & & & & & & & & & & \\
\hline 10 & ASH/SPENT SORBENT HANDLING SYS & $\$ 10.751$ & $\$ 626$ & $\$ 7.673$ & $\$ 0$ & $\$ 0$ & $\$ 19.049$ & $\$ 2,134$ & $\$ 850$ & $\$ 0$ & $\$ 22.033$ & $\$ 36$ \\
\hline 11 & ACCESSORY ELECTRIC PLANT & $\$ 20.034$ & $\$ 8,387$ & $\$ 25,825$ & $\$ 0$ & $\$ 0$ & $\$ 54.245$ & $\$ 5.633$ & $\$ 2,362$ & $\$ 0$ & $\$ 62.240$ & $\$ 100$ \\
\hline 13 & IMPROVEMENTS TO SITE & $\$ 3729$ & $\$ 2144$ & $\$ 7282$ & $\$ 0$ & $\$ 0$ & $\$ 13155$ & $\$ 1528$ & $\$ 585$ & $\$ 0$ & $\$ 15268$ & $\$ 25$ \\
\hline & & & & & & & & & & & & \\
\hline 14 & BUILDINGS \& STRUCTURES & $\$ 0$ & $\$ 33.129$ & $\$ 29,791$ & $\$ 0$ & $\$ 0$ & $\$ 62.920$ & $\$ 6.726$ & $\$ 2,823$ & $\$ 0$ & $\$ 72.469$ & $\$ 117$ \\
\hline & & & & & & & & & & & & \\
\hline & TOTAL COST & $\$ 201.728$ & $\$ 60.610$ & $\$ 167.669$ & $\$ 0$ & $\$ 0$ & $\$ 430.007$ & $\$ 46.180$ & $\$ 19.192$ & $\$ 0$ & $\$ 495,379$ & $\$ 798$ \\
\hline & & & & & & & & & & & & \\
\hline
\end{tabular}


COMMERCIALIZATION DEVELOPMENT OF OXYGEN FIRED

CFB FOR GREENHOUSE GAS CONTROL

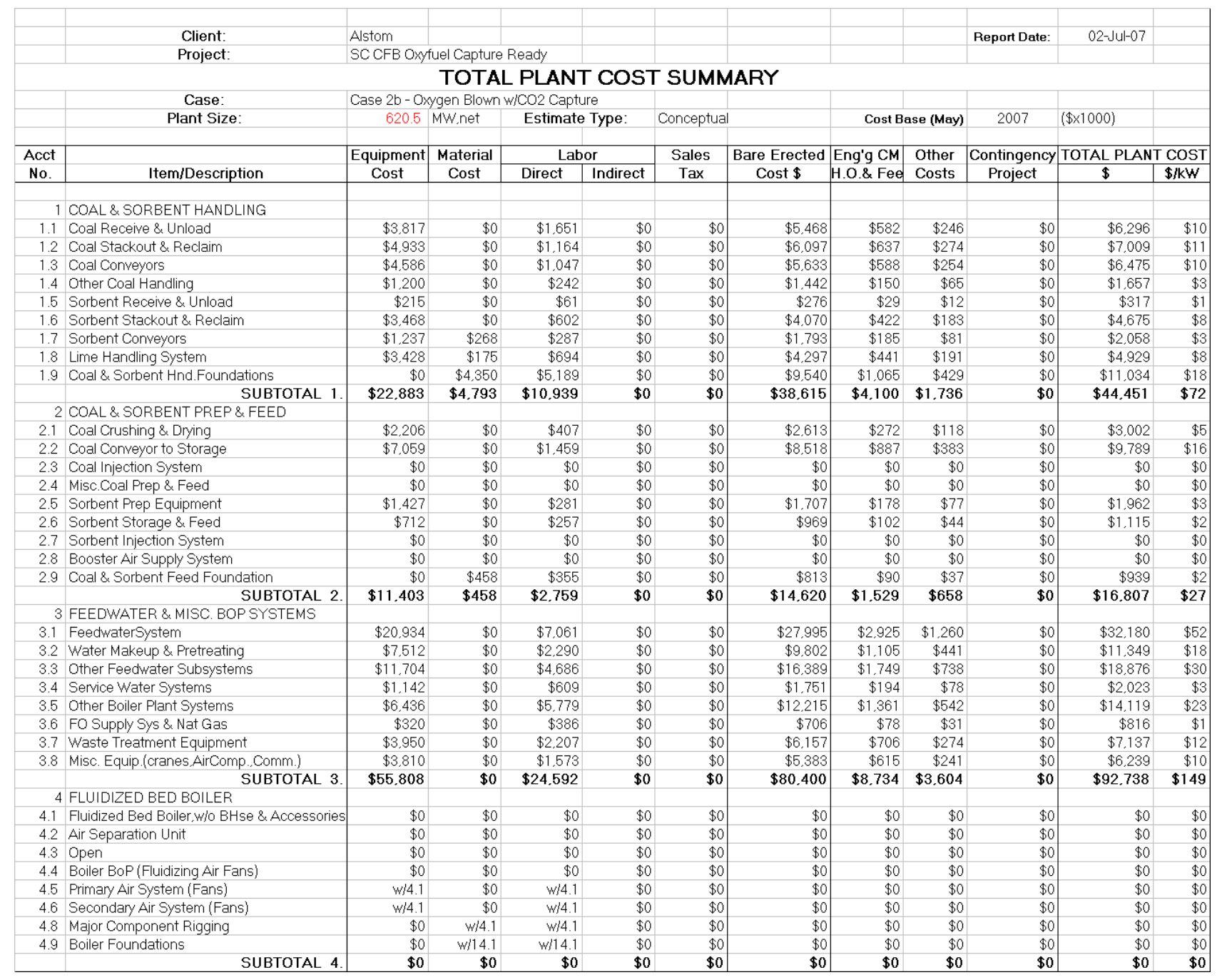


COMMERCIALIZATION DEVELOPMENT OF OXYGEN FIRED

CFB FOR GREENHOUSE GAS CONTROL

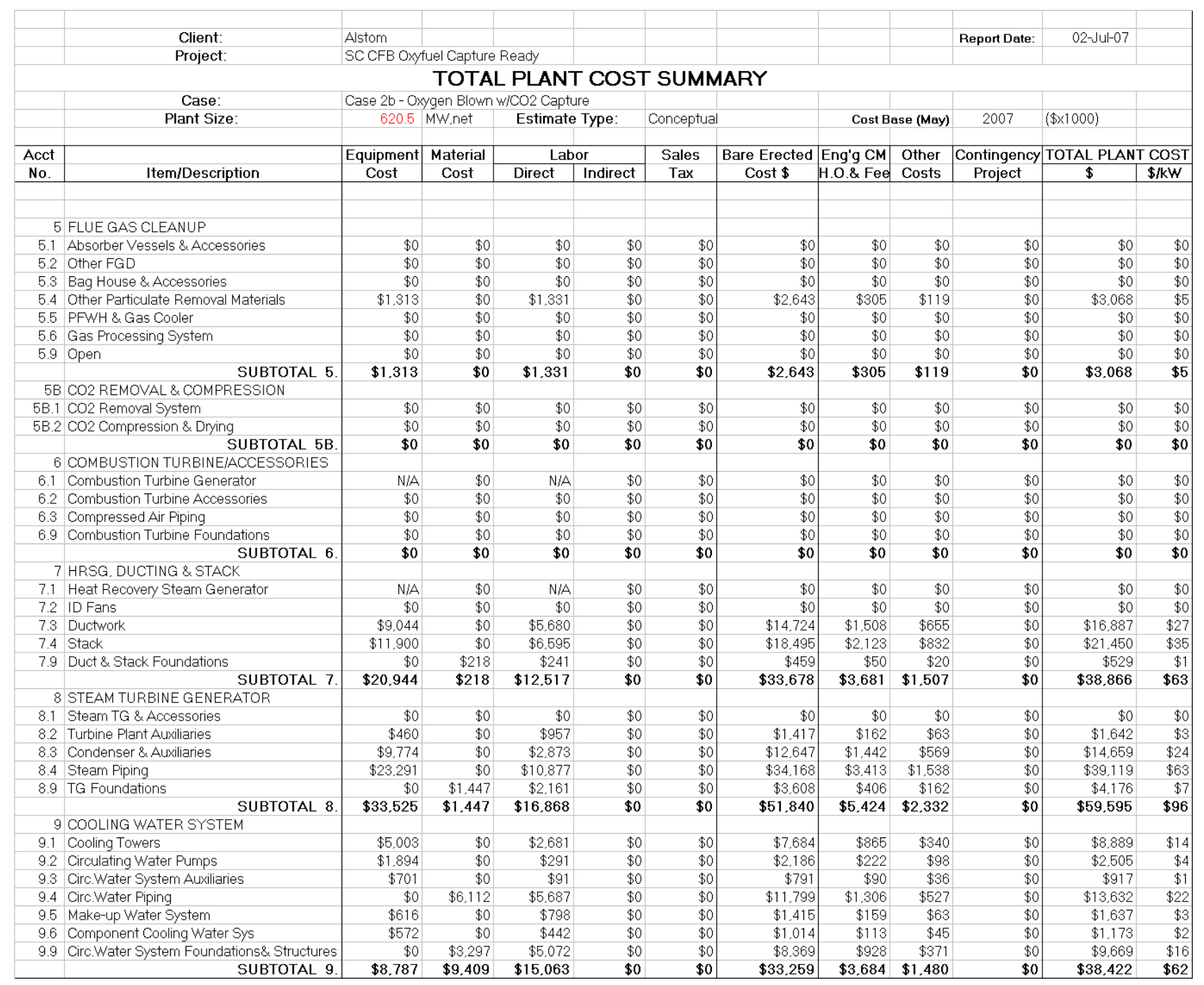


COMMERCIALIZATION DEVELOPMENT OF OXYGEN FIRED

CFB FOR GREENHOUSE GAS CONTROL

\begin{tabular}{|c|c|c|c|c|c|c|c|c|c|c|c|c|}
\hline & Client: & Alstom & & & & & & & & Report Date: & 02-Jul-07 & \\
\hline & Project: & \multicolumn{3}{|c|}{ SC CFB Oxyfuel Capture Ready } & & & & & & & & \\
\hline \multicolumn{13}{|c|}{ TOTAL PLANT COST SUMMARY } \\
\hline & Case: & \multicolumn{4}{|c|}{ Case 2b-Oxygen Blown w/CO2 Capture } & \multirow{2}{*}{\multicolumn{2}{|c|}{ Conceptual }} & \multirow{2}{*}{\multicolumn{2}{|c|}{ Cost Base (May) }} & & & \\
\hline & Plant Size: & 620.5 & MW.net & \multicolumn{2}{|c|}{ Estimate Type: } & & & & & 2007 & $(\$ \times 1000)$ & \\
\hline Acct & & \multirow{2}{*}{\begin{tabular}{|c|} 
Equipment \\
Cost
\end{tabular}} & \multirow{2}{*}{\begin{tabular}{|c|} 
Material \\
Cost \\
\end{tabular}} & \multicolumn{2}{|c|}{ Labor } & \multirow{2}{*}{\begin{tabular}{|c|} 
Sales \\
Tax \\
\end{tabular}} & \multirow{2}{*}{\begin{tabular}{|c|} 
Bare Erected \\
Cost $\$$
\end{tabular}} & Eng'g CM & Other & Contingency & \multicolumn{2}{|c|}{ TOTAL PLANT COST } \\
\hline No. & Item/Description & & & Direct & Indirect & & & H.O.\& Fee & Costs & Project & $\$$ & $\$ / \mathrm{kW}$ \\
\hline & & & & & & & & & & & & \\
\hline 10.1 & $\begin{array}{l}\text { ASHISPENT SORBENT HANDLING SYS } \\
\text { Ash Coolers }\end{array}$ & $N / A$ & $\$ 0$ & $N / A$ & $\$ 0$ & $\$ 1$ & $\$ 0$ & $\$ 0$ & & $\$ 0$ & $\$ 0$ & \\
\hline 10.2 & Cyclone Ash Letdown & N/A & $\$ 0$ & N/A & $\$ 0$ & $\$ 0$ & $\$ 0$ & $\$ 0$ & $\$ 0$ & $\$ 0$ & $\$ 0$ & $\$ 0$ \\
\hline 10.3 & HGCU Ash Letdown & N/A & $\$ 0$ & N/A & $\$ 0$ & $\$ 0$ & $\$ 0$ & $\$ 0$ & $\$ 0$ & $\$ 0$ & $\$ 0$ & $\$ 0$ \\
\hline 10.4 & High Temperature Ash Piping & N/A & $\$ 0$ & N/A & $\$ 0$ & $\$ 0$ & $\$ 0$ & $\$ 0$ & $\$ 0$ & $\$ 0$ & $\$ 0$ & $\$ 0$ \\
\hline 10.5 & Other Ash Recovery Equipment & N/A & $\$ 0$ & N/A & $\$ 0$ & $\$ 0$ & $\$ 0$ & $\$ 0$ & $\$ 0$ & $\$ 0$ & $\$ 0$ & $\$ 0$ \\
\hline 10.6 & Ash Storage Silos & $\$ 657$ & $\$ 0$ & $\$ 1.959$ & $\$ 0$ & $\$ 0$ & $\$ 2.616$ & $\$ 301$ & $\$ 116$ & $\$ 0$ & $\$ 3,033$ & $\$ 5$ \\
\hline 10.7 & Ash Transport \& Feed Equipment & $\$ 10.093$ & $\$ 0$ & $\$ 5.002$ & $\$ 0$ & $\$ 0$ & $\$ 15,095$ & $\$ 1,686$ & $\$ 675$ & $\$ 0$ & $\$ 17.455$ & $\$ 28$ \\
\hline 10.8 & Misc. Ash Handling Equipment & $\$ 0$ & $\$ 0$ & $\$ 0$ & $\$ 0$ & $\$ 0$ & $\$ 0$ & $\$ 0$ & $\$ 0$ & $\$ 0$ & $\$ 0$ & $\$ 0$ \\
\hline 10.9 & Ash/Spent Sorbent Foundation & $\$ 0$ & $\$ 626$ & $\$ 712$ & $\$ 0$ & $\$ 0$ & $\$ 1.337$ & $\$ 147$ & $\$ 60$ & $\$ 0$ & $\$ 1.544$ & $\$ 2$ \\
\hline & SUBTOTAL 10 & $\$ 10.751$ & $\$ 626$ & $\$ 7.673$ & $\$ 0$ & $\$ 0$ & $\$ 19.049$ & $\$ 2.134$ & $\$ 850$ & $\$ 0$ & $\$ 22.033$ & $\$ 36$ \\
\hline 11 & ACCESSORY ELECTRIC PLANT & & & & & & & & & & & \\
\hline 11.1 & Generator Equipment & $\$ 2,001$ & $\$ 0$ & $\$ 314$ & $\$ 0$ & $\$ 0$ & $\$ 2,315$ & $\$ 255$ & $\$ 104$ & $\$ 0$ & $\$ 2,674$ & $\$ 4$ \\
\hline 11.2 & Station Service Equipment & $\$ 5.672$ & $\$ 0$ & $\$ 1.901$ & $\$ 0$ & $\$ 0$ & $\$ 7.573$ & $\$ 829$ & $\$ 335$ & $\$ 0$ & $\$ 8.736$ & $\$ 14$ \\
\hline 11.3 & Switchgear \& Motor Control & $\$ 6,345$ & $\$ 0$ & $\$ 1.098$ & $\$ 0$ & $\$ 0$ & $\$ 7.444$ & $\$ 813$ & $\$ 331$ & $\$ 0$ & $\$ 8,588$ & $\$ 14$ \\
\hline 11.4 & Conduit \& Cable Tray & $\$ 0$ & $\$ 2.798$ & $\$ 9.866$ & $\$ 0$ & $\$ 0$ & $\$ 12.664$ & $\$ 1,378$ & $\$ 538$ & $\$ 0$ & $\$ 14.580$ & $\$ 23$ \\
\hline 11.5 & Wire \& Cable & $\$ 0$ & $\$ 5.181$ & $\$ 10.215$ & $\$ 0$ & $\$ 0$ & $\$ 15,396$ & $\$ 1,463$ & $\$ 660$ & $\$ 0$ & $\$ 17.519$ & $\$ 28$ \\
\hline 11.6 & Protective Equipment & $\$ 370$ & $\$ 0$ & $\$ 1.273$ & $\$ 0$ & $\$ 0$ & $\$ 1.642$ & $\$ 181$ & $\$ 70$ & $\$ 0$ & $\$ 1,893$ & $\$ 3$ \\
\hline 11.7 & Standby Equipment & $\$ 1.527$ & $\$ 0$ & $\$ 34$ & $\$ 0$ & $\$ 0$ & $\$ 1,561$ & $\$ 171$ & $\$ 70$ & $\$ 0$ & $\$ 1.802$ & $\$ 3$ \\
\hline 11.8 & Main Power Transformers & $\$ 4.118$ & $\$ 0$ & $\$ 155$ & $\$ 0$ & $\$ 0$ & $\$ 4.273$ & $\$ 388$ & $\$ 192$ & $\$ 0$ & $\$ 4,854$ & $\$ 8$ \\
\hline 11.9 & Electrical Foundations & $\$ 0$ & $\$ 408$ & $\$ 969$ & $\$ 0$ & $\$ 0$ & $\$ 1,377$ & $\$ 154$ & $\$ 61$ & $\$ 0$ & $\$ 1.592$ & $\$ 3$ \\
\hline & SUBTOTAL 11. & $\$ 20.034$ & $\$ 8.387$ & $\$ 25.825$ & $\$ 0$ & $\$ 0$ & $\$ 54.245$ & $\$ 5.633$ & $\$ 2.362$ & $\$ 0$ & $\$ 62.240$ & $\$ 100$ \\
\hline 12 & INSTRUMENTATION \& CONTROL & & & & & & & & & & & \\
\hline 12.1 & PC Control Equipment & $w / 12.7$ & $\$ 0$ & w/12.7 & $\$ 0$ & $\$ 0$ & $\$ 0$ & $\$ 0$ & $\$ 0$ & $\$ 0$ & $\$ 0$ & $\$ 0$ \\
\hline 12.2 & Combustion Turbine Control & N/A & $\$ 0$ & N/A & $\$ 0$ & $\$ 0$ & $\$ 0$ & $\$ 0$ & $\$ 0$ & $\$ 0$ & $\$ 0$ & $\$ 0$ \\
\hline 12.3 & Steam Turbine Control & $w / 8.1$ & $\$ 0$ & $w / 8.1$ & $\$ 0$ & $\$ 0$ & $\$ 0$ & $\$ 0$ & $\$ 0$ & $\$ 0$ & $\$ 0$ & $\$ 0$ \\
\hline 12.4 & Other Major Component Control & $\$ 0$ & $\$ 0$ & $\$ 0$ & $\$ 0$ & $\$ 0$ & $\$ 0$ & $\$ 0$ & $\$ 0$ & $\$ 0$ & $\$ 0$ & $\$ 0$ \\
\hline 12.5 & Signal Processing Equipment & W/12.7 & $\$ 0$ & w/12.7 & $\$ 0$ & $\$ 0$ & $\$ 0$ & $\$ 0$ & $\$ 0$ & $\$ 0$ & $\$ 0$ & $\$ 0$ \\
\hline 12.6 & Control Boards. Panels \& Racks & $\$ 556$ & $\$ 0$ & $\$ 323$ & $\$ 0$ & $\$ 0$ & $\$ 878$ & $\$ 98$ & $\$ 39$ & $\$ 0$ & $\$ 1.016$ & $\$ 2$ \\
\hline 12.7 & Distributed Control System Equipment & $\$ 6.170$ & $\$ 0$ & $\$ 1.046$ & $\$ 0$ & $\$ 0$ & $\$ 7.216$ & $\$ 795$ & $\$ 324$ & $\$ 0$ & $\$ 8,335$ & $\$ 13$ \\
\hline 12.8 & Instrument Wiring \& Tubing & $\$ 4.241$ & $\$ 0$ & $\$ 8.172$ & $\$ 0$ & $\$ 0$ & $\$ 12.414$ & $\$ 1.234$ & $\$ 550$ & $\$ 0$ & $\$ 14.197$ & $\$ 23$ \\
\hline 12.9 & Other I \& C Equipment & $\$ 1.585$ & $\$ 0$ & $\$ 3.489$ & $\$ 0$ & $\$ 0$ & $\$ 5.074$ & $\$ 576$ & $\$ 225$ & $\$ 0$ & $\$ 5,875$ & $\$ 9$ \\
\hline & SUBTOTAL 12. & $\$ 12.552$ & $\$ 0$ & $\$ 13.030$ & $\$ 0$ & $\$ 0$ & $\$ 25.582$ & $\$ 2.703$ & $\$ 1.137$ & $\$ 0$ & $\$ 29.423$ & $\$ 47$ \\
\hline 13 & IMPROVEMENTS TO SITE & & & & & & & & & & & \\
\hline 13.1 & Site Preparation & $\$ 0$ & $\$ 63$ & $\$ 1.215$ & $\$ 0$ & $\$ 0$ & $\$ 1.277$ & $\$ 148$ & $\$ 56$ & $\$ 0$ & $\$ 1,481$ & $\$ 2$ \\
\hline 13.2 & Site Improvements & $\$ 0$ & $\$ 2.081$ & $\$ 2,504$ & $\$ 0$ & $\$ 0$ & $\$ 4.585$ & $\$ 533$ & $\$ 204$ & $\$ 0$ & $\$ 5,322$ & $\$ 9$ \\
\hline 13.3 & Site Facilities & $\$ 3.729$ & $\$ 0$ & $\$ 3,563$ & $\$ 0$ & $\$ 0$ & $\$ 7.293$ & $\$ 847$ & $\$ 325$ & $\$ 0$ & $\$ 8.465$ & $\$ 14$ \\
\hline & SUBTOTAL 13. & $\$ 3.729$ & $\$ 2.144$ & $\$ 7.282$ & $\$ 0$ & $\$ 0$ & $\$ 13.155$ & $\$ 1.528$ & $\$ 585$ & $\$ 0$ & $\$ 15.268$ & $\$ 25$ \\
\hline 14 & BUILDINGS \& STRUCTURES & & & & & & & & & & & \\
\hline 14.1 & FB Boiler Building Foundation & $\$ 0$ & $\$ 16.241$ & $\$ 13,521$ & $\$ 0$ & $\$ 0$ & $\$ 29.762$ & $\$ 3,180$ & $\$ 1.339$ & $\$ 0$ & $\$ 34.282$ & $\$ 55$ \\
\hline 14.2 & Turbine Building & $\$ 0$ & $\$ 11.137$ & $\$ 9.826$ & $\$ 0$ & $\$ 0$ & $\$ 20.963$ & $\$ 2.246$ & $\$ 943$ & $\$ 0$ & $\$ 24,153$ & $\$ 39$ \\
\hline 14.3 & Administration Building & $\$ 0$ & $\$ 1.035$ & $\$ 1.048$ & $\$ 0$ & $\$ 0$ & $\$ 2.083$ & $\$ 223$ & $\$ 93$ & $\$ 0$ & $\$ 2.400$ & $\$ 4$ \\
\hline 14.4 & Circulation Water Pumphouse & $\$ 0$ & $\$ 222$ & $\$ 167$ & $\$ 0$ & $\$ 0$ & $\$ 390$ & $\$ 41$ & $\$ 18$ & $\$ 0$ & $\$ 449$ & $\$ 1$ \\
\hline 14.5 & Water Treatment Buildings & $\$ 0$ & $\$ 720$ & $\$ 562$ & $\$ 0$ & $\$ 0$ & $\$ 1.282$ & $\$ 137$ & $\$ 58$ & $\$ 0$ & $\$ 1.476$ & $\$ 2$ \\
\hline 14.6 & Machine Shop & $\$ 0$ & $\$ 923$ & $\$ 594$ & $\$ 0$ & $\$ 0$ & $\$ 1.517$ & $\$ 159$ & $\$ 68$ & $\$ 0$ & $\$ 1.744$ & $\$ 3$ \\
\hline 14.7 & Warehouse & $\$ 0$ & $\$ 625$ & $\$ 601$ & $\$ 0$ & $\$ 0$ & $\$ 1.226$ & $\$ 131$ & $\$ 55$ & $\$ 0$ & $\$ 1.412$ & $\$ 2$ \\
\hline 14.8 & Other Buildings \& Structures & $\$ 0$ & $\$ 1.491$ & $\$ 1,339$ & $\$ 0$ & $\$ 0$ & $\$ 2.830$ & $\$ 287$ & $\$ 121$ & $\$ 0$ & $\$ 3.238$ & $\$ 5$ \\
\hline 14.9 & Waste Treating Building \& Str. & $\$ 0$ & $\$ 734$ & $\$ 2.133$ & $\$ 0$ & $\$ 0$ & $\$ 2.867$ & $\$ 321$ & $\$ 128$ & $\$ 0$ & $\$ 3.316$ & $\$ 5$ \\
\hline & SUBTOTAL 14. & $\$ 0$ & $\$ 33.129$ & $\$ 29.791$ & $\$ 0$ & $\$ 0$ & $\$ 62.920$ & $\$ 6.726$ & $\$ 2.823$ & $\$ 0$ & $\$ 72.469$ & $\$ 117$ \\
\hline & TOTAL COST & $\$ 201.728$ & $\$ 60.610$ & $\$ 167.669$ & $\$ 0$ & $\$ 0$ & $\$ 430.007$ & $\$ 46.180$ & $\$ 19.192$ & $\$ 0$ & $\$ 495.379$ & $\$ 798$ \\
\hline
\end{tabular}

